\title{
Total Ore Processing Integration and Management
}

\author{
Final Technical Report \\ 20 August 2003 - 30 June 2006
}

\author{
written by \\ Leslie Gertsch
}

submitted

31 January 2007

DOE Award Number DE-FC26-03NT41785

University of Missouri-Rolla

Rolla, MO 65401

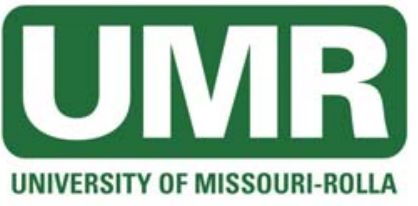




\section{Disclaimer}

This report was prepared as an account of work sponsored by an agency of the United States Government. Neither the United States Government nor any agency thereof, nor any of their employees, makes any warranty, express or implied, or assumes any legal liability or responsibility for the accuracy, completeness, or usefulness of any information, apparatus, product, or process disclosed, or represents that its use would not infringe privately owned rights. Reference herein to any specific commercial product, process, or service by trade name, trademark, manufacturer, or otherwise does not necessarily constitute or imply its endorsement, recommendation, or favoring by the United States Government or any agency thereof. The views and opinions of authors expressed herein do not necessarily state or reflect those of the United States Government or any agency thereof. 


\section{Acknowledgements}

The TOPIM project was the brainchild of Richard Gertsch and Jack Eloranta, conceived when they met at a regional technical conference of the Society of Mining, Metallurgy, and Exploration (SME) in Duluth, Minnesota. Through three proposal cycles, a preliminary ore segregation test, and over two years of DOE-supported work, they made it happen.

Richard passed away in 2005 while on the Mesabi Range, working on this project. Though the project was canceled soon after for unrelated reasons, his vision remains within this report. Hopefully, others will be able to carry it forward.

Parts of this report were extracted from papers and reports written by David Drain of the University of Missouri-Rolla, Frank Pezzuto of Minntac Mine, and Mike Orobona of Hibtac Mine.

Of the many hardworking people who were involved in the TOPIM project at the various stages of its existence, only a few can be named here:

Jim Swearingen, Jerry Dombek, Bruce Kniivila, Scott Vagle, Frank Pezzuto, and many others at U.S. Steel Corporation’s Minntac Mine near Mountain Iron, Minnesota.

Mike Young, Pete VanDelinder, Mike Orobona, Ken Rancourt, and many others at Cleveland Cliffs’ Hibtac Mine (HTC) near Hibbing, Minnesota.

Tom Palangio and Norbert Maerz of WipWare, Inc., Bonham, Ontario, Canada.

James Stewart, Leo Aguillar, and many other graduate and undergraduate students at both Michigan Technological University, Houghton, Michigan and the University of Missouri-Rolla, Rolla, Missouri.

The experts at Coleraine Research Lab and the NMMRI of the University of Minnesota at Duluth, including Pete Niles, who, though retired, graciously shared some of his thoughts and much of his archived material with us.

And last, but certainly not least, Joe Renk and Mike Mosser of the U.S. Department of Energy. Without their careful shepherding, the TOPIM project would have been much less successful than it was.

Of those many additional people who have been associated with the TOPIM project but are not be named here, please be aware that your assistance is deeply appreciated none the less.

Any errors contained in this report are the responsibility of Leslie Gertsch (UMR Rock Mechanics and Explosives Research Center, 1006 Kingshighway, Rolla, MO 65409-0660). 


\section{Abstract}

This report outlines the technical progress achieved for project DE-FC26-03NT41785 (Total Ore Processing Integration and Management) during the period 20 August 2003 through 30 June 2006. 


\section{Table of Contents}

Executive Summary

Introduction

Energy Benefits

Sponsoring Program

Goals

Scope and Plan of Work

Barriers to Success

Project History

Background

Report Layout

Data Mining 26

Minntac Mine

26

Hibtac Mine

Grindability

Minntac Mine

Hibtac Mine

Rock Physical Properties 28

Drill Monitoring

Minntac Mine

Hibtac Mine

Pi Indices

Fragmentation

Orebody Modeling

Minntac Mine

Hibtac Mine

Ore Segregation Tests

Segregation Test 1

Segregation Test 2

Segregation Test 3

Segregation Test 4

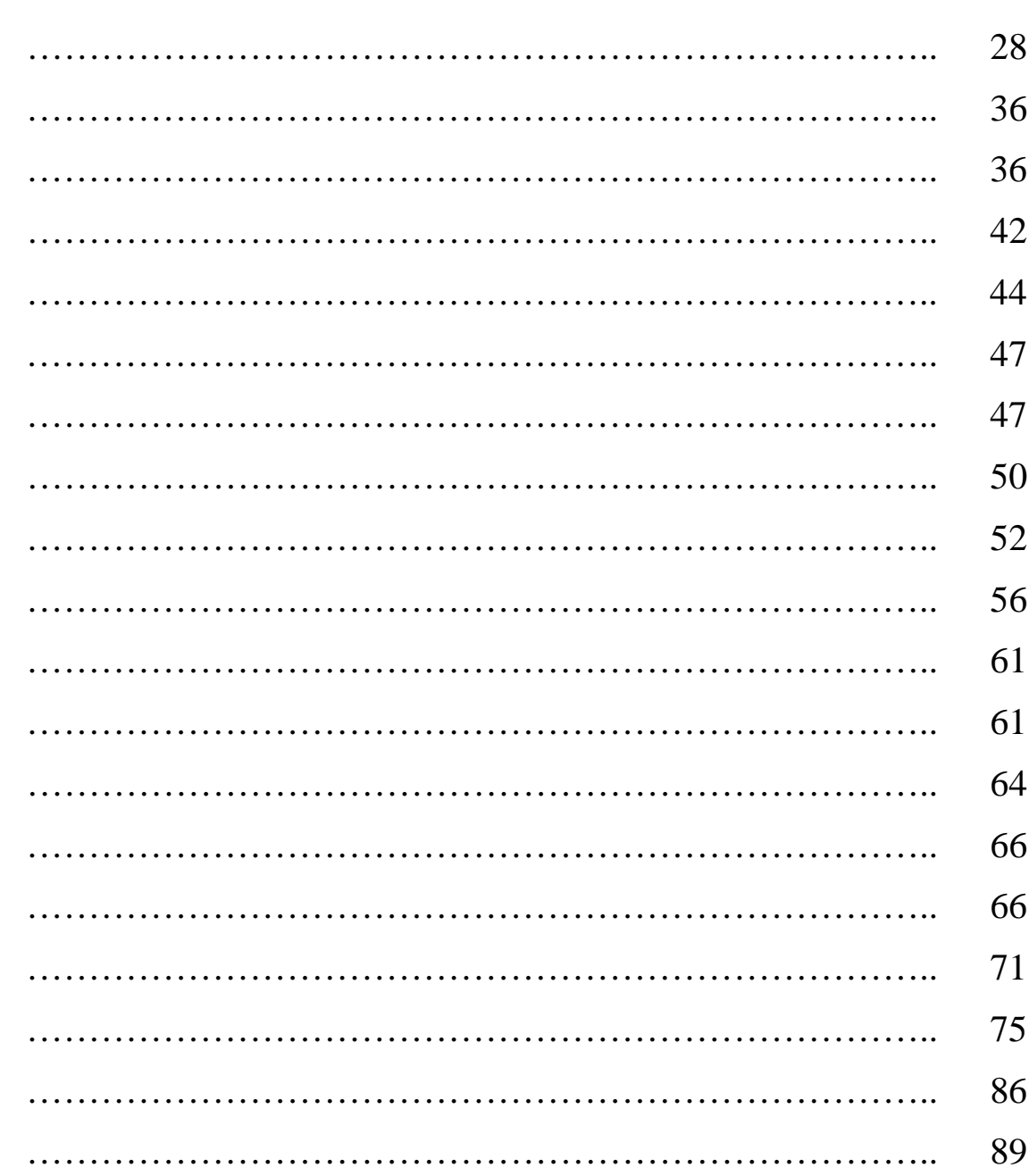

Background Data Set 
Statistical Analysis $\quad$.................................................. 96

Hibtac Mine

Minntac Mine

96

Commercialization

97

Dissemination and

108

Outreach

Conclusions

110

Useful Future Work

111

References Cited

112

Appendix: Grindability

114

Appendix: Rock Physical 117

Properties

Appendix: Vertical

Variation in Drilling

Properties for Blast 02136

Appendix: Data Summary from Ore Segregation Test

\#1

Appendix: Additional

Charts from Ore

Segregation Test \#1

Appendix: Data Summary from Ore Segregation Test \#2

Appendix: Additional

Charts from Ore

Segregation Test \#2

Appendix: Additional

Charts from Ore

Segregation Test \#3

Appendix: Additional

Charts from Background

Dataset

Appendix: Orebody

Models

Appendix: Statistical

Analysis 


\section{List of Figures}

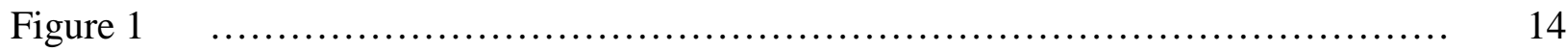

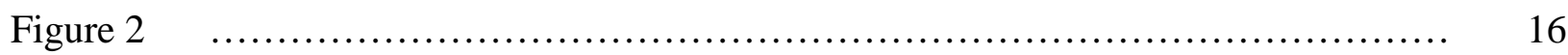

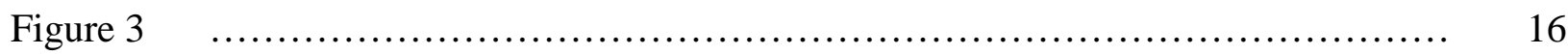

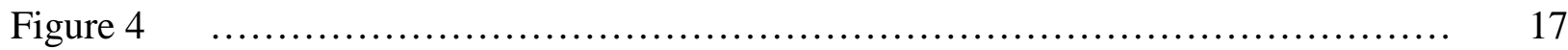

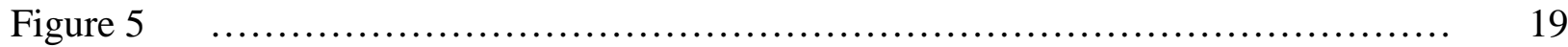

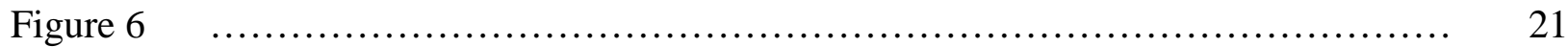

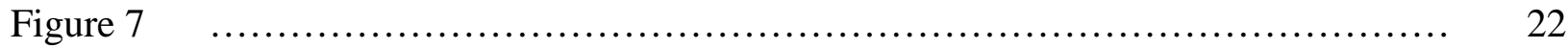

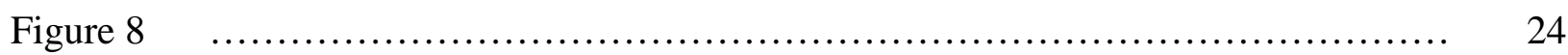

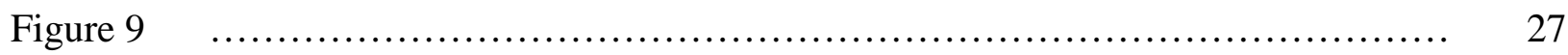

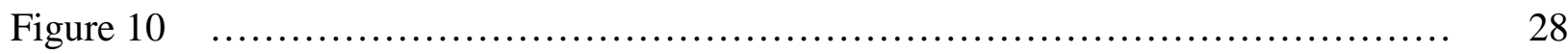

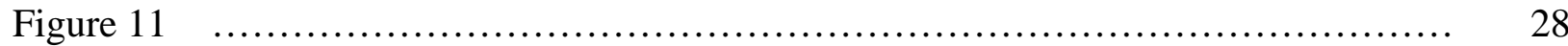

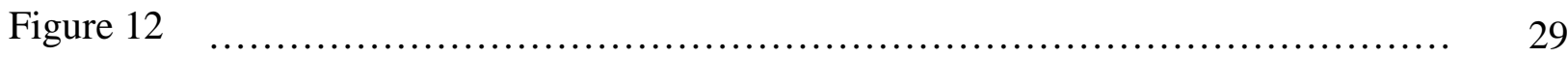

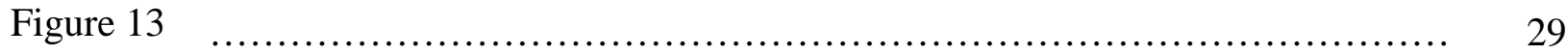

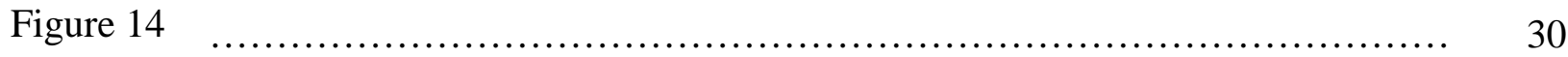

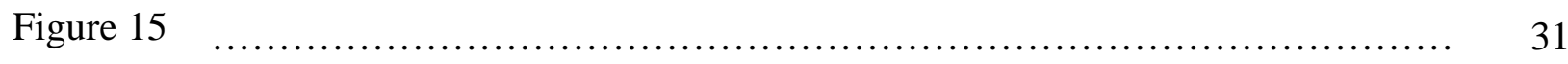

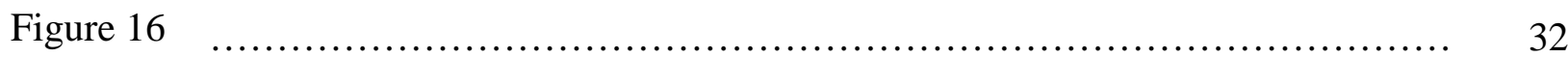

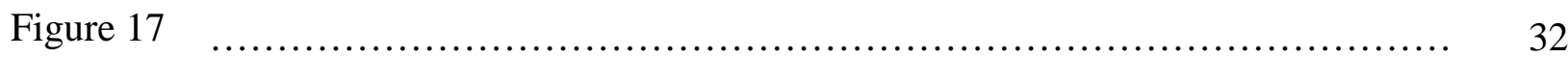

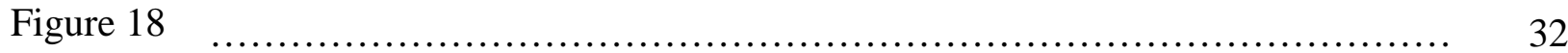

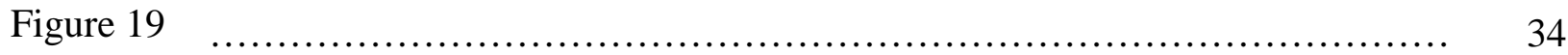

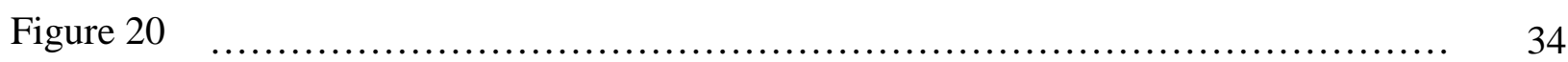

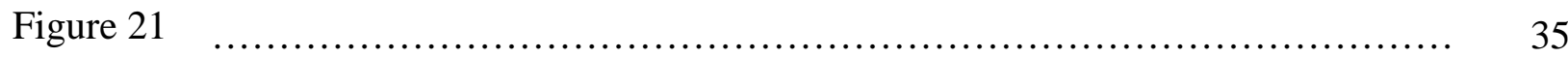

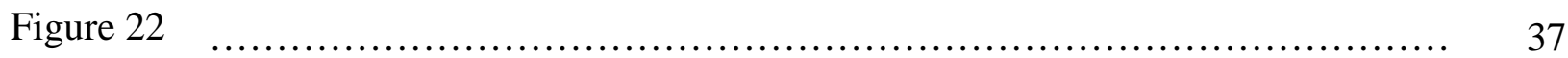

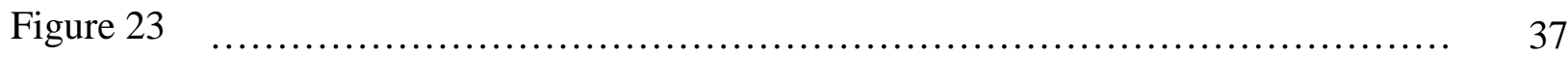

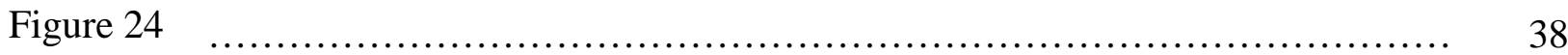

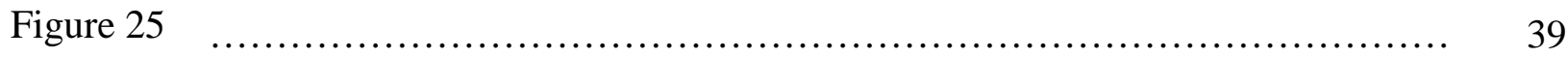

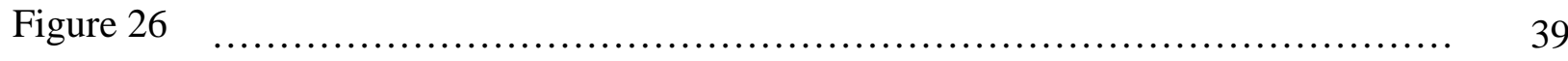

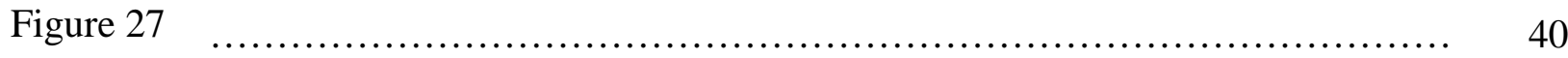

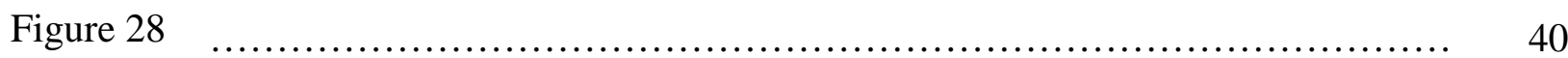

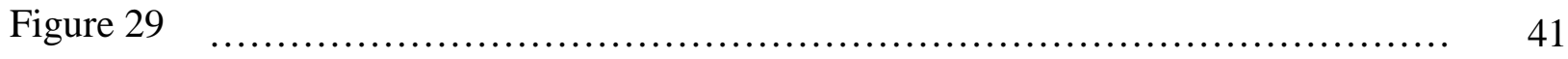

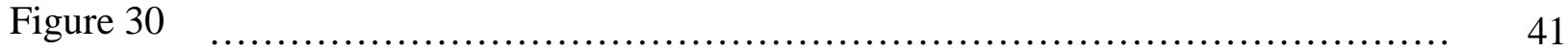

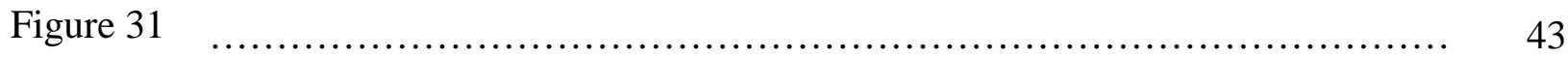




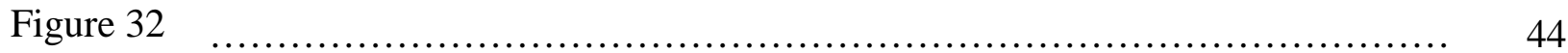

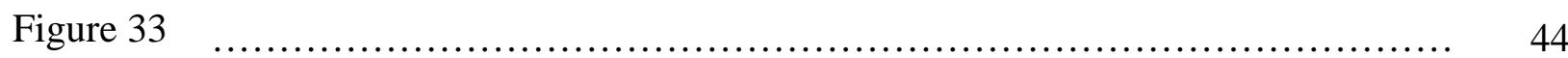

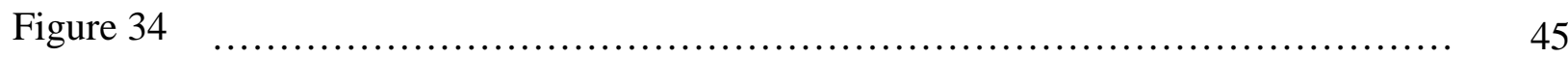

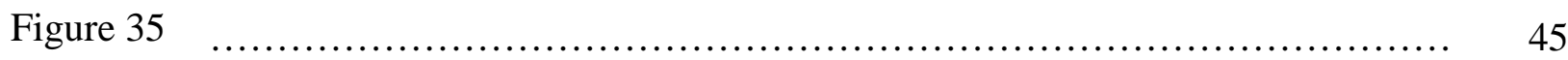

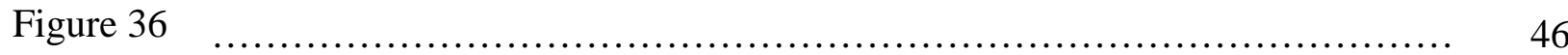

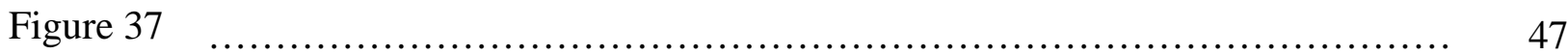

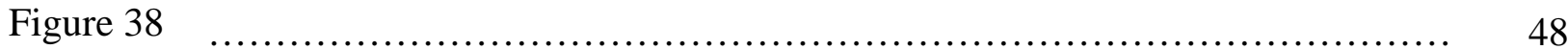

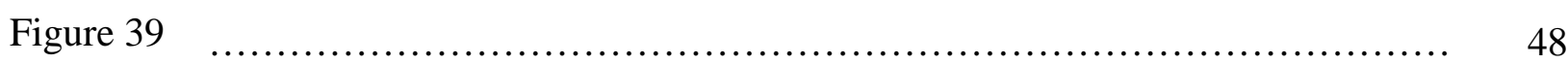

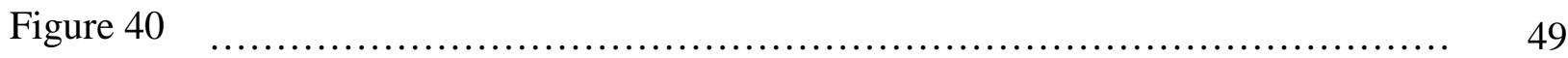

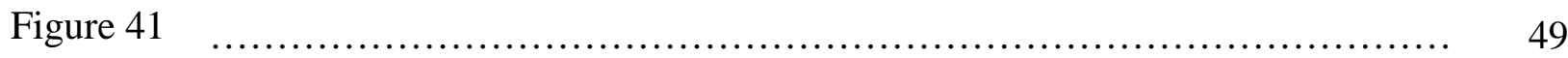

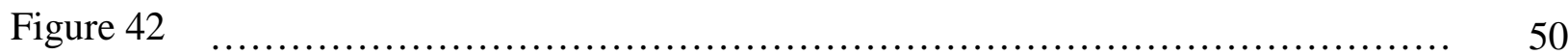

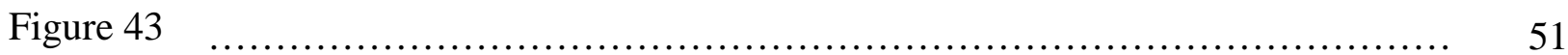

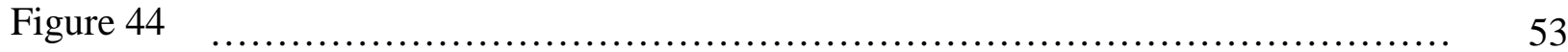

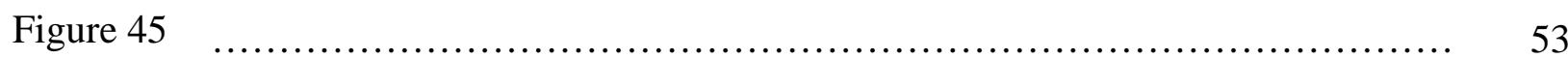

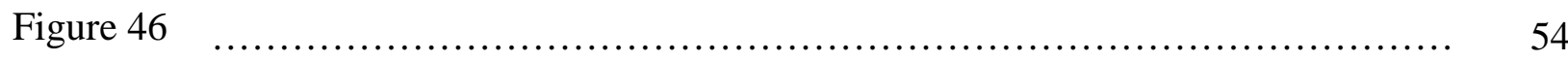

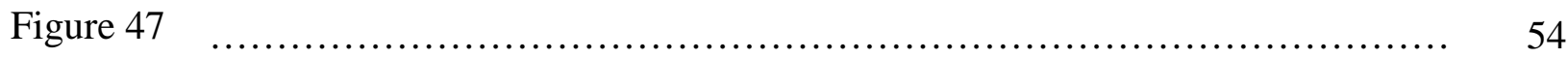

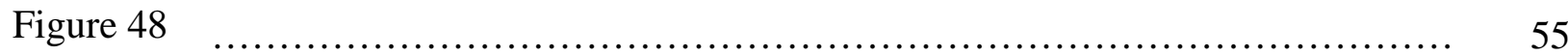

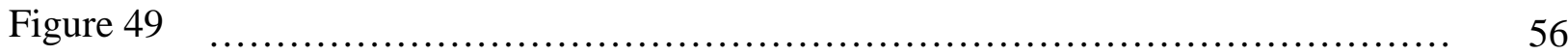

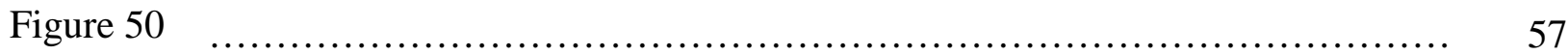

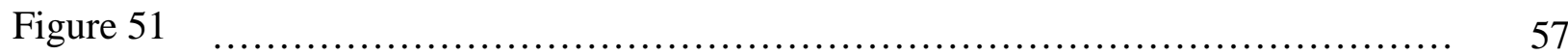

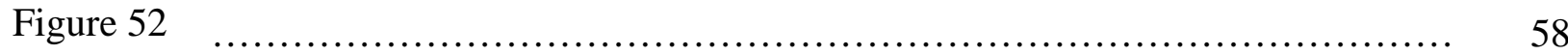

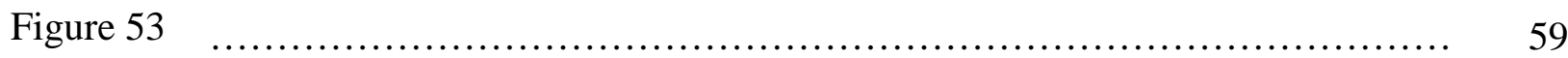

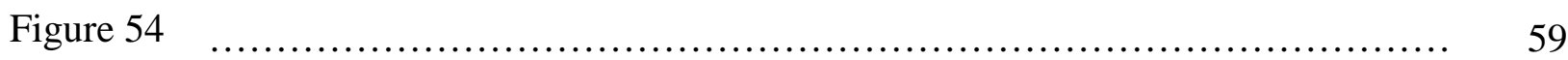

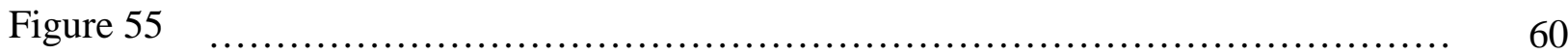

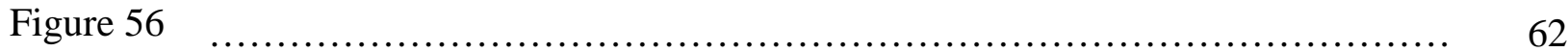

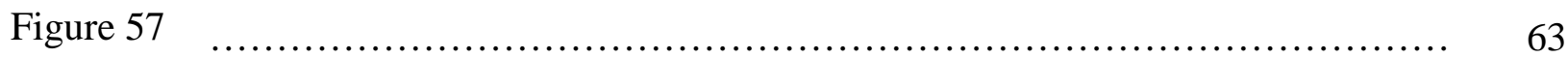

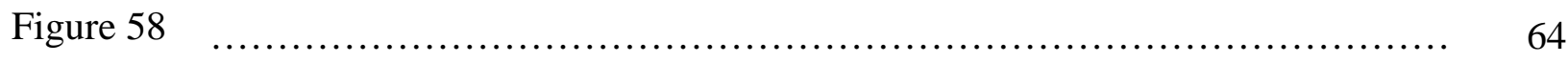

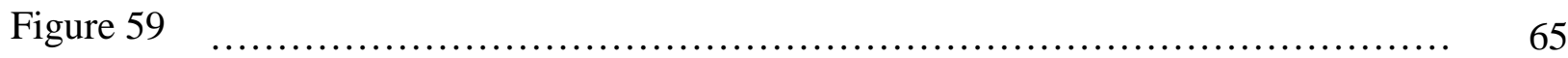

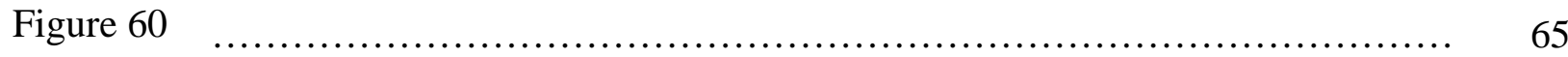

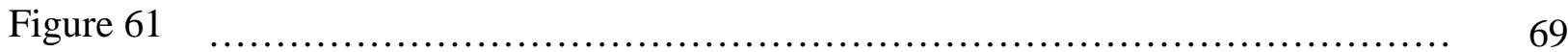

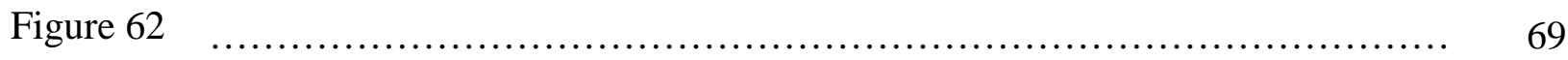

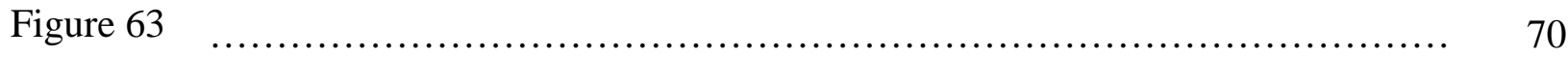




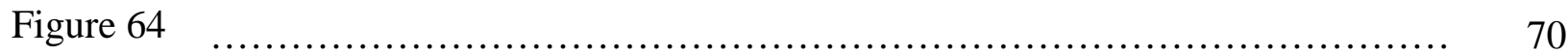

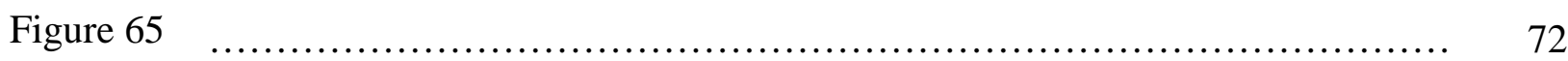

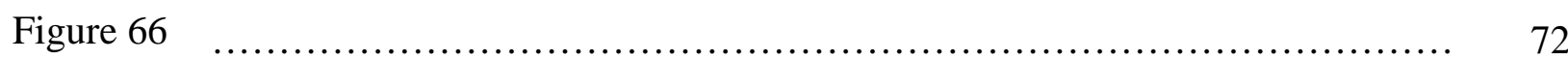

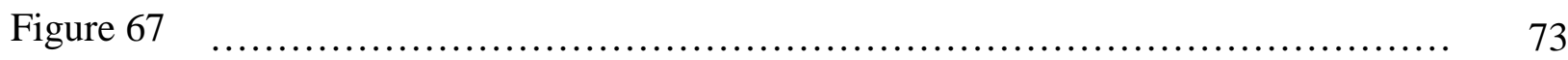

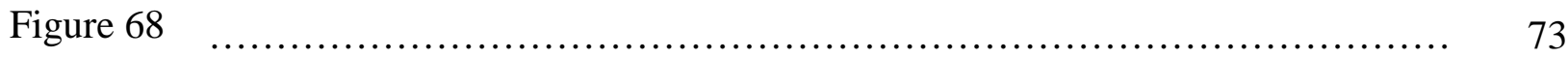

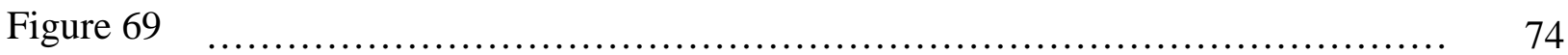

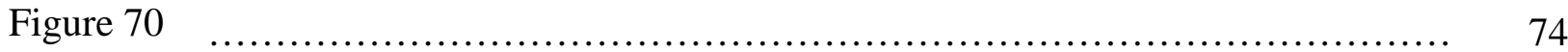

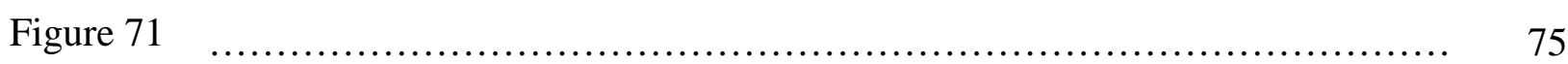

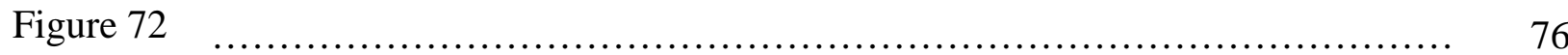

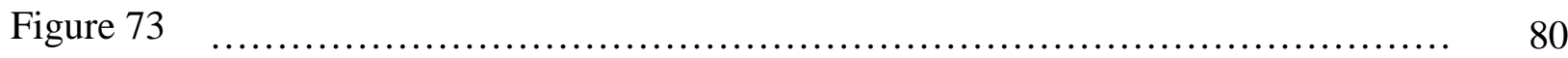

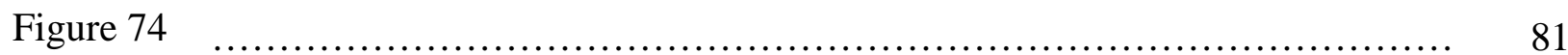

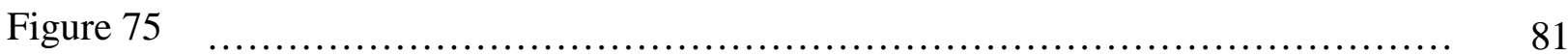

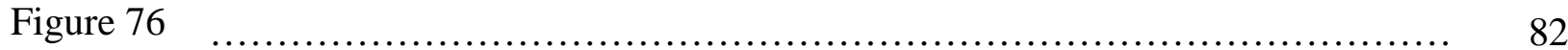

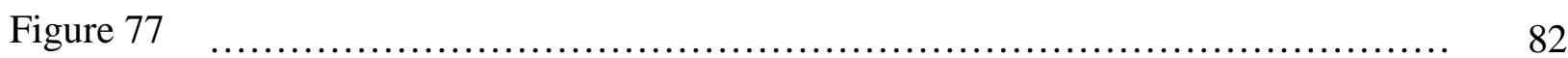

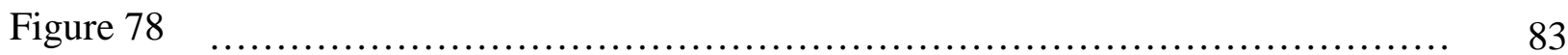

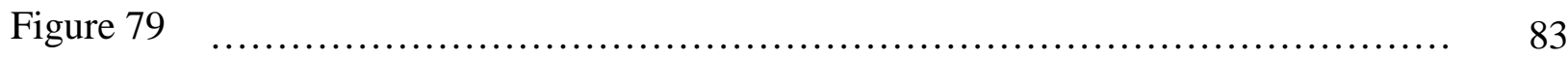

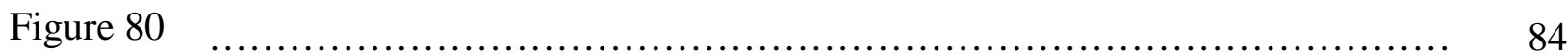

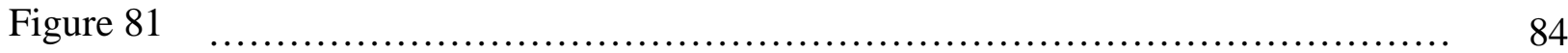

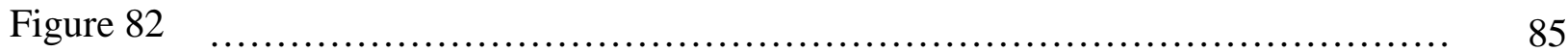

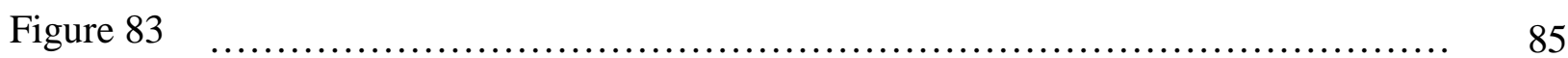

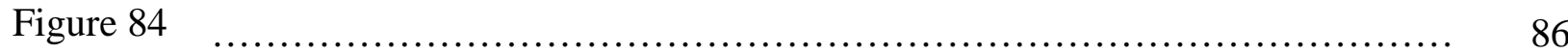

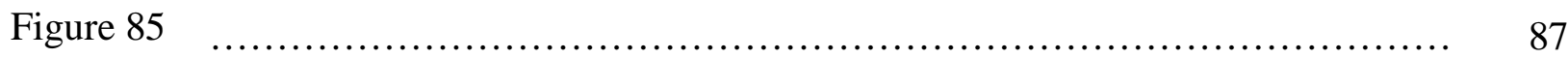

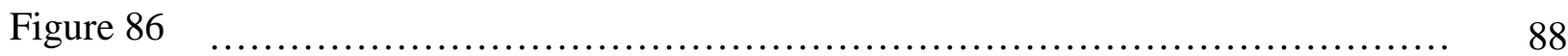

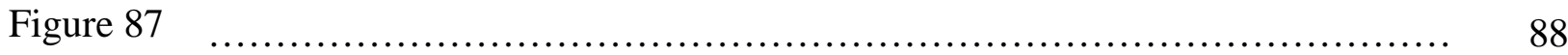

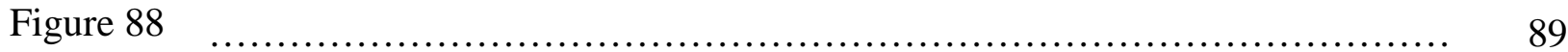

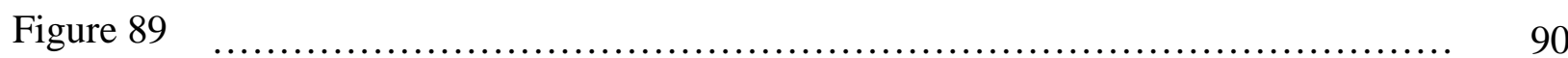

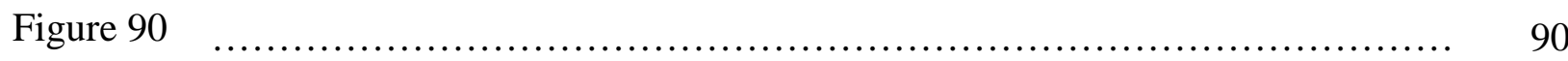

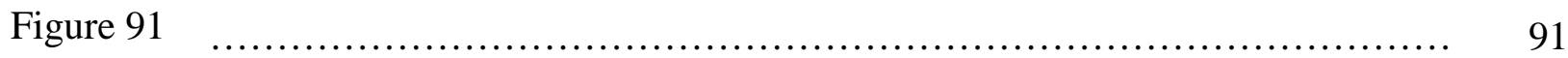

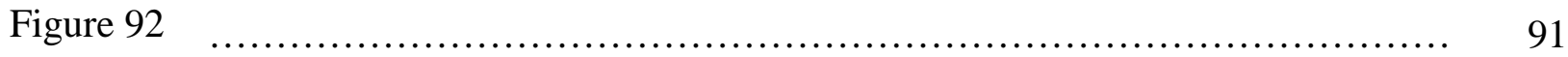

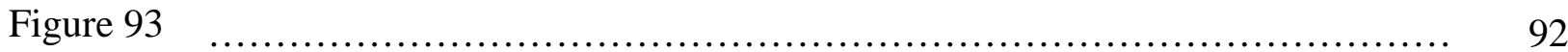

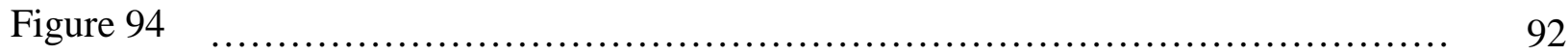

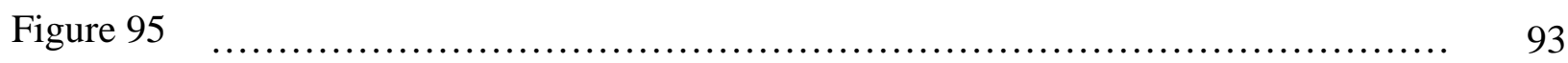




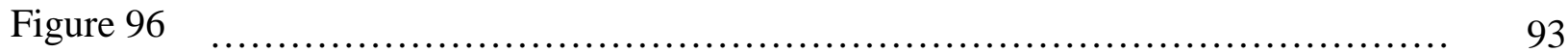

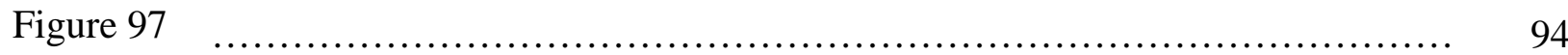

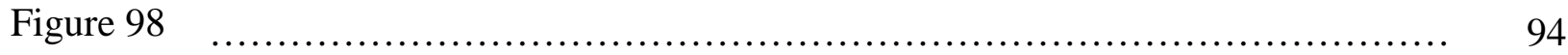

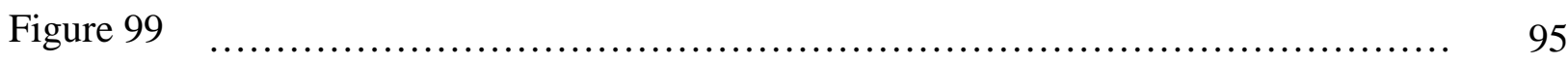

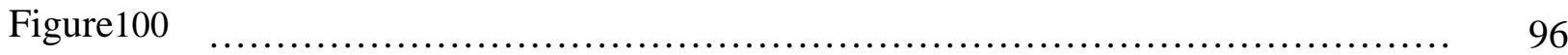




\section{List of Tables}

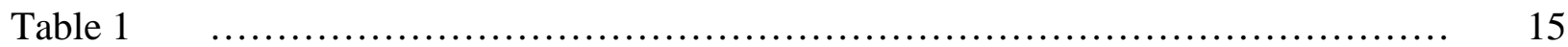

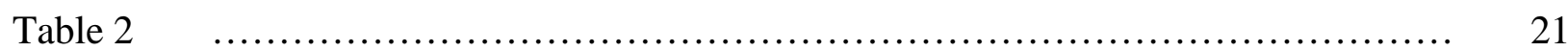

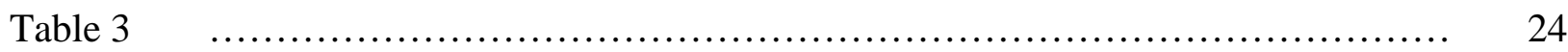

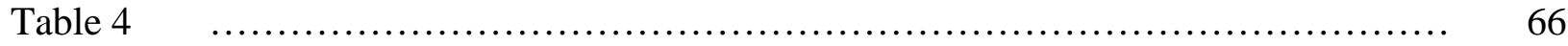

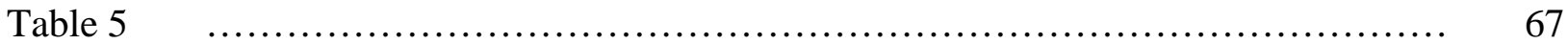

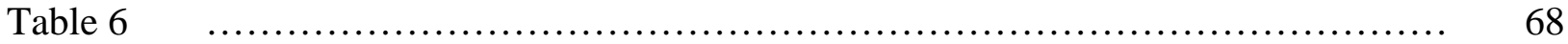

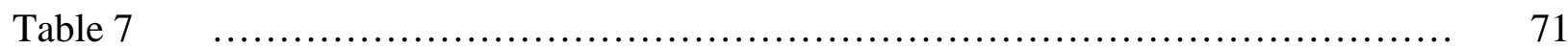

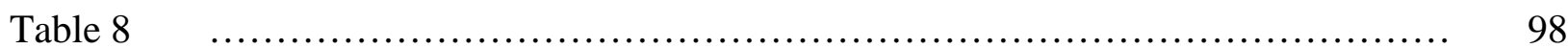

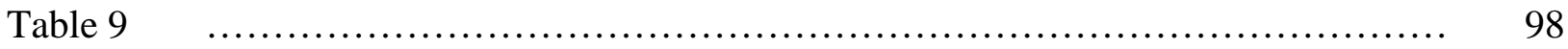

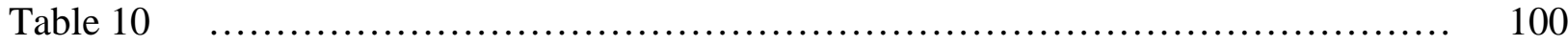

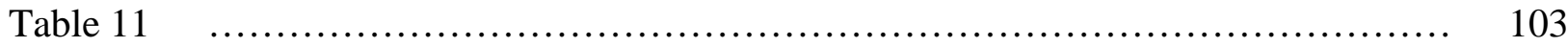

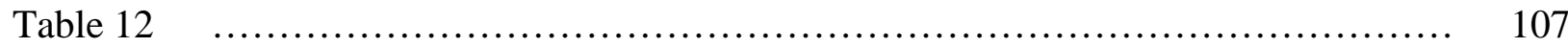




\section{Executive Summary}

The Total Ore Process Integration and Management (TOPIM) project analyzed a series of bench blasts in two iron surface mines over four years, using a variety of technologies to follow significant features in the rock mass through much of the mining and milling of the resulting muck.

With $10 \%$ savings in comminution energy, increase in iron ore production over the next ten years based on 1982-2004 trends, costs escalating with value, and energy costs of \$0.05/ $\mathrm{kWh}$, the potential cost savings by 2016 for U.S. iron producers would exceed \$2.38 billion, for U.S. metal ore producers $\$ 10.3$ billion, and for all U.S. mineral producers $\$ 38.1$ billion. The 10year energy savings for iron ore producers alone is estimated at 162,570 billion Btu.

TOPIM development was based on two principles: Baseline the current process by detailed measurements at various points in the process stream. Propose a hypothesis that can potentially improve process efficiency. Test the hypothesis by making changes to the process, and measuring the effects on the remainder of the process.

To make this enormous study manageable, it was divided into several subtasks:

- Construct a complete data flow sheet by adding the existing and planned data collection types and locations to the process flowchart.

- Improve description of already-collected ore grindability and liberation data.

- Measure the appropriate rock physical properties.

- Monitor blasthole drill performance.

- Evaluate fragmentation outcomes and predictors.

- Incorporate important process-controlling properties in the orebody model.

- Conduct ore segregation tests to evaluate the effects of changing a single factor.

- Apply rigorous statistical analysis to the data collected.

A number of papers were presented at various conferences as well as at mine meetings describing the progress of the project, and its ultimate recommendations for using TOPIM anywhere:

- Improve data collection. Measure it precisely if it affects mining or milling; don’t if it doesn't.

- Share your problems and your solutions, if not your data. Secrecy and "not invented here" blinders cost.

- Ensure your data is compatible and software packages can talk to each other. If data is needed but unavailable then the cost of collecting it was wasted.

Though TOPIM is not complete, it has enabled two major U.S. iron ore producers to improve mill throughputs by managing the information they already had. Much more can be accomplished by continuing to apply its basic principles and being willing to optimize the whole process instead of just parts of it. 


\section{Introduction}

This final technical report discusses the activities of the Total Ore Process Integration and Management (TOPIM) project team during the total period of performance: 20 August 2003 through 30 June 2006.

The TOPIM project analyzed a series of bench blasts in two iron surface mines over four years, using a variety of technologies to follow significant features in the rock mass through much of the mining and milling of the resulting muck (Figure 1). The controlling geologic features, their effects on blast design, the resulting fragmentation, and its effects on comminution and subsequent separation performance were studied in a stepwise fashion.

The research team for this multidisciplinary project consisted of major mining companies (U.S. Steel and Cleveland-Cliffs Iron), well-known universities (University of Missouri-Rolla, Michigan Technological University, and Queens University), and service companies that provide drilling, blasting, comminution, and software support to the mining and mineral processing industries (Thunderbird Pacific, WipWare, Mintec, Viking Explosives, Minnesota Explosives/ Dyno Nobel, Mount Sopris Instruments, Modular Mining, and Eloranta Associates).

The problem with controlling any complex and constantly changing industrial process is that no single current technology is sufficient to ensure optimal operation. Historically, mining and mineral processing have been optimized as individual unit operations; drill manufacturers supply drills that are economic to operate, explosives suppliers minimize blasting cost, and mill constructors design circuits that minimize energy and maximize throughput for run-of-mine ore. Each component is optimized in isolation, but the entire ore processing system is not.

To truly optimize mineral liberation at a particular site, a more unified approach must be taken. It is vitally important to analyze the component operations as a continuum. Thorough characterization of the results of blasting, crushing, and grinding provides information for improvements both up and down the ore stream. Operators have come to realize that the best approach is to relate in situ geology and blast design to the operating parameters in the transport, crushing, grinding, and concentration phases of mineral production.

A new approach was attempted in this project to actively link characterization tools and process control techniques to all points along the mining/milling process stream to allow them to respond as needed to changes in the geology at the mining face beyond standard ore grade. Basic information management techniques must be used to integrate the results for a workable "big-picture" approach to mining and processing. The focus of the TOPIM project was on enabling responsive control of the entire process rather than optimizing isolated components of it. 


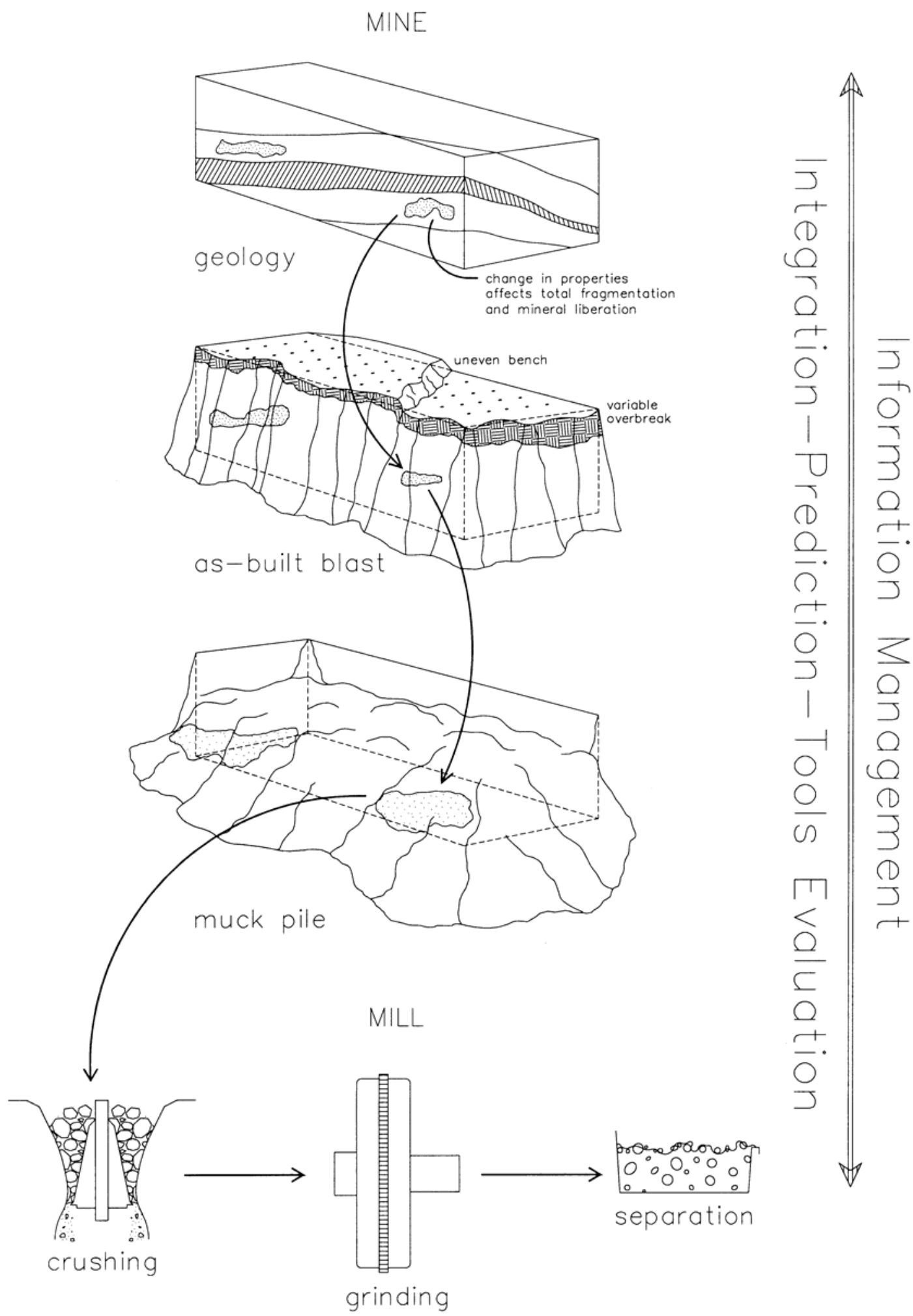

Figure 1. Schematic diagram of the TOPIM concept, which provides mine and mill personnel with the means to identify ore characteristics that affect downstream outcomes, in time to react before the ore reaches the sensitive processing step. 


\section{Energy Benefits}

The energy benefits shown in Table 1 below for iron ore are calculated in terms of one unit signifying one metric ton of iron ore, which grades from $15 \%$ to $30 \%$ iron (concentrated to about $65 \%$ iron in the pellets produced for steelmaking).

The crushing and grinding of all mineral products requires about $50 \%$ of the energy consumed in U.S. mineral processing plants (Wills, 1997). This fraction appears to be increasing as the average grade of iron orebodies decreases; Kakela (1978) reported that crushing and grinding of taconite consumes $35 \%$ of the total energy required to produce pellets. Iron milling is particularly energy-intensive because the ore is both strong and abrasive, particularly as the silica content increases. Furstenau et al. (1997a) estimate that the total energy consumption for comminution of all ores in the U.S. is 33 billion $\mathrm{kWh}$ per year. A $10 \%$ reduction in comminution energy (Furstenau et al., 1997b) is a reasonable goal using the best practices available to the minerals industry today, of which the type of practice represented by TOPIM is an important part.

One unit-year of operation is assigned as the total iron ore produced in the United States in 2006: 54 million metric tons/yr (U.S. Geological Survey, 2007). Iron ore formed 16.6\% of the value of the U.S. metallic mineral production, and $4.6 \%$ of U.S. nonfuel mineral production, in 2004 (U.S. Geological Survey, 2004). Extrapolating the trends of 2000-2004 through the next ten years (Figure 2) predicts that iron ore may contribute 23\% and 6\% of the respective values of U.S. metallic and nonfuel mineral production by 2016. Extrapolation is not as reliable as interpolation; nevertheless, these figures give some basis for understanding the magnitude of the effect of reducing energy usage in U.S. mining and milling.

The energy for comminution is overwhelmingly transmitted through electricity, used to power the motors of all the various types of crushers and grinding mills. Explosives (chemical energy) apply a much smaller amount of energy to the rock mass during initial fragmentation and are not included in the Energy Benefits table. In 2002, production of primary metals consumed 9.35\% of all the energy used in the U.S. (Energy Information Administration, 2002).

With $10 \%$ savings in comminution energy, increase in iron ore production over the next ten years predicated on the trends recorded since 1982 (Figure 3), costs escalating in step with mineral value, and energy costs of $\$ 0.05 / \mathrm{kWh}$, the potential cost savings by 2016 for U.S. iron producers would exceed $\$ 2.38$ billion, for U.S. metal ore producers $\$ 10.3$ billion, and for all U.S. mineral producers $\$ 38.1$ billion. The 10-year energy savings for iron ore producers alone is estimated at 162,570 billion Btu.

Table 1. Projected energy benefits for iron ore production from $10 \%$ savings in comminution energy.

\begin{tabular}{|c|c|c|c|c|c|}
\hline Energy Source & $\begin{array}{c}\text { Current } \\
\text { Technology } \\
\begin{array}{c}\text { (Btu/year/ } \\
\text { unit) }\end{array}\end{array}$ & $\begin{array}{c}\text { Proposed } \\
\text { Technology } \\
\begin{array}{c}\text { (Btu/year/ } \\
\text { unit) }\end{array}\end{array}$ & $\begin{array}{c}\text { Energy } \\
\text { Savings } \\
\text { (Btu/year/ } \\
\text { unit) }\end{array}$ & $\begin{array}{c}\text { Units } \\
\text { Produced } \\
\text { in } 10 \text { Years } \\
(2006-2016)\end{array}$ & $\begin{array}{c}\text { Cumulative } \\
\text { Energy } \\
\text { Savings } \\
\text { (Btu) }\end{array}$ \\
\hline electricity (iron ore) & $2,310,000$ & $2,080,000$ & 231,000 & 703.765 Mton Fe ore & $162,570 \mathrm{~B}$ \\
\hline Totals: & $2,310,000$ & $2,080,000$ & 231,000 & & $162,570 \mathrm{~B}$ \\
\hline
\end{tabular}




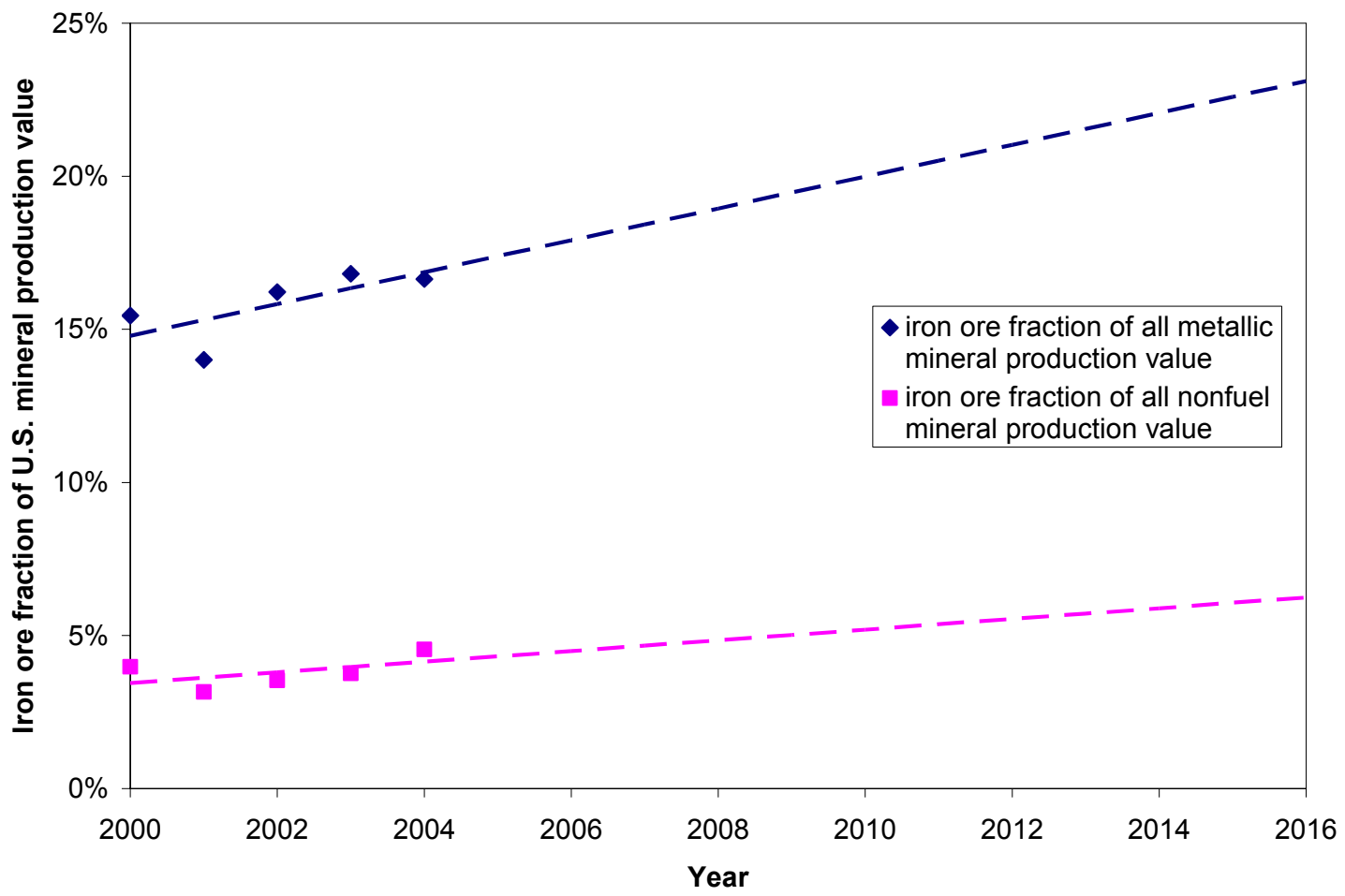

Figure 2. Proportion contributed by iron ore to the value of minerals (metallic and all nonfuel) produced in the United States (after U.S. Geological Survey, 2002 and 2004), extrapolated to 2016.

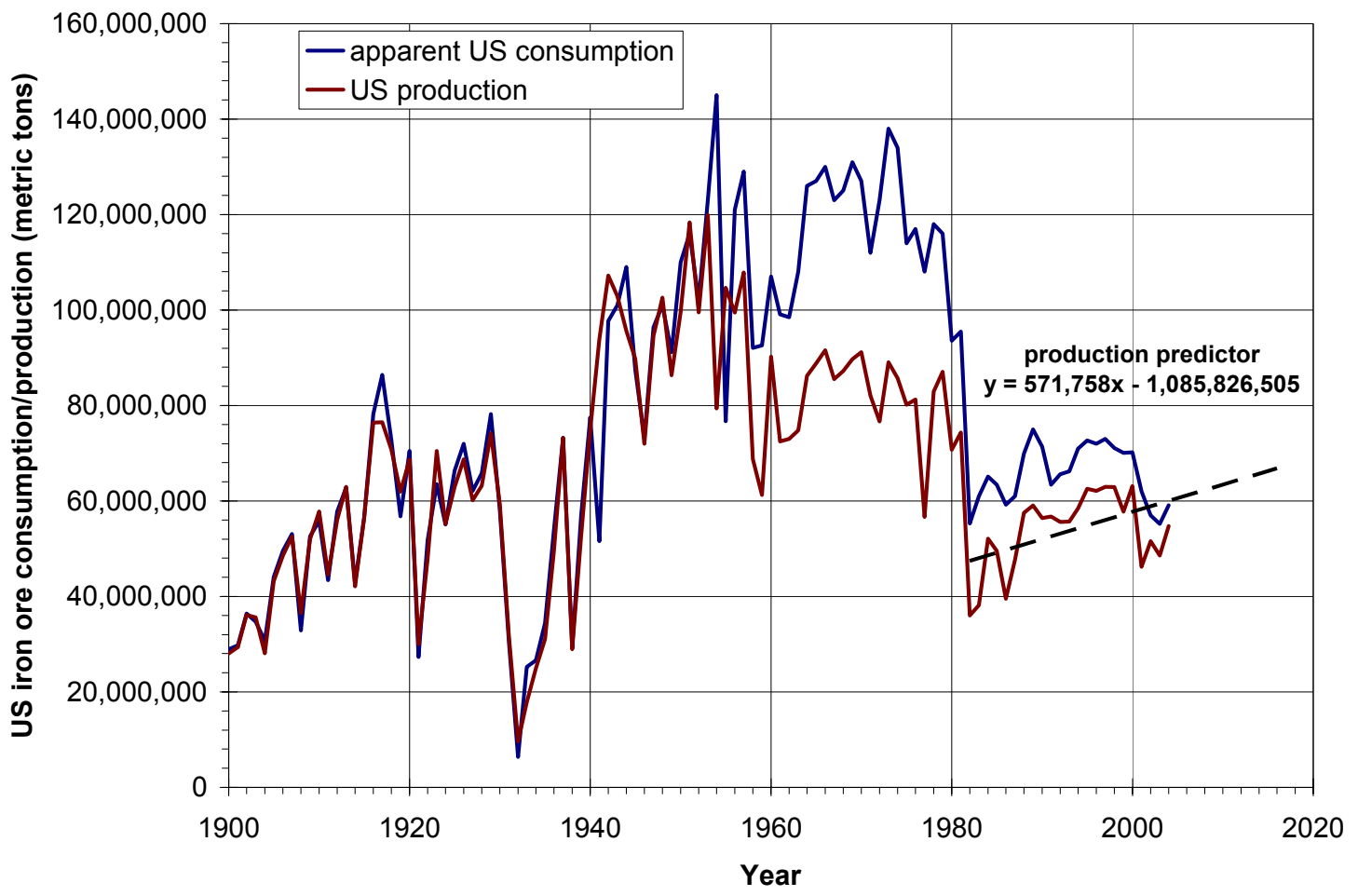

Figure 3. Historic iron ore production and consumption trends, used to predict iron ore production for 2006 through 2016 (after U.S. Geological Survey, 2005). 


\section{Sponsoring Program}

The TOPIM project was funded by the Industrial Technologies Program (ITP) Mining Industry of the Future partnership, a collaborative effort between the U.S. Department of Energy (DOE) and the National Mining Association. It is part of the portfolio of the Industrial Technologies program of the Energy Efficiency and Renewable Energy office of the DOE.

As stated by the U.S. National Academies (2005), "The mission of the ... ITP is to decrease the energy intensity of the U.S. industrial sector through a coordinated program of research and development (R\&D), validation, and dissemination of energy efficiency technologies and operating practices. To carry out this mission, the ITP partners with industry and other stakeholders in order to reduce U.S. reliance on foreign energy sources, reduce the environmental impacts of U.S. industry, increase the use of renewable energy sources, improve the competitiveness of U.S. industry, and improve the quality of life for U.S. workers, families, and communities."

Roadmap for Mineral Preparation

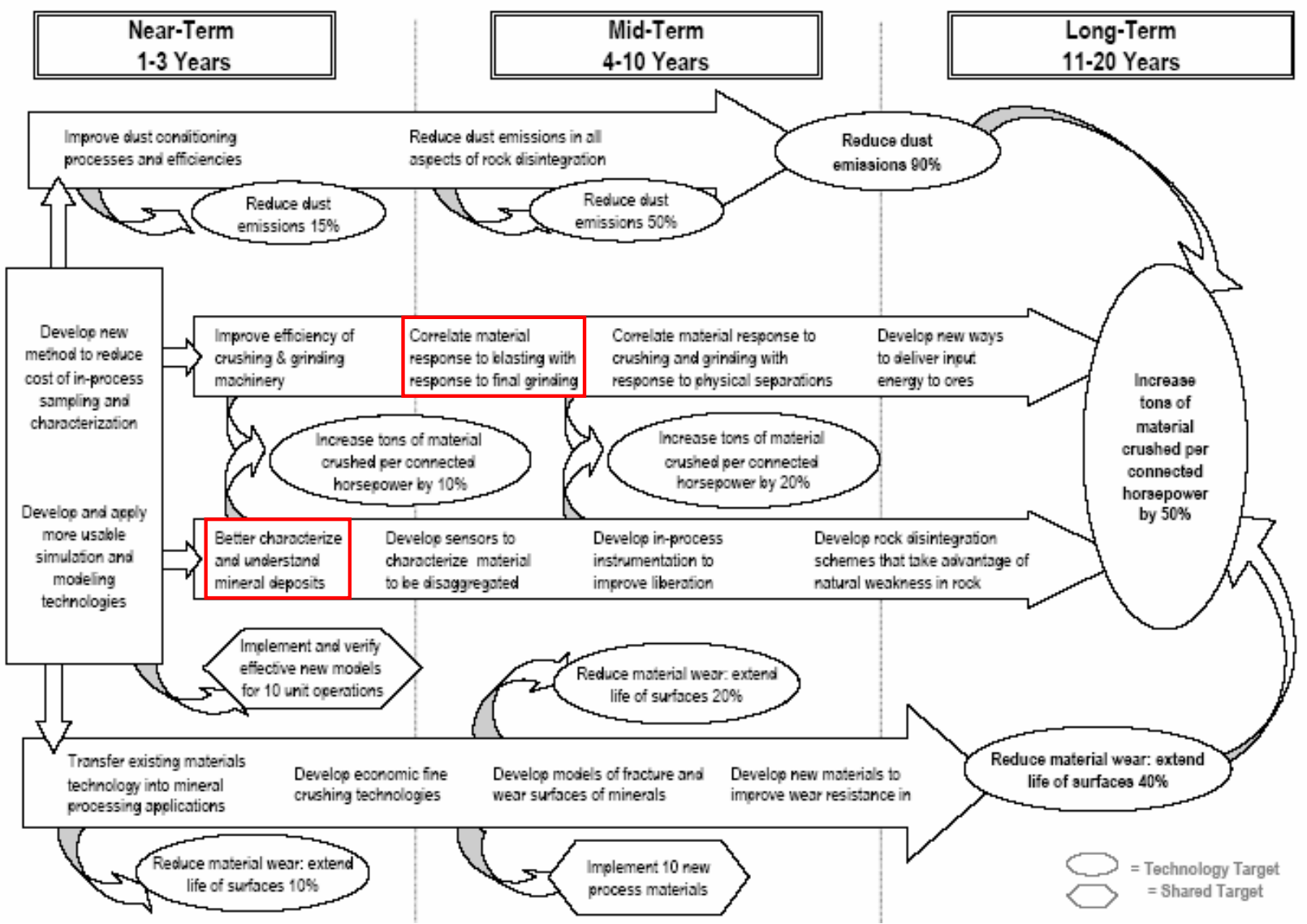

Figure 4. Where the TOPIM project fits within the goals of the Mineral Preparation Roadmap (U.S. Department of Energy, 2001). 


\section{Goals}

The TOPIM project laid out several specific goals at its outset, which also constitute the core of the approach (Figure 5):

- Determine ore characteristics that control fragmentation, comminution, liberation, concentration, and agglomeration.

- Determine how blasting affects mill performance.

- Determine how blasting can be adjusted to improve processing.

- Determine how the mill can be modified to take advantage of blasting.

- Determine how to monitor and evaluate system components (in-place ore properties, blasting, loading, hauling, muck properties, crushing, grinding, liberation, and concentration).

- Incorporate all findings in an ongoing, realtime database accessible by managers in all stages of production.

\section{Scope and Plan of Work}

Ore processing is a complex business. Traditionally mining has not needed a deeper understanding of the ore than where and at what tonnage the valuable minerals occur. As ore grades have fallen over the past few decades, other characteristics are increasingly coming into play. For example, if trace chemistry affects recovery or if rock strength affects comminution, new data - or new ways of analyzing old data - may be needed to control those factors and increase the efficiency of the mineral extraction process.

Additionally, as processes become more complex and more information is collected, management of the data becomes more complex and difficult. New data management techniques are needed. Many mining operations collect more data than they have the resources to analyze. The data can span several decades, and over that time many process changes are made. There is value to be added by reviewing the data already collected, with the improved understanding that hindsight can offer. Relationships among process performance factor can be discovered. Process improvement ideas that did not work can be discarded or the reasons for their failure discovered, permitting new ideas to develop with better chances of success.

Most importantly, historical data can gives direction to new ideas.

The TOPIM project is based on two principles: Baseline the current process by detailed measurements at various points in the process stream. After careful characterization of the process, a hypothesis that can potentially improve process efficiency is proposed. The hypothesis is then tested by making changes to the process, and measuring the effect of the change on the remainder of the process.

The two mines involved in the TOPIM project offered a unique opportunity: The ability to mine and process two different, but related, types of material in separate processing lines. With this resource, a series of hypotheses were tested and their outcomes were measured, by sending the ore that supports the hypothesis into one line, and the ore that contradicts it into another line. The measured differences in outcomes then either confirmed or denied the correctness of the hypothesis. 


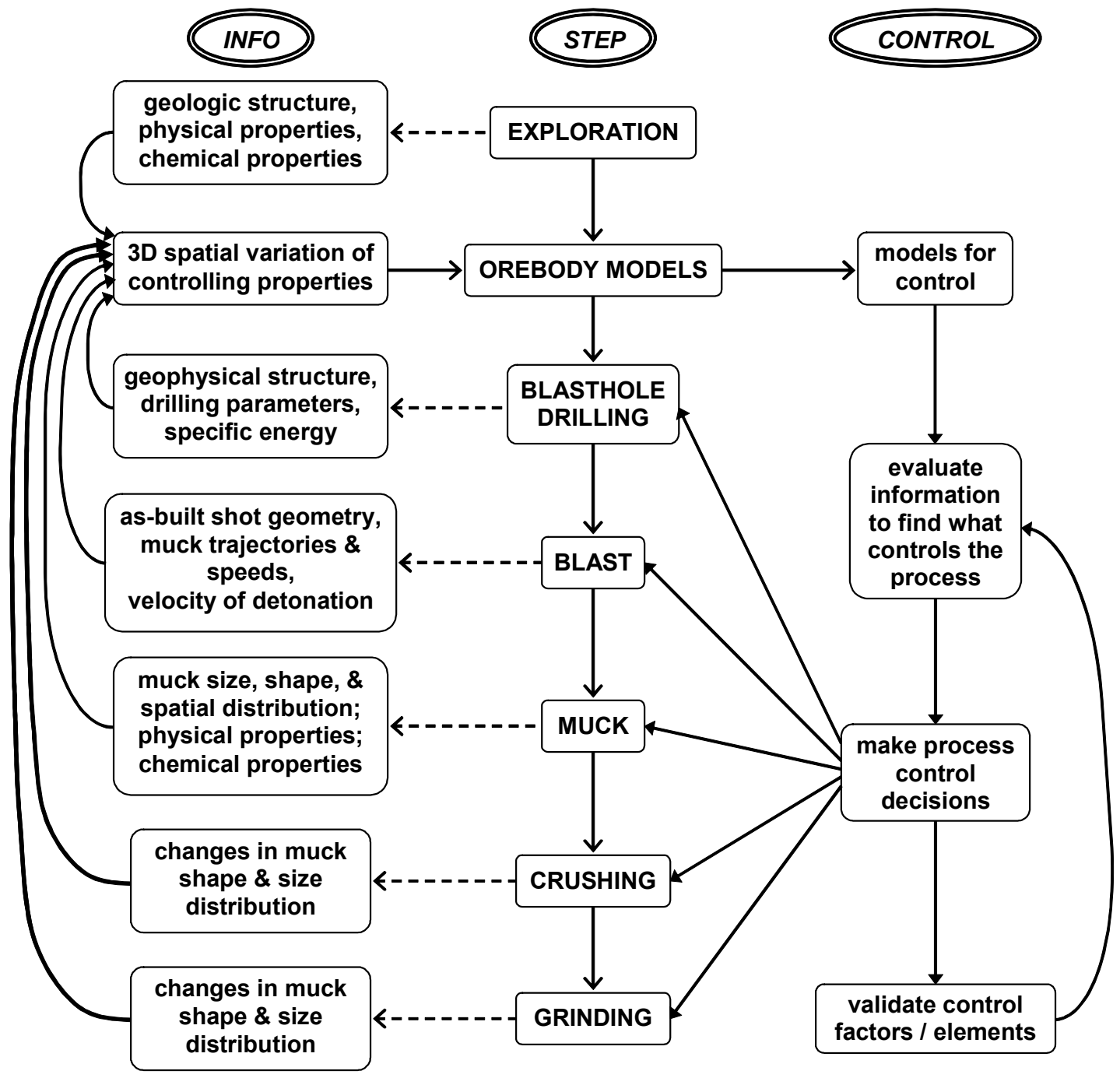

Figure 5. The technical approach to ore processing and integration that is the core of TOPIM.

\section{Barriers to Success}

At the outset of this project, a number of tasks were laid out, whose difficulty created a series of technical barriers to be overcome:

- Understanding particle size effect on grindability,

- Understanding blast damage effect on grindability,

- Optimizing blasting to improve grindability,

- Understanding and monitoring the physical parameters of the ore that control mineral liberation, and;

- Determining and implementing process improvements for blasting/crushing/grinding /liberation circuits based on upstream information. 
During the course of the project, however, several unexpected technical barriers emerged that had less to do with traditional mining and milling engineering and more to do with information technology and engineering:

- Data flow

- $\quad$ software communication issues

- timely data transfer

- Understanding the data

- $\quad$ source, algorithm, and/or pre-processing

- $\quad$ space and time intervals

- accuracy

- precision

- units

\section{Project History}

Although DOE OIT made the award in April 2003 and funding began August 20, 2003, the project actually began at a meeting at the U.S. Steel's Minnesota Taconite Mine (Minntac) in October 1997. Since then, Minntac staff and management have supported the project through its various permutations. From October 1998 to the summer of 2001, a series of discussions between the project team and Minntac staff took place in Mountain Iron, Minnesota to define the project. They involved significant time and project staff travel expense.

Project activity increased in May 2001, when Minntac hired a senior-year mining engineering student from Michigan Technological University (MTU), where the project was then based, for the summer. The student collected data that spanned the entire process from core drilling to mining, concentration, agglomeration, and pelletizing. Essential process control reports and data reported were collected and statistically analyzed.

Additionally, a series of discussions took place with Cleveland Cliffs Iron (CCI) to lay the framework for the research plan. A range of ideas to improve the project emerged.

Over the spring and summer of 2003, a series of meetings were held with two CCI mines: Northshore and Hibbing Taconite (Hibtac). The two mines have very different ore characteristics and process details. Hibtac was selected as the partner mine because it has a unique processing element: autogenous grinding mills, where the grinding media is large pieces of the ore itself. The choice permitted two distinct and very different mills to be compared, since Minntac employs a rod mill-ball mill process.

These efforts, made before the DOE funding award, involved significant resources: approximately $\$ 45,000$ from what became the project team, $\$ 30,000$ from U.S. Steel, and $\$ 10,000$ from Cleveland Cliffs. In addition, U.S. Steel provided $\$ 43,000$ to begin the project and to support a graduate student at Michigan Technological University.

After the DOE approved funding for the 3-year study that is the main topic of this report, the industrial partners contributed an additional $\$ 1,095,250$ and UMR added in $\$ 6,856$. The DOE contributed \$346,442 overall. 


\section{Background}

Both of the mines that took part in the TOPIM project operate in the Biwabik Formation of the Mesabi Iron Range in northern Minnesota. This important iron-bearing layer of Precambrian-age rock overlies quartzite of the Pokegama Formation and dips southward at a low angle (Figure 6). Although the two mines use somewhat different nomenclature when referring to those portions of the Biwabik that they mine (Table 2), the stratigraphy is basically as shown.

The higher-grade ore occurs within a 30 to 36-m section in the middle of the Lower Chert (blue in Figure 6). Beneath (pink in Figure 6) is a 9-m section of leaner ore.

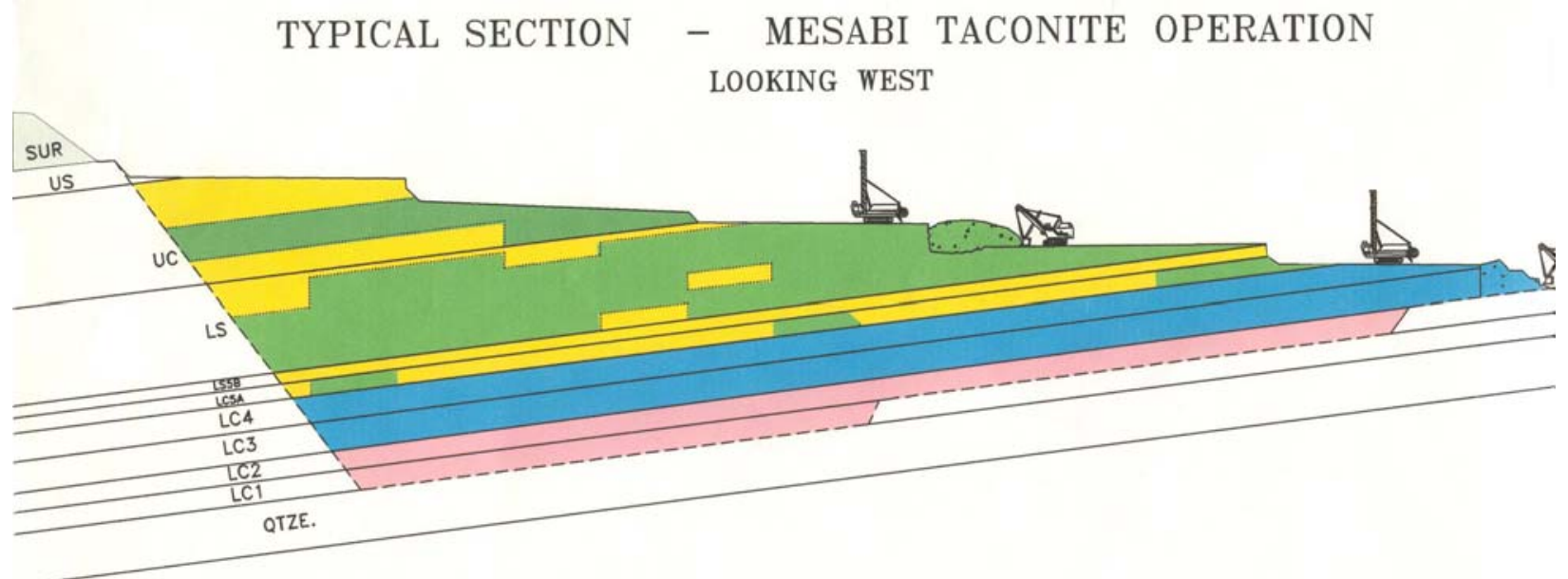

Figure 6. The basic geologic sequence of iron-bearing rock mined by the Minntac and Hibtac Mines (modified from a drawing by Minntac Mine personnel). Yellow denotes high-silica regions within the formations. SUR = surface material (glacial drift and mined waste rock), US = Upper Slatey, UC = Upper Cherty, LS = Lower Slatey, LC = Lower Cherty (contains the ore horizons).

Table 2. Correlation of layer terminology between Minntac and Hibtac mines, with general ore quality.

\begin{tabular}{|c|c|c|c|c|c|}
\hline Minntac & Hibtac & Quality & $\begin{array}{l}\text { Magnetic } \\
\text { Iron }\end{array}$ & Silica & $\begin{array}{c}\text { A- } \\
\text { Factor }\end{array}$ \\
\hline LC 1 and 2 & $1-3$ and $1-4$ & Best (3) & $20 \%+$ & $2-5 \%$ & Best \\
\hline LC 3 and 4 & $1-5$ and $1-6$ & Better (1) & $18 \%+$ & $3-6 \%$ & Better \\
\hline LC5 & $1-7$ & Smaller effect (2) & $15 \%+$ & $4-8 \%$ & Mixed \\
\hline LS & $\begin{array}{l}\text { Not present in } \\
\text { studied blasts }\end{array}$ & $\begin{array}{l}\text { Difficult, fine- } \\
\text { grained }\end{array}$ & & & \\
\hline
\end{tabular}


The process of winning iron from ore can vary from the simple to the complex, depending on the ore mineralogy and many other factors. However, each extraction operation, including both project partner mines, must perform the same basic steps:

1. Modeling - Starting with core data, model the ore, the mine and the process.

2. Mining - Blasting, excavation, and transportation.

3. Crushing - size reduction from run of mine to mill feed. Iron ore crushers are generally quite large in capacity and size input.

4. Milling - after the crushing, milling (or grinding) reduces the ore to liberation size.

5. Concentration - Concentrating the amount of iron and reducing the amount of silica.

6. Agglomeration - manufacturing the iron pellets for blast furnace feed.

Minntac Mine was begun in the 1960's near where the first shipment of iron ore from the Mesabi Iron Range was produced in the 1800's. Over the next thirty years Minntac grew to become one of the largest iron mine and mill complexes on the continent. In the late 1990's the pit haulage system was converted from rail to truck. Minntac produces approximately 13 million tons per year of taconite pellets for steelmaking, during operation of three eight-hour shifts per day, seven days a week. As presently set up, the concentrator is designed to concentrate the magnetic iron, then remove the silica, in 13 steps (Figure 7) that include:

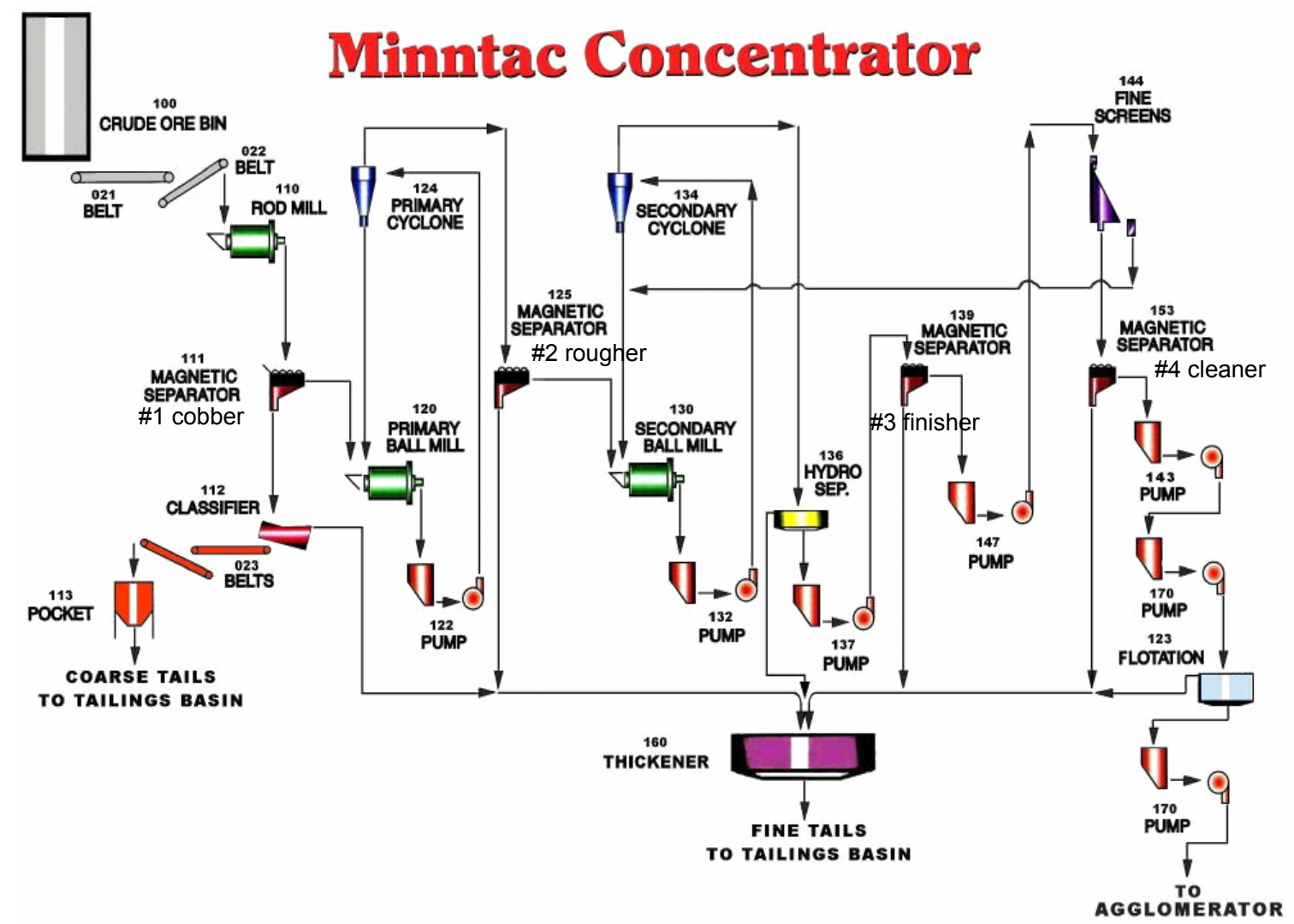

Figure 7. The Minntac concentrator circuit as it was when the TOPIM project began in 2003. 
- Crushing

- $\quad$ Rod Mill grinding

- 2 Magnetic Separations + Ball Mill grinding (Cobber and Rougher)

- Hydraulic Separation ( a thickener)

- Magnetic Separation + Ball Mill grinding (Finisher)

- Fine Screening

- Magnetic Separation (Cleaner)

- Froth Flotation

- Column Flotation

The Hibtac Mine is situated roughly in the center of the Mesabi Iron Range. The mill features two $1.5-\mathrm{m}$ gyratory crushers set to $23 \mathrm{~cm}$ opening, nine $11.0-\mathrm{m}$ diameter, fully autogenous grinding mills, and two stages of magnetic separation. Pellet production began from the Lower Cherty member of the Biwabik Formation in 1976, with the first shipment occurring in 1977 (Cliffs Mining Co., 2004). Presently they produce about five million tons per year of taconite pellets, also during 24-7 operation. Their concentration process (Figure 8) concentrates the magnetic iron content of the ore, but in five steps, and accepts the silica that comes along for the ride:

- Crushing

- Autogenous Mill grinding

- 2 Magnetic Separations (Rougher - Finisher)

- Fine Screening

- Verti-Milling

These two mines employ very different concentration processes, compared directly in Table 3. They operate in the same geological formations, but over the years they have developed different approaches to characterizing the layers. This is due partly to the fact that Minntac mines the Lower Slate as well as the Lower Chert, floating off excess silica after concentration by magnetic separation, while Hibtac works entirely within the Lower Chert, relying entirely on the results of magnetic separation.

\section{Report Layout}

The large scope and size of the TOPIM project require that this report be broken down into a number of subsidiary studies: 


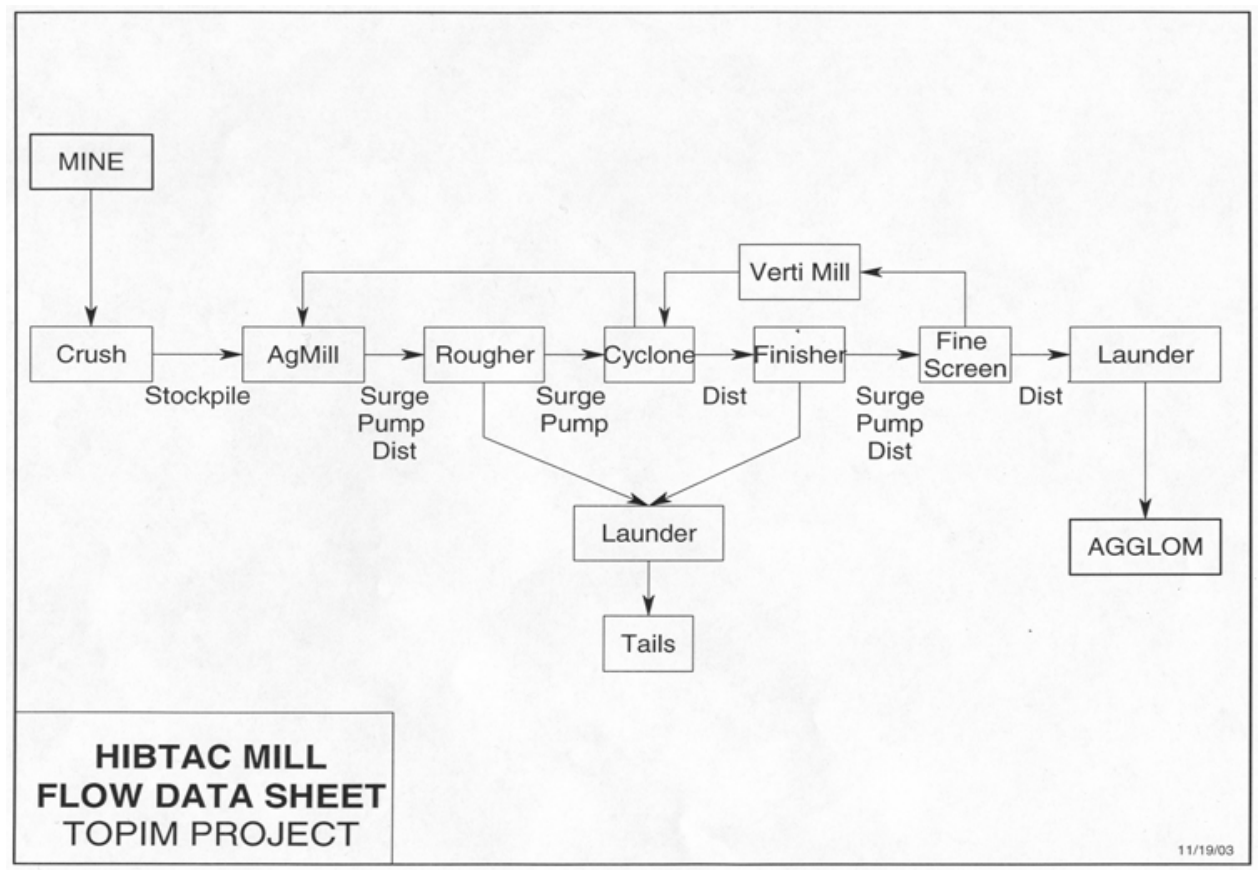

Figure 8. The Hibtac Mine concentration circuit.

- Data Mining

- Grindability

- Rock Physical Properties

- Drill Monitoring

- Fragmentation

- Orebody Modeling

- Ore Segregation Tests

Table 3. Differences in the milling and concentration processes of the two partner mines.

\begin{tabular}{|l|l|l|}
\hline \multicolumn{1}{|c|}{ PROCESS } & \multicolumn{1}{|c|}{ MINNTAC } & \multicolumn{1}{c|}{ HIBTAC } \\
\hline Milling (Grinding) & Rod mill $\rightarrow$ 2 Ball Mills & 35 ft Autogenous Mills \\
\hline Iron Concentration & $\begin{array}{l}\text { Magnetic Separation - 3 Stages } \\
\text { Cyclones - 2 } \\
\text { Hydroseparation - 1 Stage } \\
\text { Fine Screen - 1 Stage }\end{array}$ & $\begin{array}{l}\text { Magnetic Separation - 2 Stages } \\
\text { Cyclones - 2 }\end{array}$ \\
\hline Silica Concentration & Flotation Cells and Columns & Fine Screen - 1 Stage \\
\hline
\end{tabular}


- Statistical Analysis

- Commercialization

- Dissemination and Outreach

These are discussed in the following sections before some conclusions are drawn and some recommendations are made for future work. Following a list of the references cited in the report is a series of appendices containing supporting information. 


\section{Data Mining}

\section{Minntac Mine}

The mines know they need more data, but what data, where should it be collected, and how is it collected? Data collection costs money.

A data flow sheet is one tool toward a solution. The goal of data flow sheet use is to organize the data used to control processing. To control a process, many measurements are necessary, and understanding effectiveness of the measurements can be difficult. Adding new measurements is expensive and may be futile without guidance from current practice.

Constructing a data flow sheet starts with a process flow sheet and then adds the data collection points and the type of data collected at each point.

At Minntac, a data flowchart (Figure 9) was constructed by adding the most important data collection points to the process flow sheet. This flowchart incorporates the type and location of all sources of data regarding the ore and its transformation into pellets ready for shipment. The data flowchart was used extensively in the analysis of the ore segregation tests to come. 


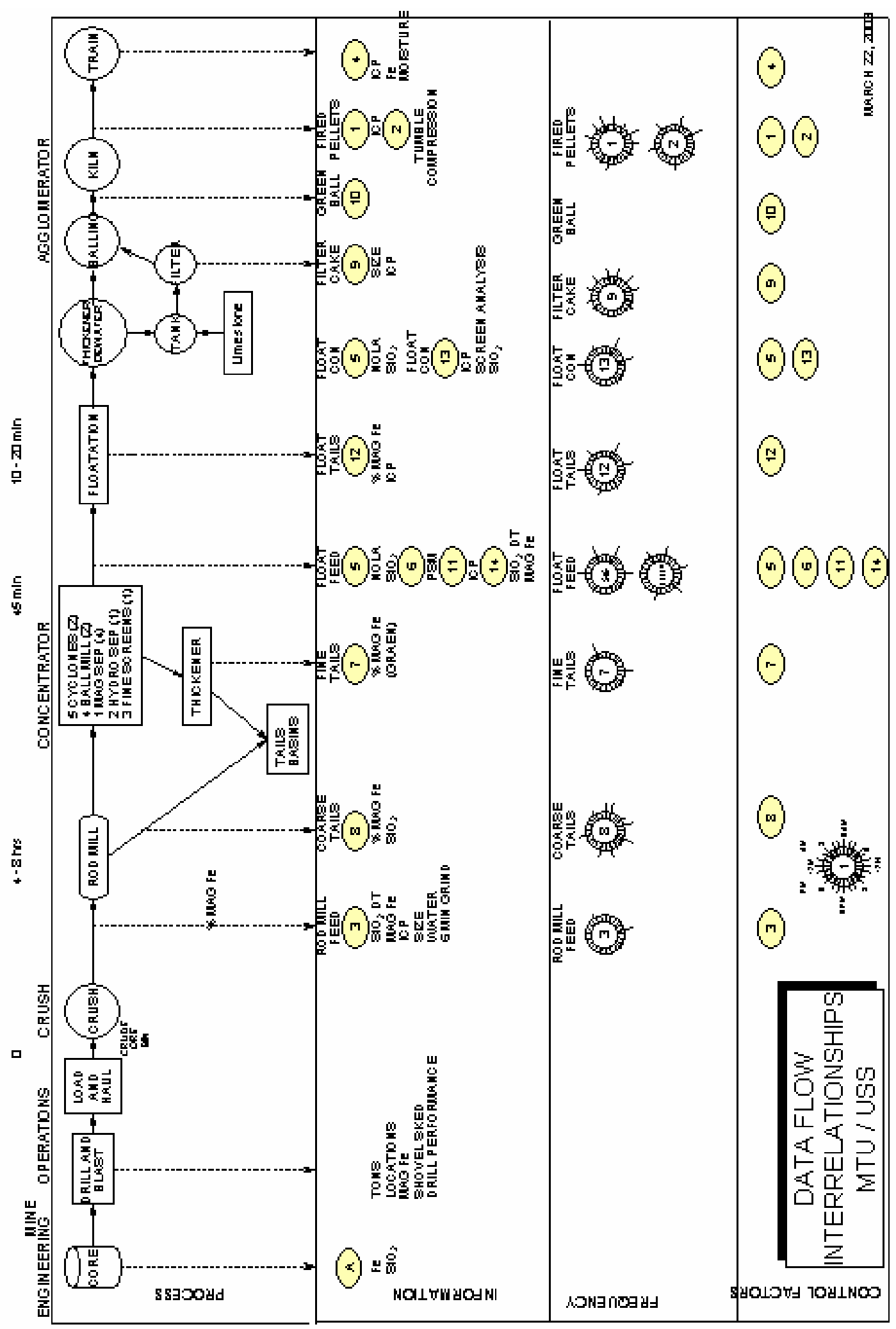

Figure 9. The flowchart developed for the Minntac Mine to show data sources and their relationships to the mining, concentrating, and agglomerating process. 


\section{Hibtac Mine}

Eloranta Associates compared powder factor to crusher performance, mill throughput, and mill power consumption for Hibtac Mine during the several years prior to DOE funding of the TOPIM project, a study which is summarized in Figures 10 through 13.

CORE LENGTH, WT REC \& SIO2

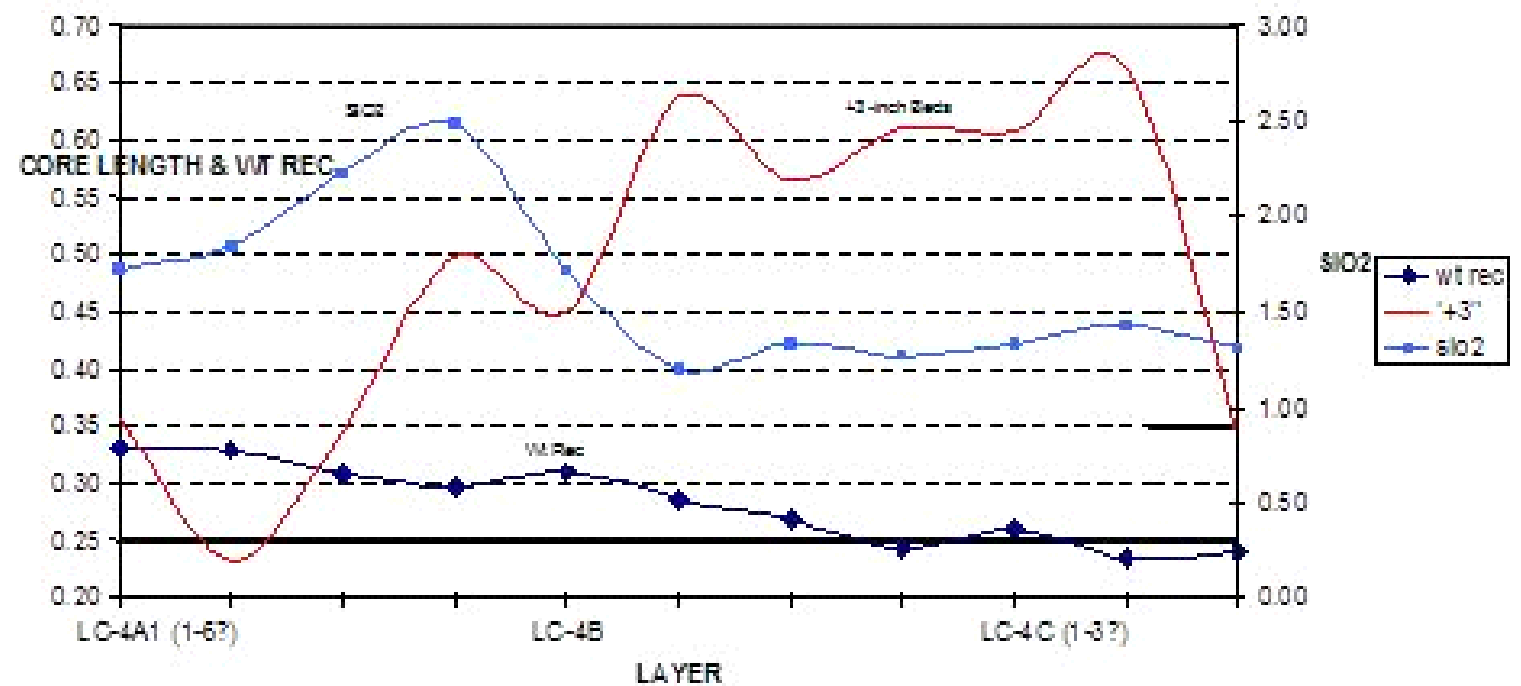

Figure 10. Hibtac Mine geologic formation versus core recovery and silica content. The two mines in this study use different labels for the ore formations, so both methods are used in this graph. From Eloranta and Workman (2003).

FragrettaionVs Becting

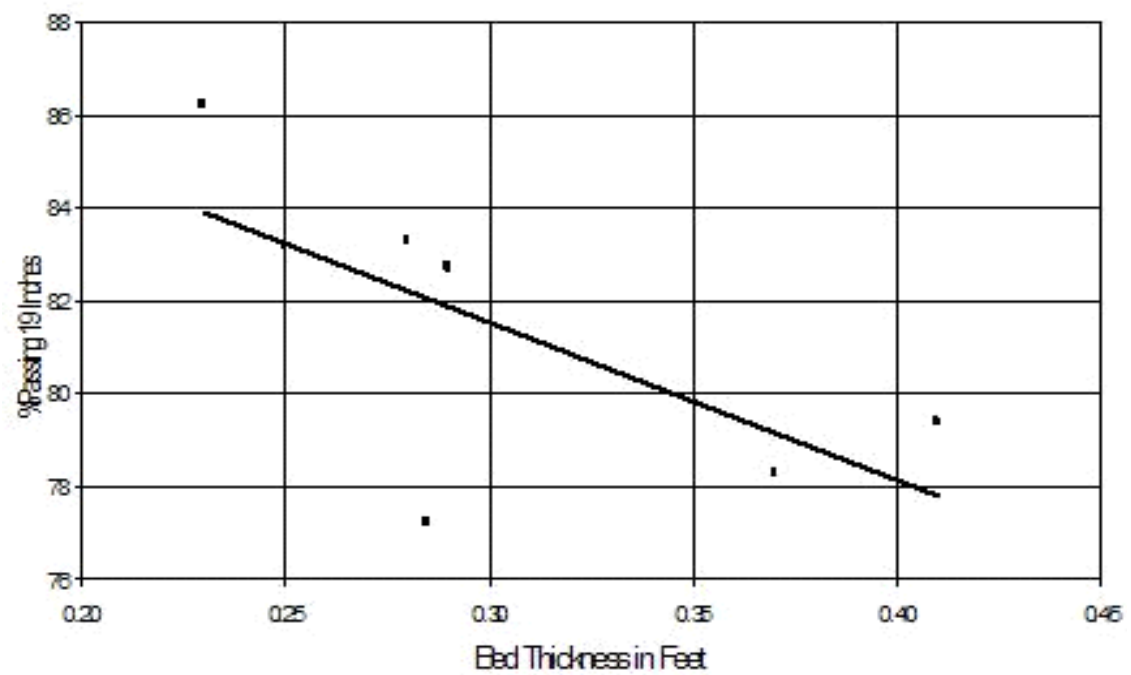

Figure 11. Hibtac Mine formation thickness versus primary fragmentation (blasting) results. From Eloranta and Workman (2003). 


\section{Mill rate v PF}

$1-3 / 4$ less than $20 \%$

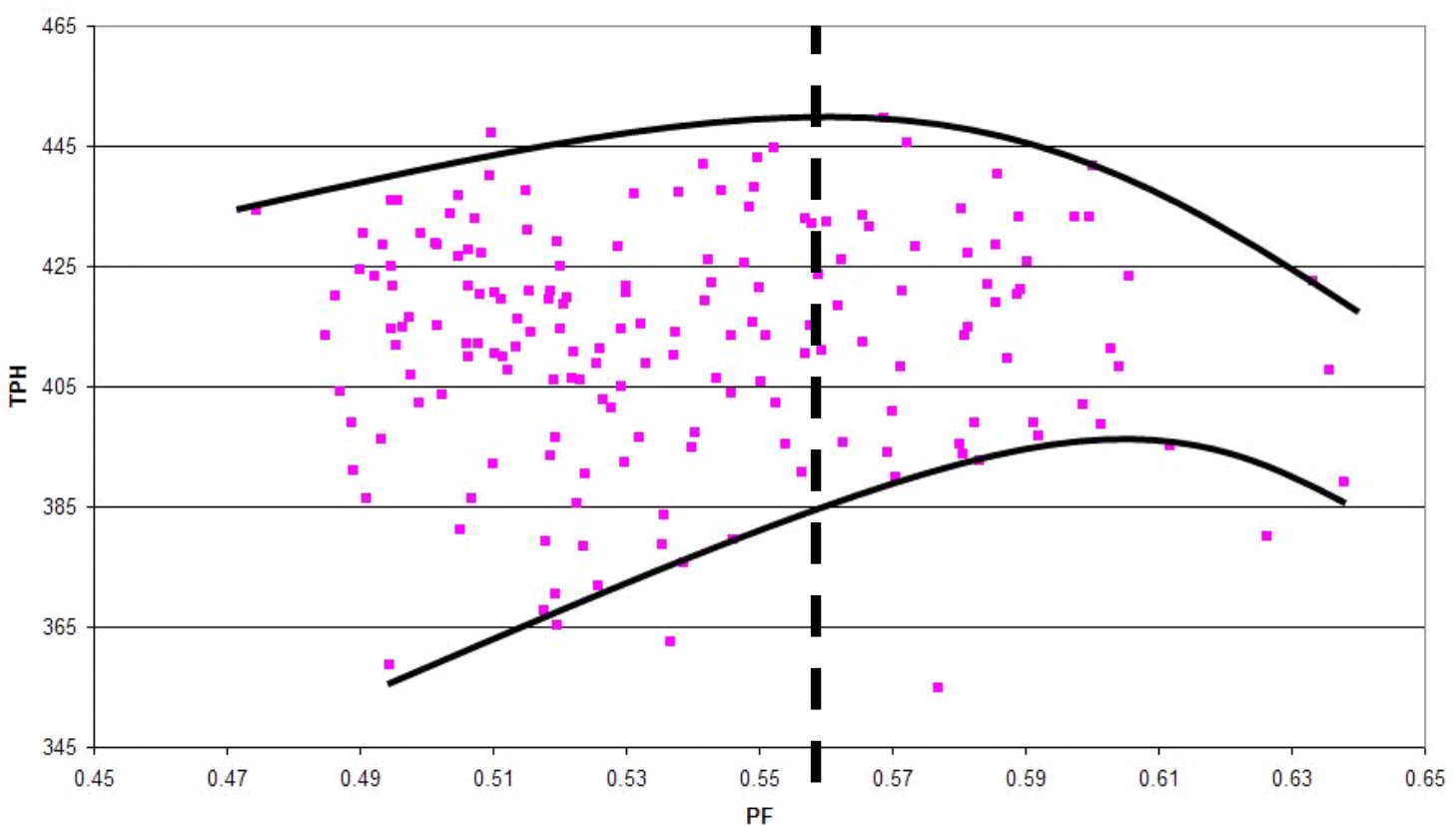

Figure 12. Hibtac Mine powder factor versus mill throughput. This was the basis for selecting the recommended powder factor (dashed line) for the first ore segregation test at Hibtac Mine. From Eloranta and Workman (2003).

Crusher Power v PF

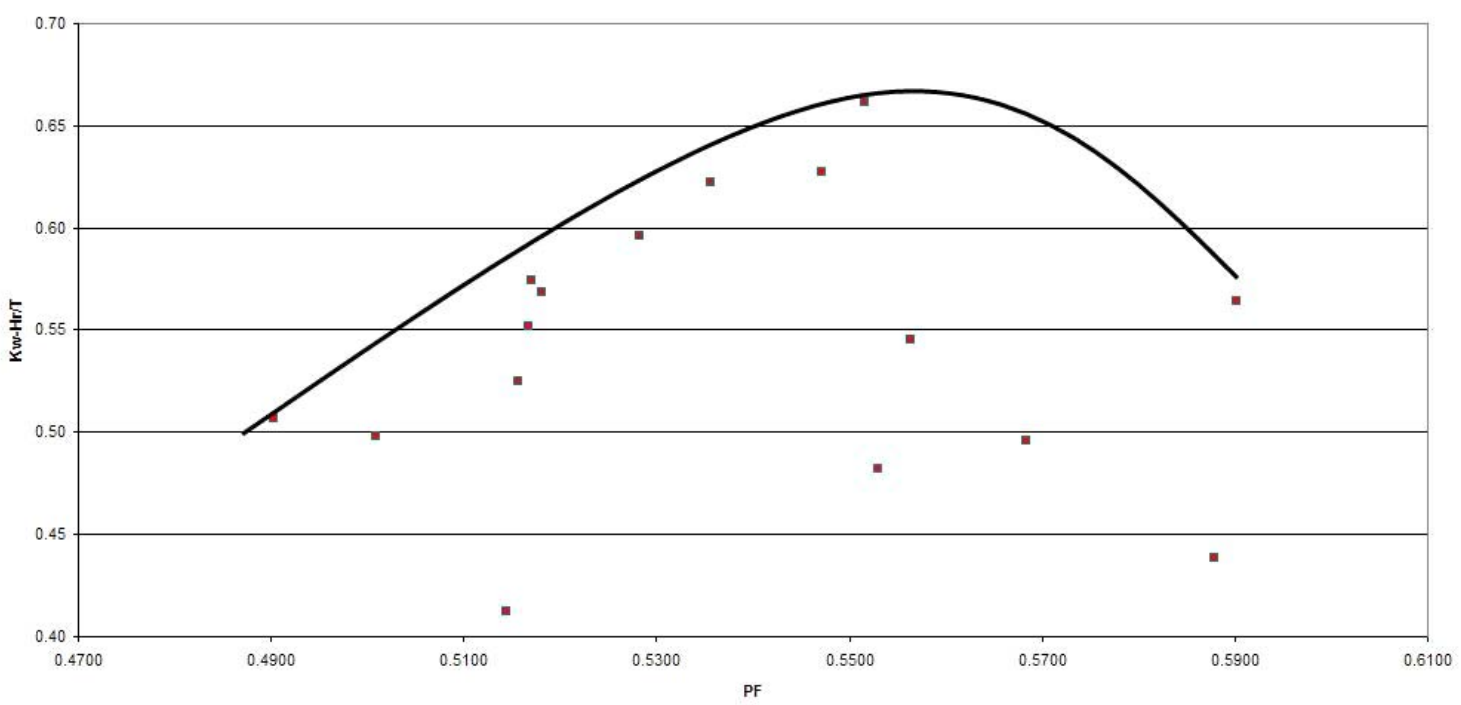

Figure 13. Sixteen months of powder factor versus normalized primary crusher power draw at Hibtac Mine. Note that the crusher can apply more energy to the feed as the ROM size decreases, but very fine blast fragmentation causes the crusher to act as a chute. This causes the reduced power draw at higher powder factors. From Eloranta and Workman (2003). 
Figure 14 illustrates a graphical analysis of six months of muck size distribution data, compared with a liberation index calculated in terms of expected grinding mill power draw, for the Hibtac Mine during the period immediately preceding the start of the TOPIM project. The liberation index is the functional equivalent to the A-factor calculated by Minntac Mine.
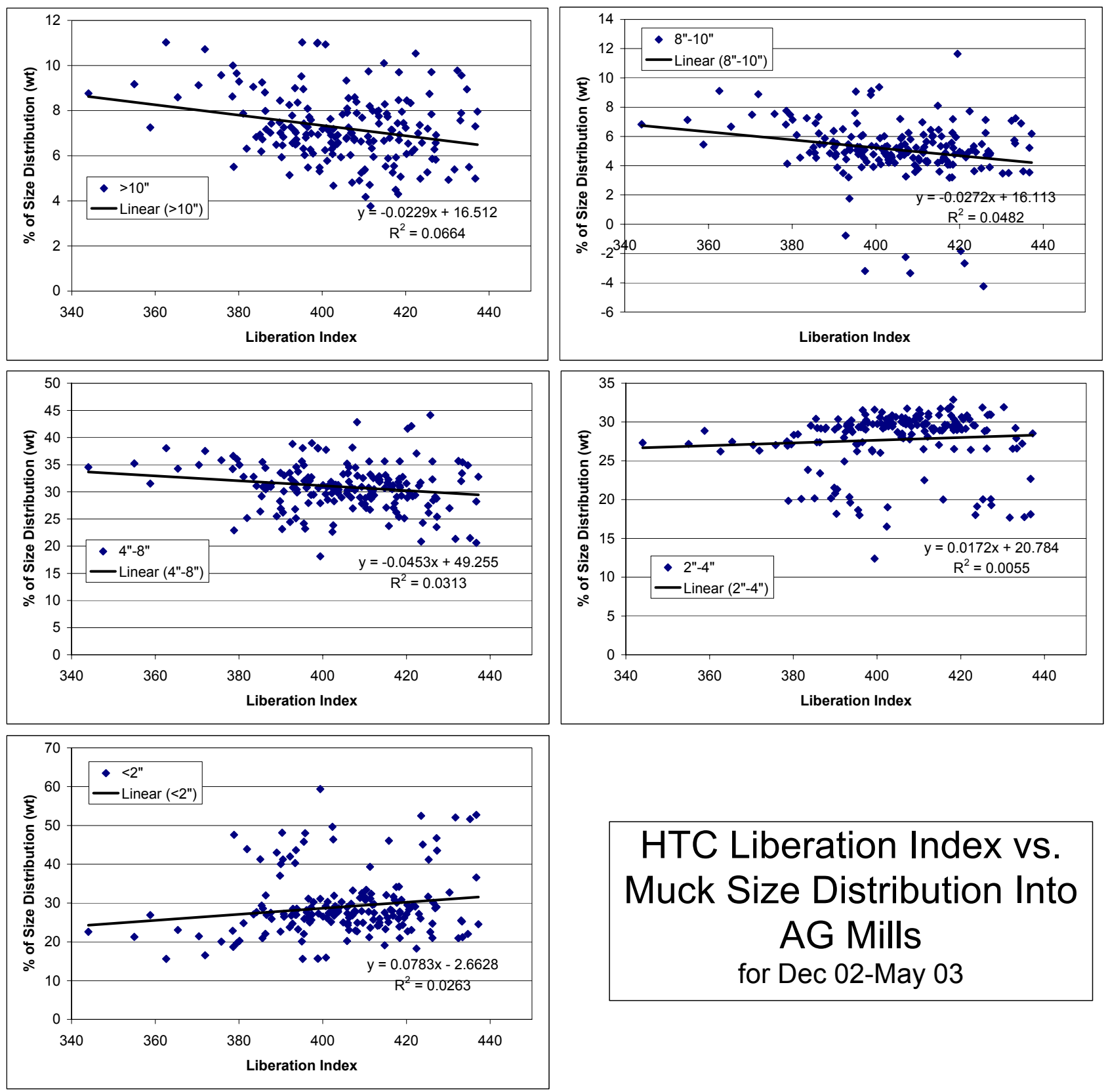

\begin{tabular}{|c|}
\hline HTC Liberation Index vs. \\
Muck Size Distribution Into \\
AG Mills \\
for Dec 02-May 03
\end{tabular}

Figure 14. Pre-TOPIM trends in Hibtac mill performance as a function of mill feed size distribution. 
Average annual mill production from 1977 to 2005 (the full life of the mine) was compared to the average normalized energy draw by the crushers and by the autogenous mills, and to powder factor. Since each average incorporates data from an entire calendar year, the effects of seasonal cycles are presumably balanced, although discussions with mine personnel are inconclusive on this. Figure 15 illustrates the basic trends with time-series plots of the data.

The powder factor has increased steadily since 1989, with a spike in 1996 and a potential jump beginning in 2005 (Figure 15A). Mill total production and production rate have reached a plateau from which they are falling slightly (Figure 15B). If iron pellet production is increasing at the same time, this would indicate increasing energy efficiency. Crushing energy requirements have increased to a plateau reminiscent of the production figures, while grinding energy is almost a mirror-image of the crushing energy curve (Figure 15C). Grinding energy is one and a half orders of magnitude greater than crushing energy, but the very close correspondence at even this relatively coarse scale indicates a tight correlation; in other words, as the energy required by crushing increases, the energy required by grinding decreases 100 -fold. The trick is to induce this behavior to happen repeatedly, and it appears that Hibtac Mine is being successful. Several aspects of the data set confirm that the performance of the autogenous grinding mills controls the performance of the circuits - not a great surprise in itself.

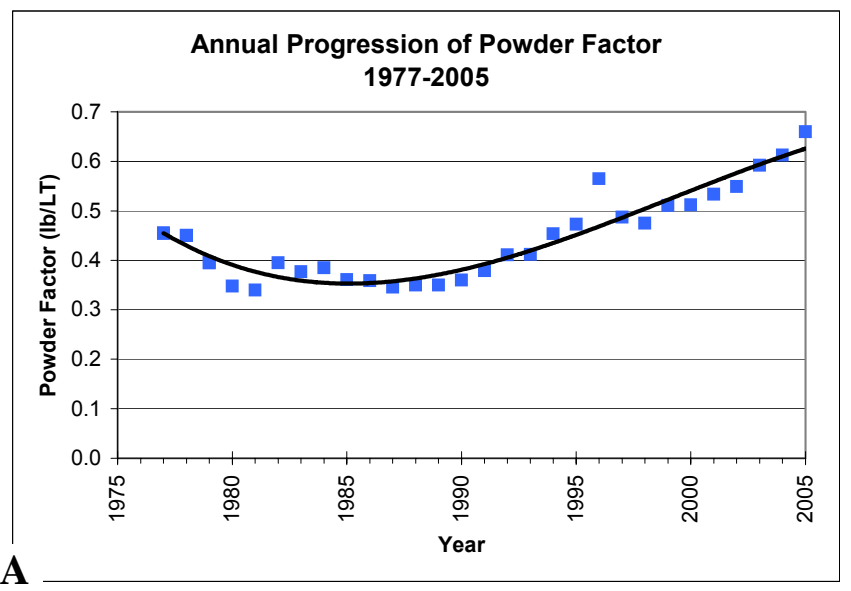

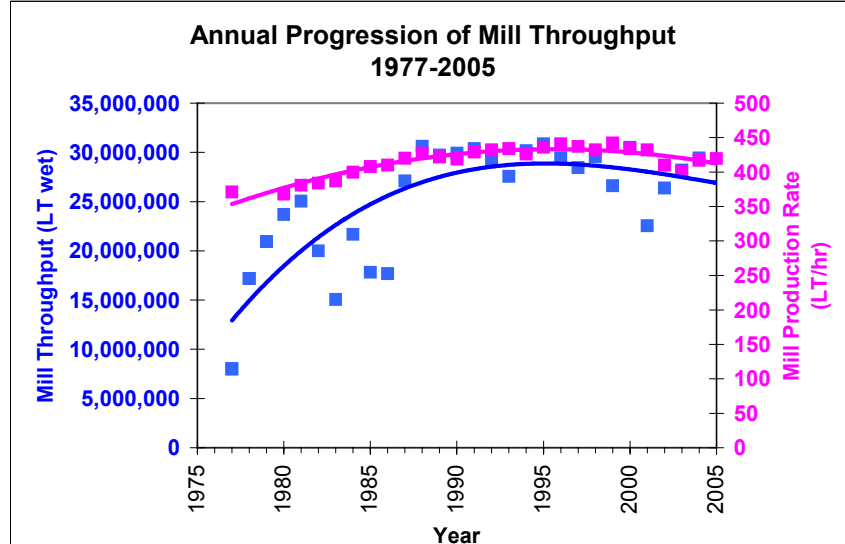

B

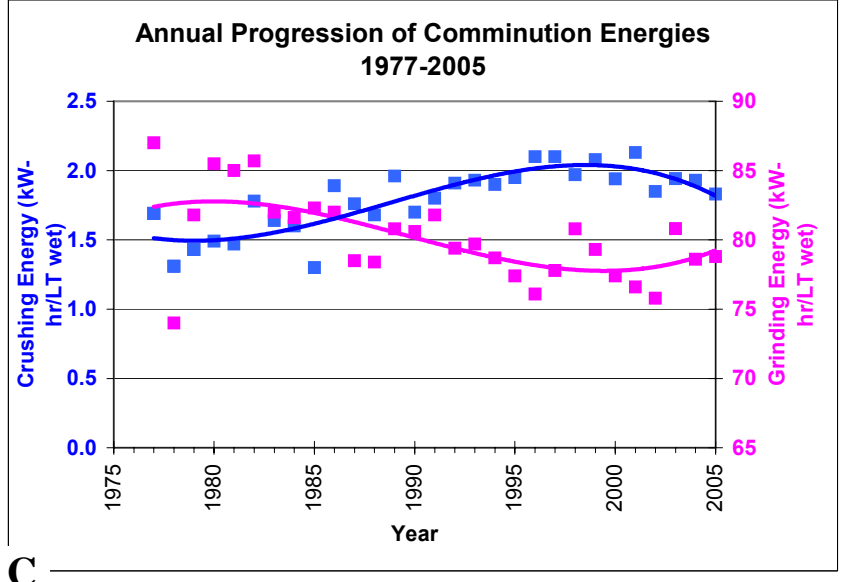

Figure 15. Average annual powder factor and mill production data for Hibtac Mine since 1977. 

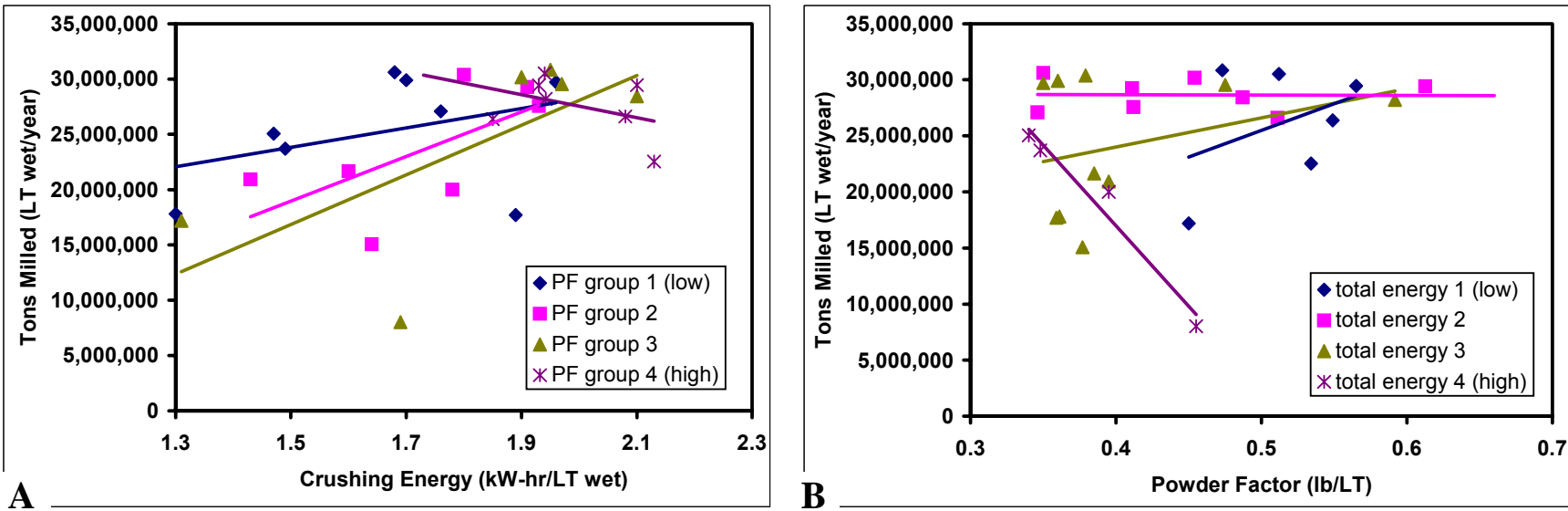

Figure 16. Some basic relationships among average annual mill production data for Hibtac Mine.
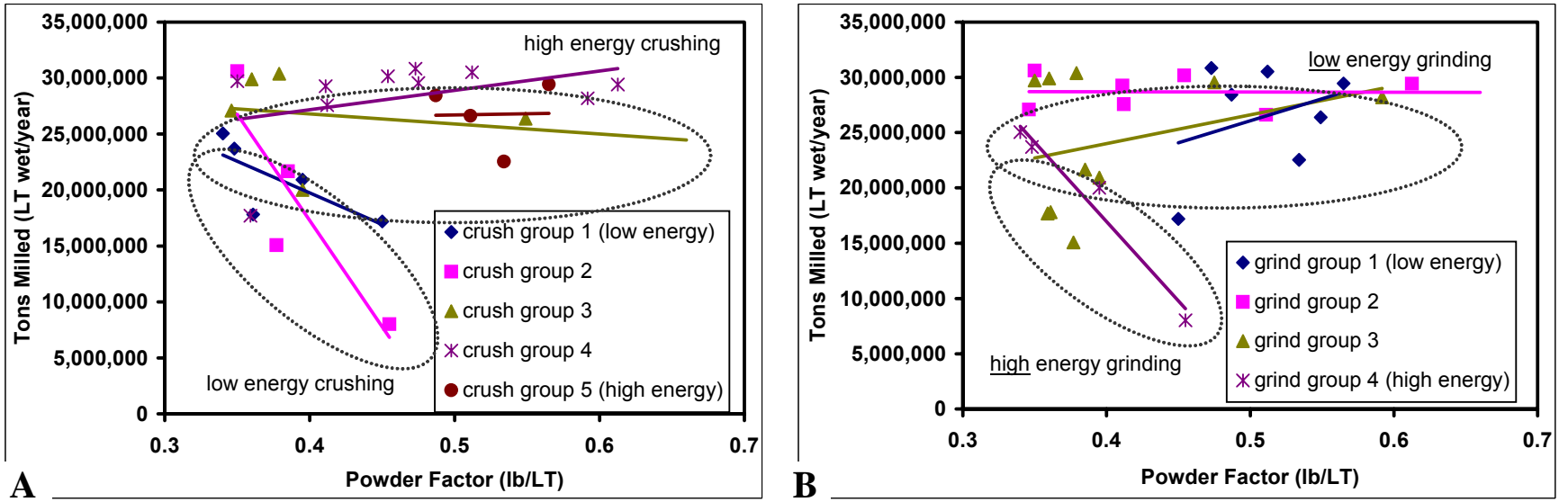

Figure 17. Total production of the mill as a function of powder factor, when crushing energy $(A)$ and grinding energy (B) are taken into account.
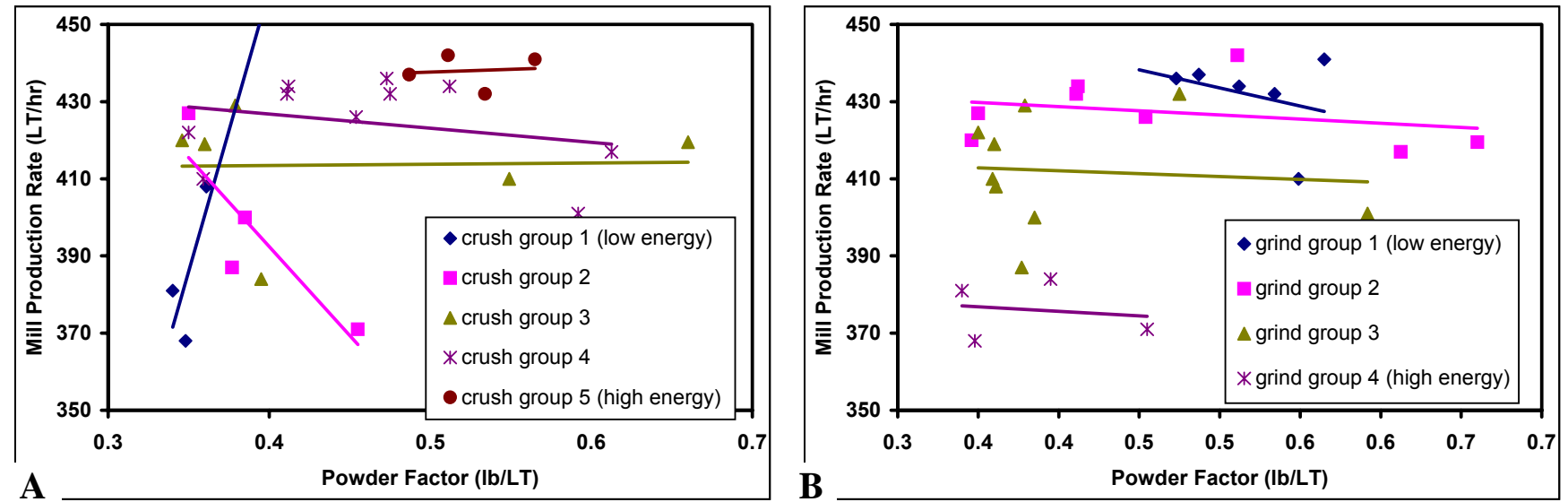

Figure 18. Mill production rate as a function of powder factor, when crushing energy $(A)$ and grinding energy (B) are taken into account. 
Bear in mind that these charts do not explicitly take account of the changing stripping ratio and geologic trends that the mine has experienced since 1977. These factors undoubtedly affect the data shown, but could not be quantified in these charts. The behavior attributed below to changes in powder factor, crushing energy, and grinding energy is actually due to changes in these factors, but since they are not included in this data set, the energy data serve as a proxy.

Figure 16A shows that more tons of ore pass through the mill when the powder factor is highest, and that crushing energy is negatively correlated with production totals for the highest powder factors. For all other powder factors, crushing energy correlates positively with production totals. In other words, the greater the portion of total energy that is devoted to crushing, even though this is an apparently minor component, the higher are the resulting production totals. Figure 5 (discussed below) supports this relationship and explores further the trends seen in Figure 16B. The energy required to grind the ore is $97 \%-98 \%$ of the total energy draw of the mill.

Figure 17A shows that tons produced is affected by powder factor only below a crushing energy of approximately $1.77 \mathrm{~kW}$-hr/long ton (wet). When crushing energy exceeds that threshold, powder factor appears to be irrelevant to the amount of iron produced. Figure 17B shows that production is negatively affected by powder factor above a grinding energy of approximately $81 \mathrm{~kW}$-hr/long ton (wet). In other words, the higher the powder factor used in the difficult regions of the mine, the lower the tons produced. This is likely a case of parallel effects rather than of direct cause and effect, so conclusions about energy control should not be drawn too quickly from this.

To restate, Figures 16 and 17 show that low energy requirements for crushing correlate with high energy requirements for grinding. Since the energy needs for grinding are 36-63 times that for crushing, more efficient crushing is strongly leveraged in the total energy balance. Moreover, the high crushing energy / low grinding energy points are those with higher production totals and production rates (Figures 18 and 19), and are essentially independent of the powder factor used to fragment the ore. Perhaps this is due to the relation of the mean size of the "grains" of iron and matrix minerals in the ore to the mean input and output sizes of the grinding circuits, and to the toughness of their inter-crystal bonding. The differences between this relationship in the difficult ores and in the more easily processed ores may be instructive for diagnostic algorithms for mill operation.

Figure 18 shows how the factors that control crushing and grinding energy requirements also affect the relationship between powder factor and the mill's production rate. The production rate of the mill is affected by the powder factor only when the energy required for crushing is below a certain threshold ( $1.7 \mathrm{~kW}-\mathrm{hr} / \mathrm{LT}$ wet). Mill production rate is slightly negatively affected by powder factor at all levels of grinding energy, and since grinding energy is so much greater than crushing energy, that is the overwhelming trend.

Figure 19 reverses the perspective on these same data, illustrating more clearly the effects that powder factor has on mill production rate. Mill production rate correlates positively with the energy required to crush the ore (Figure 19A). In fact, production rate becomes increasingly more sensitive to crushing energy as powder factor increases, but only until it exceeds about 0.50 lb/ton, at which point crushing energy becomes less important. Grinding energy and mill production rate are negatively correlated, on the other hand, but a sensitivity difference of production rate to grinding energy is again slightly evident for the highest powder factors. 

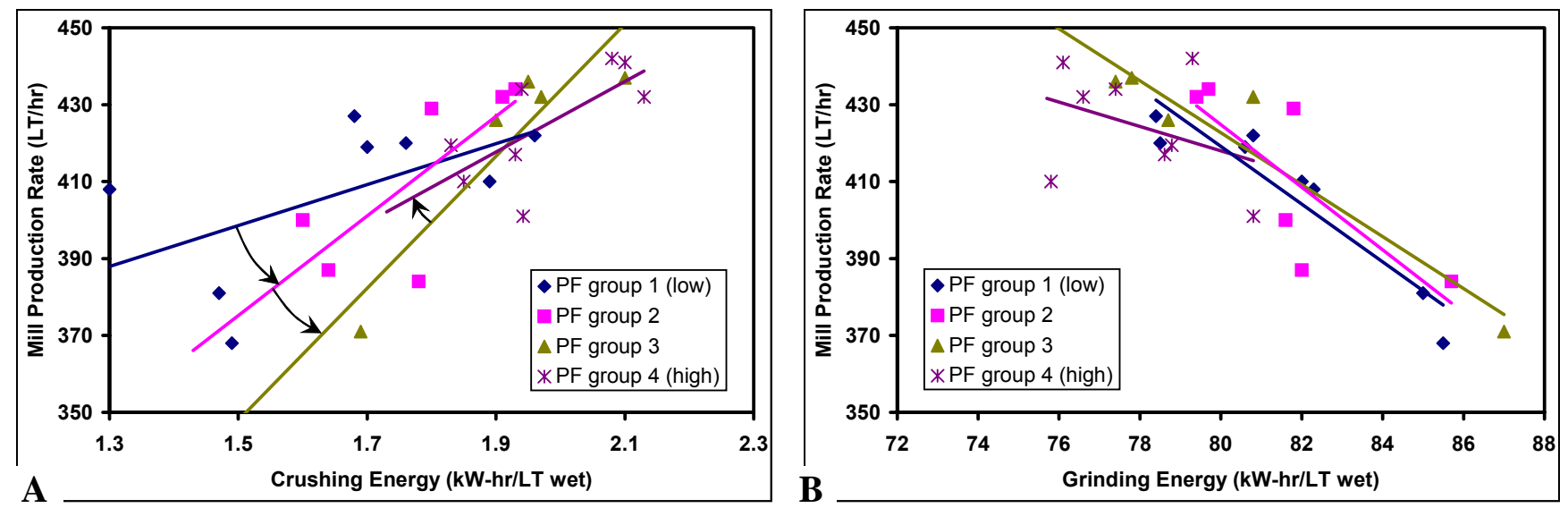

Figure 19. Mill production rate as a function of crushing energy (A) and grinding energy (B) when powder factor is taken into account.

A view of the same data but compared with some of the engineering and management trends underway at the time is shown in Figure 20. This reveals how factors that are difficult to quantify simply still have significant effects. Figure 21 shows the hidden effects of the mill improvements made in the 1980's, though that is not clear without Figure 20.

\section{Mill Rate vs. Blast Energy}

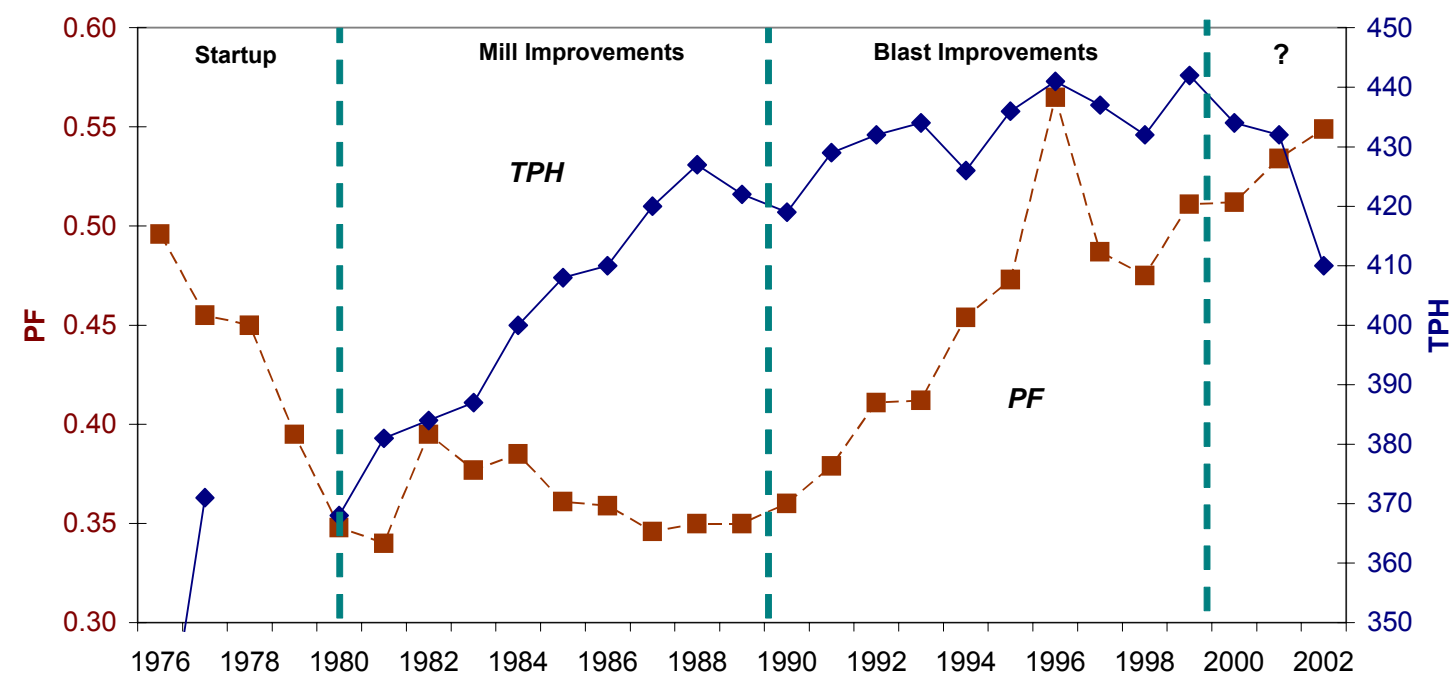

Figure 20. Historical review of mill production rate and powder factor at Hibtac Mine, correlated with some engineering and management trends. 


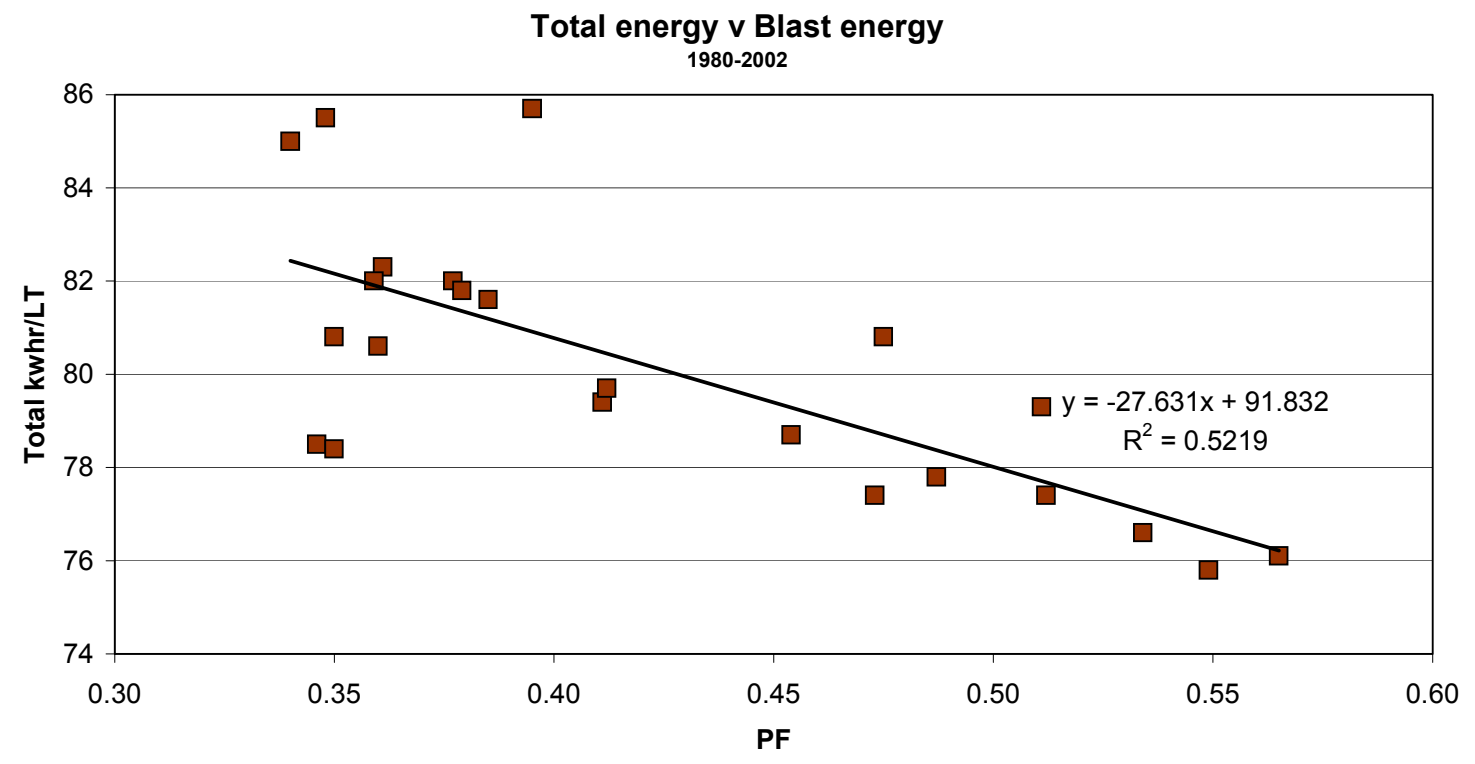

Figure 21. Historical review of the relationship of powder factor to total milling energy at Hibtac Mine. 


\section{Grindability}

Several approaches were evaluated for efficient description of the grindability curve as it is currently determined at Minntac Mine.

In the Mesabi Iron Range, the magnetic iron is contained within magnetite, which occurs in taconite as granules that average less than $0.1 \mathrm{~mm}$ in diameter. Even when they clump to form larger grains, the actual mineral crystals remain much smaller than the clump size. Therefore, the required particle size for effective separation of ore from waste is extremely fine; Minntac Mine uses the coarsest grind (85\% passing 270 mesh, or 53 microns max. size), while Hibtac Mine grinds to $80 \%$ passing 325 mesh (44 microns). Both mines follow this energy-intensive step with several stages of magnetic separation. Minntac Mine then applies hydrometallurgical techniques to remove much of the silica that remains in the concentrate.

\section{Minntac Mine}

The approach to characterizing the grindability of ore used at Minntac Mine plots the amount of time a particular sample has been ground (using very specific procedures and equipment) against the fraction of material finer than a certain particle size (53 microns, in this case) that results. The liberation constant determined by Hibtac Mine for their ore differs in the details.

The data in this example from a Minntac exploration corehole (Figure 22) has been fit with a straight line $(Y=m X+b)$ which, though simple to calculate, does not completely reflect the curve shown by the actual data points. An exponential curve can be used instead ( $Y=Y_{0}-C e^{-k X}$ ), where $Y$ is the silica content of the material produced by grinding to time $X$, and $Y_{0}$ is the curve's asymptote. Yet the results are not satisfying. Forcing the asymptote to $Y=$ $100 \%$, its correct physical value, results in curves noticeably less well-matched to the data points than letting the asymptote be fitted directly to the data with no constraints on its value. This latter approach yields curves that look more appropriate, but give unreasonably high fineness values (above 100\% passing 270 mesh) when extrapolated to grinding times longer than actually measured. It is apparent that the exponential mathematical function does not completely describe the physical processes at work. However, it comes closer to a useful equation than the more physically realistic approach does.

The silica liberation data, however, is fairly well approximated in this particular example (Figure 23) by an exponential curve. The asymptote constant $Y_{0}$ is fixed at zero in this case.

The successes of the magnetic separation and flotation stages of processing depend on accurate characterization of the energy required to grind the ore to the necessary fineness, as well as its relationships to the liberation of silica and magnetic iron. The goal of this part of the TOPIM project was to produce a tool that is easy to use and yet communicates this information clearly between mine and mill. Figure 24 illustrates one approach to combining grindability and silica liberation data, using a linear predictor for grindability and an exponential predictor for silica liberation. 


\section{Grindability Chart for Typical Sample: Descriptive Functions}

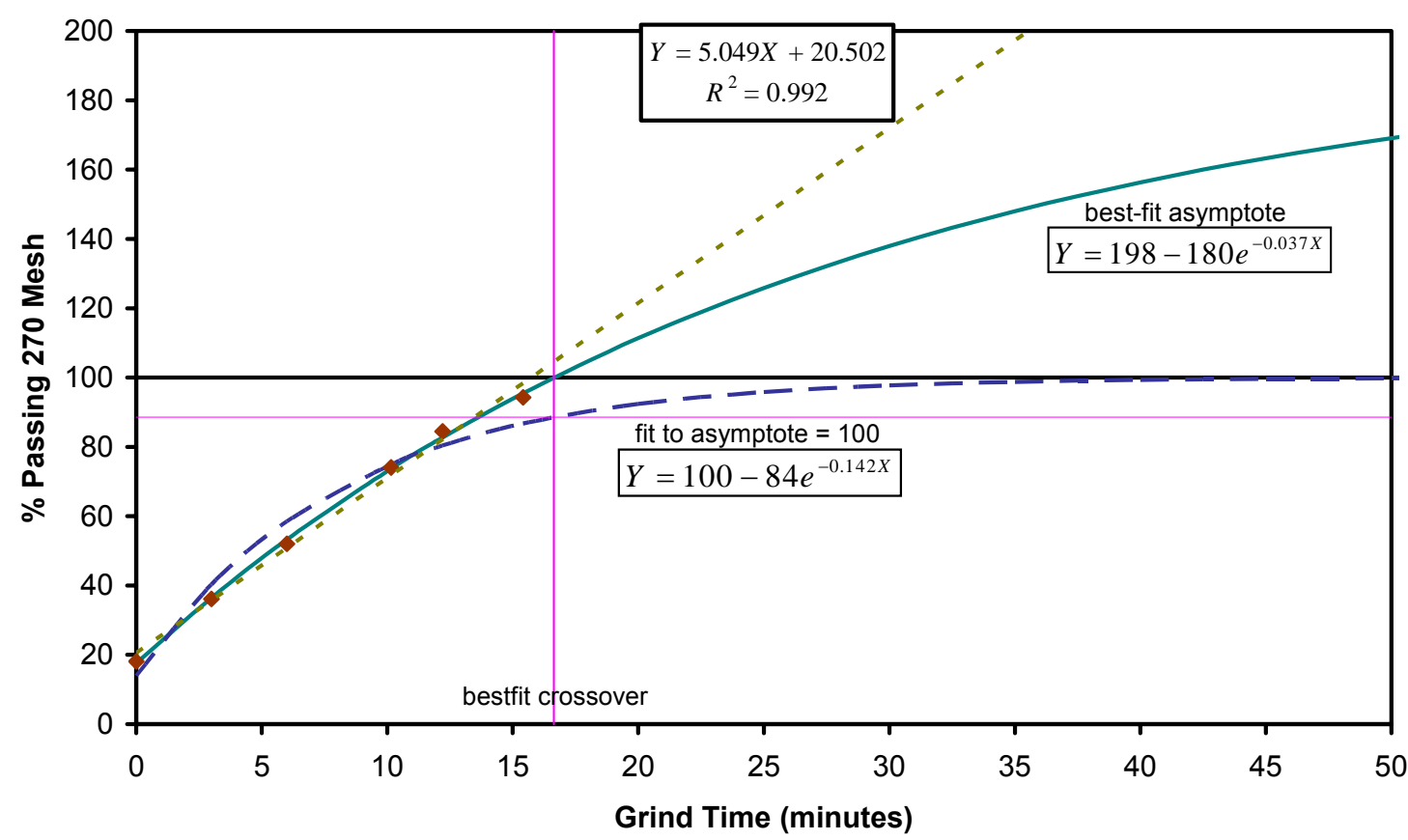

Figure 22. The approaches to characterizing grindability data that were evaluated.

Silica Liberation Chart for Typical Sample: Descriptive Functions

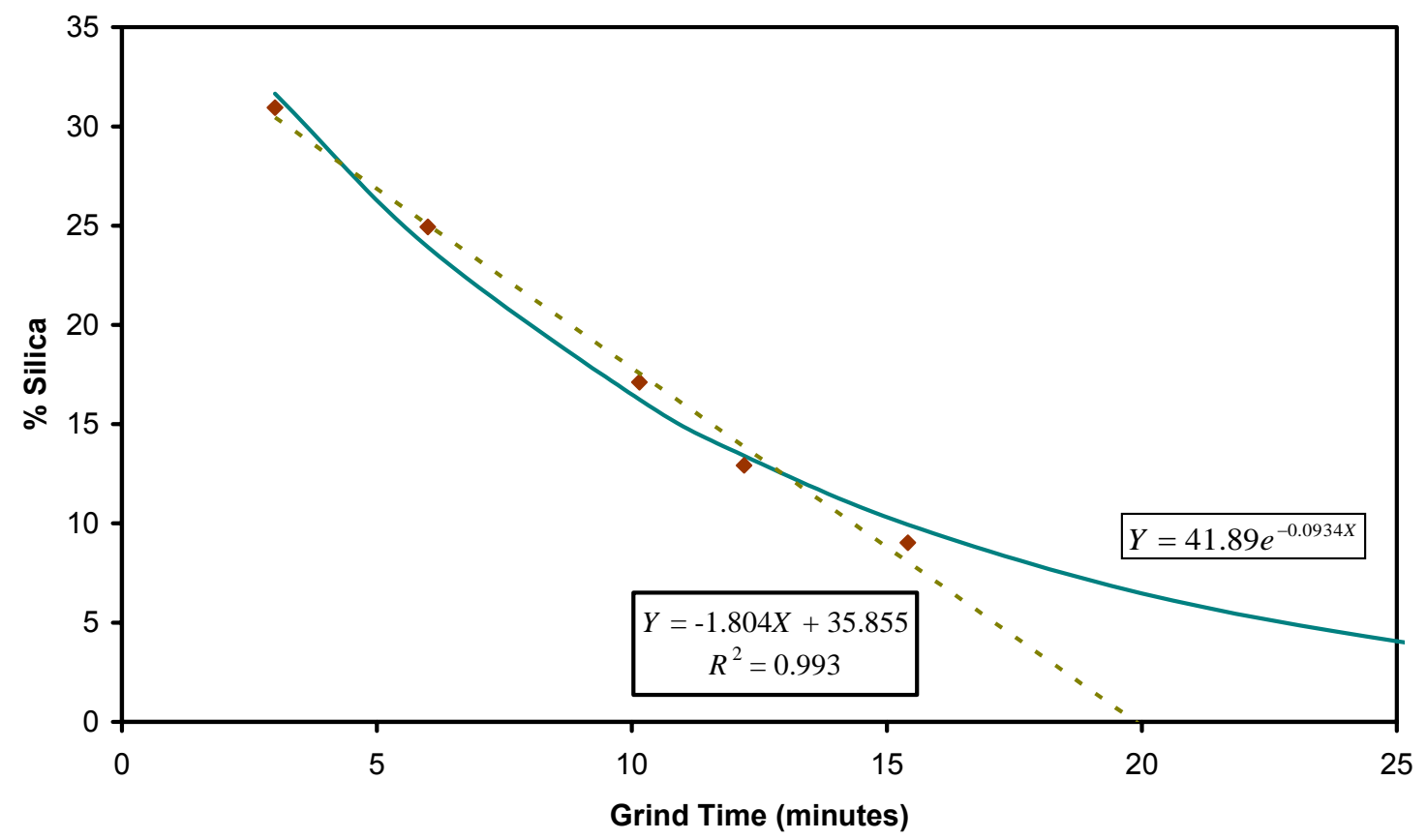

Figure 23. Some approaches to characterizing silica liberation data. 


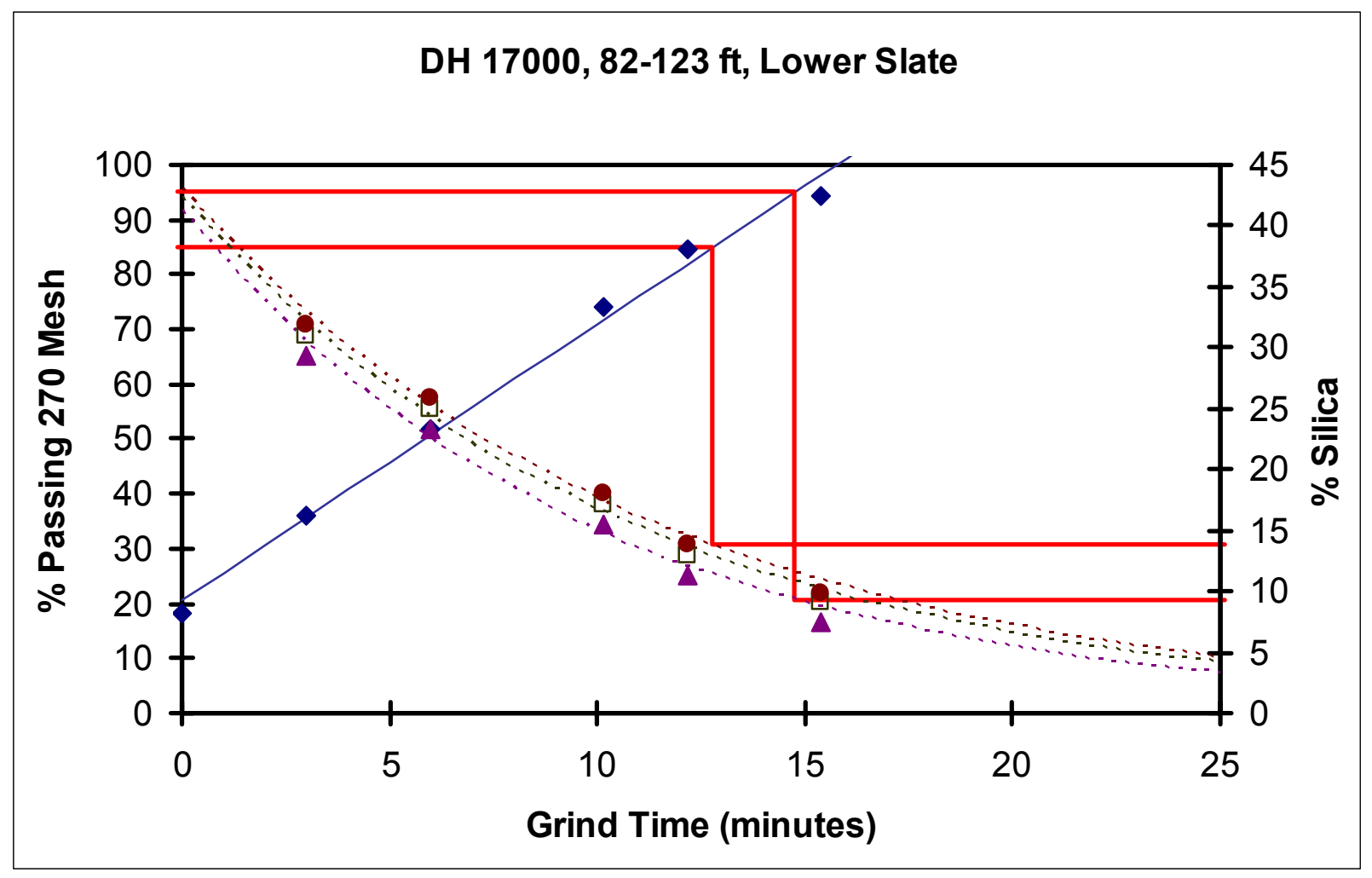

Figure 24. An example of one early-evaluated method of combining grindability and silica liberation data. The dashed lines are exponential predictors for silica liberation (measured separately for three sub-intervals). The solid blue line predicts the grindability, measured once for the full interval. The thick red lines indicate the amount of silica available at the standard particle fineness values of $85 \%$ and $95 \%$, from which A-factor is calculated.

Most of the grindability and liberation data follow these patterns, but not all. Some of the sub-intervals are not well-fit by these types of curves. Determining the meaning of such patterns with respect to ore forming processes as well as to iron ore grinding are possible topics for future research that would benefit the Mesabi Iron Range and potentially could be expanded to other mineral ores.

Further evaluation of the available data showed that using the bestfit exponential curve for the grindability data and also for the silica liberation data appears to be the best approach. This was refined by developing methods for determining the values of certain points of importance for the Minntac concentrator as it operates now (Figures 25 through 30, and the Appendix). Adoption of this way of dealing with data they already possess could make the mill more responsive to future changes in design and/or operation.

Due to the very large amount of this type of data that Minntac personnel have collected over the decades, application to the entire Minntac dataset could not be completed within the time allotted to the TOPM project. The procedures for doing so, however, are available. They require only Microsoft Excel@ equipped with the Solver module (to find solutions to iterative problems) and someone with enough time to apply them to the complete data set. 
Drillhole 27666, Depth 62-78 ft, Layer LS

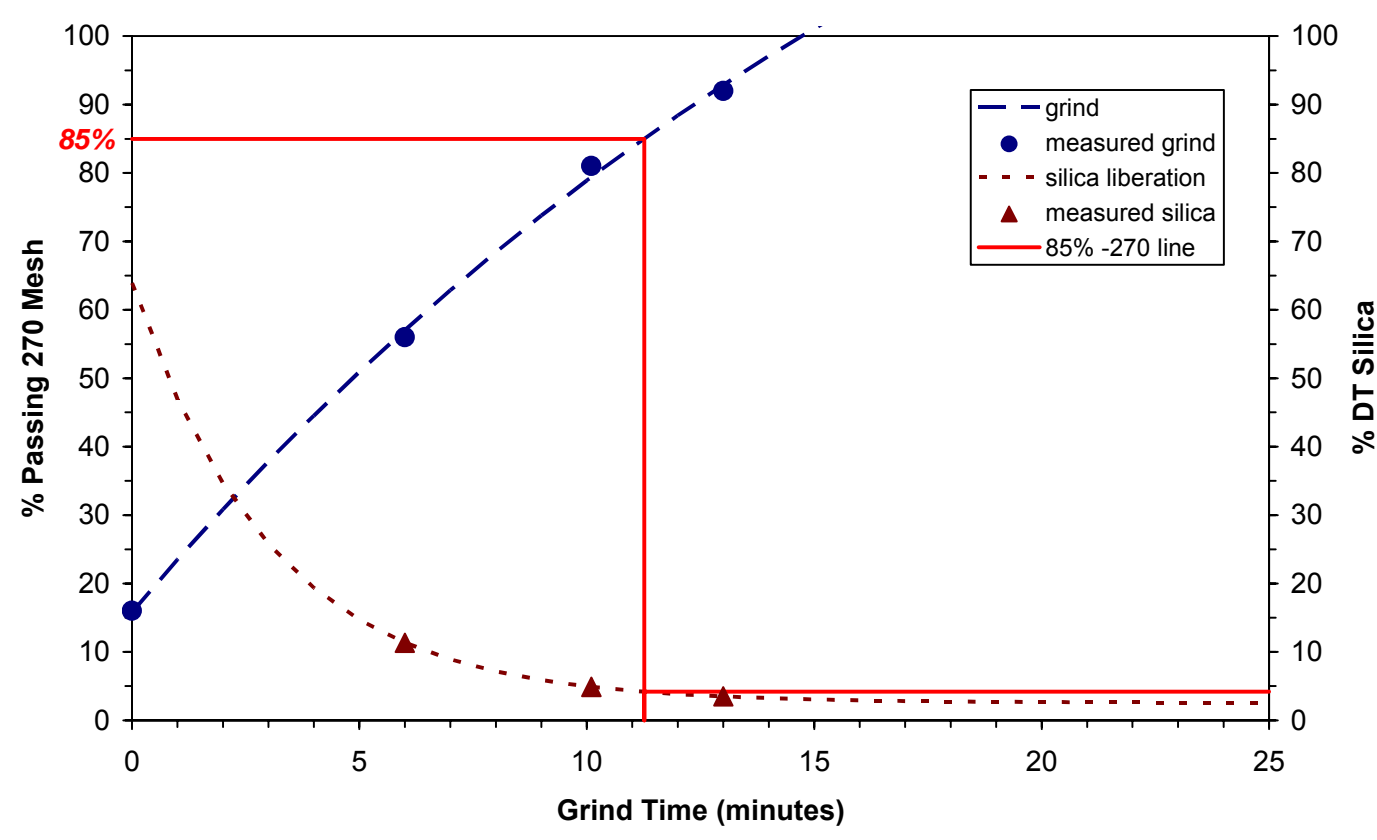

Figure 25. Example of grindability data, fitted curves, and the $\mathrm{T}_{85}$ point of interest. To reach $85 \%$ passing 270 mesh requires slightly more than 11 minutes of grinding, and liberates about $4 \%$ silica, for the ore in this particular corehole interval.

Drillhole 27666, Depth 62-78 ft, Layer LS

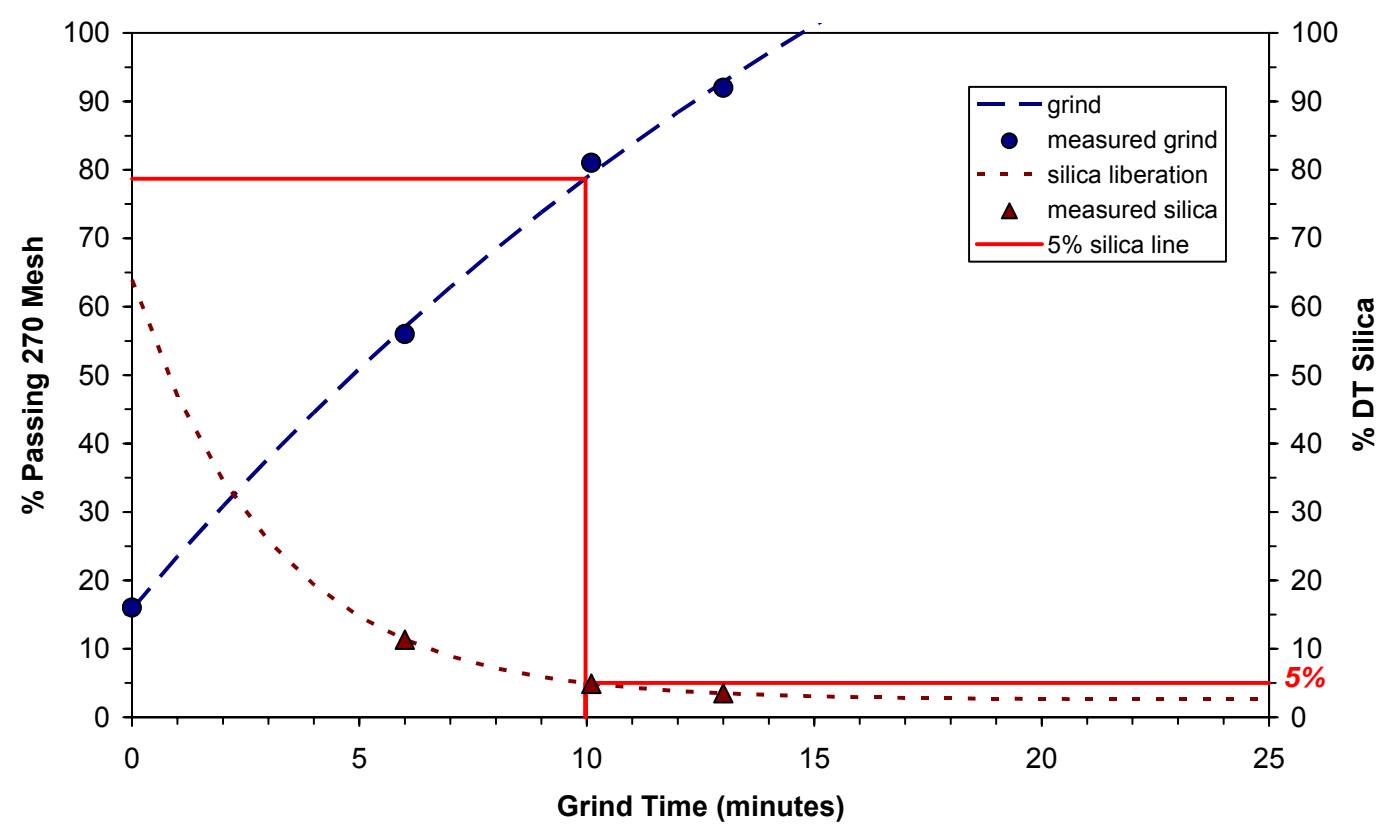

Figure 26. Example of grindability data, fitted curves, and the $T_{5}$ point of interest. To reach $5 \%$ silica liberation requires about 10 minutes of grinding, and produces a grind of which $79 \%$ is finer than 270 mesh. 
Drillhole 27666, Depth 62-78 ft, Layer LS

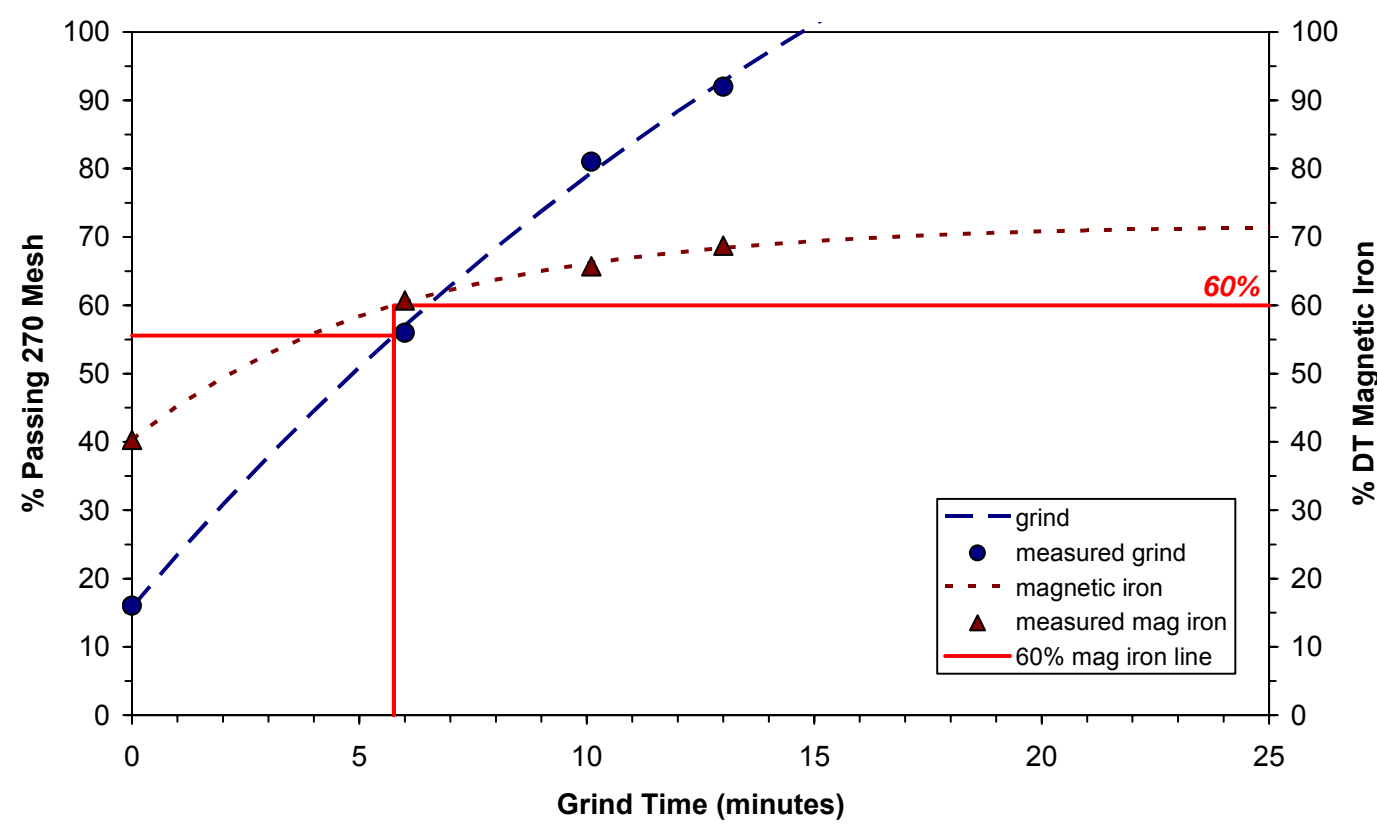

Figure 27. Example of iron liberation chart \#1, showing $60 \%$ iron liberation requirements.

Drillhole 27666, Depth 62-78 ft, Layer LS

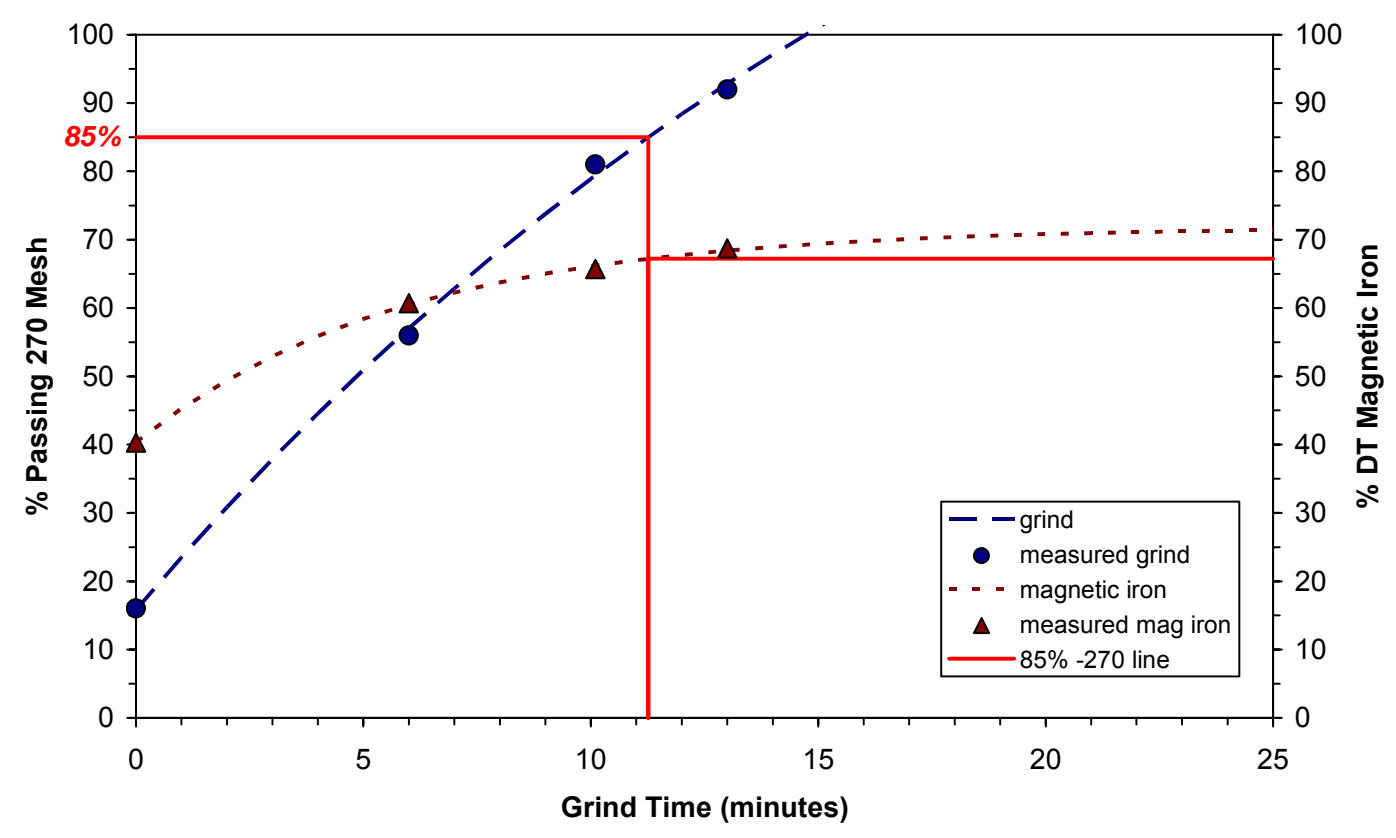

Figure 28. Example of iron liberation chart \#2, showing result of $85 \%-270$ mesh grind. 
Drillhole 27666, Depth 62-78 ft, Layer LS

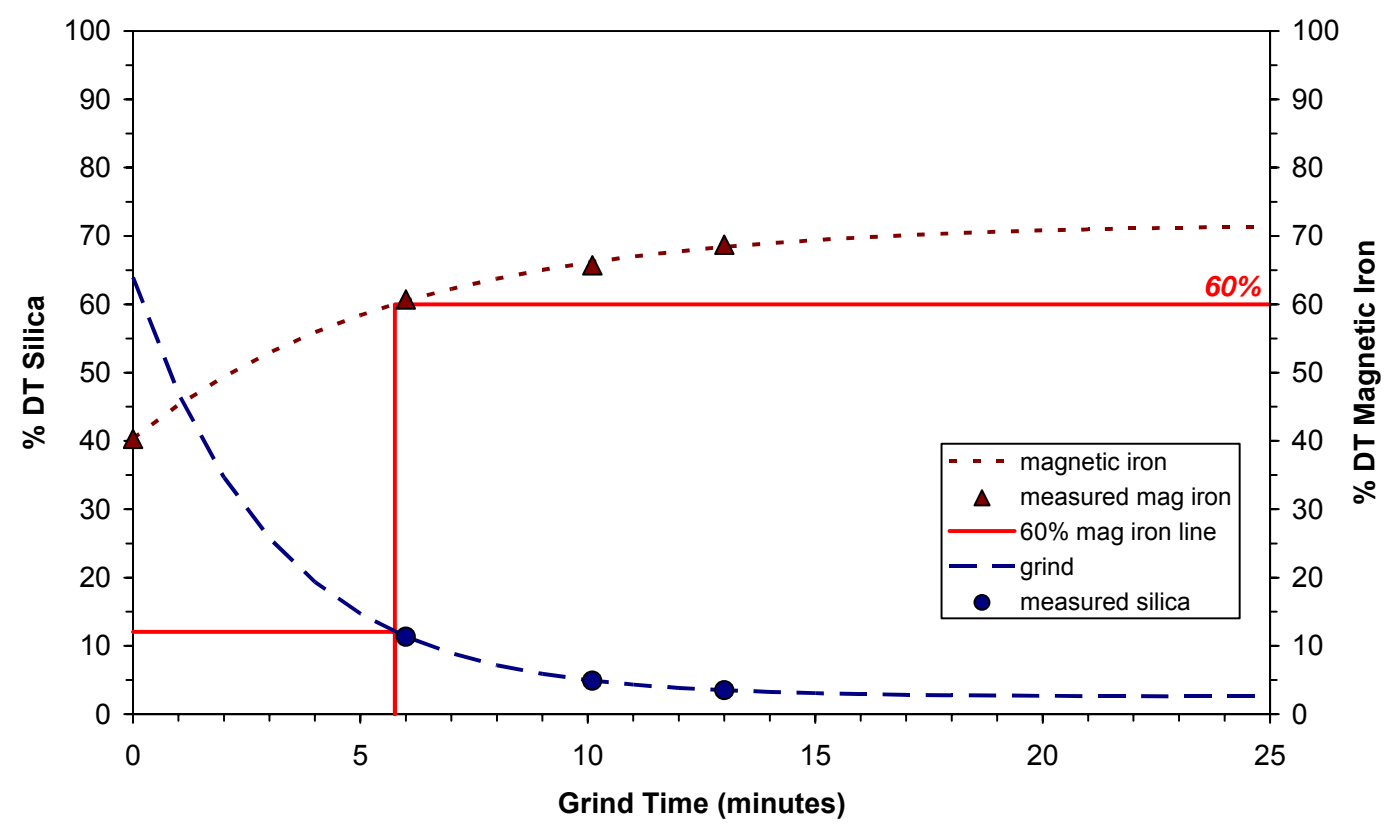

Figure 29. Example of combined silica and iron liberation chart $\# 1$, showing the silica liberation that is associated with $60 \%$ iron liberation.

Drillhole 27666, Depth 62-78 ft, Layer LS

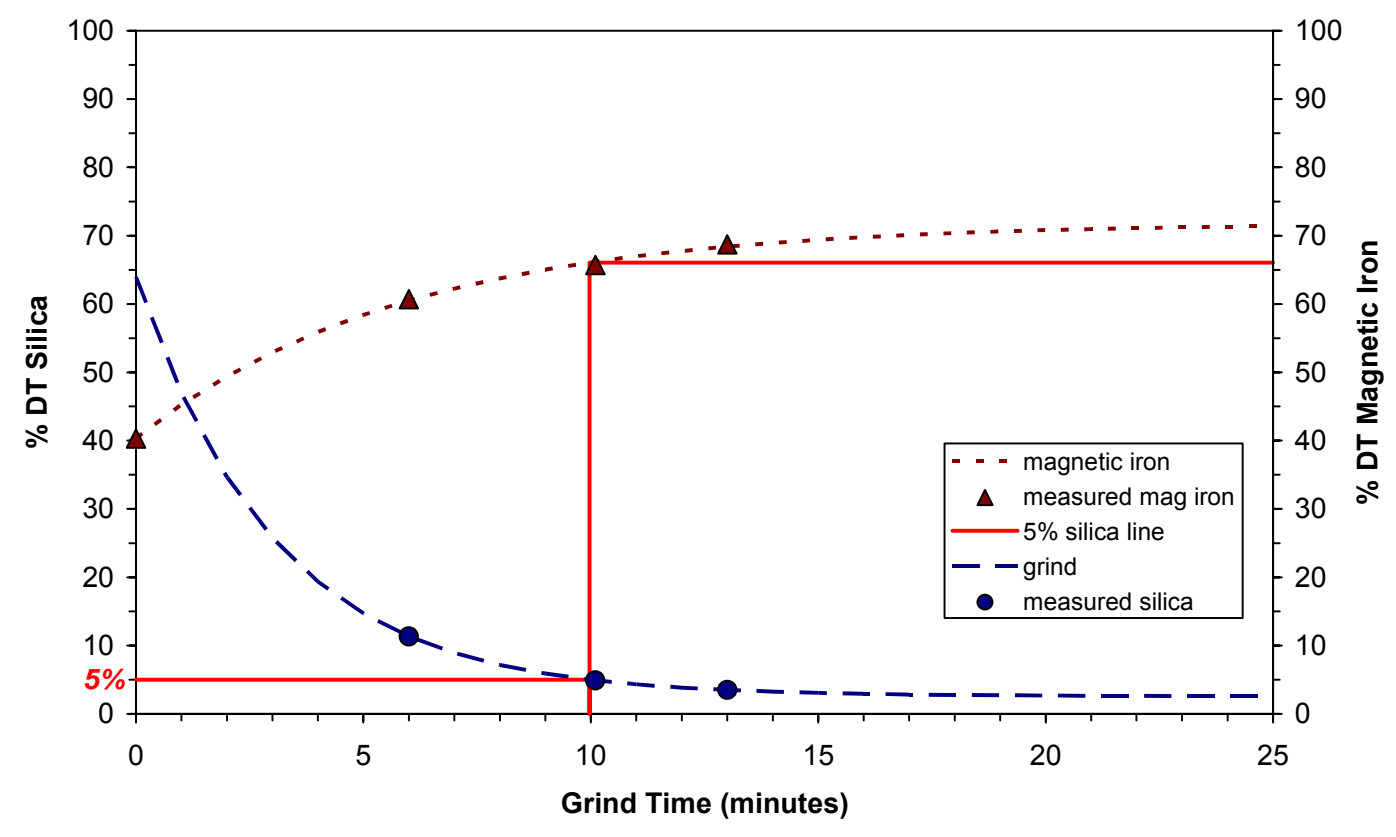

Figure 30. Example of combined silica and iron liberation chart \#2, showing the iron liberation that is associated with $5 \%$ silica liberation. 


\section{Hibtac Mine}

Hibtac Mine uses a process that is fundamentally similar to that at Minntac Mine, but differs in details of its execution. A relative liberation work index is estimated for target concentrate silica on a log/log regression curve derived from three timed grinds of $200 \mathrm{~g},-20$ mesh splits from drill core. Throughput must be maximized while blending for crude magnetic iron, weight recovery, liberation grind, and ferric/ferrous iron ratios as well as ore type, and while maintaining a narrow concentrate silica grade and minimizing grinding energy. Bond (1952) defined work input ( $W \mathrm{~J} / \mathrm{t})$ as a function of the work index $\left(W_{i} \mathrm{~J} / \mathrm{t}\right)$ and the 80 percent passing sizes of the product $\left(P_{80}\right)$ and feed $\left(F_{80}\right)$ :

$$
W=\frac{10 \cdot W_{i}}{\left(P_{80}\right)^{0.5}}-\frac{10 \cdot W_{i}}{\left(F_{80}\right)^{0.5}}
$$




\section{Rock Physical Properties}

The point-load strength and the density of the five ore layers being mined at Hibtac have been measured using samples from seven representative exploration coreholes. The average density of the six ore layers that were tested is $3.13 \mathrm{~g} / \mathrm{cm}^{3}$. The average strength of the rock, uncorrected for aspect ratio, is 5,879 psi (40.5 MPa). After correction to a length-to-diameter ratio of 2.0, the average strength is 6,479 psi (44.7 $\mathrm{MPa})$.

Figures 31 through 33 summarize the statistics of the results. Load was applied to each of the rock samples in one of two orthogonal directions: Sub-parallel to the visible layering (diametral) and perpendicular to it (axial). The anisotropy ratio is the ratio of the former to the latter. Data from one of the boreholes is not included in these figures due to its significantly different values. The results obtained by including those values are shown in the Appendix.

Figure 34 matches the average point-load strength to the ore layer.

Imprecise density is the most common error in calculation of ore reserves (Parrish, 1993; Lipton, 2000). It is not unusual for mine personnel to use a single average bulk density for the entire mine property that, on checking, is found to have been determined from a few samples during initial exploration of the orebody. The density of the samples was measured using procedure ASTM C97-02 (Absorption and Bulk Specific Gravity of Dimension Stone). Figure 35 shows the results, according to ore layer.

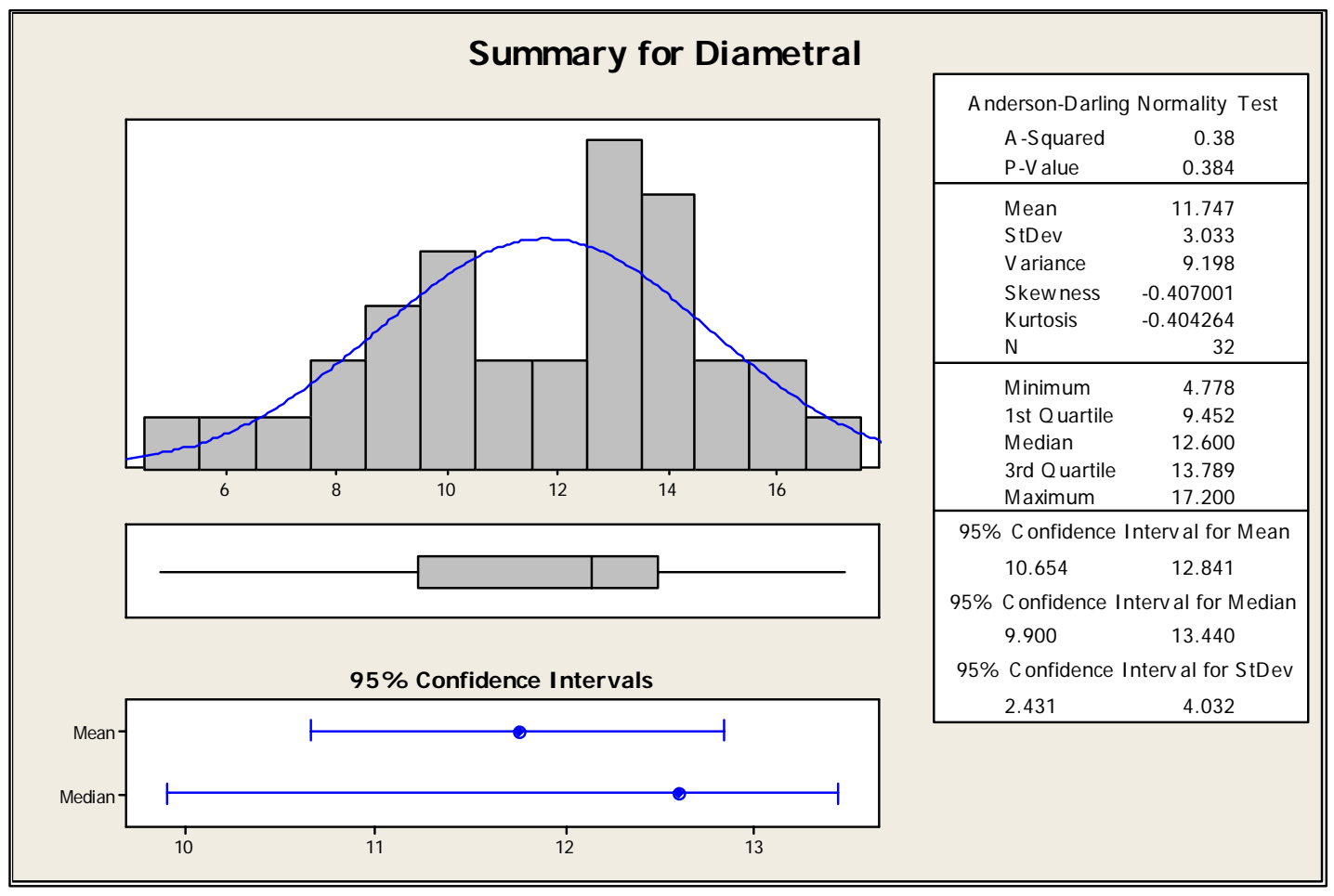

Figure 31. Diametral (parallel to layering) point-load statistical summary, excluding data from borehole 409. 


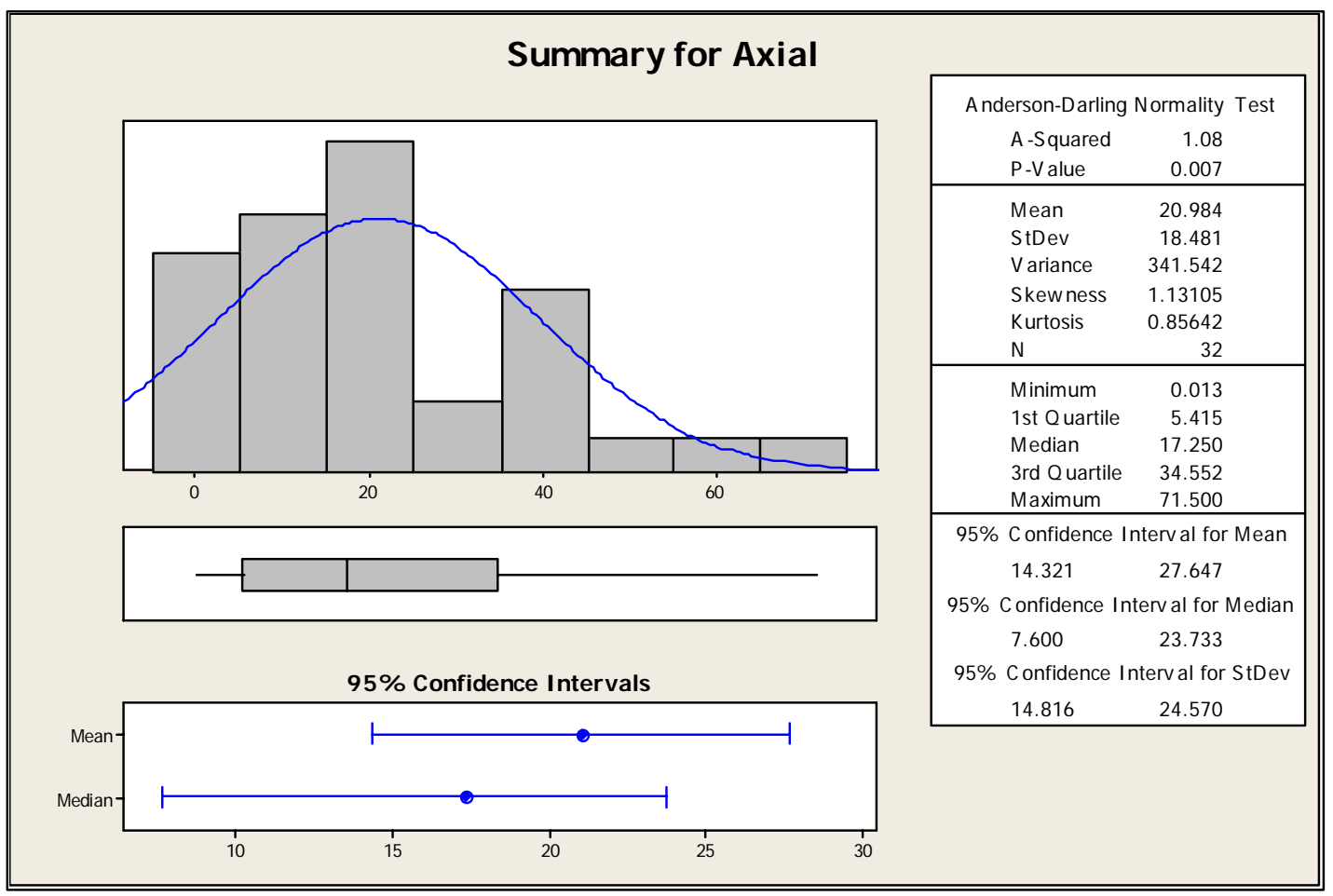

Figure 32. Axial (perpendicular to layering) point-load statistical summary, excluding data from borehole 409.

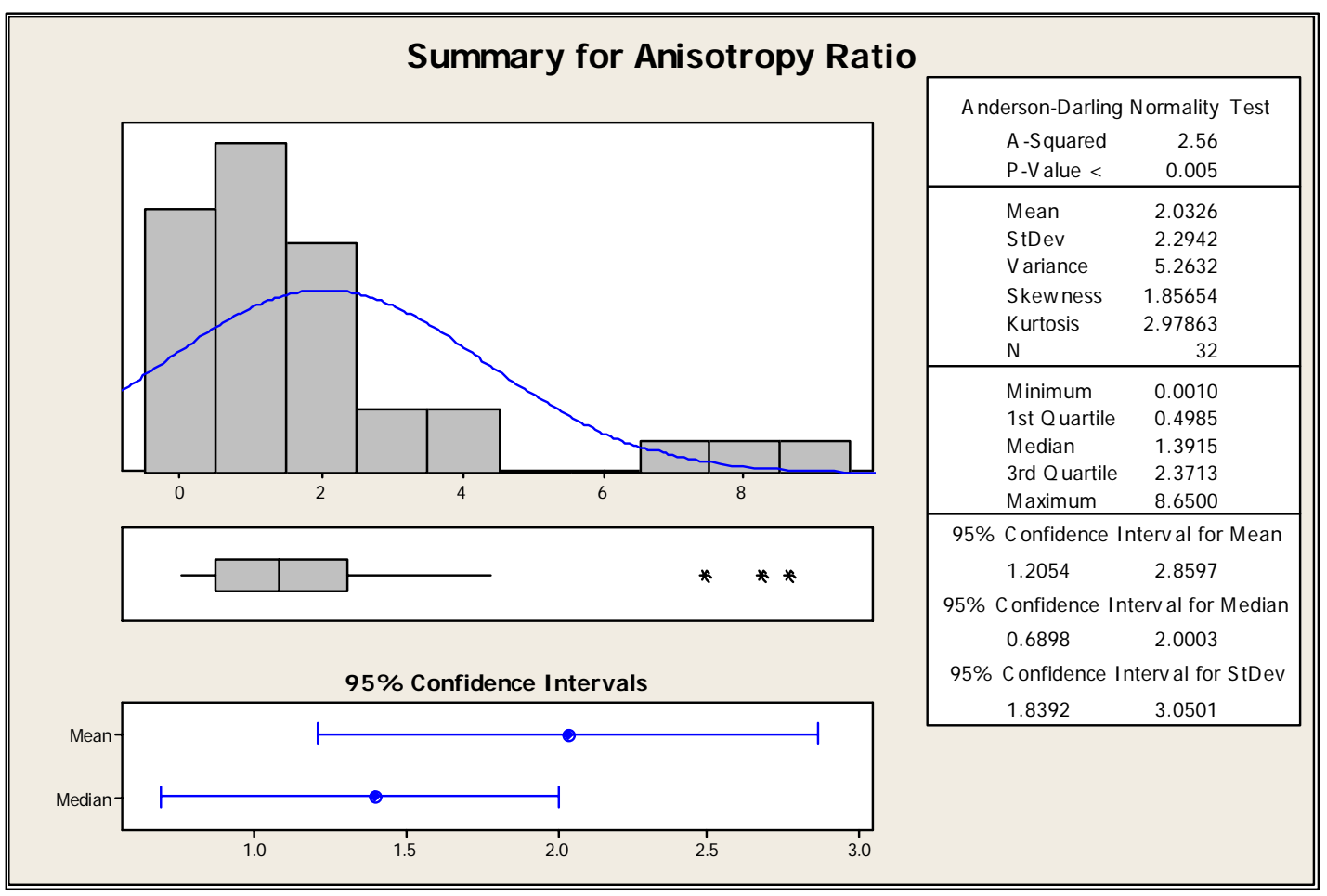

Figure 33. Point-load anisotropy ratio statistical summary, excluding data from borehole 409. 


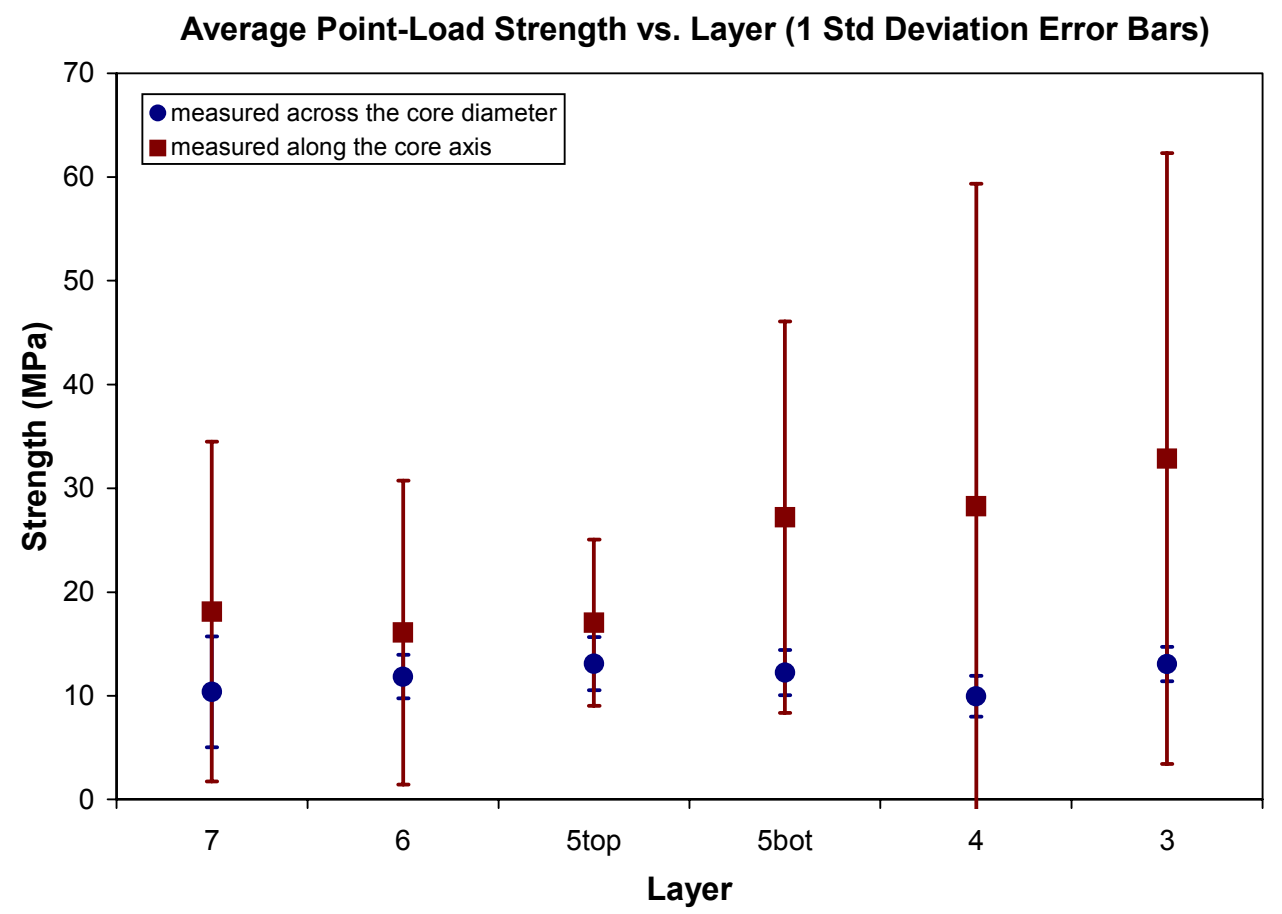

Figure 34. Point load strength of the ore layers at Hibtac Mine. Error bars are \pm one standard deviation.

Tonnage Factor vs. Layer

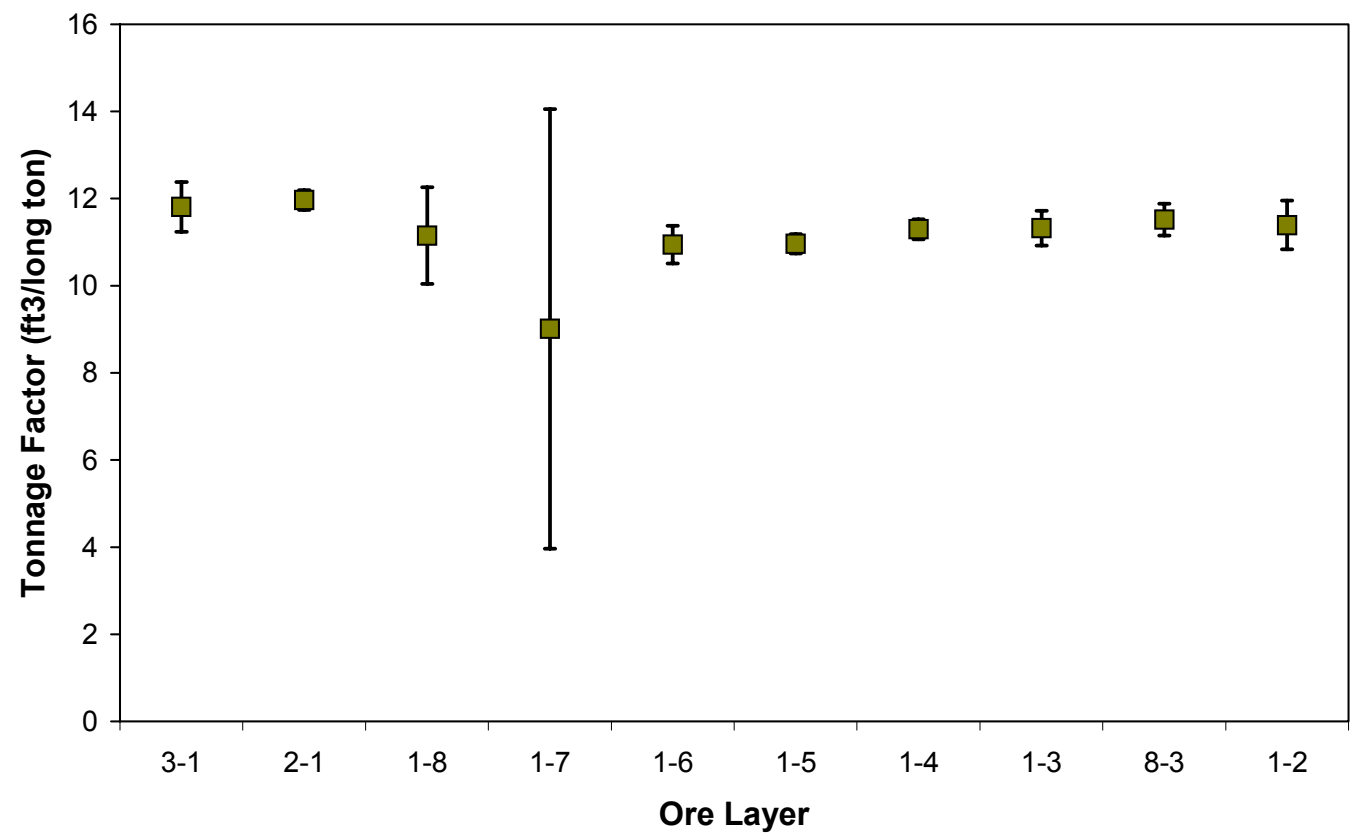

Figure 35. Variation in density expressed as tonnage factor for samples of the ore layers at Hibtac Mine. Error bars are \pm one standard deviation. 

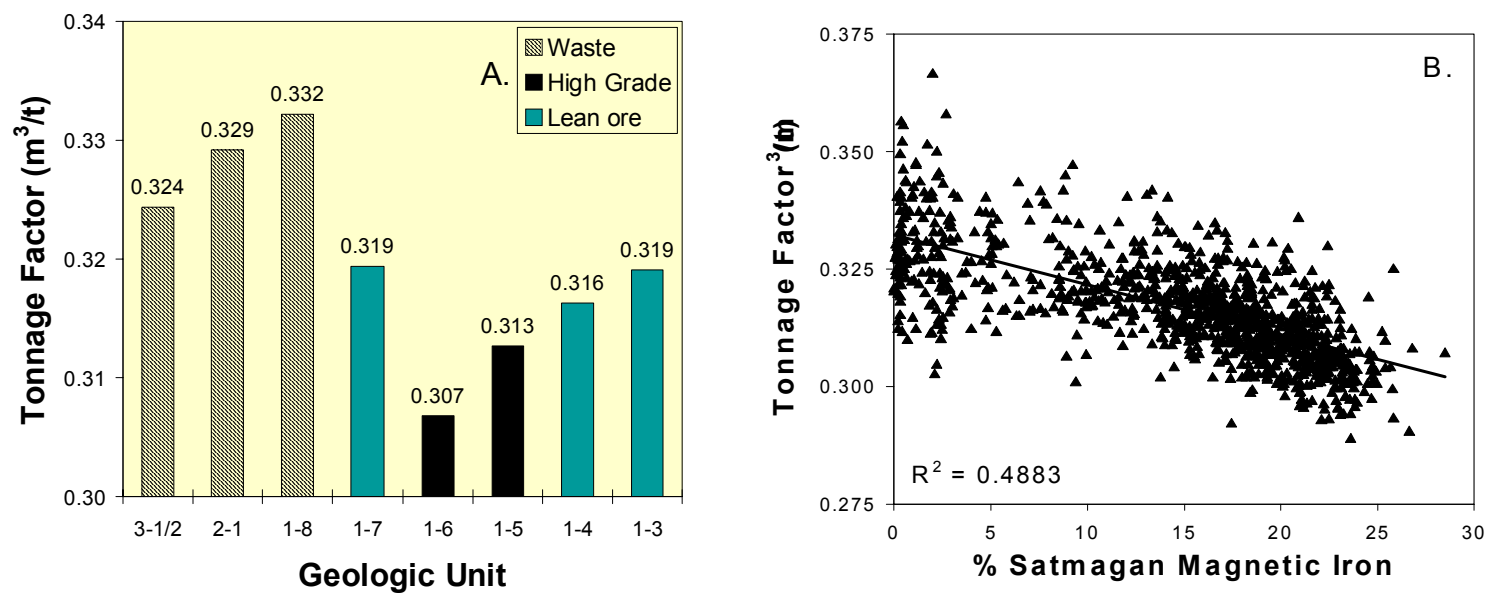

Figure 36. As expected, the density of the various iron-bearing layers varies with their magnetic iron content (Orobona et al., 2006).

As described by Orobona et al. (2006), the densities of 1,107 whole-core samples, from 77 widespread holes, were measured by a summer intern. The results showed that the lowergrade subunits, which comprise a third of the blend at Hibtac Mine, and the waste rock are markedly less dense than the historic tonnage factor of $0.307 \mathrm{~m}^{3} / \mathrm{t}$ used for all bedrock (Figure 36A). Density data plotted versus metallurgical assays show a correlation to crude magnetic iron (Figure 36B) as well as total crude iron. As a result, a script has been written into the digital block model at Hibtac Mine to calculate tonnage based on these metallurgical variables. 


\section{Drill Monitoring}

Both mines monitor the performance of at least some of their blast hole production drills, with plans for expansion of the capability. At Minntac drill performance was added to the segregation tests. At Hibtac, it has become part of the mine planning process.

Drilling rock tests the strength of the rock, which is an essential factor in comminution cost. The project envisions uses the specific energy (SE) of drilling to predict ore processing outcomes. Specific energy is the energy required to drill a unit volume of rock. For a given drilling method, SE is a function of rock type. SE includes the drilling performance parameters of rate of penetration, rotation rate, pull down force, and torque.

\section{Minntac Mine}

At Minntac, drill performance has been used for some time to guide blast designs by changing the design in response to changes expected in the rock, determined from exploration data. Project planning envisions modeling drill performance data in the same manner that ore grades are modeled, i.e. in down hole intervals. The logistics involved were significant, since the density of this data is much higher than ore grade data, and drill monitoring data have been kept separate from the data management system. That may be changing as personnel rotate into and out of work assignments. The usefulness of drill monitoring was investigated by: 1) comparing the drill performance to other qualities in the ore body, and 2) comparing drill performance to downstream processing performance in the concentrator and agglomerator. Figures 37 through 42 represent one of the patterns studied; charts are given in the Appendix for another blast.

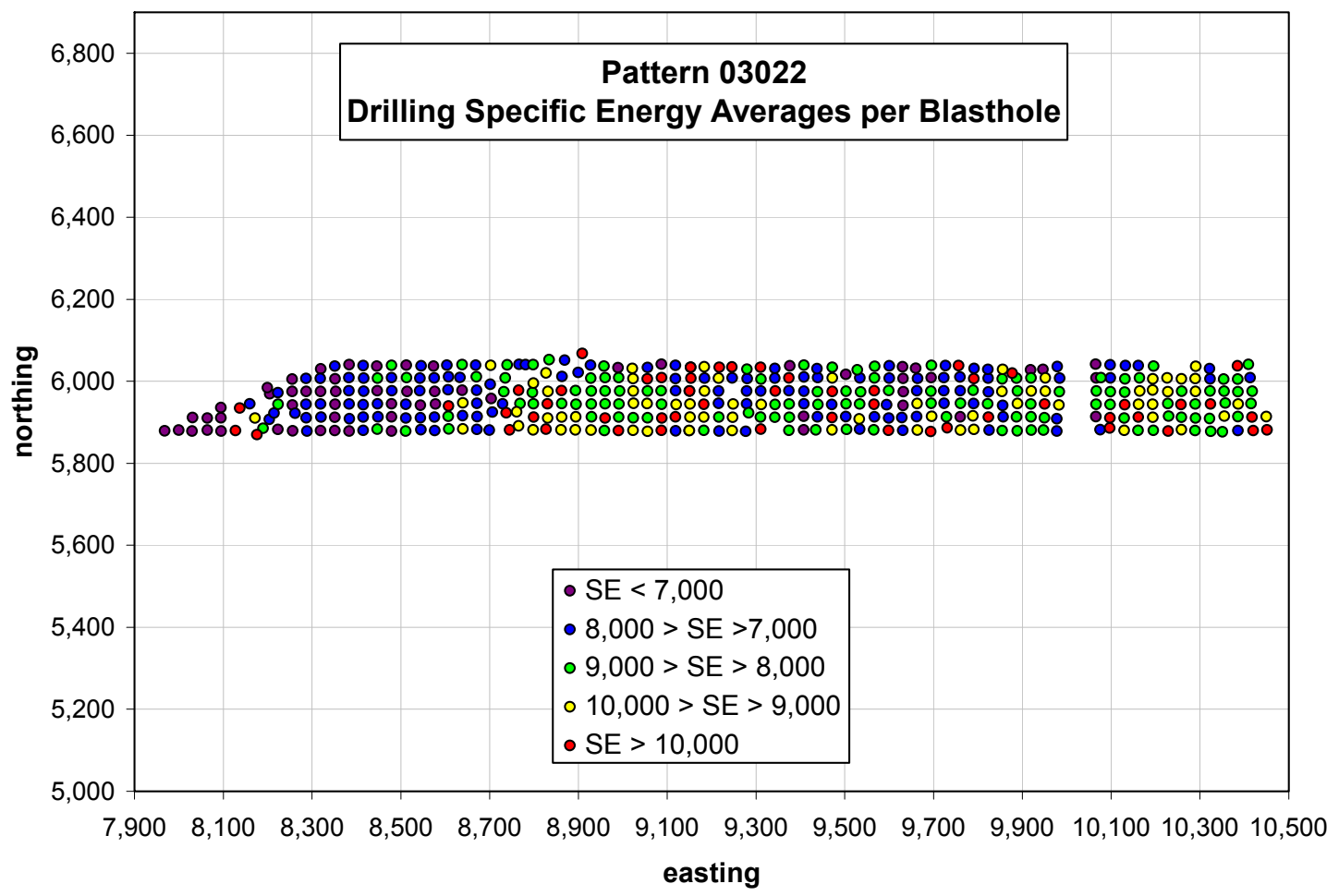

Figure 37. Variation of specific energy through a Minntac Mine blast pattern, averaged over the entire height of each blasthole. 


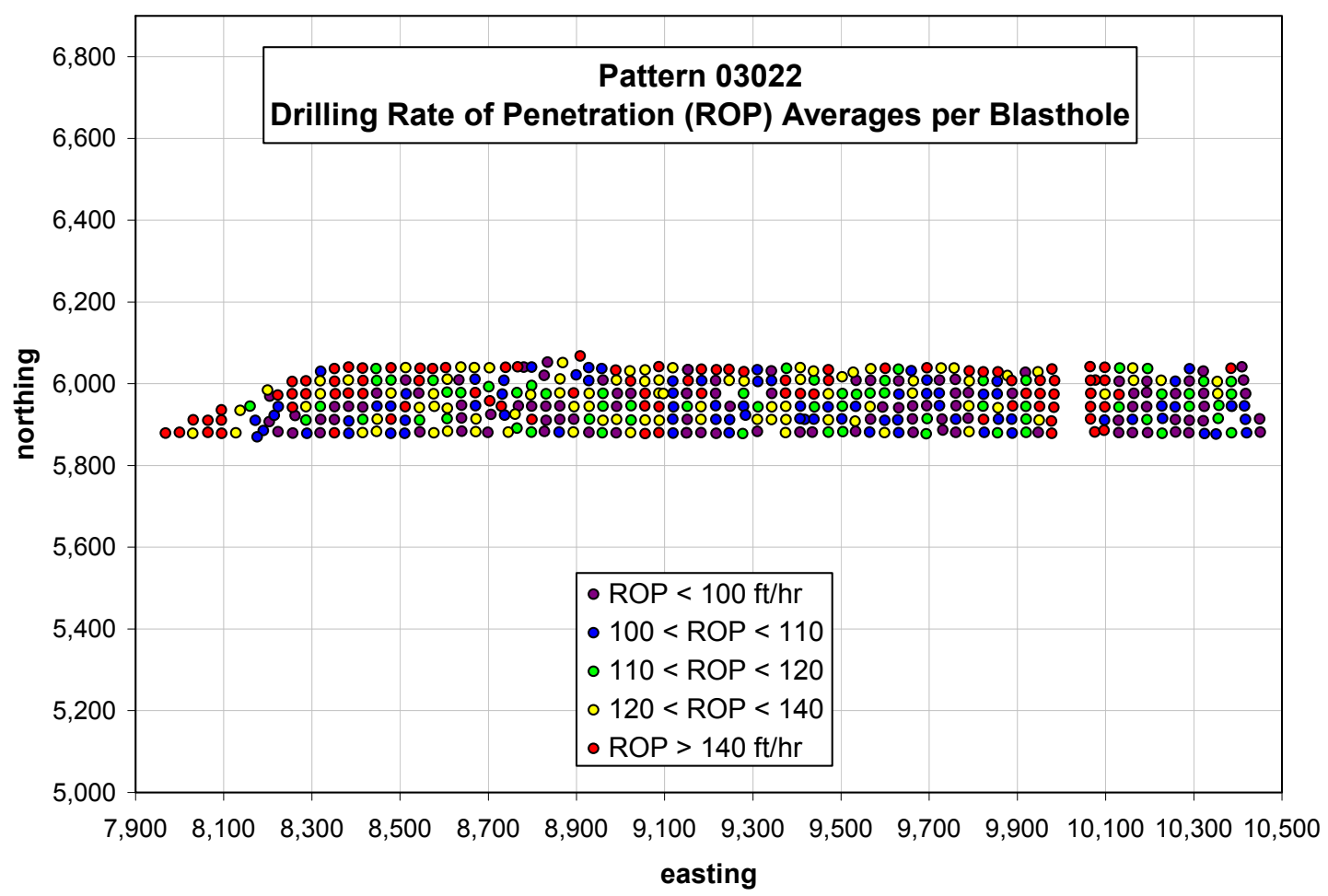

Figure 38. Variation of average penetration rate.

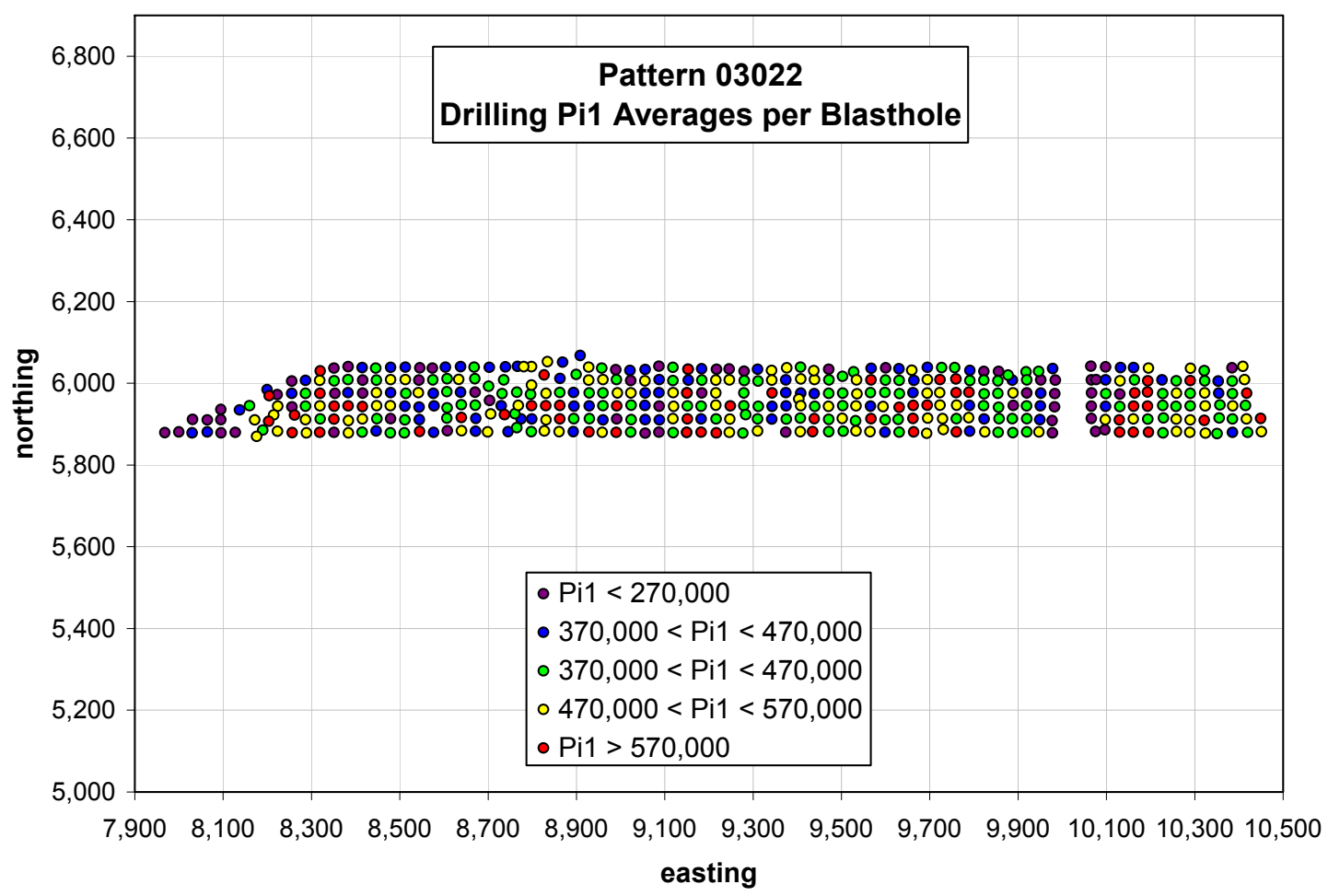

Figure 39. Variation of average $\mathrm{Pi}_{1}$ index. 


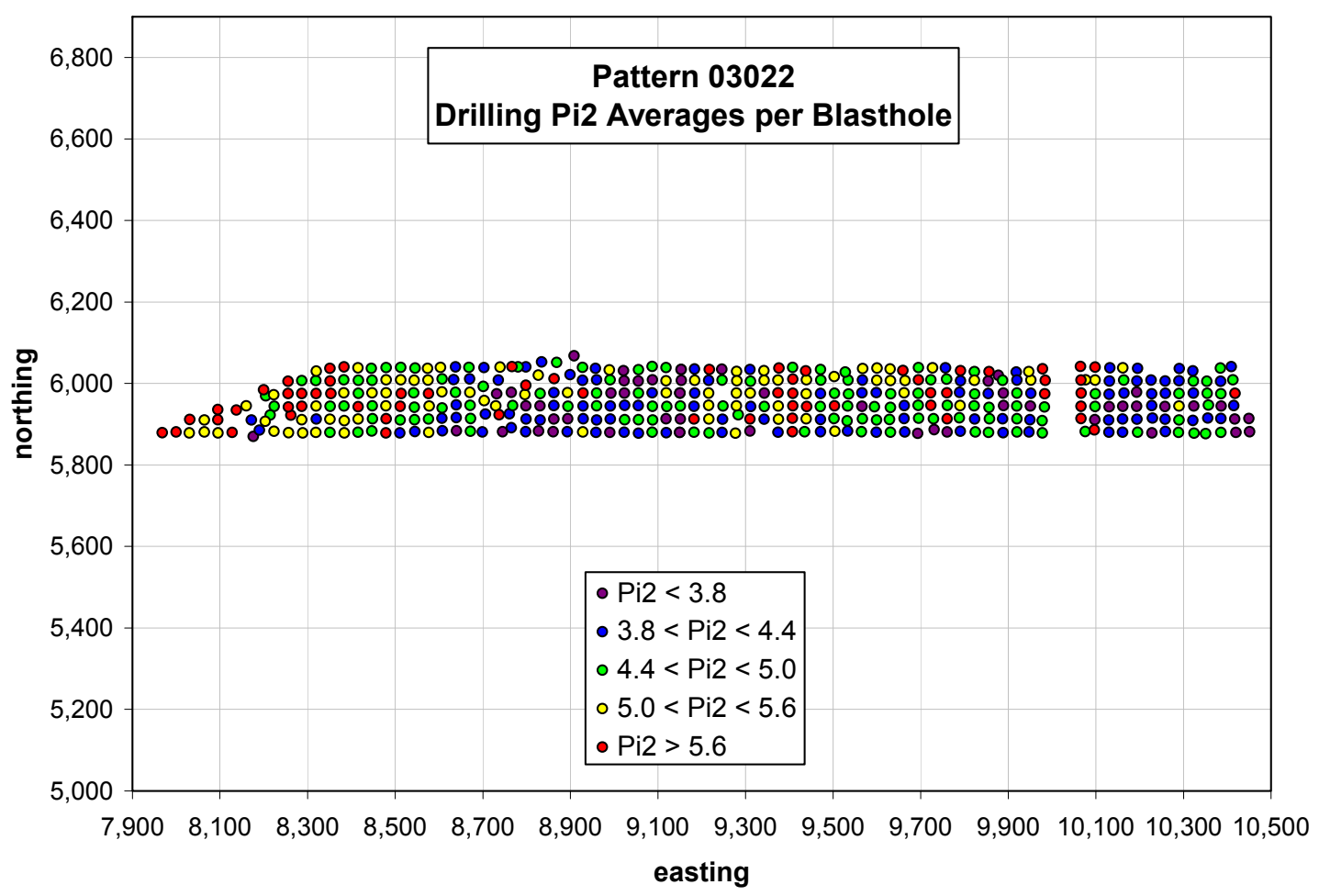

Figure 40. Variation of average $\mathrm{Pi}_{2}$ index.

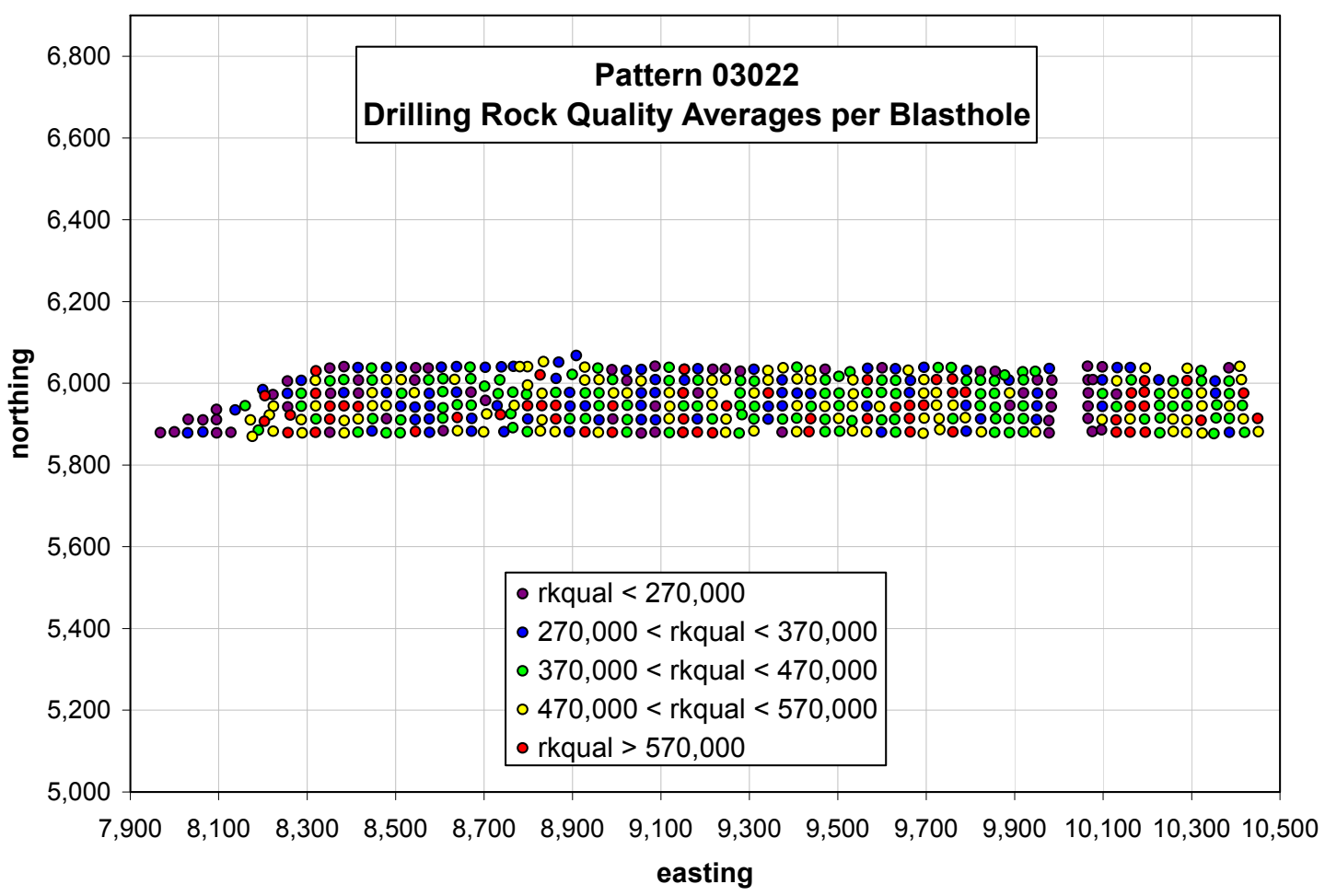

Figure 41. Variation of average rock quality index. 


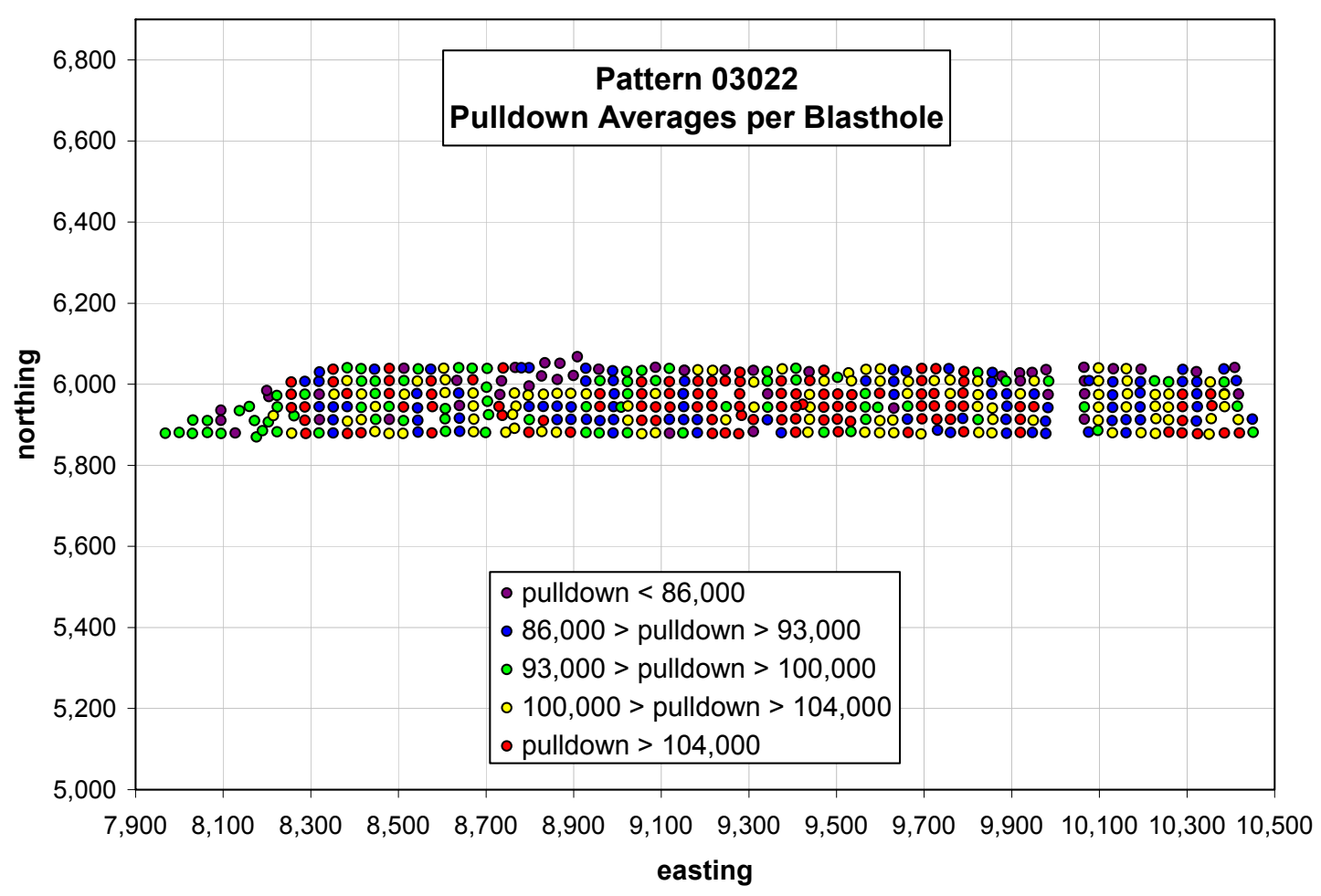

Figure 42. Variation of average drill pulldown (bit weight).

Graphical analysis of drill monitor data was not restricted to two-dimensional horizontal patterns of measured and calculated parameters averaged over the entire length of a blasthole. Vertical variations are at least as important, and are available in much higher resolution that depends only on the data acquisition rate of the drill monitor electronics. This aspect is discussed in the section on Pi Indices.

The analysis illustrated in this section represents a relatively simple, but time-consuming, application of basic capabilities of Microsoft Excel ${ }^{\odot}$. It was not applied to all the blast patterns data available only because of project time and personnel limitations. This analysis could easily be semi-automated, and would extract significantly more information than has previously been realized from data that has already been collected. This is another topic ripe for further work.

\section{Hibtac Mine}

Engineers use drill-monitoring systems to improve productivity of blast-hole rigs and fragmentation (Thompson, 1999; Vynne, 1999) and, to a lesser extent, for geologic classification (Thompson, 1999). Though commercial add-on systems are available, many drills come preequipped to record performance indicators. Specific energy (SE) can be calculated from these; it is the work done per unit volume excavated (Teale, 1965). In rotary drilling, work is a function of the pulldown $(F, \mathrm{~N})$ and torque $(T, \mathrm{~N}-\mathrm{m})$. With $R$ bit revolutions per minute, bit face area $A$ $\mathrm{m}^{2}$, and penetration rate $u \mathrm{~m} / \mathrm{min}$ : 


$$
S E=\left(\frac{F}{A}\right)+\left(\frac{2 \pi}{A}\right)\left(\frac{R T}{u}\right) .
$$

The minimum SE of rotary (blasthole) drilling is roughly correlated to the compressive strength of the material drilled (Teale, 1965). Measured SE can be exported to modeling software, then composited and contoured (Figure 43). Since SE can be considered a rough work index $(\mathrm{J} / \mathrm{t})$, contour maps highlight variations in grindability within a blast pattern. Therefore, polygons can be designed to reflect local changes in work index, and consequently mill performance. In other environments, SE contours could conceivably map alteration zones. Relatively higher values may also indicate large fragments that could damage loading equipment, cause crusher bridges, or provide grinding media for autogenous mills. If so, powder factors could be modified prior to loading and adjacent patterns could be designed to optimize fragmentation. Specific energy values are tool- and wear-dependent (Teale, 1965) and thus not readily usable for direct ore grading.

The blast pattern shown in Figure 43 is partially coincident with an area of structurallycontrolled secondary oxidation, which is modeled from diamond drill holes. Relatively broken and decomposed rocks in oxidation zones (waste) typically require less specific energy to drill than fresh ores. The contours in this plot are in units of $\mathrm{lbf} / \mathrm{in}^{2}\left(1 \mathrm{lbf} / \mathrm{in}^{2}\right.$ equals $\left.6.895 \mathrm{kPa}\right)$. Burden and spacing for the blastholes are 11 and $12.8 \mathrm{~m}$ respectively. Only holes with valid SE data are displayed. The pattern was drilled on NE-SW fences from east to west. Average hole depth is $13.4 \mathrm{~m}$, and holes are composited from data collected every $30.5 \mathrm{~cm}$, but not including previously blasted subdrill from the upper $1.5 \mathrm{~m}$.

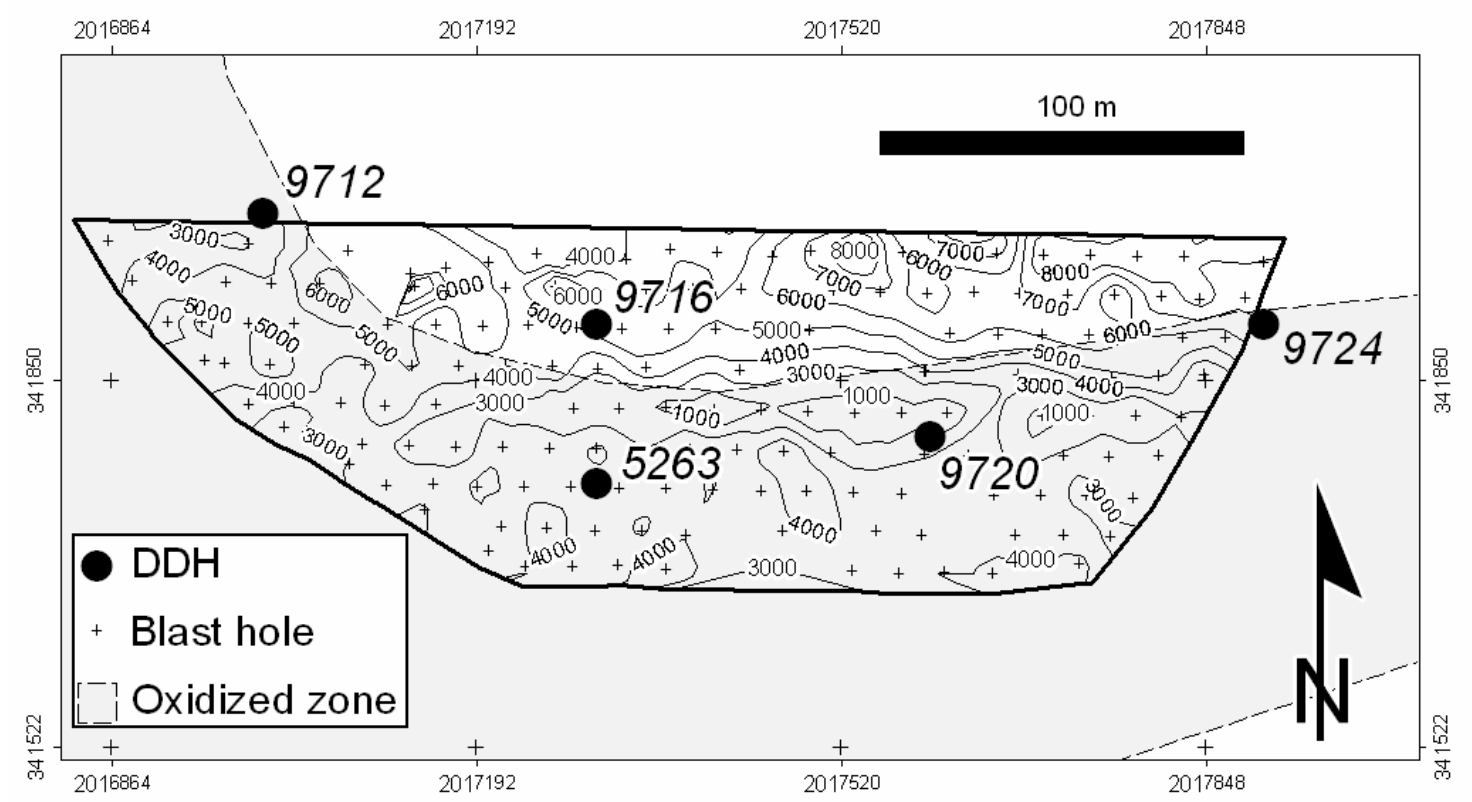

Figure 43. Example of a specific energy contour map (Orobona et al., 2006). 


\section{Pi Indices}

The rock quality index and the two dimensionless Pi $(\pi)$ indices developed by Yin and Liu (2001) are used by Minntac Mine to design their blasts, but the drill monitor data from any given pattern is not available for the design of that shot. Therefore, the blast results - which historically are difficult to quantify in a short time - must be back-analyzed for comparison with the drill monitor data to be useful for subsequent blast designs. Improving the turn-around time of blast monitoring data was one aspect of the TOPIM plans that was not able to be realized; it deserves additional study.

$\pi_{1}$ indicates the performance of the drill, while $\pi_{2}$ is a measure of the rock resistance to drilling:

$$
\pi_{1}=\frac{r N T}{F^{2}} \quad \pi_{2}=\frac{u F}{N T}
$$

$$
\begin{aligned}
& \text { Where } \quad \begin{array}{l}
u=\text { penetration rate } \\
r=\text { rock quality index } \\
N=\text { rotation rate } \\
F=\text { weight on bit (pulldown force) } \\
T=\text { torque }
\end{array}
\end{aligned}
$$

As would be expected, since a drill tends to perform better in rock that offers little resistance, $\pi_{1}$ and $\pi_{2}$ are strongly inversely correlated (Figures 44 ). Note that the relationship is a power function rather than simply linear. Low values of each index tend to be quantized, indicating that both parameters may not be useful if below certain minimum magnitudes. For this blast pattern, both minimum bounds appear to be approximately 1 . The heavy concentration of data points in the mid-range prevents the bestfit line from being skewed by a faintly visible Scurve that deviates from the bestfit line in the extreme ends of the range.

Figures 45 through 48 are the same comparison as shown in Figure 44, but for several other blast patterns shot at Minntac Mine.

In general, the three-dimensional variation of specific energy, rock quality, and the two Pi indices can be appreciated qualitatively by examination of Excel plots such as those shown here, but quantitative use of the information is more straightforward and flexible if the data is handled by commercially available orebody and mine modeling software, such as MineSight $\subset$. Such programs are designed to statistically analyze non-independent data in three dimensions and incorporate the results in three-dimensional mine plans. It is likely that more mine employees have sufficient previous training to use programs like Excel $\mathbb{C}$, with the appropriate macro programs added, than that have had training in using MineSight $\subset$. Those with the appropriate mine modeling training, however, would make much more effective use of their time by using MineSight $\subset$ or comparable orebody modeling software. 


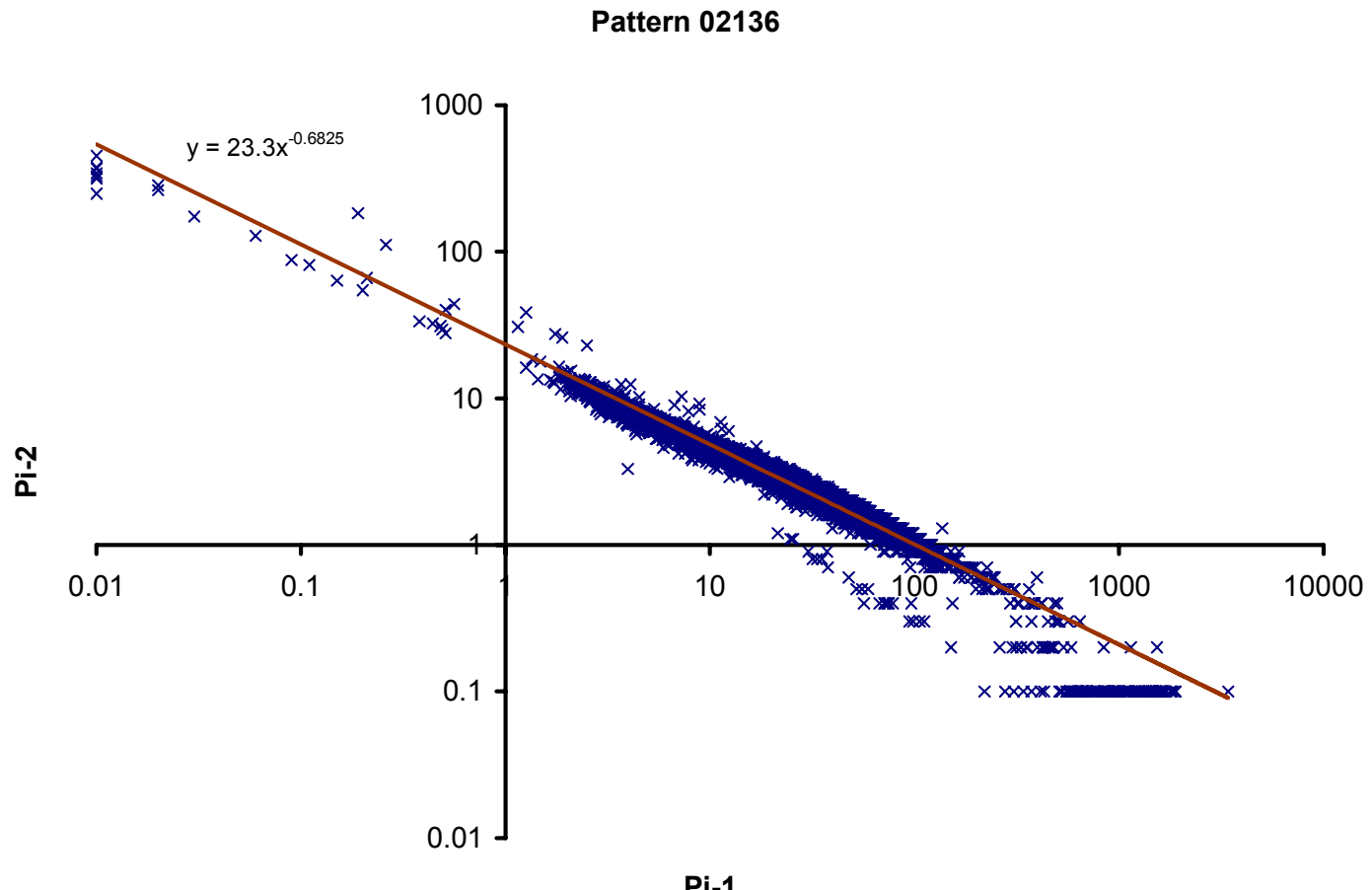

Figure 44. Pi-1 (drill performance) versus Pi-2 (rock resistance) for 20,812 monitor readings from the 234 holes of blast pattern 02136 .

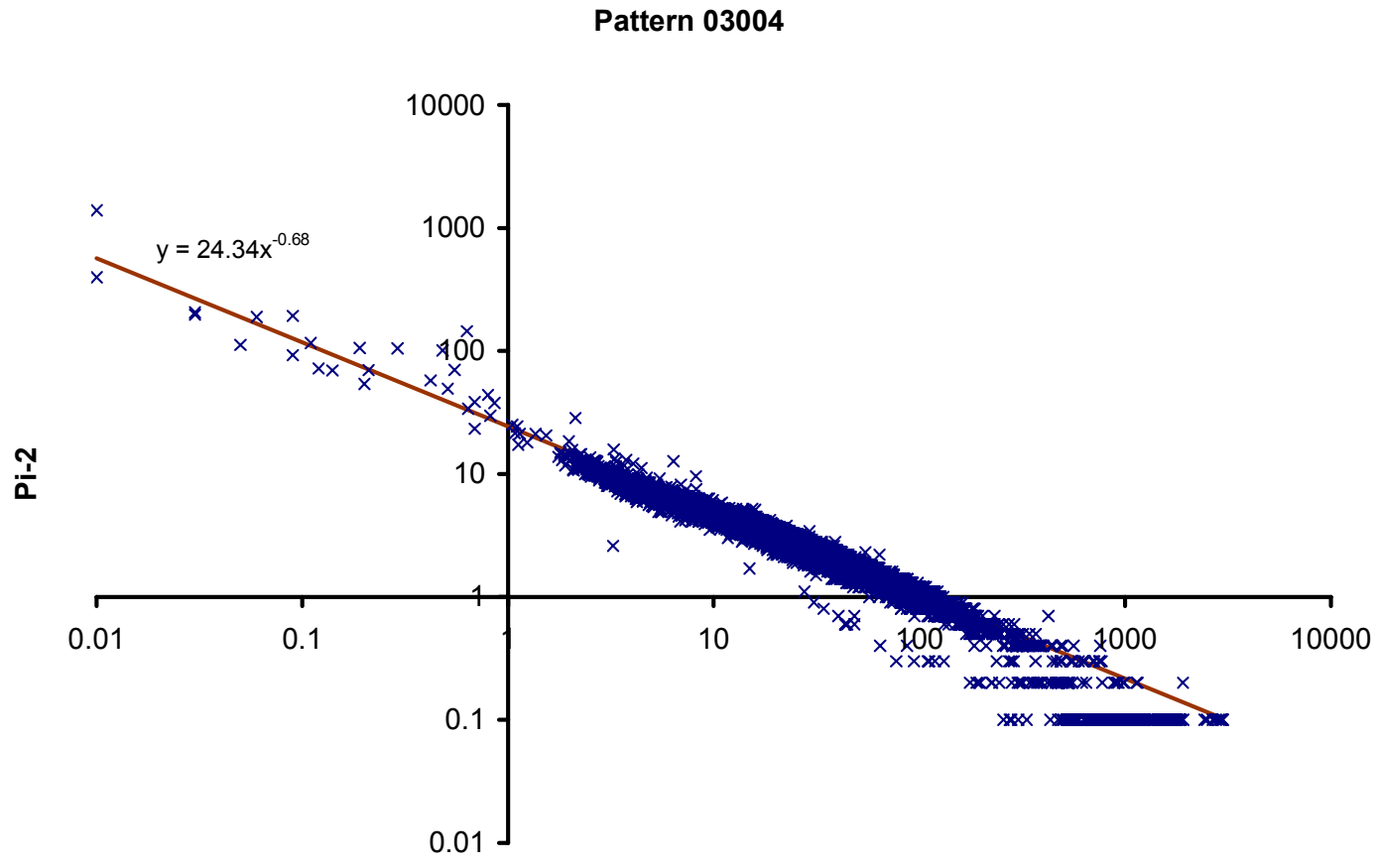

$\mathrm{Pi}-1$

Figure 45. Pi-1 (drill performance) versus Pi-2 (rock resistance) for 49,324 monitor readings from the 382 holes of blast pattern 03004. 


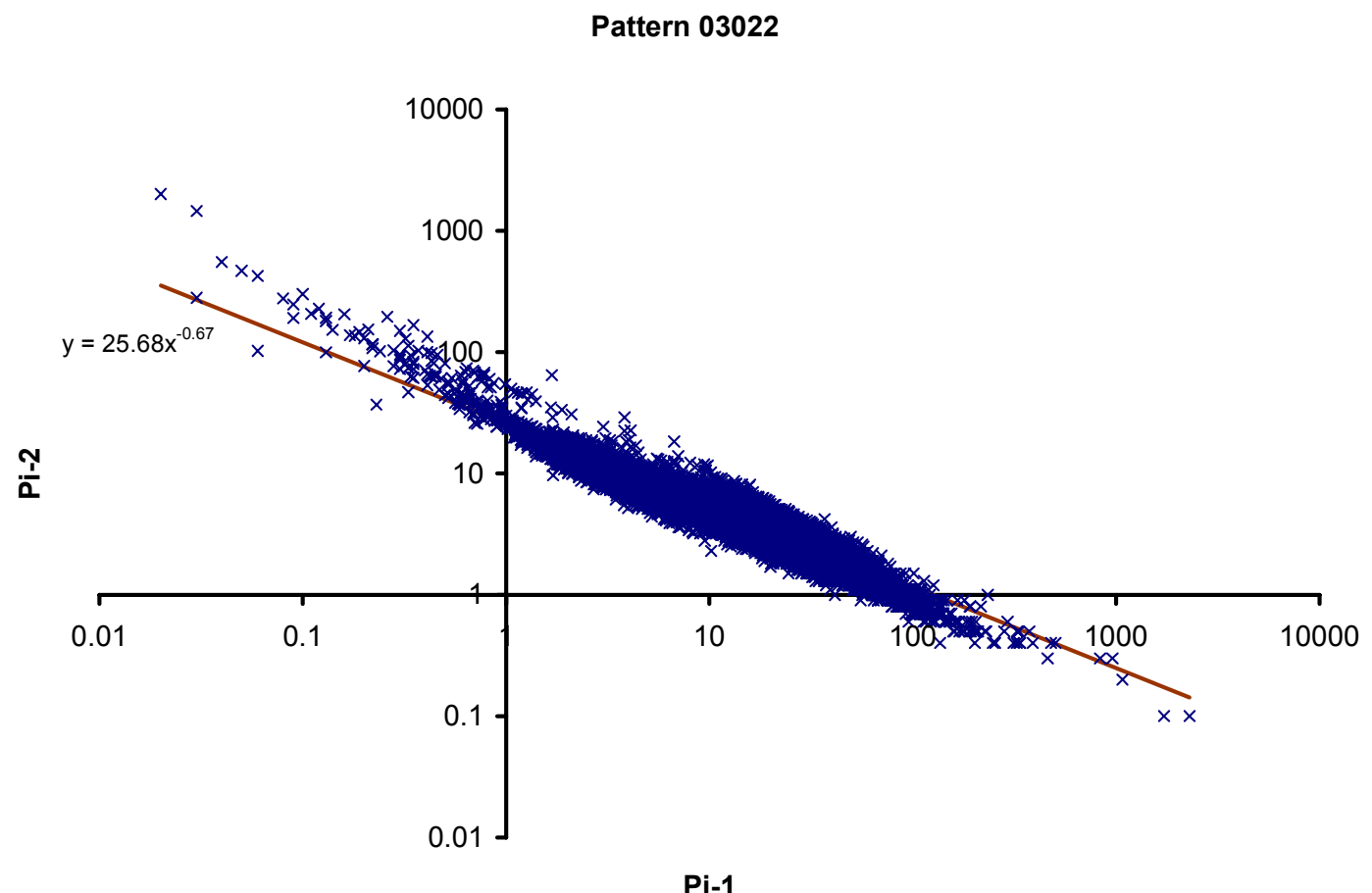

Figure 46. Pi-1 (drill performance) versus Pi-2 (rock resistance) for 106,111 monitor readings from the 423 holes of blast pattern 03022 .

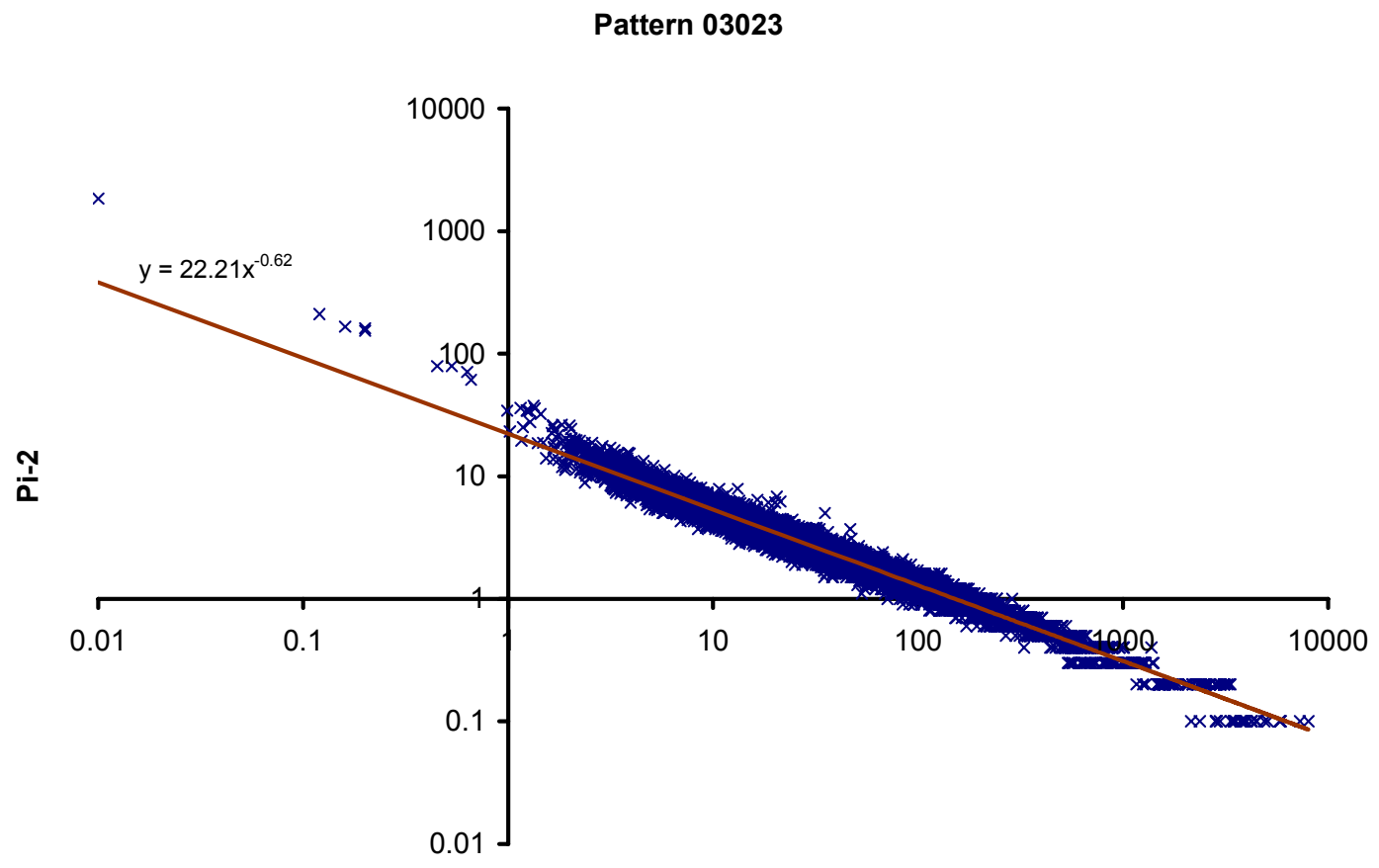

Pi-1

Figure 47. Pi-1 (drill performance) versus Pi-2 (rock resistance) for 30,289 monitor readings from the 257 holes of blast pattern 03023. 


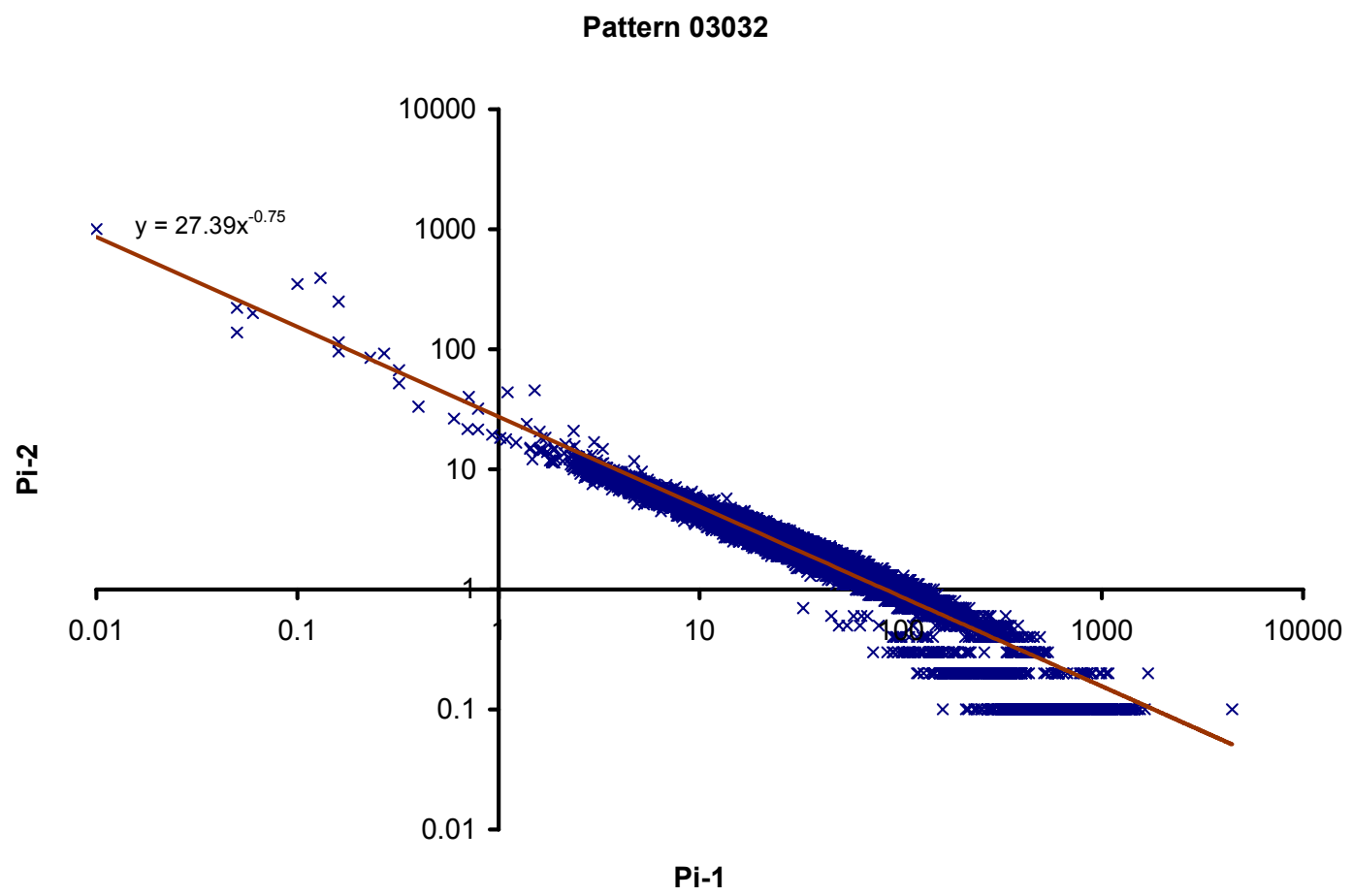

Figure 48. Pi-1 (drill performance) versus $\mathrm{Pi}-2$ (rock resistance) for 30,447 monitor readings from the 84 holes of blast pattern 03032 . 


\section{Fragmentation}

The fragment size of the muck conveyed from the Hibtac Mine crushers to the mill is monitored by a WipFrag Momentum system, installed by a team from one of the industrial partners in the TOPIM project, WipWare Inc. Figure 49 illustrates the general data acquisition setup. One camera was set up over each of the two conveyor belts, as shown in Figures 50 and 51. The computer collecting the digital images they produce is housed in the crusher control room, and calculates various parameters describing the shape and size distribution of the crushed ore (Figure 52).

Though early test work at Hibbing indicated an optimal feed distribution of 40 percent plus 6-inch, 20 percent 3- to 6-inch, and 40 percent minus 3-inch ore rock, blending has not directly included feed size but instead assumes a proper distribution reflected by the proportion of targeted geologic units in the ore blend. However, exploration drill core measurements show that fracture frequency varies within geologic units across the property (Figure 53A).

Geotechnical data, including fracture frequency and rock quality designation (RQD) are typically used for engineer's ground stability studies. Field observations indicate the frequency of subhorizontal, bedding-parallel fractures is greater than that of vertical fractures at Hibtac. Blasted fragments are typically tabular, with faces defined by joints and bedding. Therefore, geotechnical data should reflect relative fragmentation (Figure 53B). Geotechnical data are now collected on every core sample and are block modeled. These provide an index of the run-ofmine fragment size that will be incorporated into ore grading and reconciliation, and add value to drill core with a minimal time cost.

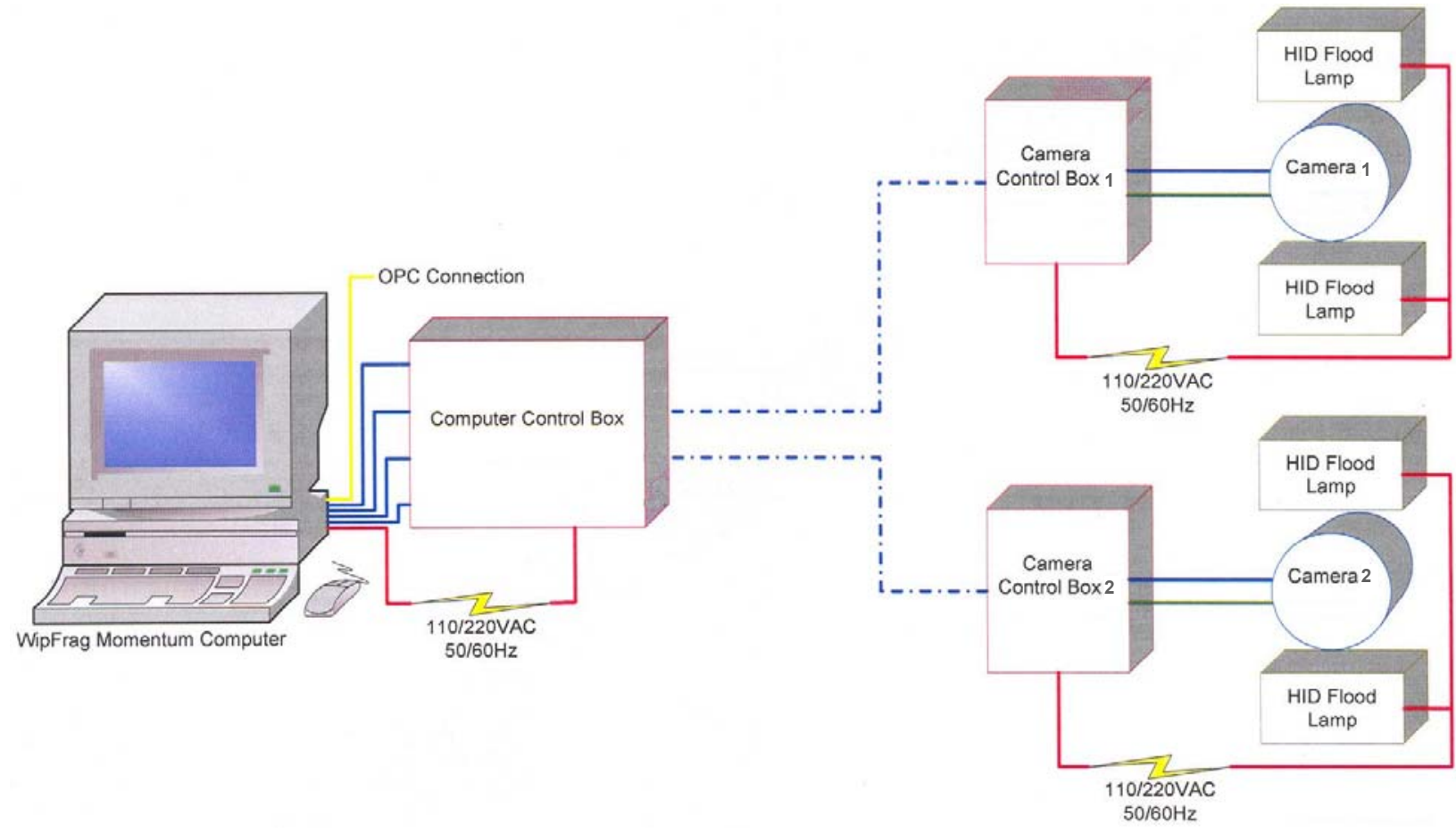

Figure 49. General setup of the WipFrag Momentum system (courtesy of WipWare Inc.). 


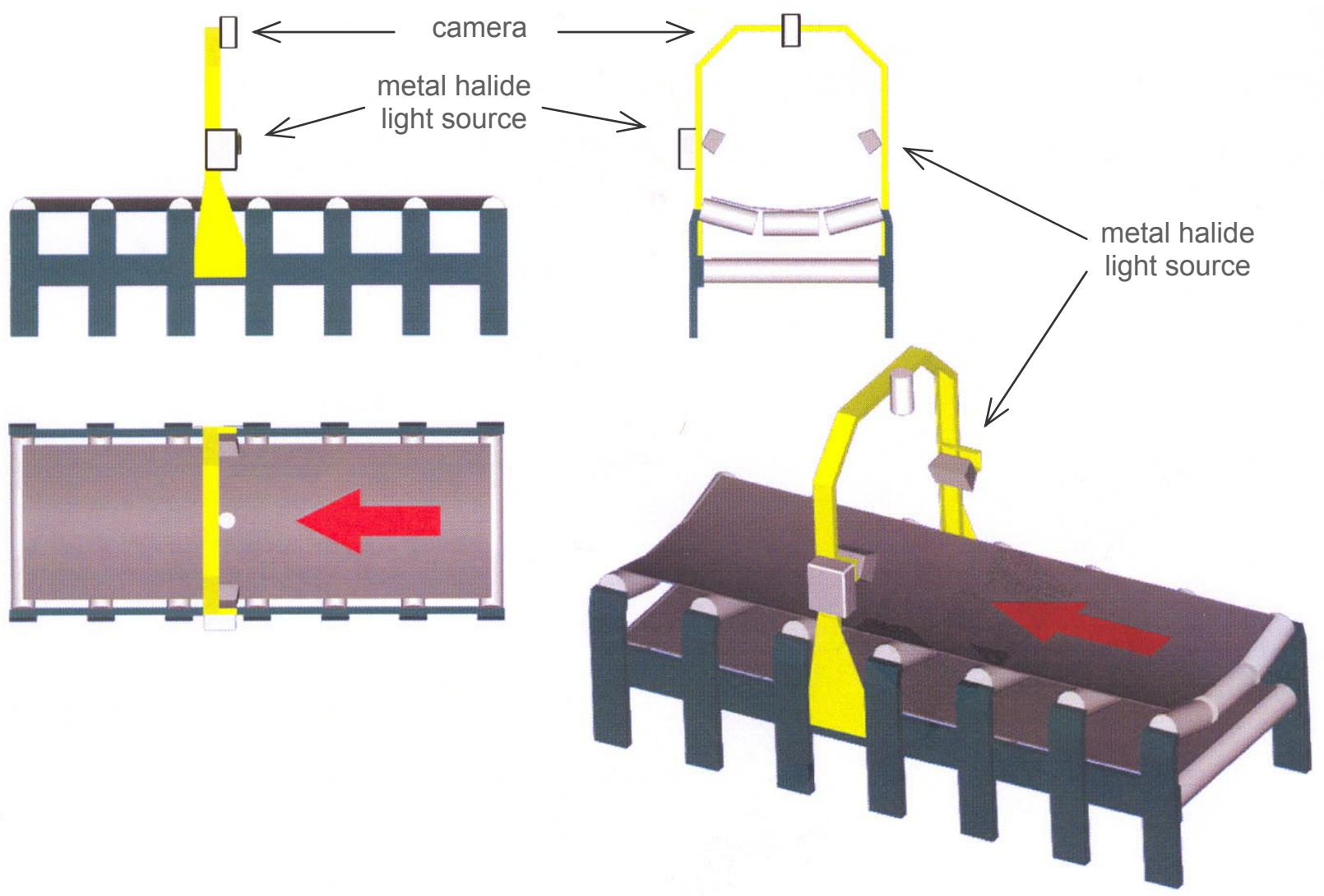

Figure 50. Physical setup of the WipFrag Momentum system (courtesy of WipWare Inc.).

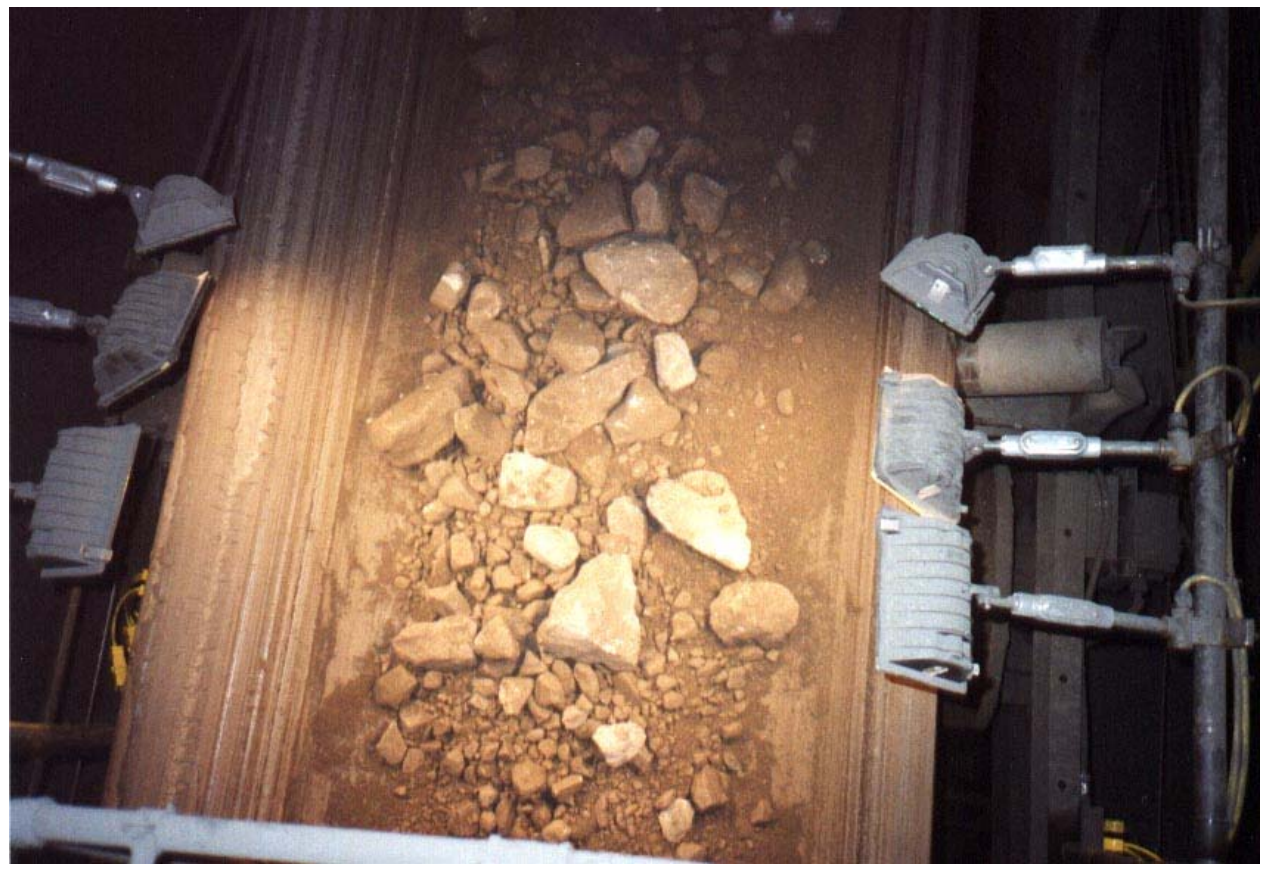

Figure 51. Typical example of the lighting of a conveyor belt for muck image analysis (courtesy of WipWare Inc.). 


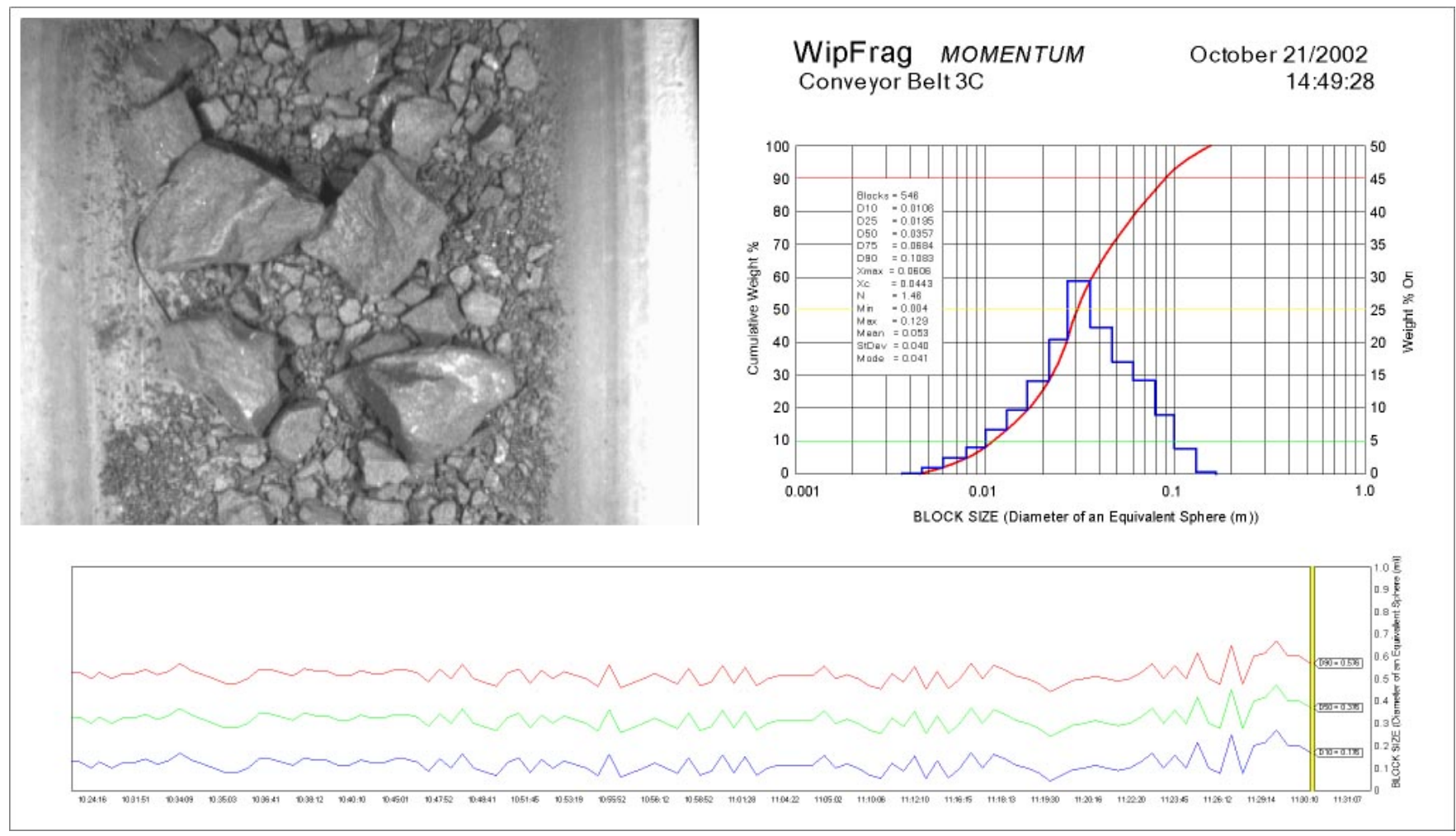

Figure 52. Example of WipFrag Momentum conveyor image analysis results (courtesy of WipWare Inc.).

Figure 53A shows the mean fracture frequency from vertical drill core samples grouped from west (Group 5) to east (Group 1) across the mine. Most fractures are subhorizontal partings. The scatter plot in Figure 53B shows the daily correlation between modeled RQD from core logging and optical analysis from the WipFrag Momentum system of mill feed on the primary ore conveyor. The inverse distance squared block model is based on only 80 core holes. Mill feed had been blasted and nominally crushed to minus $23 \mathrm{~cm}$.

Figure 54 shows the fragment size data for crushed feed on two primary ore conveyor belts measured by WipFrag Momentum over a 45 day period starting in mid-December 2004. Plotted data represent $d(\%$ passing) points. During this period, the overall size distribution closely matched the sizing specifications.

Figure 55 shows, however, that fragment size is just one of the many variables that control mill throughput. This is discussed further during the section on Ore Segregation Test 4. In general, there are enough outliers from the main population bins to suggest a positive correlation of mill throughput with a coarsening blend. This is a significant benefit of optical rock size analysis - we can eventually test whether the original specifications actually yield the optimum sizing blend without difficult and dangerous physical sampling of the ore stream. 

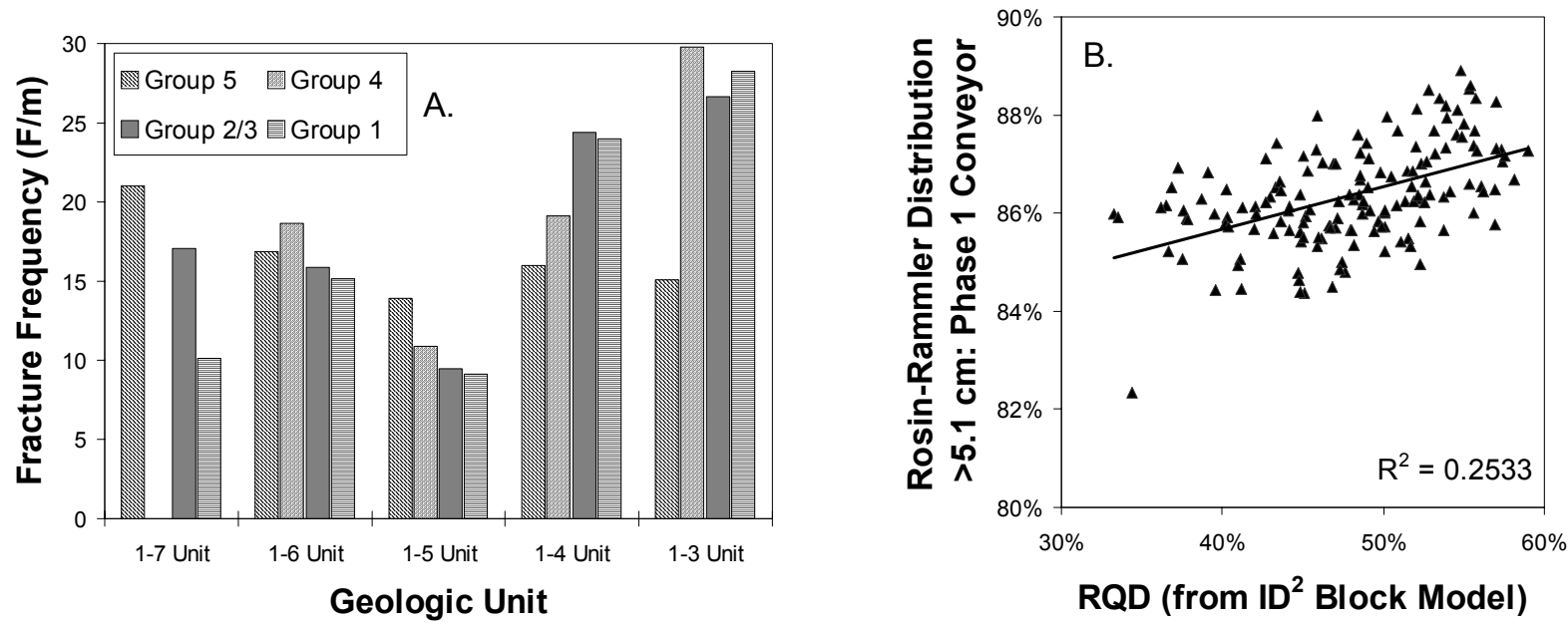

Figure 53. Use of the results of image analysis of crushed ore feed to the mill (Orobona et al., 2006).

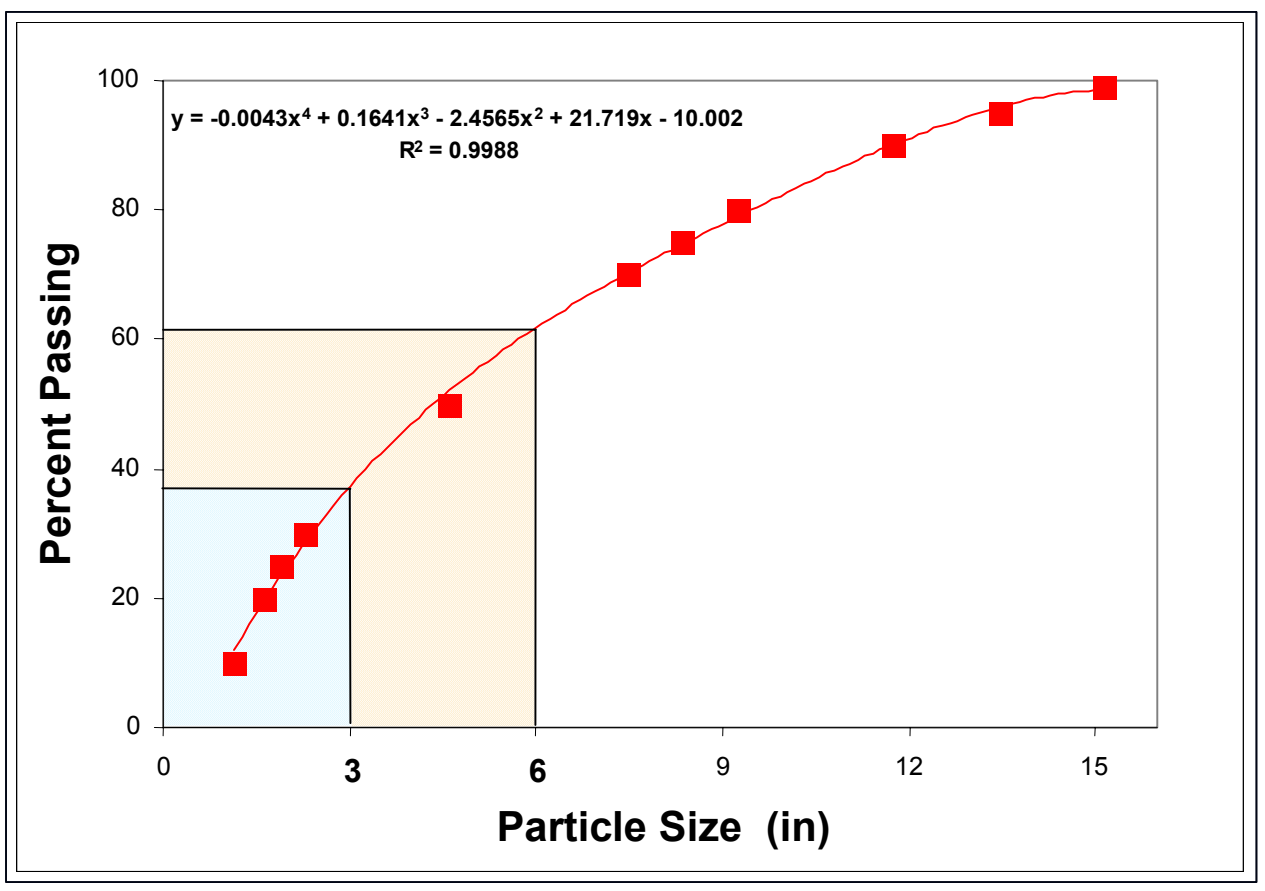

Figure 54. Conveyor muck size data from WipFrag Momentum, compared with physical sampling results (Orobona et al., 2004). 


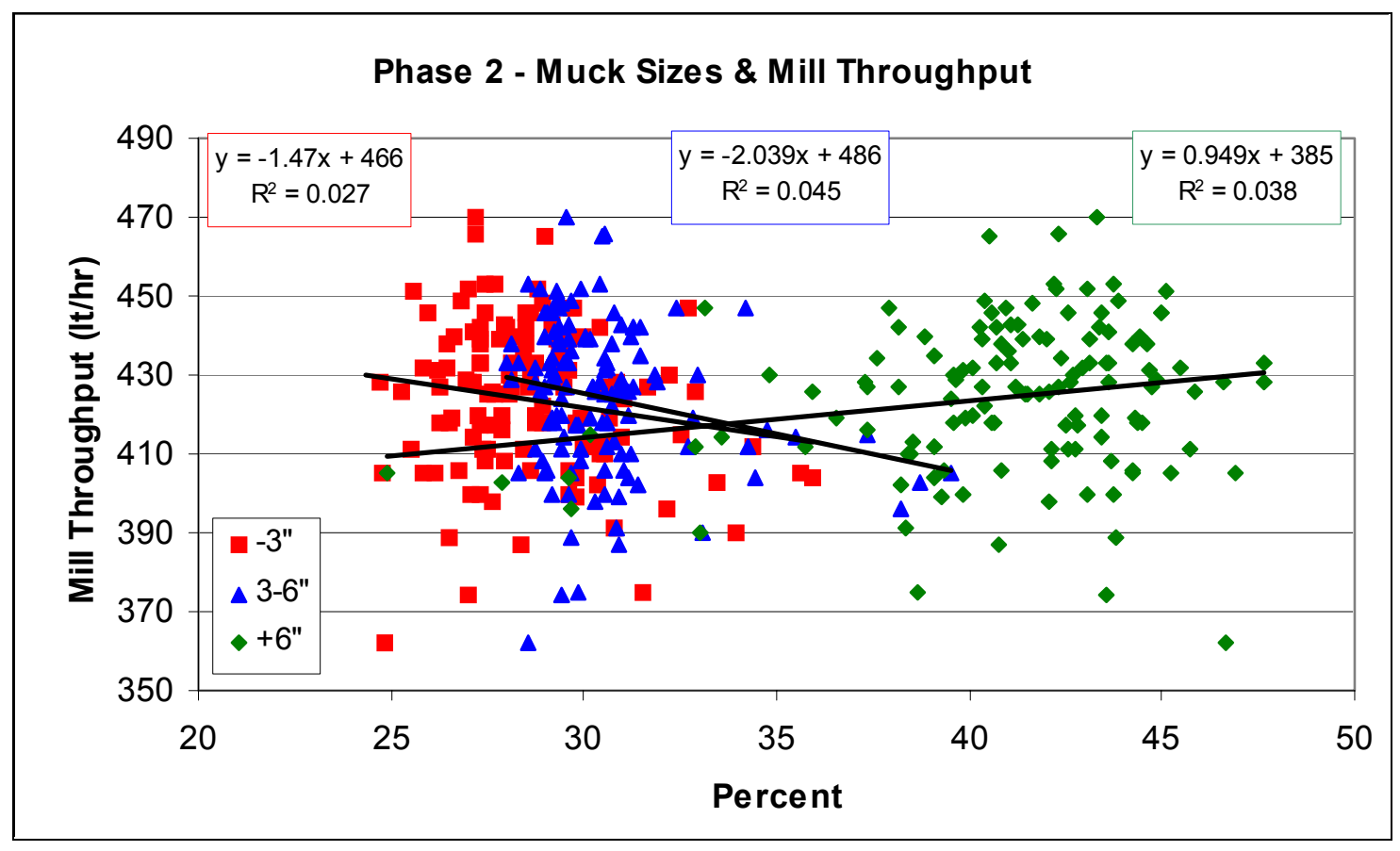

Figure 55. Plots by shift show more variability in blend size over time. 


\section{Orebody Modeling}

\section{Minntac Mine}

Orebody models are already the beginning point of the ore process control system. This project explored the addition of ore characteristics to the model to supplement the usual grade data, characteristics such as percent iron, percent silica, and A factor (liberation index).

Several ore characteristics were reviewed: a fragmentation index, trace chemistry, blast hole drill performance, and a new liberation index. The goal was to achieve greater detail on the factors that most affect comminution, concentration, and agglomeration. As ore characteristics were considered for inclusion, their usefulness was judged. The new models also had another major use: statistical comparison of the diverse but interrelated factors that control or influence the iron winning process. For example, how does liberation compare to drill performance as a predictor? Questions like this were tested in the statistical analysis discussed later in this report.

At Minntac, two block models were constructed with the MineSight ${ }^{\circledR}$ software package: a standard horizontal block model, bounded by the ore seams, and a gridded seam model, which constrained the blocks to remain within the geologic horizon. An inverse distance squared methodology was used to construct the blocks. The block size for the models is 50 by 50 by 20 feet. Figure 56 illustrates one of the applications of standard orebody models: blast design.

The assay, grindability, and liberation data from the exploration cores at Minntac Mine were composited into ore blocks that correspond to the average size of the working benches. These composited values were plotted in histograms and cumulative curves to enhance visual evaluation of their distinguishing characteristics (Appendix: Charts). Note that the HIS (high silica) and IBC (interbedded chert) designations together correspond to the Lower Slate layer. These designations reflect qualitative differences in crushing and grinding performance observed by Minntac personnel.

Two series of maps have been produced from the assay, grindability, and liberation data from the exploration cores that were incorporated into the Minntac Mine orebody model. One series consists of plan views of the orebody at constant elevations separated by 20 -ft intervals. The other series shows the geologic formation surfaces as indicated by borehole intercepts. The formations dip approximately $5^{\circ}$ to the east. The two sets of maps are similar, but the second set shows more clearly the shapes of possible original geologic features that are indicated by changes in silica and iron concentration, ore grindability, and silica and iron liberation behavior.

This model includes qualitative and quantitative ore characteristics that impact processing in addition to the usual grade data. The quantitative characteristics are A Factor, grind characteristics (six-minute grind), Davis Tube silica, Davis Tube iron, and total iron. Geological layer is incorporated qualitatively, but was not utilized in the development of the ore control block model. The blocks are generated using an inverse distance squared relationship between the exploration hole locations and the blocks, which are currently set at 50 by 50 by 20 feet in size to match the bench height in use at Minntac Mine.

The mine block models can be used to compare empirically predicted ore movement, ore movement based on the new model, and data flow from the mill. The block model is sectioned along the designated ore movement locations and current mining benches, then plotted and crosschecked against the delivered ore to the crusher (Figure 57). 


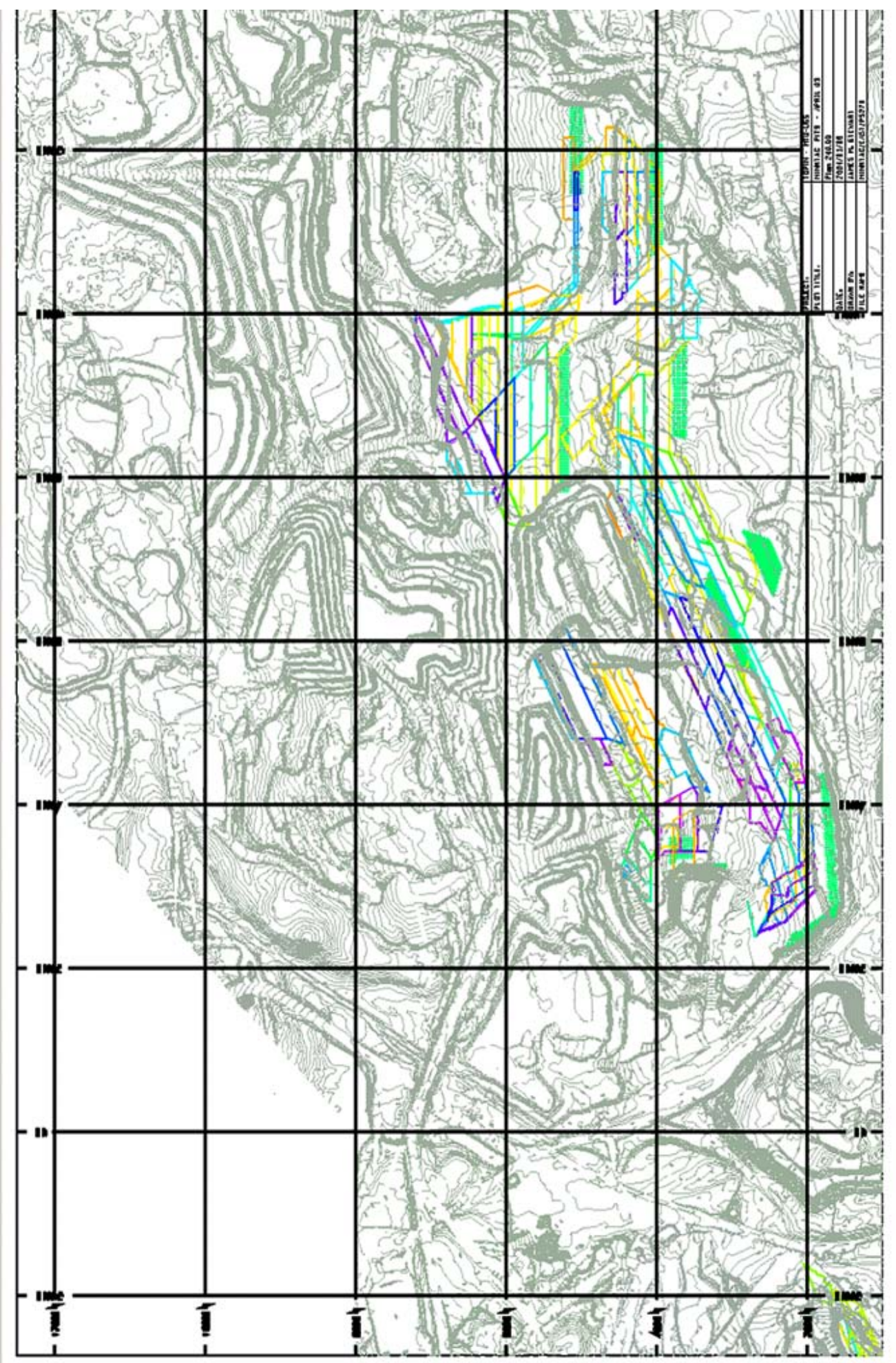

Figure 56. Some of the blasts shot in the East Pit of Minntac Mine during 2002 and 2003. Ore from several of these was the subject of Ore Segregation Tests 1 and 2. 


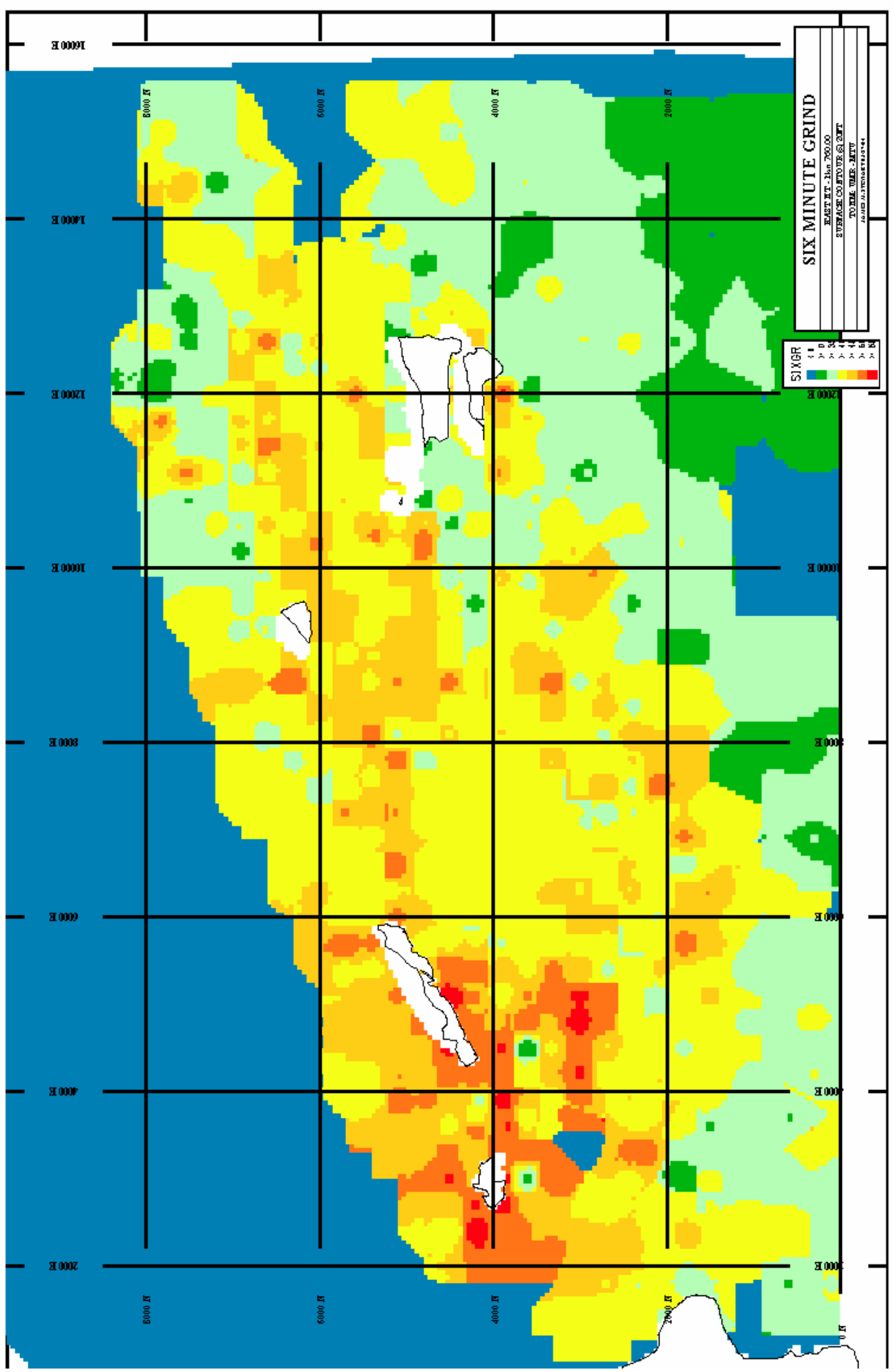

Figure 57. Plan view of variations in six-minute grind at a constant elevation in the East Pit, from the third-generation Minntac Mine block model. 


\section{Hibtac Mine}

The specific energy data calculated from the Hibtac drill monitoring program is being incorporated into the mine and orebody model (Figure 58). Individual ore polygons can be graded for specific energy and - in concert with the DISPATCH ${ }^{\circledR}$ and WipFrag ${ }^{\circledR}$ systems tracking of individual truckloads - correlated with fragmentation (Figures 59 and 60).

Contoured SE composites are now being used to refine mining polygon boundaries at Hibtac. Specific energy is useful for mapping lithologic contacts, and often reflects bed thickness and in situ fracture frequency. In addition, it may also show variations in hardness/ work index. Some of the distinct zones cross pattern progression, but some boundaries may reflect tool changeout, so care must be exercised.

For reliable long-term planning, diamond drill core is still the most reliable and best controlled sample set for measuring/modeling physical rock properties. Recent density measurements allow for creation of a tonnage factor grid based on magnetic susceptibility. Decisions have not yet been made whether modeling of other logged properties - fracture frequency, the ore blend, RQD, bed thickness - improve prediction of actual fragmentation and/or mill performance. Possible future drill monitoring of exploration drilling could allow for direct correlation of SE and geotechnical data (fracture frequency, bed thickness, etc.) at Hibtac.

The current missing component is a joint orientation/fracture mapping campaign.

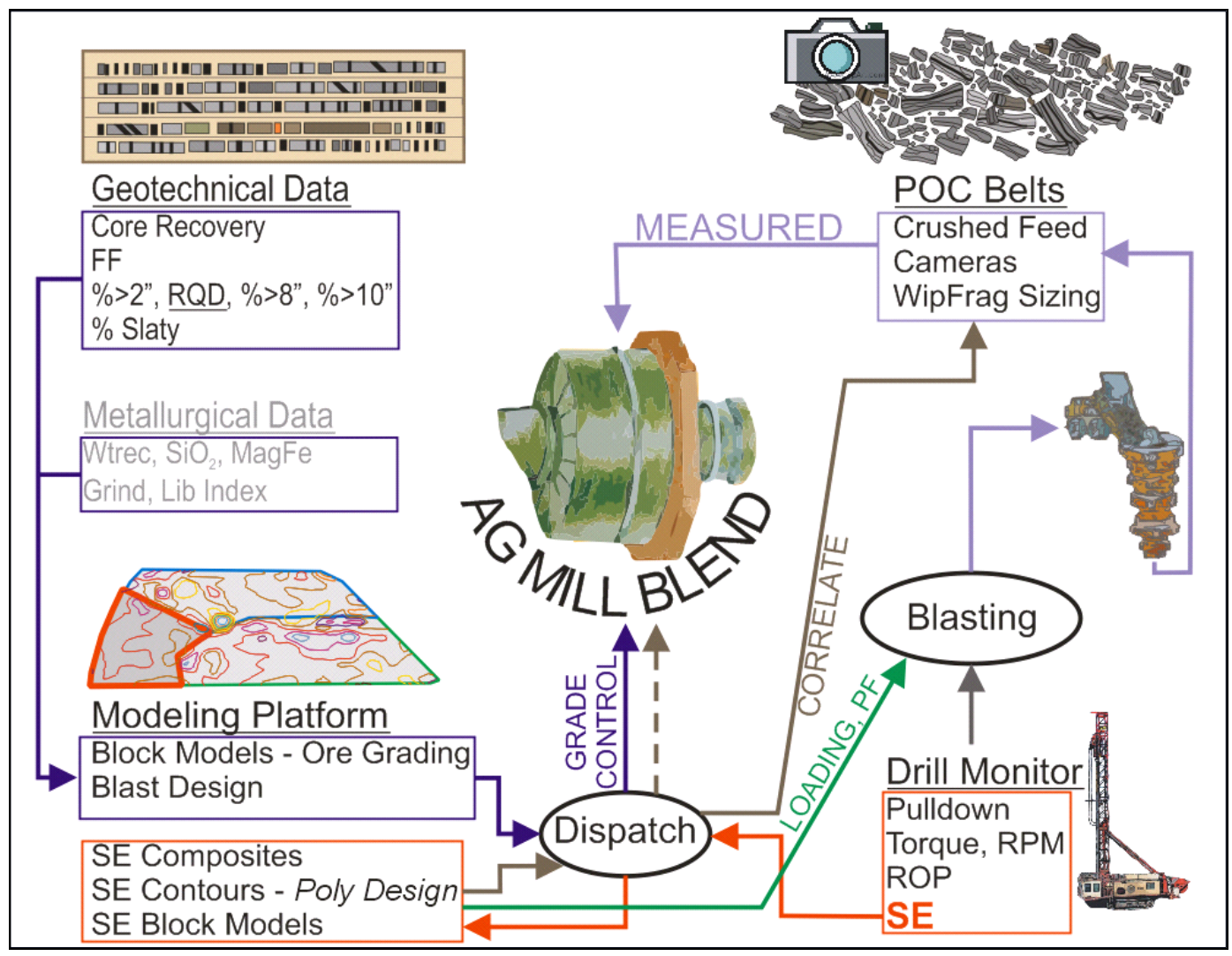

Figure 58. How Hibtac Mine is using specific energy information in mine operation (Orobona et al., 2004). 


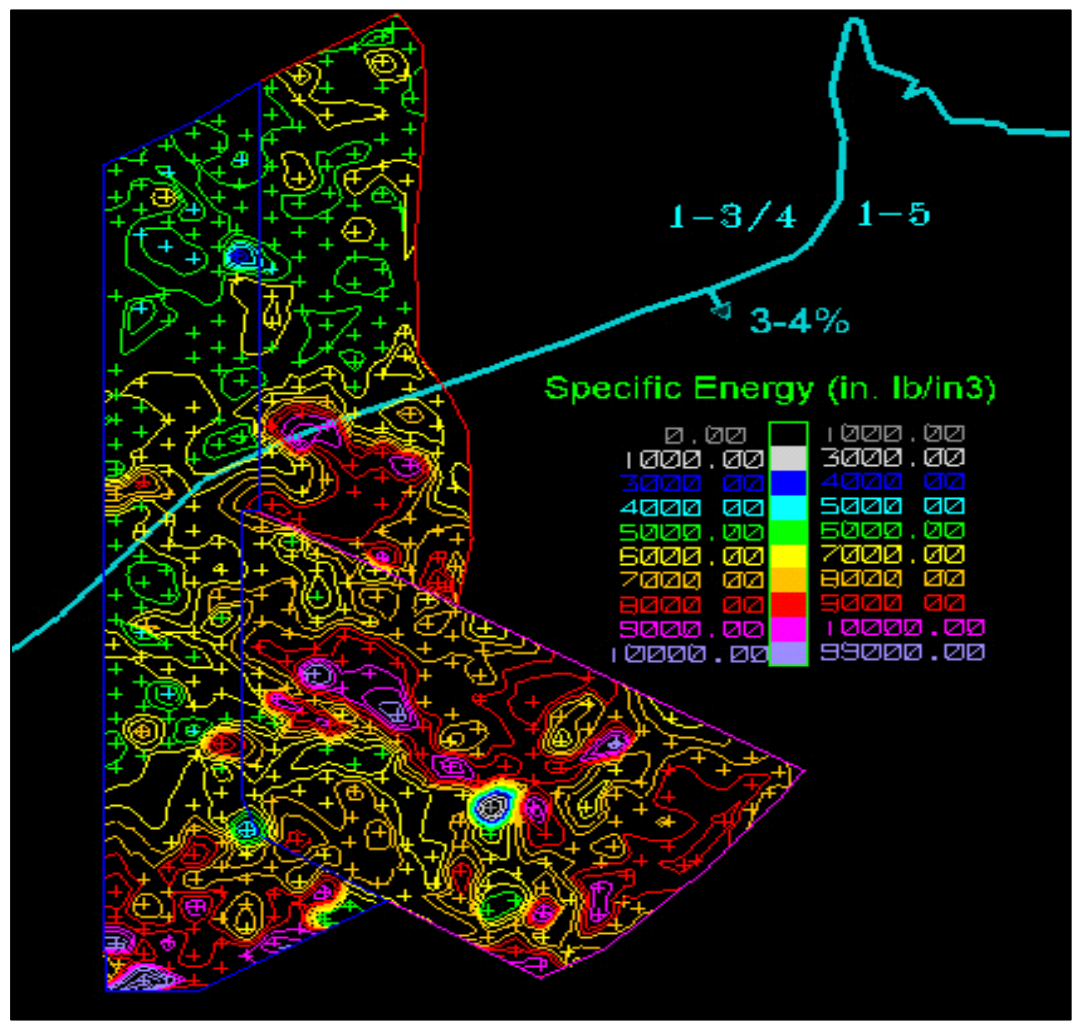

Figure 59. Contouring specific energy measured by drill monitors (Orobona et al., 2004).

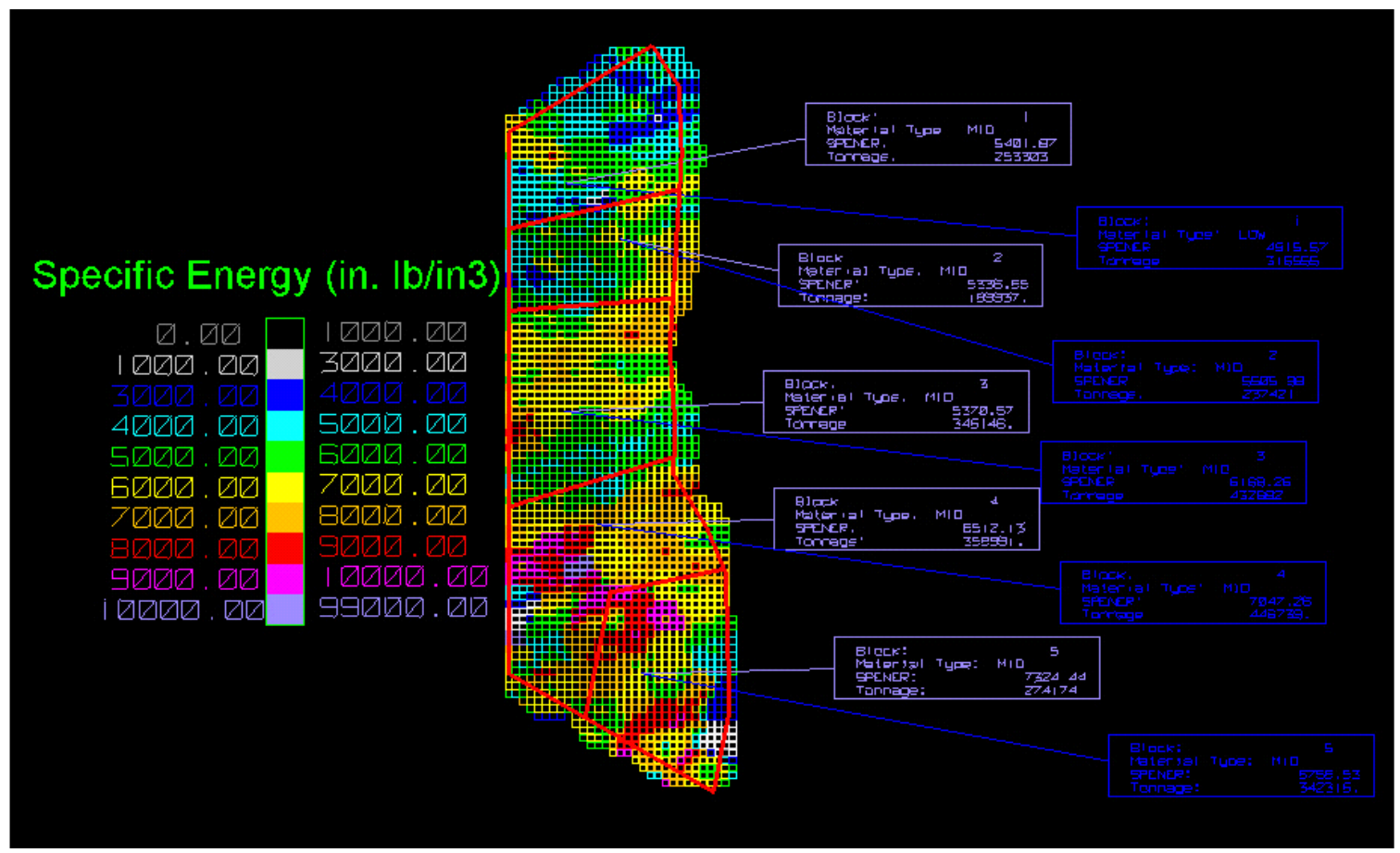

Figure 60. Ore control block model of specific energy (Orobona et al., 2004). 


\section{Ore Segregation Tests}

Several experiments in which ore was treated separately on the basis of some pre-mapped factor were conducted at Minntac Mine and at Hibtac Mine.

The following sections describe the initial results and the simple hypothesis testing that was applied. The data also were subjected to more rigorous statistical examination that is reported separately in a following section of this report.

\section{Ore Segregation Test 1}

The first ore segregation test was conducted at Minntac Mine in April 2003 and lasted five days. For these tests, the ore was segregated by a silica liberation index called the A factor, a test that predicts the amount of grinding needed to liberate a given amount of silica. Silica liberation is an essential quality of iron ore.

Ore for which silica was predicted to be difficult to liberate (high A factor) was sent to one line of the processing plant (Step 1-2). Ore that was predicted to be easy to liberate the silica (low A factor) was sent to the other line (Step 3). The physical layout of the Minntac crusher and concentrator allowed complete separation of the segregated product streams up to the froth flotation tanks. During the tests, the usual data was augmented by additional sampling.

The ore streams loaded into the two crushers were crushed separately, then ground in separate rod mills and passed through four separation stages (rougher, cobber, finisher, and cleaner) before being re-combined to enter the froth flotation tanks where the excess silica is removed.

The A factor segregation also caused segregation of the ore by the percent of calcium oxide, and manganese, which may be proxies of other, geologically and mineralogically related elements. Table 4 outlines the expected differences between the segregated ore streams. Of these compounds the iron and silica are of the most immediate interest. The segregation was tracked as far as possible through the concentrator and into the agglomerator. Magnetic iron, alumina, magnesia, calcium oxide, and manganese concentrations, in addition to silica, are monitored daily in the Minntac Mill.

Table 4. Summary Characteristics of the Ore in the Segregation Test. (Low A-factor $=$ easier liberation, High A-factor $=$ difficult liberation.)

\begin{tabular}{|r|c|c|}
\cline { 2 - 3 } \multicolumn{1}{c|}{} & $\begin{array}{c}\text { Liberation } \\
\text { Difficult }\end{array}$ & $\begin{array}{c}\text { Liberation } \\
\text { Easier }\end{array}$ \\
\hline Geology & Slate & Chert \\
Magnetic Iron & Lower & Higher \\
Silica & Higher & Lower \\
Grinding & Needs More & Needs Less \\
A-factor & High & Low \\
\hline
\end{tabular}


Table 5. Data comparisons between the low-A factor and the high-A factor ore processing lines before, during, and after Ore Segregation test 1 , at $90 \%$ confidence level. "X" indicates a statistically significant difference for the comparison marked.

\begin{tabular}{|c|c|c|c|c|c|}
\hline \multicolumn{2}{|c|}{ STATISTICALLY SIGNIFICANT } & \multicolumn{4}{|c|}{ Low Line Rod Mill <> High Line Rod Mill } \\
\hline DIFFERENCES (space) & $\mathrm{Al}$ & $\mathrm{Ca}$ & $\mathrm{Mg}$ & $\mathrm{Mn}$ & $\mathrm{SiO} 2$ \\
\hline $\begin{array}{r}\text { Before Test } \\
\text { During Test } \\
\text { After Test }\end{array}$ & $\mathbf{X}$ & $\mathbf{X}$ & & $\mathbf{X}$ & $\mathbf{x}$ \\
\hline
\end{tabular}

\begin{tabular}{|c|c|c|c|c|c|c|c|c|}
\hline \multirow{3}{*}{$\begin{array}{l}\text { STATISTICALLY SIGNIFIC } \\
\text { DIFFERENCES (space) }\end{array}$} & \multicolumn{7}{|c|}{ Low Line <> High Line (Met Report) } & \multirow{3}{*}{$\begin{array}{c}\text { RMF } \\
3 / 4 \text { to } 1 / 2 "\end{array}$} \\
\hline & RMF & Concent. & C-Tails & F-Tails & RMF & RMF & RMF & \\
\hline & mag Fe & mag Fe & mag Fe & mag Fe & $\mathrm{khw} / \mathrm{t}$ & $-3 / 4 "$ & $-1 / 2 "$ & \\
\hline Before Test & & & & & $\mathbf{X}$ & $\mathbf{X}$ & & $\mathbf{X}$ \\
\hline During Test & & & & $\mathbf{X}$ & $\mathbf{x}$ & $\mathbf{x}$ & & \\
\hline After Test & & & $\mathbf{X}$ & $\mathbf{x}$ & $\mathbf{x}$ & & & \\
\hline
\end{tabular}

The results of basic statistical analysis of the first ore segregation test are summarized in Tables 5 and 6, and in the accompanying data tables and figures (Figures 61 through 64, and Appendices). This analysis tested the hypothesis that two average data values are equal, at the $90 \%$ confidence level, using the $\boldsymbol{t}$ statistic. The strong conclusion, that they are not equal, indicates that a statistically significant difference exists between the two; these are indicated in the tables by X's. The variances of the distributions being compared are unknown; they are assumed to be equal since the same processes and instruments were used to measure all of them. In addition, the analysis was repeated with the variances assumed unequal. There was little change in the results. These results are not reported here, since that analysis was less rigorous.

In the rod mill feed (i.e., the mine output from the benches, after passing through the crusher) and in the coarse tailings from the rougher, the amount of magnetic iron is the same in both ore streams, at $90 \%$ confidence. By the time the finely ground ore has gone through the cobber, finisher, and cleaner, and has reached the re-combination point at the flotation tanks, that is no longer the case: more magnetic iron remains in the fine tailings from the high-A factor line than those from the low-A factor line. The high-A factor line also appeared at first look to require more power to grind its ore, but examination of pre- and post-test data shows that this is normally the case. It may be due to differences in make/model of the equipment and variation in maintenance schedules, in addition to physical differences in the ore.

The two crushed ore streams as fed into the rod mills do contain different amounts of silica, as expected, but they also appear to contain different amounts of alumina and calcium oxide. This may be due to the mineralogy of the orebody, in which calcium and aluminum deposition is correlated with silica deposition. The reported measurement variances, an independent check of the hypothesis-test results, indicate that the alumina result may not be significant.

As mentioned, to check the results and the process by which they are reached, data from the two ore processing streams were analyzed also before and after the segregation test. In most cases there were no significant differences, but in a few cases there were. For example, the manganese content of the ore being fed into the rod mill which later ground the low-A factor ore was higher than for the ore going into the rod mill which later ground the high-A factor ore. 
Also, the power draw for one of the two crushers is always higher than for the other. These, and similar comparison results, indicate that steady state may not be an accurate assumption for the combined ore stream constituents outside the time boundary of the segregation tests. They also point out where differences may exist that are due not to variation in measured ore stream constituents, but rather to other causes such as equipment differences and operational (e.g., setpoint) differences.

The most noteworthy result of comparing temporal change in parameter values is that silica content, more than any other element, varies outside the time limits of the test. This is true less often for magnesium and calcium.

Table 6. Data comparisons with the same parameter before, during, and after Ore Segregation test 1. " $X$ " indicates a statistically significant difference for the comparison marked.

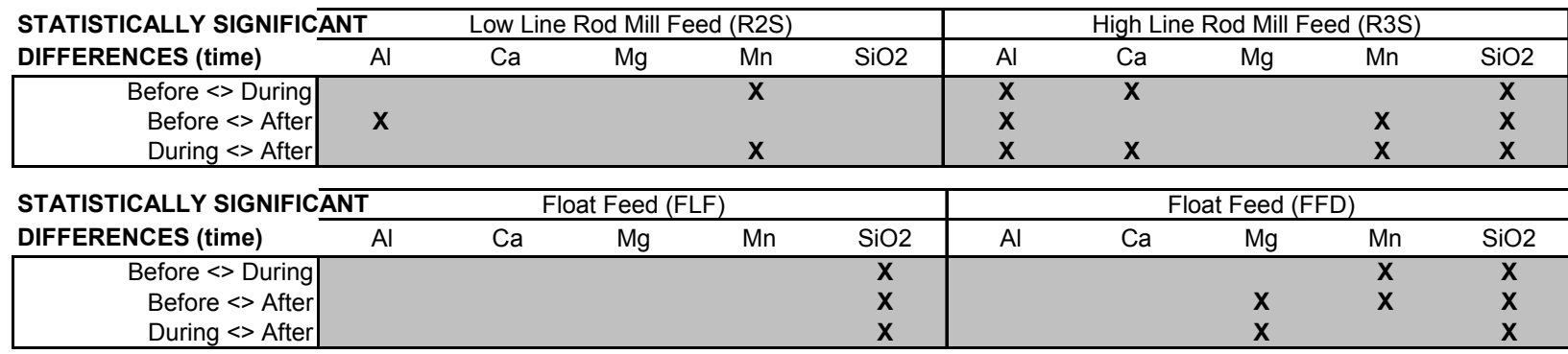

\begin{tabular}{|c|c|c|c|c|c|c|c|c|c|c|}
\hline \multicolumn{2}{|c|}{ STATISTICALLY SIGNIFICANT } & \multicolumn{4}{|c|}{ Float Concentrate (FC3) } & \multicolumn{5}{|c|}{ Float Tails (FLT) } \\
\hline DIFFERENCES (time) & $\mathrm{Al}$ & $\mathrm{Ca}$ & $\mathrm{Mg}$ & $\mathrm{Mn}$ & $\mathrm{SiO} 2$ & $\mathrm{Al}$ & $\mathrm{Ca}$ & $\mathrm{Mg}$ & $\mathrm{Mn}$ & $\mathrm{SiO} 2$ \\
\hline $\begin{array}{r}\text { Before }<>\text { During } \\
\text { Before }<>\text { After } \\
\text { During }<>\text { After }\end{array}$ & & & $\mathbf{x}$ & & $\mathbf{x}$ & & $\begin{array}{l}\mathbf{X} \\
\mathbf{X}\end{array}$ & $\begin{array}{l}X \\
X\end{array}$ & $\mathbf{X}$ & $\begin{array}{l}x \\
x \\
x\end{array}$ \\
\hline
\end{tabular}

\begin{tabular}{|c|c|c|c|c|c|c|c|c|c|c|}
\hline \multicolumn{2}{|c|}{ STATISTICALLY SIGNIFICANT } & \multicolumn{4}{|c|}{ Column Float Feed (CFD) } & \multicolumn{5}{|c|}{ Column Float Concentrate (CFC) } \\
\hline DIFFERENCES (time) & Al & $\mathrm{Ca}$ & $\mathrm{Mg}$ & $\mathrm{Mn}$ & $\mathrm{SiO} 2$ & $\mathrm{Al}$ & $\mathrm{Ca}$ & $\mathrm{Mg}$ & $\mathrm{Mn}$ & $\mathrm{SiO} 2$ \\
\hline Before <> During & & & & & $\mathbf{X}$ & & & & & $\mathbf{X}$ \\
\hline Before $<>$ After & & & $\mathbf{x}$ & & $\mathbf{x}$ & & & $\mathbf{X}$ & & $\mathbf{x}$ \\
\hline During $\ll$ After & & & $\mathbf{x}$ & & $\mathbf{x}$ & & & $\mathbf{x}$ & & $\mathbf{x}$ \\
\hline
\end{tabular}

\begin{tabular}{|c|c|c|c|c|c|c|c|c|c|c|}
\hline \multicolumn{2}{|c|}{ STATISTICALLY SIGNIFICANT } & \multicolumn{4}{|c|}{ Column Float Tails (CFF) } & \multicolumn{5}{|c|}{ Filter Cake \#2 (FC2) } \\
\hline DIFFERENCES (time) & $\mathrm{Al}$ & $\mathrm{Ca}$ & $\mathrm{Mg}$ & $\mathrm{Mn}$ & $\mathrm{SiO} 2$ & $\mathrm{Al}$ & $\mathrm{Ca}$ & $\mathrm{Mg}$ & $\mathrm{Mn}$ & $\mathrm{SiO} 2$ \\
\hline Before $<>$ During & & & $\bar{X}$ & & $\bar{X}$ & & $\bar{X}$ & $\bar{X}$ & & $\bar{x}$ \\
\hline Before $<>$ After & & & $\mathbf{x}$ & & $\mathbf{x}$ & & $\mathbf{x}$ & & & $\mathbf{x}$ \\
\hline During $<>$ After & & $\mathbf{x}$ & $\mathbf{x}$ & & $\mathbf{x}$ & & $\mathbf{x}$ & $\mathbf{x}$ & & \\
\hline
\end{tabular}

\begin{tabular}{|c|c|c|c|c|c|}
\hline \multicolumn{2}{|c|}{ STATISTICALLY SIGNIFICANT } & \multicolumn{3}{|c|}{ Filter Cake \#3 (FC3) } & \multirow[b]{2}{*}{$\mathrm{SiO} 2$} \\
\hline DIFFERENCES (time) & $\mathrm{Al}$ & $\mathrm{Ca}$ & $\mathrm{Mg}$ & $\mathrm{Mn}$ & \\
\hline $\begin{array}{r}\text { Before }<>\text { During } \\
\text { Before }<>\text { After } \\
\text { During }<>\text { After }\end{array}$ & & & $\mathbf{x}$ & & $\mathbf{x}$ \\
\hline
\end{tabular}




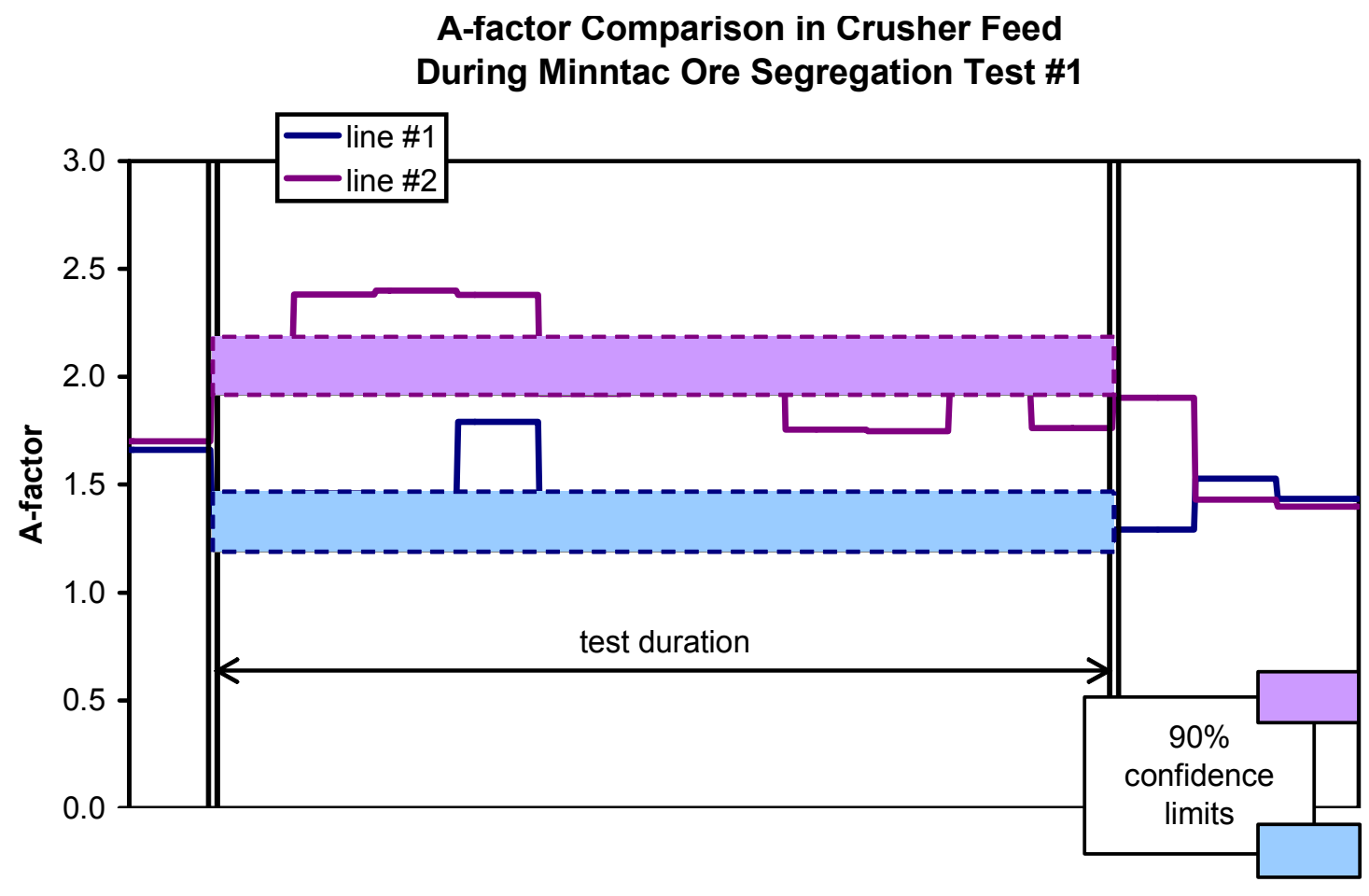

Figure 61. Comparison of the measured $A$ factor in the two lines. Ore segregation had been performed by the mine dispatcher on the basis of $A$ factor that had been modeled on data collected from exploration coreholes, so this result verifies that general procedure.

\section{Silica Comparison in Crusher Feed During Minntac Ore Segregation Test \#1}

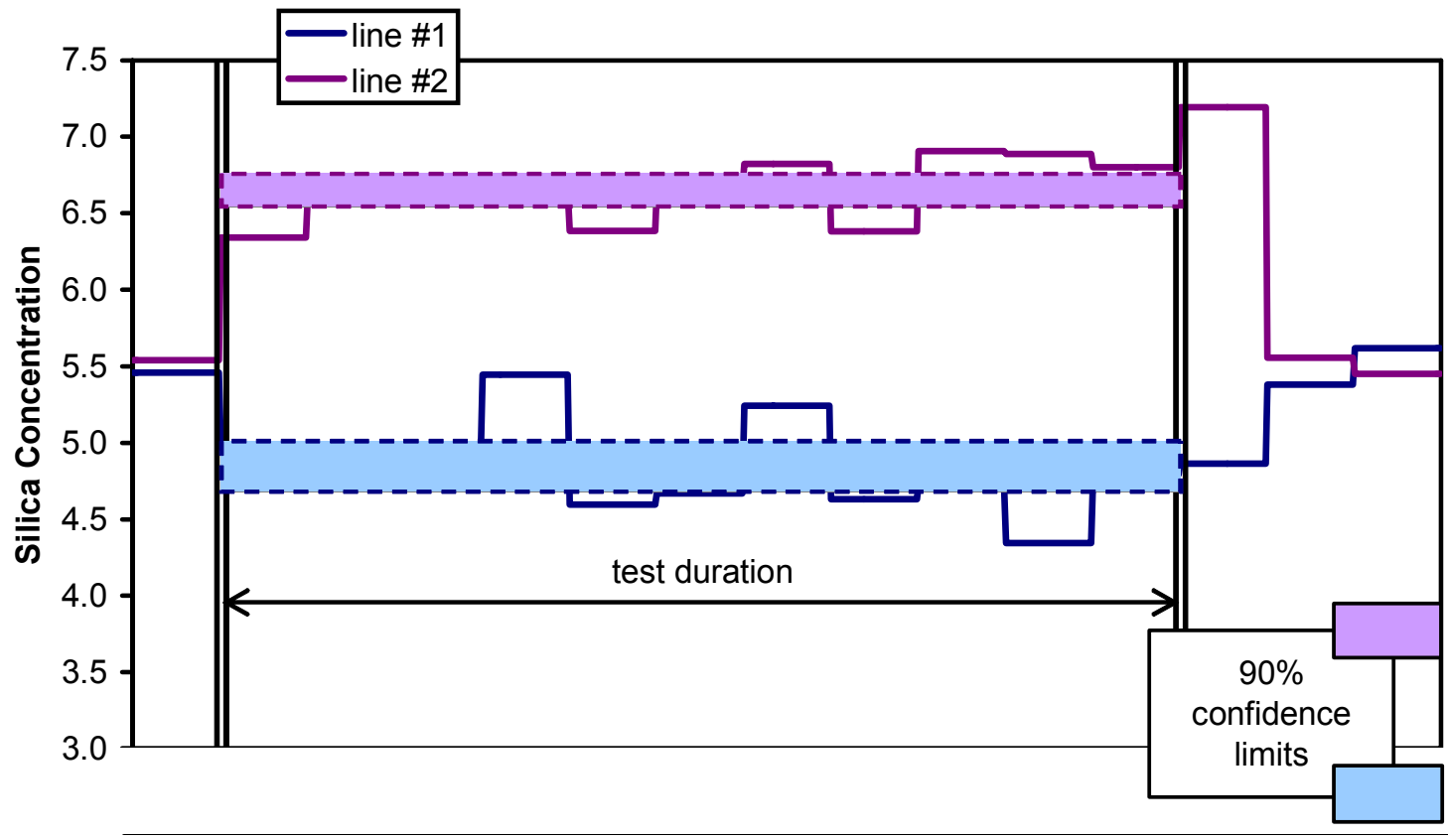

Figure 62. Silica content as incorporated in the orebody model is correlated with A factor. Line \#1 (Step 1-2) is the high A factor line. The confidence limits are symmetric about the test average. 


\section{Silica Concentration in Rod Mill \#3 Feed Minntac Ore Segregation Test \#1}

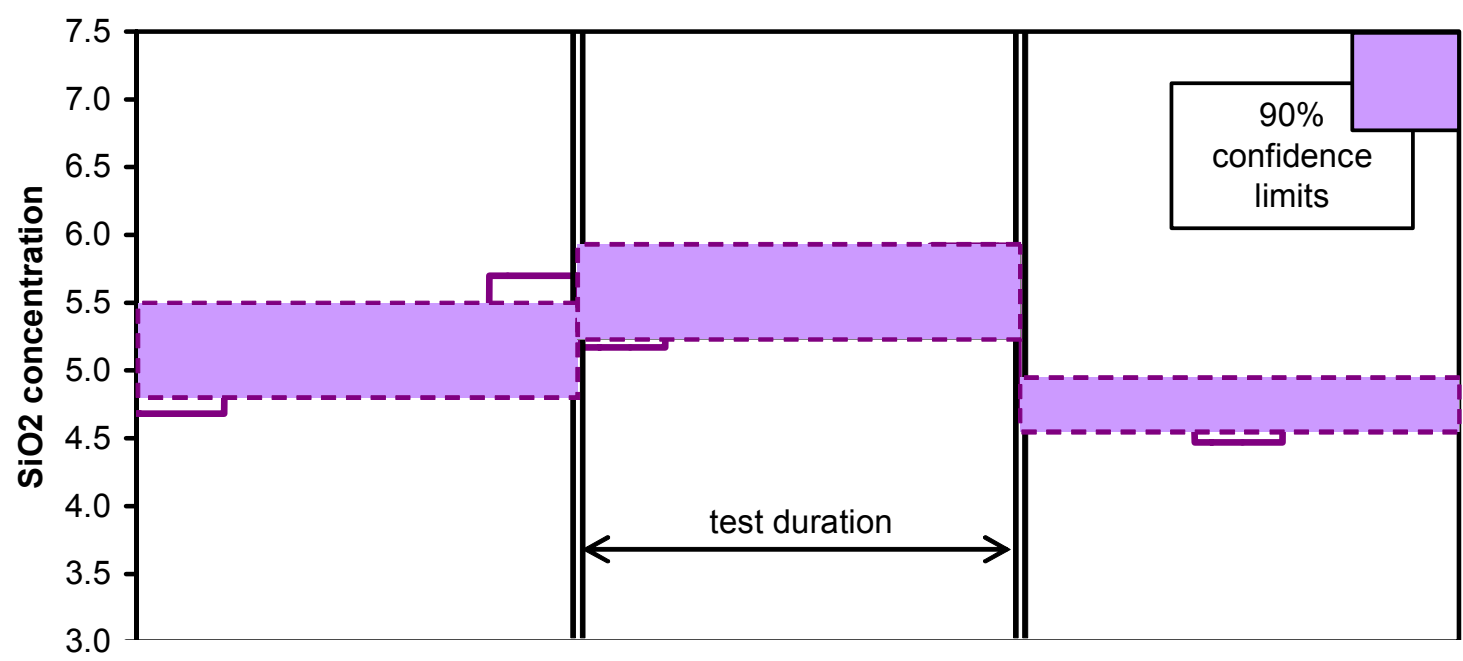

Figure 63. This value of silica concentration is measured in the mill. Compare with the values in Figure 62 , which are interpolated from relatively widely space exploration corehole data.

\section{Manganese Concentration in Rod Mill \#3 Feed Minntac Ore Segregation Test \#1}

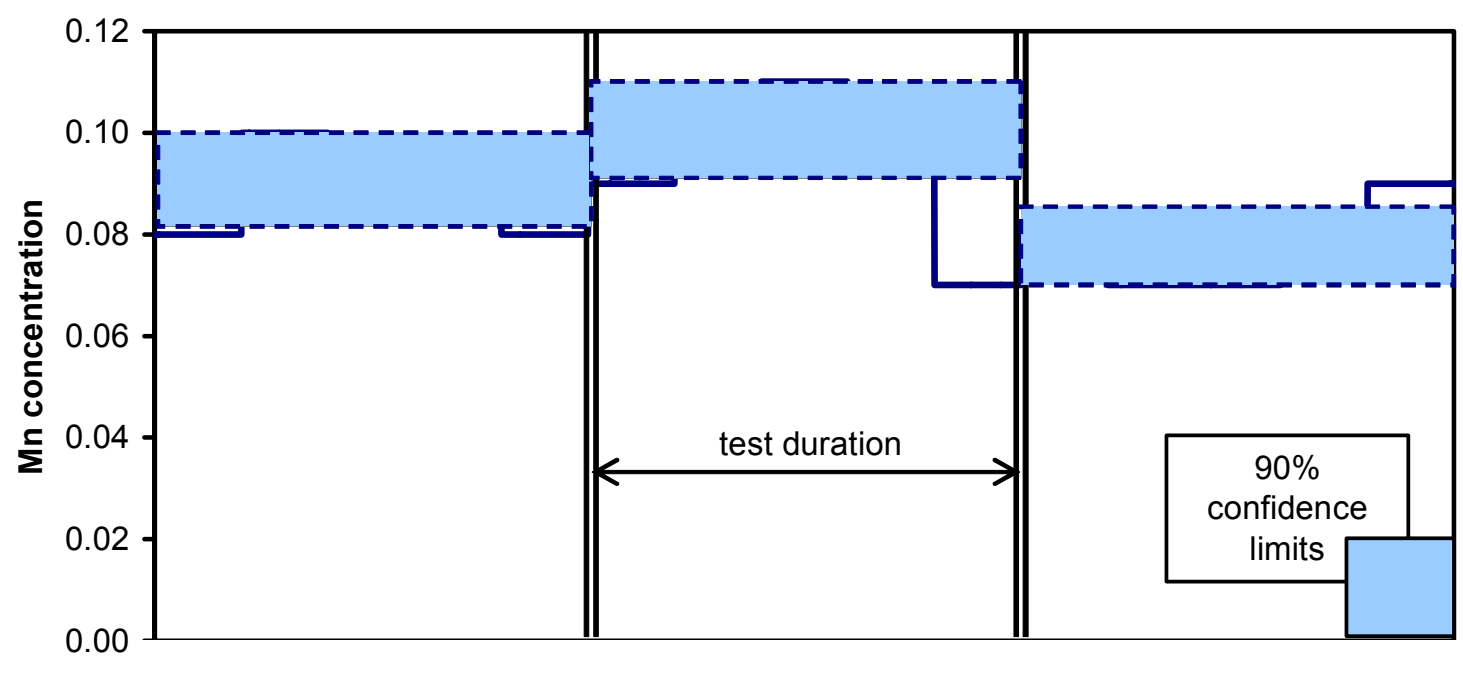

Figure 64. The manganese concentration closely follows the silica trend. This is one example of a possible proxy for A factor, if for some reason it could not be estimated or measured more directly. 


\section{Ore Segregation Test 2}

The second ore segregation test conducted at Minntac Mine occurred in May 2003 and lasted ten days. Basic hypothesis testing results are shown in Table 7.

As was seen during test \#1, the high- and low-A factor lines showed different levels of silica, calcium oxide, and alumina. This time there were also differences in levels of magnesium and manganese. Again, it must be noted that the reported instrument errors were extremely high for alumina readings, due possibly in the latter case to the levels measured being nearly below the detection limit of the inductively coupled plasma (ICP) equipment.

The power draw to the primary crushers for the two lines was not significantly different before, during, or after this test, even though their performance did change during the test; apparently both crushers reacted similarly (less grinding energy required) even though their feedstock was different. Overall, the results of test \#2 are much less clear-cut than for test \#1 and caused some puzzlement. Figures 65 through 71 illustrate this.

One of the conclusions drawn from these results was that even more data needed to be collected before and after the segregation part of the test, to obtain a clearer picture of "steadystate,” or at least, non-segregated, conditions. In addition, data from additional mill sensors was brought into the project data stream. Some of the findings of the Statistical Analysis also shed light on the apparently anomalous behavior of this test.

Table 7. Some data comparisons between the low-A factor and the high-A factor ore processing lines before, during, and after Ore Segregation test 2 , at $90 \%$ confidence level. " $X$ " indicates a statistically significant difference for the comparison marked.

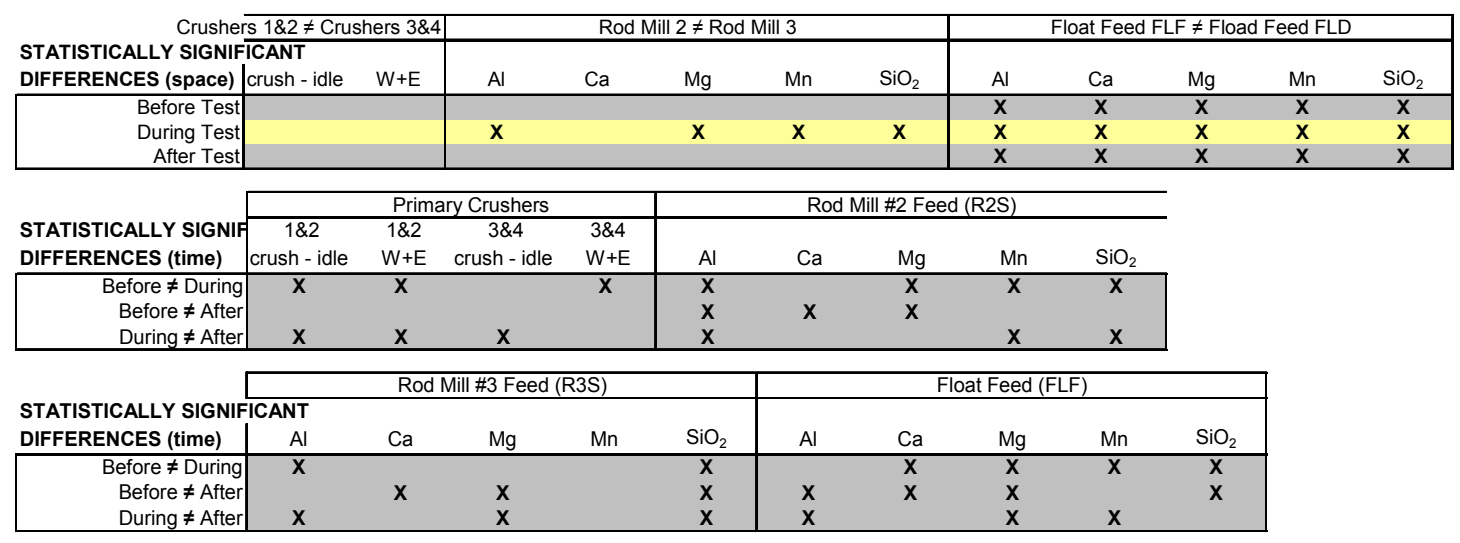

\begin{tabular}{|c|c|c|c|c|c|c|c|c|c|c|c|c|c|c|c|}
\hline \multirow{2}{*}{\multicolumn{2}{|c|}{ STATISTICALLY SIGNIFICANT }} & \multicolumn{4}{|c|}{ Float Feed (FFD) } & \multicolumn{5}{|c|}{ Float Concentrate (FC3) } & \multicolumn{5}{|c|}{ Float Tails (FLT) } \\
\hline & & & & & & & & & & & & & & & \\
\hline DIFFERENCES (time) & Al & $\mathrm{Ca}$ & $\mathrm{Mg}$ & $\mathrm{Mn}$ & $\mathrm{SiO}_{2}$ & Al & $\mathrm{Ca}$ & $\mathrm{Mg}$ & $\mathrm{Mn}$ & $\mathrm{SiO}_{2}$ & Al & $\mathrm{Ca}$ & $\mathrm{Mg}$ & $\mathrm{Mn}$ & $\mathrm{SiO}_{2}$ \\
\hline Before $\neq$ During & & $\mathbf{X}$ & $\mathbf{X}$ & $\mathbf{X}$ & $\mathrm{X}$ & & $\mathbf{X}$ & $\mathbf{x}$ & $\bar{X}$ & & $\mathbf{X}$ & $\mathbf{X}$ & $\bar{X}$ & $\bar{X}$ & \\
\hline Before $\neq$ After & $\mathbf{x}$ & $\mathbf{x}$ & $\mathbf{x}$ & & $\mathbf{x}$ & $\mathbf{x}$ & $\mathbf{x}$ & $\mathbf{x}$ & & & $\mathbf{x}$ & $\mathbf{x}$ & $\mathbf{x}$ & $\mathbf{x}$ & \\
\hline During $\neq$ After & $\mathrm{x}$ & & & $\mathbf{x}$ & & $\mathbf{x}$ & & & $\mathbf{x}$ & $\mathbf{x}$ & $\mathbf{x}$ & & & & $\mathbf{x}$ \\
\hline
\end{tabular}




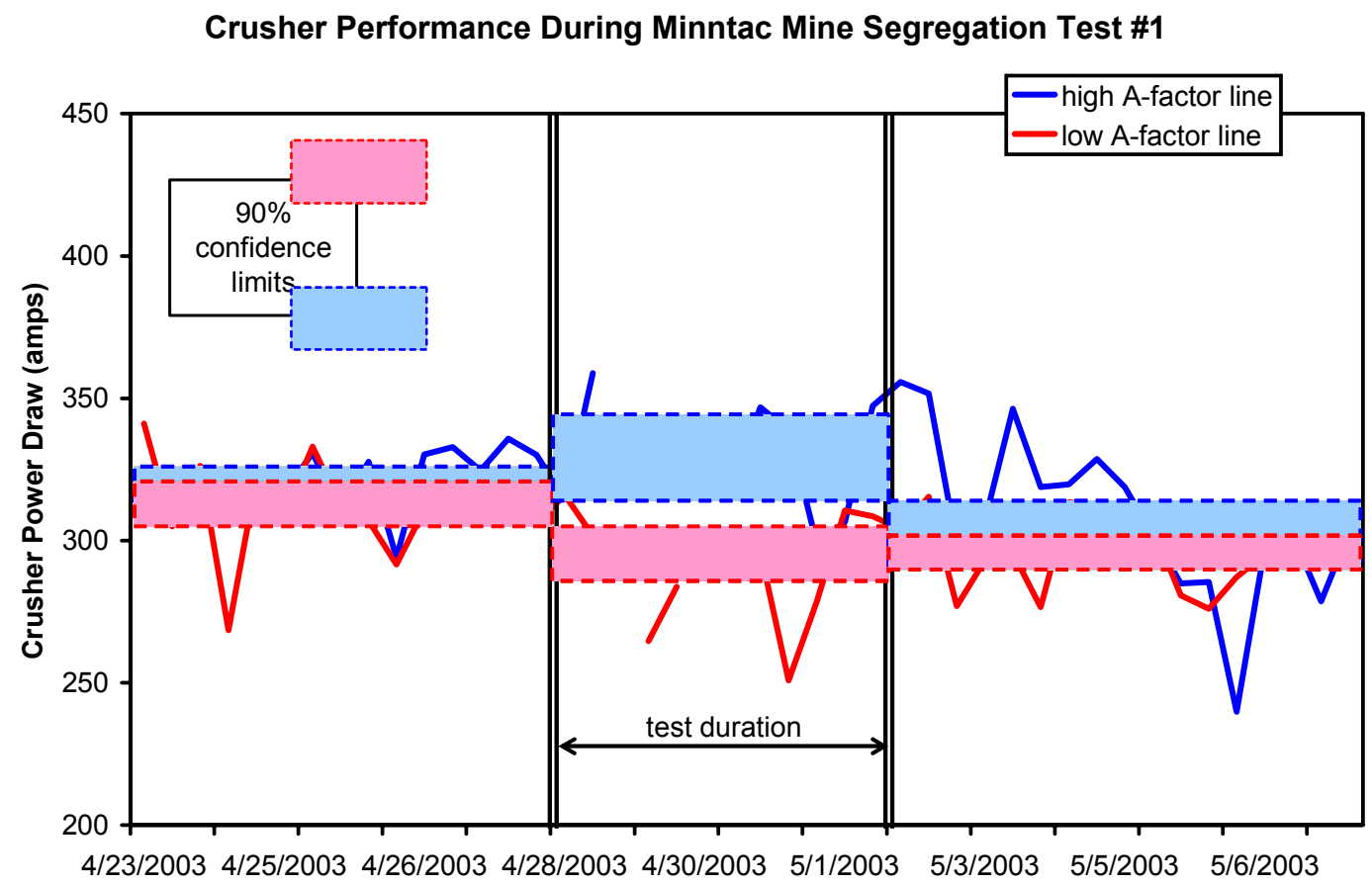

Figure 65.

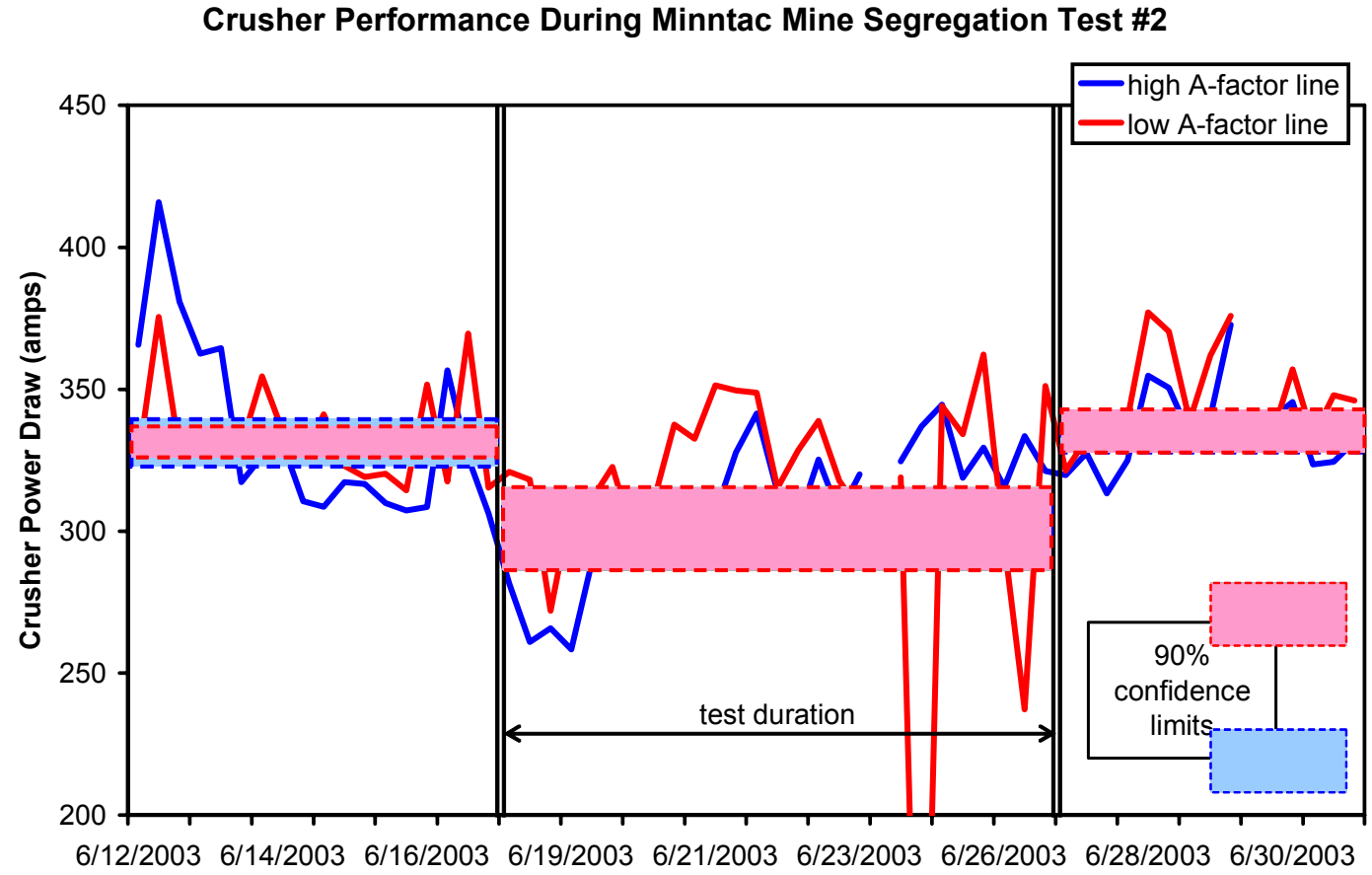

Figure 66. 


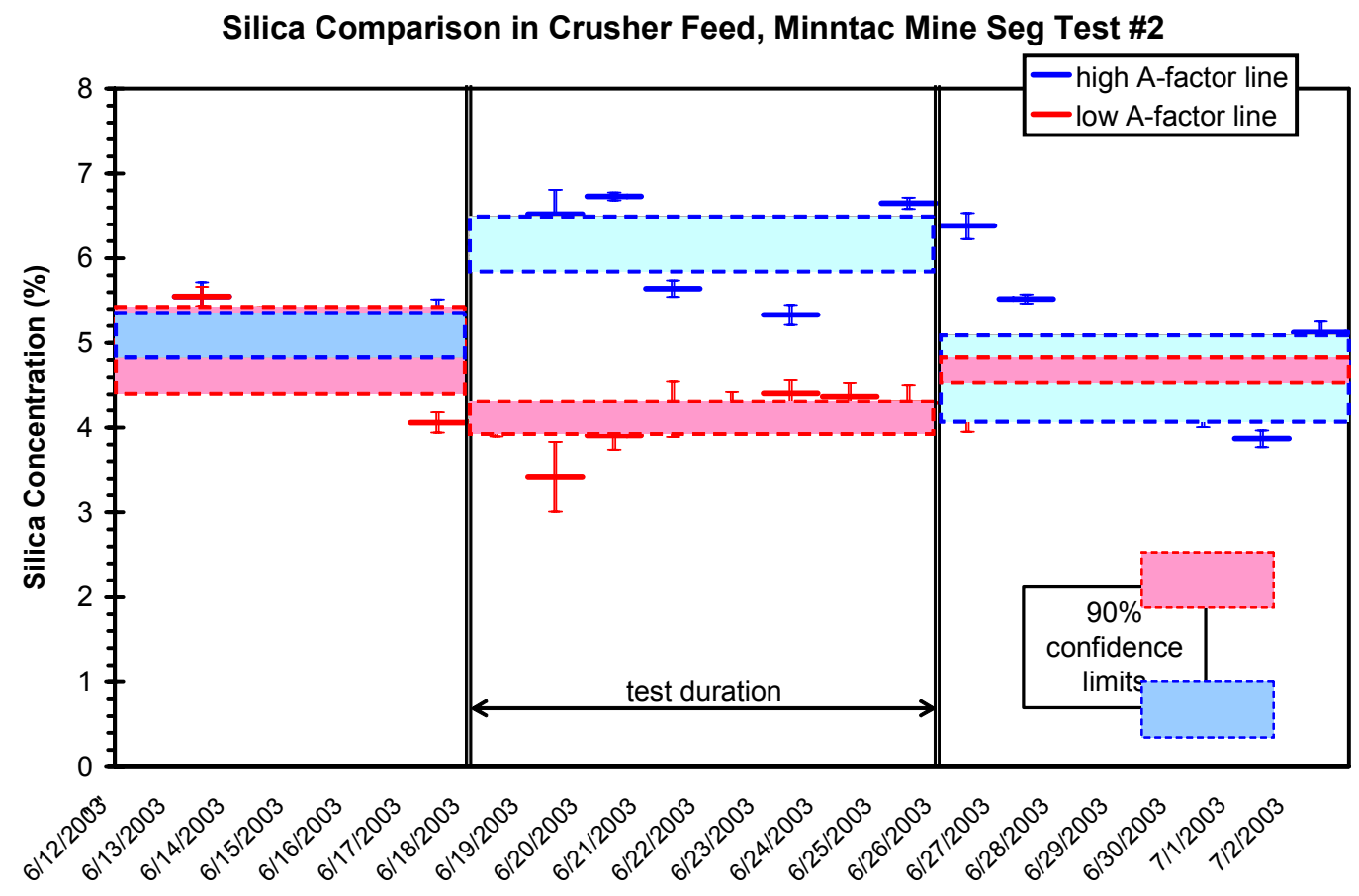

Figure 67.

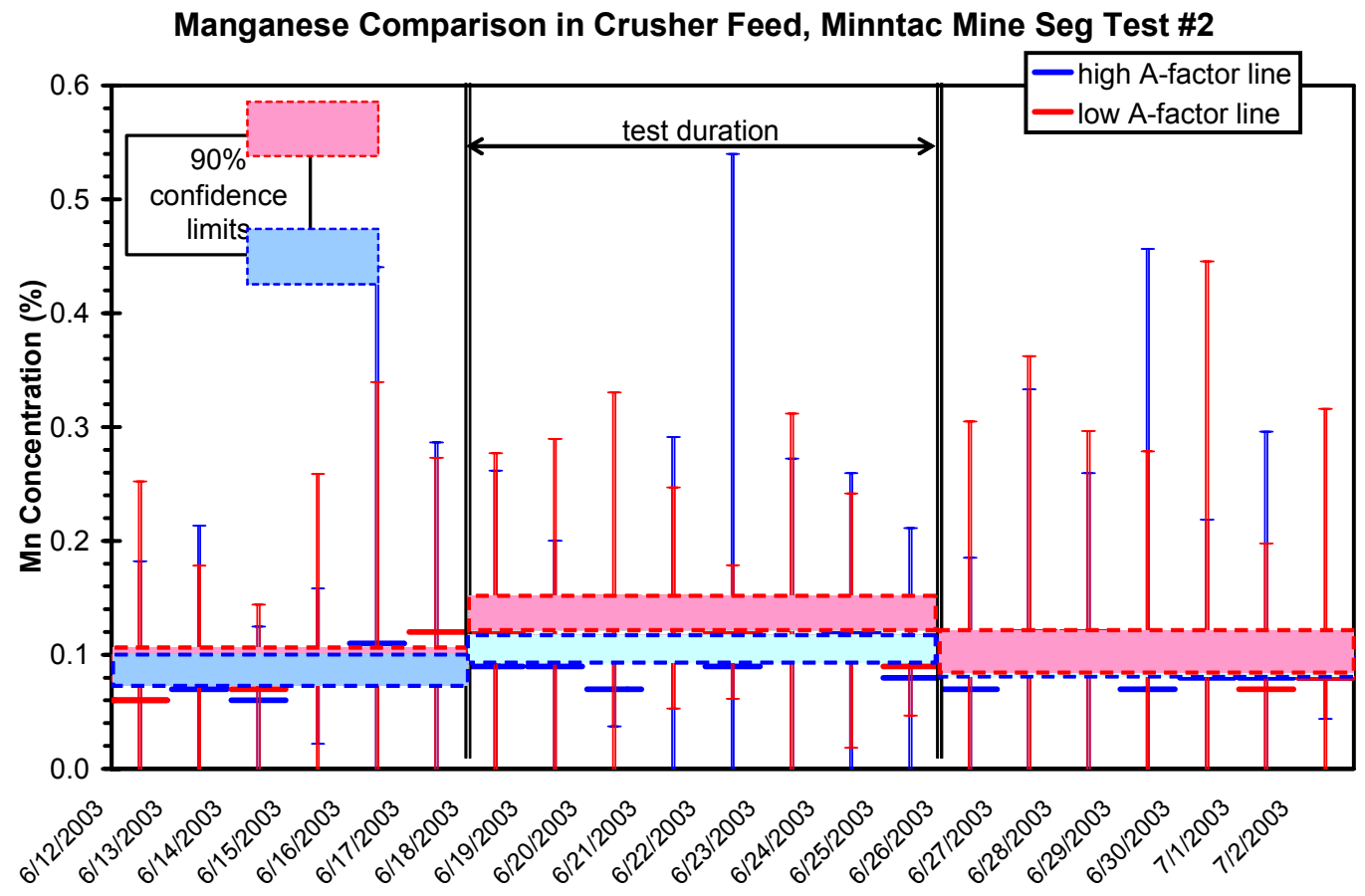

Figure 68. 


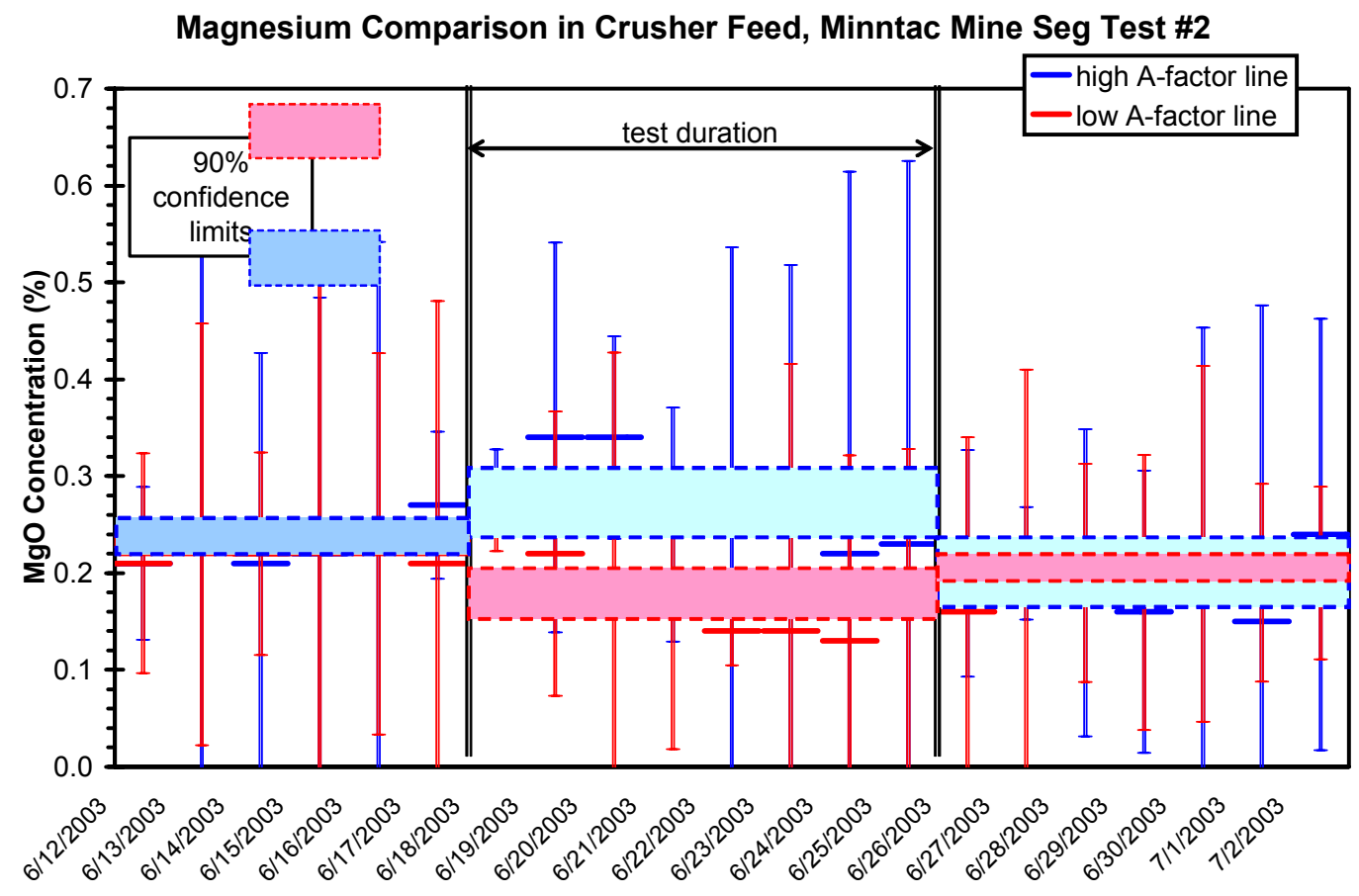

Figure 69.

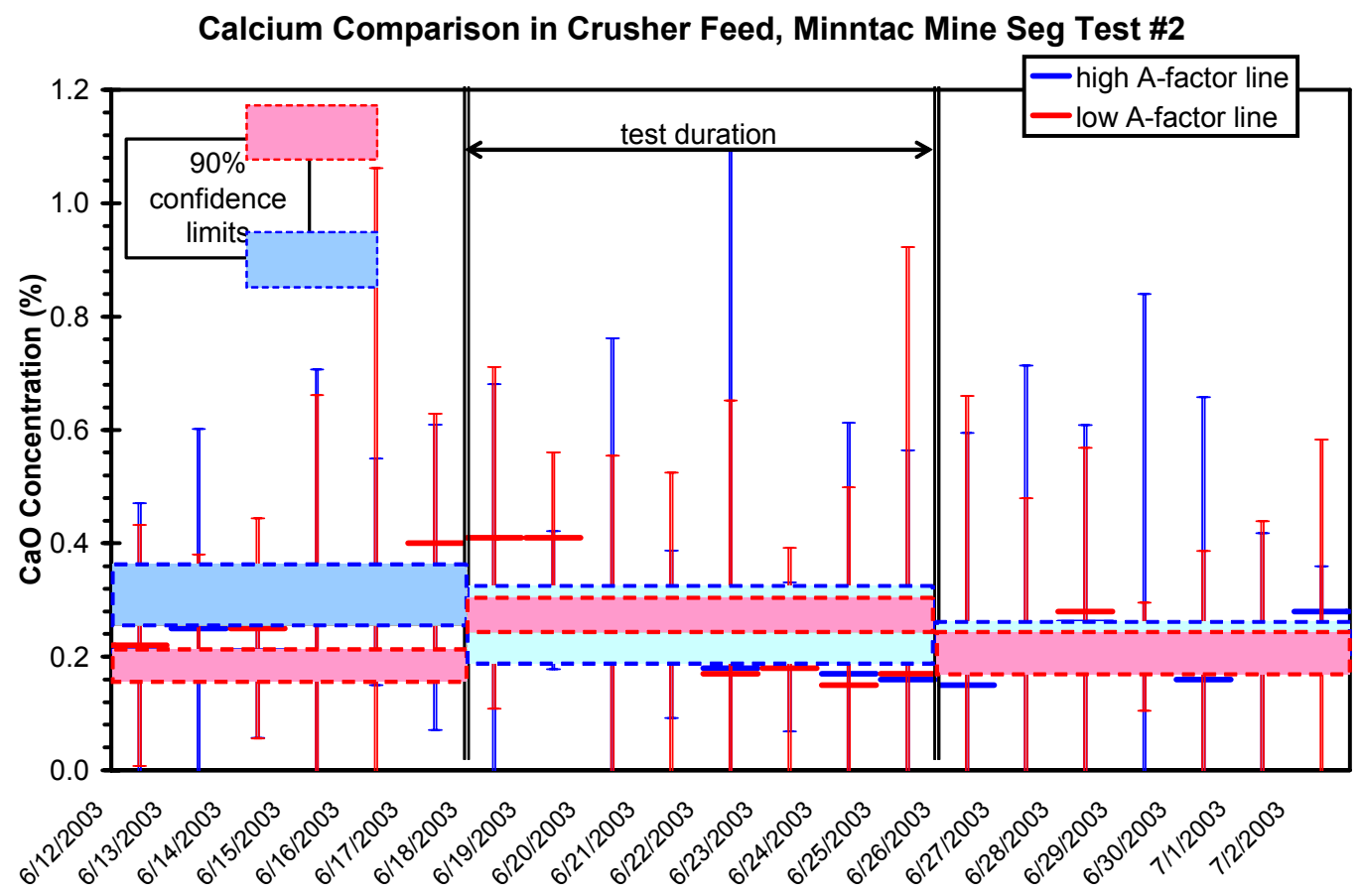

Figure 70. 


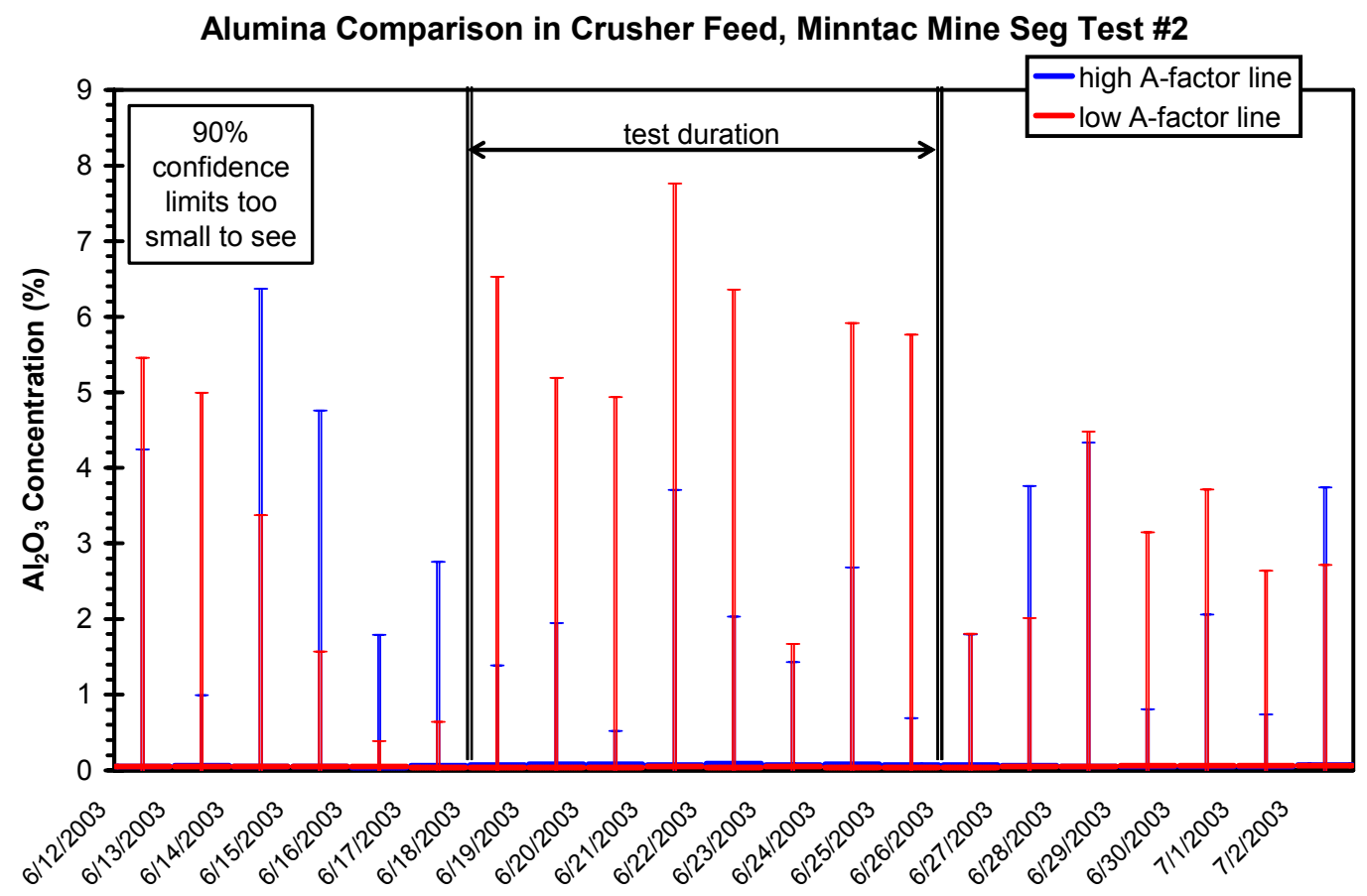

Figure 71.

\section{Ore Segregation Test 3}

For the third 10-day ore segregation test, data were collected for 18 days prior to and 18 days following the test. As in previous tests, the ore was segregated on the basis of A-factor.

Figure 72 shows that the energy required for the two ore streams did change somewhat during the test. There appear to be two causes for the higher power draw in the high A-factor line: a slightly different set point for the grind, and the greater resistance of the high A-factor ore. Set point was one of the control factors in the mill that was usually controlled independently from the segregation test operation and therefore added even more complexity to the results.

Crude ore passing through the high A-factor line was subjected to a higher grind set point (higher percentage of particles passing 270 mesh, or 53 microns) than that for the low A-factor line. A finer grind takes more energy and time and ultimately lowers mill throughput. This equates to a higher power requirement per ton, since more power is needed to achieve the desired grind set point. Data also indicate that the high A-factor crude ore was harder, and thus more difficult to grind anyway. Charts of the results are included in the Appendix.

The rate at which a concentrator line produces product depends upon a complex interplay of variables such as magnetic iron concentration, ore hardness, grind set points, rod and ball charge levels, maintenance/breakdown disruptions, and power allotment. To confidently evaluate the effect of the test on concentrate production rate for both lines, these variables should be factored in along with consideration of the effects of shovel location changes. 


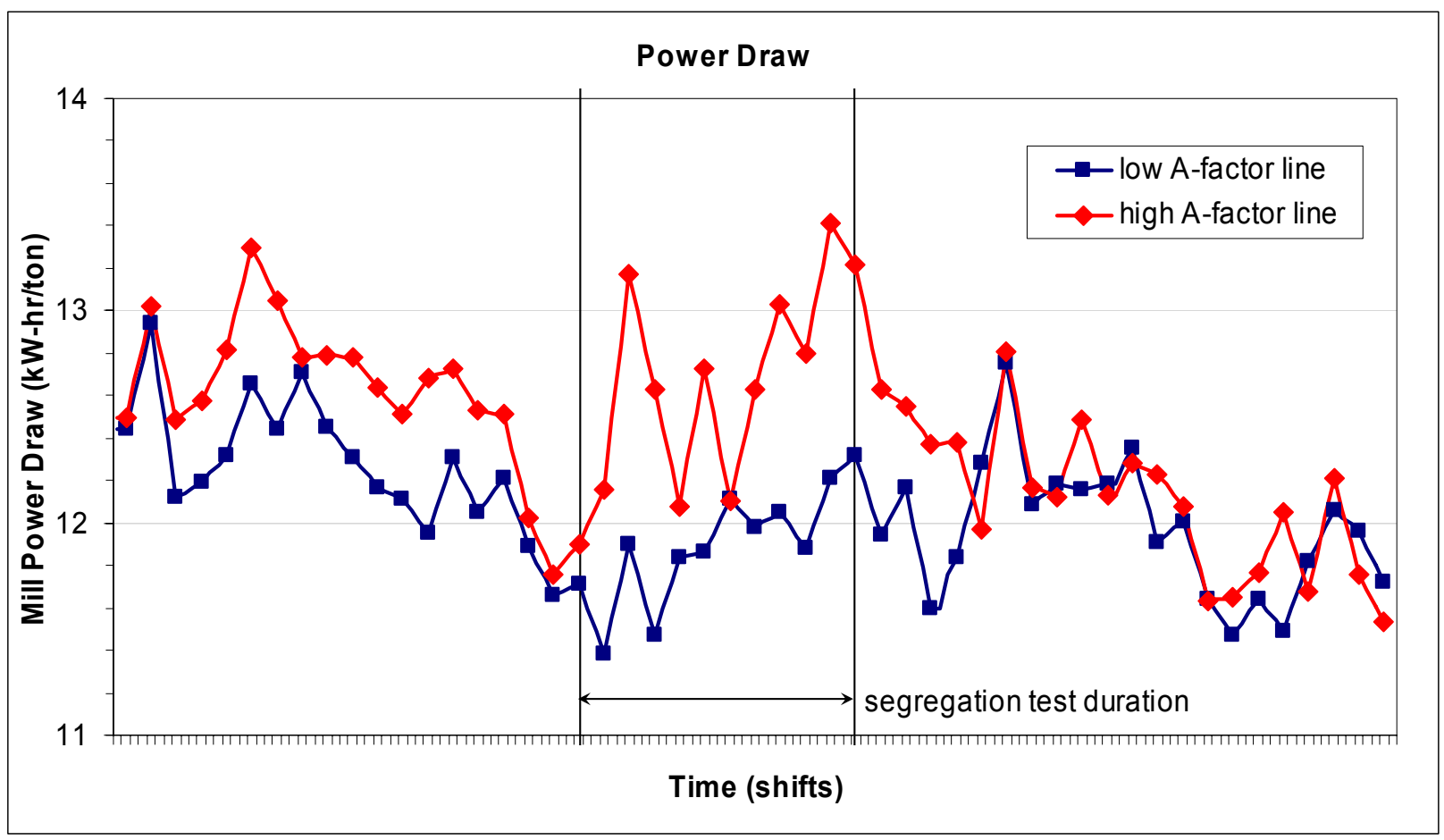

Figure 72. Energy usage per ton of ore before, during, and after Ore Segregation Test 3.

As it turned out, the start of the test coincided with the mining of a very low-silica pocket of ore. This introduced some operational issues that very likely confounded some of the data trends. During the test, the mine maintained the best split possible for the given production and location constraints they had to work with. It was noticed that the A-factor of the low-A factor line was lowered more than that of the high-A factor line was raised.

None of the measured ore quality changes were manipulated, but the segregation by Afactor affected most of those other qualities. Magnetic iron, coarse tails, fine tails, silica, and grind all were seen to change in response to the split.

The remainder of the discussion in this section is excerpted from a report written by Minntac personnel. Some of the terminology is different from that used elsewhere in this report, so the next paragraph contains both sets of terms. Geologic codes are explained in Figure 6.

Figures 73 through 84 then illustrate some of the complex behavior seen during Segregation Test 3 in a fashion similar to the charts created for the Background Data Set. This is to permit comparison of "steady state" mill behavior with that observed during Segregation Test 3. 


\section{The Segregation}

Ore was segregated by A-Factor, with low values going to Step 1/2 and high values going to Step 3. During the test, the mine maintained the best split possible for the given production and location constraints. During the test, the average split was 0.42 , before and after values were about the same, 1.63 . Values to either Step were rarely above 2.0. Overall, Step $1 \& 2$ A-Factor was lowered more than Step 3 was raised.

All other ore quality changes were not manipulated, but the Segregation by A-Factor affected most of the other qualities.

\begin{tabular}{|l|l|l|}
\hline A-Fac & Step 1\&2 & Step 3 \\
\hline Before & 1.62 & 1.61 \\
\hline SPLIT & 1.30 & 1.72 \\
\hline After & 1.63 & 1.64 \\
\hline Change & -0.32 & +0.10 \\
\hline
\end{tabular}
Magnetic iron, coarse tails, fine tails, silica, grind exhibited a change in response to the split.

\section{Layers}

Segregation was achieved by adding ore from the high-indicated silica regions (HIS) and lowering the amount of LC $1 \& 2$ and somewhat lowering the amount of LC $3 \& 4$ to the high Afactor line blend (Step 3). Conversely, the low A-factor line (Step 1-2) received less HIS with a corresponding increase in LC 1\&2. The amount of interbedded chert (IBC) was increased to both lines about one-third of the way into the test. For about the center half of the test, the contribution of LC $3 \& 4$ was reduced to both lines. The most noticeable layer changes were, to

\begin{tabular}{|l|c|c|r|r|}
\hline Step 1\&2 & HIS & IBC & LC3\&4 & LC1\&2 \\
\hline Before & $18.8 \%$ & $4.2 \%$ & $45.1 \%$ & $31.1 \%$ \\
\hline SPLIT & $10.3 \%$ & $13.5 \%$ & $39.5 \%$ & $35.2 \%$ \\
\hline After & $16.7 \%$ & $14.5 \%$ & $37.4 \%$ & $31.4 \%$ \\
\hline Step 3 & HIS & IBC & LC3\&4 & LC1\&2 \\
\hline Before & $18.6 \%$ & $4.1 \%$ & $45.3 \%$ & $32.0 \%$ \\
\hline SPLIT & $31.9 \%$ & $13.2 \%$ & $33.9 \%$ & $19.5 \%$ \\
\hline After & $17.6 \%$ & $13.9 \%$ & $35.4 \%$ & $33.3 \%$ \\
\hline
\end{tabular}
summarize: An increase in the HIS split; a decrease in the LC $1 \& 2$ split; adding IBC to both lines; and lowering LC 3\&4 to both lines.

\section{Magnetic Iron Feed}

The Segregation of Mag Fe from the mine was not as pronounced as other qualities. Mag Fe was about the same for mine indicated Step 3 and slightly higher for mine indicated Step 1\&2. Analysis of the rod mill feed showed a similar but slightly different picture of the duration of the test; the rod mill saw a very slight increase in Step 1\&3 and a slight decrease in Step 3.

During the Segregation, maintaining the iron values in the feed encountered some difficulty, consequently a tendency to "top off" Step 3 with the best ore available. Step 3, then was a blend of high A-Factor ore that had

\begin{tabular}{|l|r|r|}
\hline MI Fe & Step 1\&2 & Step 3 \\
\hline Before & $19.7 \%$ & $19.7 \%$ \\
\hline SPLIT & $20.4 \%$ & $19.7 \%$ \\
\hline After & $19.8 \%$ & $19.5 \%$ \\
\hline RMF Fe & Step 182 & Step 3 \\
\hline Before & $19.77 \%$ & $19.84 \%$ \\
\hline SPLIT & $19.80 \%$ & $19.43 \%$ \\
\hline After & $19.71 \%$ & $19.60 \%$ \\
\hline
\end{tabular}
lower iron values combined with smaller amount of low A-factor ore that had high iron values.

\section{Magnetic Iron in Tails}

While the iron feed to the plant was virtually the same for both Steps, the tails for each Step were different. For Step $1 \& 2$ the low A-Factor feed caused the amount of iron in the tails to decrease, while the Step 3 iron in the tails increased somewhat. For Step 1\&2 the low A-Factor feed caused the amount of iron in the tails to decrease, while the Step 3 iron in the tails remained about the same. 
The difference in the coarse and fine tails response to A-Factor is reasonable, and is a result of mineral grain size.

Low A-Factor ore has a coarser grain than high AFactor, and a coarse grain separation is easier to achieve than a fine grain separation. When the ore is coarsely ground, the low A-Factor ore exhibits an ability to reject more tails for the amount of iron recovered than the high A-Factor. When the ore is finely ground, no additional advantage is gained in iron recovery.

\begin{tabular}{|l|r|c|}
\hline TAILS & & \\
\hline STEP 1\&2 & Course & Fine \\
\hline Before & $2.85 \%$ & $1.06 \%$ \\
\hline SPLIT & $2.66 \%$ & $1.06 \%$ \\
\hline After & $2.75 \%$ & $1.17 \%$ \\
\hline STEP 3 & Course & Fine \\
\hline Before & $3.09 \%$ & $1.02 \%$ \\
\hline SPLIT & $3.15 \%$ & $1.44 \%$ \\
\hline After & $2.90 \%$ & $1.24 \%$ \\
\hline
\end{tabular}

Conversely, high A-Factor ore has a finer grain than low A-Factor, and a fine grain ore can still exhibit good recoveries when coarsely ground. This is because the magnetic recovery is still recovers the iron, although the iron grains are smaller the low A-Factor. However, the coarse recovery of the fine grained ore does lose somewhat more iron. The situation changes in the fine tails. Simply put, the fined grained ore is more difficult to liberate. A grind fine enough to liberate the silica leaves more iron behind in the high A-Factor ore than the low.

\section{Magnetic Iron Recovery}

The combined effects of the changes in tailings losses results in a decrease in recovery of the high AFactor ore, while the low A-Factor ore increases at a lesser amount.

Recovery for the combined Steps is a $1.1 \%$ decrease in total. Assuming a 13Mlt production per year, this represents a pellet loss of 143,000 LT per

\begin{tabular}{|l|r|r|}
\hline \multicolumn{2}{|l|}{ Fe RECOVERY } & \\
\hline & STEP 1\&2 & STEP 3 \\
\hline Before & $93.6 \%$ & $93.1 \%$ \\
\hline SPLIT & $93.9 \%$ & $91.6 \%$ \\
\hline After & $93.4 \%$ & $93.0 \%$ \\
\hline Change & $+0.4 \%$ & $-1.5 \%$ \\
\hline
\end{tabular}
year.

\section{Grinding for Magnetic Iron Recovery}

One premise of the test was that blending for A-Factor Differences can cause over an under grinding of the high A-Factor and over grind of the low. Differences in coarse and fine grinding may significant. Because grind is only measured after concentration of the iron, the effect of coarse and fine grind could not be quantified. Arguably, the most effective new sampling for process control would be to measure iron losses after each separation, whether magnetic or hydro.

\begin{tabular}{|l|r|r|}
\hline CONC \% -270 & \\
\hline & STEP 1\&2 & STEP 3 \\
\hline Before & $85.4 \%$ & $85.0 \%$ \\
\hline SPLIT & $84.6 \%$ & $86.4 \%$ \\
\hline After & $85.2 \%$ & $85.8 \%$ \\
\hline Change & $-0.30 \%$ & $+0.97 \%$ \\
\hline
\end{tabular}

\section{Silica Feed}

Along with the A-Factor Segregation, silica was also segregated. This is reasonable, high A-Factor ore tends to be high silica ore.

Silica was measured at four points in the process stream. Three of which are processing plant feed: mine indicated, mine indicated after crossover in the crusher, and rod mill feed. (The fourth was measured after concentration, see

\begin{tabular}{|c|c|c|}
\hline \multicolumn{2}{|c|}{ STREND SiO $_{2}$} & \\
\hline & S1/2 & S3 \\
\hline Before & $5.15 \%$ & $5.13 \%$ \\
\hline SPLIT & $4.79 \%$ & $5.99 \%$ \\
\hline After & $5.37 \%$ & $5.36 \%$ \\
\hline Change & $-0.47 \%$ & $+0.74 \%$ \\
\hline
\end{tabular}
below.) 
The mine indicated was recorded for the STREND report. The STREND exhibited the largest change due to the Segregation with Step $1 \& 2$ reduced almost $0.5 \%$ and Step 3 increase almost $0.75 \%$ for a total change of $1.5 \%$.

After the crossover at the crusher, the Segregation to the two Steps was reduced, but still had a total change of

\begin{tabular}{|l|r|r|}
\hline \multicolumn{3}{|c|}{ MIS SiO $_{2}$ w/ Crossover } \\
\hline & \multicolumn{1}{|c|}{ S 1/2 } & \multicolumn{1}{c|}{ S 3 } \\
\hline Before & $5.46 \%$ & $5.44 \%$ \\
\hline SPLIT & $5.01 \%$ & $5.91 \%$ \\
\hline After & $5.63 \%$ & $5.62 \%$ \\
\hline Change & $-0.53 \%$ & $+0.39 \%$ \\
\hline
\end{tabular}
almost $1 \%$. Thus the segregation to the rod mill was still effective.

The Davis Tube silica analysis of the rod mill feed was consistently lower than the mine indicated before, during and after the Segregation. However, the change in the DT silica was less than was accounted for by the mine indicated with crossover for Step 1\&2, but was more in Step 3, although the differences were not large.

The differences in mine indicated, mine indicated with crossover, and rod mill feed DT indicate some difficulty in predicting and controlling silica.

\begin{tabular}{|l|r|r|}
\hline \multicolumn{4}{|c|}{ Rod Mill DT $\mathbf{S i O}_{2}$} & & \\
\hline & $\mathrm{S} \mathrm{1/2}$ & \multicolumn{1}{|c|}{$\mathrm{S} \mathrm{3}$} \\
\hline Before & $4.13 \%$ & $4.09 \%$ \\
\hline SPLIT & $3.89 \%$ & $4.87 \%$ \\
\hline After & $4.40 \%$ & $4.40 \%$ \\
\hline Change & $-0.37 \%$ & $+0.63 \%$ \\
\hline
\end{tabular}

\section{Product Silica}

The fourth silica measurement performed after concentration indicated that the net test result was a lowering of the silica during the Segregation, although only a $0.24 \%$ reduction (at most, the change from before and after was $0.27 \%$ ). However, the Davis Tube analysis of the concentrate contradicted this.

Because the concentrate for the two Steps are combined before the silica is measured, the contributions from the low and

\begin{tabular}{|l|r|r|}
\hline $\mathbf{S i O}_{2}$ & $\begin{array}{r}\text { Flot } \\
\text { Feed }\end{array}$ & $\begin{array}{r}\text { DT } \\
\text { Conc }\end{array}$ \\
\hline Before & $5.27 \%$ & $3.62 \%$ \\
\hline SPLIT & $5.17 \%$ & $3.87 \%$ \\
\hline After & $5.54 \%$ & $3.95 \%$ \\
\hline Change & $-0.24 \%$ & $0.08 \%$ \\
\hline
\end{tabular}
high A-Factor ore to the silica outcome cannot be quantified. As a minimum, it may be surmised that if the silica in Step 1\&2 was decreased, the decrease was greater than any increase in Step3.

Changes on the flotation tails percent silica were mixed. There was a large increase from before to during, but the increase continued after the Segregation. This is not surprising as a large part of silica rejection to the flotation tails is due to the amount of silica in the plant feed. For any given liberation, the higher silica ore will have more silica rejected.

\section{Grind}

\begin{tabular}{|l|r|}
\hline SiO2 & Tails \% \\
\hline Before & $25.9 \%$ \\
\hline SPLIT & $28.0 \%$ \\
\hline After & $29.2 \%$ \\
\hline Change & $+0.51 \%$ \\
\hline & $27.54 \%$ \\
\hline
\end{tabular}

We have already seen that the concentrate grind increased for the high A-Factor ore in Step 3 over Step 1\&2. This result should indicate that the high A-Factor ore requires more grinding to liberate the silica (and Fe) in the plant feed. However, the set points were not maintained at a constant level, due to operating requirements. (One condition of the Segregation Test was to not lose production.) Therefore the result is equivocal.

However, it must be observed that there was an increase in product silica in the high A-Factor ore that was accompanied by an increase in grind. Grind increased and silica increased.

\begin{tabular}{|l|r|}
\hline Flot Feed & $\mathbf{\% - 2 7 0}$ \\
\hline Before & $81.2 \%$ \\
\hline SPLIT & $81.6 \%$ \\
\hline After & $83.6 \%$ \\
\hline Change & $-0.76 \%$ \\
\hline
\end{tabular}


Flotation feed grind remained about the same from before the Segregation to during. However, it increased more from the Segregation to after.

\section{Amine Consumption}

Although the amine rate varied considerably during before, after, and during the Segregation Test, there was an average decrease during the Segregation of $0.23 \mathrm{lbs} / \mathrm{lt}$. The average decrease during the Segregation was 21\% over before and after.

\begin{tabular}{|l|r|}
\hline AMINE & Lbs/LT \\
\hline Before & 0.119 \\
\hline SPLIT & 0.087 \\
\hline After & 0.101 \\
\hline Change & -0.023 \\
\hline
\end{tabular}

\section{Production Rates and Grind}

The rod mill feed rate did not change much on the average during the Segregation. Step 3 had more of a change, even though it was only a 2.5\% decrease. The production rate of Step 3 was about 44 ltph higher than Step 1\&2, which was about 4 times greater than the change caused by the Segregation on Step 3.

\begin{tabular}{|l|r|r|r|r|}
\hline & \multicolumn{2}{|l|}{ Tons/hr Con } & \multicolumn{2}{c|}{ Tons/hr \%-270 } \\
\hline & S 1\&2 & S 3 & S 1\&2 & S 3 \\
\hline Before & 128.0 & 141.0 & 109.4 & 119.9 \\
\hline Split & 130.5 & 135.6 & 110.4 & 117.1 \\
\hline After & 131.3 & 145.4 & 111.9 & 124.7 \\
\hline Change & 0.82 & -7.6 & -0.24 & -5.2 \\
\hline \%Change & $0.63 \%$ & $-5.31 \%$ & $-0.22 \%$ & $-4.24 \%$ \\
\hline
\end{tabular}

\begin{tabular}{|l|r|r|}
\hline \multicolumn{4}{|c|}{ Rod Mill Feed tons/hr } & \\
\hline & S 1\&2 & \multicolumn{1}{|c|}{ S 3 } \\
\hline Before & 419.0 & 462.1 \\
\hline Split & 423.8 & 460.1 \\
\hline After & 429.9 & 481.3 \\
\hline Change & -0.63 & -11.6 \\
\hline
\end{tabular}

Concentrate production rate mirrored rod mill feed rate with little effect on Step 1\&2 and a small decrease in concentrate production rate for Step 3.

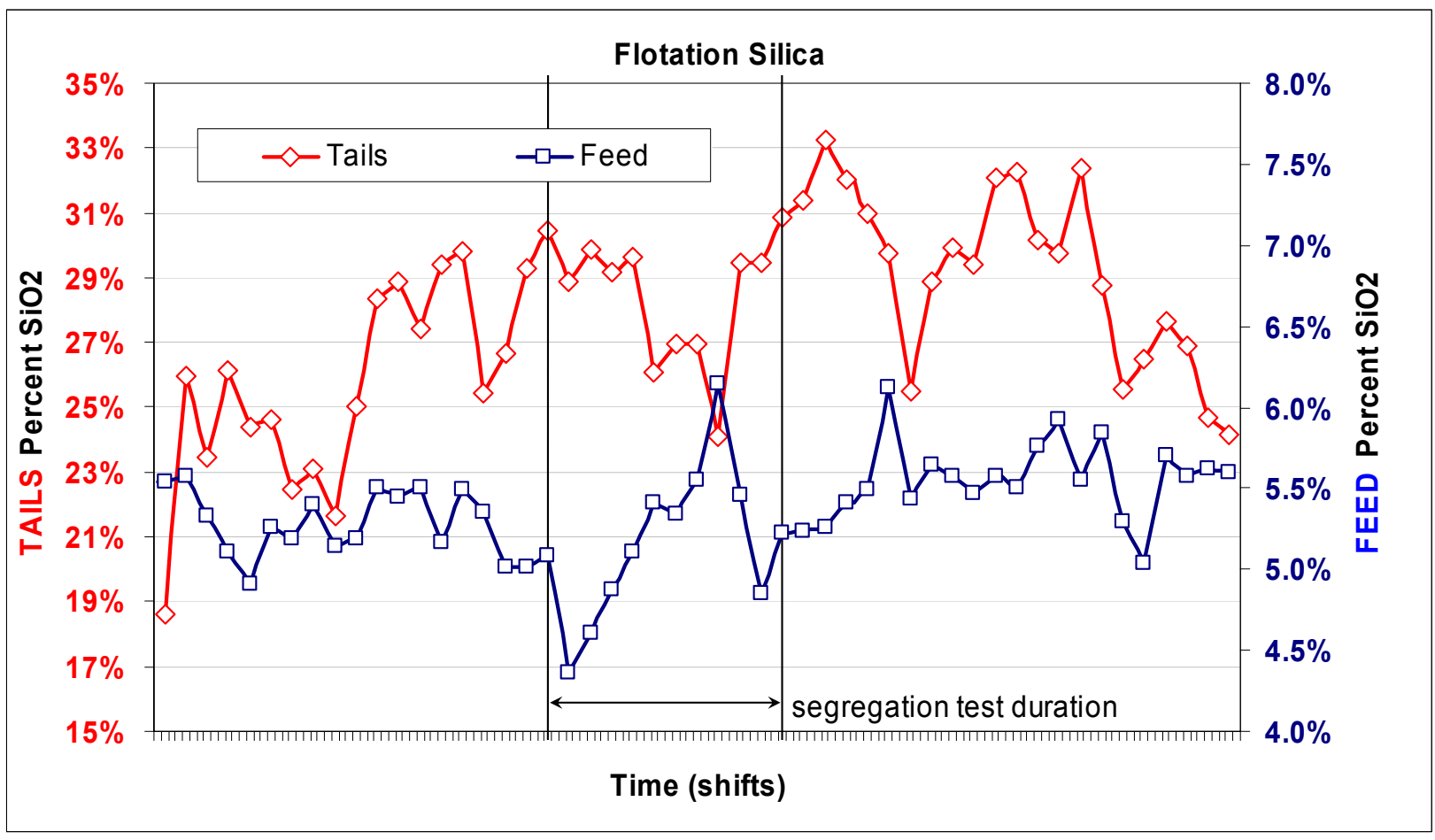

Figure 73. Change in silica measured in the flotation feed associated with Segregation Test 3. 


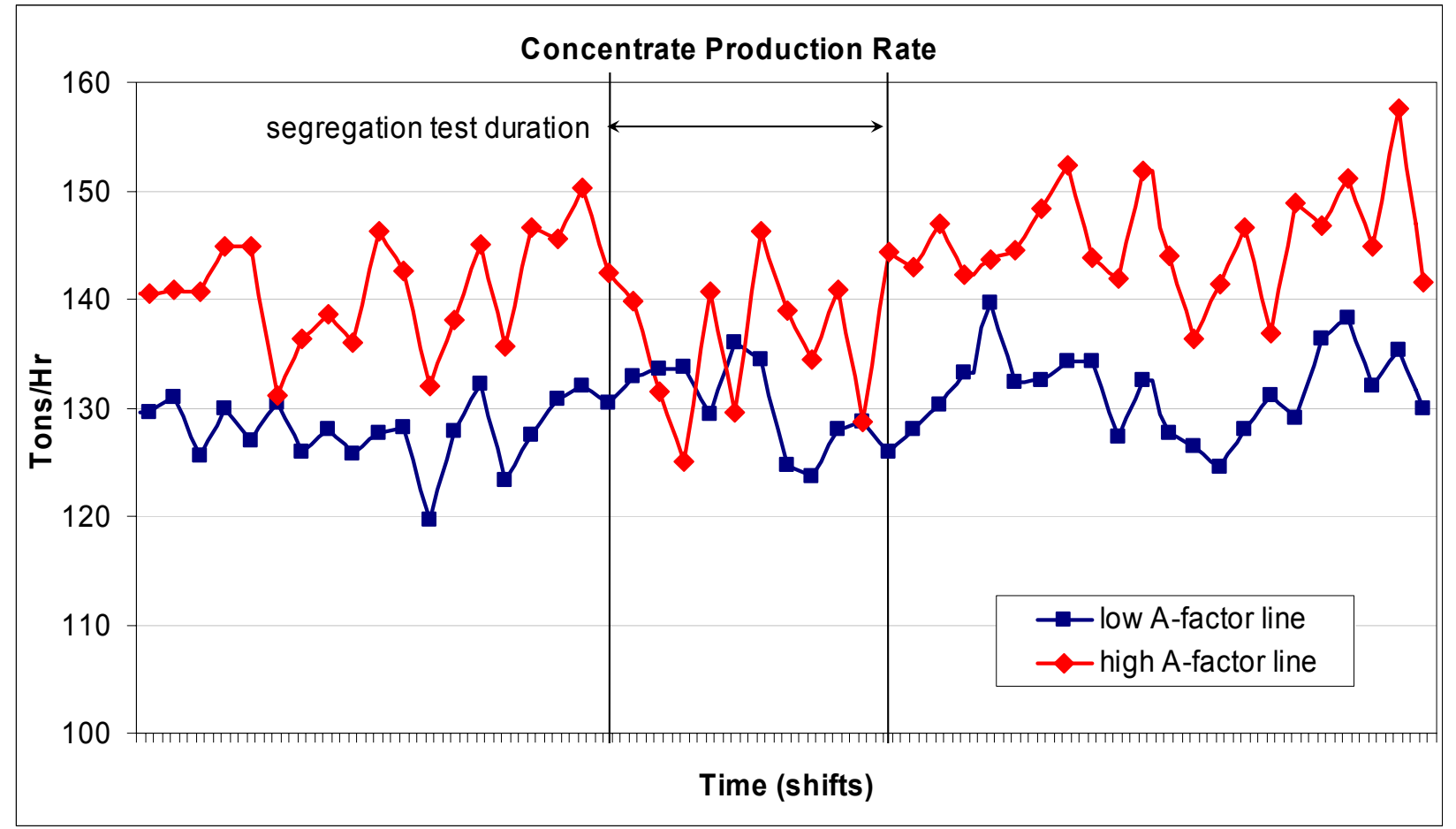

Figure 74. Change in concentrate production rate associated with Segregation Test 3.

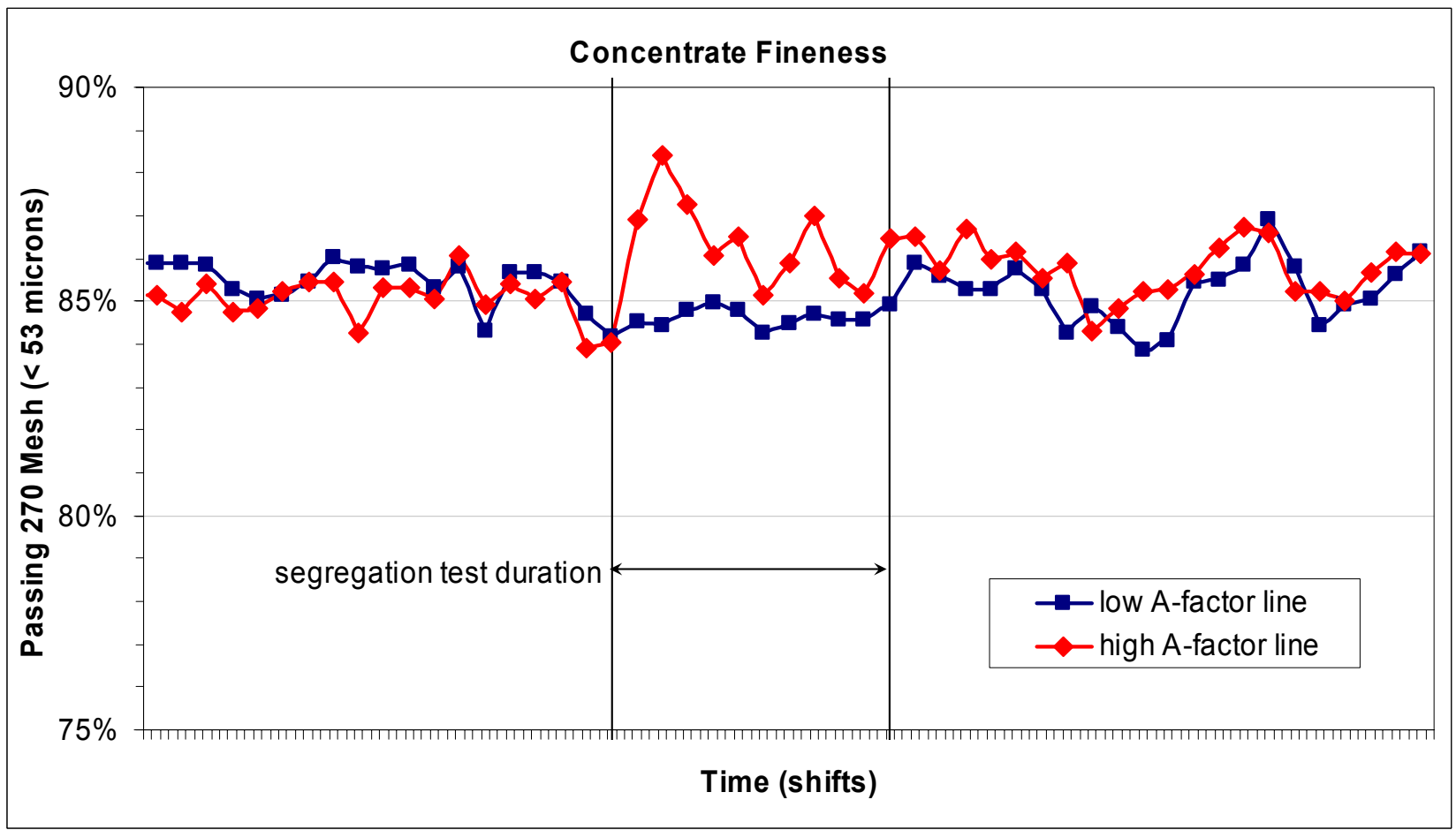

Figure 75. The concentrate fineness increased for the difficult-to-grind ore during Segregation Test 3. 


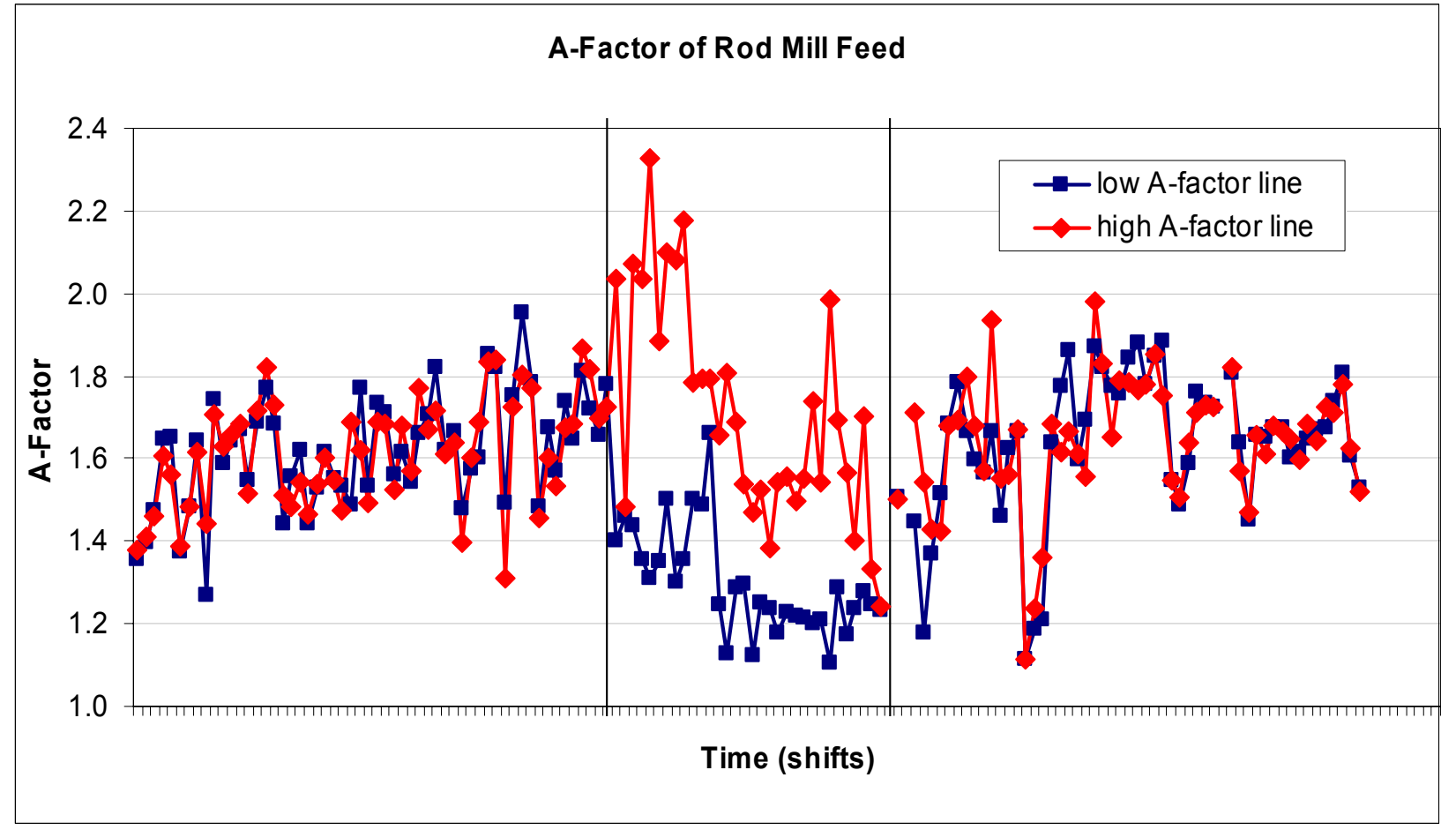

Figure 76. Change in A factor that directed the ore split during Segregation Test 3.

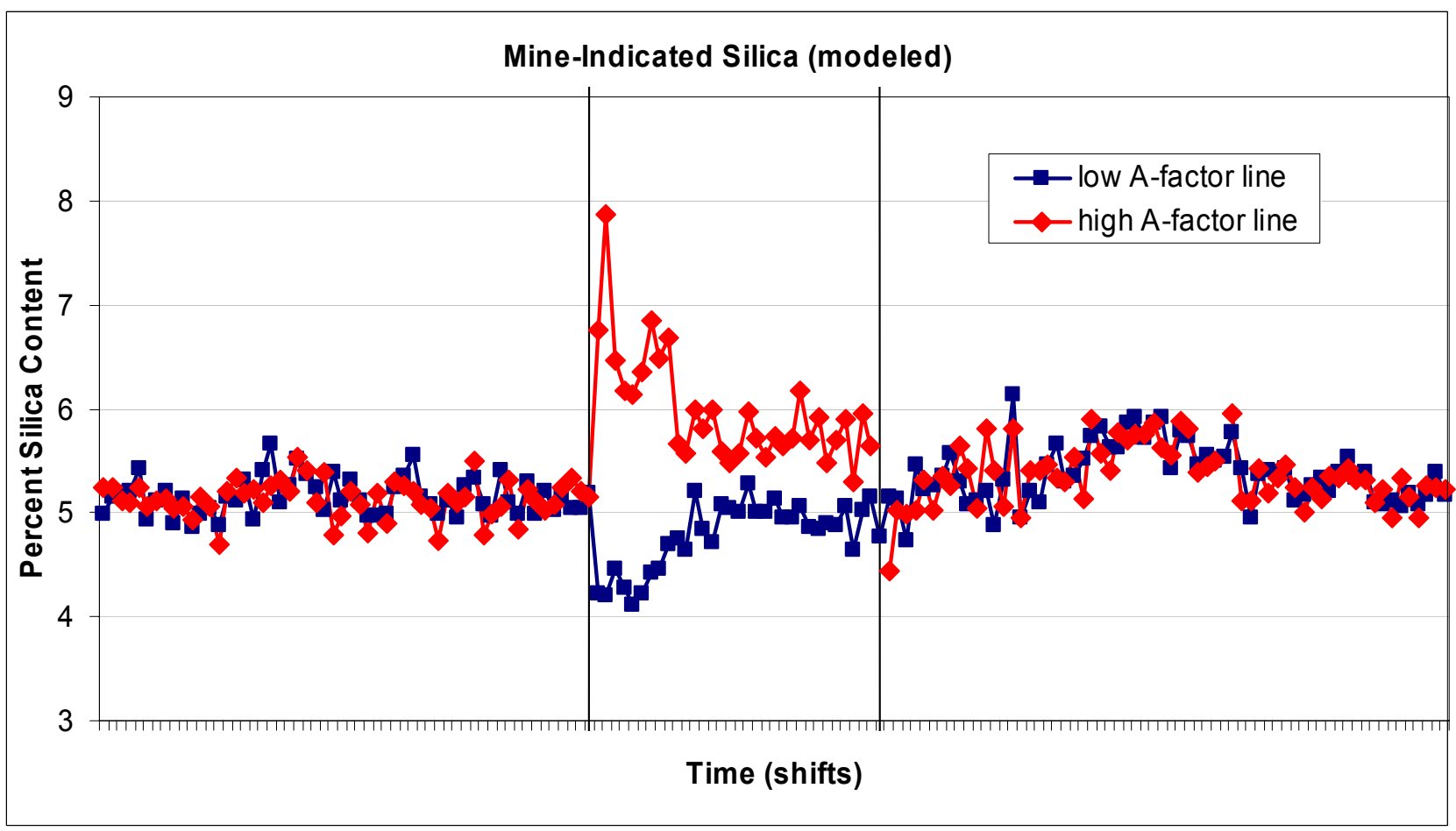

Figure 77. Change in silica concentration from the orebody model associated with Segregation Test 3. This is linked to the "mine-indicated" A factor used to direct the trucks to the crushers. 


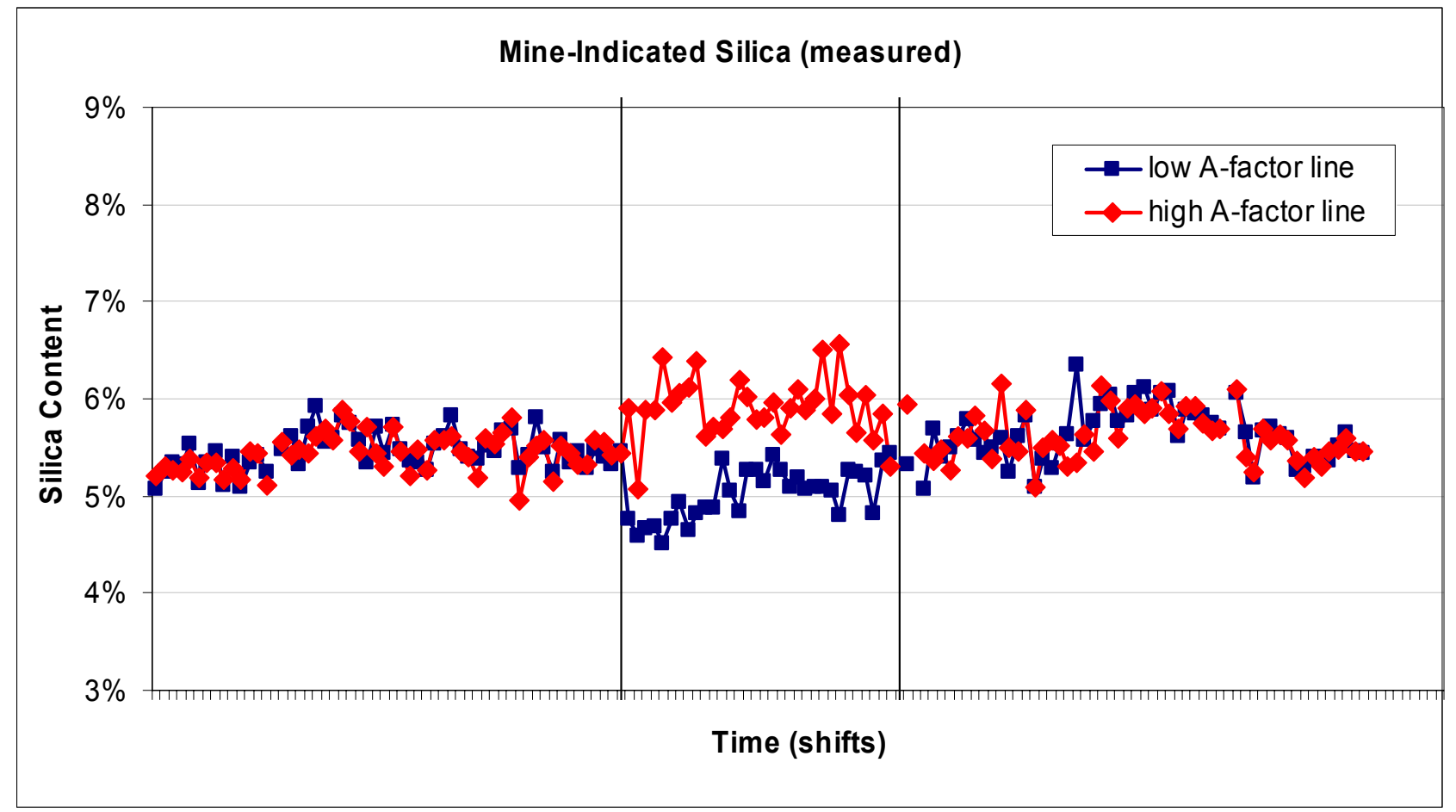

Figure 78. This is the silica concentration measured in the ore stream at the crusher. Though more even than the directing parameter, it does show significant difference between the mill lines during the test.

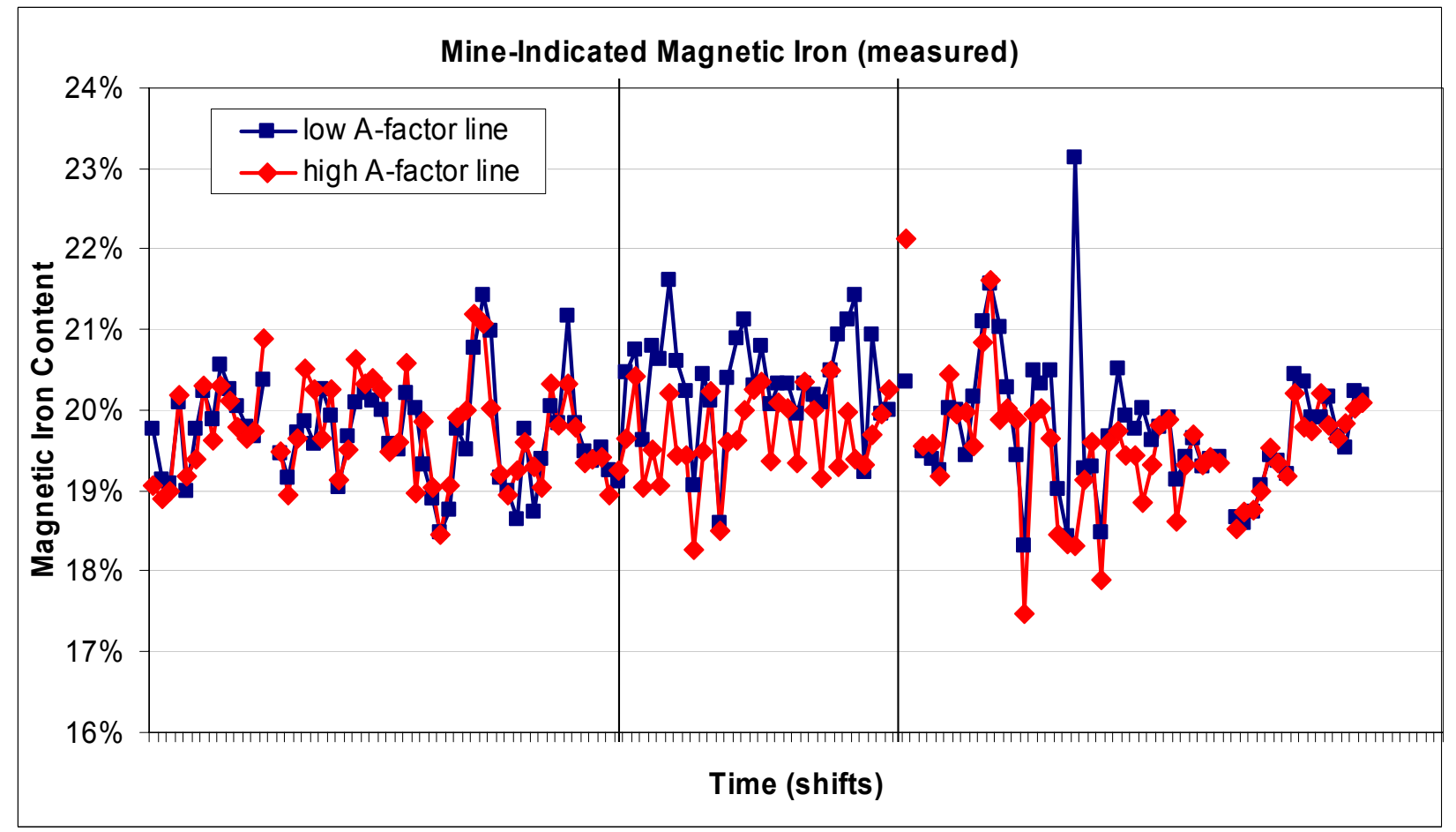

Figure 79. Change in magnetic iron content did occur during the test, but it is difficult to see visually. 


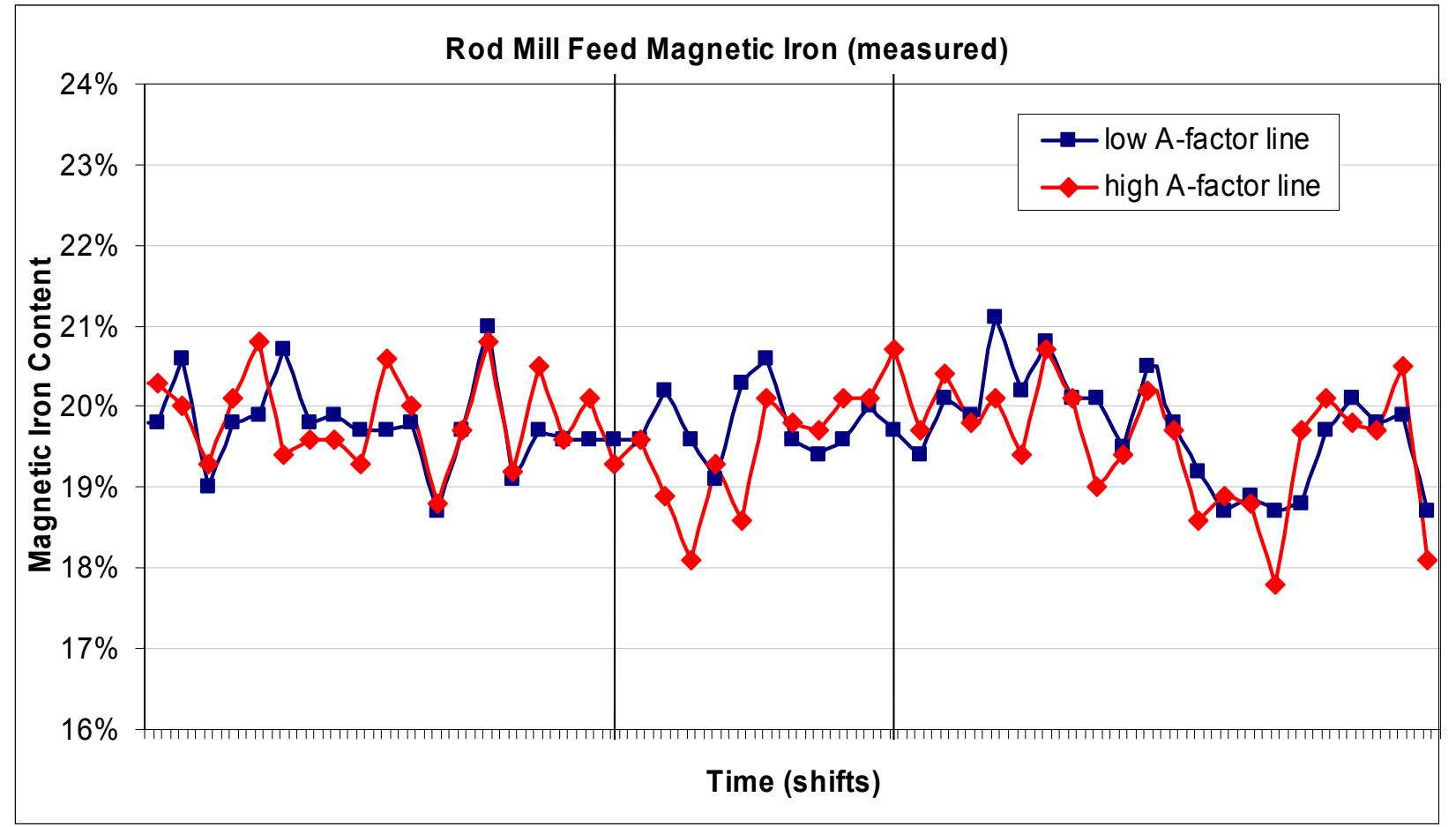

Figure 80. Energy usage per ton of ore before, during, and after Ore Segregation Test 3.

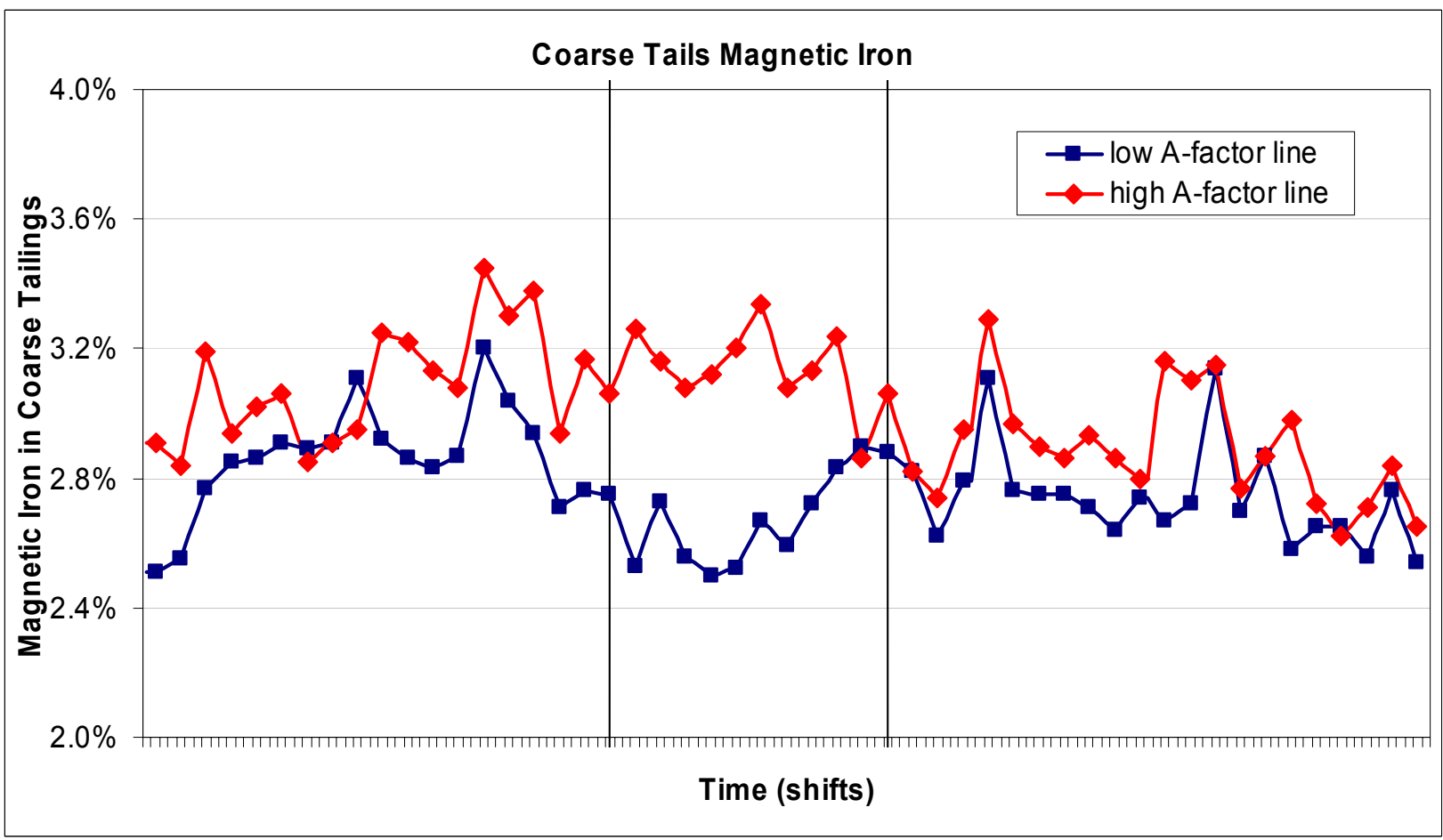

Figure 81. Energy usage per ton of ore before, during, and after Ore Segregation Test 3. 


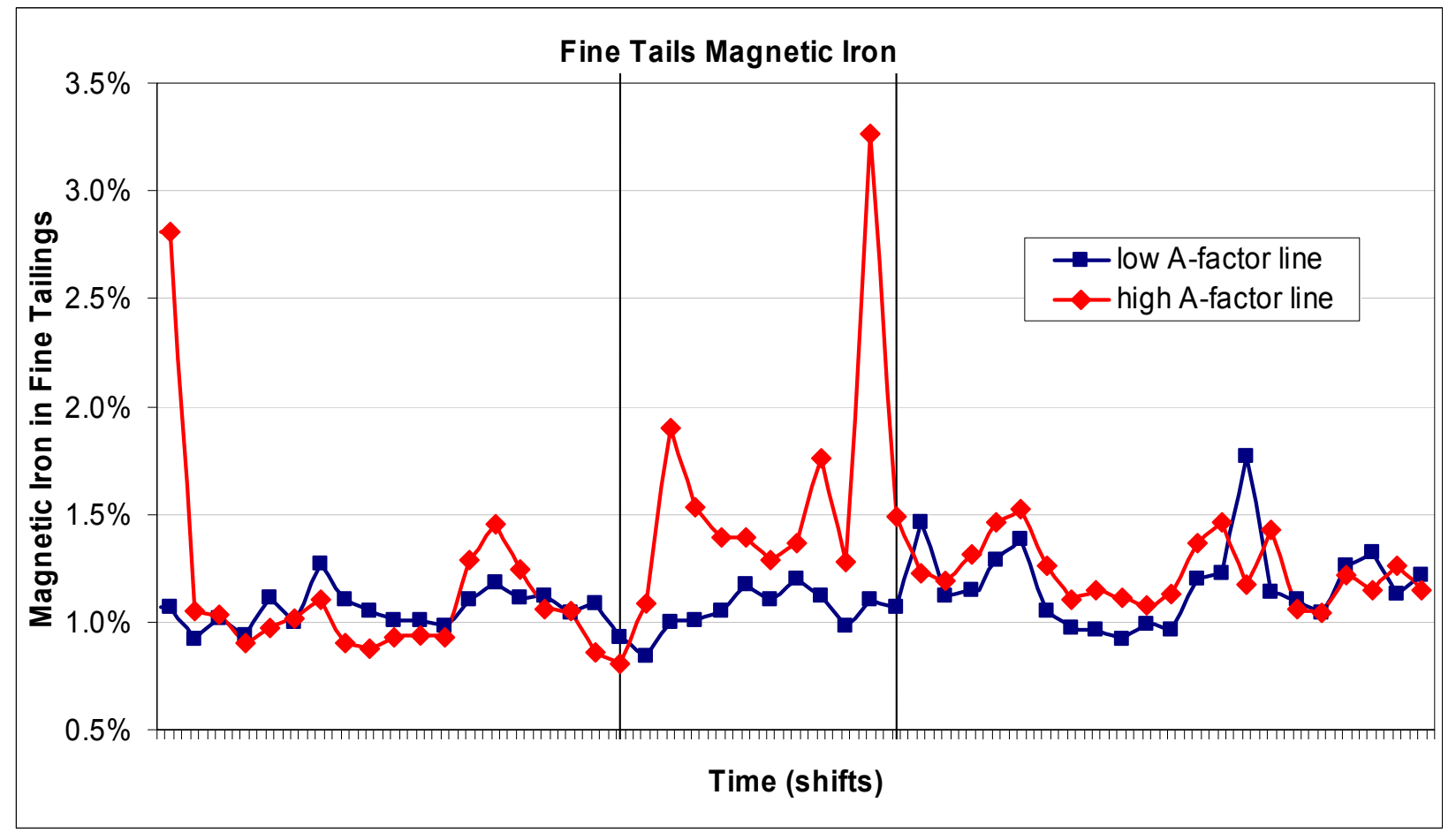

Figure 82. Fine tails magnetic iron concentration before, during, and after Ore Segregation Test 3.

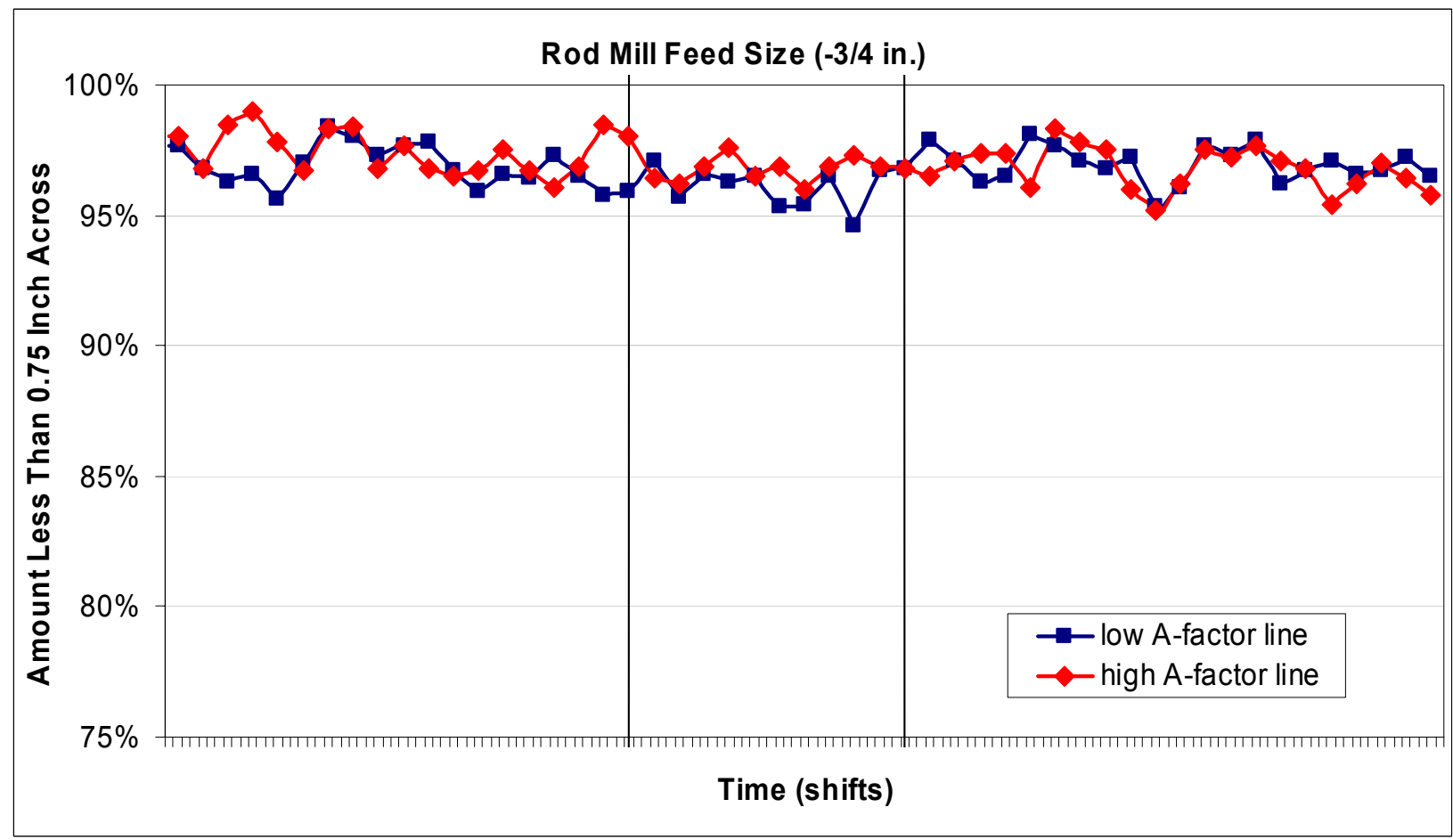

Figure 83. There is little discernible difference in the passing-0.75-inch material during Ore Segregation Test 3. 


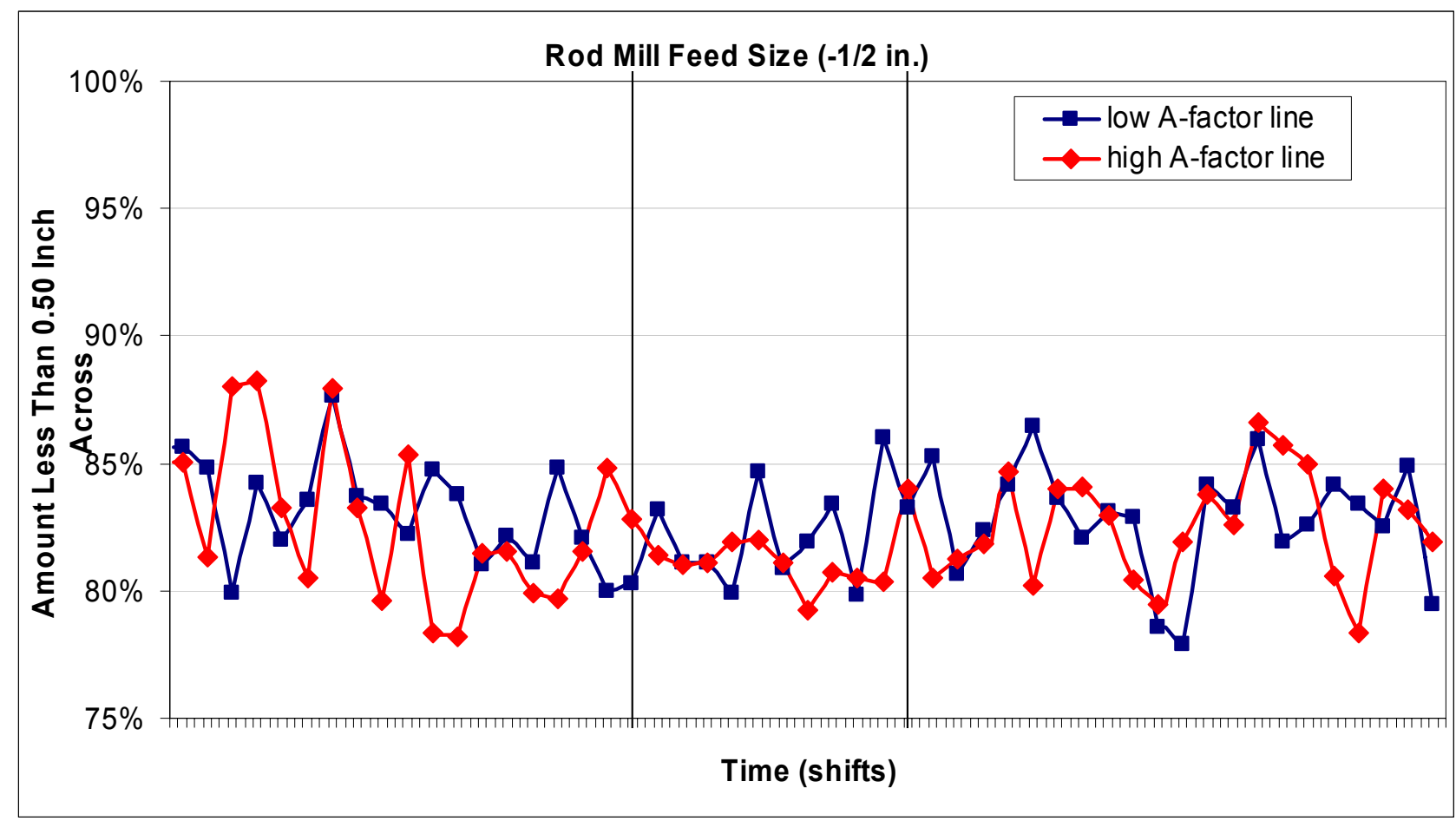

Figure 84. The variation in the passing-0.5-inch portion of the rod mill feed is higher than the larger (passing 0.75 -inch) material, but less so in the high A-factor line during Ore Segregation Test 3.

The major difficulty in following the movement of ore during all ore segregation tests is at the mining face itself. The locations where the shovels work are recorded intermittently, preventing precise measurement at the beginning of how much ore is mined from which face, and where that face actually is in relation to the block model. In addition, the direction of shovel advance must be inferred indirectly. One solution would be to survey each active mining face daily, but a better one would be to monitor shovel location with a GPS system. This would permit more exact ore tracking and better correlation to loading position and tons produced. It also would allow the blocks in the ore control model to be decreased in size, increasing the resolution of the pass-through information. Presently, ore movement must be extracted from the Pit to Crusher report, combined with the Summary Mine Indicated Analysis and the shovel location report. They do not always correlate well, for various reasons including incorrect entry of source and destination codes. Ease of use, ease of data transfer, and robustness of the several independent record-keeping systems are the most important information technology characteristics that prevent completion of the TOPIM protocol.

\section{Ore Segregation Test 4}

This final segregation test was conducted at Hibtac Mine, culminating a series of tests they had conducted of the effect of powder factor on mill performance (Eloranta, 2003). Its analysis depended also on a dataset collected from mid-December 2004 through late January 2005. Figure 85 shows one of the long-term results of the test: The development of a linear regression model that accounts for $80-90 \%$ of the variation in mill production rate. 
The top ore layer (1-7 and sometimes part of 1-6) has a strong positive effect on mill throughput. This was expected, from longtime empirical observations by mine personnel, and has now been quantified.

The middle ore layer (1-5) has a strong negative effect on mill throughput. This was not expected, since this layer was believed to provide the all-important large rock chunks to the autogenous grinding mills. Standard wisdom was that $40 \%$ of the mill feed needed to be material larger than 10 inches in size, but Figures 86 and 87 clearly show that fragments larger than some minimum size are associated with decreases in mill production rate. This may be associated with the effects of differing residence times of rock fragments of various sizes and densities in the different parts of the circuit.

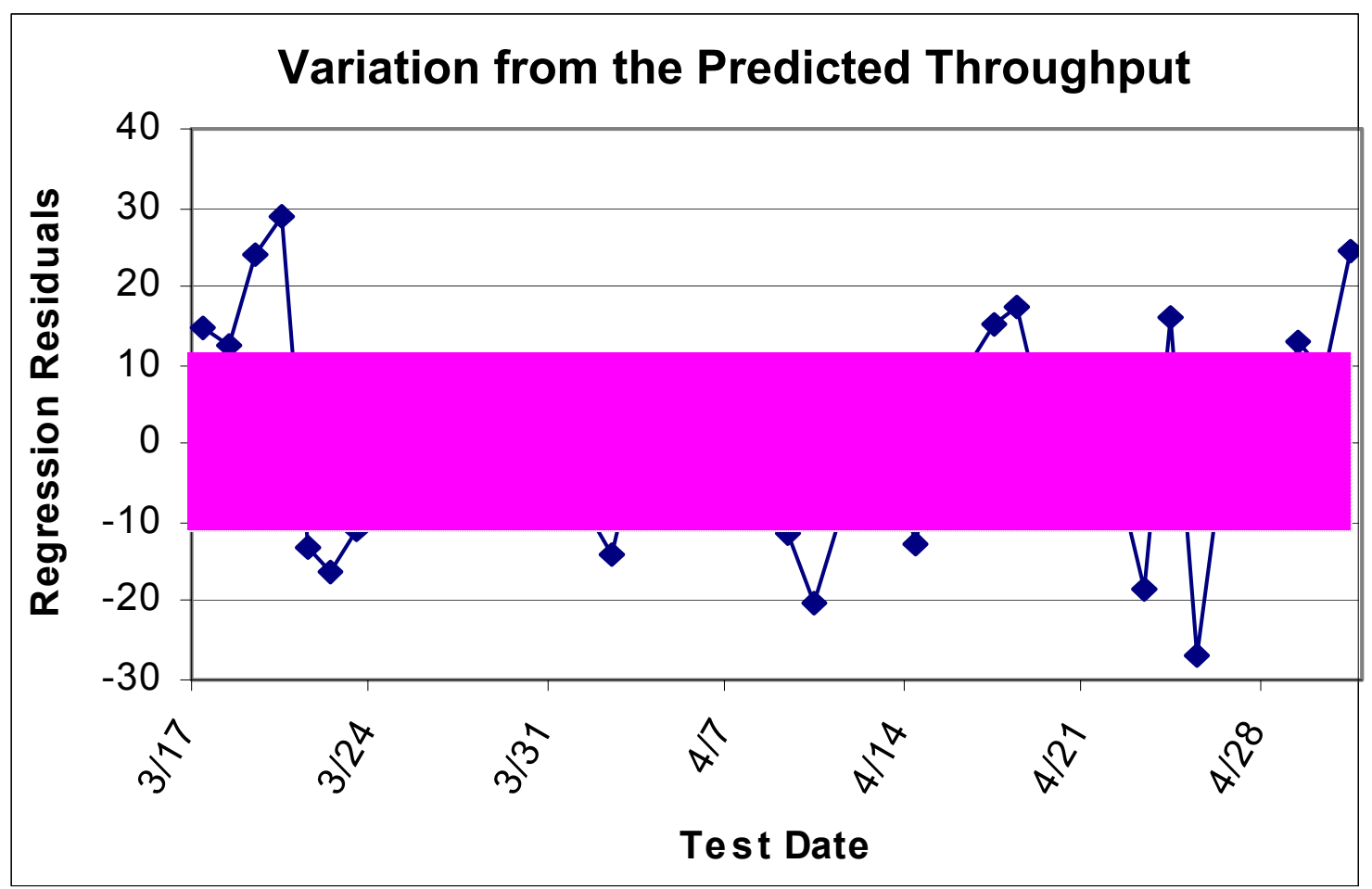

Figure 85. Variation of mill performance from that predicted, during Ore Segregation Test 4 at Hibtac Mine, using the linear regression model developed by mine personnel.

High-silica ore increases plant throughput. This also was unexpected, but reasons are available to explain it:

- High silica ore has its tailings rejected early in the process.

- This reduces the load on the rest of the process; although recovery is lower, the process may be more efficient.

This finding indicates that the high-silica ore may be a suitable candidate for separate treatment. 
The lower ore layers (1-3 and 1-4) increase mill throughput. This is both unexpected and unexplained. The rock must be easier to grind than expected.

Generally, the larger the fragment, the slower the throughput, because even though large chunks grind the small particles, the large chunks have a longer residence time, thus lowering overall throughput.

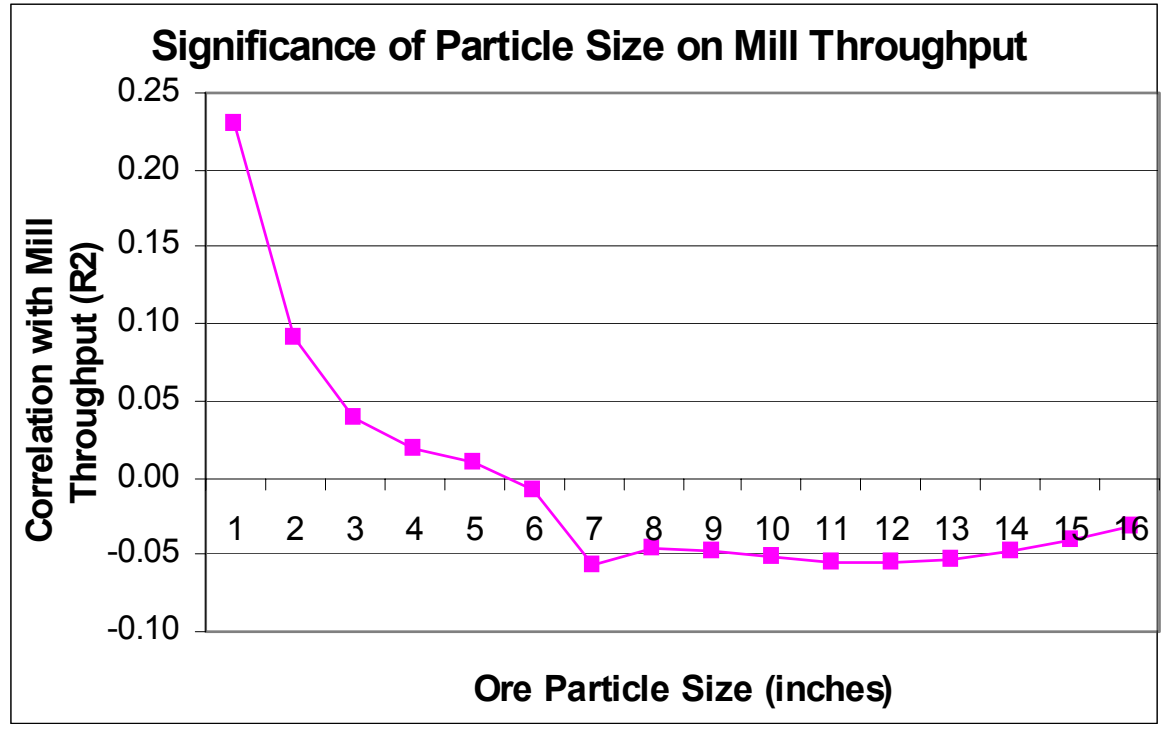

Figure 86. First-order analysis of the amount of change of various ore layer constituents during Ore Segregation Test 3.

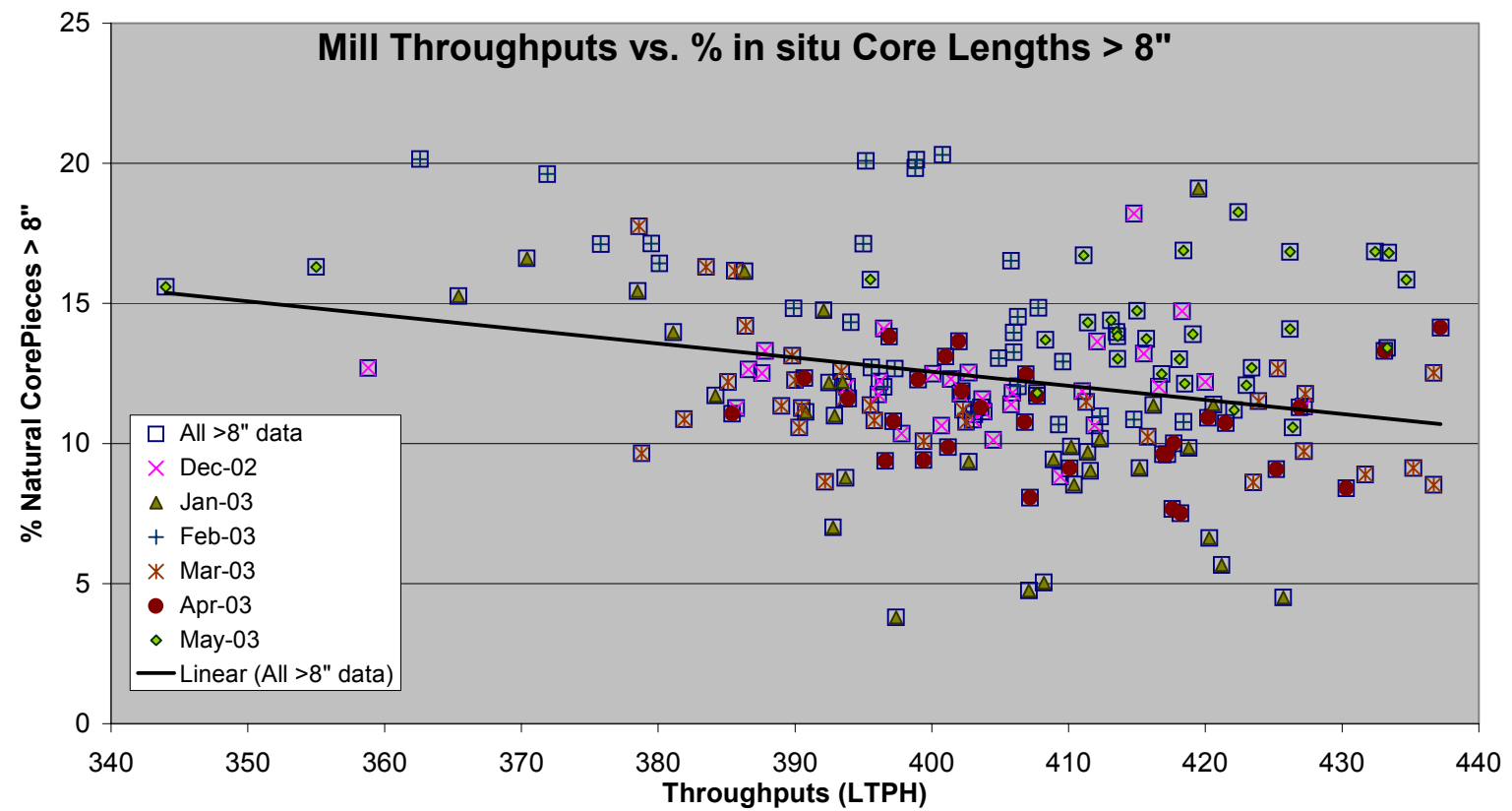

Figure 87. Independent verification of the slowdown in mill production caused by larger fragments, as indicated by RQD data from exploration coreholes (Orobona et al., 2006). 


\section{Background Data Set}

A new dataset to illustrate ordinary, non-segregated operation of the mine and mill was collected at Minntac Mine to assist in the evaluation of the previous segregation test results. Beginning in mid-November, it ended on 31 December, 2004. As for the segregation tests, some of the data was collected every shift, but much it was collected once a day. The latter group were interpolated to create shift-resolution plots. Gaps in the data lines are due to obvious sensor malfunctions. Anomalous data whose cause was uncertain were left in the charts.

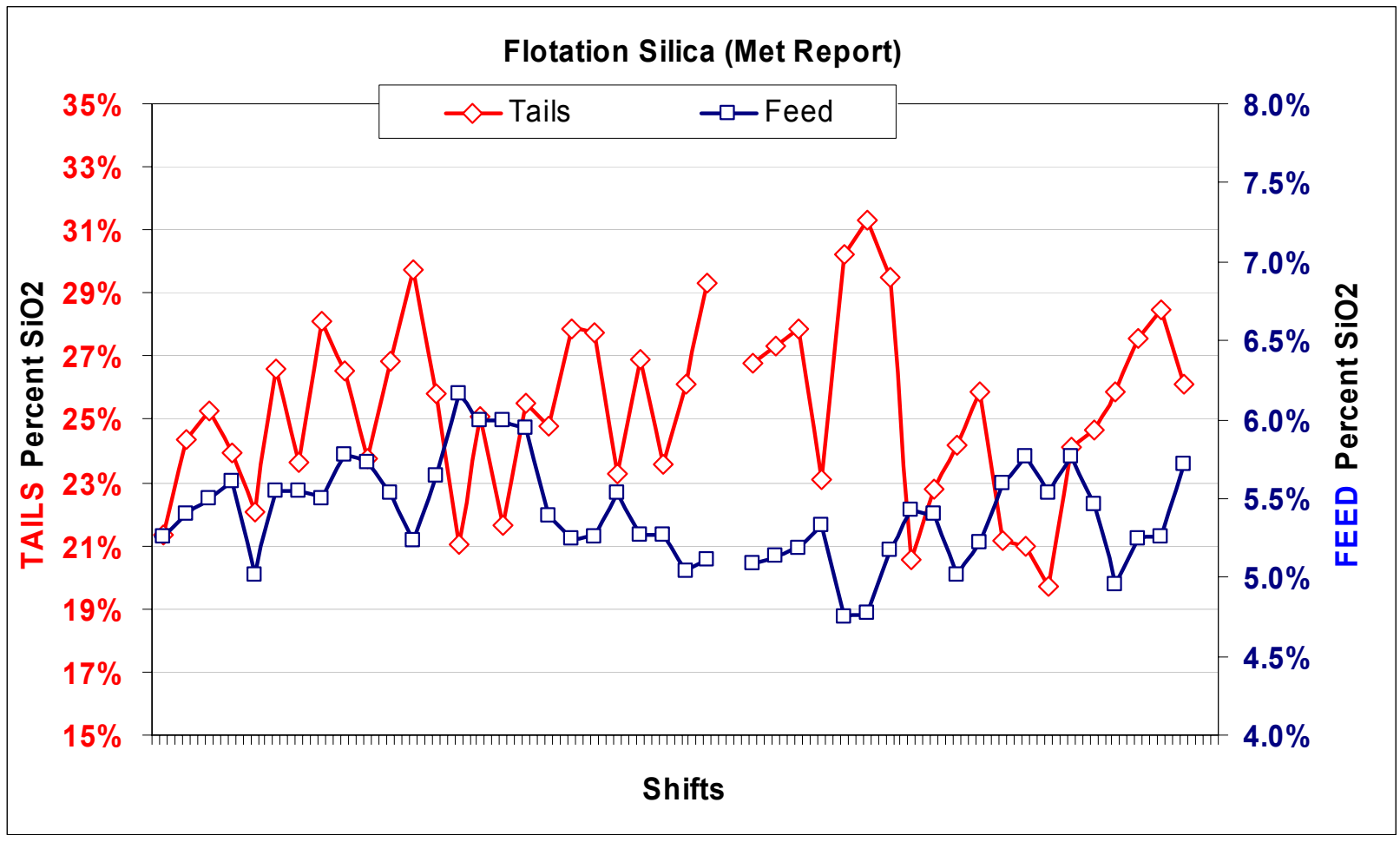

Figure 88. Silica concentration in the flotation tank feed, background dataset. Compare to Figure 73. 


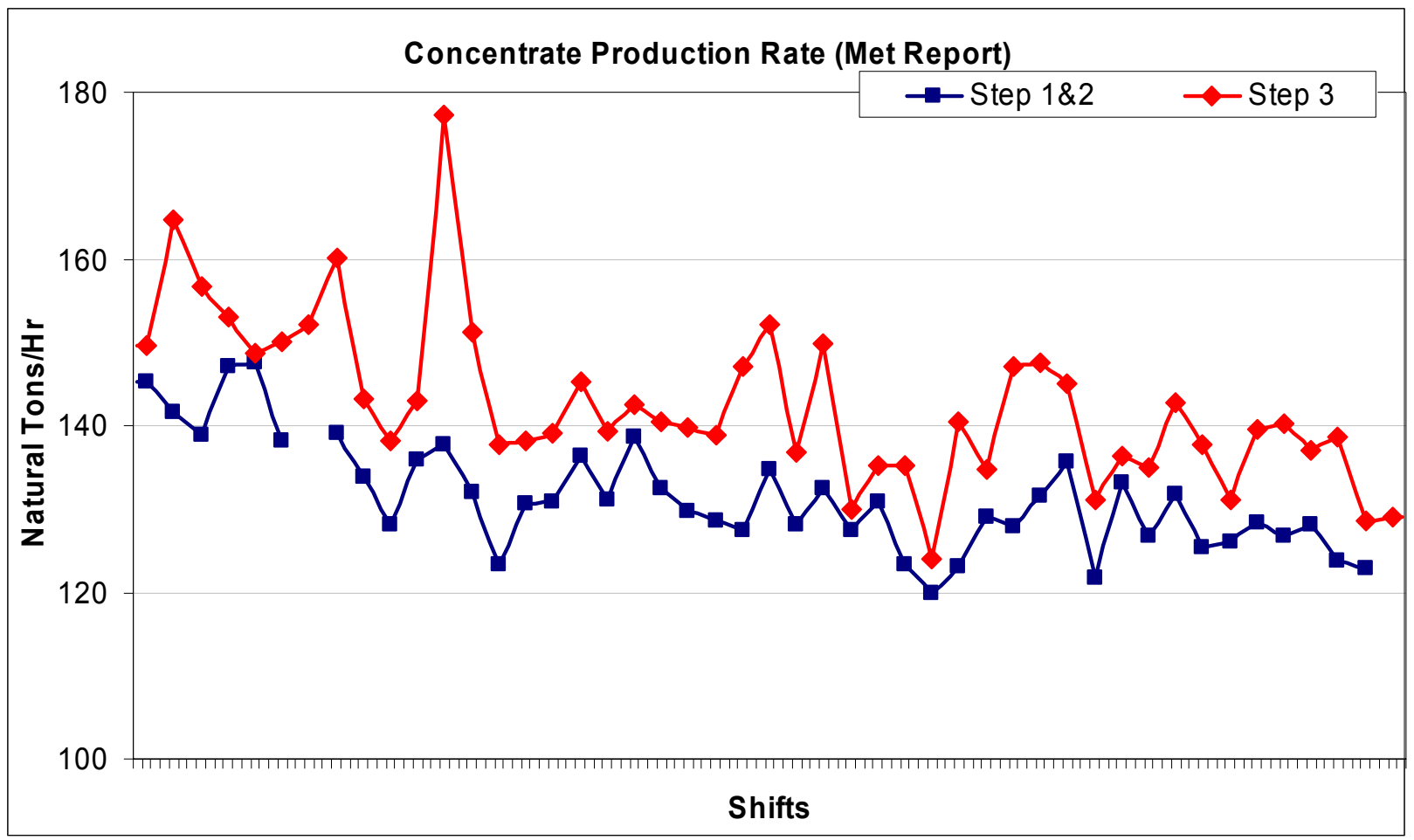

Figure 89. The concentrate production rate of the two lines generally varies together, background data. Compare to Figure 74.

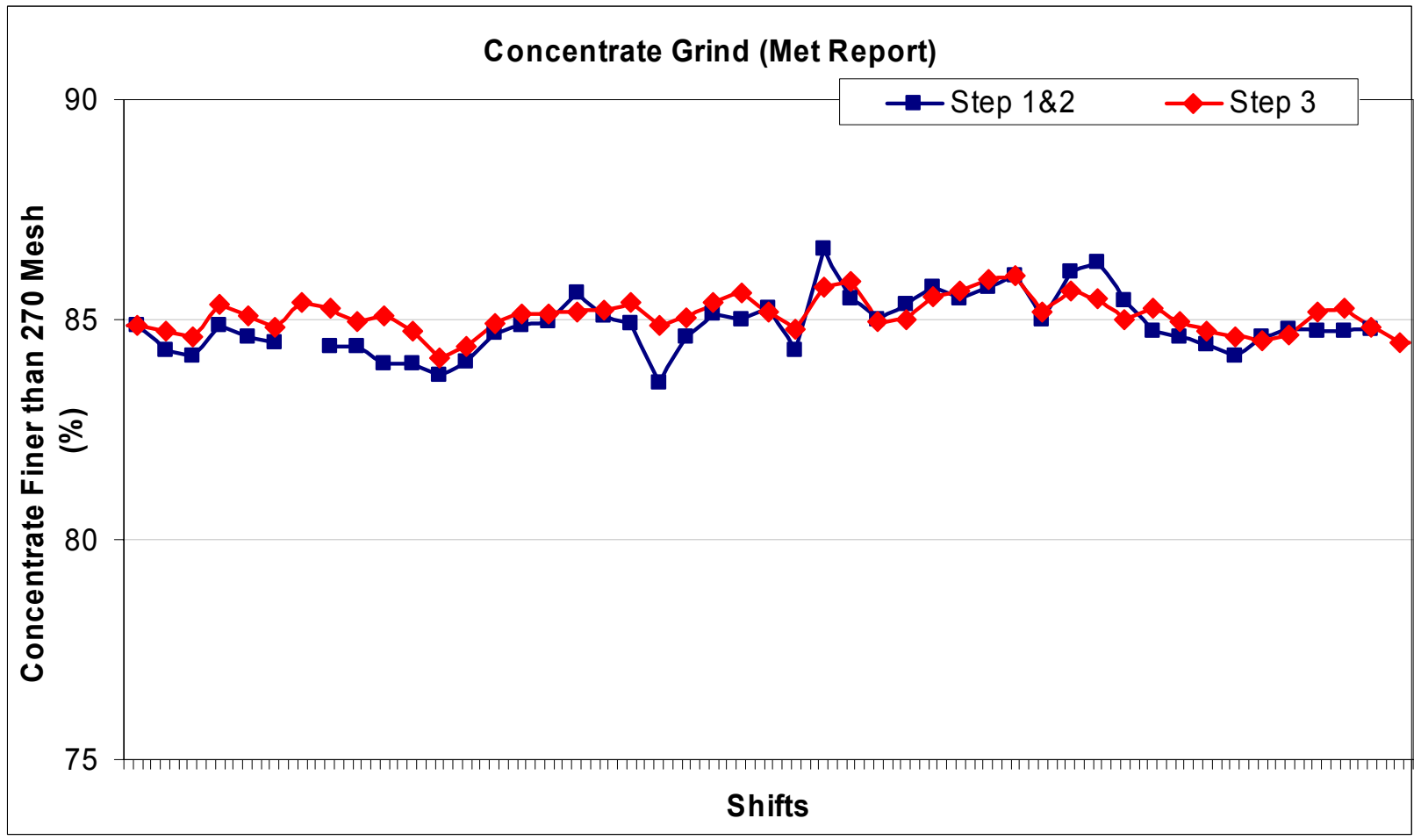

Figure 90. The line that takes the low-A factor during a segregation test (1\&2) experiences less variation in the fineness of the concentrate than the other line does, during ordinary operation. Compare to Figure 75. 


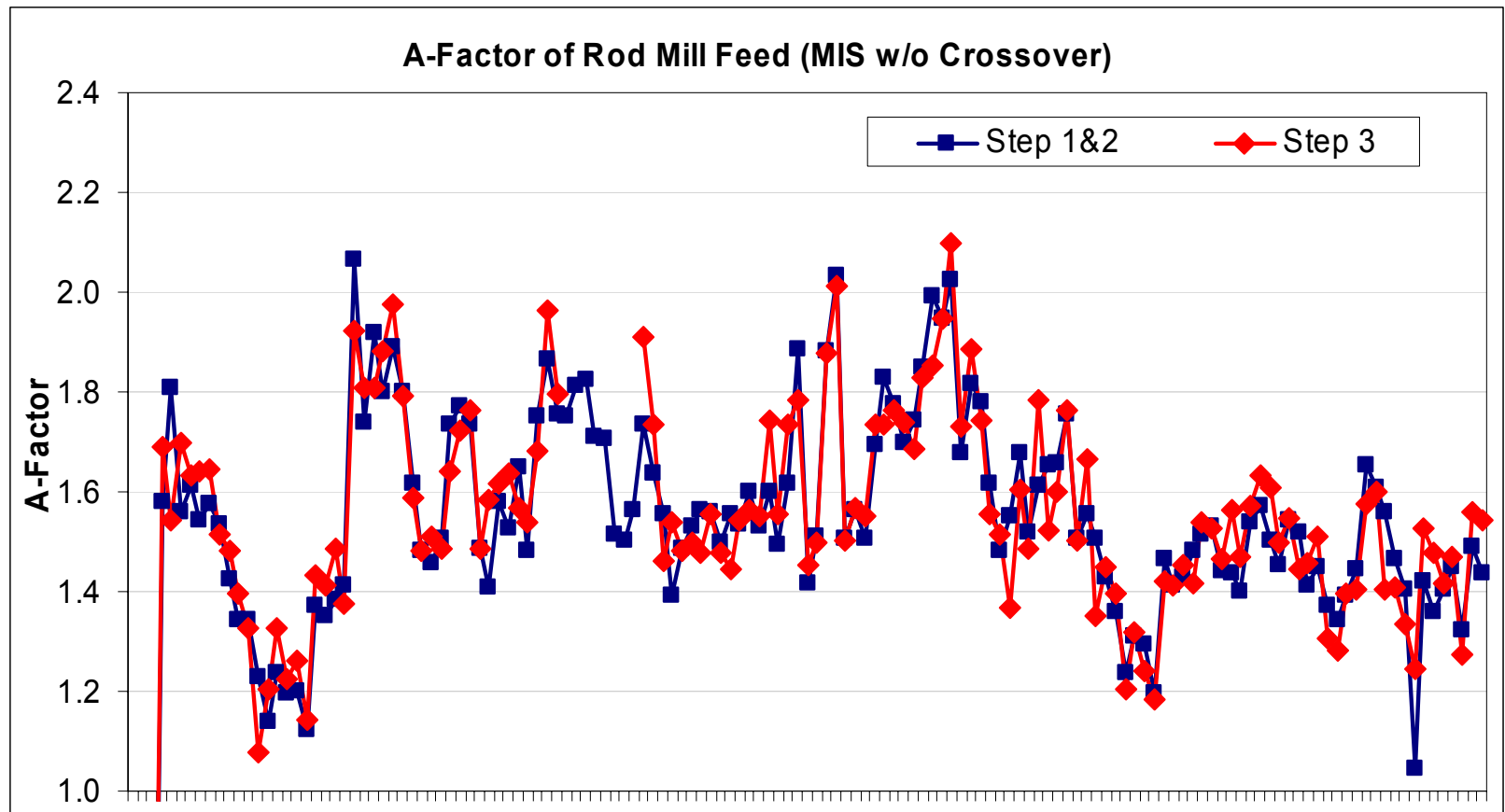

Shifts

Figure 91. Variation of $A$ factor in the rod mill feed varies with time, when the usual practice in ore blending is followed. Compare to Figure 76.

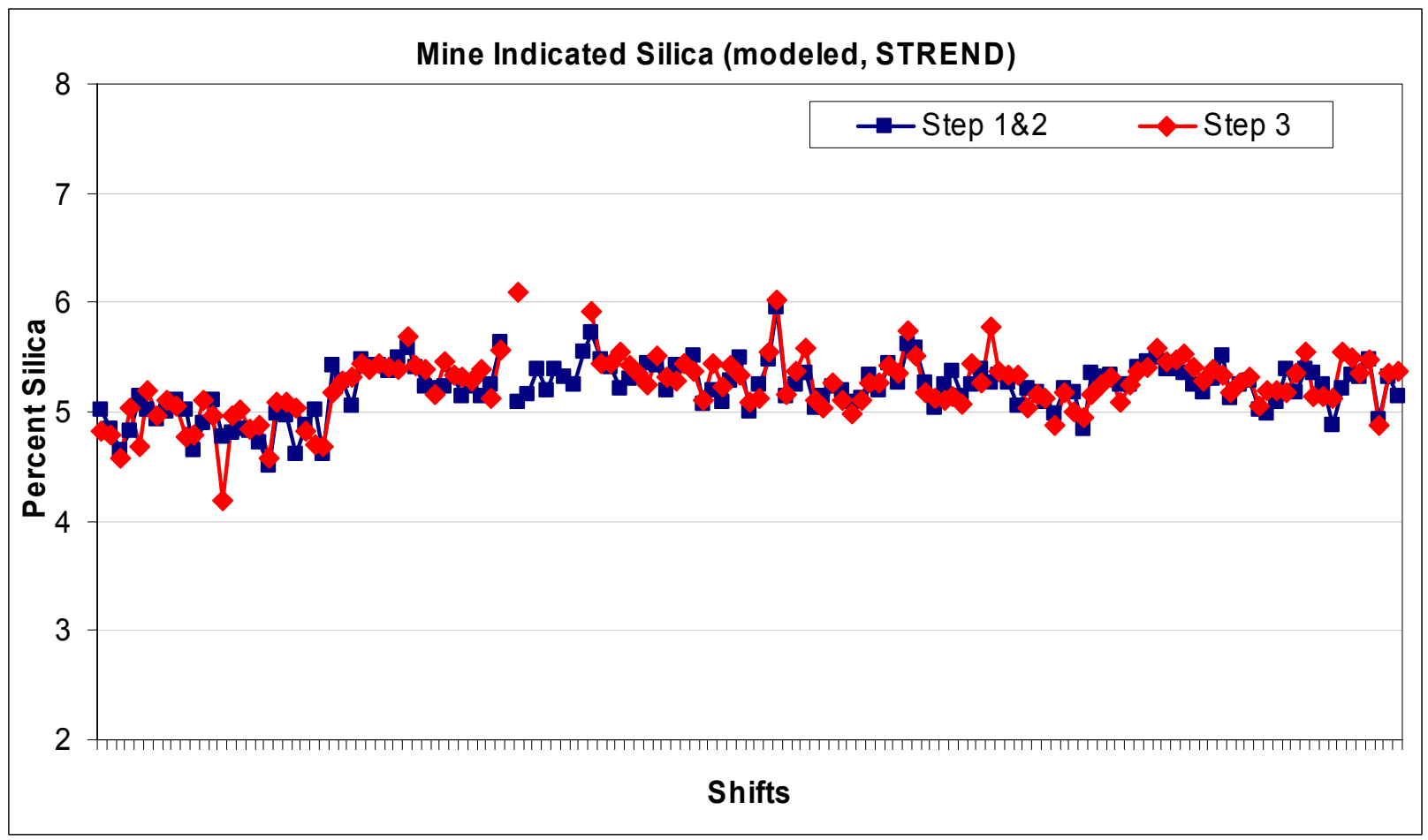

Figure 92. Silica content of the ore indicated by interpolation of exploration core measurements, background data. Compare to Figure 77. 


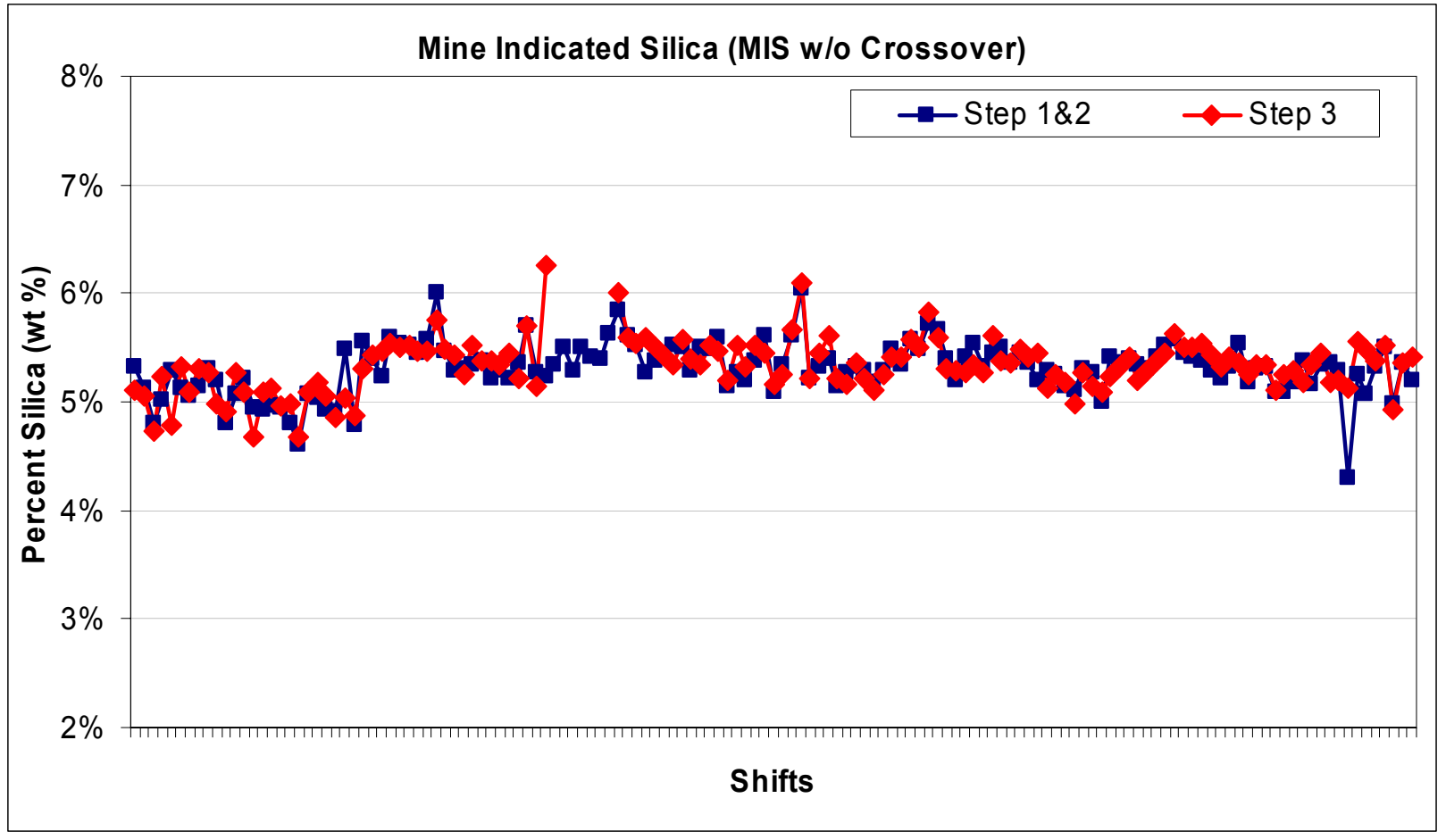

Figure 93. Actual silica content of the ore at the crushers, during ordinary operation. Compare to Figure 78.

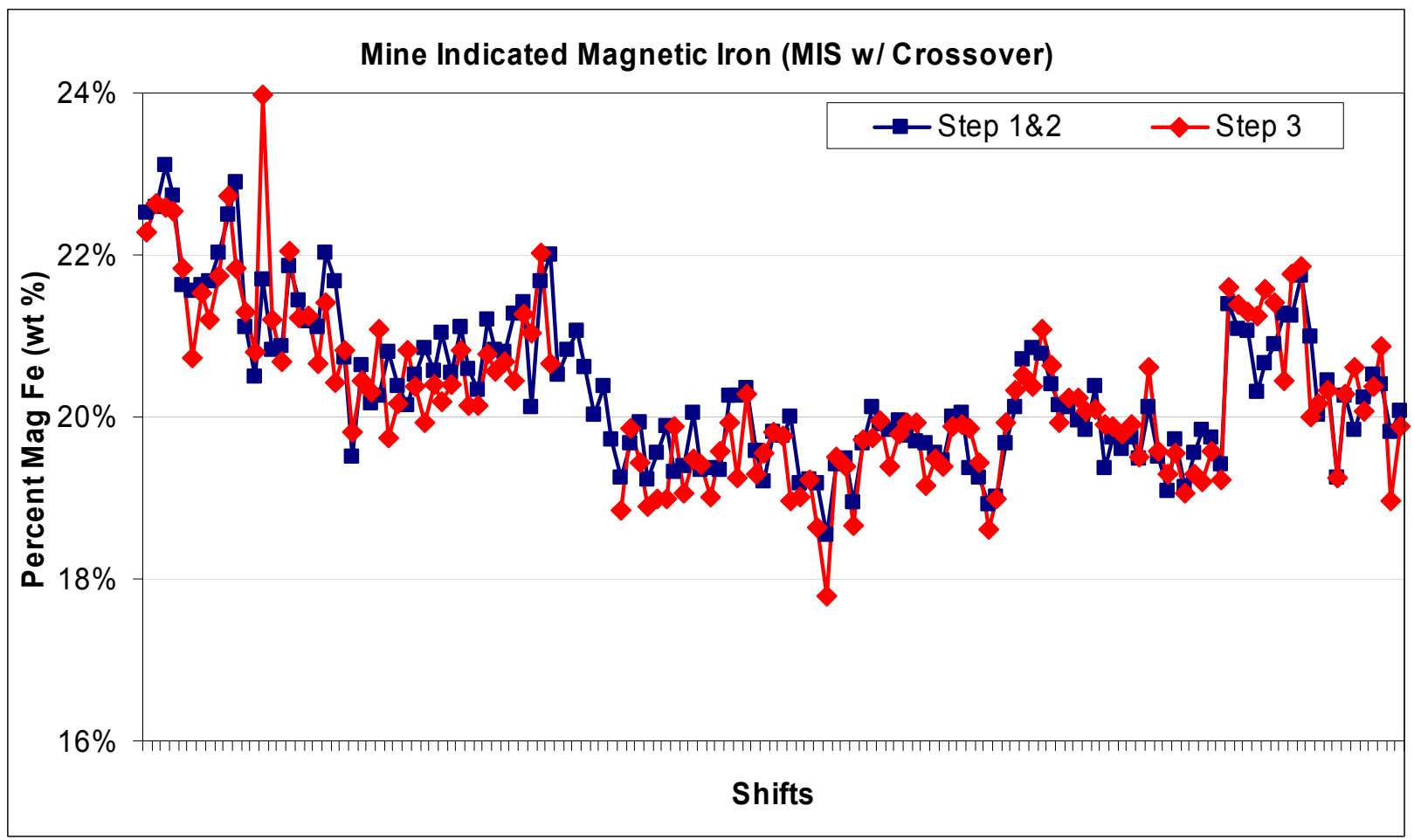

Figure 94. Actual magnetic iron content of the ore at the crushers. Compare to Figure 79. 


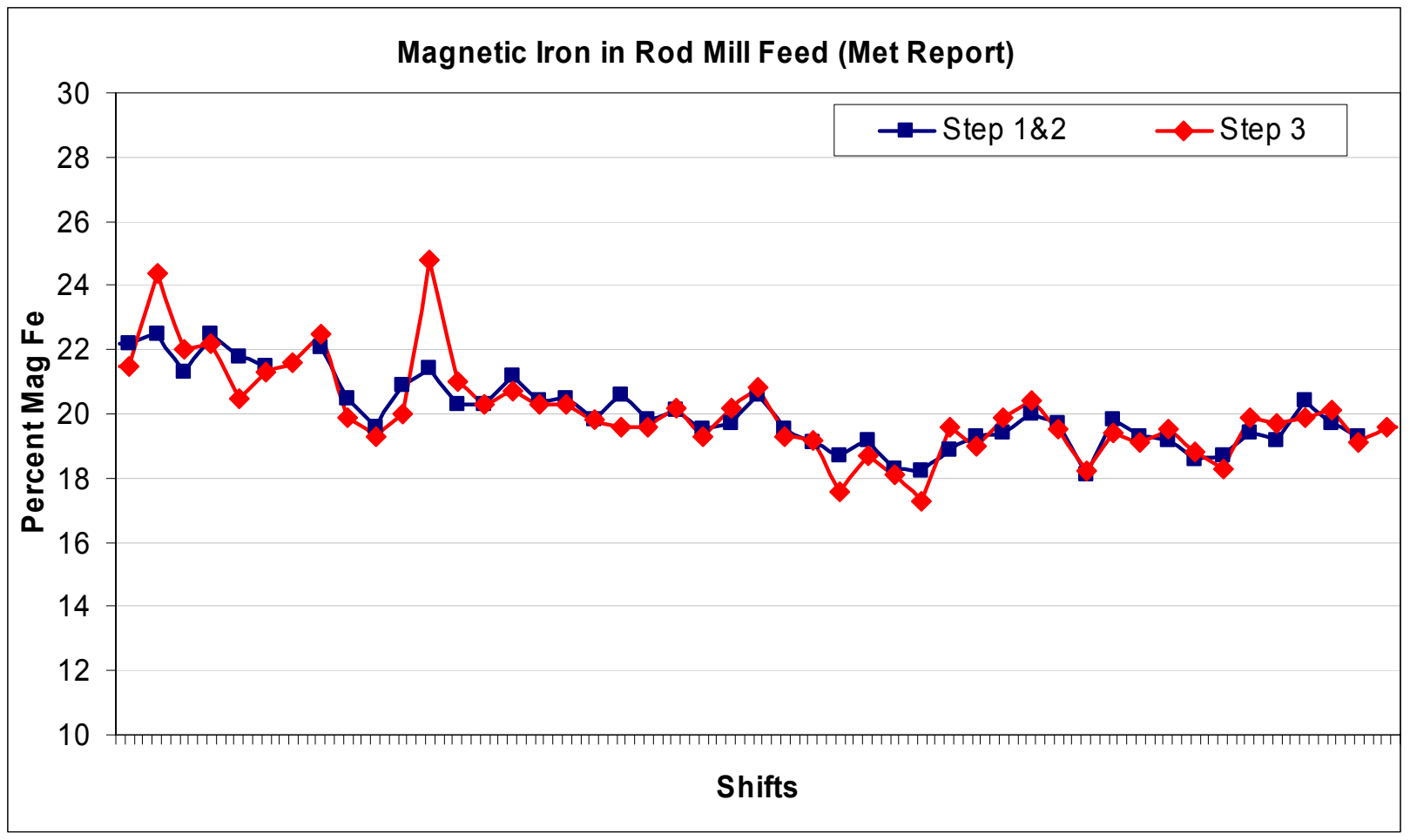

Figure 95. Magnetic iron concentration in the rod mill feedstock. Compare to Figure 80.

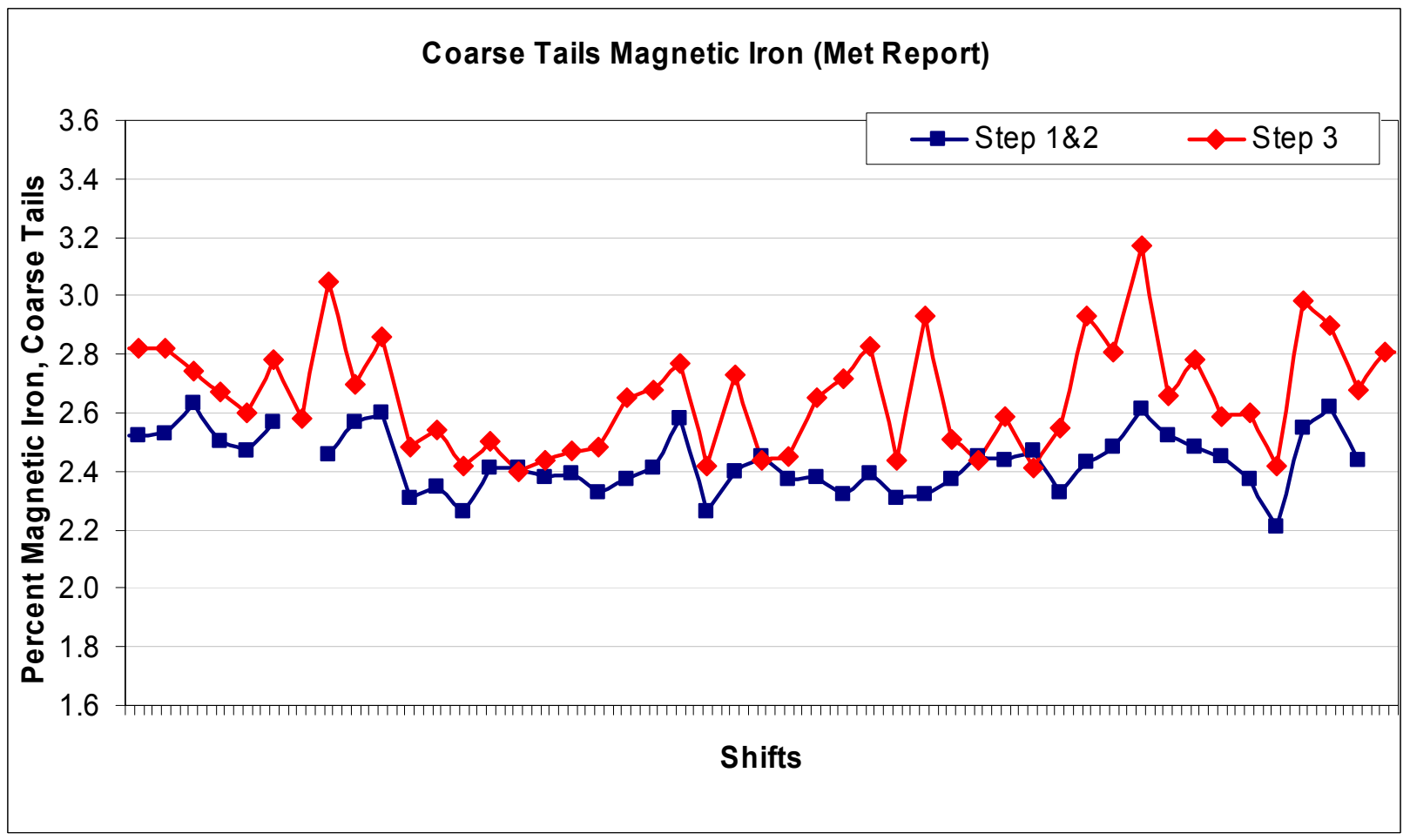

Figure 96. Magnetic iron concentration in the coarse tailings. Compare to Figure 81. 


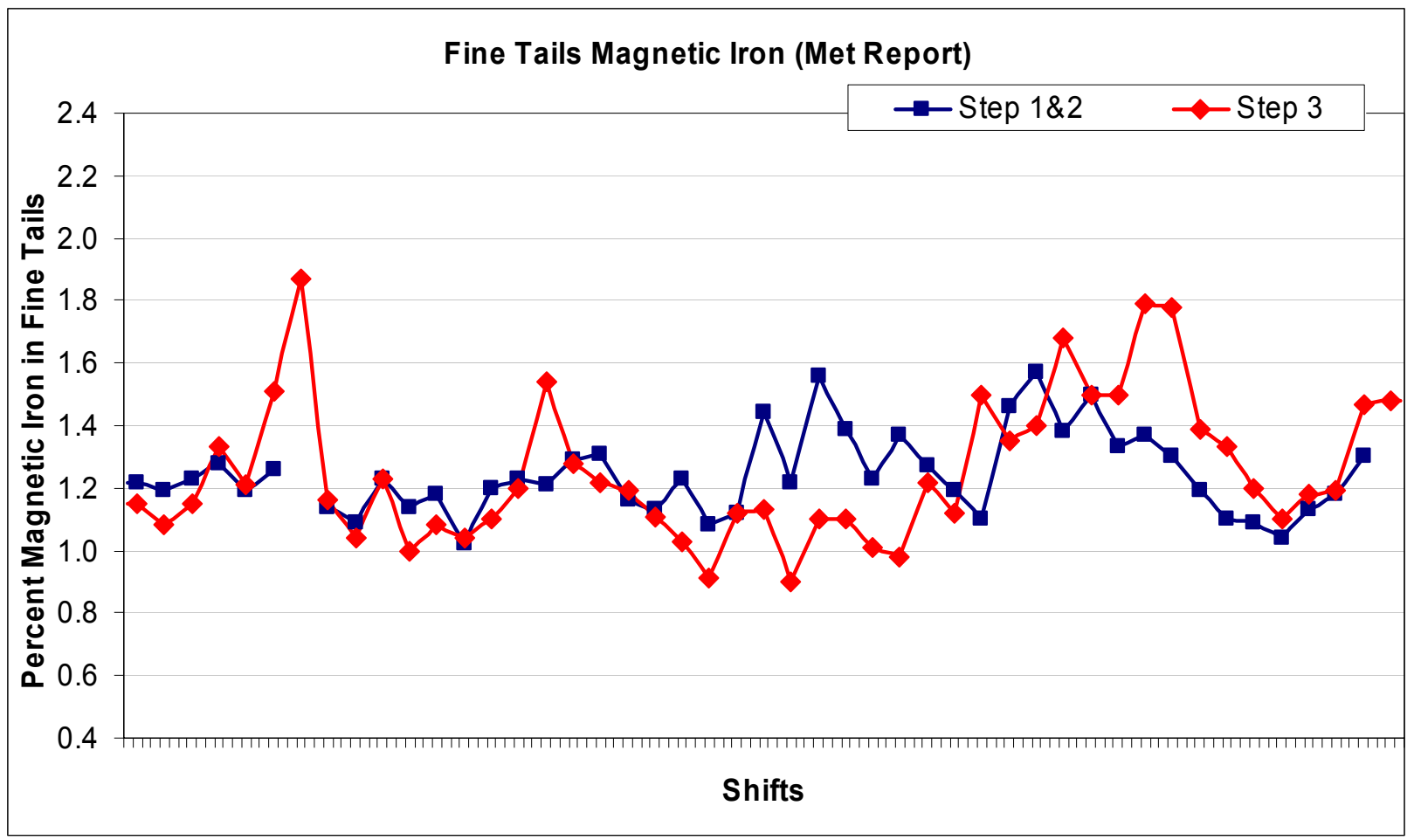

Figure 97 . Magnetic iron concentration in the fine tailings. Compare to Figure 82.

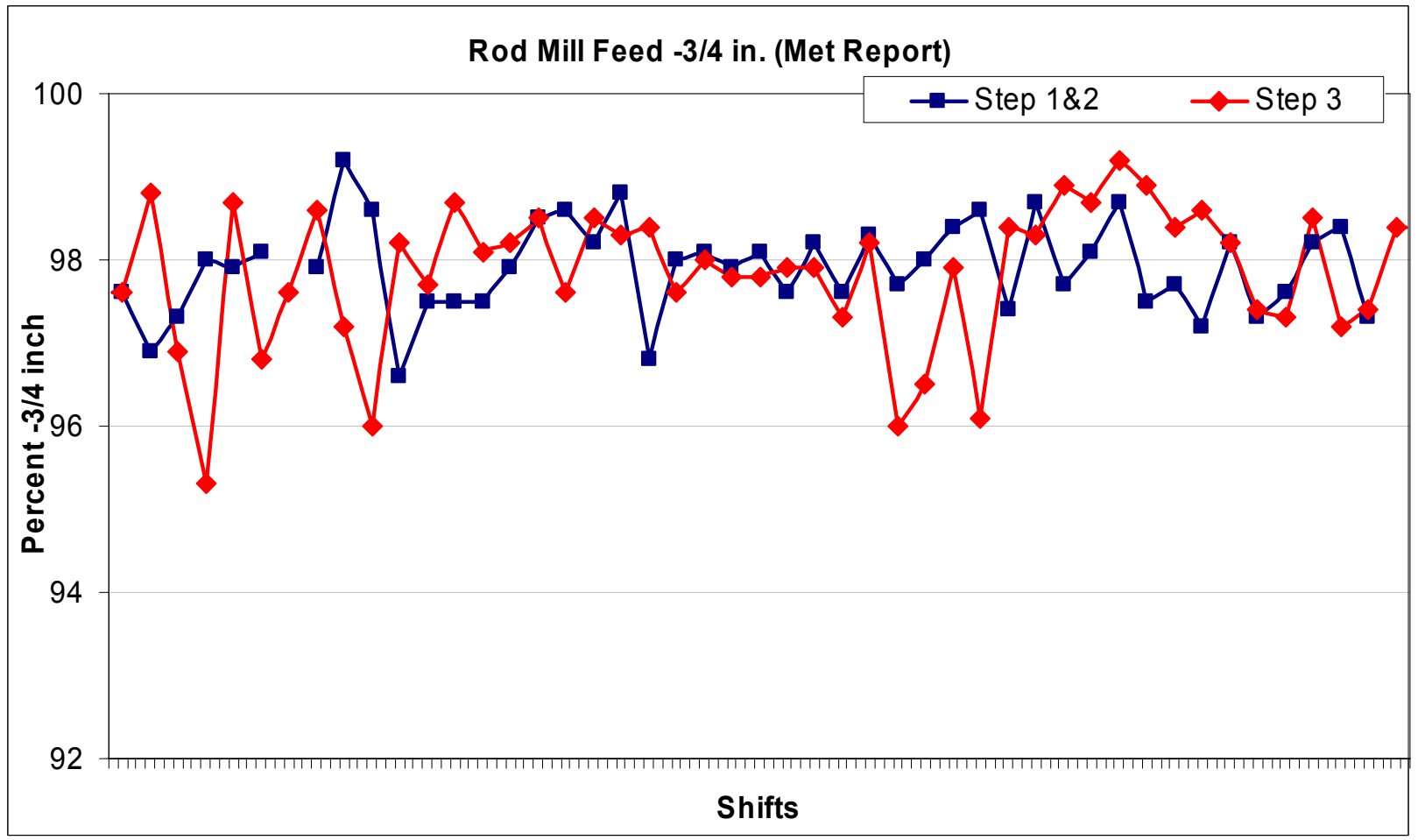

Figure 98. Crushed rock size variation during ordinary operation. Compare to Figure 83. 


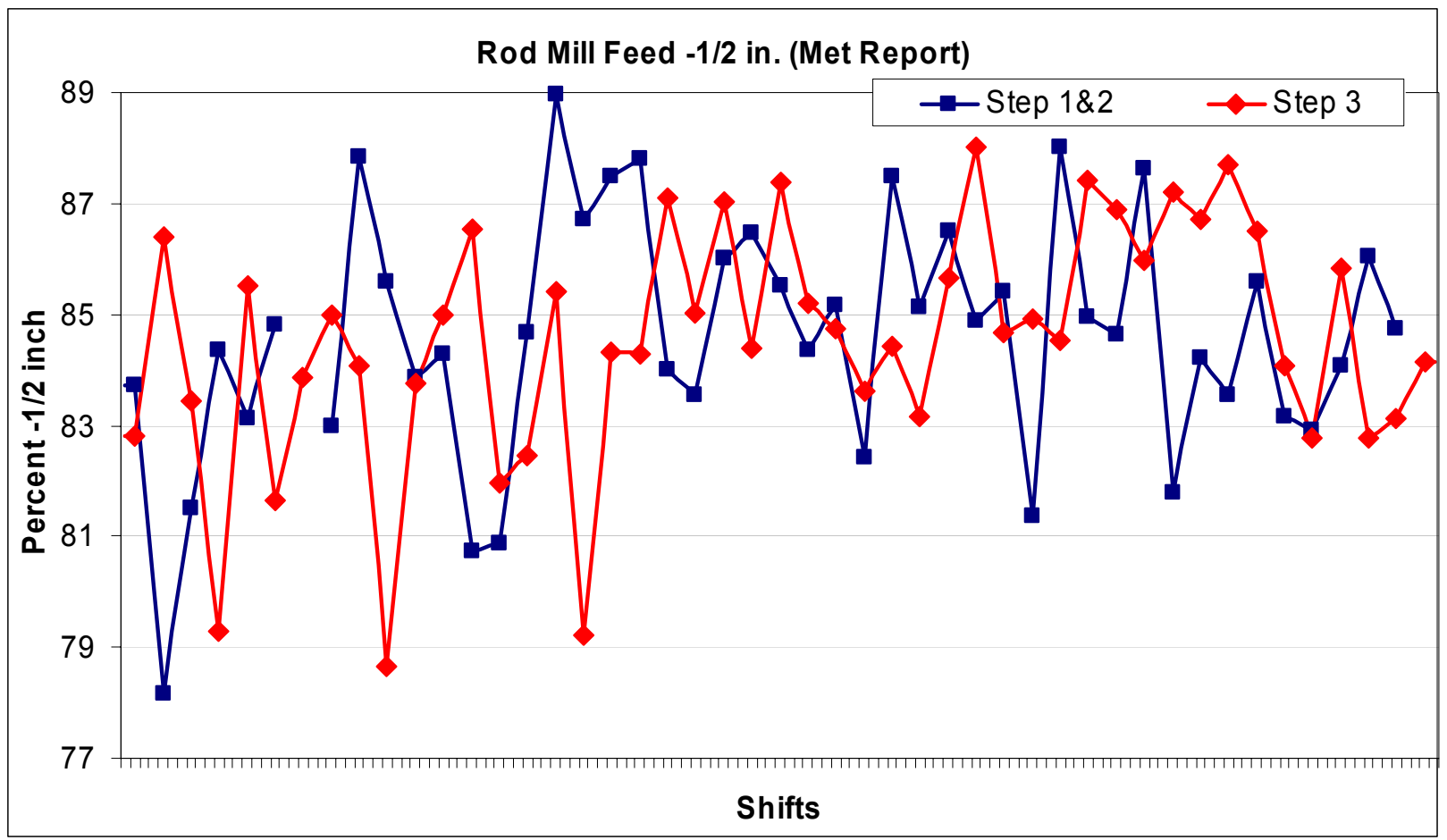

Figure 99. More crushed rock size variation during ordinary operation. Compare to Figure 84 . 


\section{Statistical Analysis}

\section{Hibtac Mine}

The predictability of crushed ore size distribution from source layer data at Hibtac Mine was evaluated by more rigorous statistical analysis than previously discussed. Multiple linear regression was not able to predict size distribution, but a cluster-analysis derivative method was surprisingly capable. Hibtac Mine personnel were able to modify the multiple linear regression approach to explain $80-90 \%$ of the variability seen in the mill throughput. After an eight-month evaluation period, the mine engineers added this data analysis step to their mine planning procedure.

The successful multiple linear regression analysis incorporates 16 mine and mill variables (powder factor, two modeled size fractions, liberation index, predicted grind, total crude iron, Satmagan iron, sat ratio, DSC, geologic blend, ambient temperature, cobbing hours, feeder plugs, and percent feeder run time-of-mill time). Figure 100 illustrates how variations in plant performance are generally well-predicted by the procedure. The outlier on December $28^{\text {th }}$ coincides with low cobbing availability and equipment downtime. Mill productivity appeared to be most influenced, as usual, by ore quality as indicated by the liberation index - the higher the liberation index, the lower the throughput.

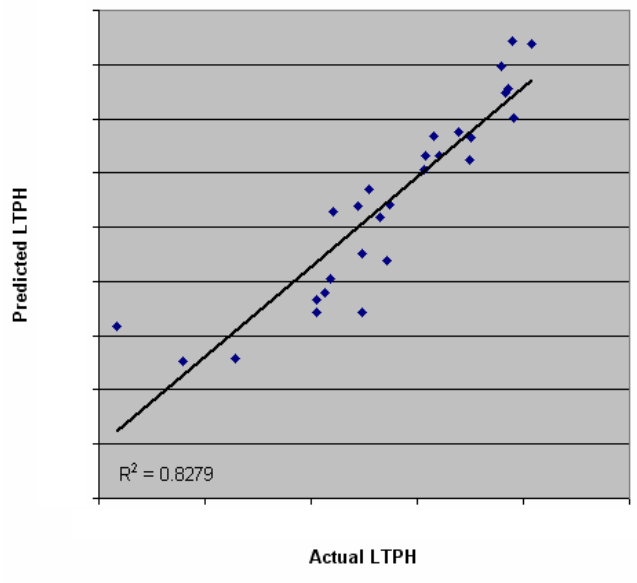

Regression Analysis - Residuals, December 2005

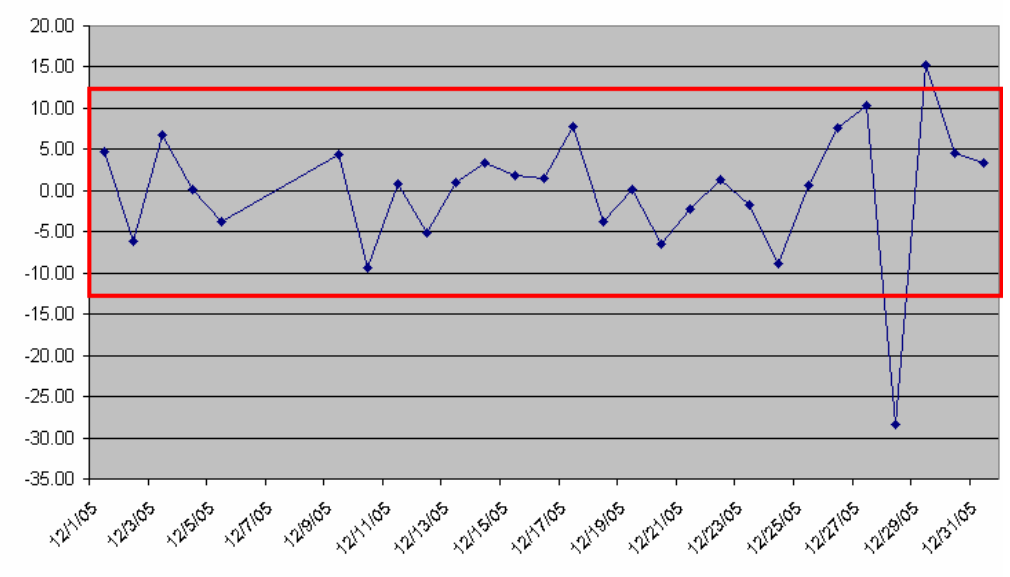

Figure 100. Straightforward linear regression of 16 variables at Hibtac successfully explains mill throughput trends for December 2005 (Orobona et al., 2006). 


\section{Minntac Mine}

Professor of statistics and mathematics Dr. David Drain of UMR conducted a series of detailed studies of some of the datasets collected during ore segregation tests, as well as some additional datasets obtained to help clarify the initial findings. The following paragraphs in this section are excerpted from his report, which is included in the Appendix in its entirety.

The ultimate goal of this research is to find a way to manage an iron processing plant to achieve maximum output while minimizing energy use, waste and other costs. An essential step in achieving this goal is to discover and quantify relationships between input material properties, measurable production parameters and output characteristics. We approached this first step through the use of multiple regression analysis to predict variables of interest with other variables in the data; for example, we predicted mine output using incoming material characteristics.

The first data set consisted of 168 observations on five variables collected from January through June, 2004 at Minntac Mine. The data was collected passively (without deliberate process interventions) during this time. A more extensive set of data from Minntac Mine was obtained from an experiment conducted from July 7 through August 26, 2004. For part of this time (July 25-August 5) input was deliberately manipulated to send better ore to Step 12 and lower-quality ore to Step 3 equipment. No other variables were controlled during this time and mine operators made adjustments as they normally would to keep output within specifications.

The data exhibited significant multicollinearity. when examined with the basic correlation analysis technique. An alternate way to comprehend high dimensional data with a complex correlation structure is to perform a principal components analysis (PCA). PCA reduces the dimension of a problem by finding linear combinations of the original variables that contain the information in those variables. The first component found is that linear combination explaining the most variation; the second component is the linear combination orthogonal to the first explaining the most remaining variation. One difficulty with PCA is interpretation of the components. In many cases during this analysis, no variable dominates the component, nor do any group of logically associated variables so we would find it quite difficult to make use of this component to explain any patterns in the data.

Nearly any variable we attempted to predict was predictable to some extent. For example, 98\% of the variation in V15 is predicted with Equipment (Step 1-2 or 3), V13, V14 and V12. Other variables were more difficult to predict: only $25 \%$ of the variation in V12 was predicted in most models. A table summarizing the amount of variance predicted $\left(\mathrm{R}^{2}\right)$ and the predictors is shown in Tables 9 and 10 (Table 8 is the key to the variable names).

A graphic summary of the various multiple linear regression analyses done is shown in Table 11. Variables for which predictions were attempted are shown at the left margin of the table. Potential predictors are listed at the top of the table. If multiple analyses were done for a variable, multiple lines appear for it in the table.

Multiple linear regression was performed in Minitab, a standard statistical software package. 
Table 8. Key to the meanings of the variables.

\begin{tabular}{|c|c|}
\hline Variable & variable description \\
\hline Equipment & which mill line was used \\
\hline Experiment & whether the ore was being split into two lines on the basis of mine-model parameters before crushing \\
\hline V01-MISAFactor & A-factor (a liberation index) of crusher feed (according to mine model) \\
\hline V02-StrendSilica & silica content (\%) \\
\hline V03-METDTSilica & Davis-tube silica content of the rod mill feed \\
\hline V04-MisSilica & silica content of crusher feed (according to mine model) \\
\hline V05-ConcSilica & silica content of the flotation feed or the concentrate \\
\hline V07-MISHIS & $\%$ of high-silica ore in crusher feed (according to mine model) \\
\hline V08-MISIBC & $\%$ of interbedded chert in crusher feed (according to mine model) \\
\hline V09-MISLL34 & $\%$ of layers 3 and 4 in crusher feed (according to mine model) \\
\hline V10-MISLL12 & $\%$ of layers 1 and 2 in crusher feed (according to mine model) \\
\hline V11-MisMagFe & magnetic iron content in the crusher feed (according to mine model) \\
\hline V12-MagFeRMF & magnetic iron content of the rod mill feed \\
\hline V13-MetCoarseTai & magnetic iron content of the coarse tailings \\
\hline V14-MetFineTails & magnetic iron content of the fine tailings \\
\hline V15-MetMagFeReco & magnetic iron recovery (fraction) \\
\hline V16-ConcMagFe & magnetic iron content of the concentrate that goes to the agglomerator \\
\hline V17-RMFGrindlnde & the grind index of the rod mill feed \\
\hline V18-RMFT85 & the time required to grind the rod mill feed so that $85 \%$ passes 270 mesh \\
\hline V19-RMF6MinAbbe & the six-minute grind index (fraction passing 270 mesh) of the rod mill feed \\
\hline V20-ConcGrind & the six-minute grind index (fraction passing 270 mesh) of the concentrate -- average of all mill lines \\
\hline V21-StrendFloatF & the $\%$ of the feed to the flotation cells that is finer than 270 mesh \\
\hline V22-RodMillFeedR & the rod mill feed rate \\
\hline V23-ConcProdRate & the production rate of iron concentrate that goes to the agglomerator \\
\hline V24-MetDryRecove & magnetic iron recovery, calculated on a dry weight basis \\
\hline V26-AmineRate & the rate of addition of amine to the flotation cells, to remove the silica \\
\hline V27-MetPowerDraw & the power draw of the concentrator \\
\hline V28-RMF34 & fraction of $0.75 "$ stone in the rod mill feed \\
\hline V29-RMF12 & fraction of $0.5 "$ stone in the rod mill feed \\
\hline V50-Total Slate & total fraction of the slate formations in crusher feed \\
\hline V51-(V11-V12) & the difference between the magnetic iron content of the rod mill feed and the coarse tailings \\
\hline
\end{tabular}

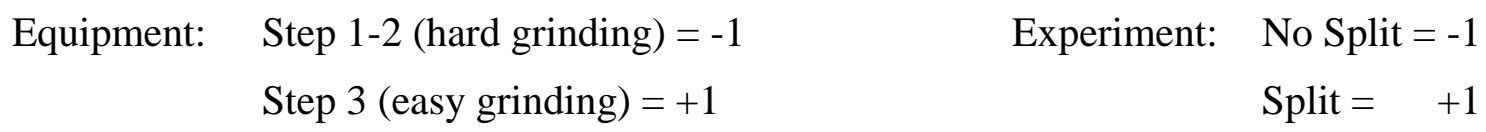

Table 9. The predictive equations determined.

\begin{tabular}{|c|c|c|}
\hline $\mathbf{r}^{2}$ & MEAN & \\
\hline & & FE TAILS - PREDICTION. INPUT = ALL BEFORE + T/S + STEP \\
\hline $60 \%$ & 0.0114 & $\begin{array}{l}\text { V14-MetFineTailsFe }=0.0298+0.00457 \text { V50-Total Slate }+0.00114 \text { V18-RMFT85 + } 0.0955 \text { V03- } \\
\text { METDTSilica }+0.00866 \text { V07-MISHIS }+0.0264 \text { V29-RMF12 }-0.0618 \text { V28-RMF34 + } \\
\text { 0.000279 Equipment }\end{array}$ \\
\hline $55 \%$ & 0.0291 & $\begin{array}{l}\text { V13-MetCoarseTailsFe }=0.0401+0.00163 \text { Equipment }-0.000029 \text { V22-RodMillFeedRate + } 0.0119 \text { V07- } \\
\text { MISHIS - } 0.00461 \text { V08-MISIBC }\end{array}$ \\
\hline & & SILICA - PREDICTION. INPUT = ALL BEFORE + T/S + STEP \\
\hline $85 \%$ & 5.29 & V02-StrendSilica = - 0.598 + 9.70 V03-METDTSilica + 98.9 V04-MisSilica \\
\hline $34 \%$ & 0.427 & V03-METDTSilica $=-0.00033-0.083$ V04-MisSilica +0.00905 V02-StrendSilica \\
\hline $84 \%$ & 0.0552 & V04-MisSilica = $0.0140+0.00786$ V02-StrendSilica - 0.0071 V03-METDTSilica \\
\hline
\end{tabular}


Table 9. Continued.

\begin{tabular}{|c|c|c|}
\hline $\mathbf{r}^{2}$ & MEAN & \\
\hline & & MAGFE - PREDICTION. INPUT = ALL BEFORE + T/S + STEP \\
\hline $83 \%$ & 0.933 & $\begin{array}{c}\text { V15-MetMagFeRecovery }=0.832+0.641 \text { V12-MagFeRMF + 0.000826 V17-RMFGrindIndex - } 1.88 \\
\text { V13-MetCoarseTailsFe - 0.0205 V50-Total Slate }\end{array}$ \\
\hline \multirow[t]{2}{*}{$49 \%$} & 0.654 & $\begin{array}{c}\text { V16-ConcMagFe }=0.672-0.297 \text { V03-METDTSilica + 0.0158 V07-MISHIS + 0.0121 V09-MISLL34 - } \\
\text { 0.827 V04-MisSilica + 0.00610 V02-StrendSilica }\end{array}$ \\
\hline & & GRIND - PREDICTION. INPUT = ALL BEFORE + T/S + STEP \\
\hline $47 \%$ & 0.854 & $\begin{aligned} \text { V20-ConcGrind } & =0.823+0.0510 \text { V07-MISHIS + } 0.402 \text { V03-METDTSilica + } 0.0668 \text { V29-RMF12 - } \\
& 0.259 \text { V12-MagFeRMF }\end{aligned}$ \\
\hline \multirow[t]{2}{*}{$34 \%$} & 82.0 & $\begin{array}{l}\text { V21-StrendFloatFeedGrind }=102-114 \text { V12-MagFeRMF - } 15.7 \text { V07-MISHIS + } 323 \text { V04-MisSilica - } \\
\text { 1.15 V18-RMFT85 + 6.15 V08-MISIBC }\end{array}$ \\
\hline & & PRODUCTION - PREDICTION. INPUT = ALL BEFORE + T/S + STEP \\
\hline $59 \%$ & 0.0276 & $\begin{aligned} \text { V52-NormPower }= & -0.00411-0.00104 \text { Equipment }+0.00745 \text { V09-MISLL34 + 0.197 V04-MisSilica + } \\
& \text { 0.0806 V12-MagFeRMF + 0.0184 V26-AmineRate }\end{aligned}$ \\
\hline \multirow[t]{2}{*}{$58 \%$} & 0.103 & $\begin{aligned} \text { V26-AmineRate } & =3.36-5.74 \text { V16-ConcMagFe + } 0.0619 \text { V09-MISLL34 - } 0.0137 \text { V18-RMFT85 - } 2.04 \\
& \text { V04-MisSilica + 0.519 V28-RMF34 + 0.0193 V27-MetPowerDraw }\end{aligned}$ \\
\hline & & SILICA - INTERACTION. INPUT = V1 - V6 ONLY \\
\hline $9 \%$ & & $\begin{array}{c}\text { V06-MetFloatTailsSilica }=0.143-1.61 \text { V03-METDTSilica + 0.0223 V01-MISAFactor + } 0.0131 \text { V02- } \\
\text { StrendSilica + 0.35 V04-MisSilica + 1.51 V05-ConcSilica }\end{array}$ \\
\hline $57 \%$ & 1.60 & $\begin{array}{c}\text { V01-MISAFactor }=-0.109+0.0758 \text { V02-StrendSilica - 5.96 V03-METDTSilica + 38.9 V04-MisSilica - } \\
\text { 12.6 V05-ConcSilica + 0.346 V06-MetFloatTailsSilica }\end{array}$ \\
\hline $86 \%$ & 5.29 & $\begin{aligned} \text { V02-StrendSilica } & =-0.407+0.186 \text { V01-MISAFactor + 14.0 V03-METDTSilica + 89.4 V04-MisSilica - } \\
& \text { 5.56 V05-ConcSilica }+0.548 \text { V06-MetFloatTailsSilica }\end{aligned}$ \\
\hline $52 \%$ & 0.0427 & $\begin{array}{c}\text { V03-METDTSilica }=-0.0132-0.00653 \text { V01-MISAFactor + 0.0100 V02-StrendSilica - } 0.091 \text { V04- } \\
\text { MisSilica }+0.482 \text { V05-ConcSilica - 0.0264 V06-MetFloatTailsSilica }\end{array}$ \\
\hline $86 \%$ & 0.0552 & $\begin{aligned} \text { V04-MisSilica }= & 0.0100+0.00316 \text { V01-MISAFactor }+0.00658 \text { V02-StrendSilica }-0.0093 \text { V03- } \\
& \text { METDTSilica }+0.114 \text { V05-ConcSilica }-0.00124 \text { V06-MetFloatTailsSilica }\end{aligned}$ \\
\hline \multirow[t]{2}{*}{$37 \%$} & 0.0536 & $\begin{aligned} \text { V05-ConcSilica } & =0.0266-0.00691 \text { V01-MISAFactor }-0.00228 \text { V02-StrendSilica }+0.275 \text { V03- } \\
& \text { METDTSilica }+0.635 \text { V04-MisSilica }+0.0118 \text { V06-MetFloatTailsSilica }\end{aligned}$ \\
\hline & & FE - INTERACTION. INPUT = ALL BEFORE + T/S + STEP + INTERVARIABLES \\
\hline $49 \%$ & 0.198 & $\begin{aligned} \text { V11-MisMagFe }= & 0.239-0.000611 \text { Equipment - 0.00747 V01-MISAFactor - 0.00391 V02-StrendSilica - } \\
& 0.0270 \text { V10-MISLL12 }\end{aligned}$ \\
\hline $25 \%$ & 0.197 & V12-MagFeRMF = $0.176-0.000130$ Equipment + 0.0363 V08-MISIBC + 0.0442 V09-MISLL34 \\
\hline $52 \%$ & 0.0291 & $\begin{array}{l}\text { V13-MetCoarseTailsFe }=0.0421+0.00179 \text { Equipment }+0.0108 \text { V07-MISHIS - } 0.000034 \text { V22- } \\
\text { RodMillFeedRate }\end{array}$ \\
\hline $54 \%$ & 0.0114 & $\begin{array}{c}\text { V14-MetFineTailsFe }=-0.00574+0.000255 \text { Equipment }+0.00853 \text { V50-Total Slate + } 0.000978 \text { V18- } \\
\text { RMFT85 + 0.0892 V03-METDTSilica }\end{array}$ \\
\hline $98 \%$ & 0.933 & $\begin{array}{c}\text { V15-MetMagFeRecovery }=0.901-0.000017 \text { Equipment - } 1.48 \text { V13-MetCoarseTailsFe - } 2.31 \text { V14- } \\
\text { MetFineTailsFe + 0.514 V12-MagFeRMF }\end{array}$ \\
\hline $100 \%$ & Lo Ex & $\begin{array}{c}\text { V15-MetMagFeRecovery }=0.907-0.000002 \text { Equipment - } 1.47 \text { V13-MetCoarseTailsFe - } 2.17 \text { V14- } \\
\text { MetFineTailsFe + 0.472 V12-MagFeRMF }\end{array}$ \\
\hline $55 \%$ & 0.654 & $\begin{aligned} \text { V16-ConcMagFe } & =0.675-0.000048 \text { Equipment }-0.256 \text { V03-METDTSilica }+0.0220 \text { V07-MISHIS + } \\
& \text { 0.00765 V09-MISLL34 - 0.701 V04-MisSilica + 0.00441 V02-StrendSilica }-0.00625 \\
& \text { V50-Total Slate }\end{aligned}$ \\
\hline $51 \%$ & 0.000658 & $\begin{aligned} \text { V51 }(\text { V11-V12 })= & 0.0112-0.00100 \text { Equipment }+0.314 \text { V04-MisSilica }-0.00329 \text { V01-MISAFactor }+ \\
& 0.0106 \text { V09-MISLL34 }\end{aligned}$ \\
\hline
\end{tabular}


Table 10.

\begin{tabular}{|c|c|c|}
\hline \multirow[t]{2}{*}{$\mathbf{r}^{2}$} & \multirow[t]{2}{*}{ MEAN } & \\
\hline & & LAYERS W/ HIS \& IBC \\
\hline $47 \%$ & 0.198 & V11-MisMagFe $=0.175+0.0465$ V08-MISIBC + 0.0460 V09-MISLC34 \\
\hline $17 \%$ & 0.0427 & V03-METDTSilica $=0.0550-0.0208$ V09-MISLC34 - 0.0128 V10-MISLC12 \\
\hline $17 \%$ & 0.0536 & V05-ConcSilica $=0.0484+0.0210$ V08-MISIBC +0.0101 V10-MISLC12 \\
\hline \multirow[t]{2}{*}{$17 \%$} & 0.654 & V16-ConcMagFe = $0.659-0.0178$ V08-MISIBC - 0.00855 V10-MISLC12 \\
\hline & & LAYERS W/ TOTAL SLATE \\
\hline $31 \%$ & 0.198 & V11-MisMagFe $=0.197+0.0204$ V09-MISLC34 - 0.0240 V10-MISLC12 \\
\hline $15 \%$ & 0.0427 & V03-METDTSilica $=0.0380+0.0165$ V50-Total Slate \\
\hline $11 \%$ & 0.0536 & V05-ConcSilica = $0.0591-0.0138$ V09-MISLC34 \\
\hline \multirow[t]{2}{*}{$11 \%$} & 0.654 & V16-ConcMagFe = $0.650+0.0117$ V09-MISLC34 \\
\hline & & PRODUCTION - PREDICTION. INPUT = ALL BEFORE + T/S + STEP \\
\hline $59 \%$ & 0.0276 & $\begin{array}{c}\text { V52-NormPower }=-0.00411-0.00104 \text { Equipment }+0.00745 \text { V09-MISLC34 + 0.197 V04-MisSilica + } \\
\text { 0.0806 V12-MagFeRMF }+0.0184 \text { V26-AmineRate }\end{array}$ \\
\hline \multirow[t]{2}{*}{$58 \%$} & 0.103 & 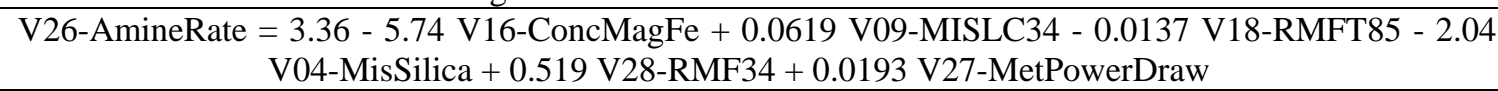 \\
\hline & & SILICA - INTERACTION. INPUT = V1 - V6 ONLY \\
\hline $9 \%$ & & $\begin{array}{c}\text { V06-MetFloatTailsSilica }=0.143-1.61 \text { V03-METDTSilica + 0.0223 V01-MISAFactor + } 0.0131 \text { V02- } \\
\text { StrendSilica }+0.35 \text { V04-MisSilica }+1.51 \text { V05-ConcSilica }\end{array}$ \\
\hline $57 \%$ & 1.60 & $\begin{array}{c}\text { V01-MISAFactor }=-0.109+0.0758 \text { V02-StrendSilica }-5.96 \text { V03-METDTSilica + 38.9 V04-MisSilica - } \\
12.6 \text { V05-ConcSilica }+0.346 \text { V06-MetFloatTailsSilica }\end{array}$ \\
\hline $86 \%$ & 5.29 & $\begin{array}{c}\text { V02-StrendSilica }=-0.407+0.186 \text { V01-MISAFactor + 14.0 V03-METDTSilica + 89.4 V04-MisSilica - } \\
\text { 5.56 V05-ConcSilica + 0.548 V06-MetFloatTailsSilica }\end{array}$ \\
\hline $52 \%$ & 0.0427 & $\begin{array}{c}\text { V03-METDTSilica }=-0.0132-0.00653 \text { V01-MISAFactor }+0.0100 \text { V02-StrendSilica - } 0.091 \text { V04- } \\
\text { MisSilica + 0.482 V05-ConcSilica - 0.0264 V06-MetFloatTailsSilica }\end{array}$ \\
\hline $86 \%$ & 0.0552 & $\begin{aligned} \text { V04-MisSilica }= & 0.0100+0.00316 \text { V01-MISAFactor }+0.00658 \text { V02-StrendSilica }-0.0093 \text { V03- } \\
& \text { METDTSilica }+0.114 \text { V05-ConcSilica }-0.00124 \text { V06-MetFloatTailsSilica }\end{aligned}$ \\
\hline \multirow[t]{2}{*}{$37 \%$} & 0.0536 & $\begin{aligned} \text { V05-ConcSilica } & =0.0266-0.00691 \text { V01-MISAFactor }-0.00228 \text { V02-StrendSilica }+0.275 \text { V03- } \\
& \text { METDTSilica + 0.635 V04-MisSilica }+0.0118 \text { V06-MetFloatTailsSilica }\end{aligned}$ \\
\hline & & FE - PREDICTION. INPUT = ALL BEFORE + T/S + STEP + INTERVARIABLES \\
\hline $49 \%$ & 0.198 & $\begin{aligned} \text { V11-MisMagFe }= & 0.239-0.000611 \text { Equipment - 0.00747 V01-MISAFactor - 0.00391 V02-StrendSilica - } \\
& 0.0270 \text { V10-MISLC12 }\end{aligned}$ \\
\hline $25 \%$ & 0.197 & V12-MagFeRMF = 0.176 - 0.000130 Equipment + 0.0363 V08-MISIBC + 0.0442 V09-MISLC34 \\
\hline $52 \%$ & 0.0291 & $\begin{array}{c}\text { V13-MetCoarseTailsFe }=0.0421+0.00179 \text { Equipment }+0.0108 \text { V07-MISHIS - } 0.000034 \text { V22- } \\
\text { RodMillFeedRate }\end{array}$ \\
\hline $54 \%$ & 0.0114 & $\begin{array}{c}\text { V14-MetFineTailsFe }=-0.00574+0.000255 \text { Equipment }+0.00853 \text { V50-Total Slate }+0.000978 \text { V18- } \\
\text { RMFT85 + 0.0892 V03-METDTSilica }\end{array}$ \\
\hline $98 \%$ & 0.933 & $\begin{array}{c}\text { V15-MetMagFeRecovery }=0.901-0.000017 \text { Equipment - } 1.48 \text { V13-MetCoarseTailsFe - 2.31 V14- } \\
\text { MetFineTailsFe + 0.514 V12-MagFeRMF }\end{array}$ \\
\hline $100 \%$ & Lo Ex & $\begin{array}{c}\text { V15-MetMagFeRecovery }=0.907-0.000002 \text { Equipment - } 1.47 \text { V13-MetCoarseTailsFe - } 2.17 \text { V14- } \\
\text { MetFineTailsFe + 0.472 V12-MagFeRMF }\end{array}$ \\
\hline $55 \%$ & 0.654 & $\begin{aligned} & \text { V16-ConcMagFe }=0.675-0.000048 \text { Equipment }-0.256 \text { V03-METDTSilica }+0.0220 \text { V07-MISHIS + } \\
& \text { 0.00765 V09-MISLC34 - 0.701 V04-MisSilica + 0.00441 V02-StrendSilica - } 0.00625 \\
& \text { V50-Total Slate }\end{aligned}$ \\
\hline $51 \%$ & 0.000658 & $\begin{aligned} \text { V51 }(\text { V11-V12 })= & 0.0112-0.00100 \text { Equipment }+0.314 \text { V04-MisSilica }-0.00329 \text { V01-MISAFactor }+ \\
& 0.0106 \text { V09-MISLC34 }\end{aligned}$ \\
\hline
\end{tabular}


The correlation coefficient $\left(\mathrm{R}^{2}\right)$ is coded by four symbols:

$$
\begin{array}{ll}
0-24 \% & \circ \\
25-49 \% & \bullet \\
50-74 \% & \text { D } \\
75-100 \% & \text { - }
\end{array}
$$

The nature of a variable's influence is coded as follows:

$$
\begin{aligned}
& \nabla \text { Negative influence } \\
& \Delta \quad \text { Positive influence }
\end{aligned}
$$

So, for example, the first line of Table 11 tells us that V01 was predicted by the variables V02-V06 with a correlation coefficient between $50 \%$ and $74 \%$. We can also see the influences of variables V02, V04, and V06 were positive (positive sign on $\mathrm{R}^{2}$ ) and the influences of the remaining predictors were negative. Variables without a sign either were not ever included in the model or were not significant predictors.

Point estimates for any predicted variable can be computed by substituting predictor variable values into the appropriate prediction equation. Point estimates in themselves convey no information about their precision or believability, so interval estimates are used when these properties are of interest.

Confidence interval estimates for the average response at a given set of predictor settings, and prediction interval estimates for an individual response under the same conditions are available in Minitab. Confidence intervals will always be more precise (narrower) than prediction intervals because the latter must account for individual response variability from the mean. Both types of intervals will be narrowest near the mean of the predictor values and predictions at extremes of the predictors will be least precise.

Predictions can only be made with confidence under similar conditions and with similar predictor settings as those encountered during the period of observation. Extrapolation is easy to avoid with simple one-variable models because it is obvious when the limits of the predictor variable are reached. With multivariate models this is more difficult because a combination of predictor settings can be well outside the range of the original data even when each individual predictor is within its range.

Plant operations require frequent human intervention and adjustment of equipment settings that were not recorded or accounted for during the period of observation. These could have the effect of accentuating or hiding some effects that might have been discovered in a more controlled experiment.

Unobserved variables can also have the effect of causing spurious correlations between other variables by affecting both variables in unison. For this reason, we should be careful to interpret correlations and predictions within a scientific framework: if there is not good reason to expect one variable to cause a difference in another, we should not infer such causal action even in the presence of significant correlation.

Some data was given by shift, some by day, so shiftly data was averaged to create one observation per day. Variables were renamed consistently with naming syntax for Minitab. 
Indicator variables for experiment $(-1=$ no experiment) and equipment $(-1=$ step 12$)$ were created. Some analyses required lagged variables, which are simply prior observations of the same variable. For example Lag2(x)=the value of $x$ two days before this one. Products and powers of variables were also created for some analyses.

\section{Phase 1 version 1}

The basic goal of this first phase of research was to predict output (ConLTPH) with other variables available. Best subsets regression indicated that Lab Magfe and MIGI Sl account for $47 \%$ of the variance in ConLTPH. Residual analysis showed significant partial autocorrelations for at least the first three time periods; this observation prompted the version 2 analysis below.

\section{Phase 1 version 2}

In this second phase of the analysis of the passive data set we included an EWMA predictor for the output. The decision to add this predictor was based upon our belief that unmeasured (or unmeasurable) variables were influencing output, and that information on one day's output could probably be obtained from an observation of the process performance on prior days. The EWMA is the tool of choice for such prediction because it provides a predictor with an adjustable length of memory - the relative importance of recent data can be changed to optimize prediction. In this case an EWMA predictor with lambda $=0.27538$ was used to predict output based on prior outputs. This particular value of lambda was chosen because it minimized the prediction error (in the absence of other predictors). Using this type of predictor, a prediction $\left(\mathrm{y}_{\mathrm{n}}\right)$ for each day's output $\left(\mathrm{x}_{\mathrm{n}}\right)$ is made as follows:

$$
y_{n}=\lambda x_{n-1}+(1-\lambda) y_{n-1}
$$

Stepwise regression analysis indicated that the EWMA predictor, Abbe, and Lab MagFe are useful predictors, eventually accounting for two thirds of the variance in the data.

\section{Phase 2}

We investigated the relationship between High Silica/IBC and coarse /fine tails. ANCOVA (analysis of covariance) was used with stream (12 or 3) as the sole categorical variable. HIS has a significantly positive effect on Coarse tails, and IBC has a significantly negative effect. 50\% of the variation in coarse fines was accounted for by this model. HIS has a significantly positive effect on fine tails, and IBC has a significantly positive effect as well. 38\% of the observed variation in fine tails was accounted for by this model.

We also investigated relationships between High Silica/IBC and percent dry recovery and Float feed Davis tube weight recovery). 10\% of the observed variation in Dry Recovery was accounted for by this model. HIS had a significantly negative effect on the result. Only $4 \%$ of the observed variation in Davis Tube readings was accounted for by this model, but both HIS and IBC had significantly positive effects.

Finally we investigated relationships between High Silica/IBC and concentrate silica and flotation silica. $10 \%$ of the variation in Concentrator percent silica was predictable with HIS and IBC. Only IBC was a (positively) significant predictor. A negligible percent of the variation in TailsSiO2 was predicted. About $10 \%$ of the variation in float Feed SiO2 was predicted, and IBC was the only (positively) significant predictor. 
Table 11. Graphical presentation of the results of the statistical analysis.

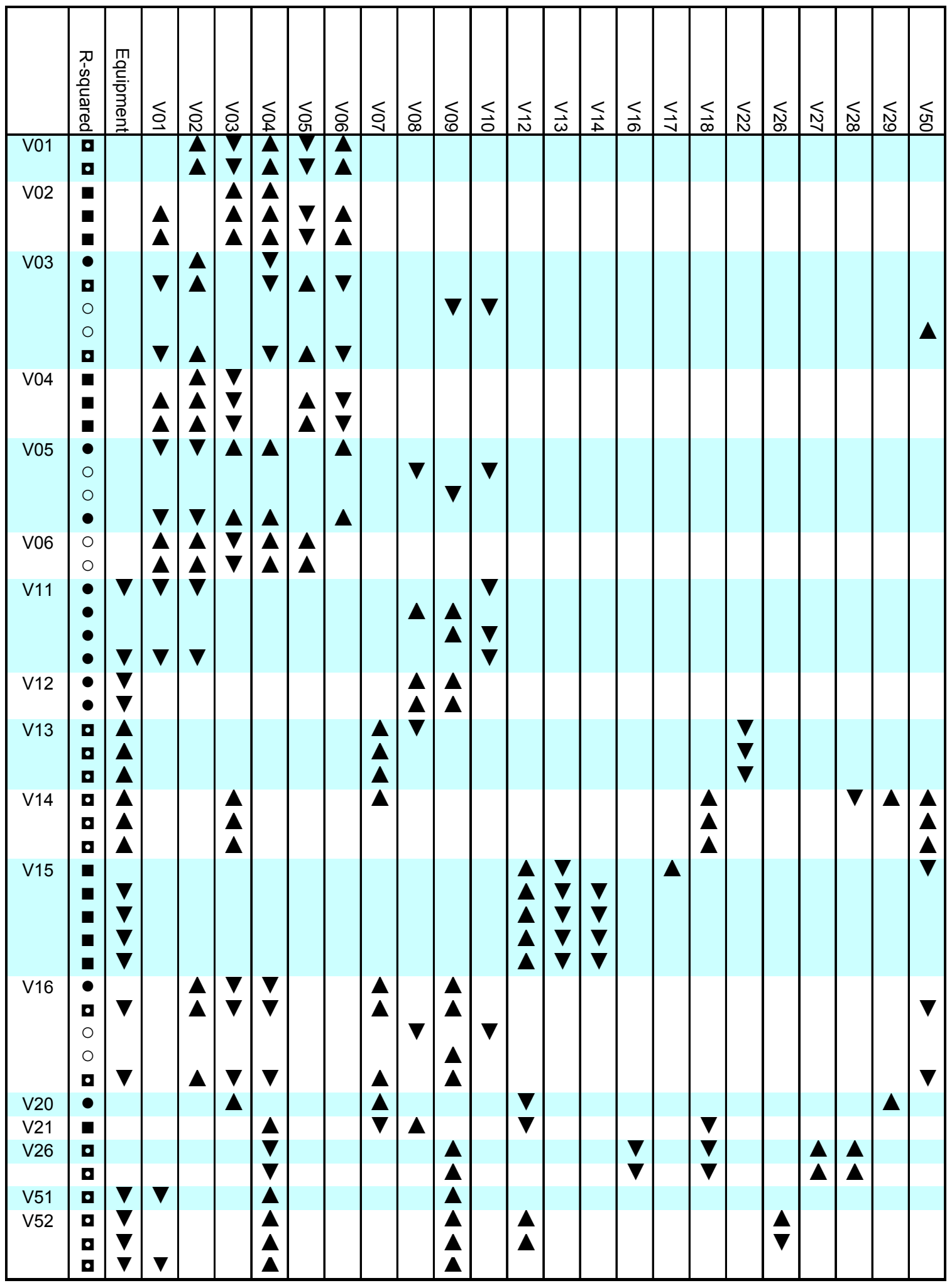




\section{Phase 3 version 1}

The general goal of this phase of analysis is to predict variables from one another, with special focus on (13) met rpt mag fe coarse and (14) met rpt mag fe fine. The difference between (11) and (12) is also somewhat of a mystery so efforts were made to predict that difference.

V11-V12 is predicted well (67\% R-sq) by V24, V02, V10 and V15.

Coarse tails MagFe is predicted fairly well (45\% R-sq) by four variables: V02, V07, V04, and V22.

Fine tails MagFe is predicted only partially (best R-sq is 28\%). Predictors change throughout the stepwise procedure indicating some complex relationships among the predictors: V01, V03, V07, V17 predict $18 \%$ of variance, but V01, V02, V07, and V11 predict 28\%.

Power draw is very well predicted by Rod Mill Feed, but this is no surprise - more material to process means more power draw. When the residuals from this regression are predicted, HIS (V07) is the most powerful predictor, but there are still apparent time trends.

V16 (concentrate mag Fe) prediction is trivial if concentrate silica is included, but leaving it out, $66 \%$ of the variation is predicted by V02, V03, V04, V17, V09, V26

Amine rate (V26) is predicted moderately well (R-sq=37\%) by V28, V10, V03, V19, V09, and V11.

\section{Phase 3 version 2}

This version of the analysis presents minor enhancements and corrections compared to the prior version.

\section{Phase 4 version 1}

This analysis consisted of a simple comparison with the time split in addition to equipment split. Total slate was defined as HIS+IBC. The +1 side of the split is consistently more variable and has larger fine tails than the -1 side, and that the experiment made results worse (as expected) in the +1 side of the split, but did not improve performance in the -1 side of the split (not expected).

\section{Phase 4 version 2}

In this analysis we discovered that, for the equipment getting the better input material, fine tails were generally unaffected by the experiment. For the equipment getting the more difficult input material, fine tails were significantly affected by the experiment. The equipment getting the more difficult input material ( +1 above) was also more variable that the other equipment set, whether during the experiment or not.

Coarse tails for both equipment lines were affected by the experiment: the equipment receiving the better material had lower coarse tails and the equipment getting the harder material had higher coarse tails. Predictions including total slate (HIS+IBC) were done for important responses.

For fine tails (as the response) stepwise regression led to the following model: 


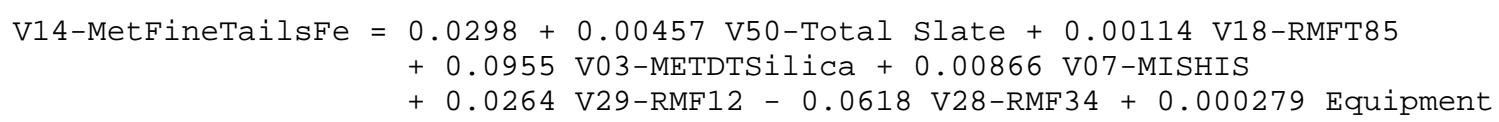

The stepwise procedure selected a variable set predicting $60 \%$ of the variation in fine V14 (fine tails Fe). (Note that the same procedure only predicted $25 \%$ of the variation in the response if the outliers were left in the data.) V50,18, 3, 7, 29, 28, and equipment were selected as predictors. The final regression confirmed this conclusion, and validated the assumptions necessary for valid tests and predictions. Note that a more parsimonious model is available: V50, V18, and V03.

The corresponding analysis for coarse tails prediction is shown below: $\begin{aligned} \text { V13-MetCoarseTailsFe }= & 0.0401+0.00163 \text { Equipment }-0.000029 \text { V22-RodMillFeedRate } \\ & +0.0119 \text { V07-MISHIS }-0.00461 \text { V08-MISIBC }\end{aligned}$

Prediction of coarse tails (V13) was attempted using the dataset with outliers (for fine tails) removed using the following candidate predictors: V1, 2, 4, 11, 7, 8, 9, 10, 28, 29, 3, 12, 17, 18, 19, 22, and equipment. These are variables determined before the processing step occurs. Equipment, V07, V22 and V08 were selected as predictors. The regression with only these variables confirmed that tests and predictions can be made validly.

We also investigated inter-relationships between V02, V03 and V04. This analysis was done on the dataset with the fine tails outliers removed. An additional observation was removed after it appeared as an outlier in the first of the regression analyses.

These variables are all positively correlated with one another. Regression analyses confirm this relationship. 85\% of the variation in V02 is accounted for by the other variables. Only V02 predicted V03, and it predicted 34\% of the variation in V03. Only V02 predicted V04, and with $84 \%$ of the variation accounted for.

Distributions of all variables and descriptive statistics were also generated.

\section{Phase 4 version 3}

This phase of work commenced with a grind analysis: predictive models for V15, V16, V20 and V21. The following variables were considered as candidate predictors for this set of analyses: Equipment, V1, V2, V4, V11, V7, V8, V9, V10, V28, V29, V3, V12, V18, V17, V19, V22, V13, V11 and V50 (total slate). Outliers (according to previous fine tails regressions) were removed before analysis.

For V15-MetMagFe, the equipment seemed to be the most important predictor, but when Experiment is added as a variable (because it was confounded with equipment) it seems that the observed variation in V15 may be mostly due to the experiment, but is not well-predicted by other variables.

For ConMagFe, Five variables predicted $49 \%$ of the variance in the response. Model assumptions seem to be satisfied. Significant predictors were V03-METDTSilica, V07-MISHIS, V09-MISLL34, V04-MisSilica and V02-StrendSilica. 
For ConcGrind, four variables (V07-MISHIS, V03-METDTSilica, V29-RMF12, V12MagFeRMF) predicted $44 \%$ of the variation.

For StrendFloatF, five variables were required to predict $30 \%$ of the variation: V12MagFeRMF, V07-MISHIS, V04-MisSilica, V18-RMFT85 and V08-MISIBC.

The next analysis was of power draw normalized by feed rate: V52NormPower=V27/V22. Predictor candidates included all other variables. 59\% of the variation is accounted for by a five-variable model including Equipment, V09-MISLL34,

V04-MisSilica, V12-MagFeRMF and V26-AmineRate.

Next was an analysis to predict amine rate (V26). Six variables predicted $55 \%$ of the variation in the response: V16-ConcMagFe, V09-MISLL34, V18-RMFT85, V04-MisSilica, V28-RMF34 and V27-MetPowerDraw.

V06 (float tails silica) has not been included in any analysis to date - even as a candidate predictor. This variable was created from col BL: Met Report Flotation Tails \% SiO2. V06 is highly correlated with other silica variables.

\section{Phase 4 version 4}

This phase of the analysis consisted of checking some prior results. In cases where updates or corrections are made, only the final results are reported in the summary at the beginning of this report. This document should be used rather than the prior one when reporting final results.

\section{Phase 4 version 5}

This phase of analysis consisted of further regression analyses and refinements of prior analyses. In particular:

V11-MisMagFe versus V08-MISIBC, V09-MISLL34

V03-METDTSilica versus V09-MISLL34, V10-MISLL12

V05-ConcSilica versus V08-MISIBC, V10-MISLL12

V16-ConcMagFe versus V08-MISIBC, V10-MISLL12

V11-MisMagFe versus V09-MISLL34, V10-MISLL12

V03-METDTSilica versus V50-Total Slate

V05-ConcSilica versus V09-MISLL34

V16-ConcMagFe versus V09-MISLL34

Some histograms missing from prior analyses were also supplied.

\section{Phase 5}

This phase of the analysis was directed at predicting V12 - MagFeRMF - using shiftspecific data and lagged variables. The results, summarized below, show that prediction is better during the time the experiment was run. This is not surprising, as incoming material quality was 
more controlled during this time. Prediction quality by equipment set was comparable regardless of whether the experiment was in progress or not.

Table 12. Result of Phase 5 statistical analysis.

\begin{tabular}{|c|c|c|c|c|c|c|c|c|}
\hline \multirow{2}{*}{$\begin{array}{l}\text { Exp. } \\
\text { No }\end{array}$} & \multicolumn{3}{|c|}{ Equipment set 1} & \multicolumn{5}{|c|}{ Equipment set 2} \\
\hline & $\begin{array}{l}\text { Predictor } \\
\text { Constant } \\
\text { V07-MISHIS } \\
\text { V04-MisSilica } \\
\text { E125V11-MisMagFe } \\
\text { E125V28-RMF34 } \\
\text { E25V01-MISAFactor } \\
\text { E25V10-MISLL12 } \\
\text { R-Sq }=45.4 \%\end{array}$ & $\begin{array}{r}\text { Coef } \\
-\odot .2136 \\
\odot .0006 \odot \\
\odot .005 \odot \\
1.3138 \\
0.1454 \\
\odot .009907 \\
-\odot .01977\end{array}$ & $\begin{array}{c}P \\
0.523 \\
0.968 \\
0.989 \\
0.026 \\
0.587 \\
0.324 \\
0.172\end{array}$ & $\begin{array}{l}\text { Predictor } \\
\text { Constant } \\
\text { V@7-MISHIS } \\
\text { V04-MisSilica } \\
\text { E125V11-MisMagFe } \\
\text { E125V28-RMF34 } \\
\text { E25V01-MISAFactor } \\
\text { E25V10-MISLL12 } \\
\text { R-Sq }=47.0 \%\end{array}$ & $\begin{array}{r}\text { Coef } \\
0.0360 \\
-0.04890 \\
0.2519 \\
1.3970 \\
-0.1300 \\
0.00755 \\
-0.01512\end{array}$ & $\begin{array}{r}\text { SE Coef } \\
0.2161 \\
0.01781 \\
\odot .3869 \\
0.5184 \\
0.2161 \\
0.01519 \\
0.01635\end{array}$ & $\begin{array}{r}\mathrm{T} \\
0.17 \\
-2.75 \\
0.65 \\
2.69 \\
-0.60 \\
0.50 \\
-0.92\end{array}$ & $\begin{array}{l}P \\
0.869 \\
0.010 \\
0.519 \\
0.011 \\
0.552 \\
0.622 \\
0.362\end{array}$ \\
\hline Yes & $\begin{array}{l}\text { Predictor } \\
\text { Constant } \\
\text { V07-MISHIS } \\
\text { V04-MisSilica } \\
\text { E125V11-MisMagFe } \\
\text { E125V28-RMF34 } \\
\text { E25V01-MISAFactor } \\
\text { E25V10-MISLL12 } \\
\text { R-Sq }=88.9 \%\end{array}$ & $\begin{array}{r}\text { Coef } \\
-1.0 .06 \\
-0.01664 \\
0.069 \\
1.377 \\
2.0109 \\
-0.00770 \\
-0.08996\end{array}$ & $\begin{array}{ll}\text { P } & \\
& \\
& 0.816 \\
& 0.961 \\
& 0.644 \\
& 0.103 \\
0.921 \\
0.078\end{array}$ & $\begin{array}{l}\text { Predictor } \\
\text { Constant } \\
\text { V07-MISHIS } \\
\text { V04-MisSilica } \\
\text { E125V11-MisMagFe } \\
\text { E125V28-RMF34 } \\
\text { E25V01-MISAFactor } \\
\text { E25V10-MISLL12 } \\
\text { R-Sq }=86.4 \%\end{array}$ & $\begin{array}{r}\text { Coef } \\
-0.405 \\
-0.00893 \\
-0.532 \\
3.069 \\
0.067 \\
-\odot .02112 \\
0.02439\end{array}$ & $\begin{array}{r}\text { SE Coef } \\
1.696 \\
0.03637 \\
1.034 \\
3.087 \\
1.982 \\
0.01712 \\
0.06859\end{array}$ & $\begin{array}{r}T \\
-0.24 \\
-0.25 \\
-0.51 \\
0.99 \\
0.03 \\
-1.23 \\
0.36\end{array}$ & $\begin{array}{l}P \\
0.827 \\
0.822 \\
0.642 \\
0.393 \\
0.975 \\
0.305 \\
0.746\end{array}$ \\
\hline
\end{tabular}




\section{Commercialization}

Commercialization was planned in two broad phases.

Phase I was focused on evaluating the use of three different data collection products in new ways, or to use their data in new ways. Fragmentation control using WipFrag was successful. WipWare image analysis system was used to measure the size distribution of the feed to the crushers and mills at Hibtac Mine. Adjustments were made to blasting and the effect of the adjustments on fragmentation and plant performance was so successful that use of the data is becoming part of standard mine planning practice. Specific energy calculated from drill performance data at Hibtac Mine was also successful and is being used in the same way.

An additional set of instruments - downhole geophysical sensors provided by Mount Sopris - and also drill performance data provided by Thunderbird Pacific were to be included in these evaluations at Minntac Mine as the project progressed. Unfortunately, it had not advanced beyond general discussions with mine personnel before the TOPIM project was terminated.

The goals of Phase I were:

- Use size analysis imaging system to optimize and control autogenous mill feed.

- Use drill performance monitoring to predict and control comminution energy and liberation.

- Use drill performance monitoring to increase concentrator efficiency.

- Use blasthole geophysics to predict comminution and concentrator performance.

Phase II was planned to develop a suite of measurement tools and methodologies to improve process performance, with the details depending on the results of Phase I. Both this and those parts of Phase I that could not be done would make excellent targets for new studies. The ever-increasing sophistication and capability of sensors of all types, including many never before used in mine environments (e.g., terahertz imaging), promise the potential of additional information. That potential must be checked so the useful approaches can be focused on.

The goals of Phase II were:

- New process control methods and protocol.

- First customers - host sites.

- TOPIM system provided to customer by industrial partners, and disseminated through publications and industry contacts.

All the industry partners, particularly in the area of support services, had expressed interest in expanding the applications for which their products could be used. 


\section{Dissemination and Outreach}

A number of papers were presented at various conferences as well as mine meetings.

- The TOPIM project is mentioned on these websites

- http://rockproducts.com/mag/rock_umr_research_looks/

- http://www.newswise.com/articles/view/501949/

- One technical paper was prepared for and two presentations were given at the SME Annual Meeting held in Salt Lake City, UT in 2005.

- Total Ore Processing Integration And Management: Improving Understanding and Control of the Entire Ore Process - presentation and paper

- Ore Characterization for Process Control: An Update of a Mesabi Range Project - presentation

- Mike Orobona of Hibtac Mine presented a paper at the regional technical meeting of the Duluth SME Chapter in April, 2005 (Orobona, M.J.T., L. Gertsch, J. Eloranta, R. Gertsch, K.P. Rancourt, and P.R. VanDelinder, "Modeling downstream mill performance with drill performance at Hibbing Taconite”).

- Mike Orobona of Hibtac Mine presented a paper at the Society of Economic Geologists’ 2006 Conference, held in Keystone, Colorado on 14-16 May 2006. (M. J. T. Orobona, L. Gertsch, and J. W. Eloranta, "Exploring the Data - Adding Value with Non-traditional Geologic Initiatives on Minnesota’s Mesabi Range”).

- A large number of internal reports were generated, for example:

- Peter VanDelinder, Jack Eloranta, and Michael Orobona, "Blasting for Improved Autogenous Milling at Hibbing Taconite Company,” February 2004. 


\section{Conclusions}

The systems approach taken by the TOPIM project team to optimize the system rather than just each individual step should be a standard method used to improve the cost-effectiveness of any industrial undertaking. Some key points:

- Add value, not reduce costs (can blasting get any cheaper?).

- Test a specific hypothesis (if $X$ occurs, then $Y$ happens).

- Make one change and see what happens.

- One measurement is worth 1,000 opinions.

- Negative results count.

- There are no magic bullets.

- Increase understanding, then increase control.

Improve data precision. Older measurement methods were sometimes cruder than methods available today, and it is much easier now to calculate precise values for different situations than it once was. Just because something has always been done a certain way is not necessarily a good reason it must continue to be done that way. For example, as Hibtac Mine discovered (Orobona et al., 2006),

Proper tonnage factors ... improve blast pattern loading, reconciliation, and reduce the discount between predicted and actual weight recovery. Royalties paid on a per-modeled ton basis ... [are] reduced for leaner ore blasts. The cost of the testing program was a few weeks' time of a summer intern.

Inter-mine data sharing, both within companies and between companies, must increase. While it is not easy to estimate the near-term cost of confidential data becoming known to competitors, it is much more difficult to quantify the cost of opportunities lost and steps retraced by engineers unaware of the findings of others dealing with the same problems. Difficulty calculating something does not mean that it is negligible. On the contrary, over time this cost is likely to be very substantial. Secrecy slows down the entire industry.

Inter-region and inter-commodity data sharing with iron mines in other ranges, and with other metal and non-metal mines. Many of the issues and/or their solutions are common to other ores, other locations, even other industries. The "not invented here" philosophy is a handicap.

Software communication issues became a problem that is slowly improving. Many of the programs used by mines and mills for process control and data acquisition interact poorly. This makes it difficult for engineering managers to access the information they need to make decisions in a timely manner. Some parts of the TOPIM project could not be completed due to data format problems. For example, attempts to include data from blasthole drill performance monitors into the orebody model remain a recommendation for future work at Minntac Mine. Determining shovel locations foundered on an even simpler problem: incompletely archived records. Information technology incompatibilities have been major hurdles to enhancing the flow of information from exploration to mining to processing on a real-time basis. 


\section{Useful Future Work}

The effort begun before this project was funded by the DOE must not end with this report. The increasing difficulty of iron extraction, as with other mineral products, mandates more efficient use of information throughout the process stream, starting with data collected during prospecting and exploration. Seamless integration of all data, from all steps of mineral production, is the key.

Any one of these studies, individually or combined, could benefit mines in the Mesabi Range and elsewhere:

- Use grindability/liberation index more effectively in mine planning and dispatching.

- Measure only the rock properties that most control fragmentation and milling - a few well-targeted parameters are more effective than a scattered, over-measured approach.

- Adjust powder factor to bench conditions.

- Incorporate all these in orebody and mine models.

- Monitor drill performance - real-time updating of models.

- Use better statistical analysis methods - available and useful. 


\section{References Cited}

Bond, F.C., 1952, The third theory of comminution: American Institute of Mining Engineers Transactions, v. 193, p. 484-494.

Cleveland Cliffs Inc., 2004. "Mining Operations and Technology," available online at http://www.cleveland-cliffs.com/mining/hibbing/ (accessed 30 Jan 2007).

Eloranta, Jack and Lyle Workman, 2003. Review of blasting and shovel loading practice at Hibtac Mine.

Energy Information Administration, Office of Energy Markets and End Use, Energy Consumption Division, Form EIA-846, '2002 Manufacturing Energy Consumption Survey,' and Office of Oil and Gas, Petroleum Supply Division, Form EIA-810, 'Monthly Refinery Report' for 2002, accessed 29 January 2007 at www.eia.doe.gov/emeu/mecs/ mecs2002/data02/excel/table10.1_02.xls.

Lipton, I.T., 2000, Modeling bulk density — The importance of getting it right: Australasian Institute of Mining and Metallurgy, 4th International Mining Geology Conference, Coolum, Queensland, Australia, Proceedings, p. 291-297.

Orobona et al., 2006, "Exploring the Data - Adding Value with Non-traditional Geologic Initiatives on Minnesota’s Mesabi Range,” SEG Annual Meeting, May 14 - 16, Keystone, CO.

Parrish, I.S., 1993, Tonnage factor - a matter of some gravity: Mining Engineering, v. 45, p. 1268-1271.

Teale, R., 1965, The concept of specific energy in rock drilling: International Journal of Rock Mechanics and Mining Science, v. 2, p. 57-73.

Thompson, D., 1999, Modern drilling and blasting technology at the Minntac mine: Blasting Analysis International, Inc., $1^{\text {st }}$ International Surface Blasting Conference, Duluth, Minnesota, Proceedings, p. 77-96.

U.S. Department of Energy, 2001. available online at http://www1.eere.energy.gov/industry/ program_areas/industries.html (accessed November 2006).

U.S. Geological Survey, 2005. "Iron ore statistics,” in Kelly, T.D., and Matos, G.R., comps., Historical statistics for mineral and material commodities in the United States: U.S Geological Survey Data Series 140, available online at http://pubs.usgs.gov/ds/2005/140/. (accessed 29 January 2007.)

U.S. Geological Survey, 2007. Mineral Commodity Summaries, Iron Ore, January 2007, available online at http://minerals.usgs.gov/minerals/pubs/commodity/iron_ore/index. html\#mcs (accessed 29 January 2007).

U.S. Geological Survey, 2002 and 2004. Minerals Yearbook commodity survey, available online at

http://minerals.usgs.gov/minerals/pubs/commodity/statistical_summary/index.html\#myb (accessed 29 January 2007).

U.S. National Academies of Sciences and Engineering, 2005. Decreasing Energy Intensity in Manufacturing: Assessing the Strategies and Future Directions of the Industrial 
Technologies Program, National Academies Board on Manufacturing and Engineering Design, available online at http://books.nap.edu/openbook.php?record_id=11243\& page $=1$ (accessed December 2006).

Yin, K.T. and H.T. Liu, 2001. Using Information Extracted From Drill Data to Improve Blasting Design and Fragmentation. Fragblast - The Int'l J for Blasting and Fragmentation, Vol 5, No. 3 / Sept 2001, pp 157-179.

Vynne, J., 1999, Drill monitoring developments and the utilization of the drill data: Blasting Analysis International, Inc., ${ }^{\text {st }}$ International Surface Blasting Conference, Duluth, Minnesota, Proceedings, p. 185-196. 


\section{Appendix: Grindability}

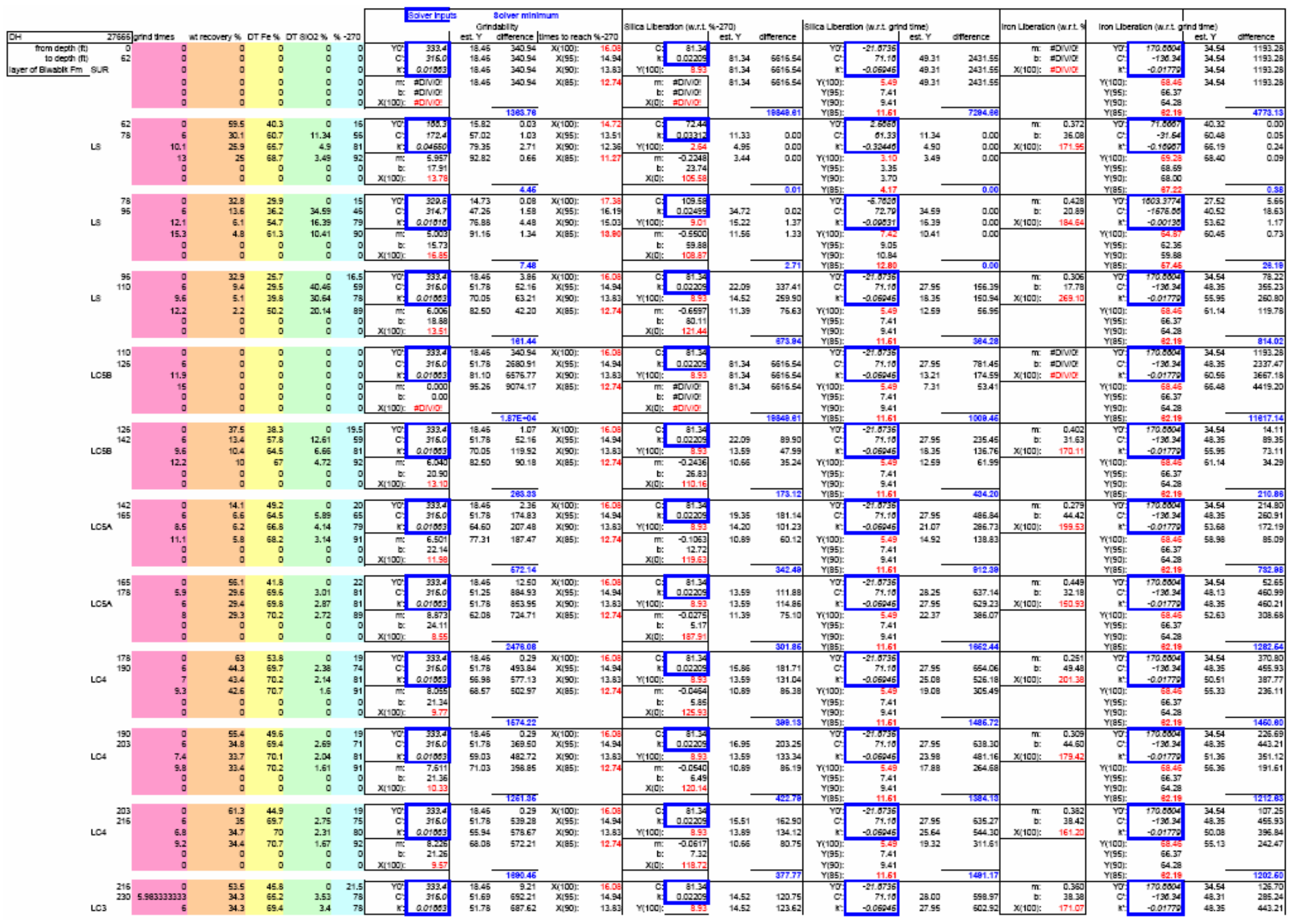




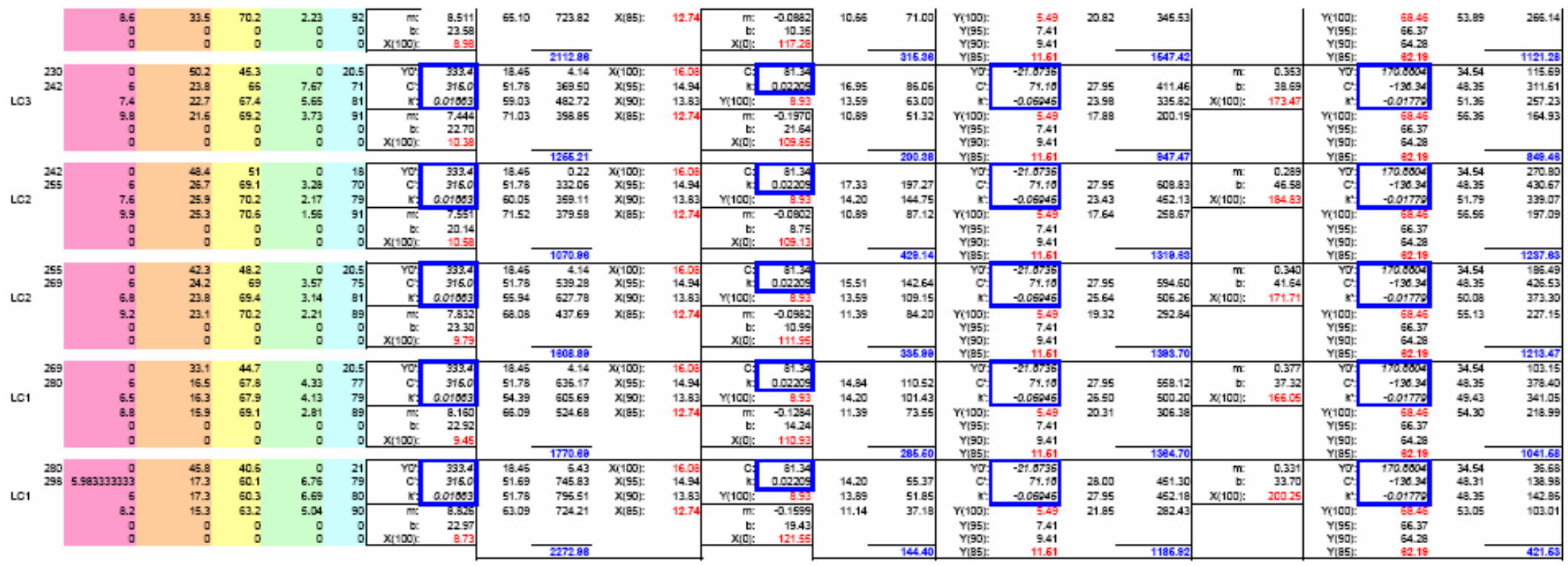

The preceeding table is an example of the calculations used to produce the figures shown in the section discussing the grindability study. The calculations consist of a series of iterative regression curve-fits - linear and various exponential - recorded by their curve equation constants and several points of particular interest on the curves.

The following table is a typical summary of these grindability calculation constants for some of the exploration holes associated with a particular blast at Minntac Mine.

\begin{tabular}{|c|c|c|c|c|c|c|c|c|c|c|c|c|c|c|c|c|c|c|c|c|c|c|}
\hline & & & & & & คnes-IIme & fnes-time & & nes-9me fines-tlne & & & & & & & & silcarline silca- & & & | Iron- & & \\
\hline DDHA & easting & northing & elev layer & $\operatorname{from}(\mathrm{t})$ & to (7) & \begin{tabular}{|l|l|} 
slope \\
\end{tabular} & Intercept & & & slope & Intercept & & & slope & Intercept & & $k \quad r$ & slo & Interc & & & \\
\hline & $\begin{array}{l}-12010 \\
-10010\end{array}$ & -3012 & 963 LS & & & 4.96074 & 20.77 & 186.27 & $\begin{array}{lll}168.67 & 0.039494\end{array}$ & $\begin{array}{l}-0.373757 \\
\end{array}$ & 44.48 & 61.91 & & -1.764086 & & -21.83555 & & & & 147.25 & & \\
\hline 17000 & $\begin{array}{l}-12010 \\
+10010\end{array}$ & -3012 & 963 LS & 107 & 121 & 4.96074 & 20.77 & 186.27 & $\begin{array}{lll}168.67 & 0.039494\end{array}$ & $\begin{array}{l}-0.373757 \\
373756\end{array}$ & $\begin{array}{r}42.85 \\
5.35\end{array}$ & & & & & & $60.25-0.043178$ & 0.332287 & 34.06 & 145.50 & -10605 & \\
\hline 17000 & $\begin{array}{l}-12010 \\
-12010 \\
-12010\end{array}$ & $\begin{array}{r}-3012 \\
-3012 \\
\end{array}$ & $\begin{array}{l}9633 \mathrm{LS} \\
963 \mathrm{CSB}\end{array}$ & ${ }_{123}^{121}$ & $\begin{array}{l}123 \\
142\end{array}$ & $\begin{array}{l}4.960072 \\
5571037\end{array}$ & $\begin{array}{l}20.77 \\
21.85 \\
\end{array}$ & $\begin{array}{l}186.27 \\
174.53\end{array}$ & $\begin{array}{l}168.6780 .039994 \\
15627\end{array}$ & & $\begin{array}{l}25.35 \\
2705\end{array}$ & & $\begin{array}{l}0.01768 \\
0.02589\end{array}$ & & & & $\begin{array}{r}6025-0.043183 \\
2728-0.124865\end{array}$ & 0.332287 & $\begin{array}{l}3216 \\
3230\end{array}$ & 144.31 & & \\
\hline 17000 & $\begin{array}{l}-1221016 \\
-12010\end{array}$ & $\begin{array}{r}-3012 \\
-3012\end{array}$ & $963 \angle C 5 A$ & $\begin{array}{l}723 \\
142 \\
142\end{array}$ & $\begin{array}{l}122 \\
160\end{array}$ & $\begin{array}{l}2.7151037 \\
6.16544\end{array}$ & ${ }_{2395}^{21.105}$ & $\begin{array}{l}174.03 \\
162.03\end{array}$ & $\begin{array}{lll}1462.19 & 0.062198\end{array}$ & $\begin{array}{l}-0.239699 \\
-0.300322\end{array}$ & ${ }_{3171}^{27.06}$ & $\begin{array}{l}45.20 \\
68.79\end{array}$ & 0.0225865 & -1.2600564 & $\begin{array}{l}20.74 \\
2281\end{array}$ & $\begin{array}{l}2.940450 \\
3.00902\end{array}$ & $3825-0.262732$ & 0.037016 & 34.32 & 73.460 & -3360 & 02185 \\
\hline 17000 & $\begin{array}{l}-12010 \\
-12010\end{array}$ & -3012 & 3 LC4 & 160 & & $\begin{array}{l}0.0502667 \\
6.0027\end{array}$ & 25.13 & $\begin{array}{l}702.05 \\
165.59 \\
\end{array}$ & $145.18 \quad 0.058074$ & & 22.26 & $\begin{array}{l}80.99 \\
40.96\end{array}$ & & & 16.30 & & $25.40-0.279456$ & & $\begin{array}{l}34.69 \\
38.69\end{array}$ & & & \\
\hline 17000 & -12010 & -3012 & 9 & 177 & & 6.002 & 25.13 & 165. & & & 19. & & & & 13.98 & & $25.40=0$ & & 40.29 & 71 & & \\
\hline 17000 & -12010 & -3012 & 9 & 200 & & 5.432 & & $18:$ & 10. & & & & & & 20.46 & & $1-0.1$ & & & & & \\
\hline 177000 & $\begin{array}{l}-12010 \\
-12010\end{array}$ & $\begin{array}{r}-3012 \\
-3012 \\
-3012\end{array}$ & $\begin{array}{l}963 \mathrm{LC} 2 \\
963\left\llcorner C_{2}\right.\end{array}$ & $\begin{array}{l}247 \\
257\end{array}$ & 257 & & $\begin{array}{l}24.92 \\
2492\end{array}$ & $\begin{array}{l}150.96 \\
150.95\end{array}$ & $\begin{array}{r}130.53 \\
130.0720\end{array}$ & & $\begin{array}{l}27.42 \\
27.52\end{array}$ & $\begin{array}{l}87.17 \\
85.81\end{array}$ & & & 18 & $\begin{array}{l}4-0.750722 \\
-0.550935 \\
4\end{array}$ & $\begin{array}{l}681 \\
677\end{array}$ & & 38.81 & $\begin{array}{l}71.96 \\
77.49\end{array}$ & & 87224 \\
\hline & $\begin{array}{l}-12010 \\
-12010 \\
-12010\end{array}$ & $\begin{array}{l}-3012 \\
-3012 \\
\end{array}$ & $963 \mathrm{LC2}^{9}$ & & & & $\begin{array}{l}249.98 \\
2492\end{array}$ & & $13053 \quad 0.072016$ & $\begin{array}{l}-0.265335 \\
-028535\end{array}$ & & $\begin{array}{l}65.81 \\
76.48\end{array}$ & 0.0374175 & $\begin{array}{l}-1.57805 \\
-1.57805\end{array}$ & $\begin{array}{l}18.54 \\
19.39\end{array}$ & & $\begin{array}{l}6-0.231677 \\
6-0.231678\end{array}$ & & $\begin{array}{l}39.31 \\
39.31 \\
31\end{array}$ & $\begin{array}{l}72.49 \\
7148\end{array}$ & & \\
\hline 17000 & $\begin{array}{l}-12010 \\
-12010\end{array}$ & -3012 & 963 LC1 & 291 & 318 & 6.093187 & 23.78 & $\begin{array}{l}154.80 \\
154.80\end{array}$ & $135.38 \quad 0.066135$ & $\begin{array}{l}-0.2836955 \\
-0.2865\end{array}$ & 28.71 & $\begin{array}{l}76.460 \\
76.21\end{array}$ & 0.034168 & $\begin{array}{l}-1.5756539 \\
-1.55769\end{array}$ & $\begin{array}{l}20.05 \\
20.05\end{array}$ & 0.865583 & $34.62-0.241321$ & 0.36697 & 34.91 & 71.66 & $\begin{array}{l}-26.32 \\
-31.74\end{array}$ & $4-0.168287$ \\
\hline
\end{tabular}




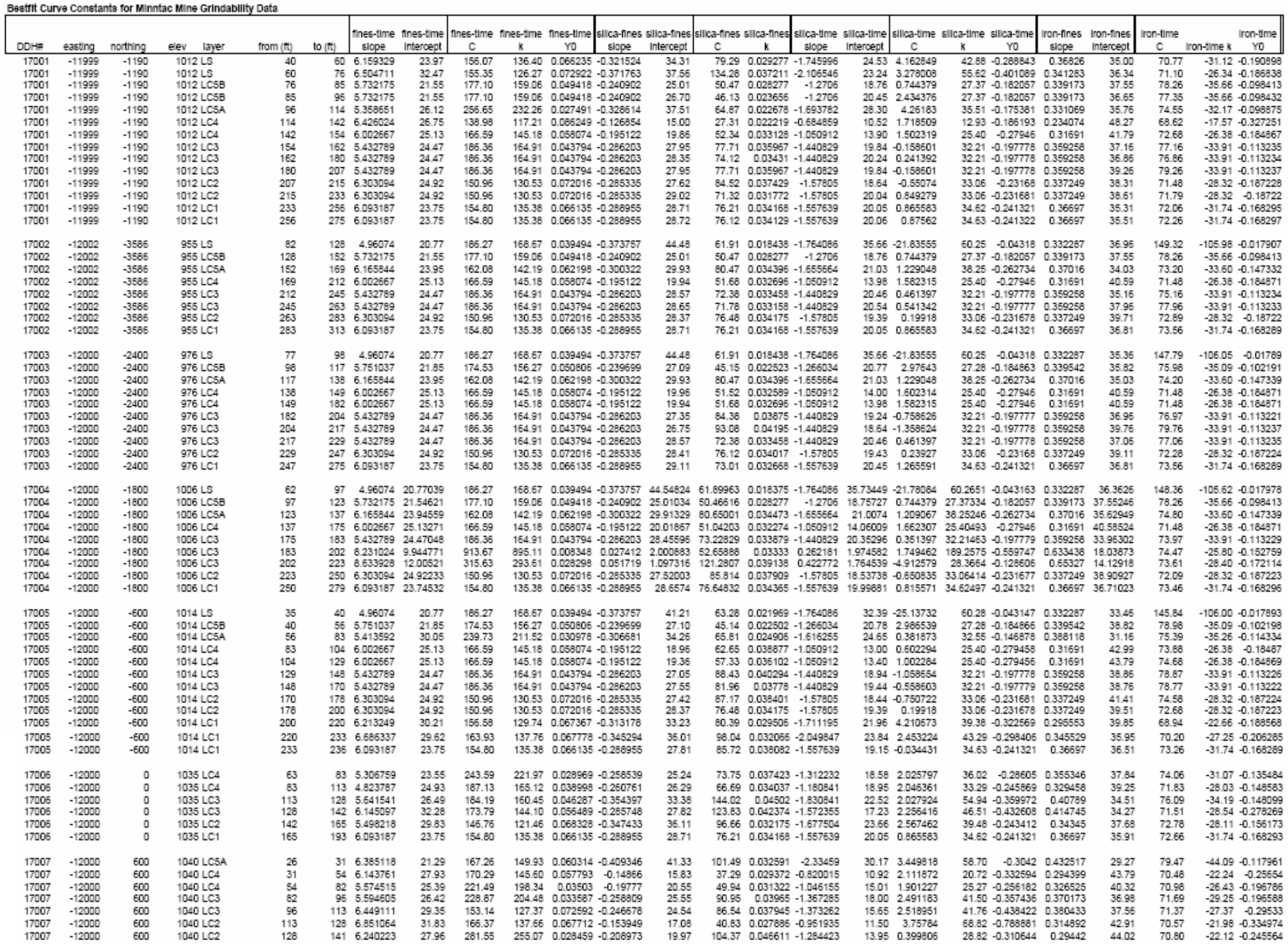




\section{Appendix: Rock Physical Properties}

Point-Load Measurement Statistical Summary, Including Data from Borehole 409:
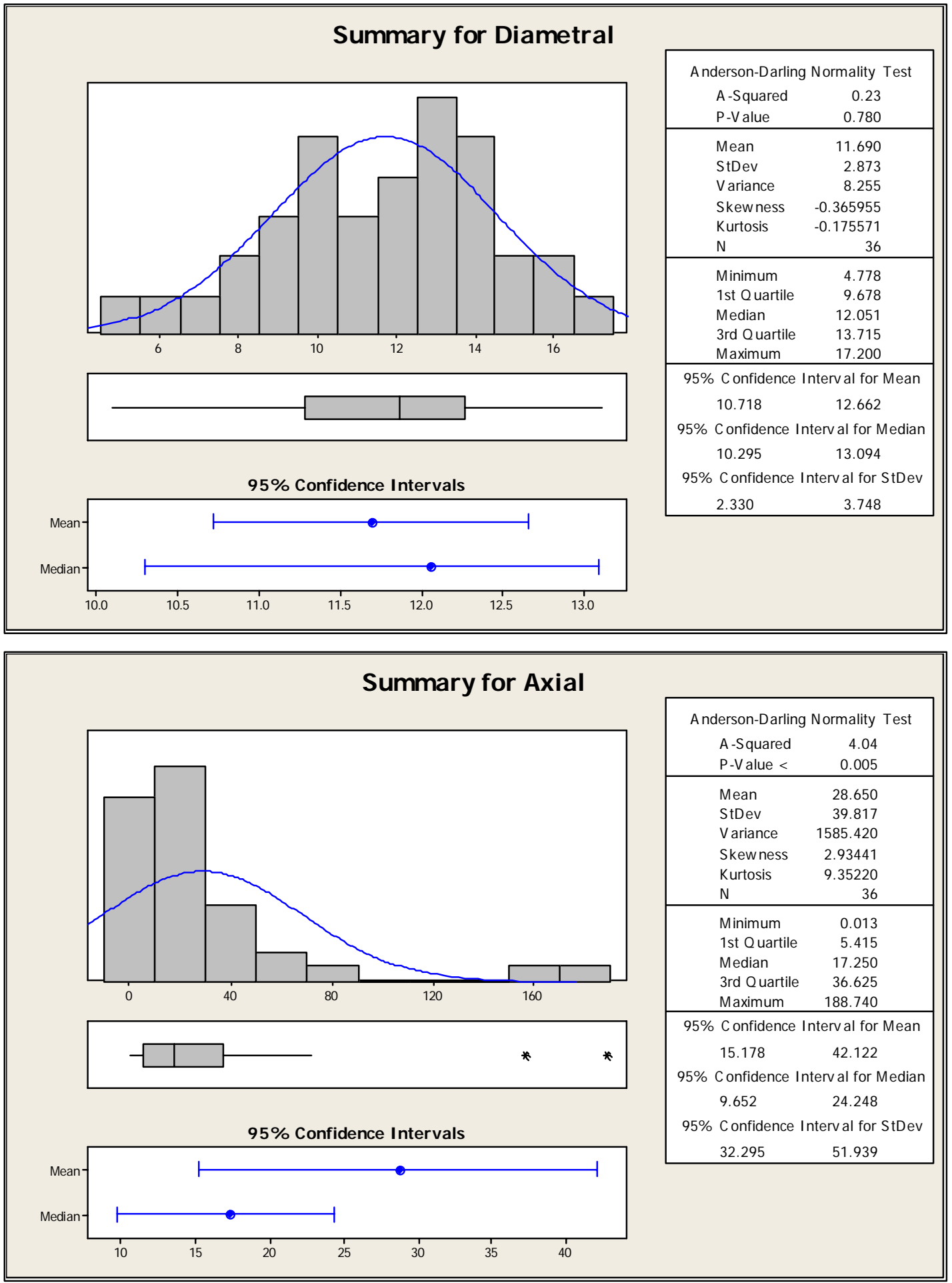


\section{Appendix: Vertical Variation in Drilling Properties for Blast 02136}

The following charts are organized in groups according to the parameter being charted. Within each group the charts progress from the surface to the maximum depth drilled, in increments of $5 \mathrm{ft}$.

\section{Specific Energy of Drilling}

Pattern 02136, Specific Energy, Surface to $5 \mathrm{ft}$ Depth (approximate borehole locations)

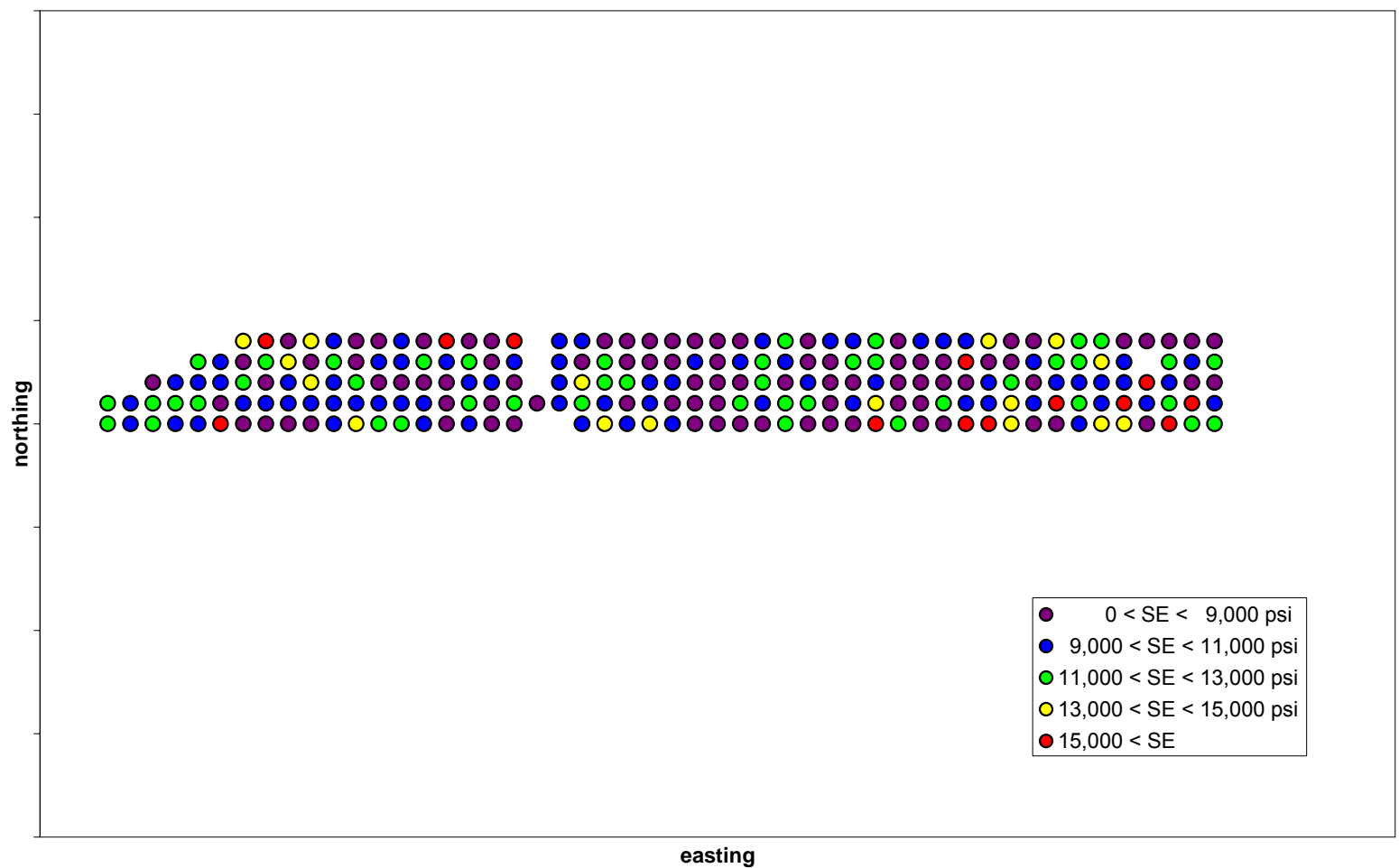


Pattern 02136, Specific Energy, 5 to $10 \mathrm{ft}$ Depth (approximate borehole locations)

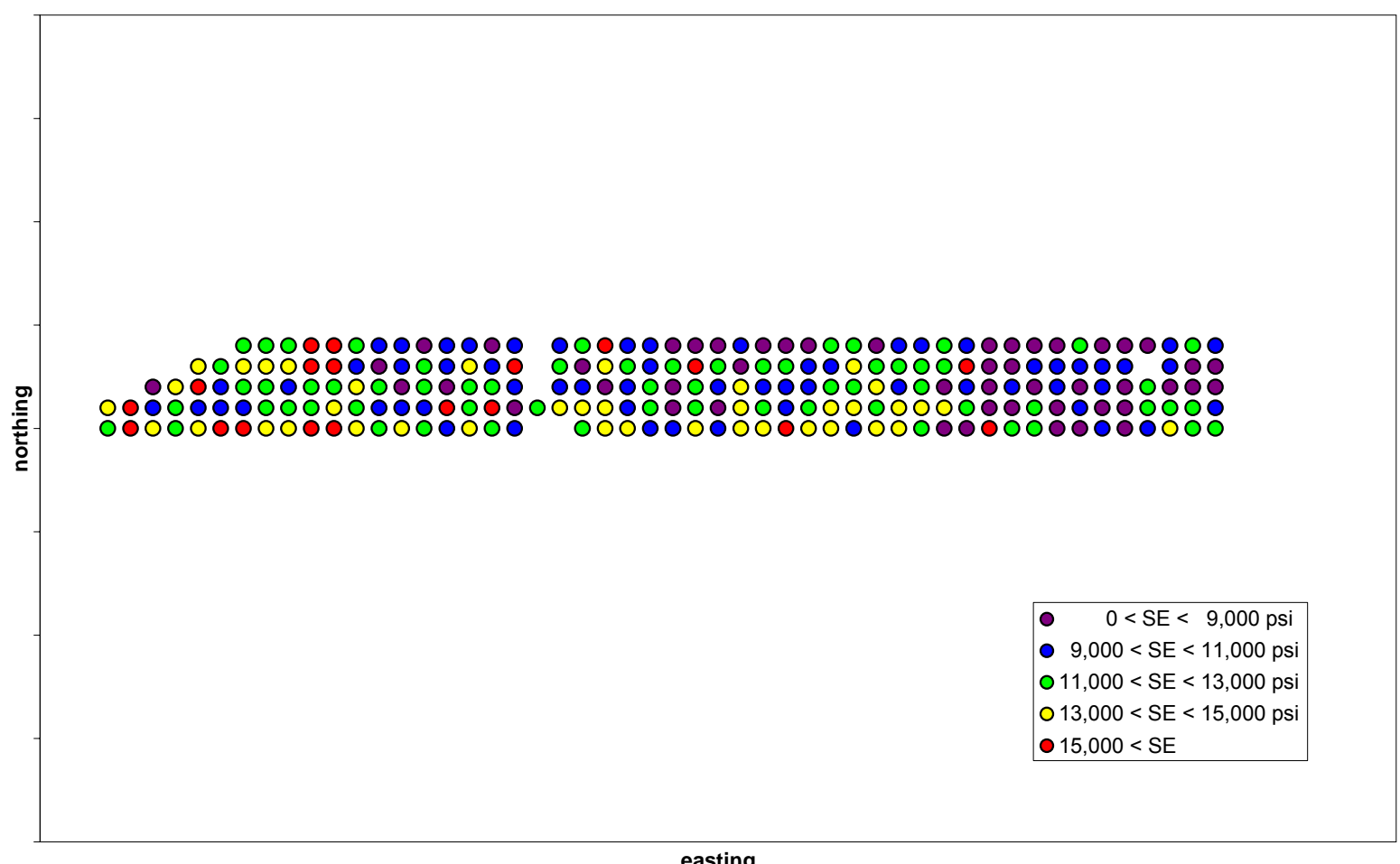

easting

Pattern 02136, Specific Energy, 10 to $15 \mathrm{ft}$ Depth (approximate borehole locations)

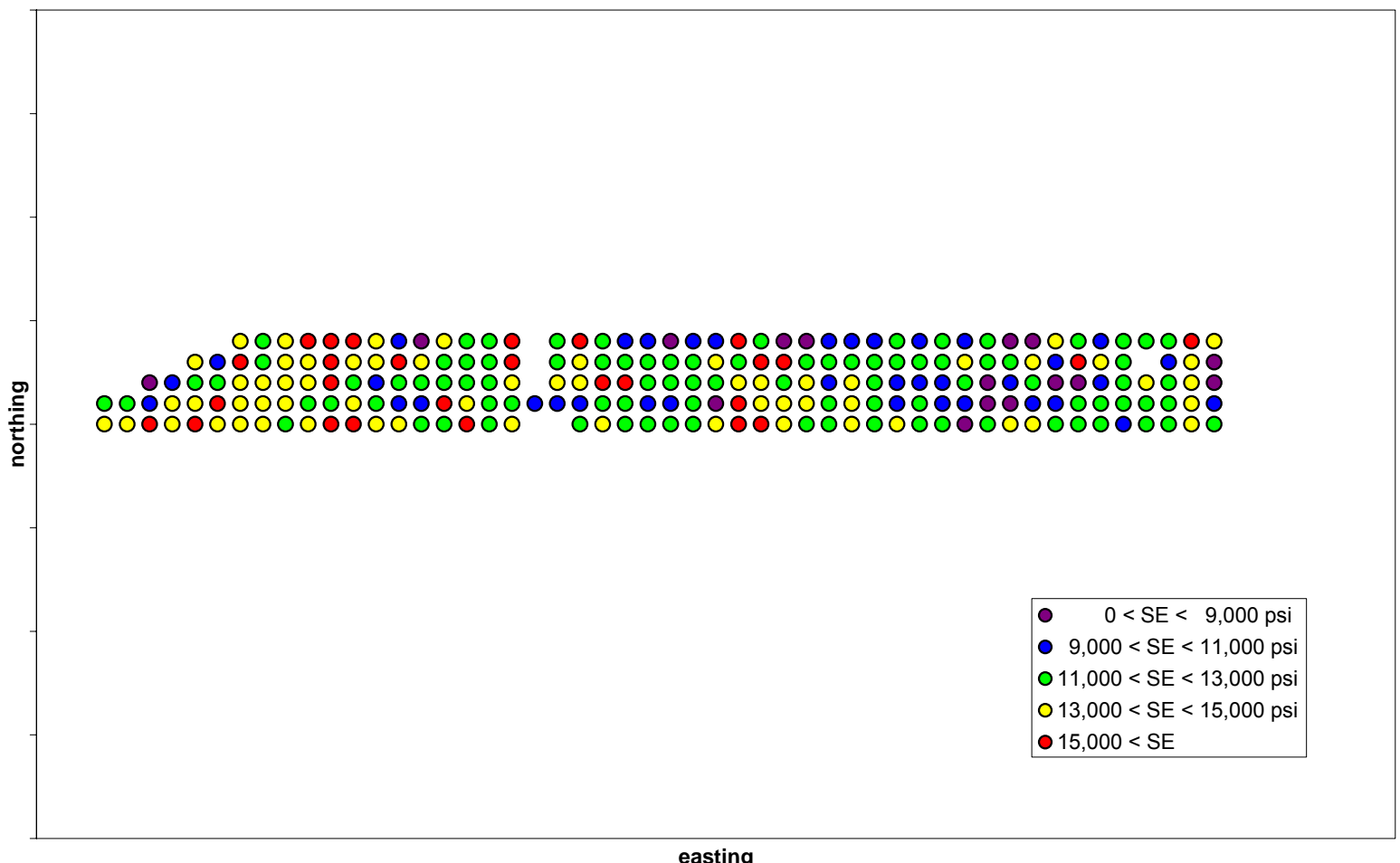

easting 
Pattern 02136, Specific Energy, 15 to $20 \mathrm{ft}$ Depth (approximate borehole locations)

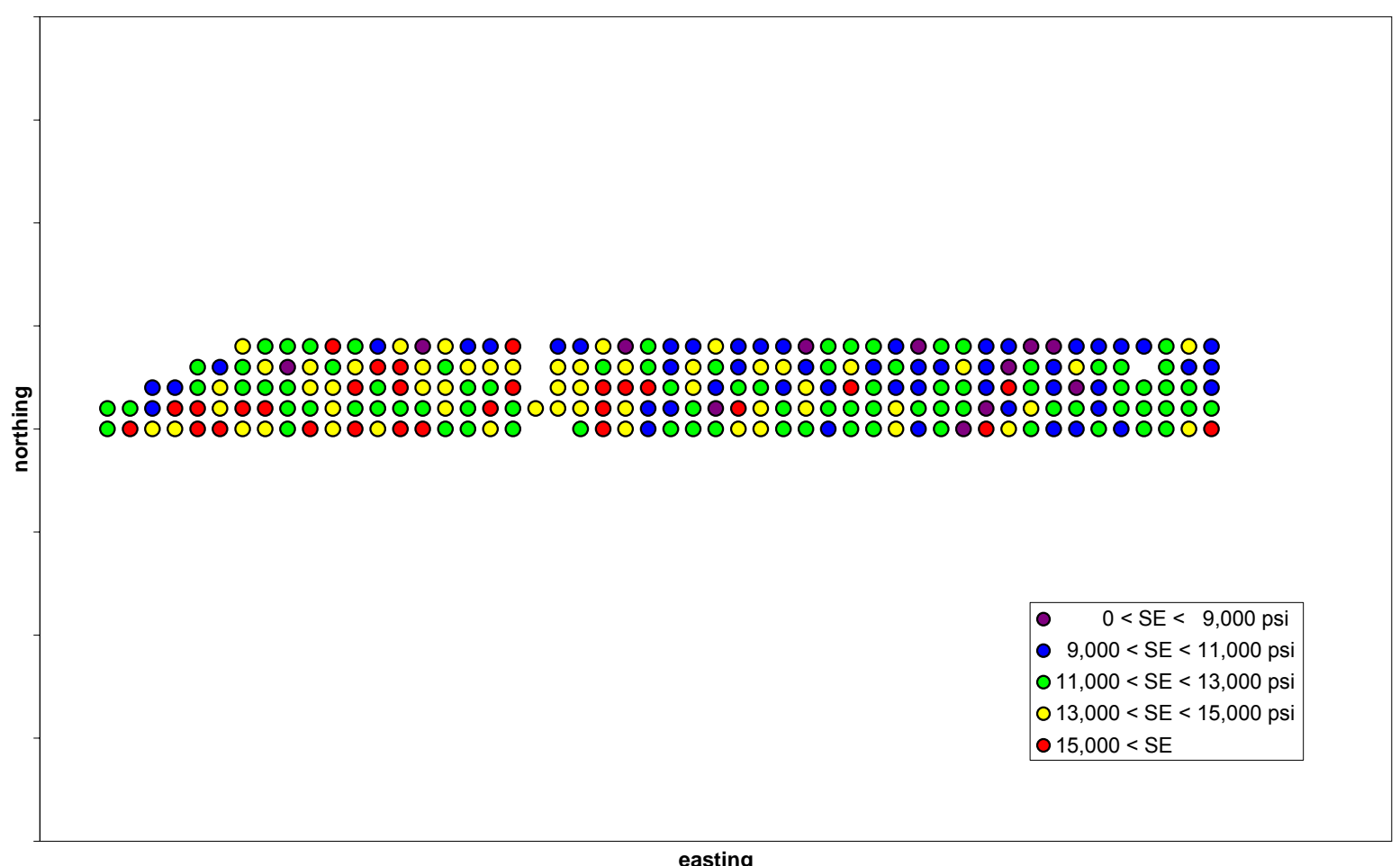

easting

Pattern 02136, Specific Energy, 20 to $25 \mathrm{ft}$ Depth (approximate borehole locations)

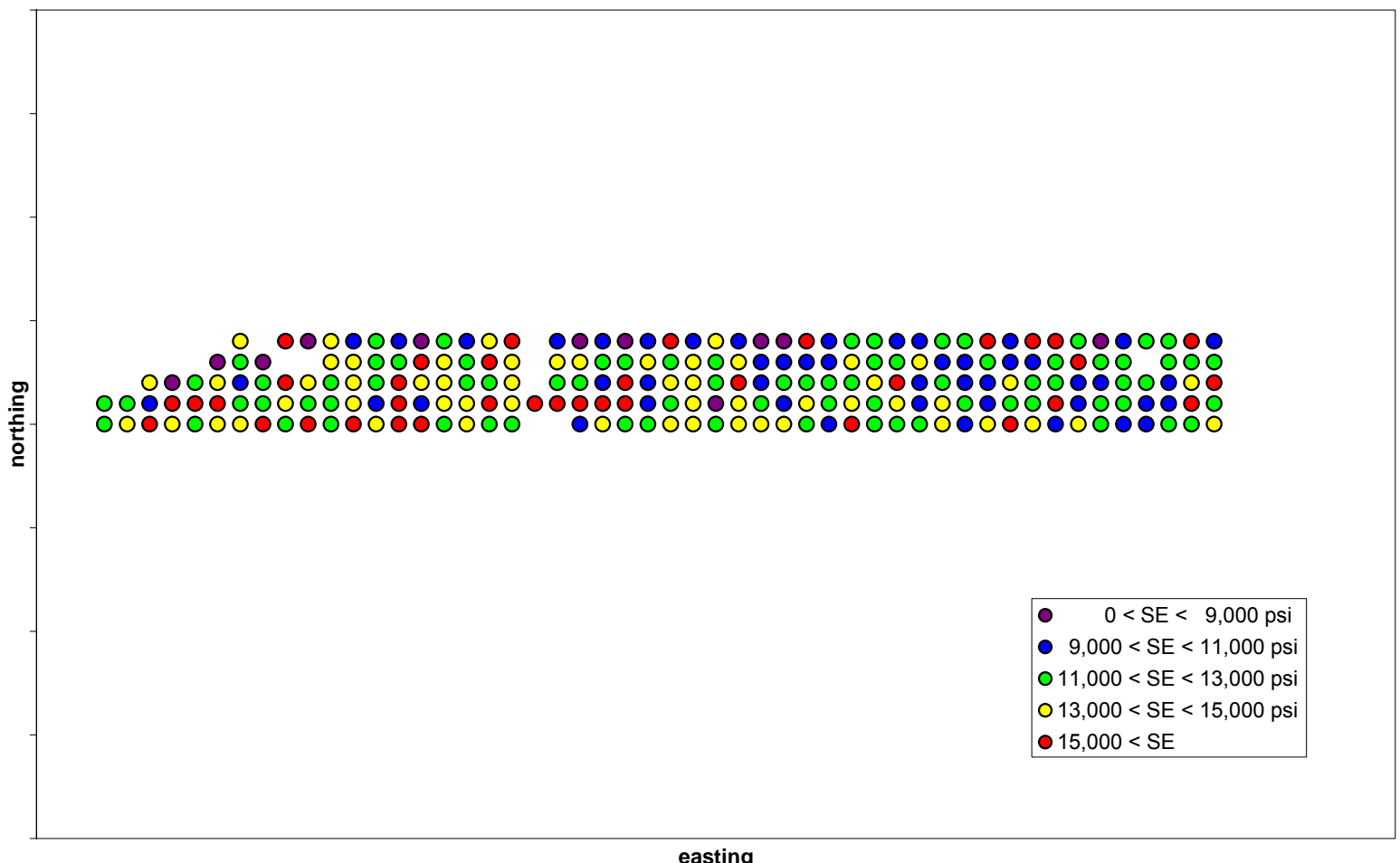

easting 
Pattern 02136, Specific Energy, 25 to $30 \mathrm{ft}$ Depth (approximate borehole locations)

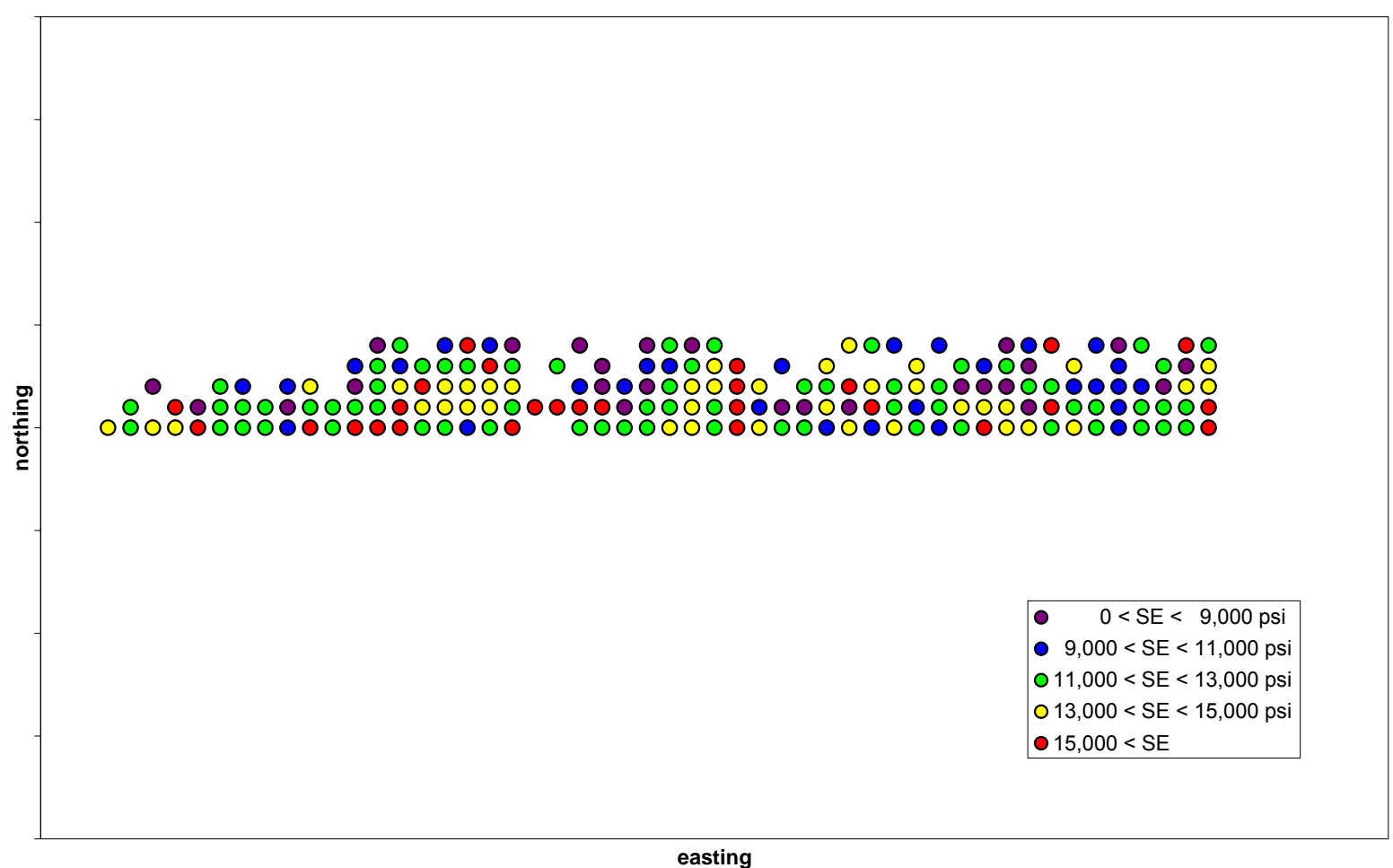

\section{Rock Quality}

Pattern 02136, Rock Quality, Surface to $5 \mathrm{ft}$ Depth (approximate borehole locations)

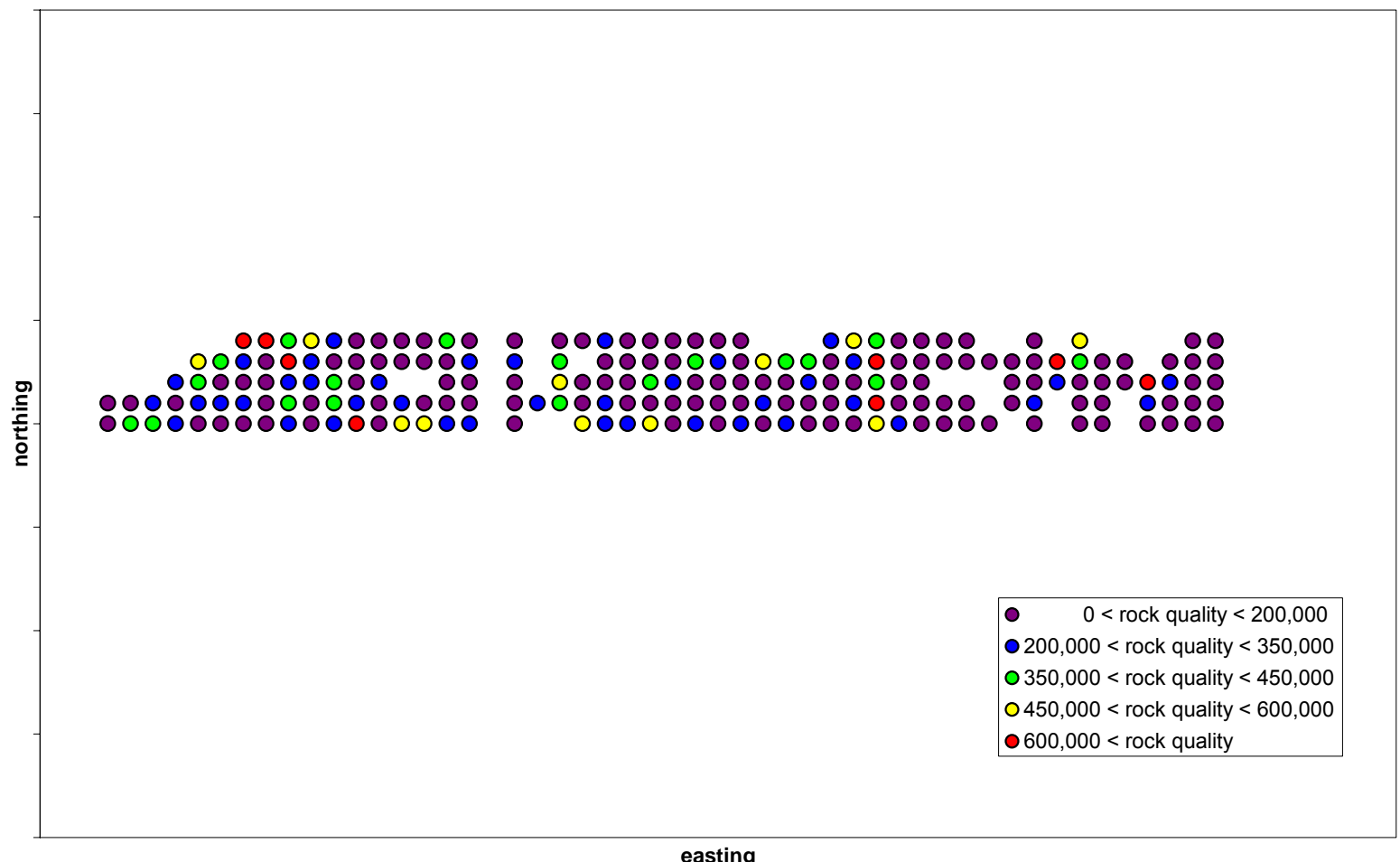


Pattern 02136, Rock Quality, 5 to $10 \mathrm{ft}$ Depth (approximate borehole locations)

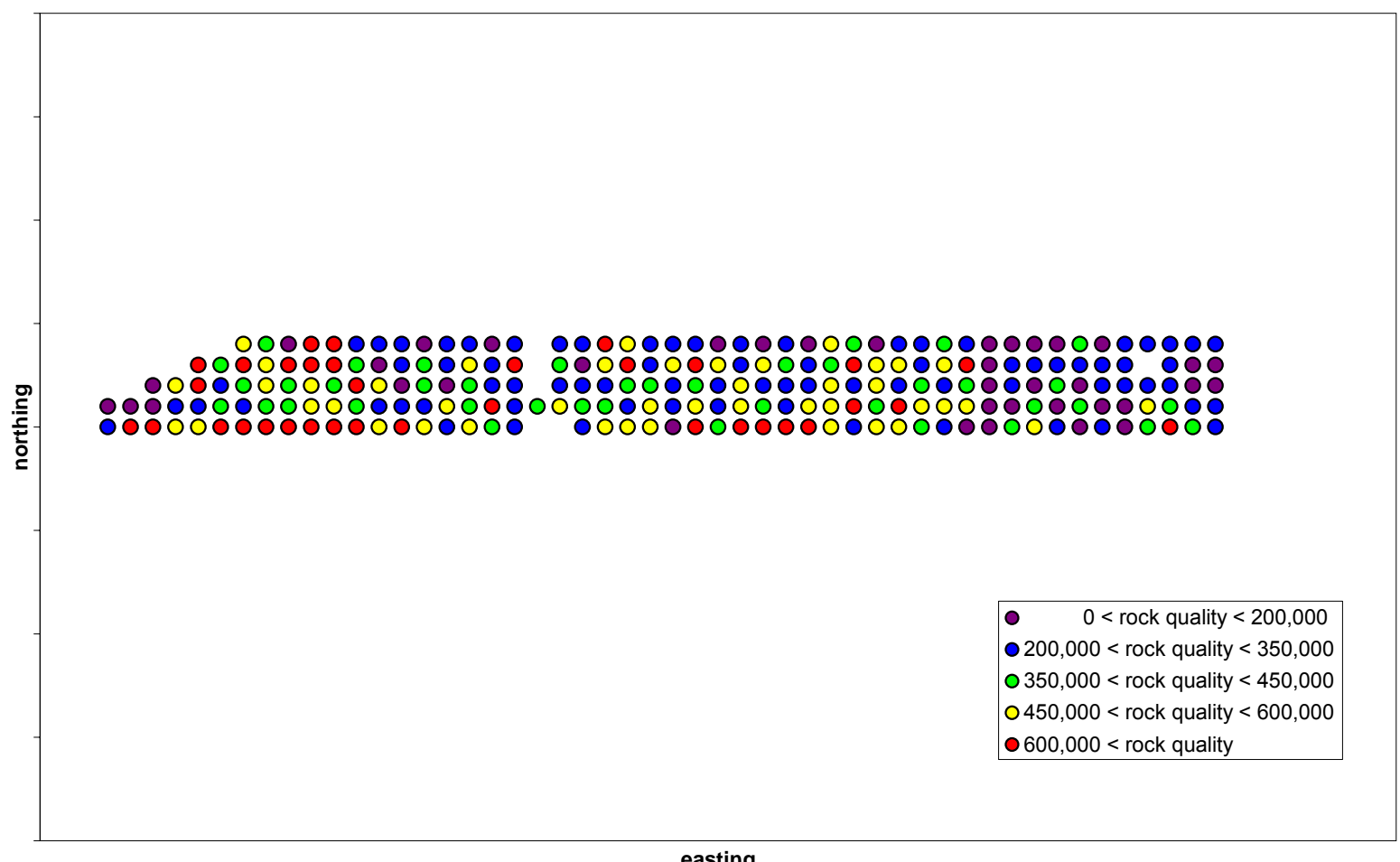

easting

Pattern 02136, Rock Quality, 10 to $15 \mathrm{ft}$ Depth (approximate borehole locations)

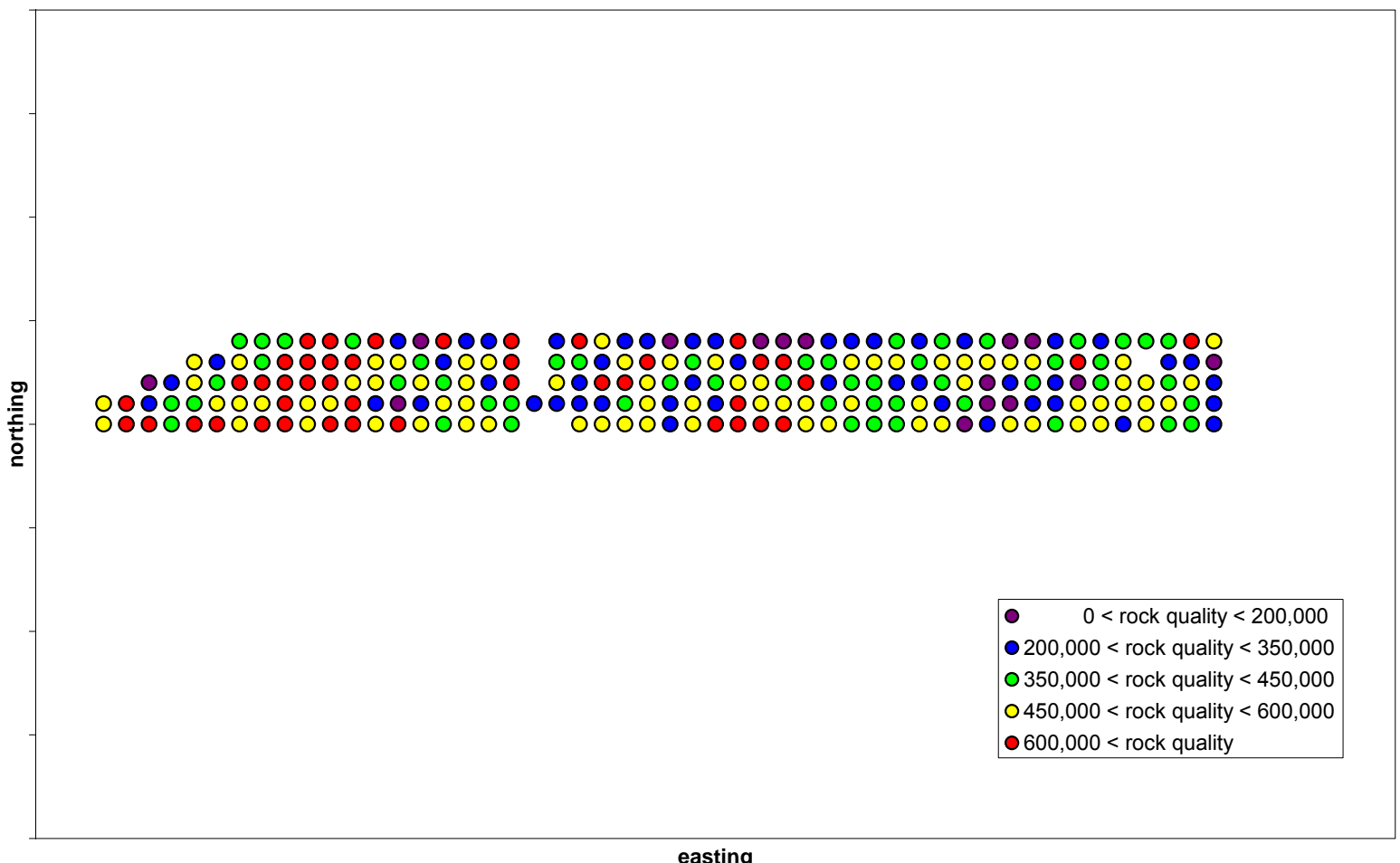

easting 
Pattern 02136, Rock Quality, 15 to $20 \mathrm{ft}$ Depth (approximate borehole locations)

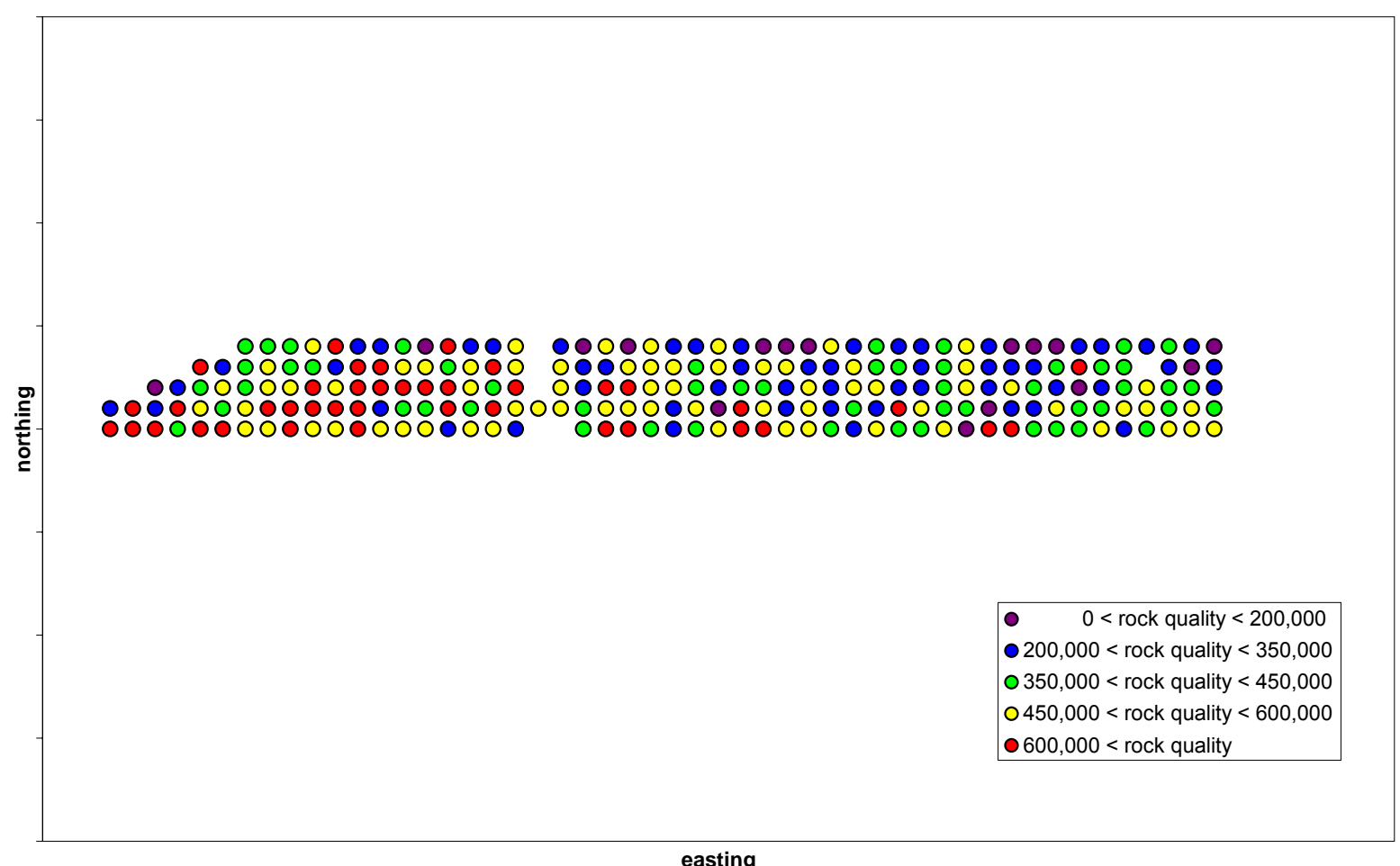

easting

Pattern 02136, Rock Quality, 20 to $25 \mathrm{ft}$ Depth (approximate borehole locations)

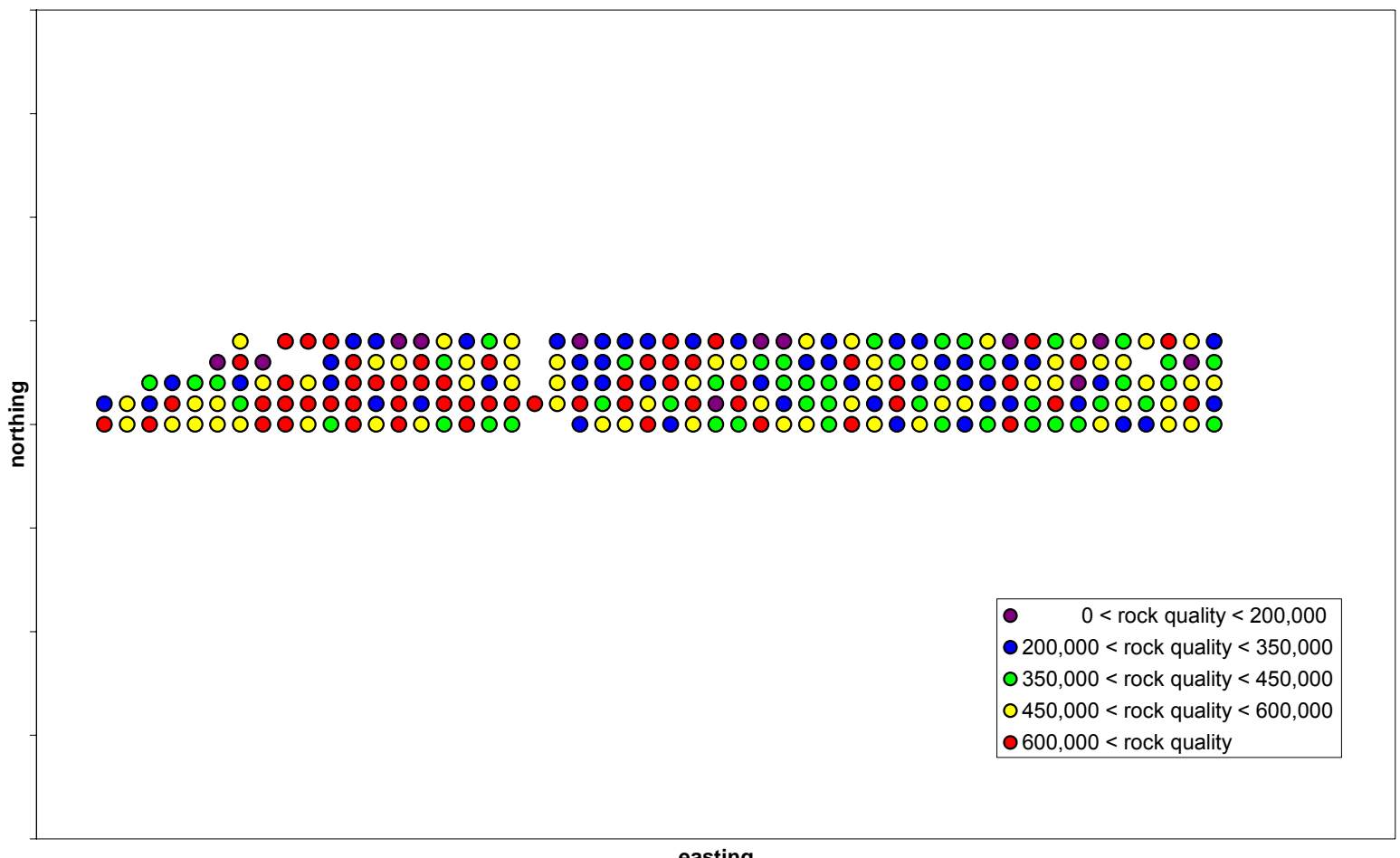

easting 
Pattern 02136, Rock Quality, 25 to $30 \mathrm{ft}$ Depth (approximate borehole locations)

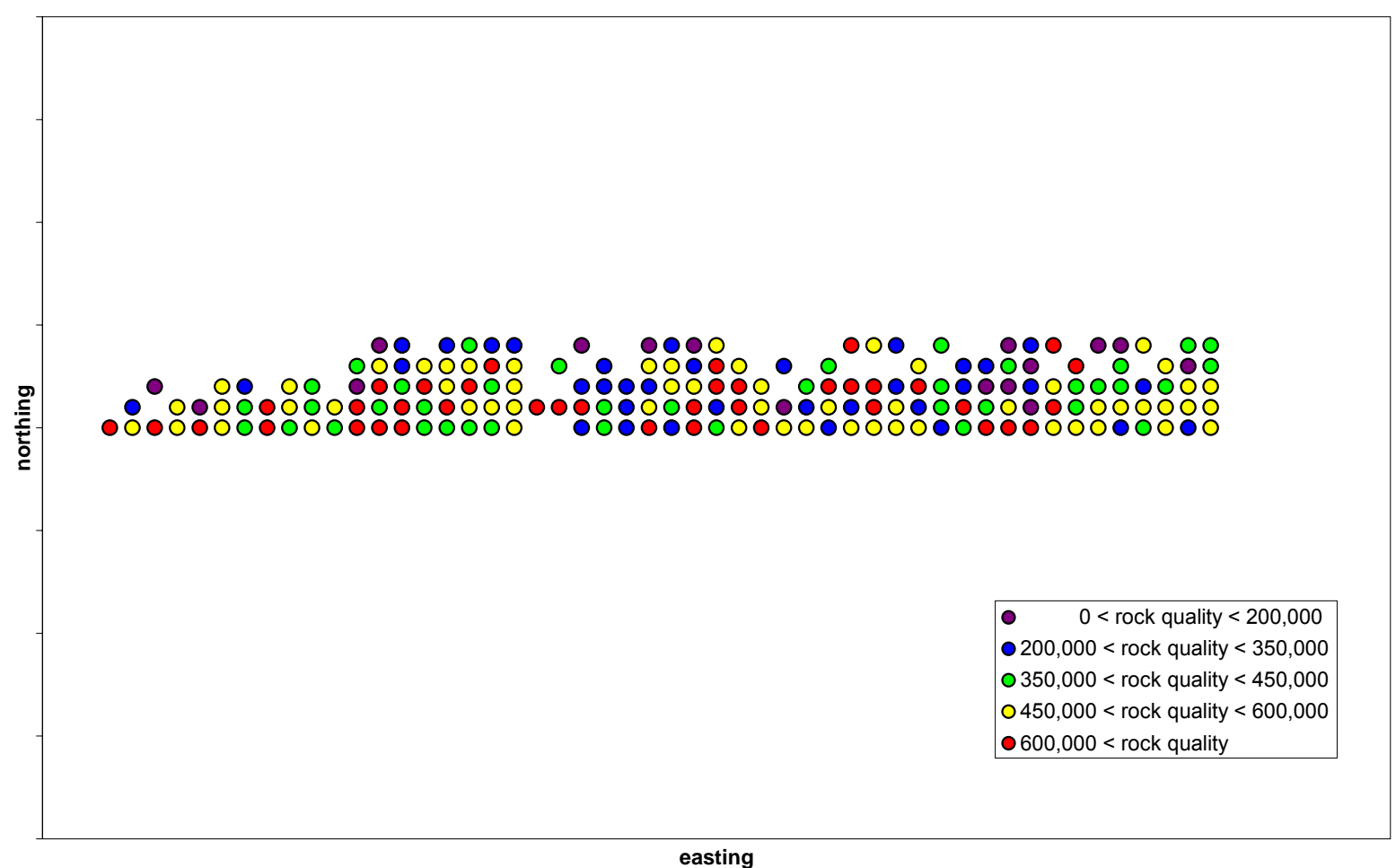

\section{Pi-1 (Drill Performance)}

Pattern 02136, Pi-1, Surface to $5 \mathrm{ft}$ Depth (approximate borehole locations)

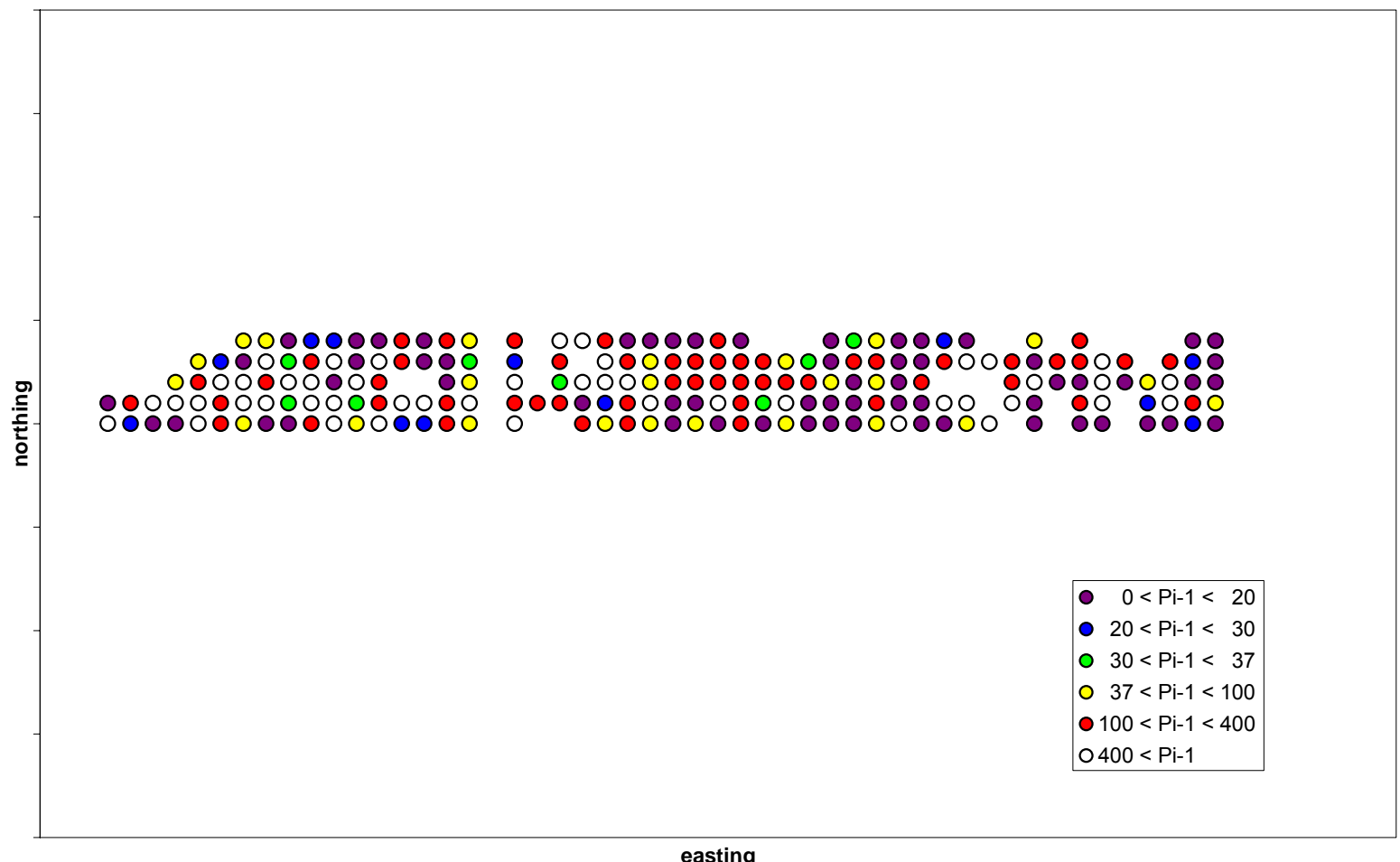


Pattern 02136, Pi-1, 5 to $10 \mathrm{ft}$ Depth (approximate borehole locations)

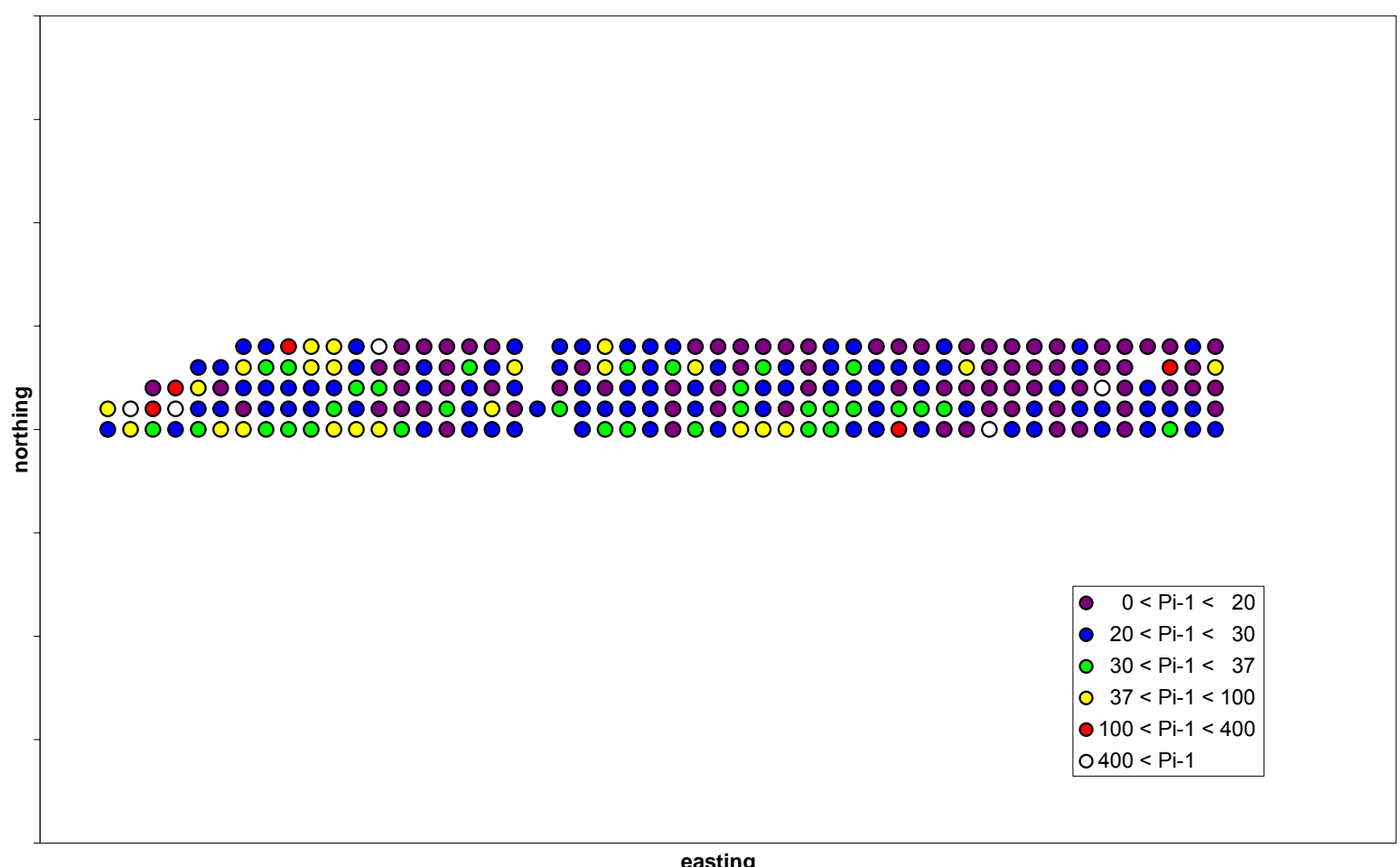

easting

Pattern 02136, Pi-1, 10 to $15 \mathrm{ft}$ Depth (approximate borehole locations)

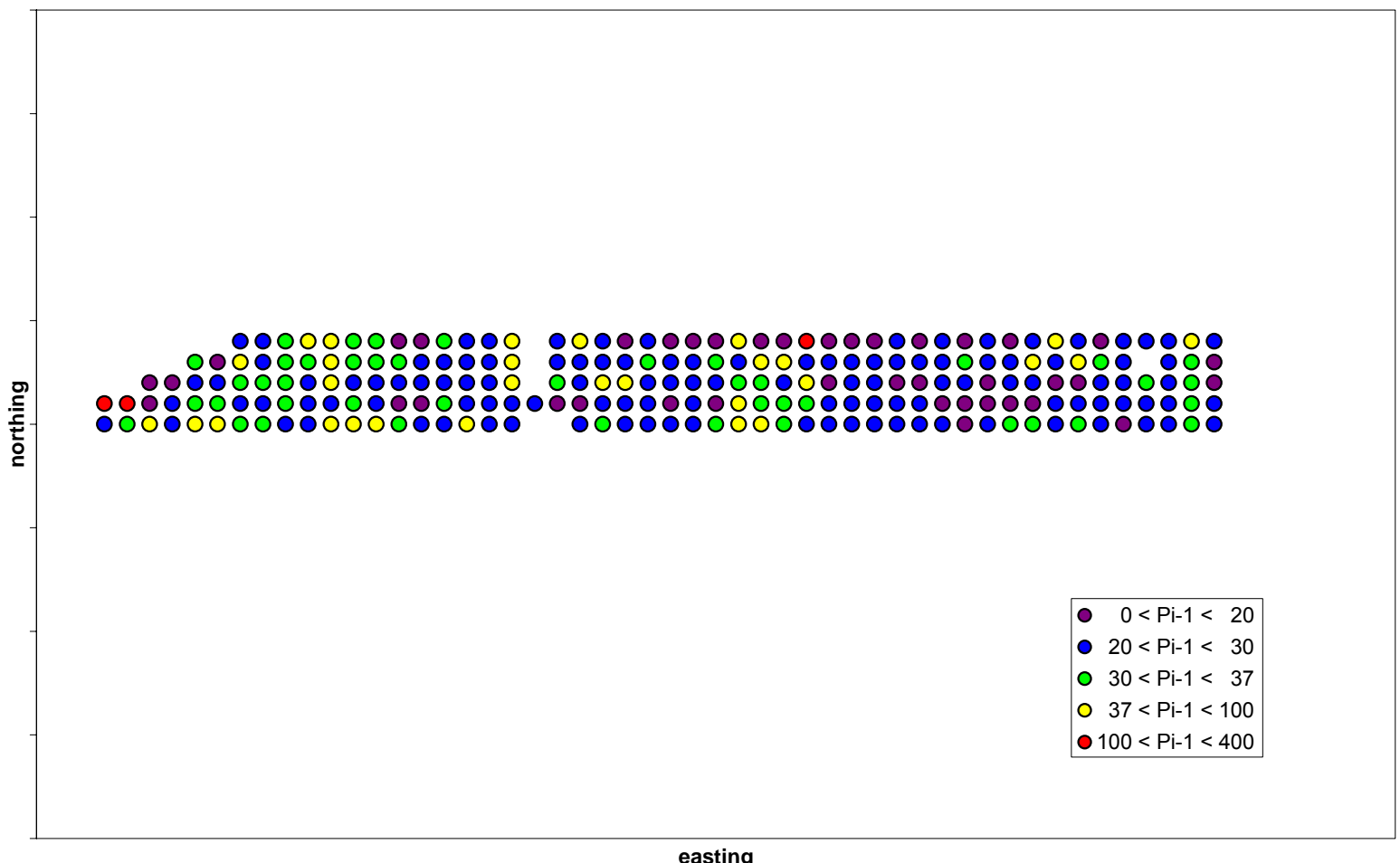

easting 
Pattern 02136, Pi-1, 15 to $20 \mathrm{ft}$ Depth (approximate borehole locations)

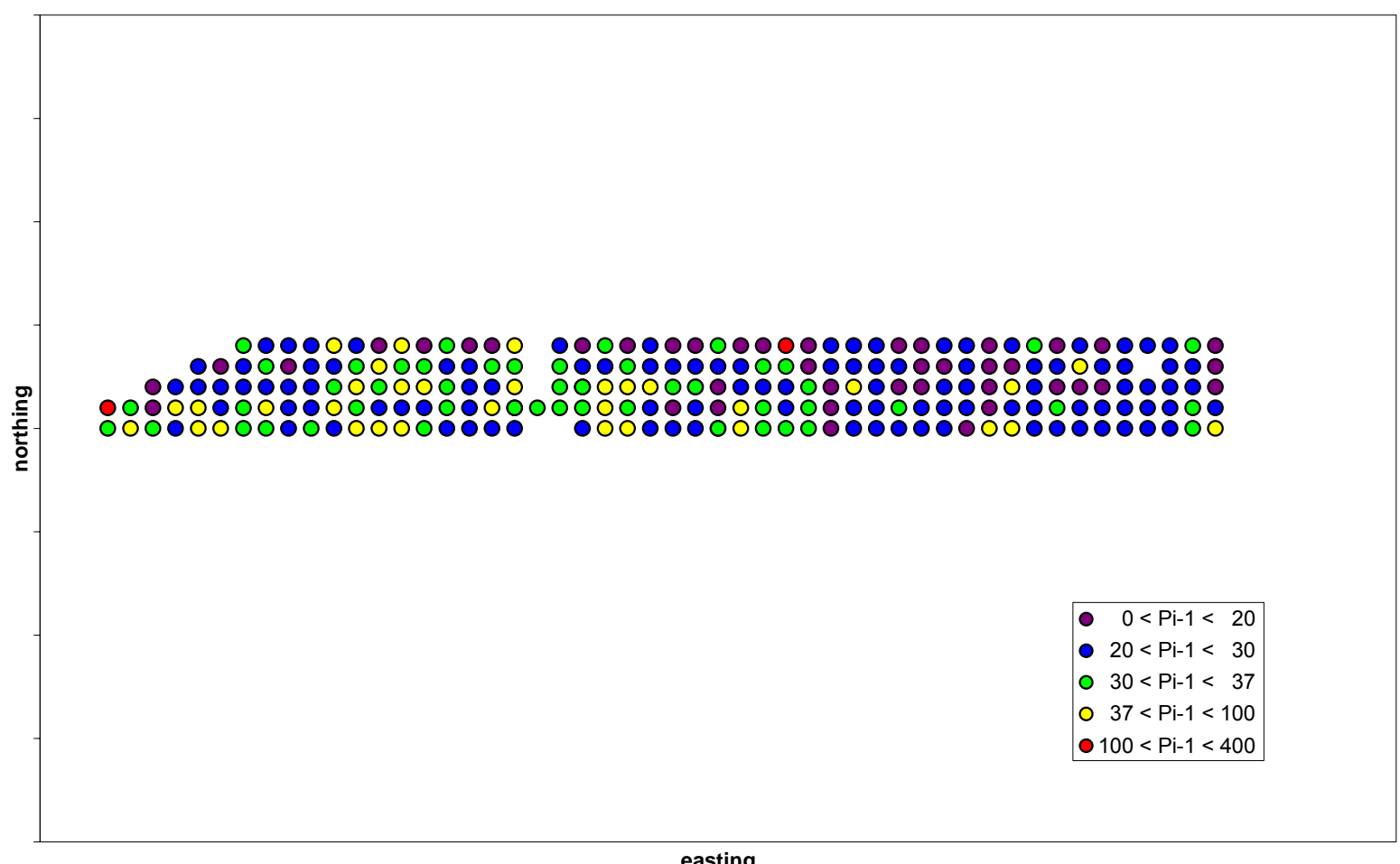

easting

Pattern 02136, Pi-1, 20 to $25 \mathrm{ft}$ Depth (approximate borehole locations)

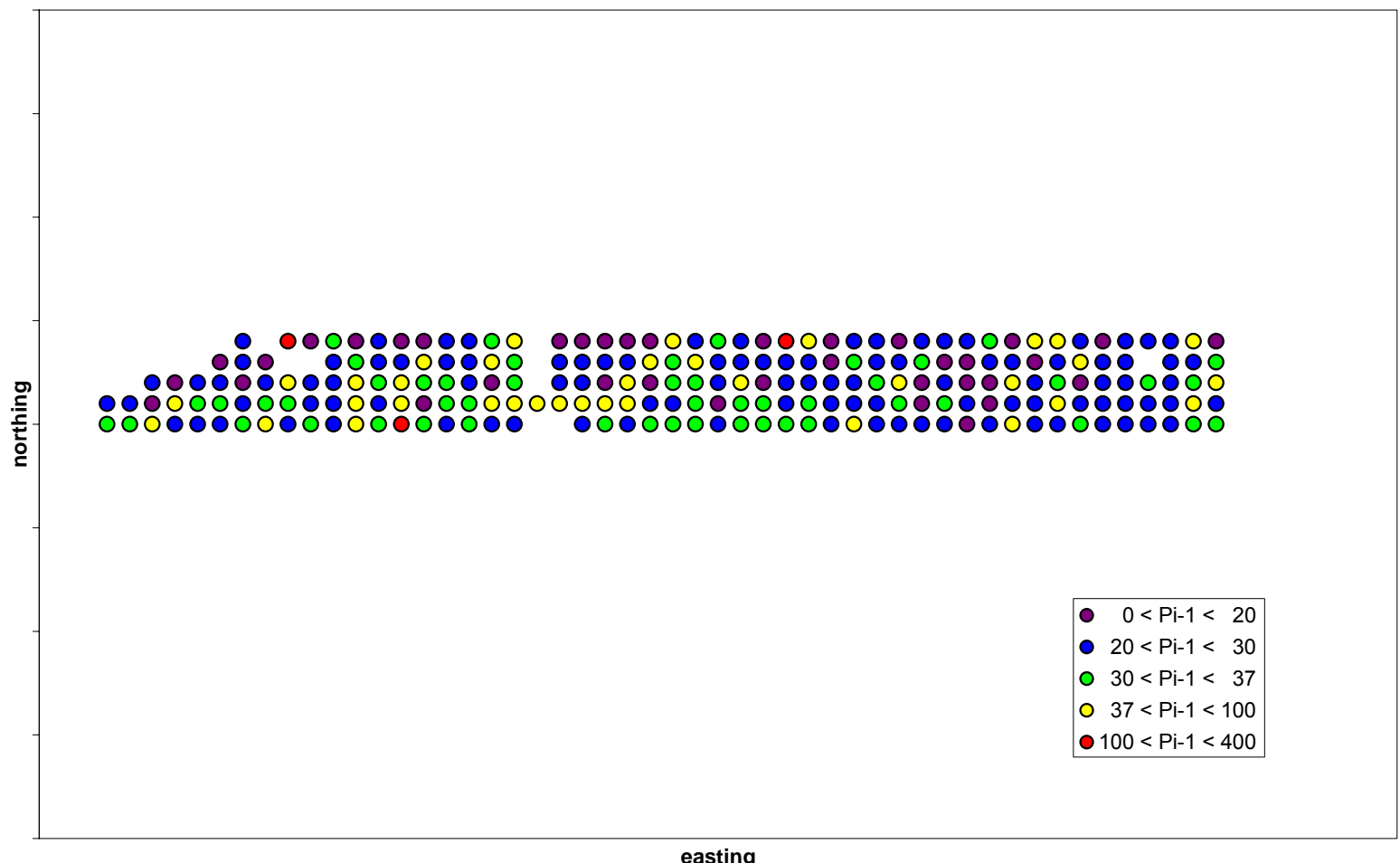

easting 
Pattern 02136, Pi-1, 25 to $30 \mathrm{ft}$ Depth (approximate borehole locations)

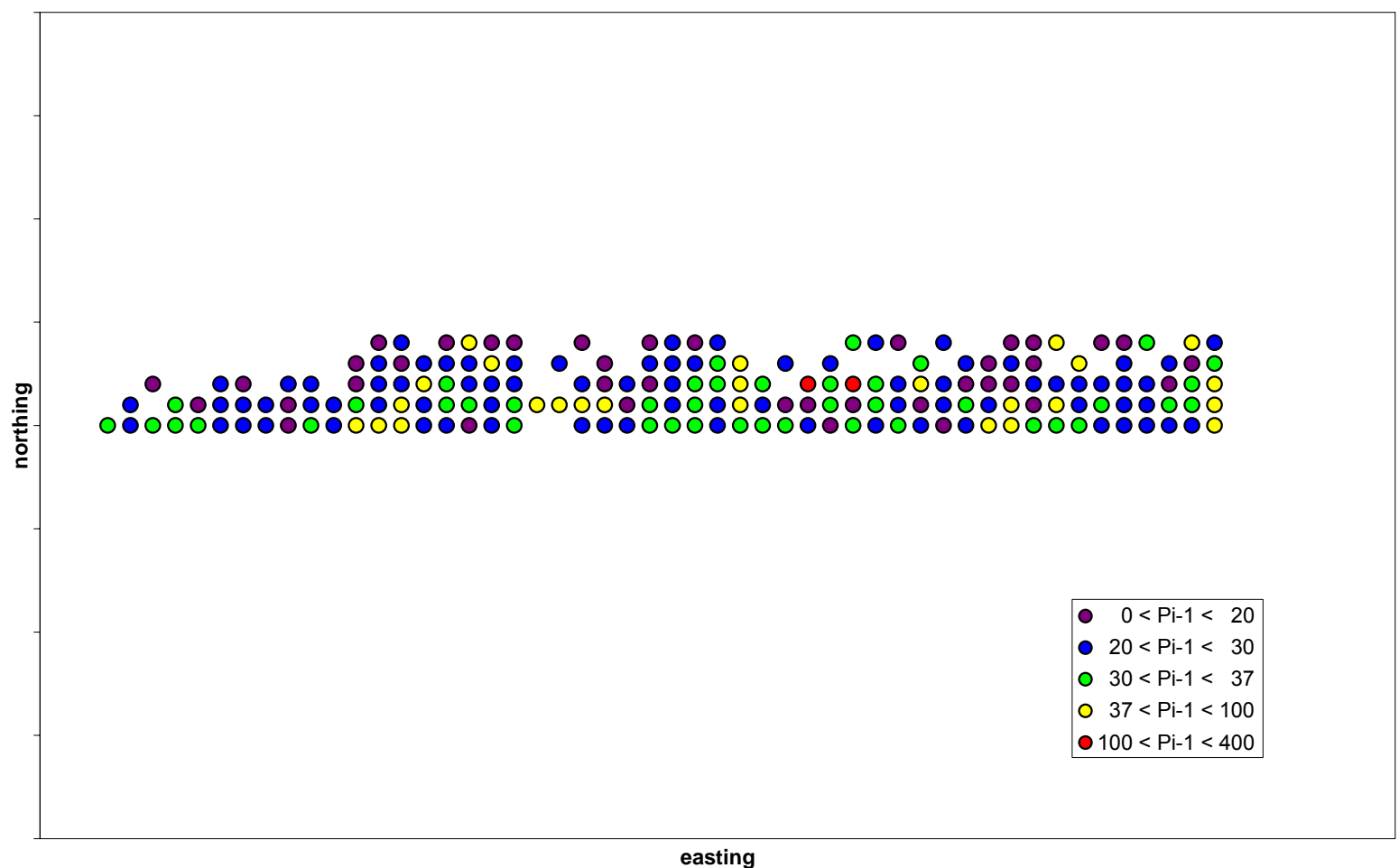

\section{Pi-2 (Rock Resistance)}

Pattern 02136, Pi-2, Surface to $5 \mathrm{ft}$ Depth (approximate borehole locations)

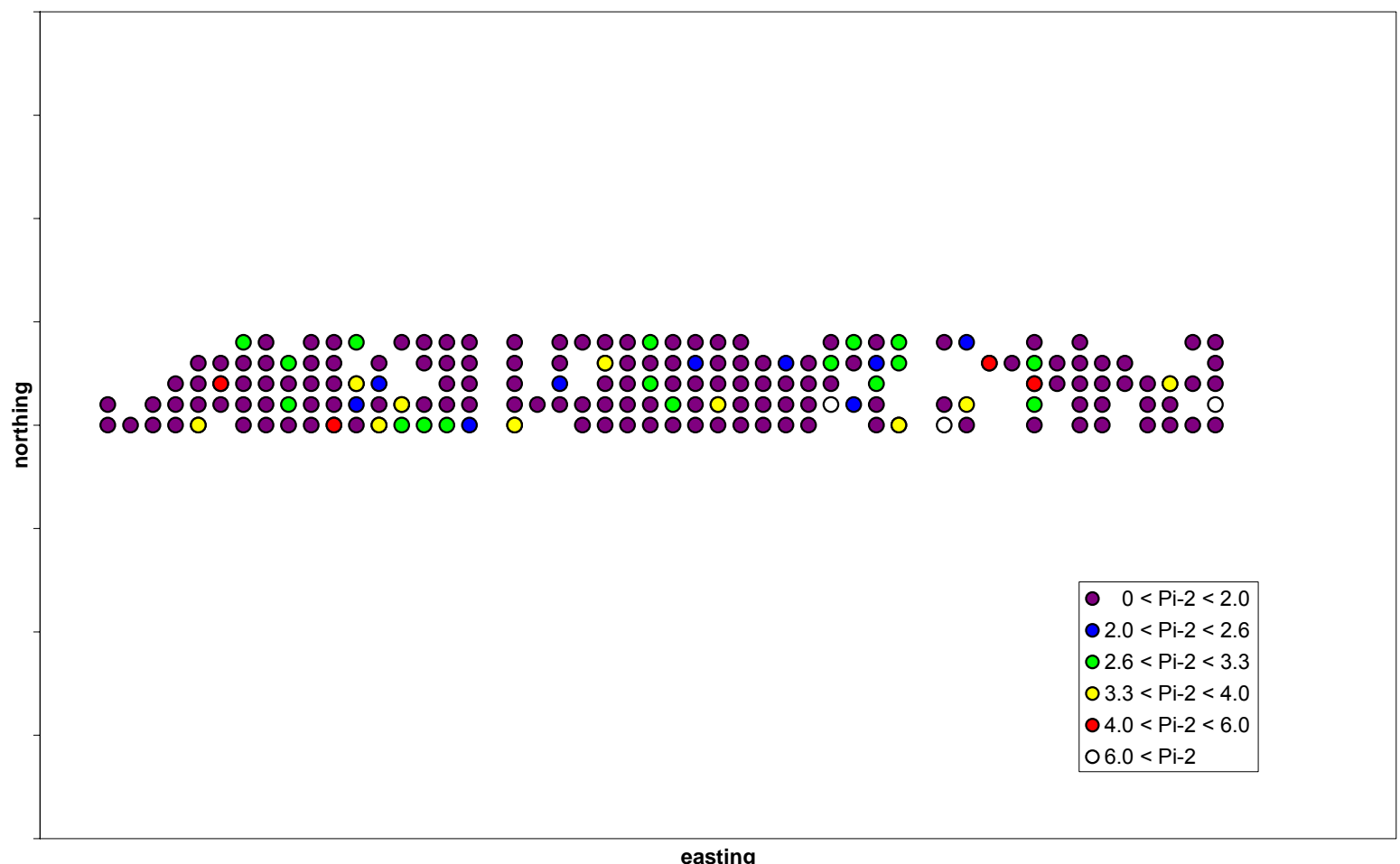


Pattern 02136, Pi-2, 5 to $10 \mathrm{ft}$ Depth (approximate borehole locations)

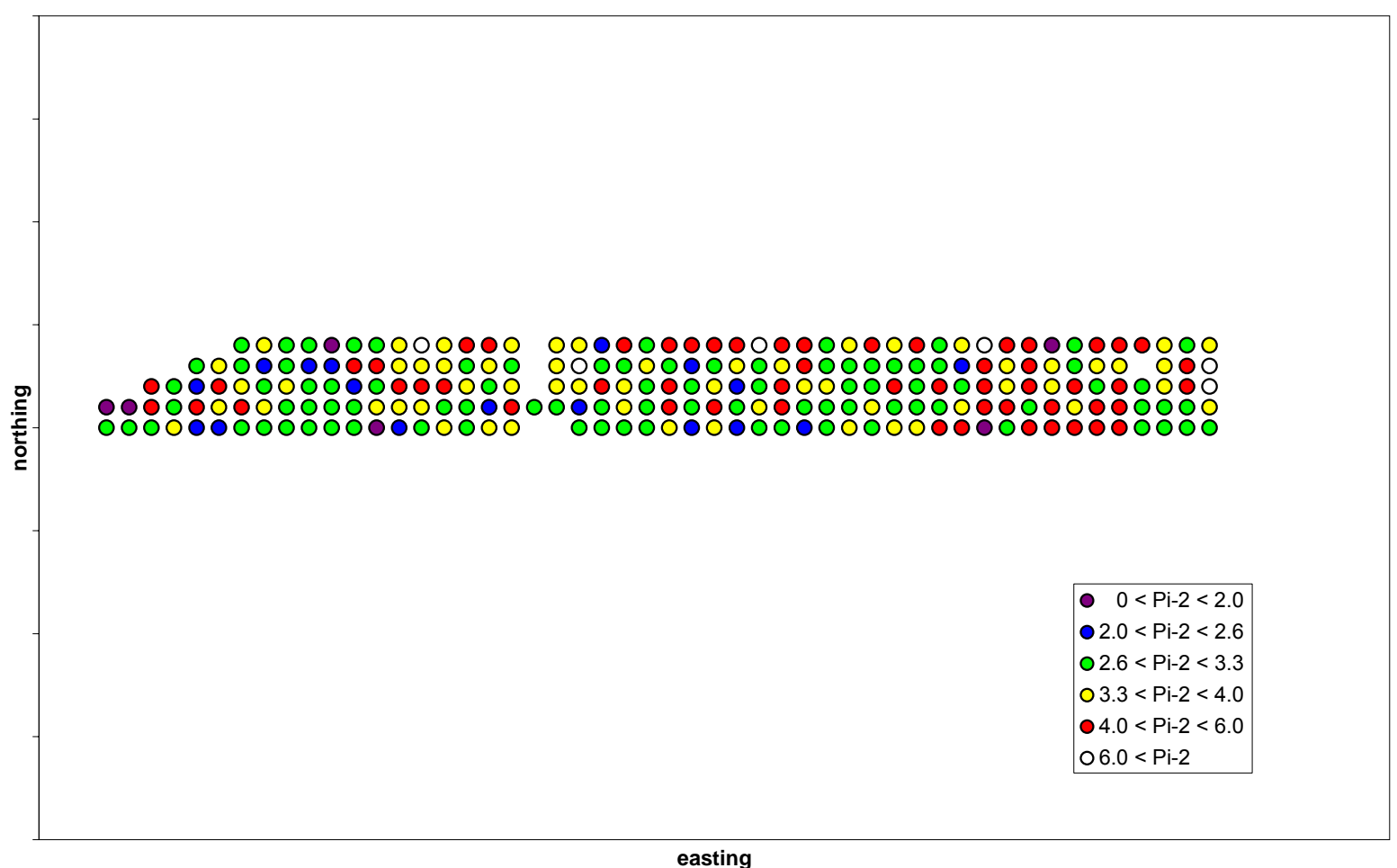

easting

Pattern 02136, Pi-2, 10 to $15 \mathrm{ft}$ Depth (approximate borehole locations)

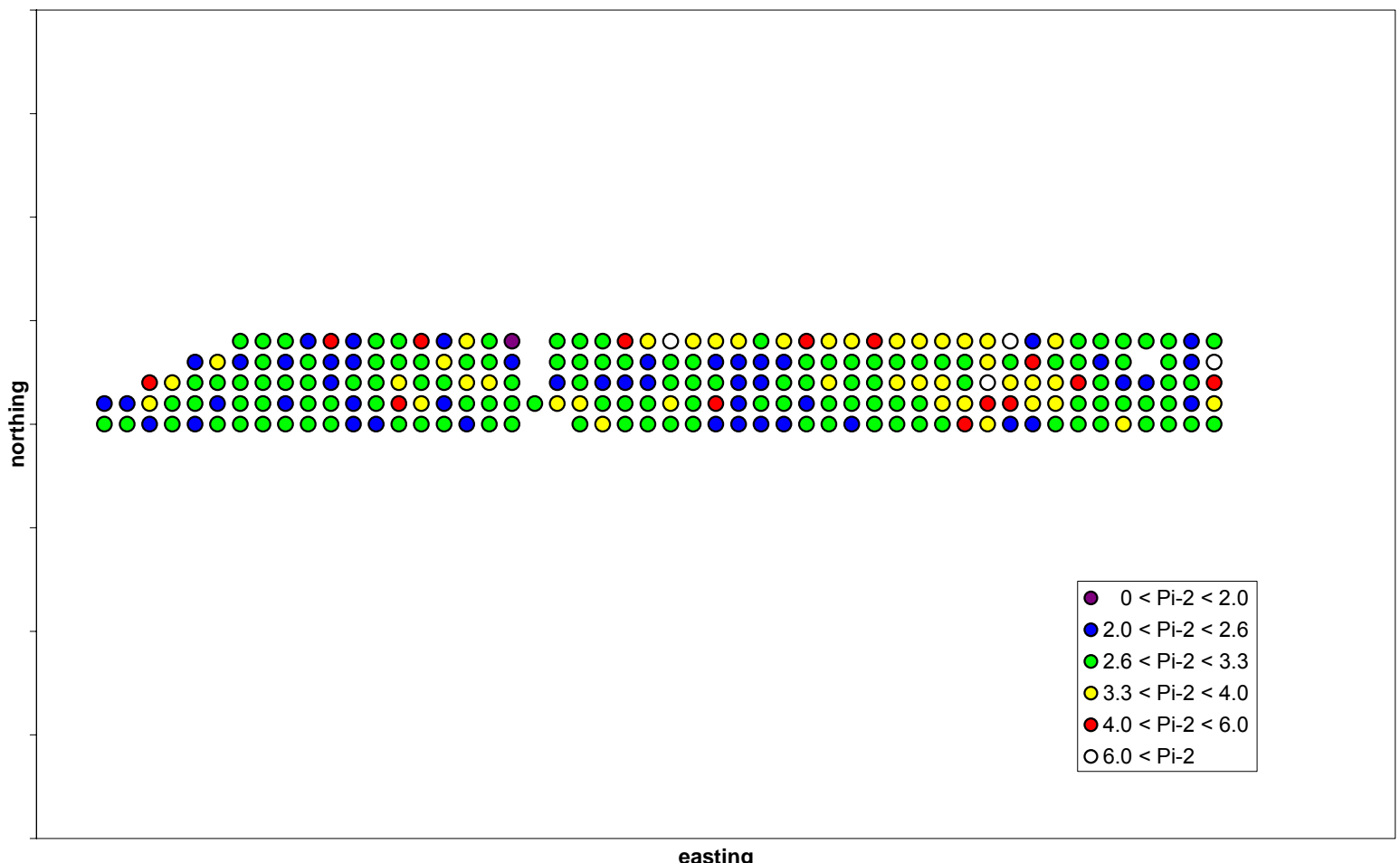

easting 
Pattern 02136, Pi-2, 15 to $20 \mathrm{ft}$ Depth (approximate borehole locations)

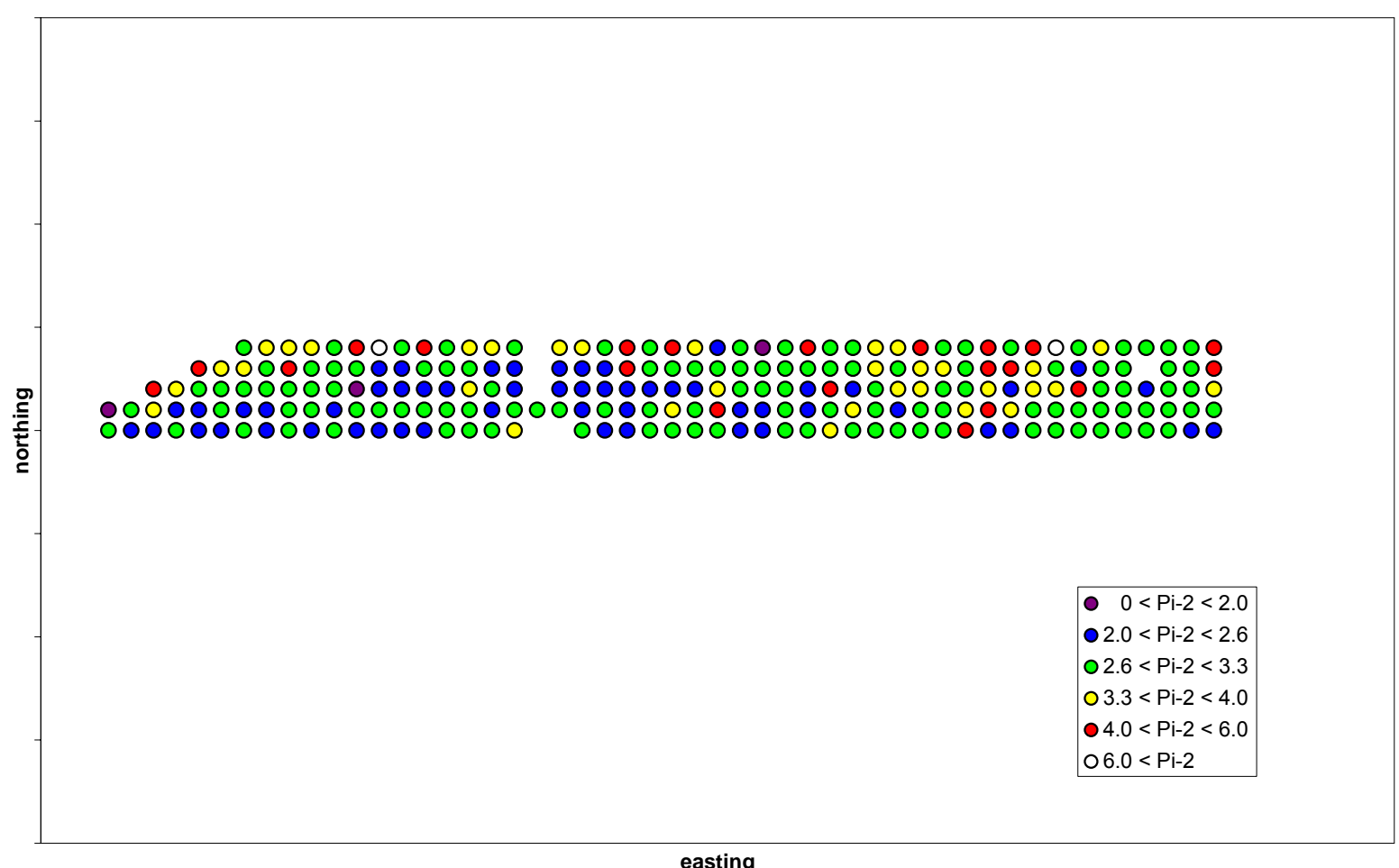

easting

Pattern 02136, Pi-2, 20 to $25 \mathrm{ft}$ Depth (approximate borehole locations)

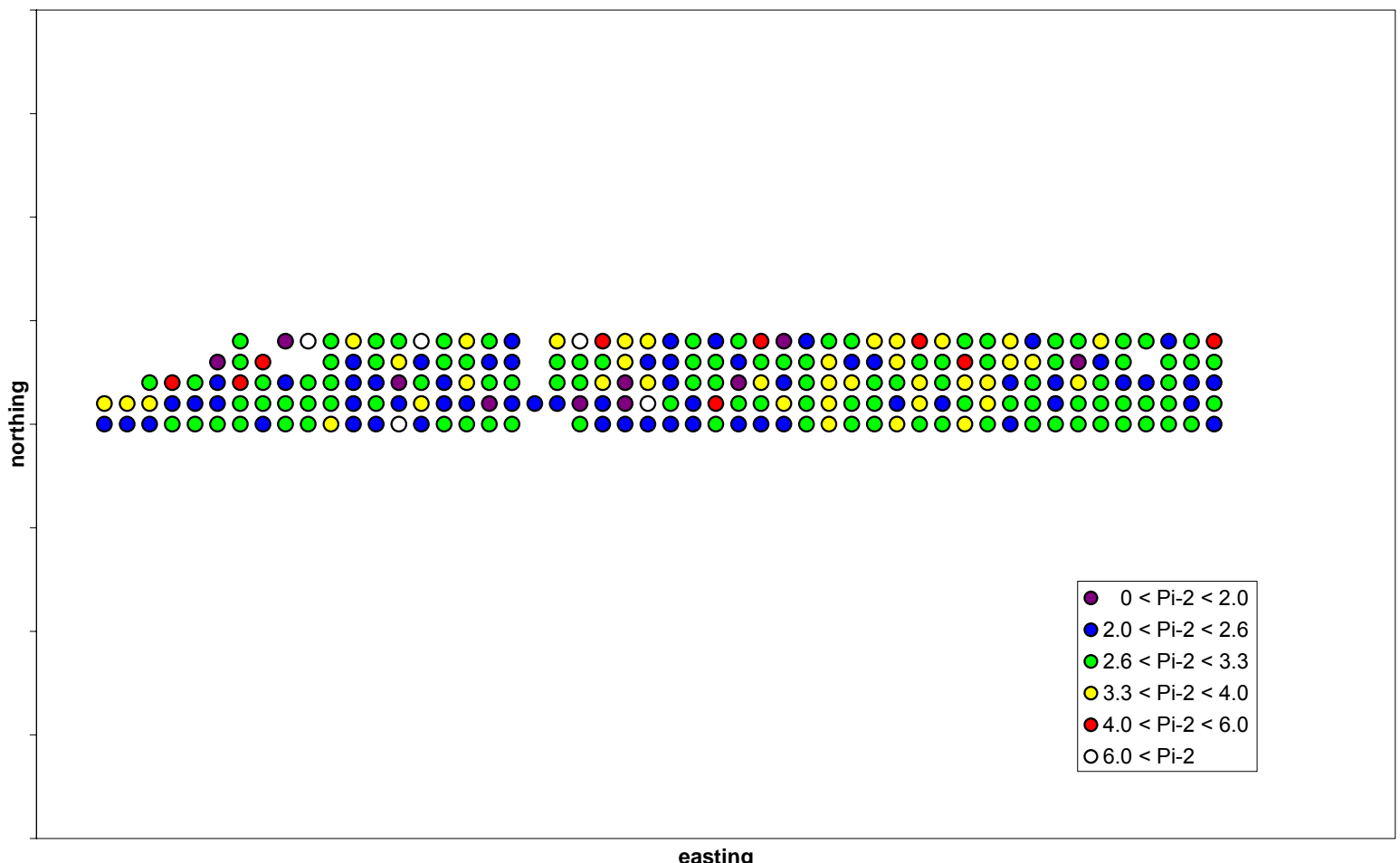

easting 
Pattern 02136, Pi-2, 25 to $30 \mathrm{ft}$ Depth (approximate borehole locations)

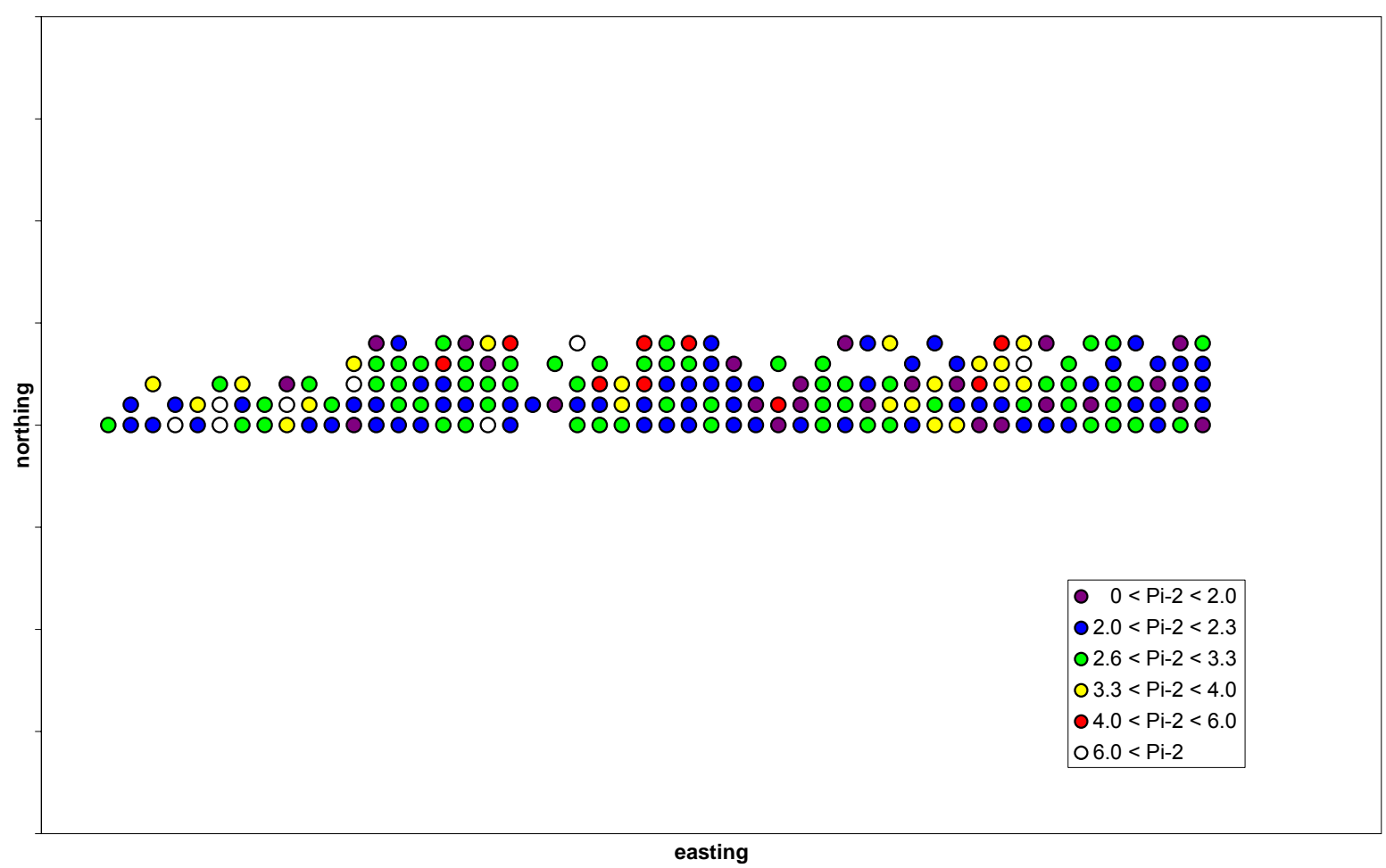




\section{Appendix: Data Summary from Ore Segregation Test \#1}

\begin{tabular}{|c|c|c|c|c|c|c|c|c|c|c|c|c|c|c|c|}
\hline & \multicolumn{5}{|c|}{ Low Line Rod Mill Feed (R2S) } & \multicolumn{5}{|c|}{ High Line Rod Mill Feed (R3S) } & \multicolumn{5}{|c|}{ Float Feed (FLF) } \\
\hline & ICP & ICP & $\mathrm{ICP}$ & ICP & ICP & ICP & ICP & ICP & ICP & ICP & ICP & ICP & $\mathrm{ICP}$ & ICP & ICP \\
\hline AVERAGES & $\mathrm{Al}$ & $\mathrm{Ca}$ & $\mathrm{Mg}$ & $\mathrm{Mn}$ & $\mathrm{SiO} 2$ & Al & $\mathrm{Ca}$ & $\mathrm{Mg}$ & $\mathrm{Mn}$ & $\mathrm{SiO} 2$ & Al & $\mathrm{Ca}$ & $\mathrm{Mg}$ & $\mathrm{Mn}$ & $\mathrm{SiO} 2$ \\
\hline Before Test & 0.0525 & 0.265 & 0.228 & 0.0775 & 5.19 & 0.0475 & 0.288 & 0.235 & 0.0900 & 5.13 & 0.0580 & 0.353 & 0.273 & 0.0860 & 5.50 \\
\hline During Test & 0.0425 & 0.238 & 0.200 & 0.1100 & 4.39 & 0.0625 & 0.190 & 0.233 & 0.1000 & 5.55 & 0.0609 & 0.265 & 0.245 & 0.1082 & 5.09 \\
\hline After Test & 0.0360 & 0.276 & 0.216 & 0.0760 & 4.77 & 0.0360 & 0.276 & 0.220 & 0.0780 & 4.70 & 0.0512 & 0.359 & 0.279 & 0.0847 & 5.24 \\
\hline \multicolumn{16}{|l|}{ STD DEVIATIONS } \\
\hline Before Test & 0.0096 & 0.0173 & 0.0206 & 0.0050 & 0.437 & 0.0096 & 0.0171 & 0.0173 & 0.0082 & 0.306 & 1.706 & 0.1978 & 0.0616 & 0.0946 & 0.0704 \\
\hline During Test & 0.0096 & 0.0435 & 0.0356 & 0.0216 & 0.697 & 0.0096 & 0.0216 & 0.0171 & 0.0082 & 0.294 & 0.899 & 0.2213 & 0.0604 & 0.1045 & 0.0962 \\
\hline After Test & 0.0055 & 0.0611 & 0.0288 & 0.0089 & 0.400 & 0.0055 & 0.0251 & 0.0122 & 0.0084 & 0.178 & 2.495 & 0.1420 & 0.0894 & 0.0606 & 0.0639 \\
\hline \multicolumn{16}{|c|}{ 90\% CONFIDENCE LIMITS } \\
\hline Before Test & 0.0113 & 0.0204 & 0.0243 & 0.0059 & 0.514 & 0.0113 & 0.0201 & 0.0204 & 0.0096 & 0.360 & 0.776 & 0.0899 & 0.0280 & 0.0430 & 0.0320 \\
\hline During Test & 0.0113 & 0.0512 & 0.0419 & 0.0254 & 0.820 & 0.0113 & 0.0254 & 0.0201 & 0.0096 & 0.345 & 0.491 & 0.1209 & 0.0330 & 0.0571 & 0.0526 \\
\hline After Test & 0.0052 & 0.0582 & 0.0275 & 0.0085 & 0.382 & 0.0052 & 0.0239 & 0.0117 & 0.0080 & 0.169 & 1.056 & 0.0601 & 0.0378 & 0.0257 & 0.0271 \\
\hline
\end{tabular}

\begin{tabular}{|c|c|c|c|c|c|c|c|c|c|c|c|c|c|c|c|}
\hline & \multicolumn{5}{|c|}{ Float Feed (FFD) } & \multicolumn{5}{|c|}{ Float Concentrate (FC3) } & \multicolumn{5}{|c|}{ Float Tails (FLT) } \\
\hline & ICP & ICP & ICP & ICP & ICP & ICP & ICP & $\mathrm{ICP}$ & ICP & ICP & ICP & ICP & ICP & ICP & ICP \\
\hline AVERAGES & $\mathrm{Al}$ & $\mathrm{Ca}$ & $\mathrm{Mg}$ & $\mathrm{Mn}$ & $\mathrm{SiO} 2$ & $\mathrm{Al}$ & $\mathrm{Ca}$ & $\mathrm{Mg}$ & $\mathrm{Mn}$ & $\mathrm{SiO} 2$ & $\mathrm{Al}$ & $\mathrm{Ca}$ & $\mathrm{Mg}$ & $\mathrm{Mn}$ & $\mathrm{SiO} 2$ \\
\hline Before Test & 0.036667 & 0.233 & 0.168 & 0.061 & 4.05 & 0.057705 & 3.59 & 1.11 & 0.0734 & 3.63 & 0.153 & 0.668 & 0.736 & 0.1553 & 22.08 \\
\hline During Test & 0.049167 & 0.155 & 0.146 & 0.338 & 3.43 & 0.067174 & 3.61 & 1.12 & 0.0907 & 3.66 & 0.189 & 0.787 & 0.921 & 0.2075 & 25.42 \\
\hline After Test & 0.046111 & 0.222 & 0.356 & 0.303 & 3.68 & 0.055323 & 3.61 & 1.13 & 0.0715 & 3.66 & 0.164 & 0.750 & 0.914 & 0.1669 & 24.49 \\
\hline \multicolumn{16}{|l|}{ STD DEVIATIONS } \\
\hline Before Test & 2.83 & 0.248 & 0.117 & 0.129 & 0.0728 & 1.63 & 0.0759 & 0.0644 & 0.0880 & 0.0852 & 0.636 & 0.1281 & 0.0440 & 0.0714 & 0.0800 \\
\hline During Test & 2.57 & 1.688 & 0.135 & 0.107 & 0.0521 & 1.60 & 0.0898 & 0.0524 & 0.0832 & 0.0894 & 0.602 & 0.1167 & 0.0437 & 0.0532 & 0.0435 \\
\hline $\begin{array}{r}\text { After Test } \\
\end{array}$ & 3.68 & 1.264 & 0.157 & 0.139 & 0.0655 & 1.43 & 0.0932 & 0.0509 & 0.0904 & 0.0796 & 0.616 & 0.1200 & 0.0534 & 0.0716 & 0.0501 \\
\hline \multicolumn{16}{|c|}{ 90\% CONFIDENCE LIMITS } \\
\hline Before Test & 1.29 & 0.113 & 0.0530 & 0.0587 & 0.0331 & 0.348 & 0.0162 & 0.0138 & 0.0188 & 0.0182 & 0.289 & 0.0582 & 0.0200 & 0.0324 & 0.0364 \\
\hline During Test & 1.33 & 0.875 & 0.0700 & 0.0555 & 0.0270 & 0.396 & 0.0223 & 0.0130 & 0.0206 & 0.0221 & 0.312 & 0.0605 & 0.0226 & 0.0276 & 0.0225 \\
\hline After Test & 1.51 & 0.518 & 0.0643 & 0.0572 & 0.0269 & 0.303 & 0.0198 & 0.0108 & 0.0192 & 0.0169 & 0.270 & 0.0526 & 0.0234 & 0.0314 & 0.0220 \\
\hline
\end{tabular}

\begin{tabular}{|c|c|c|c|c|c|c|c|c|c|c|c|c|c|c|c|}
\hline & \multicolumn{5}{|c|}{ Column Float Feed (CFD) } & \multicolumn{5}{|c|}{ Column Float Concentrate (CFC) } & \multicolumn{5}{|c|}{ Column Float Tails (CFF) } \\
\hline & ICP & ICP & ICP & ICP & ICP & ICP & ICP & ICP & ICP & ICP & ICP & ICP & $\mathrm{ICP}$ & ICP & ICP \\
\hline AVERAGES & $\mathrm{Al}$ & $\mathrm{Ca}$ & $\mathrm{Mg}$ & $\mathrm{Mn}$ & $\mathrm{SiO} 2$ & $\mathrm{Al}$ & $\mathrm{Ca}$ & $\mathrm{Mg}$ & $\mathrm{Mn}$ & $\mathrm{SiO} 2$ & $\mathrm{Al}$ & $\mathrm{Ca}$ & $\mathrm{Mg}$ & $\mathrm{Mn}$ & $\mathrm{SiO} 2$ \\
\hline Before Test & 0.121 & 0.389 & 0.504 & 0.116 & 15.1 & 0.105 & 0.372 & 0.454 & 0.1119 & 12.14 & 0.166 & 0.439 & 0.631 & 0.135 & 22.5 \\
\hline During Test & 0.139 & 0.333 & 0.543 & 0.141 & 15.5 & 0.115 & 0.297 & 0.455 & 0.1309 & 11.37 & 0.197 & 0.367 & 0.694 & 0.170 & 24.2 \\
\hline After Test & 0.127 & 0.433 & 0.601 & 0.123 & 15.4 & 0.103 & 0.415 & 0.510 & 0.1124 & 11.23 & 0.183 & 0.515 & 0.812 & 0.154 & 24.7 \\
\hline \multicolumn{16}{|l|}{ STD DEVIATIONS } \\
\hline Before Test & 0.784 & 0.170 & 0.0644 & 0.1163 & 0.0872 & 0.985 & 0.145 & 0.0698 & 0.0983 & 0.0562 & 0.470 & 0.163 & 0.0597 & 0.0823 & 0.0483 \\
\hline During Test & 0.724 & 0.191 & 0.0591 & 0.0995 & 0.0501 & 0.933 & 0.253 & 0.0774 & 0.0780 & 0.0628 & 0.559 & 0.130 & 0.0493 & 0.0789 & 0.0474 \\
\hline After Test & 0.888 & 0.187 & 0.0548 & 0.0790 & 0.0504 & 1.199 & 0.141 & 0.0732 & 0.0629 & 0.0541 & 0.543 & 0.162 & 0.0622 & 0.0872 & 0.0567 \\
\hline \multicolumn{16}{|c|}{ 90\% CONFIDENCE LIMITS } \\
\hline Before Test & 0.344 & 0.0743 & 0.0282 & 0.0510 & 0.0382 & 0.432 & 0.064 & 0.0306 & 0.0431 & 0.0246 & 0.206 & 0.0716 & 0.0262 & 0.0360 & 0.0212 \\
\hline During Test & 0.396 & 0.1043 & 0.0323 & 0.0543 & 0.0273 & 0.510 & 0.138 & 0.0423 & 0.0426 & 0.0343 & 0.324 & 0.0753 & 0.0286 & 0.0458 & 0.0275 \\
\hline After Test & 0.364 & 0.0768 & 0.0225 & 0.0324 & 0.0207 & 0.508 & 0.060 & 0.0310 & 0.0266 & 0.0229 & 0.230 & 0.0687 & 0.0263 & 0.0369 & 0.0240 \\
\hline
\end{tabular}




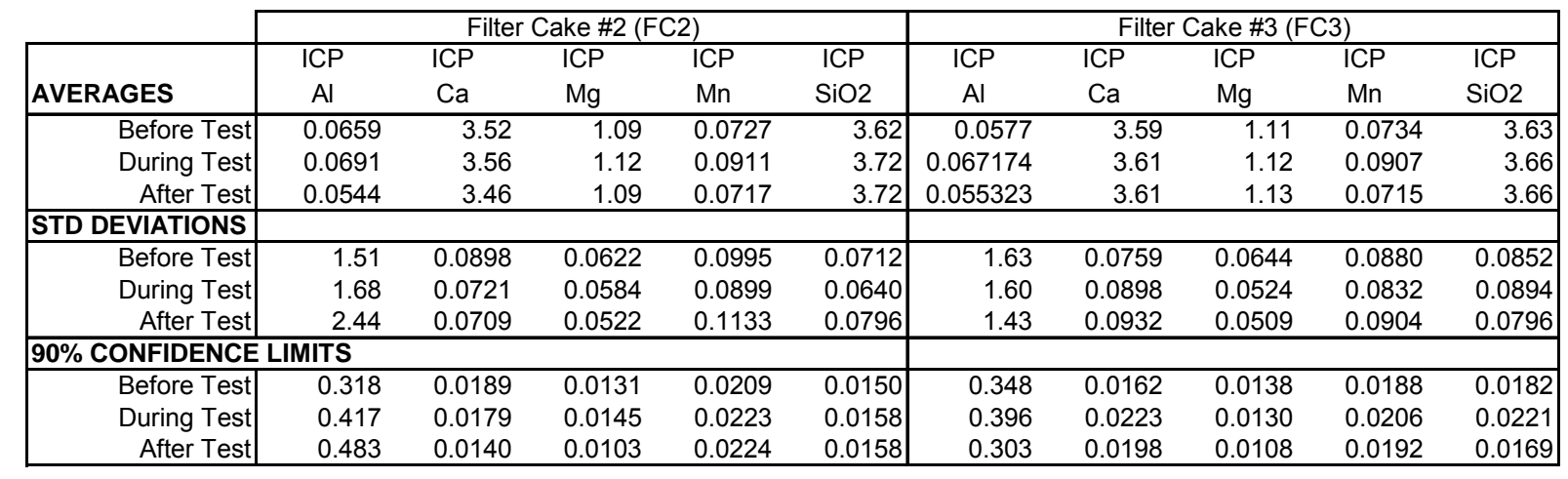

\begin{tabular}{|c|c|c|c|c|c|c|c|c|c|c|c|c|c|c|c|c|}
\hline & \multicolumn{7}{|c|}{ S-trend General Values } & \multicolumn{5}{|c|}{ Step 1\&2, S-trend } & \multicolumn{4}{|c|}{ Step 3, S-trend } \\
\hline & IND & FLF & FLF & amine & FLF & FL,TLS & FLF & NOLA & NOLA & filter & line & pellet & NOLA & NOLA & filter & line \\
\hline AVERAGES & TOT & $\mathrm{SiO} 2$ & $-270 \mathrm{M}$ & $\mathrm{lb} /$ ton & DTREC & $\mathrm{SiO} 2$ & -DT & $\operatorname{targ}$ & comp & cake & pellets & trains & $\operatorname{targ}$ & comp & cake & pellets \\
\hline Before Test & 5.66 & 5.41 & 85.1 & 0.135 & 95.1 & 22.9 & 1.358 & 3.89 & 3.90 & 3.62 & 4.20 & 4.19 & 3.95 & 3.97 & 3.63 & 4.22 \\
\hline During Test & 5.47 & 5.25 & 85.8 & 0.119 & 95.2 & 24.2 & 1.409 & 4.04 & 4.02 & 3.71 & 4.21 & 4.24 & 3.94 & 3.92 & 3.68 & 4.24 \\
\hline After Test & 5.44 & 5.24 & 85.1 & 0.126 & 95.6 & 25.0 & 1.811 & 3.89 & 3.90 & 3.69 & 4.22 & 4.23 & 3.87 & 3.86 & 3.62 & 4.19 \\
\hline \multicolumn{17}{|l|}{ STD DEVIATIONS } \\
\hline Before Test & 0.314 & 0.461 & 1.387 & 0.0238 & 0.384 & 2.20 & 0.378 & 0.0772 & 0.0872 & 0.0974 & 0.0570 & 0.0674 & 0.0488 & 0.0872 & 0.0457 & 0.0742 \\
\hline During Test & 0.252 & 0.280 & 0.905 & 0.0341 & 0.447 & 3.31 & 0.110 & 0.0700 & 0.0870 & 0.1162 & 0.1621 & 0.0697 & 0.0498 & 0.0769 & 0.0836 & 0.1314 \\
\hline After Test & 0.136 & 0.306 & 1.448 & 0.0233 & 0.466 & 2.57 & 1.119 & 0.0617 & 0.0861 & 0.0914 & 0.0790 & 0.0794 & 0.0925 & 0.0929 & 0.0880 & 0.1002 \\
\hline \multicolumn{17}{|c|}{ 90\% CONFIDENCE LIMITS } \\
\hline Before Test & 0.143 & 0.210 & 0.631 & 0.0108 & 0.175 & 1.20 & 0.172 & 0.0351 & 0.0397 & 0.0443 & 0.0259 & 0.0333 & 0.0222 & 0.0397 & 0.0208 & 0.0337 \\
\hline During Test & 0.156 & 0.174 & 0.561 & 0.0211 & 0.277 & 2.05 & 0.068 & 0.0434 & 0.0540 & 0.0721 & 0.1005 & 0.0512 & 0.0309 & 0.0477 & 0.0518 & 0.0815 \\
\hline After Test & 0.042 & 0.095 & 0.449 & 0.0072 & 0.153 & 0.80 & 0.347 & 0.0192 & 0.0267 & 0.0284 & 0.0245 & 0.0272 & 0.0287 & 0.0288 & 0.0273 & 0.0311 \\
\hline
\end{tabular}

\begin{tabular}{|c|c|c|c|c|c|c|c|c|c|c|}
\hline \multirow[b]{2}{*}{ AVERAGES } & \multirow[b]{2}{*}{$\begin{array}{c}\mathrm{wt} \% \\
\mathrm{Fe}\end{array}$} & \multicolumn{9}{|c|}{ Step 1\&2, Mine-indicated Values } \\
\hline & & $\mathrm{SiO} 2$ & $\begin{array}{c}\text { mag } \\
\mathrm{Fe}\end{array}$ & COIL & HIS & UC & $\begin{array}{c}\text { A- } \\
\text { factor }\end{array}$ & IBC & L3-4 & L1-2 \\
\hline Before Test & -- & -- & -- & -- & -- & -- & -- & -- & -- & -- \\
\hline During Test & 28.7 & 4.84 & 20.2 & 18.2 & 7.94 & 1.15 & 1.37 & 2.29 & 62.3 & 25.3 \\
\hline After Test & -- & -- & -- & -- & -- & -- & -- & -- & -- & - \\
\hline \multicolumn{11}{|l|}{ STD DEVIATIONS } \\
\hline Before Test & -- & -- & -- & -- & -- & -- & -- & -- & -- & -- \\
\hline During Test & 1.17 & 0.310 & 0.825 & 2.20 & 6.80 & 1.04 & 0.165 & 3.07 & 12.9 & 9.04 \\
\hline After Test & -- & -- & -- & -- & -- & -- & -- & -- & -- & - \\
\hline \multicolumn{11}{|c|}{ 90\% CONFIDENCE LIMITS } \\
\hline Before Test & -- & -- & -- & -- & -- & -- & -- & -- & -- & -- \\
\hline During Test & 0.638 & 0.170 & 0.451 & 1.20 & 3.72 & 0.990 & 0.0900 & 1.91 & 7.02 & 4.94 \\
\hline After Test & -- & -- & -- & -- & -- & -- & -- & -- & -- & - \\
\hline
\end{tabular}




\begin{tabular}{|c|c|c|c|c|c|c|c|c|c|c|}
\hline \multirow[b]{2}{*}{ AVERAGES } & \multicolumn{10}{|c|}{ Step 3, Mine-indicated Values } \\
\hline & $\begin{array}{c}\mathrm{wt} \% \\
\mathrm{Fe}\end{array}$ & $\mathrm{SiO} 2$ & $\begin{array}{c}\mathrm{mag} \\
\mathrm{Fe}\end{array}$ & COIL & HIS & UC & $\begin{array}{c}\text { A- } \\
\text { factor }\end{array}$ & IBC & L3-4 & L1-2 \\
\hline Before Test & -- & -- & -- & -- & -- & -- & -- & -- & -- & - \\
\hline During Test & 26.4 & 6.64 & 18.6 & 12.7 & 47.7 & 4.60 & 2.04 & 3.57 & 24.0 & 26.0 \\
\hline After Test & -- & -- & -- & -- & -- & -- & -- & -- & -- & -. \\
\hline \multicolumn{11}{|l|}{ STD DEVIATIONS } \\
\hline Before Test & -- & -- & -- & -- & -- & -- & -- & -- & -- & - \\
\hline During Test & 1.20 & 0.206 & 0.855 & 2.88 & 9.76 & 2.38 & 0.250 & 4.49 & 8.75 & 15.6 \\
\hline After Test & -- & -- & -- & -- & -- & -- & -- & -- & -- & - \\
\hline \multicolumn{11}{|c|}{ 90\% CONFIDENCE LIMITS } \\
\hline Before Test & -- & -- & -- & -- & -- & -- & -- & -- & -- & - \\
\hline During Test & 0.656 & 0.112 & 0.467 & 1.57 & 5.33 & 10.6 & 0.137 & 2.78 & 4.78 & 8.50 \\
\hline After Test & -- & -- & -- & -- & -- & -- & -- & -- & -- & - \\
\hline
\end{tabular}

\begin{tabular}{|c|c|c|c|c|c|c|c|c|c|c|c|c|c|c|c|c|}
\hline & \multicolumn{8}{|c|}{ Step 1\&2, Met Report } & \multicolumn{8}{|c|}{ Step 3, Met Report } \\
\hline & RMF & Con & Crs Tails & Fne Tails & RMF & RMF & RMF & RMF & RMF & Con & Crs Tails & Fne Tails & RMF & RMF & RMF & RMF \\
\hline AVERAGES & mag $\mathrm{Fe}$ & mag $\mathrm{Fe}$ & mag Fe & mag Fe & khw/t & $-3 / 4 "$ & $-1 / 2^{\prime \prime}$ & $3 / 4$ to $1 / 2^{\prime \prime}$ & $\operatorname{mag} \mathrm{Fe}$ & mag $\mathrm{Fe}$ & mag Fe & mag Fe & khw/t & $-3 / 4 "$ & $-1 / 2^{\prime \prime}$ & $3 / 4$ to $1 / 2 "$ \\
\hline Before Test & 18.3 & 65.3 & 2.53 & 1.11 & 10.7 & 96.7 & 82.7 & 14.0 & 17.9 & 65.3 & 2.67 & 1.22 & 11.8 & 97.9 & 81.3 & 16.7 \\
\hline During Test & 19.1 & 65.7 & 2.63 & 1.05 & 10.7 & 96.3 & 80.1 & 16.2 & 17.8 & 65.7 & 2.75 & 1.44 & 12.3 & 97.4 & 79.7 & 17.7 \\
\hline After Test & 20.0 & 65.5 & 2.74 & 1.13 & 11.8 & 96.9 & 80.3 & 16.5 & 20.0 & 65.6 & 2.85 & 1.27 & 13.1 & 97.7 & 80.9 & 16.8 \\
\hline \multicolumn{17}{|l|}{ STD DEVIATIONS } \\
\hline Before Test & 0.922 & 0.154 & 0.104 & 0.055 & 0.304 & 0.507 & 0.769 & 1.17 & 0.396 & 0.154 & 0.139 & 0.148 & 0.203 & 1.158 & 2.244 & 1.507 \\
\hline During Test & 1.412 & 0.278 & 0.103 & 0.077 & 0.331 & 0.365 & 1.64 & 1.74 & 0.730 & 0.278 & 0.196 & 0.100 & 0.309 & 0.460 & 1.733 & 1.279 \\
\hline After Test & 0.783 & 0.170 & 0.052 & 0.061 & 0.205 & 0.573 & 2.51 & 2.48 & 0.591 & 0.111 & 0.108 & 0.117 & 0.265 & 0.990 & 1.254 & 0.336 \\
\hline \multicolumn{17}{|c|}{ 90\% CONFIDENCE LIMITS } \\
\hline Before Test & 0.879 & 0.146 & 0.099 & 0.053 & 0.290 & 0.483 & 0.733 & 1.12 & 0.378 & 0.146 & 0.133 & 0.141 & 0.194 & 1.104 & 2.14 & 1.44 \\
\hline During Test & 1.346 & 0.265 & 0.098 & 0.073 & 0.316 & 0.348 & 1.56 & 1.66 & 0.696 & 0.265 & 0.187 & 0.095 & 0.294 & 0.439 & 1.65 & 1.22 \\
\hline After Test & 0.747 & 0.162 & 0.049 & 0.058 & 0.196 & 0.546 & 2.39 & 2.36 & 0.695 & 0.131 & 0.127 & 0.138 & 0.312 & 1.165 & 1.48 & 0.395 \\
\hline
\end{tabular}

Terms and abbreviations:

$\begin{aligned} \text { RMF } & \text { rod mill feed } \\ \text { Con } & \text { concentrate } \\ \text { Crs } & \text { coarse } \\ \text { Fne } & \text { fine } \\ \text { Mag Fe } & \text { magnetic iron content } \\ \text { kwh/t } & \text { kilowatt-hours/ton } \\ \text { NOLA } & \text { nuclear on-line analyzer } \\ \text { FLF } & \text { flotation cell feed } \\ \text { ICP } & \text { inductively coupled plasma analysis }\end{aligned}$

$\mathrm{SiO} 2$ silica

UC Upper Chert formation

HIS high-silica portion of UC

IBC inter-bedded chert portion of UC

L1-2 Lower Slate layers 1 and 2

L3-4 Lower Slate layers 3 and 4

IND TOT indicated total iron

TLS tailings

Rod mill 2 and Step 1\&2 refer to the low-A factor line. Rod mill 3 and Step 3 refer to the high-A factor line. 


\section{Appendix: Additional Charts from Ore Segregation Test \#1}

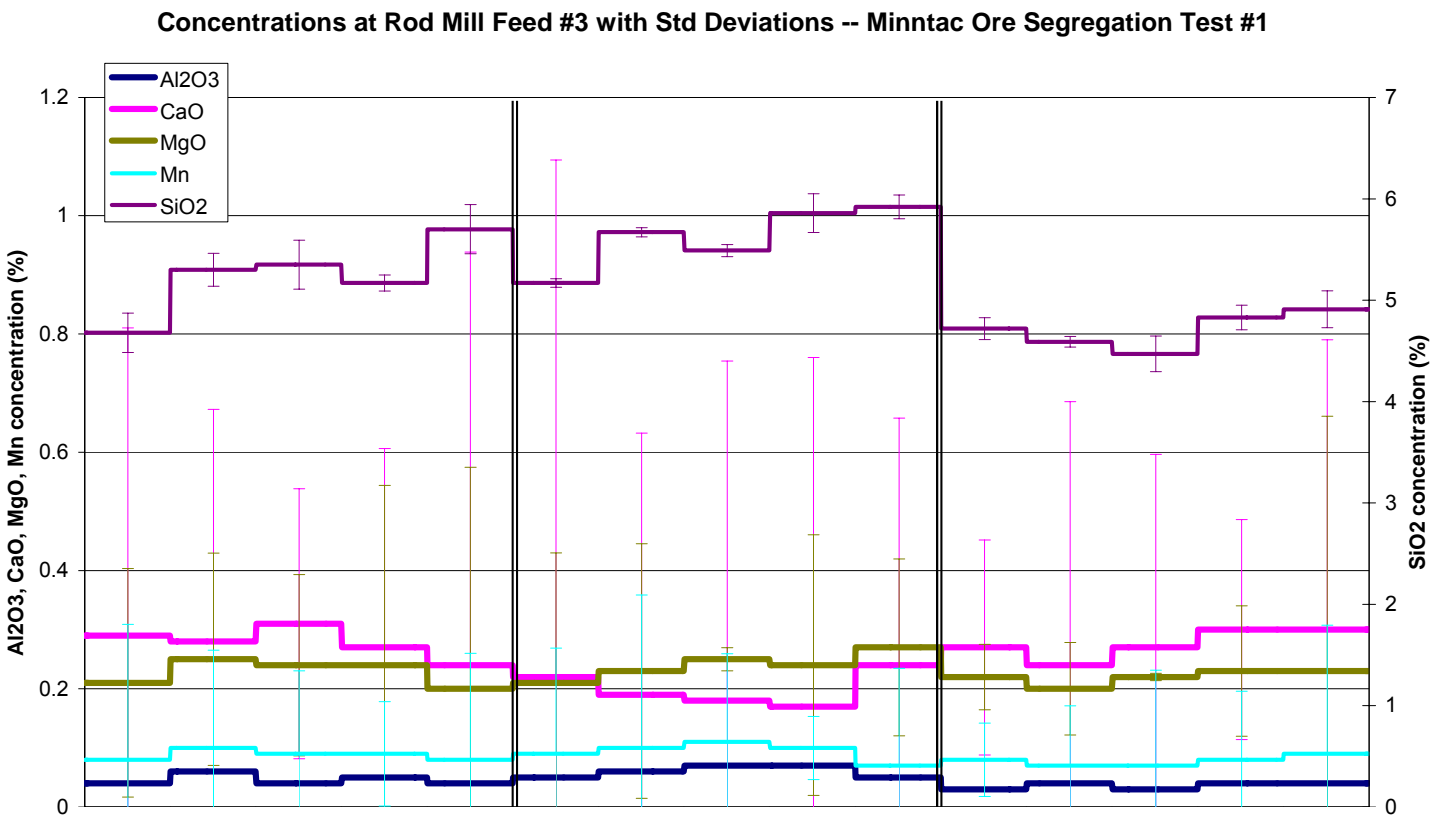

\begin{tabular}{|c|c|c|c|c||c|c|c|c|c||c|c|c|c|c|} 
22-Apr- & $23-A p r-$ & $24-A p r-$ & $25-A p r-$ & $26-A p r-$ & $27-A p r-$ & $28-A p r-$ & $29-A p r-$ & $30-A p r-$ & 1-May- & 2-May- & 3-May- & 4-May- & 5-May- & 6-May- \\
03 & 03 & 03 & 03 & 03 & 03 & 03 & 03 & 03 & 03 & 03 & 03 & 03 & 03 & 03
\end{tabular}

Concentrations at Rod Mill Feed \#2 with Std Deviations -- Minntac Ore Segregation Test \#1

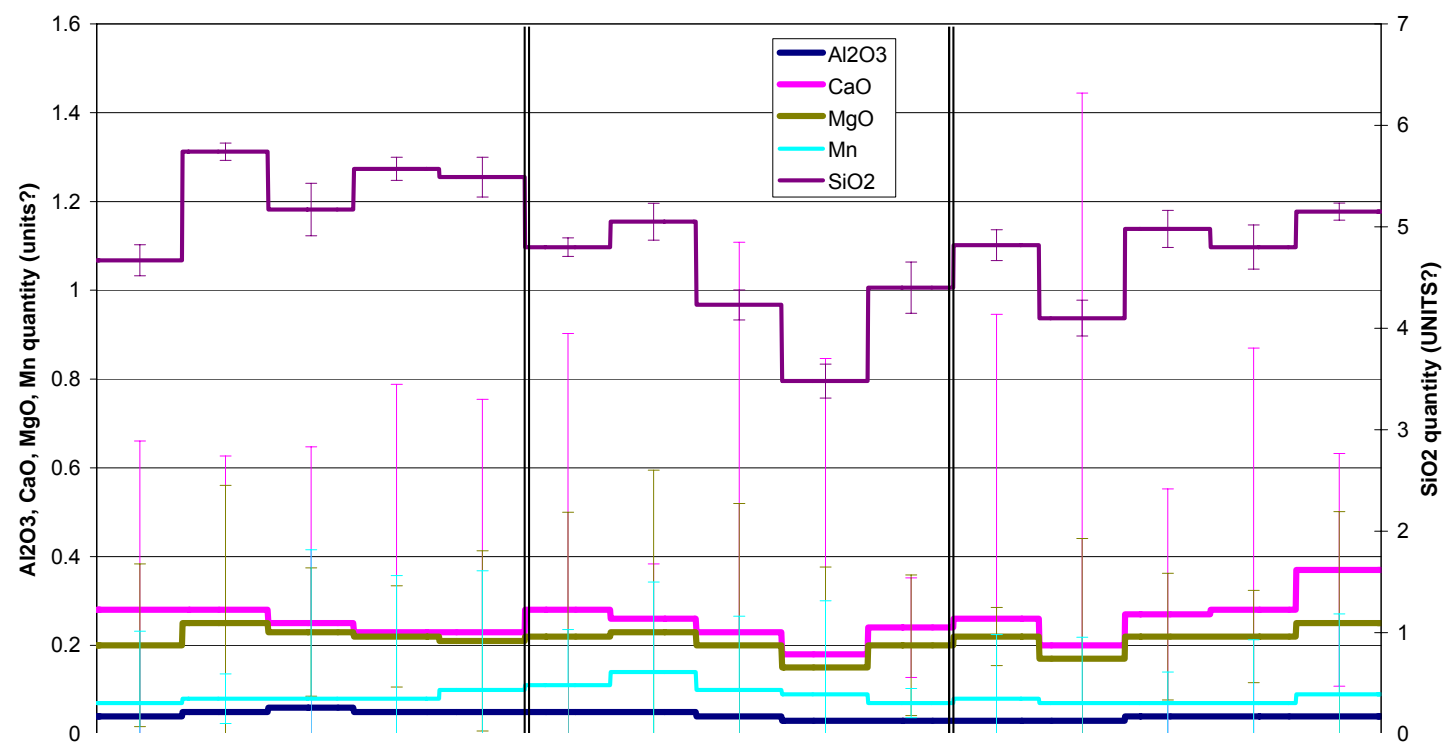

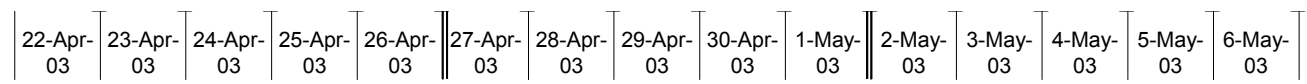




\section{Appendix: Data Summary from Ore Segregation Test \#2}

\begin{tabular}{|c|c|c|c|c|c|c|c|c|c|c|c|c|c|c|}
\hline & \multicolumn{4}{|c|}{ Secondary Crusher Power } & \multicolumn{5}{|c|}{ Rod Mill \#2 Feed (R2S) } & \multicolumn{5}{|c|}{ Rod Mill \#3 Feed (R3S) } \\
\hline & $1 \& 2$ & $1 \& 2$ & $3 \& 4$ & $3 \& 4$ & ICP & ICP & ICP & ICP & ICP & ICP & ICP & $\mathrm{ICP}$ & ICP & ICP \\
\hline AVERAGES & crush - idle & $W+E$ & crush - idle & $W+E$ & $\mathrm{Al}$ & $\mathrm{Ca}$ & $\mathrm{Mg}$ & $\mathrm{Mn}$ & $\mathrm{SiO}_{2}$ & $\mathrm{Al}$ & $\mathrm{Ca}$ & $\mathrm{Mg}$ & $\mathrm{Mn}$ & $\mathrm{SiO}_{2}$ \\
\hline \begin{tabular}{|r|} 
Before Test \\
\end{tabular} & 335 & 300 & 334 & 289 & 0.0483 & 0.298 & 0.227 & 0.0867 & 4.99 & 0.0517 & 0.273 & 0.230 & 0.0800 & 5.12 \\
\hline During Test & 306 & 261 & 310 & 271 & 0.0425 & 0.244 & 0.171 & 0.1300 & 4.12 & 0.0763 & 0.223 & 0.266 & 0.0950 & 6.18 \\
\hline After Test & 333 & 284 & 339 & 279 & 0.0567 & 0.218 & 0.198 & 0.0950 & 4.71 & 0.0550 & 0.213 & 0.187 & 0.0900 & 4.58 \\
\hline \multicolumn{15}{|l|}{ STD DEVIATIONS } \\
\hline \begin{tabular}{|c|} 
Before Test \\
\end{tabular} & 31.7 & 44.7 & 18.1 & 16.7 & 0.00408 & 0.0637 & 0.0163 & 0.0216 & 0.558 & 0.00753 & 0.0615 & 0.0228 & 0.0200 & 0.310 \\
\hline During Test & 24.7 & 21.4 & 63.0 & 28.4 & 0.00463 & 0.1070 & 0.0398 & 0.0200 & 0.324 & 0.00744 & 0.0537 & 0.0540 & 0.0169 & 0.490 \\
\hline After Test & 15.1 & 28.0 & 31.8 & 32.8 & 0.00516 & 0.0349 & 0.0172 & 0.0207 & 0.175 & 0.00837 & 0.0484 & 0.0339 & 0.0200 & 0.621 \\
\hline \multicolumn{15}{|l|}{ 90\% CONFIDENCE LIMITS } \\
\hline $\begin{array}{r}\text { Before Test } \\
\end{array}$ & 13.9 & 19.6 & 7.93 & 7.32 & 0.00336 & 0.0524 & 0.0134 & 0.0178 & 0.459 & 0.00619 & 0.0506 & 0.0188 & 0.0165 & 0.255 \\
\hline During Test & 9.29 & 8.06 & 23.7 & 10.71 & 0.00310 & 0.0717 & 0.0267 & 0.0134 & 0.217 & 0.00498 & 0.0359 & 0.0362 & 0.0113 & 0.328 \\
\hline After Test & 6.00 & 11.12 & 12.6 & 13.07 & 0.00425 & 0.0287 & 0.0142 & 0.0171 & 0.144 & 0.00688 & 0.0398 & 0.0279 & 0.0165 & 0.511 \\
\hline
\end{tabular}

\begin{tabular}{|c|c|c|c|c|c|c|c|c|c|c|}
\hline & \multicolumn{5}{|c|}{ Float Feed (FLF) } & \multicolumn{5}{|c|}{ Float Feed (FFD) } \\
\hline & ICP & ICP & ICP & $\mathrm{ICP}$ & ICP & ICP & ICP & $\mathrm{ICP}$ & $\mathrm{ICP}$ & ICP \\
\hline AVERAGES & $\mathrm{Al}$ & $\mathrm{Ca}$ & $\mathrm{Mg}$ & $\mathrm{Mn}$ & $\mathrm{SiO}_{2}$ & $\mathrm{Al}$ & $\mathrm{Ca}$ & $\mathrm{Mg}$ & $\mathrm{Mn}$ & $\mathrm{SiO}_{2}$ \\
\hline \begin{tabular}{|r|} 
Before Test \\
\end{tabular} & 0.0000 & 0.424 & 0.309 & 0.0935 & 5.60 & 0.0428 & 0.277 & 0.188 & 0.0678 & 4.11 \\
\hline During Test & 0.0700 & 0.322 & 0.265 & 0.1300 & 5.40 & 0.0435 & 0.212 & 0.156 & 0.0900 & 3.87 \\
\hline After Test & 0.0771 & 0.268 & 0.240 & 0.1000 & 5.35 & 0.0479 & 0.181 & 0.144 & 0.0705 & 3.88 \\
\hline \multicolumn{11}{|l|}{ STD DEVIATIONS } \\
\hline $\begin{array}{r}\text { Before Test } \\
\end{array}$ & 0.00470 & 0.0892 & 0.0242 & 0.0218 & 0.163 & 0.00461 & 0.0633 & 0.0198 & 0.0140 & 0.199 \\
\hline During Test & 0.00690 & 0.1397 & 0.0580 & 0.0193 & 0.302 & 0.00487 & 0.0827 & 0.0314 & 0.0135 & 0.229 \\
\hline After Test & 0.00845 & 0.0532 & 0.0280 & 0.0152 & 0.251 & 0.00535 & 0.0375 & 0.0168 & 0.0113 & 0.210 \\
\hline \multicolumn{11}{|c|}{ 90\% CONFIDENCE LIMITS } \\
\hline \begin{tabular}{rl|} 
Before Test \\
\end{tabular} & 0.00199 & 0.0378 & 0.0103 & 0.00922 & 0.0689 & 0.00189 & 0.0260 & 0.00811 & 0.00572 & 0.0814 \\
\hline During Test & 0.00253 & 0.0513 & 0.0213 & 0.00707 & 0.1108 & 0.00174 & 0.0296 & 0.01126 & 0.00483 & 0.0818 \\
\hline After Test & 0.00318 & 0.0200 & 0.0105 & 0.00571 & 0.0946 & 0.00213 & 0.0149 & 0.00667 & 0.00449 & 0.0836 \\
\hline
\end{tabular}

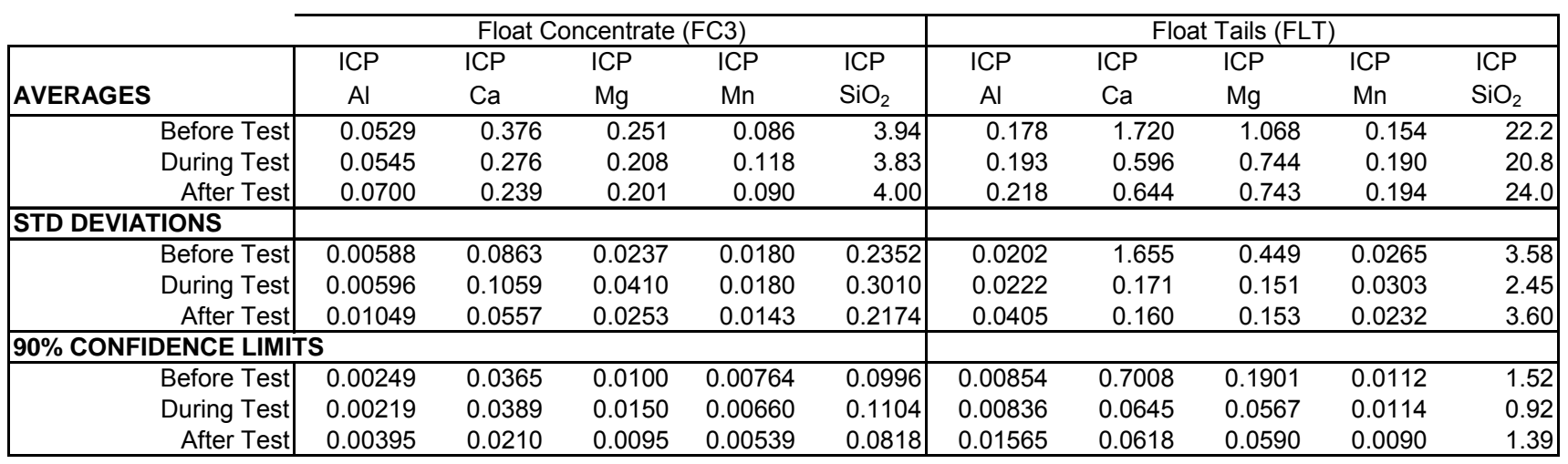


Terms and abbreviations:

$\begin{aligned} \text { RMF } & \text { rod mill feed } \\ \text { Con } & \text { concentrate } \\ \text { Crs } & \text { coarse } \\ \text { Fne } & \text { fine } \\ \text { Mag Fe } & \text { magnetic iron } \\ \text { kwh/t } & \text { kilowatt-hours/ton } \\ \text { NOLA } & \text { nuclear on-line analyzer } \\ \text { FLF \& FFD } & \text { flotation cell feed } \\ \text { FC3 } & \text { flotation concentrate (output value) } \\ \text { FLT } & \text { flotation tails (output waste) }\end{aligned}$

$\mathrm{SiO} 2$ silica

UC Upper Chert formation

HIS high-silica portion of UC

IBC inter-bedded chert portion of UC

L1-2 Lower Slate layers 1 and 2

L3-4 Lower Slate layers 3 and 4

IND TOT indicated total iron

TLS tailings

ICP inductively coupled plasma analysis 


\section{Appendix: Additional Charts from Ore Segregation Test \#2}

Crusher Performance During Minntac Mine Segregation Test \#1

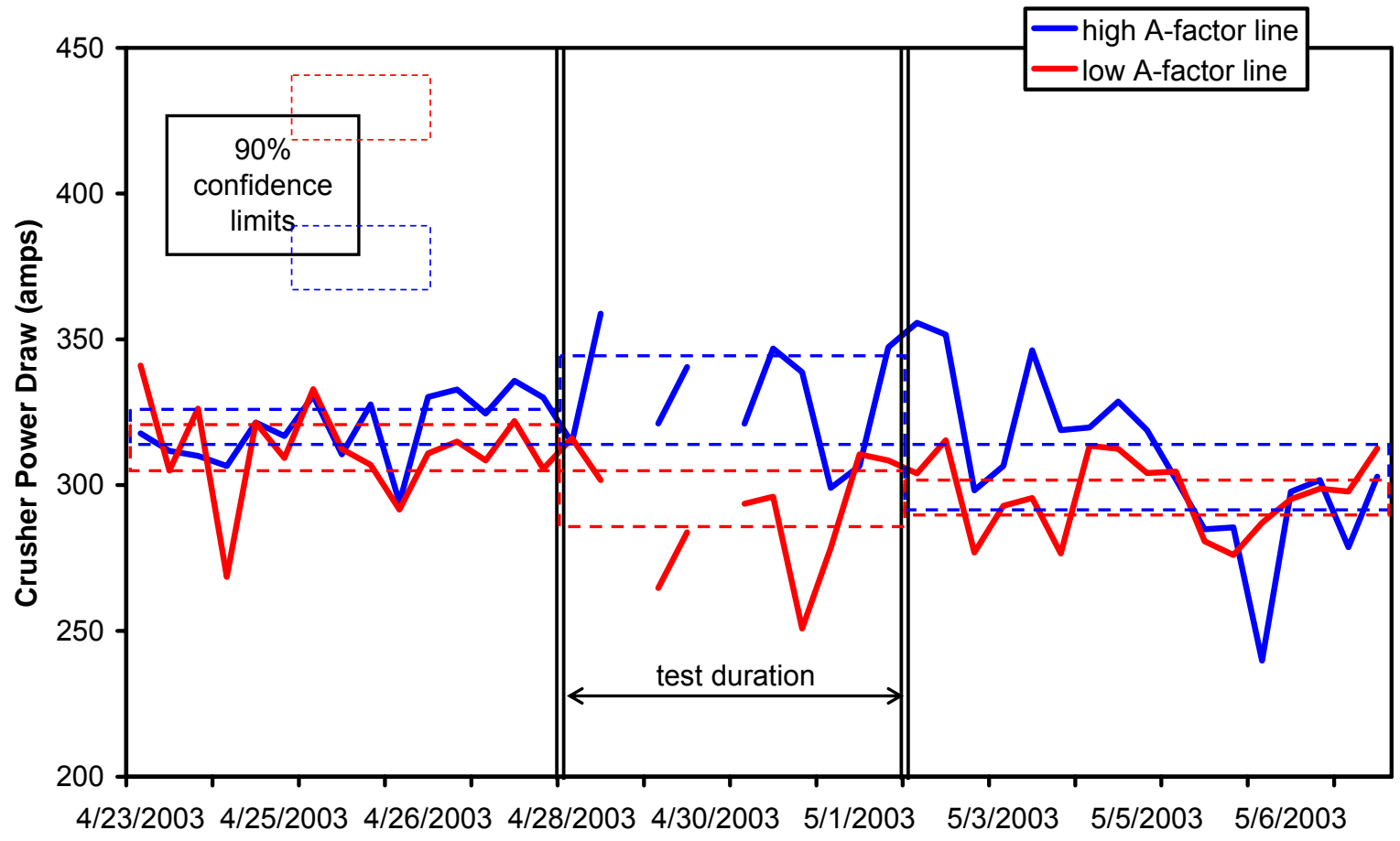

Crusher Performance During Minntac Mine Segregation Test \#2

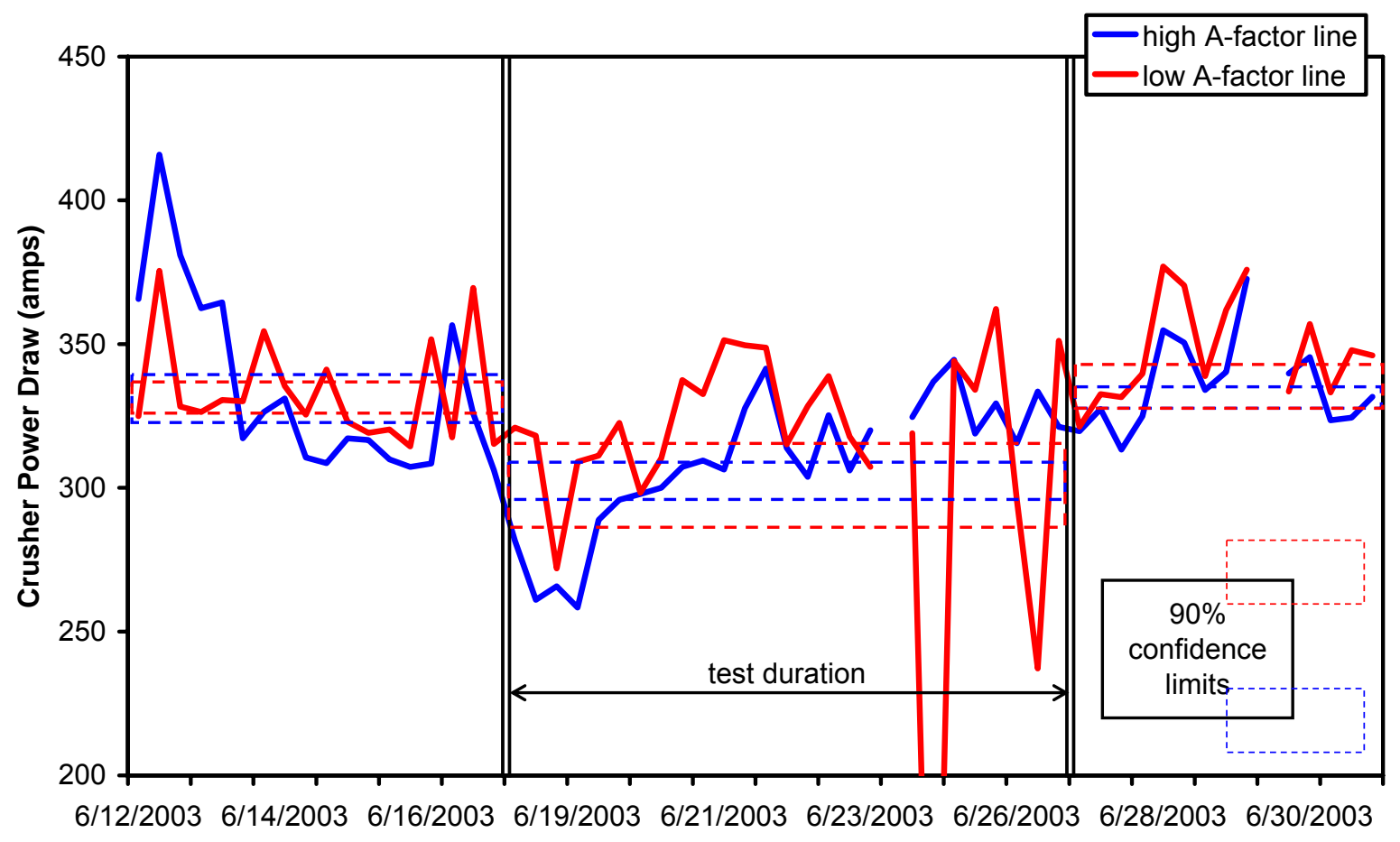


Silica Comparison in Crusher Feed, Minntac Mine Seg Test \#2
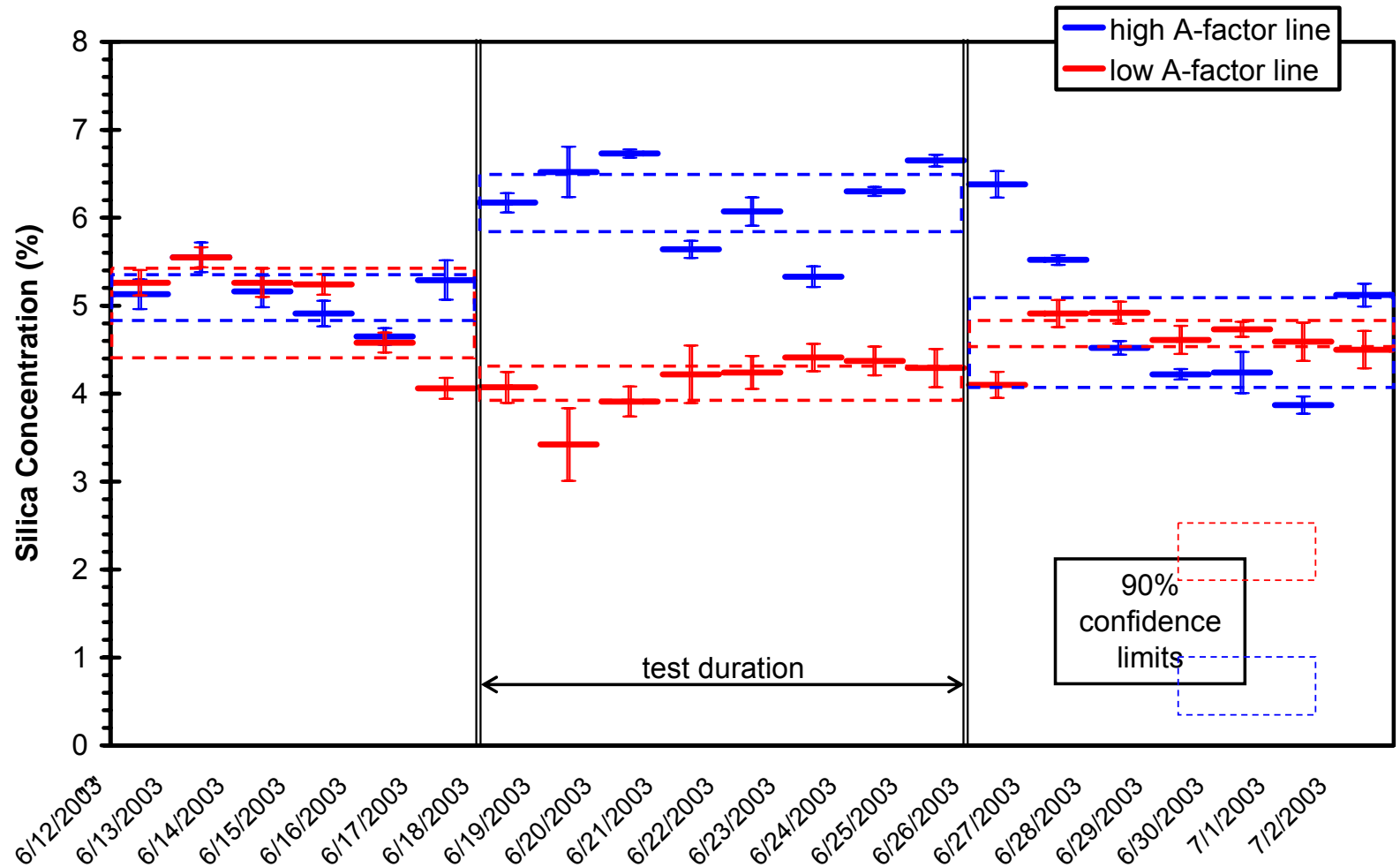

Manganese Comparison in Crusher Feed, Minntac Mine Seg Test \#2

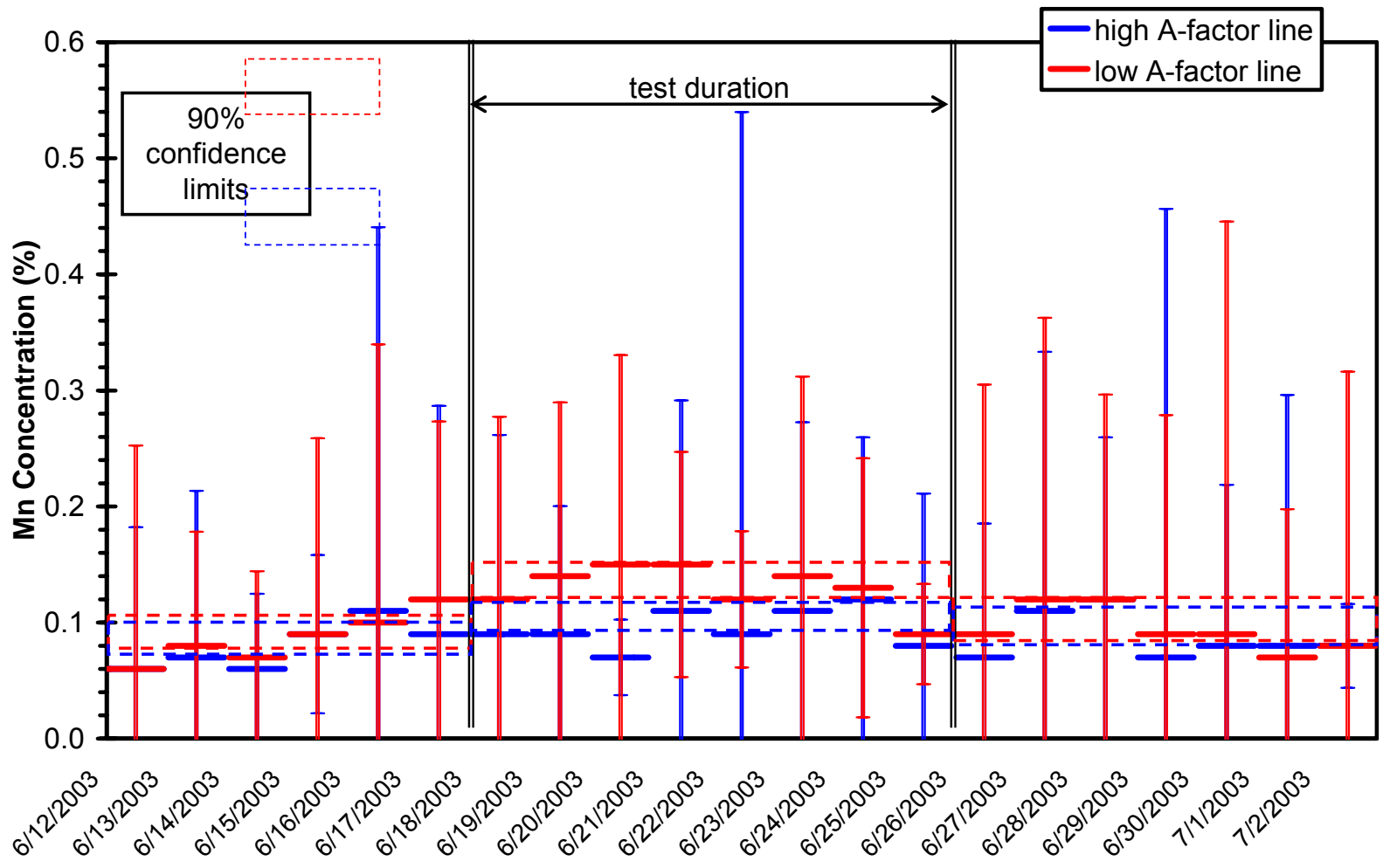


Magnesium Comparison in Crusher Feed, Minntac Mine Seg Test \#2
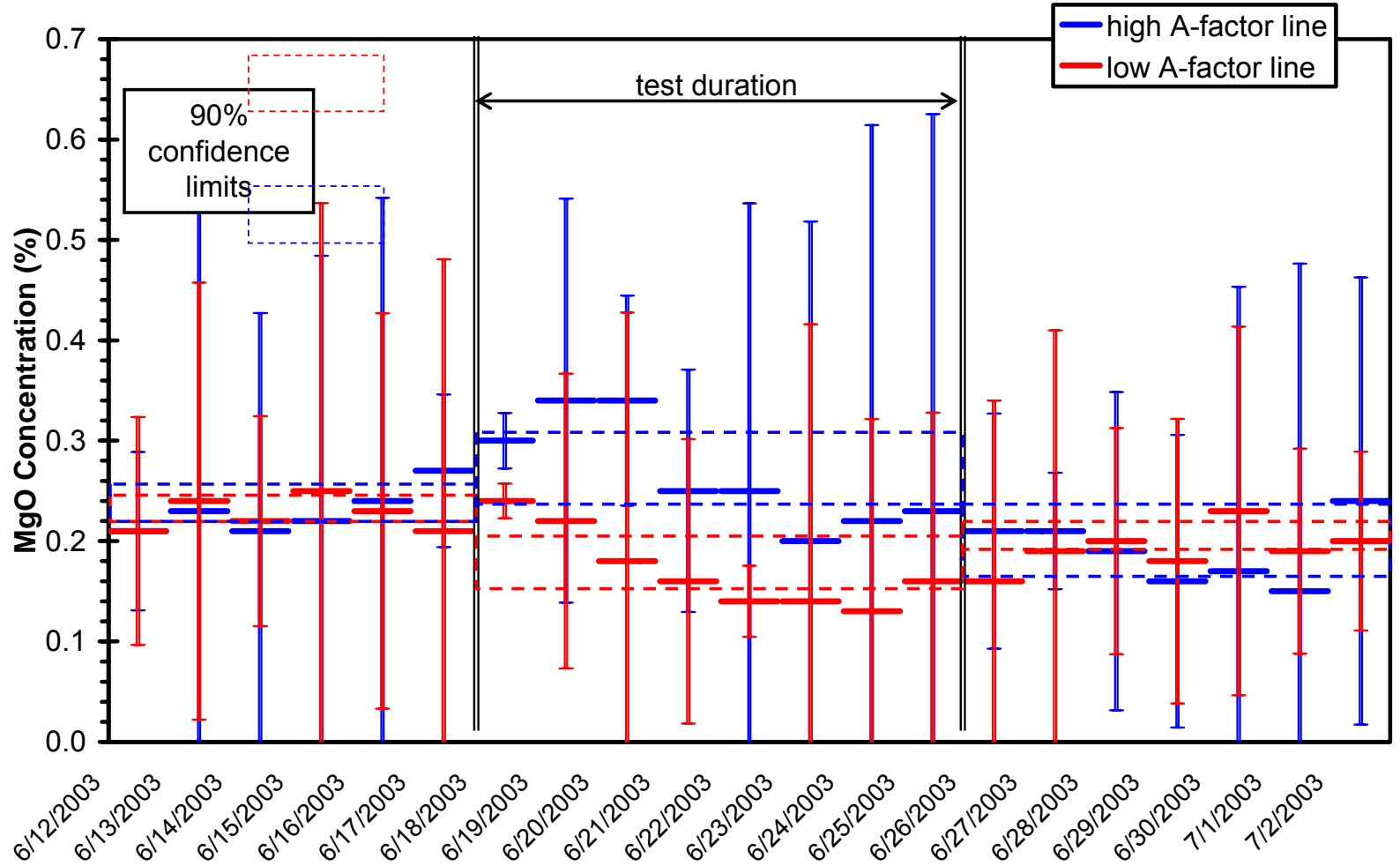

Calcium Comparison in Crusher Feed, Minntac Mine Seg Test \#2

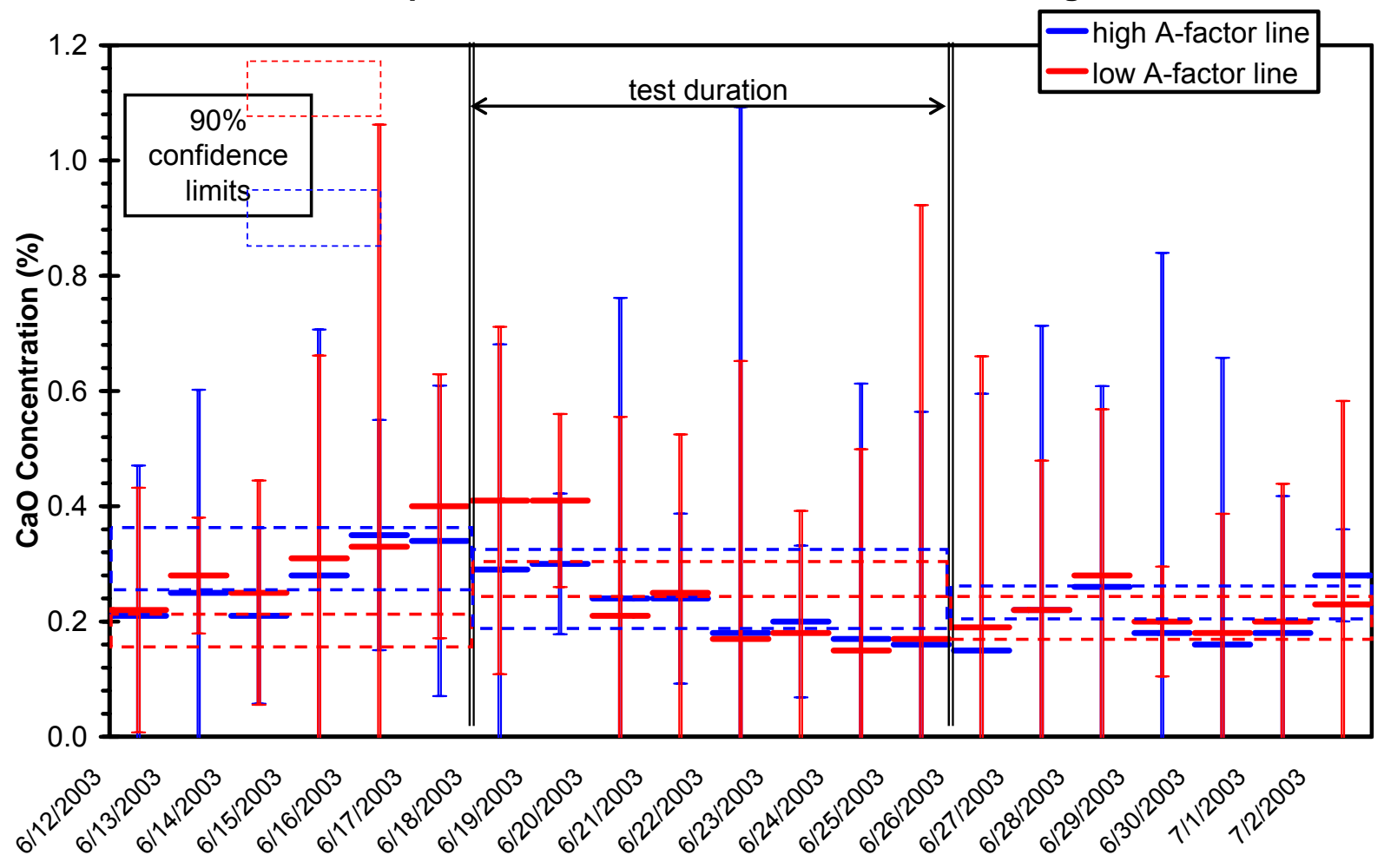




\section{Alumina Comparison in Crusher Feed, Minntac Mine Seg Test \#2}

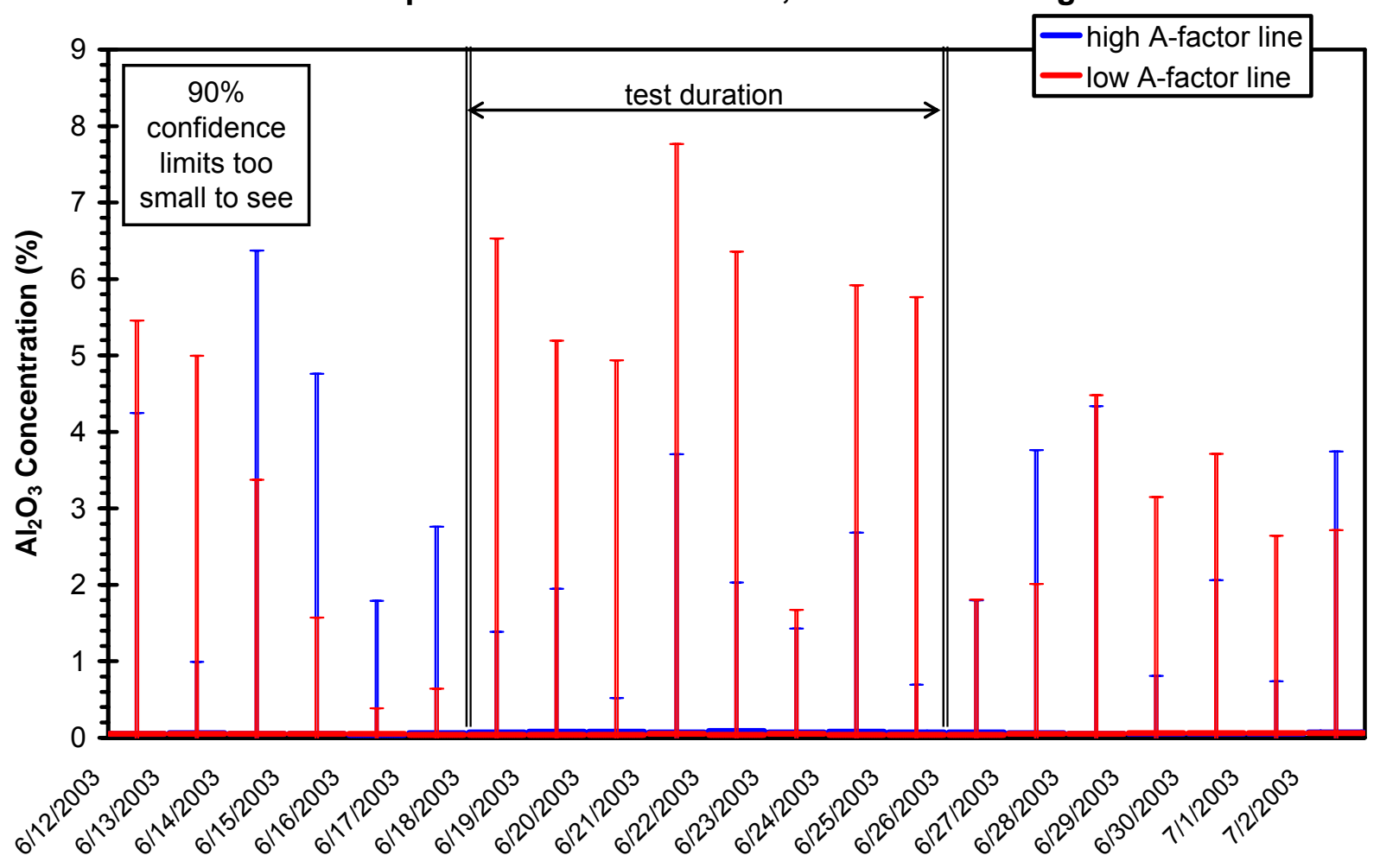




\section{Appendix: Additional Charts from Ore Segregation Test \#3}
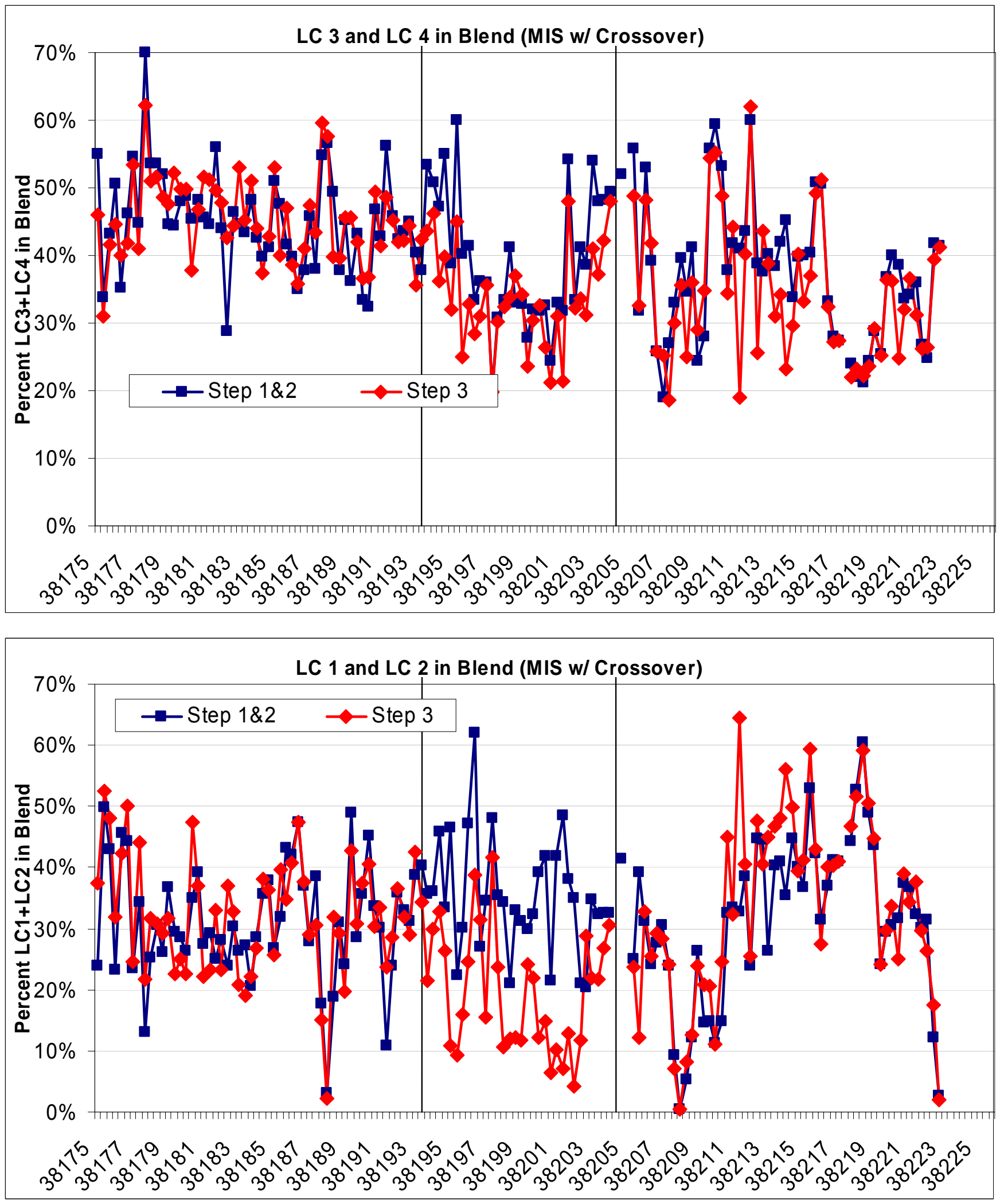

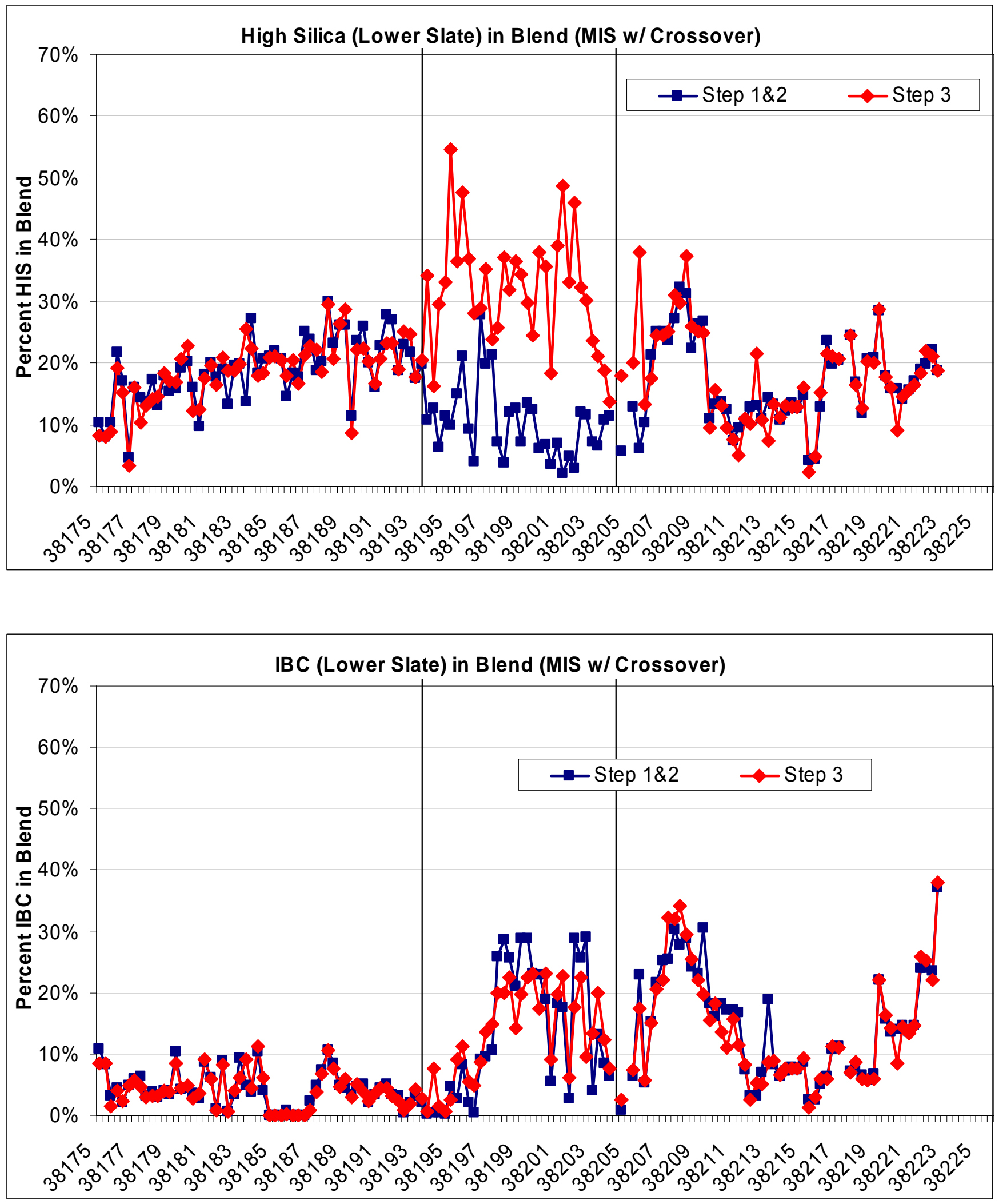

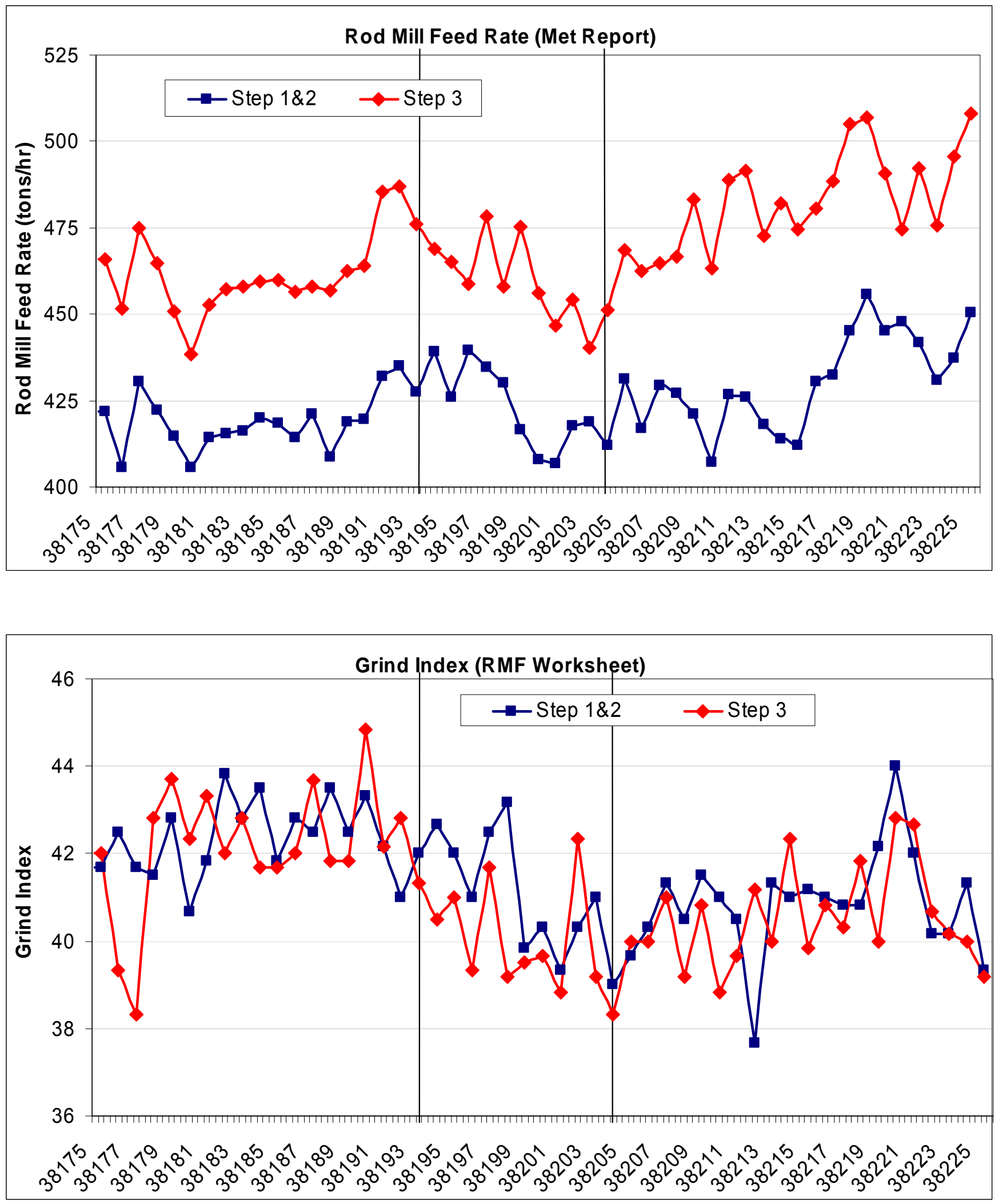

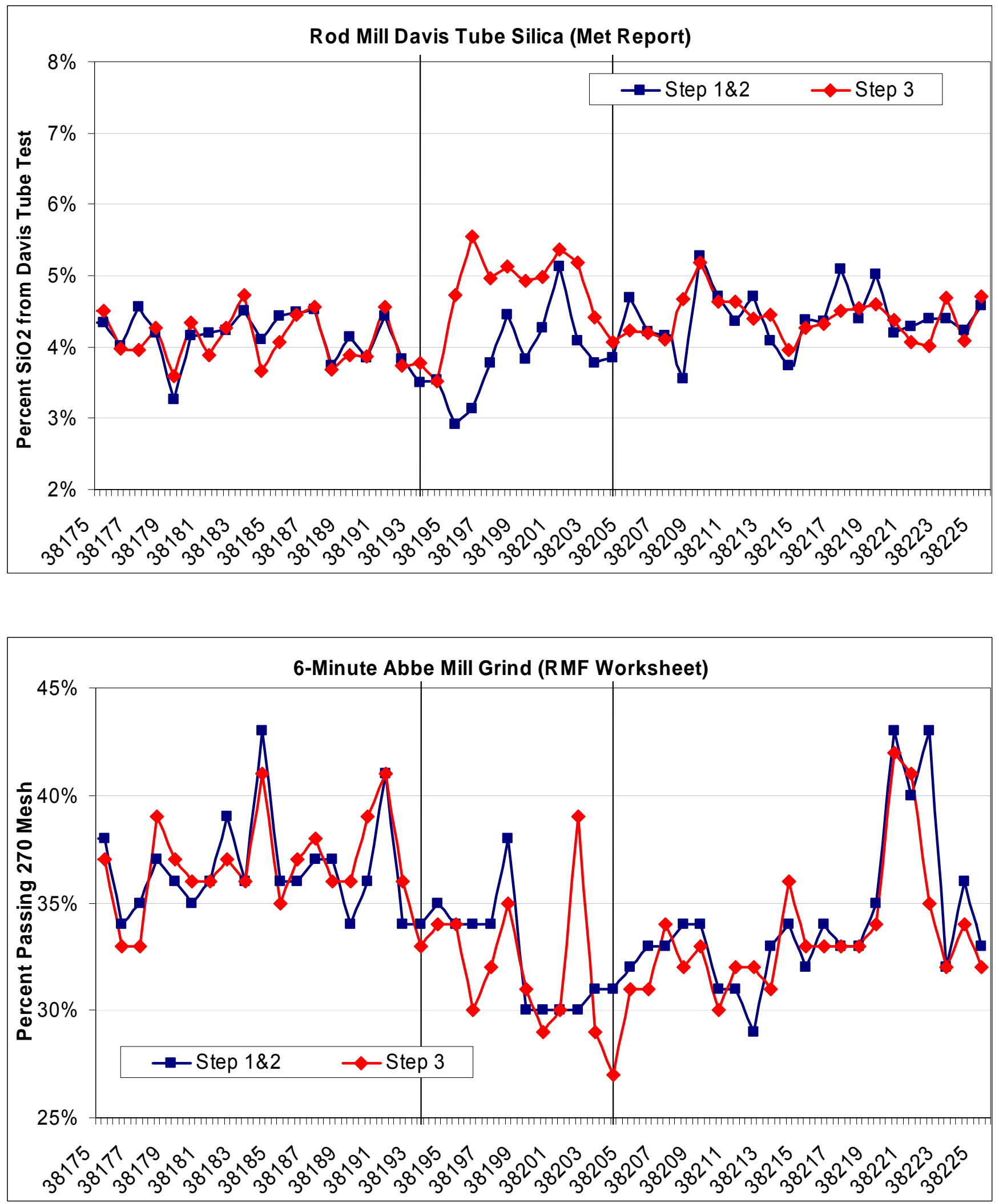

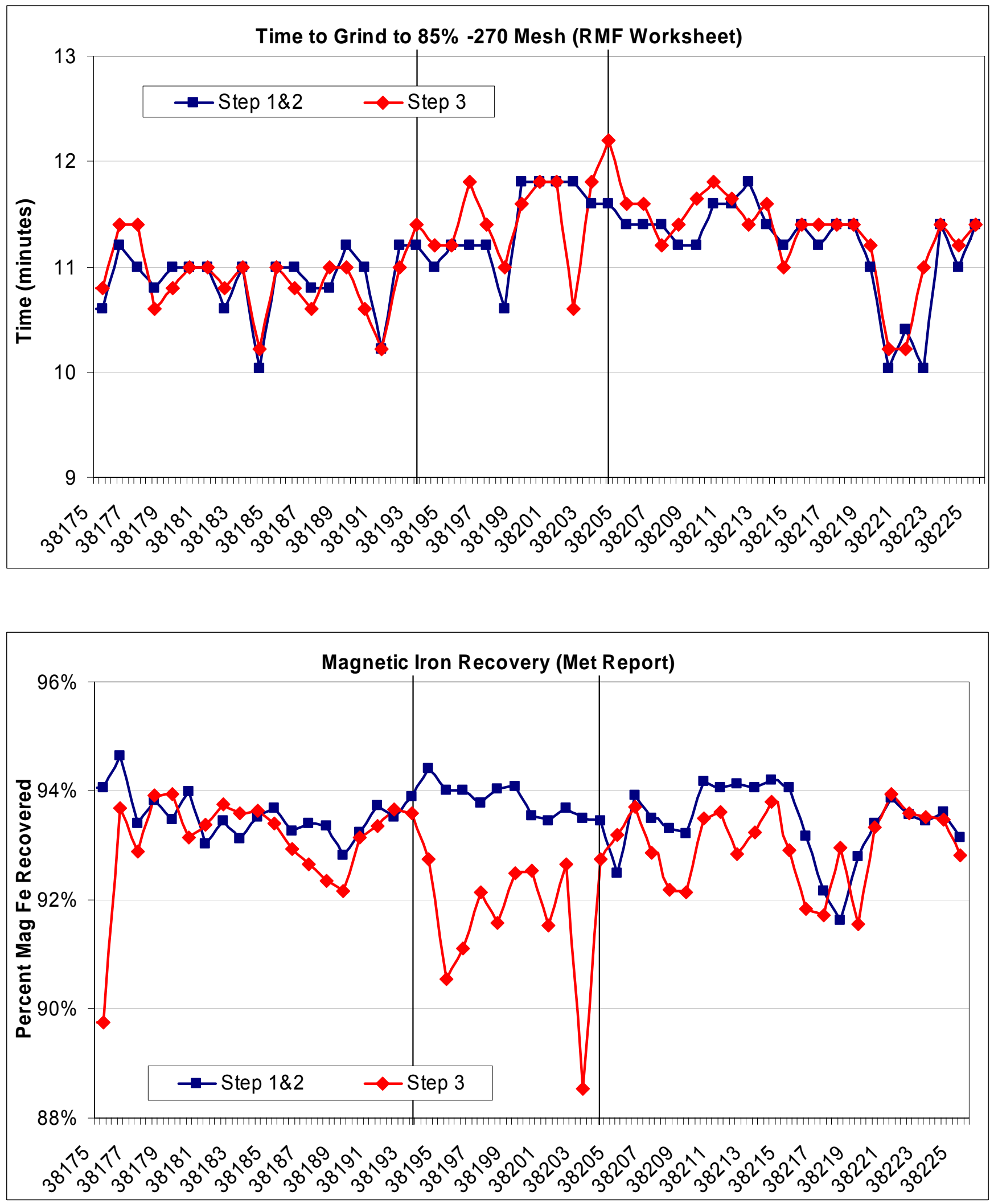

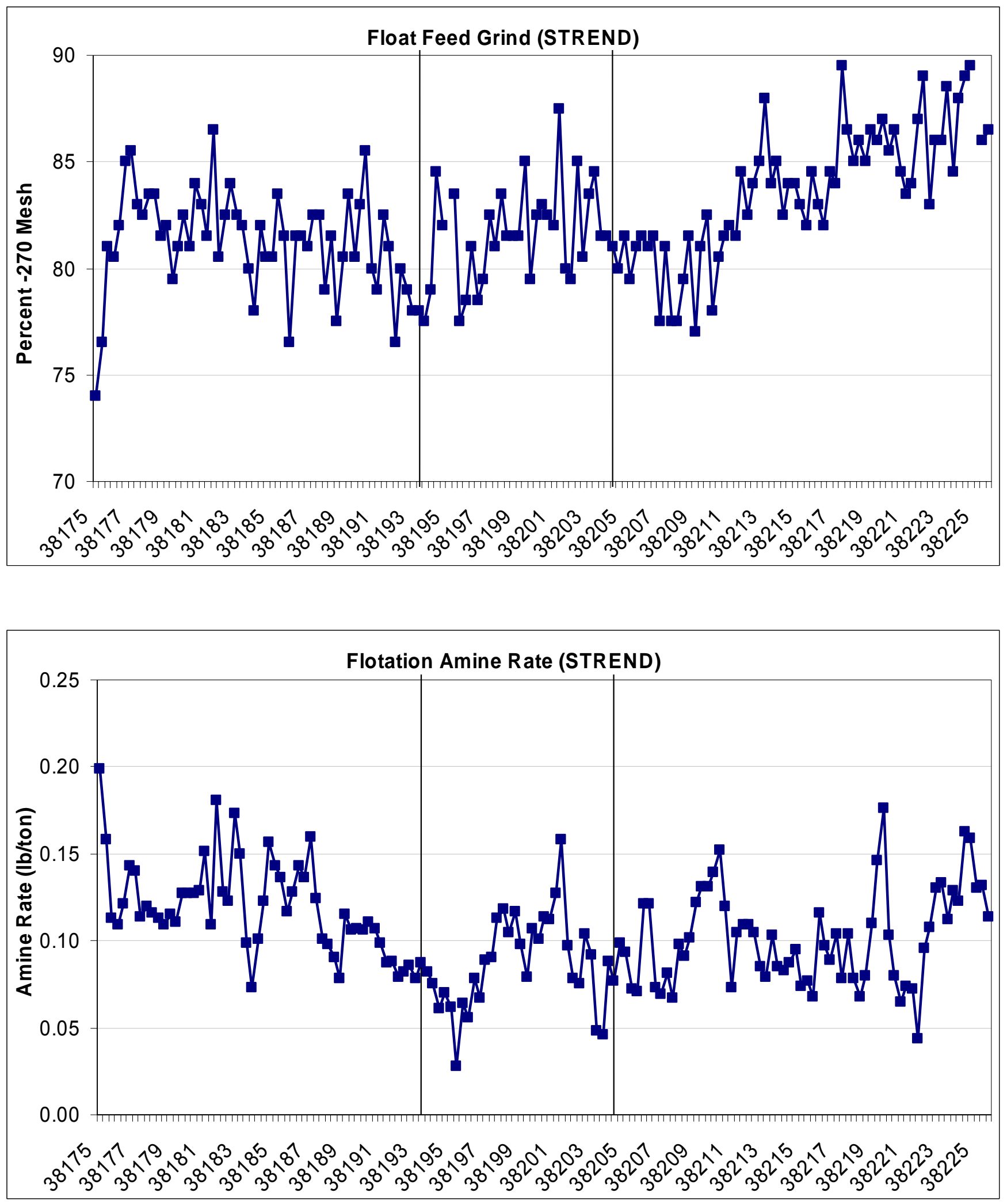

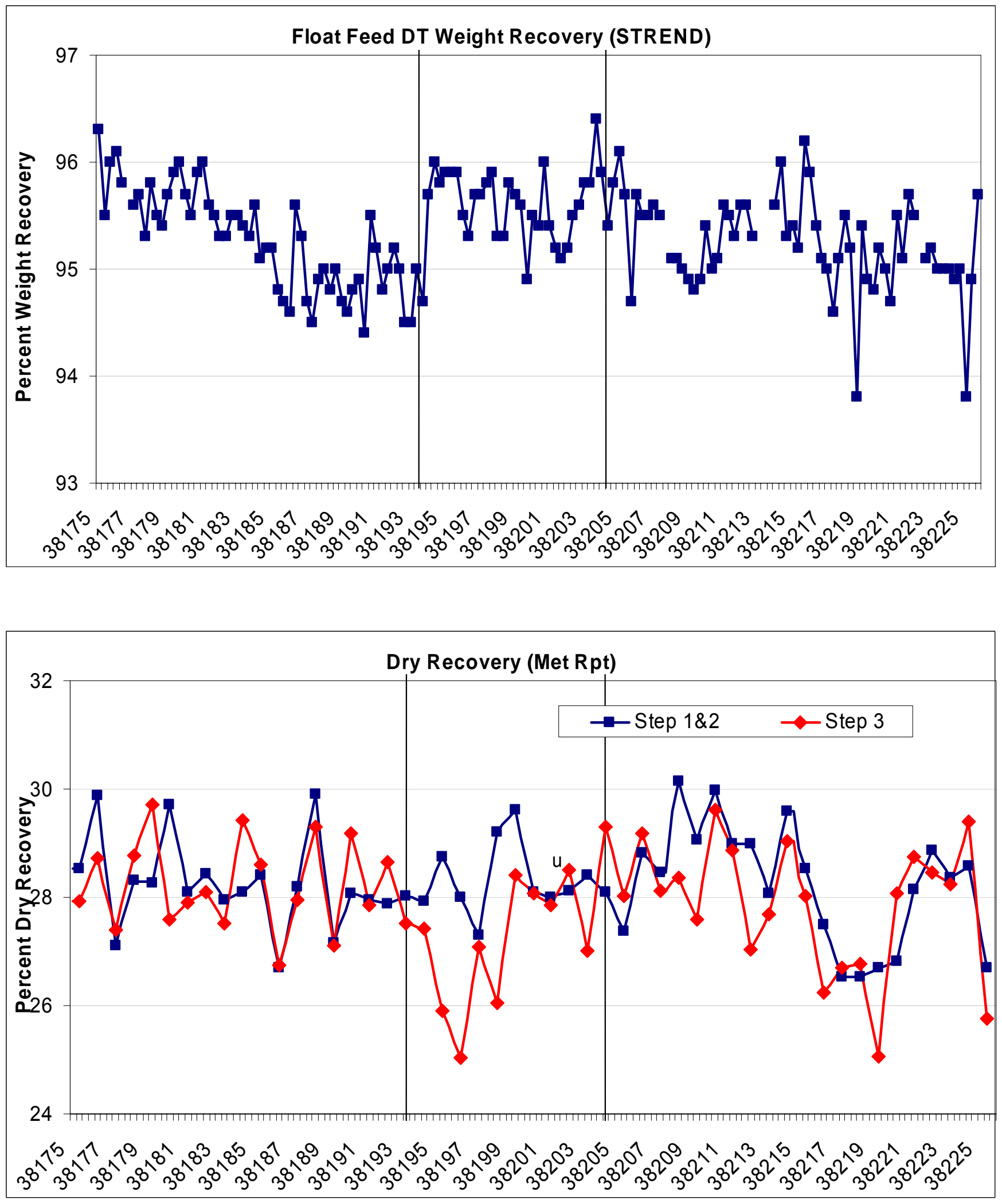
Appendix: Additional Charts from Background Dataset
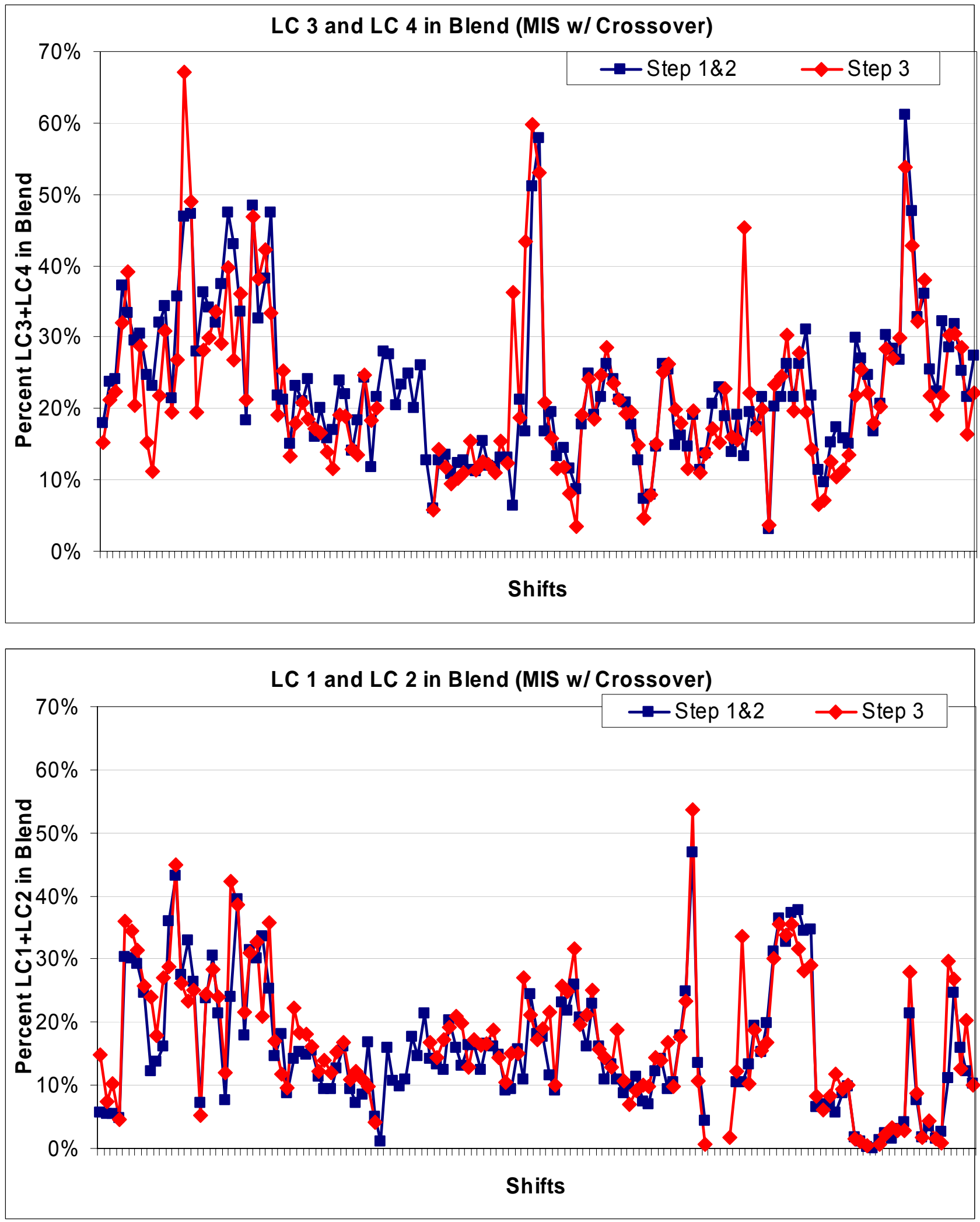

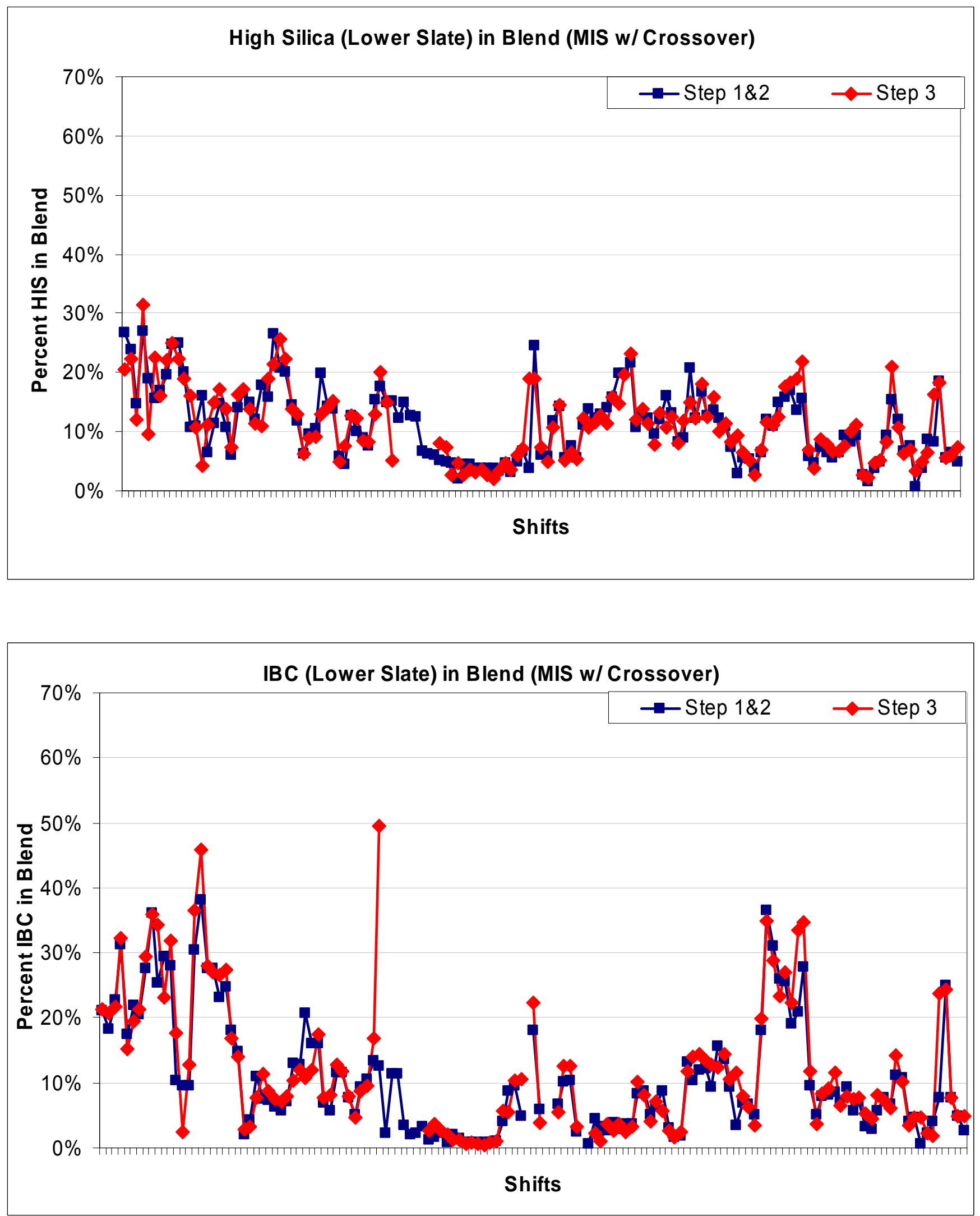

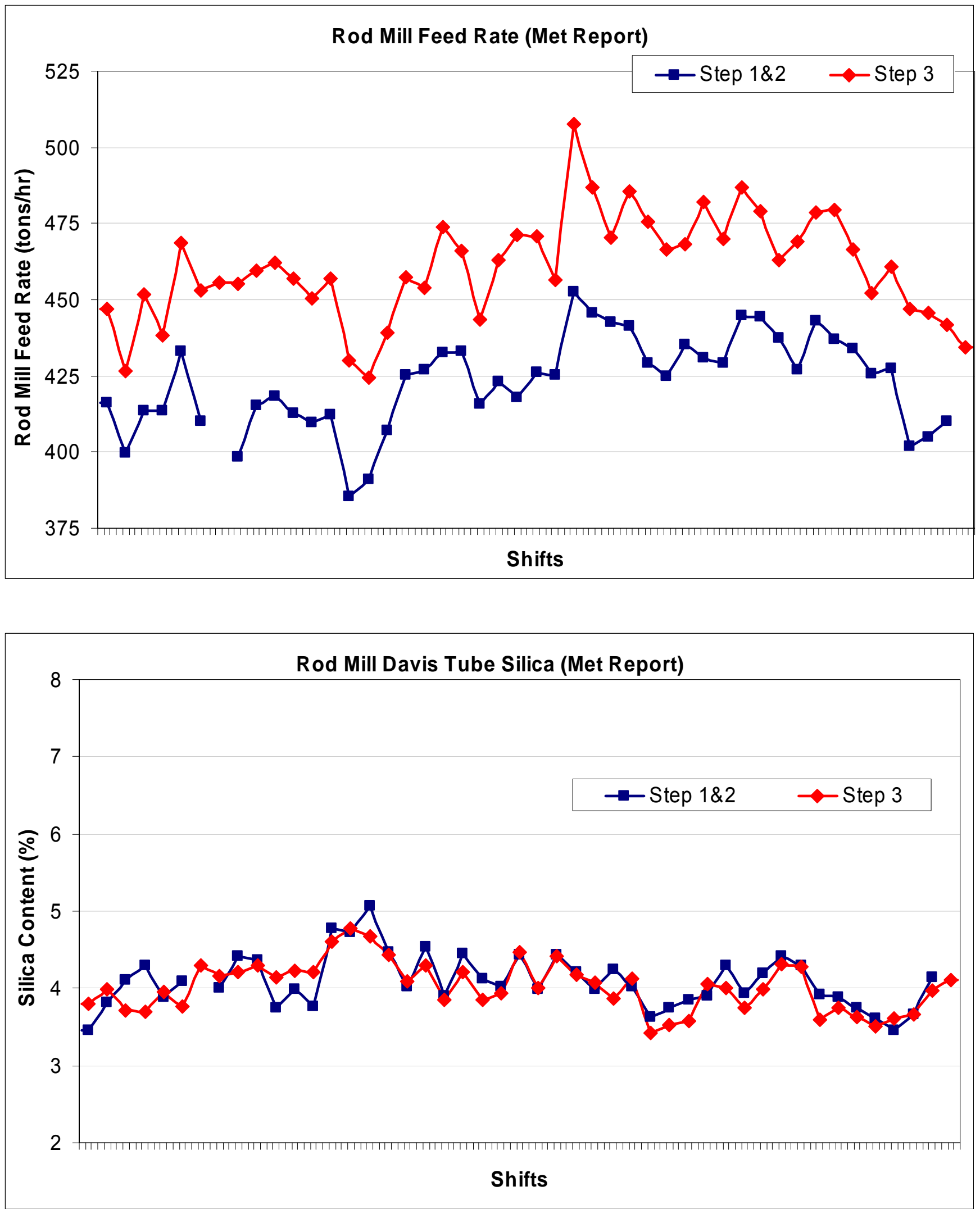

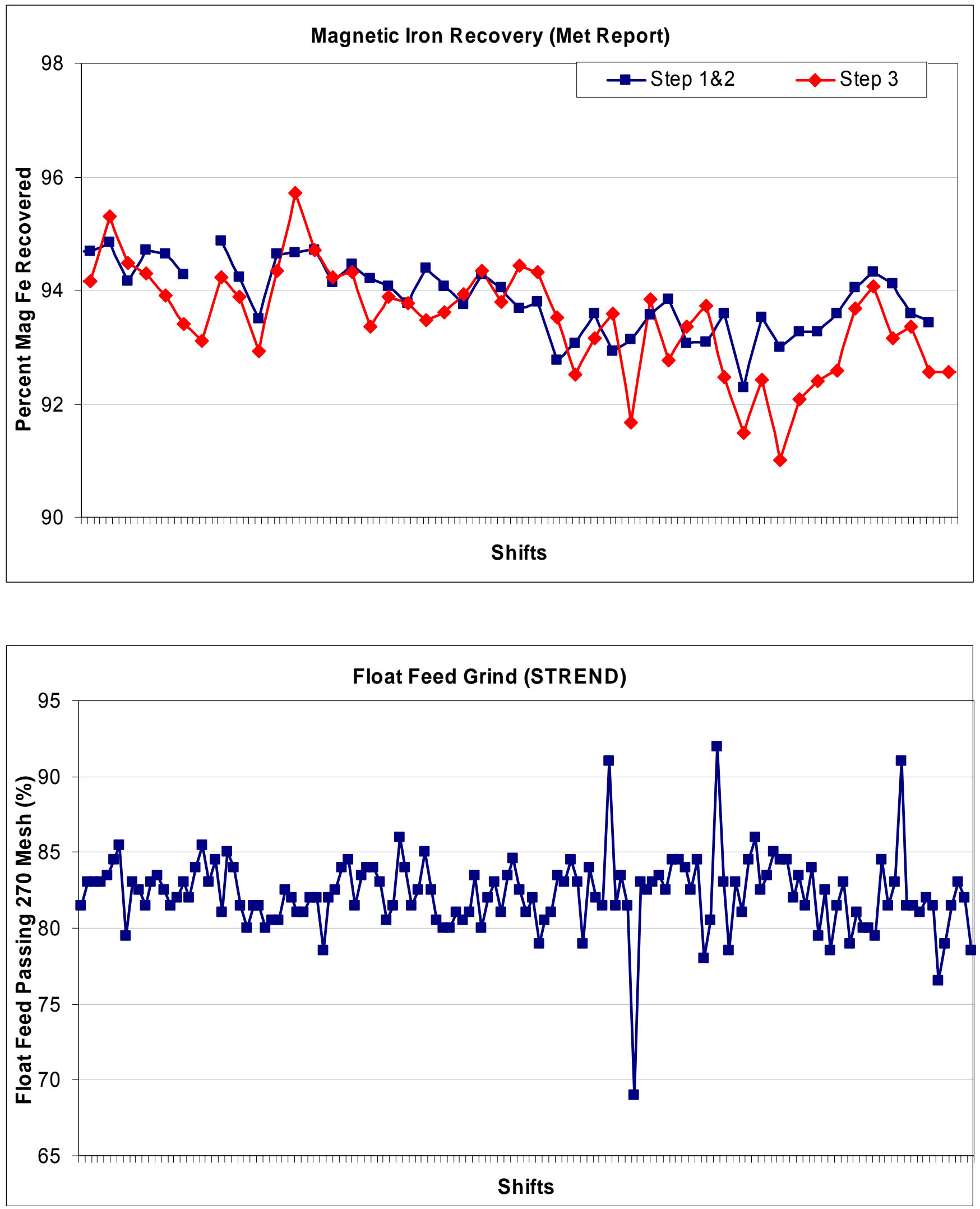

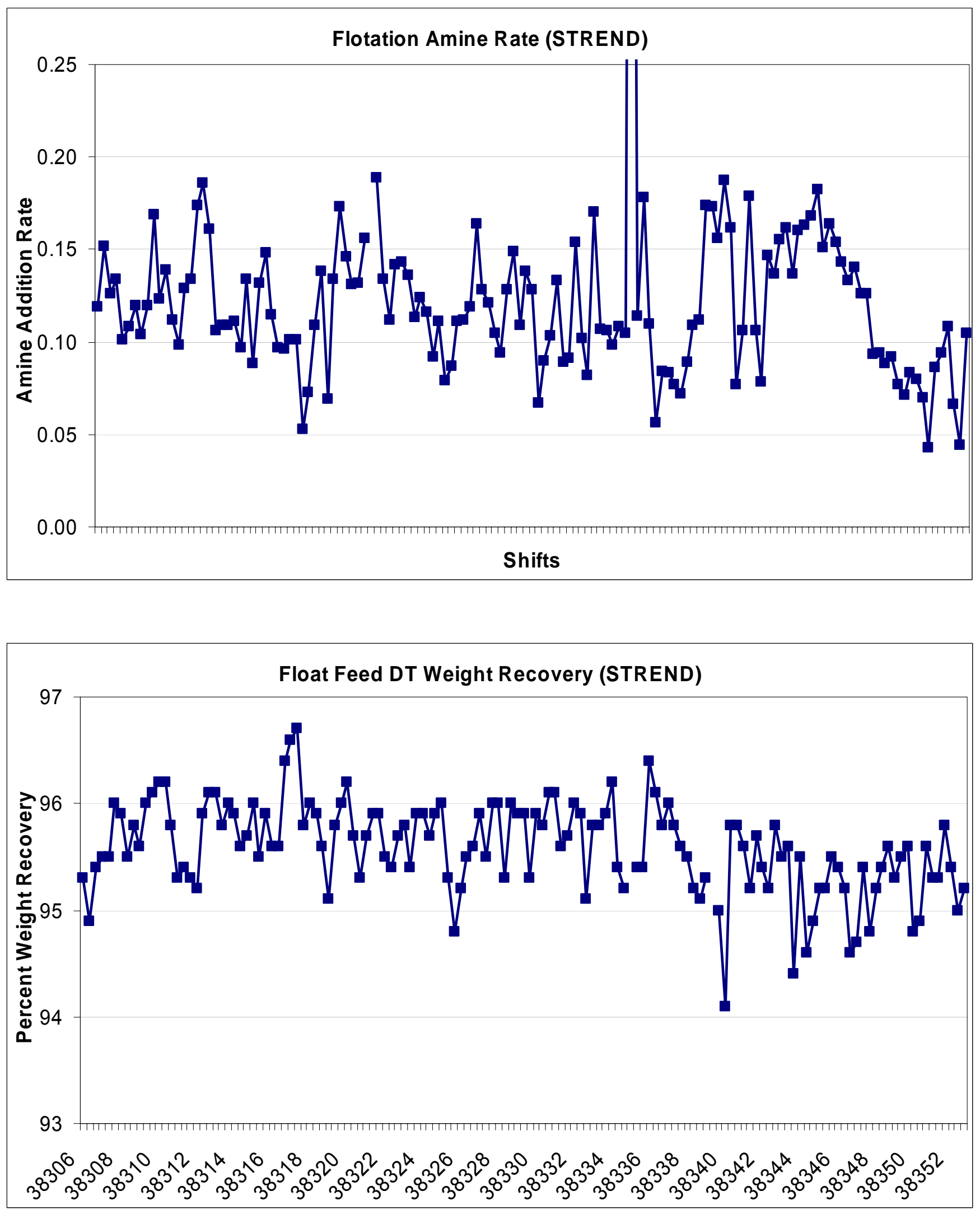


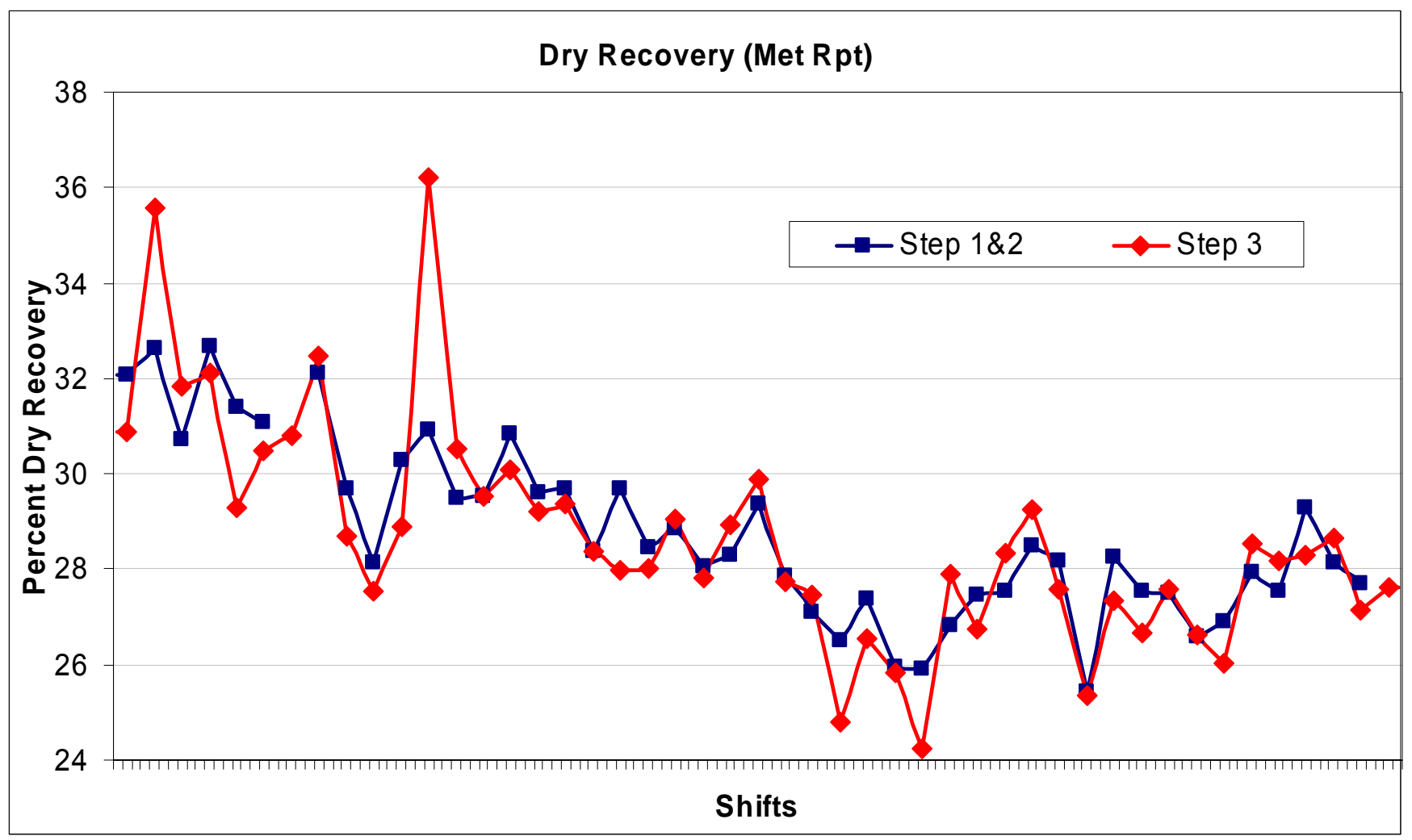




\section{Appendix: Orebody Models}

Charts of Ore Grindability, by Layer, from UMR Orebody Model for Minntac Mine.
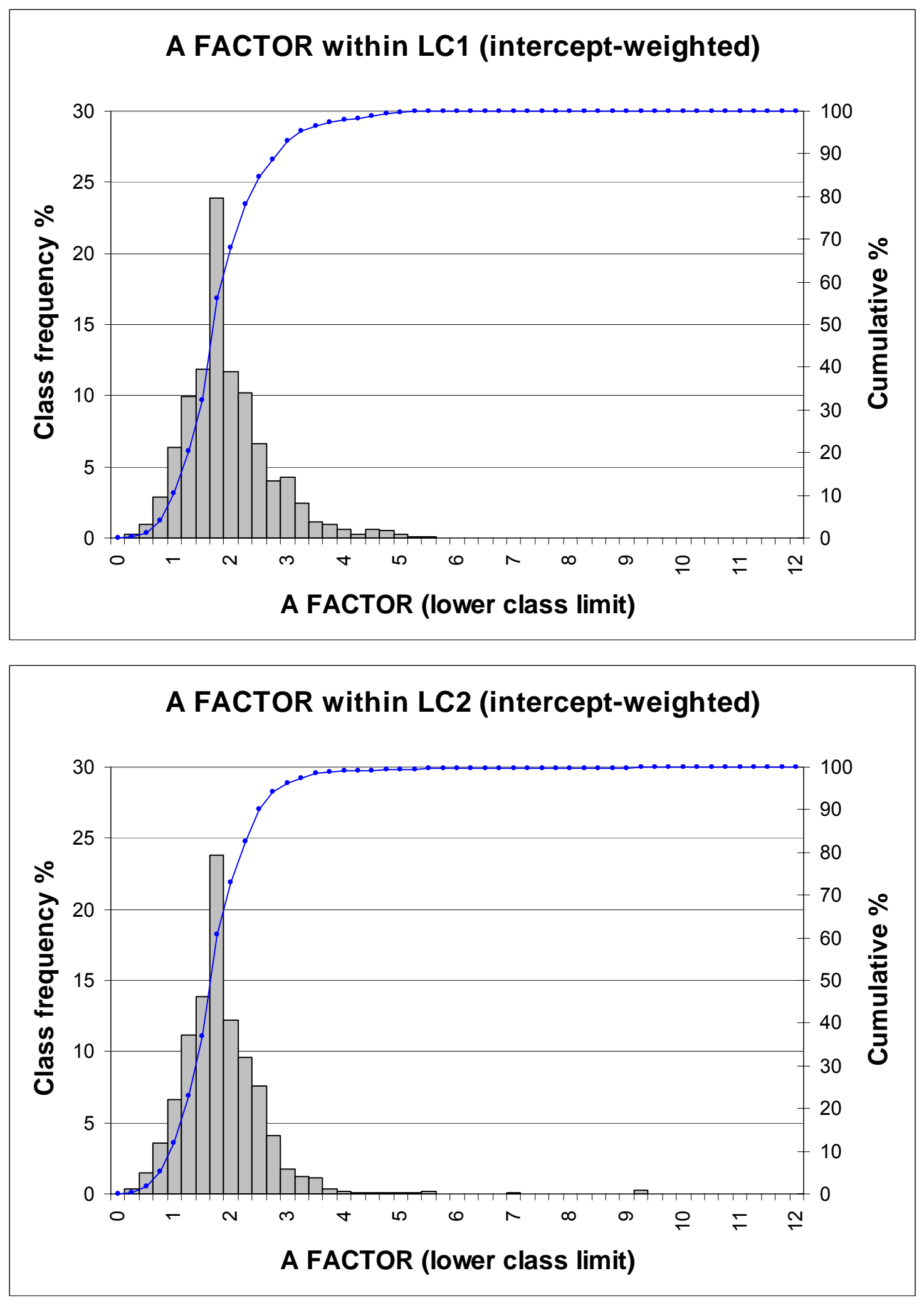

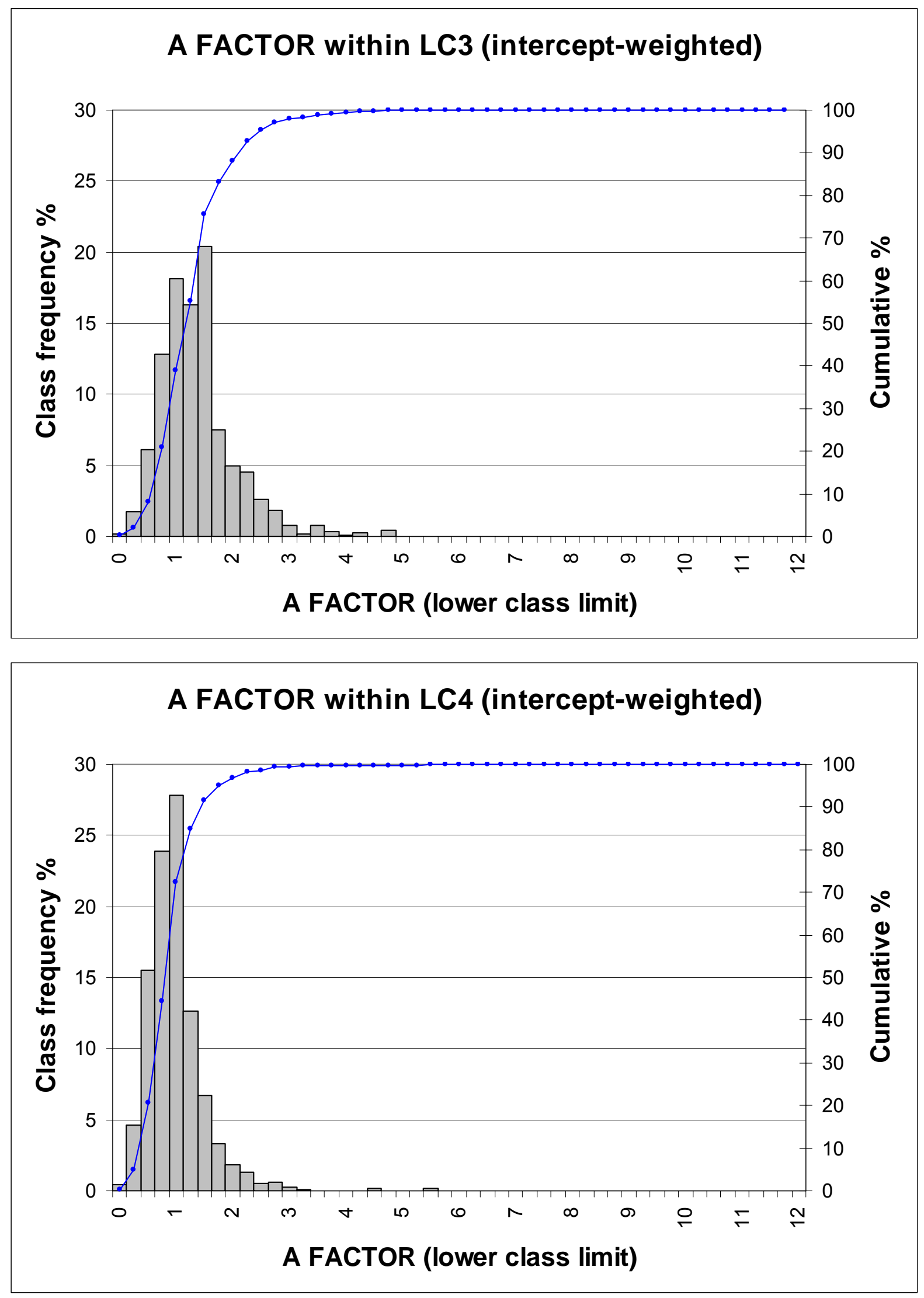

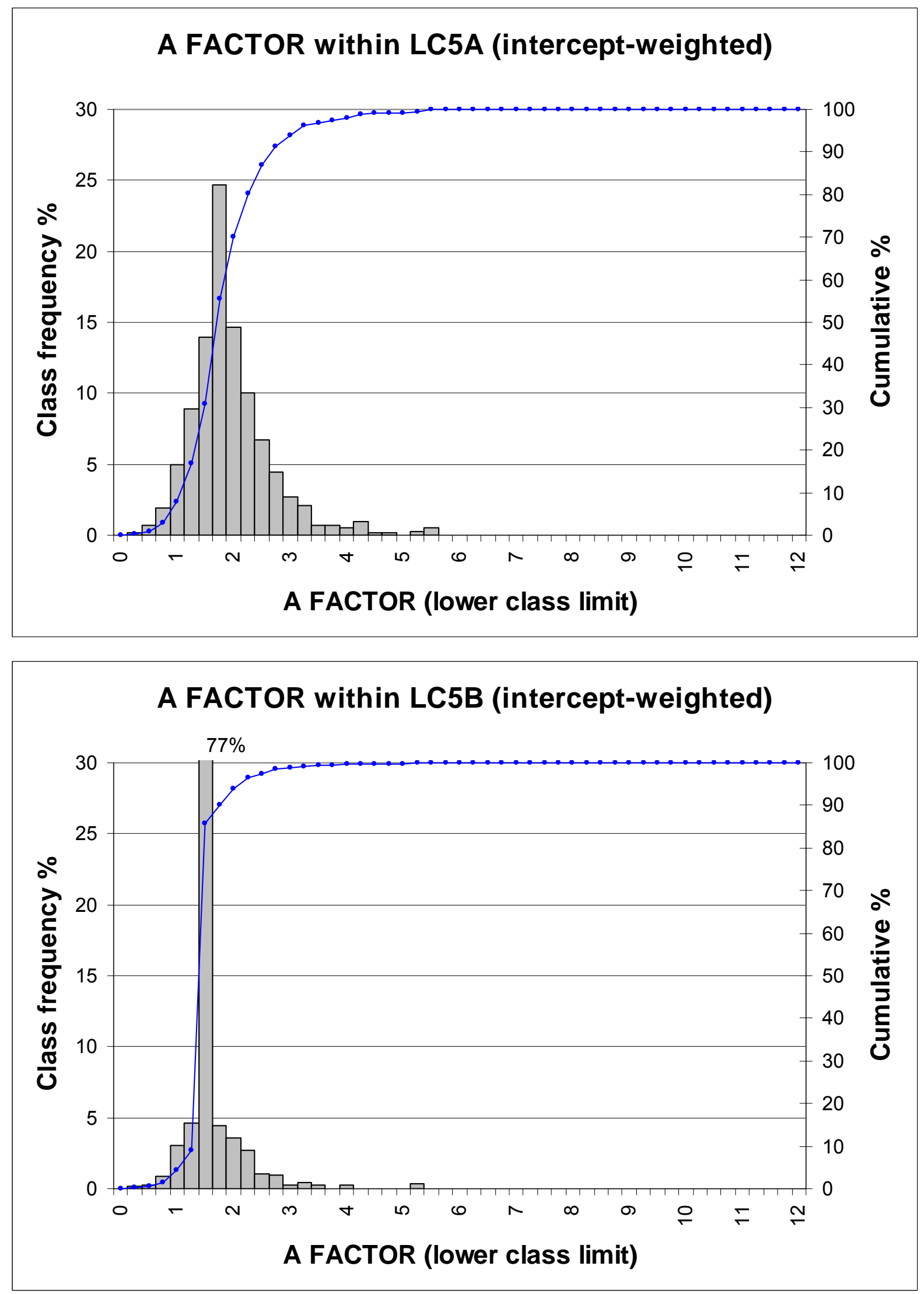

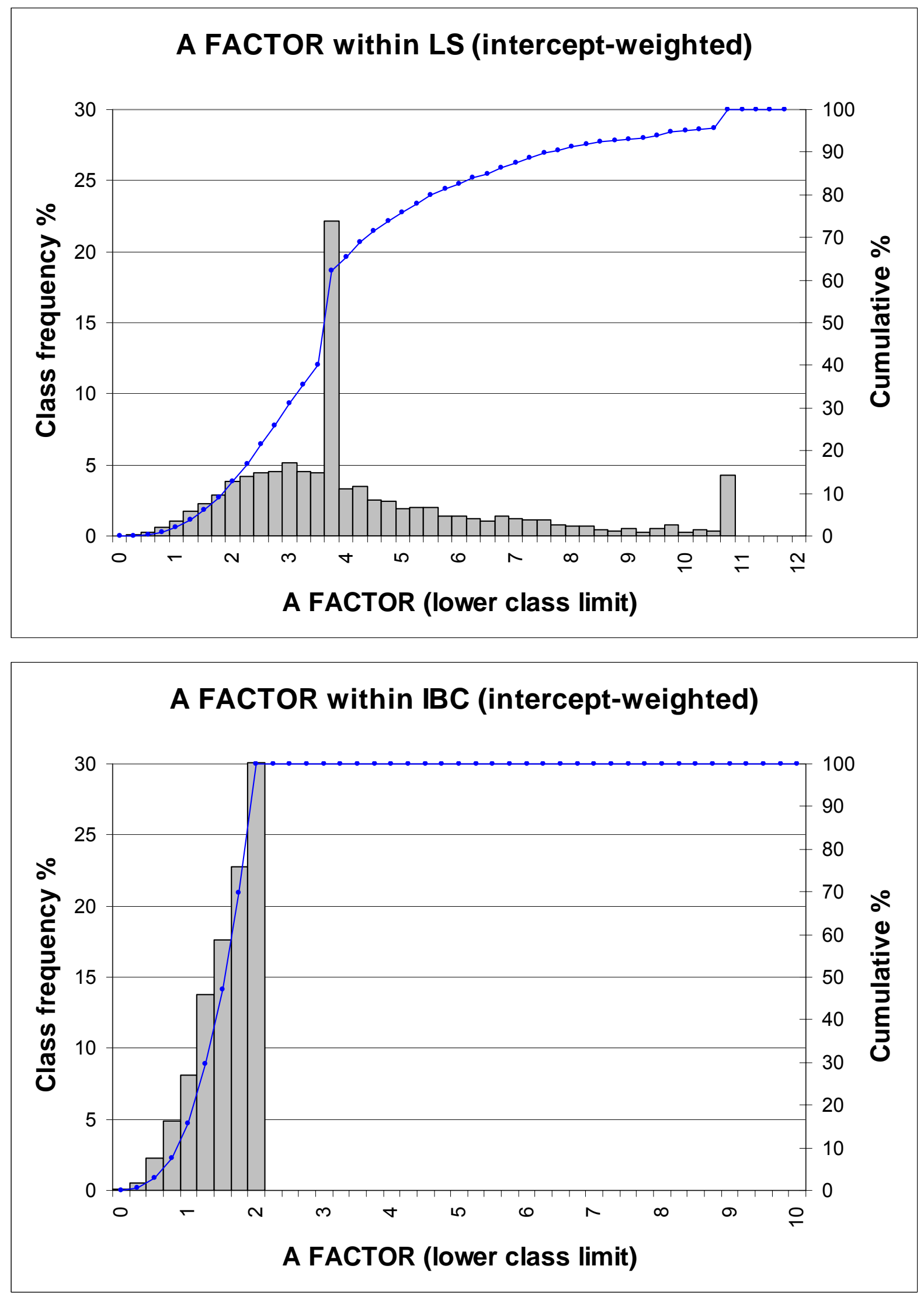

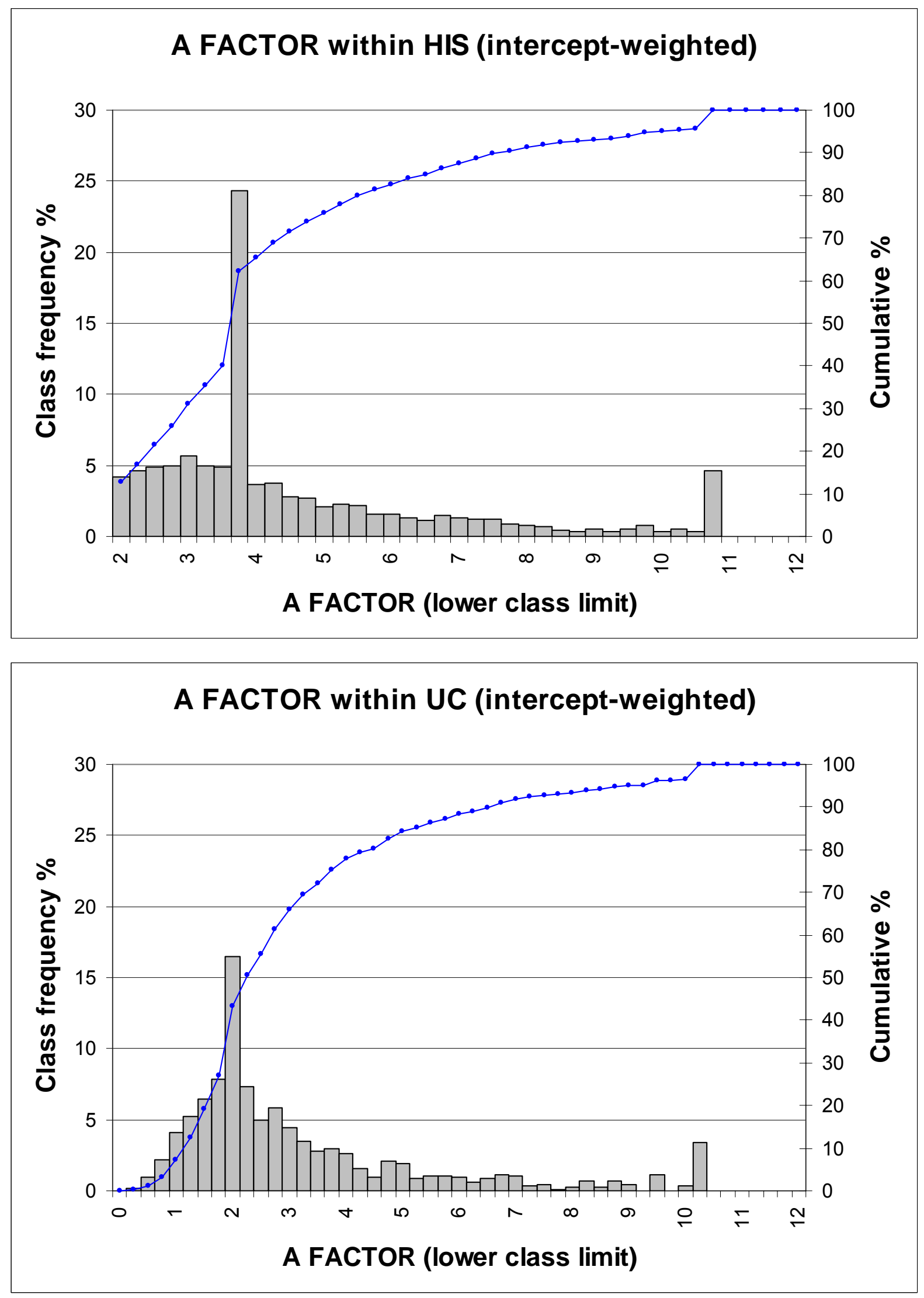
Charts of Iron Content, by Layer, from Orebody Model for Minntac Mine
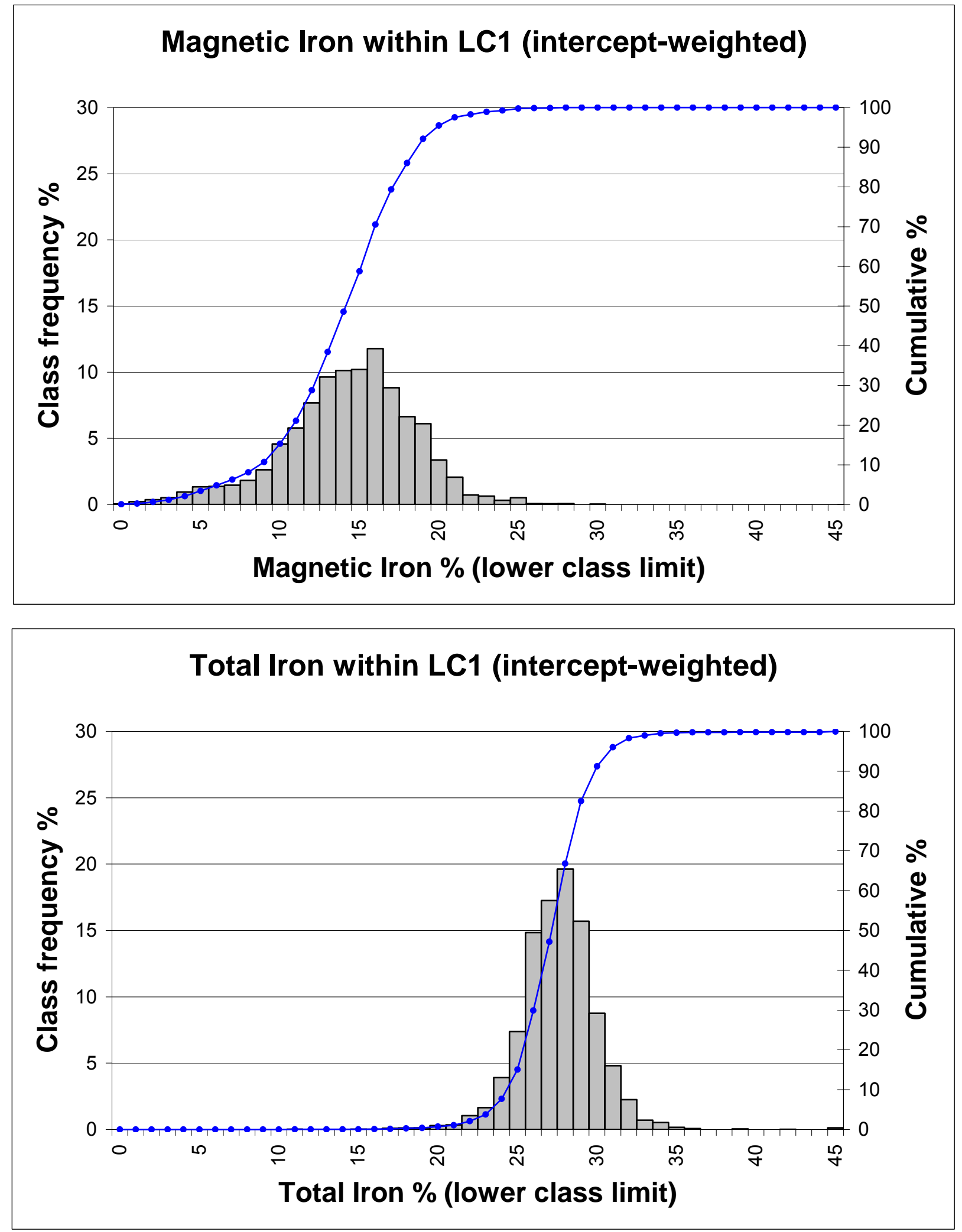

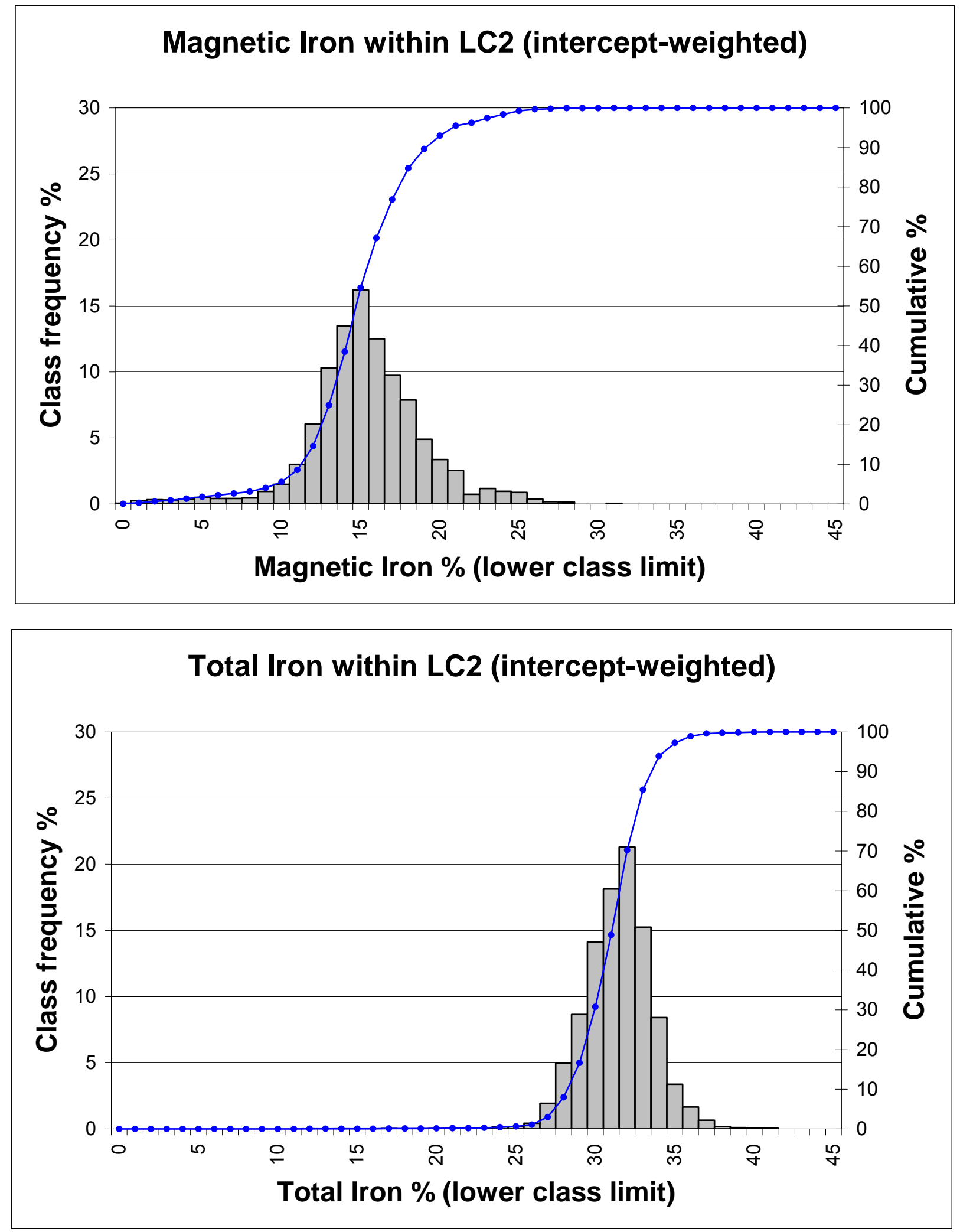

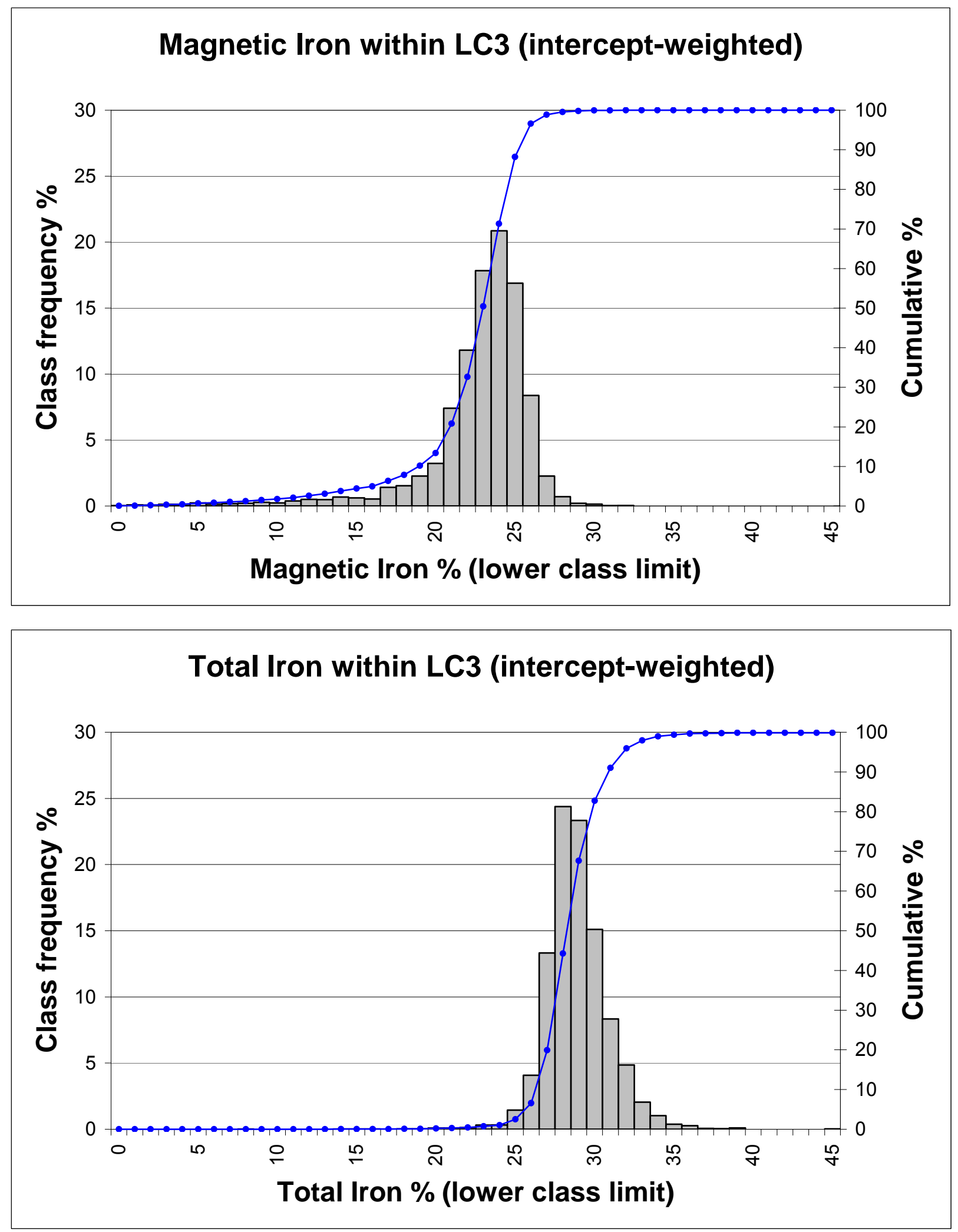

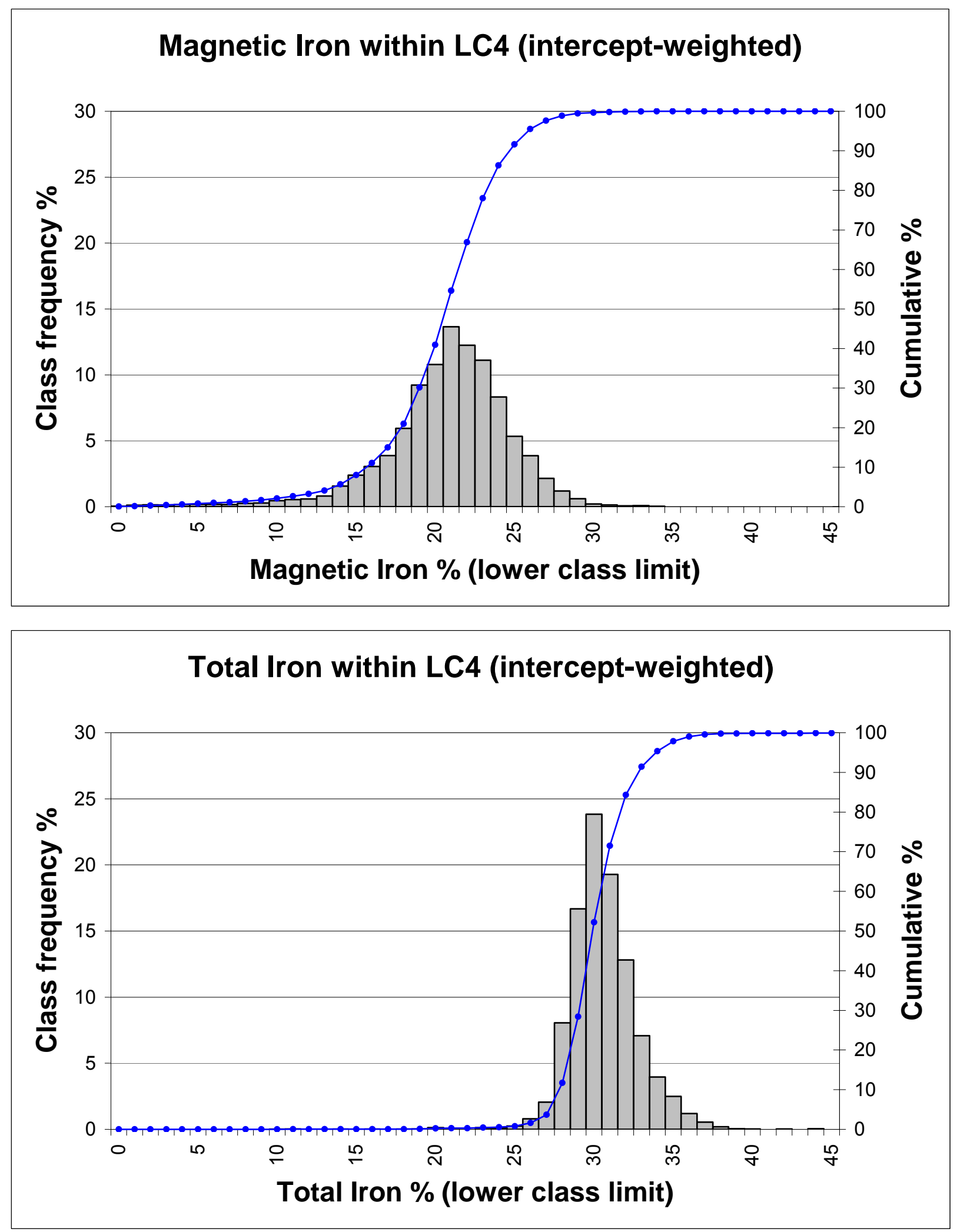

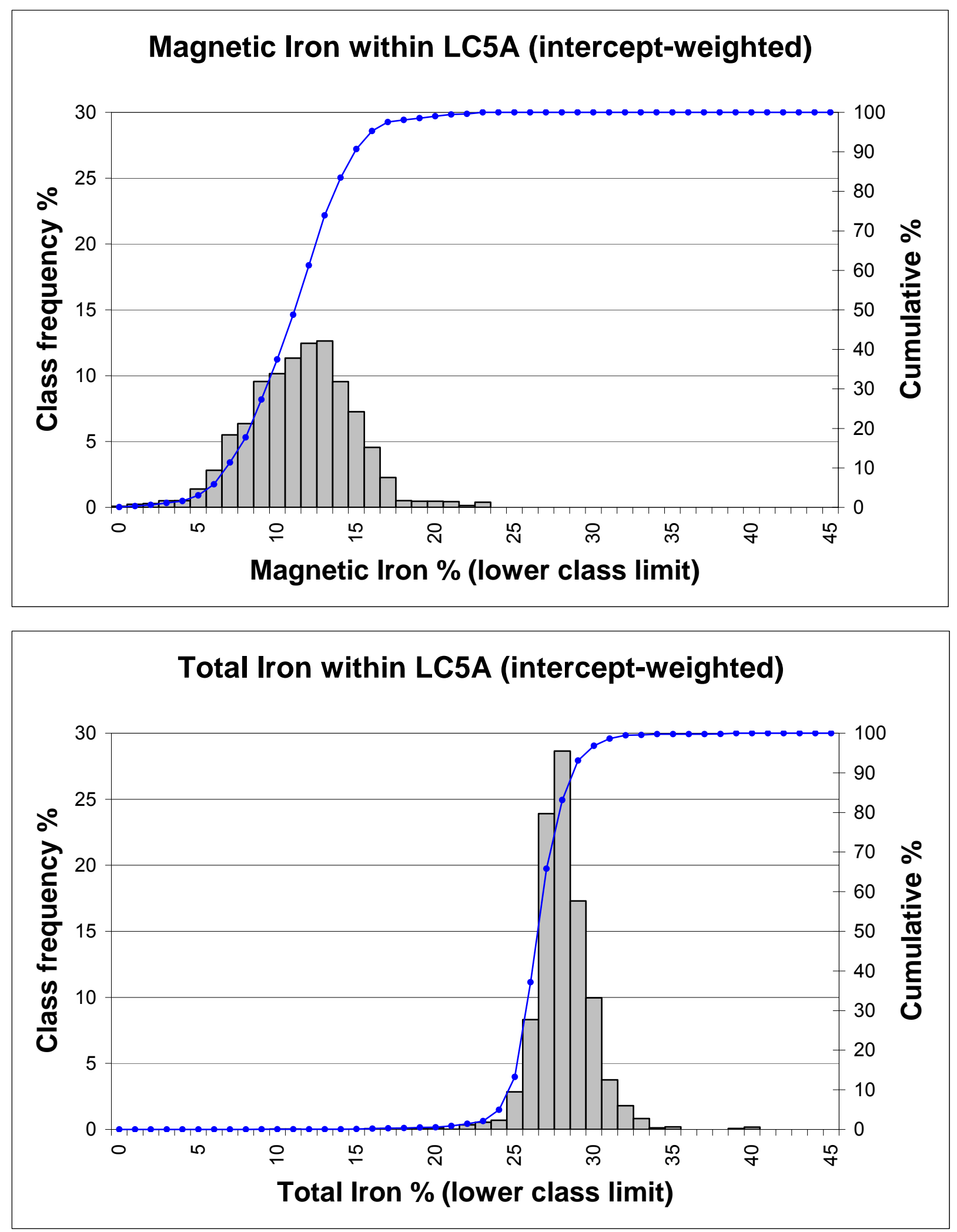

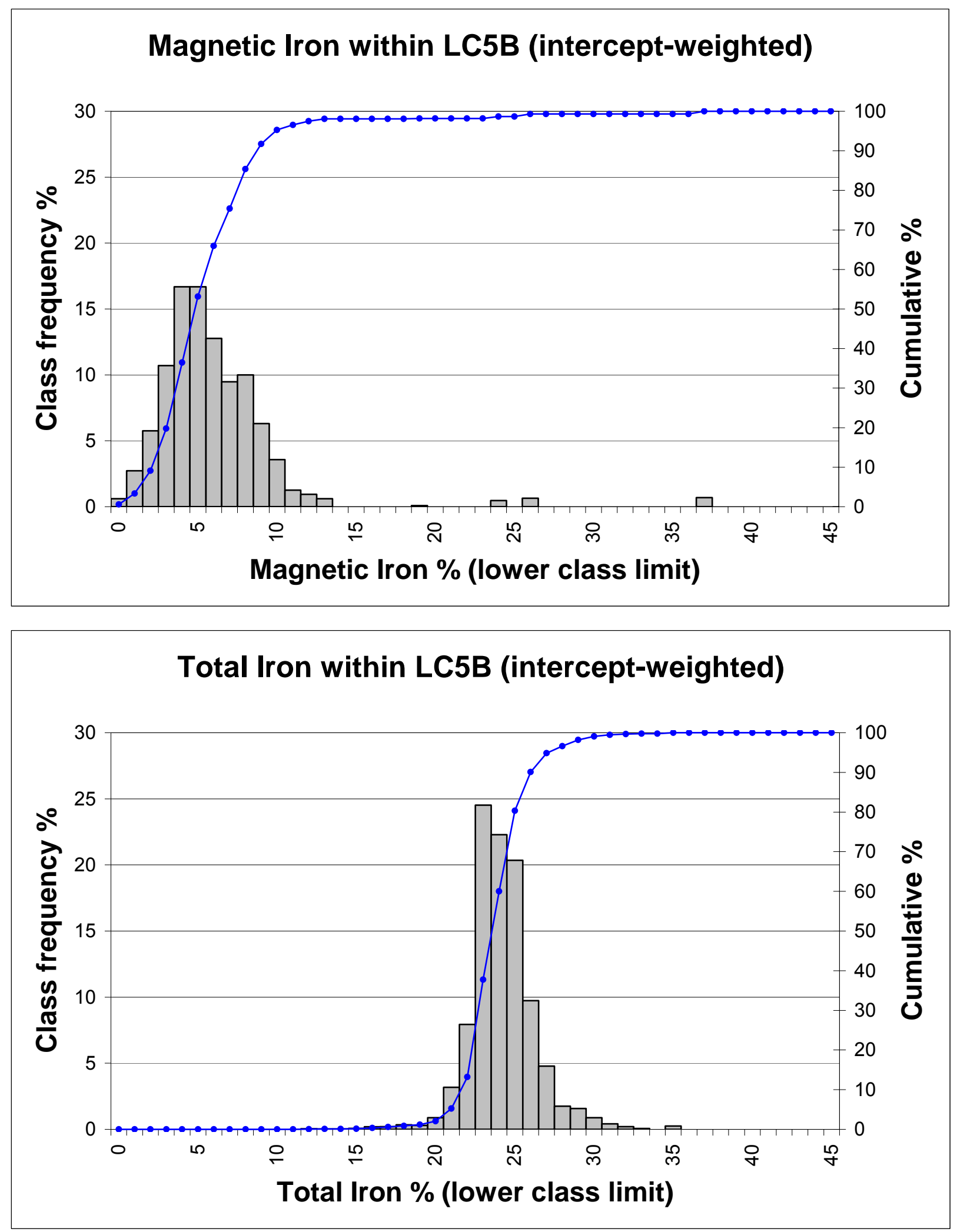

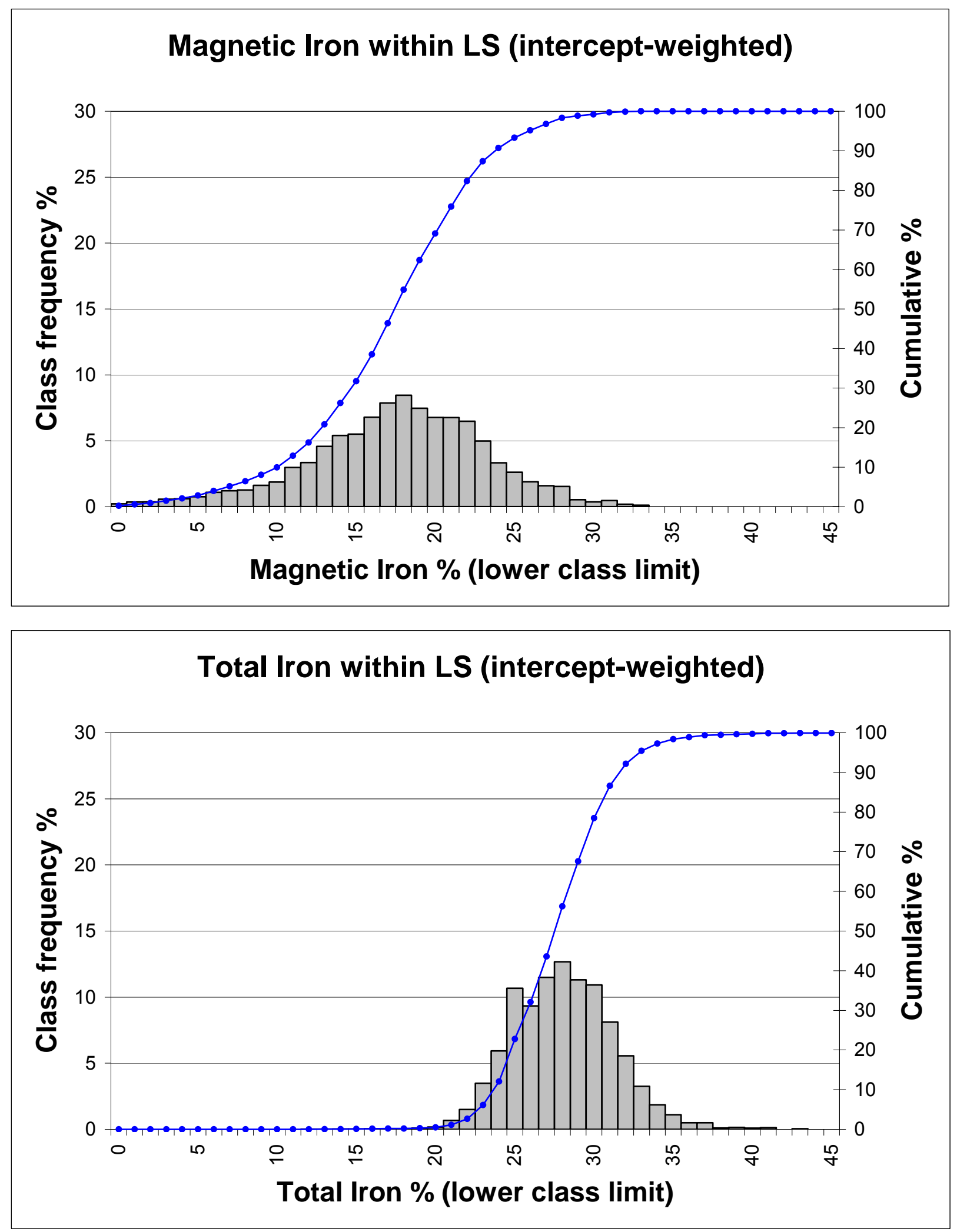

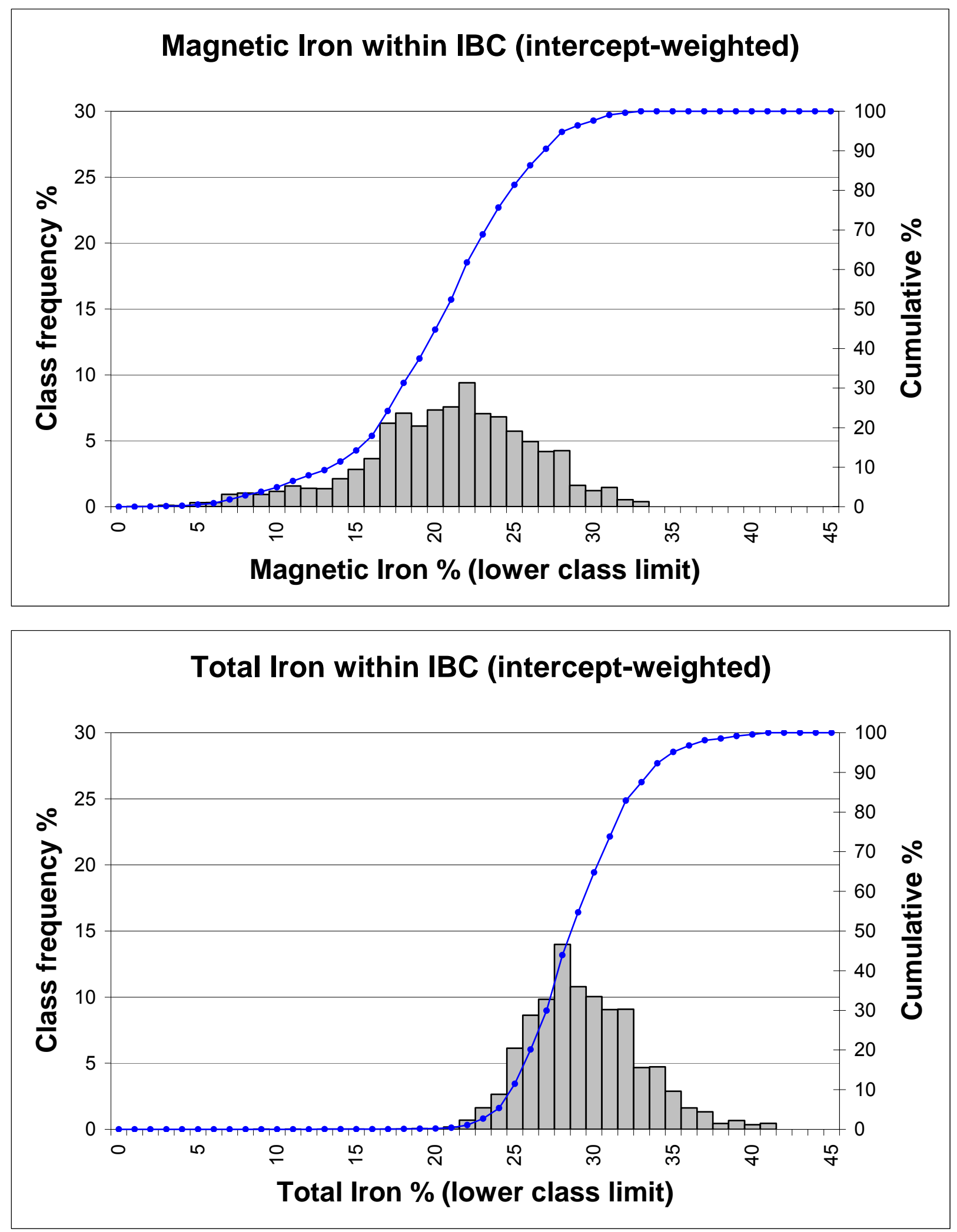

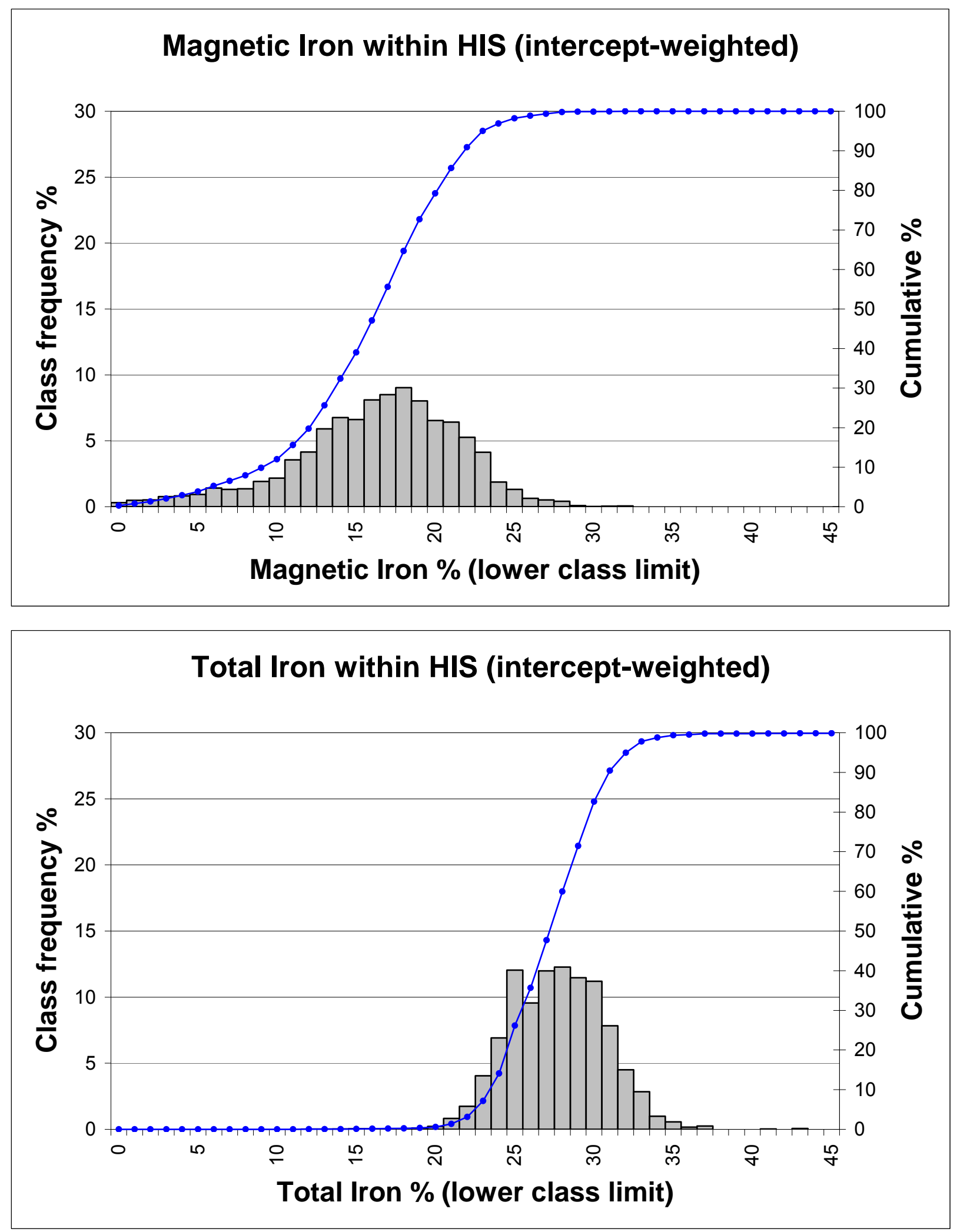

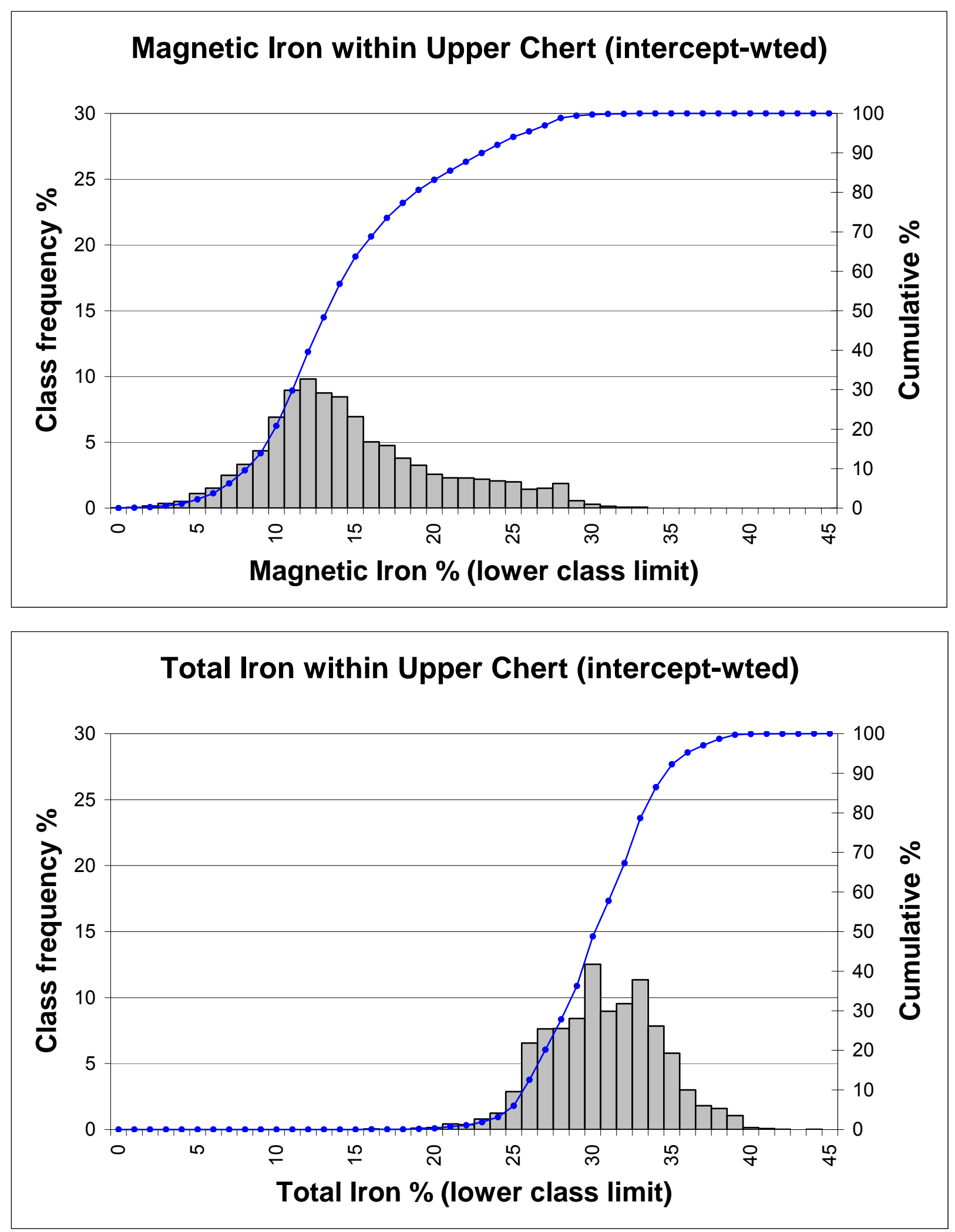
Charts of Concentrate Silica, by Layer, from Orebody Model for Minntac Mine
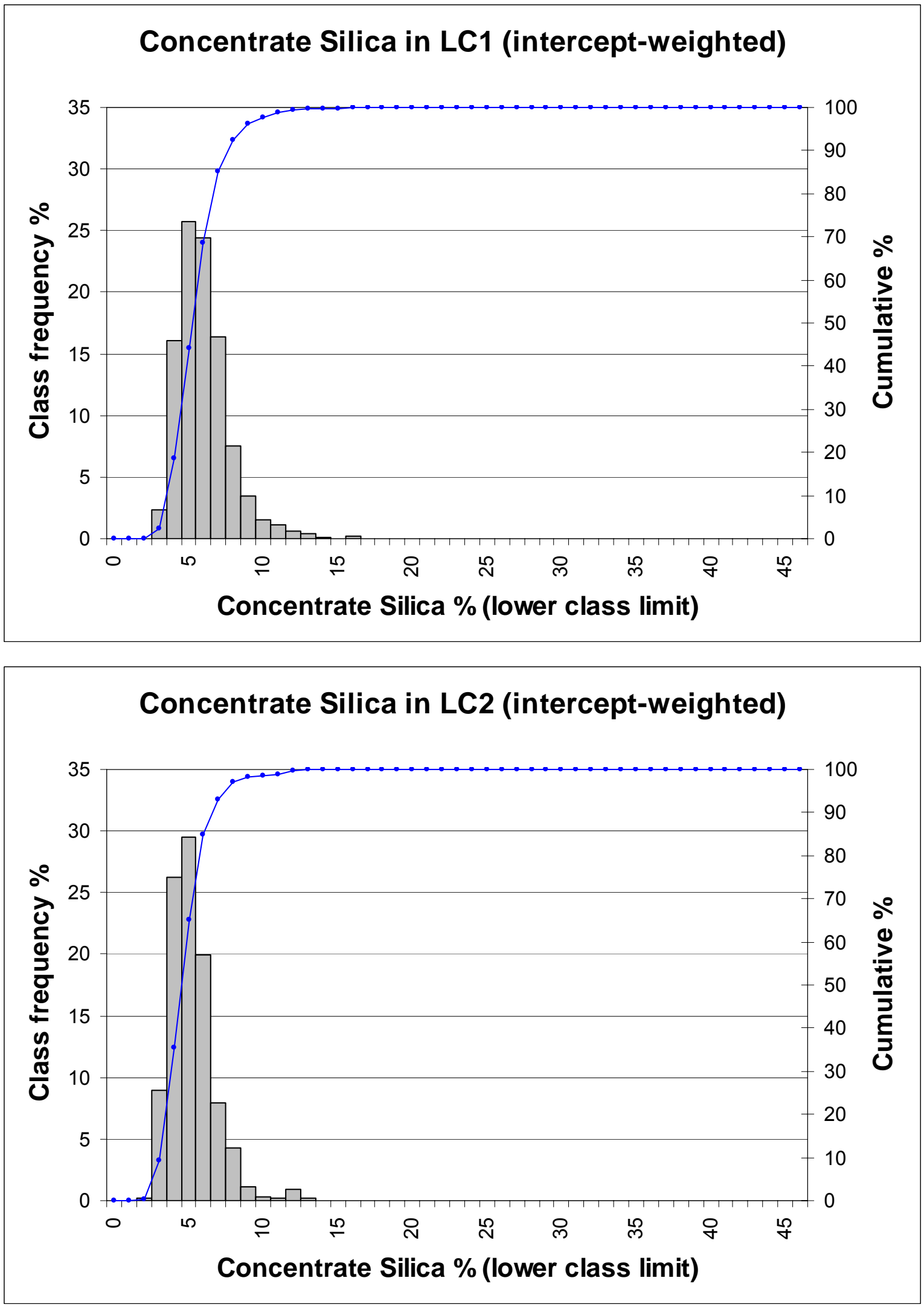

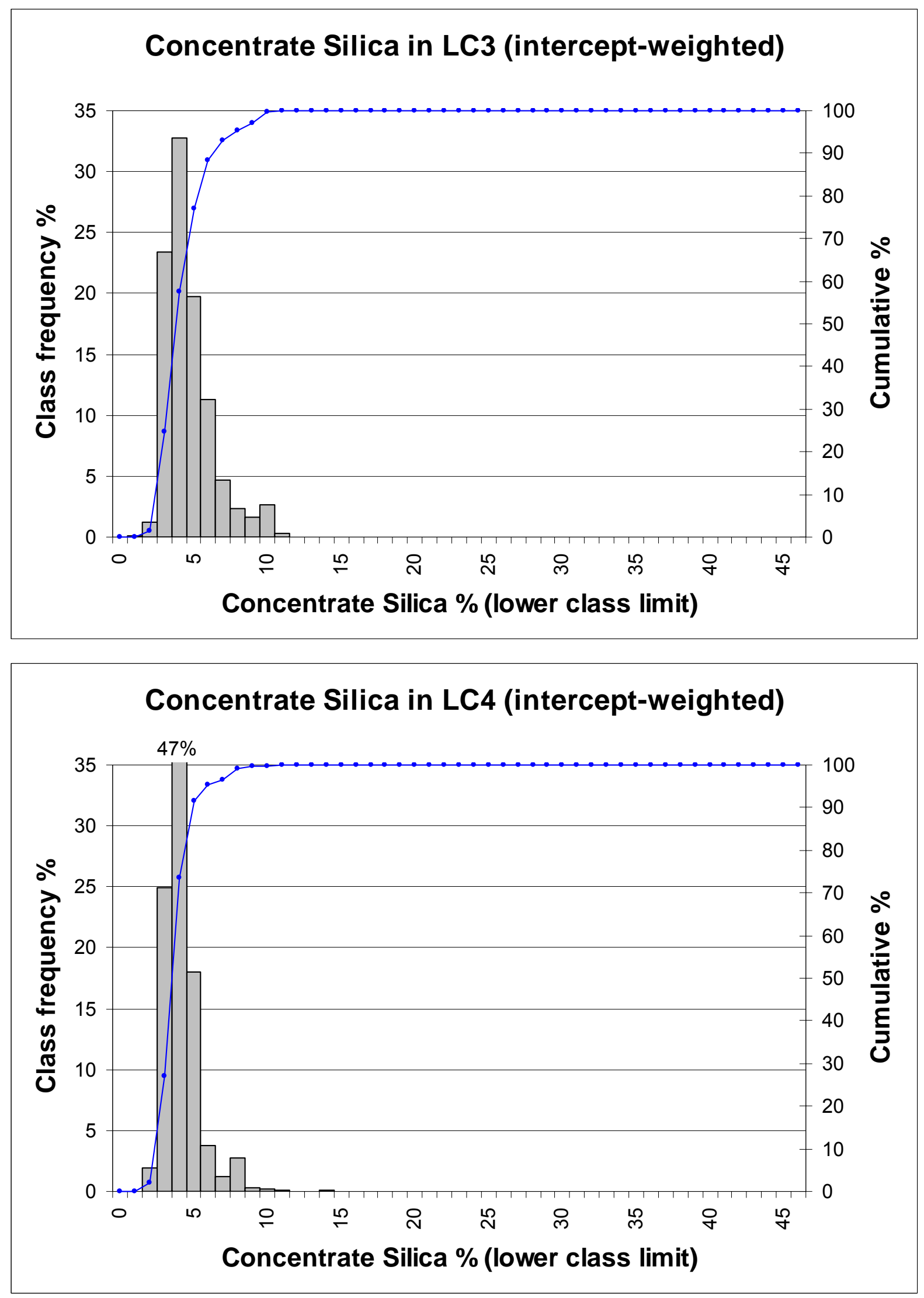

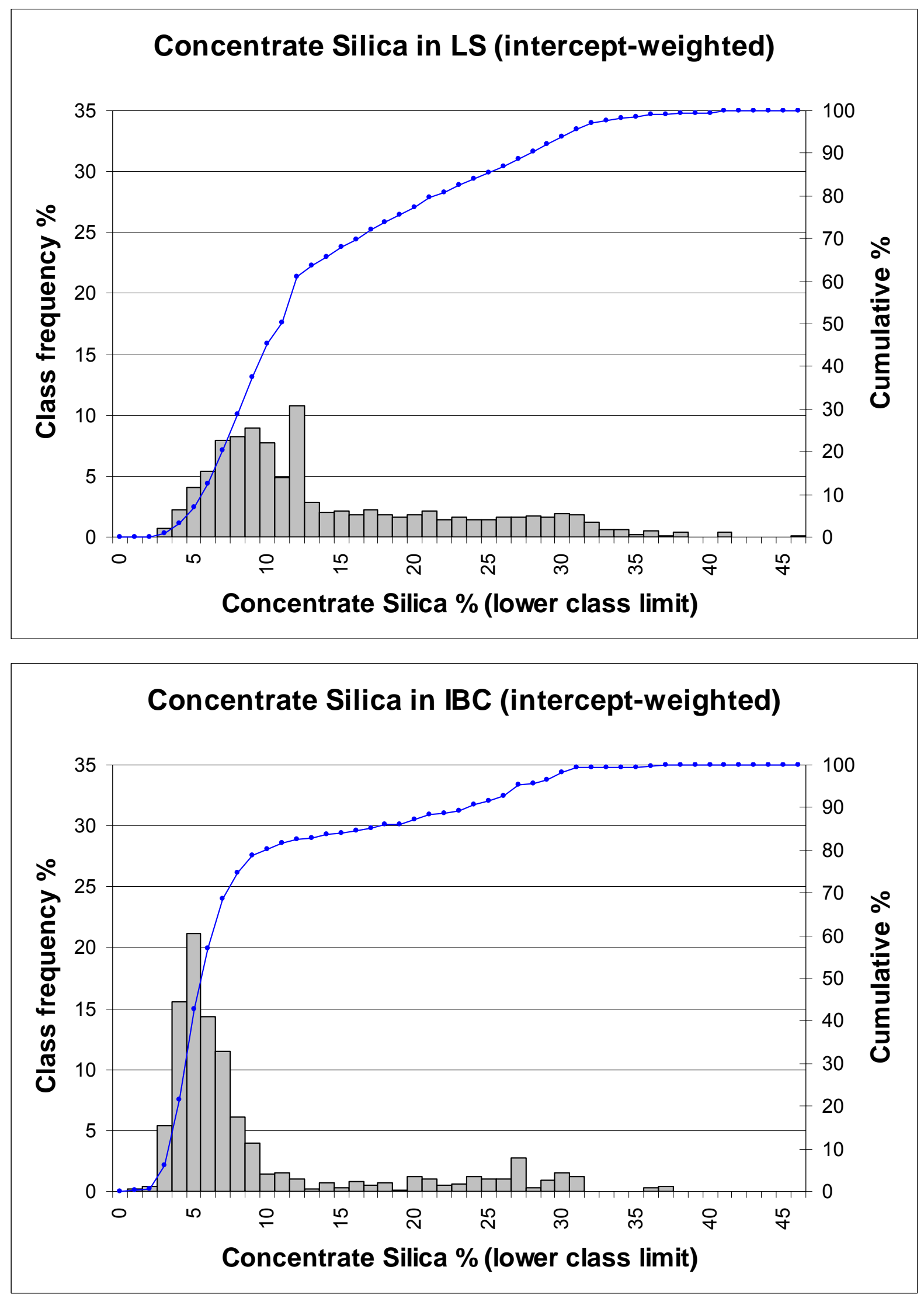

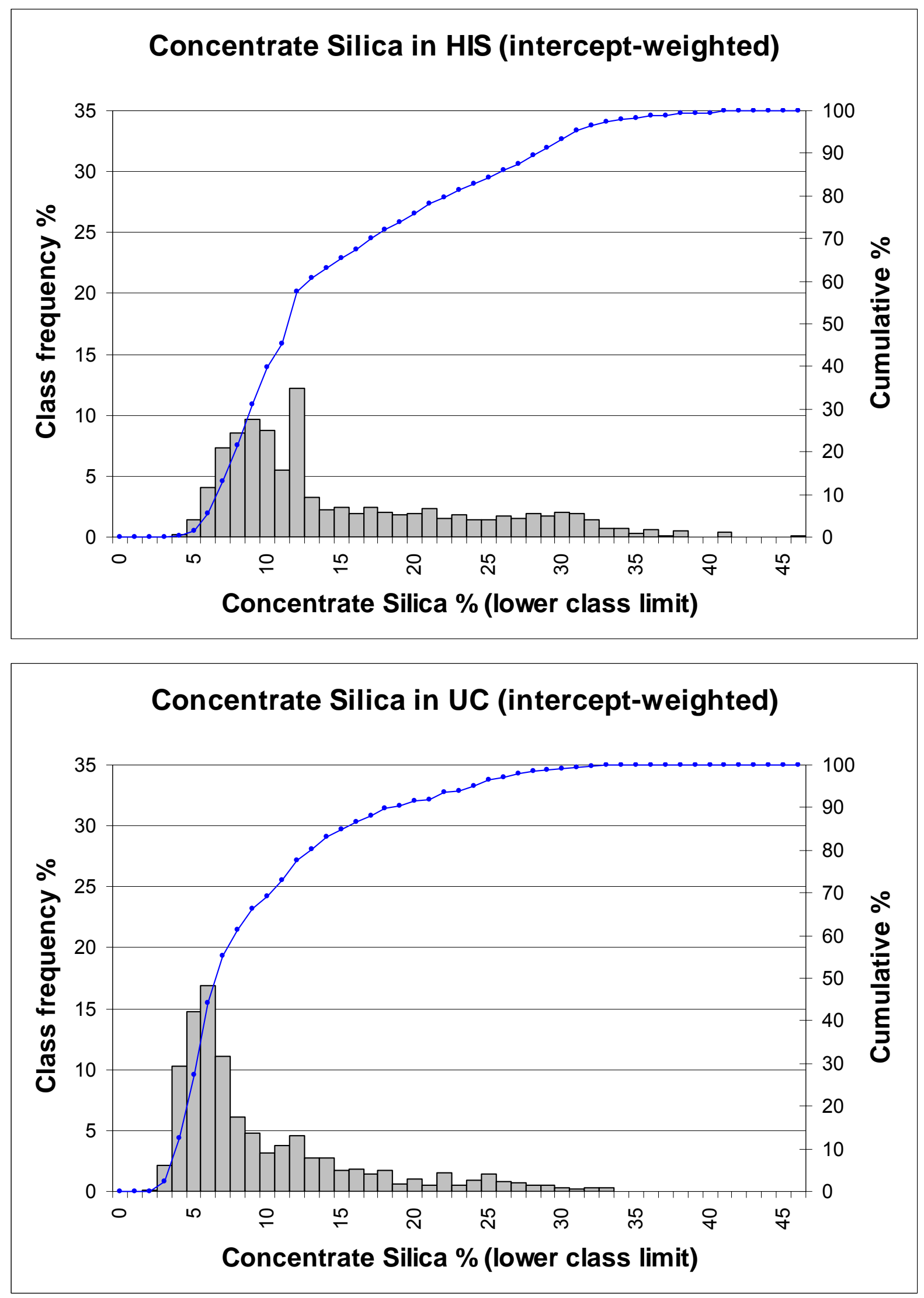
Appendix: Statistical Analysis

Final Report on Statistical Analysis for Mintac Data

Dr. David Drain

29 January 2007 


\section{Introduction}

\section{Research goals}

The ultimate goal of this research is to find a way to manage an iron processing plant to achieve maximum output while minimizing energy use, waste and other costs. An essential step in achieving this goal is to discover and quantify relationships between input material properties, measurable production parameters and output characteristics. We approached this first step through the use of multiple regression analysis to predict variables of interest with other variables in the data; for example, we predicted mine output using incoming material characteristics.

\section{Experimentation and data collection}

The first data set consisted of 168 observations on five variables collected from January through June, 2004. The data was collected passively (without deliberate process interventions) during this time. The variables were ConLTPH, Lab Magfe, MIGI Sl, MIGI Rst and Abbe PAD\#.

A more extensive set of data from MINTAC was obtained from an experiment conducted from July 7 through August 26, 2004. For part of this time (July 25-August 5) input was deliberately manipulated to send better ore to Step 12 and lower-quality ore to Step 3 equipment. No other variables were controlled during this time and mine operators made adjustments as they normally would to keep output within specifications. Variables collected were:

\begin{tabular}{|l|l|l|l|}
\hline V01-MISAFactor & V09-MISLL34 & V16-ConcMagFe & V23-ConcProdRate \\
\hline V02-StrendSilica & V10-MISLL12 & V17-RMFGrindIndex & V24-MetDryRecovery \\
\hline V03-METDTSilica & V11-MisMagFe & V18-RMFT85 & V25-FFDTRecovery \\
\hline V04-MisSilica & V12-MagFeRMF & V19-RMF6MinAbbe & V26-AmineRate \\
\hline V05-ConcSilica & V13-MetCoarseTailsFe & V20-ConcGrind & V27-MetPowerDraw \\
\hline V07-MISHIS & V14-MetFineTailsFe & V21-StrendFloatFeedGrind & V28-RMF34 \\
\hline V08-MISIBC & V15-MetMagFeRecovery & V22-RodMillFeedRate & V29-RMF12 \\
\hline
\end{tabular}

V06-MetFloatTailsSiO2 was added in November 2004.

\section{Discoveries}

\section{Summary statistics}

Univariate summary statistics are shown below for each variable included in the analysis. 


\section{Results for OutFine $=1$ \\ Results for: Pezutto phase IV ver03.MTW \\ Descriptive Statistics: Equipment, V22-RodMillF, V24-MetDryRe, ...}

\begin{tabular}{|c|c|c|c|c|c|}
\hline Variable & $\mathrm{N}$ & Mean & StDev & Minimum & Maximum \\
\hline Equipment & 93 & -0.0108 & 1.005 & -1.000 & 1.000 \\
\hline V22-RodMillFeedR & 93 & 446.02 & 26.80 & 405.47 & 506.85 \\
\hline V24-MetDryRecove & 93 & 28.108 & 1.025 & 25.040 & 30.150 \\
\hline V12-MagFeRMF & 93 & $\odot .19719$ & 0.00630 & $\odot .17800$ & $\odot .21100$ \\
\hline V23-ConcProdRate & 93 & 135.71 & 7.89 & 119.58 & 152.41 \\
\hline V๑5-ConcSilica & 93 & ๑. 053551 & 0.003405 & $\odot .043600$ & $\odot .061500$ \\
\hline V16-ConcMagFe & 93 & 0.65425 & $\odot .00287$ & 0.64760 & 0.66260 \\
\hline V20-ConcGrind & 93 & 0.85386 & $\odot .00813$ & $\odot .83860$ & 0.88400 \\
\hline V13-MetCoarseTai & 93 & ○. 029090 & 0.002223 & $\odot .025000$ & $\odot .034500$ \\
\hline V14-MetFineTails & 93 & 0.011409 & $\odot .0 \odot 1972$ & $\odot .00810 \odot$ & $\odot .01900 \odot$ \\
\hline V15-MetMagFeReco & 93 & $\odot .93245$ & 0.00763 & 0.90560 & 0.94640 \\
\hline V27-MetPowerDraw & 93 & 12.258 & 0.432 & 11.380 & 13.300 \\
\hline V๑3-METDTSilica & 93 & 0.042726 & $\odot .004996$ & $\odot .029200$ & $\odot .055400$ \\
\hline V28-RMF34 & 93 & ๑.96883 & 0.00842 & 0.94600 & 0.99000 \\
\hline V29-RMF12 & 93 & $\odot .82493$ & $\odot .02311$ & $\odot .77930$ & $\odot .88270$ \\
\hline V17-RMFGrindInde & 93 & 41.319 & 1.457 & 37.670 & 44.830 \\
\hline V19-RMF6MinAbbe & 93 & 0.34634 & 0.03429 & $\odot .27000$ & 0.43000 \\
\hline V18-RMFT85 & 93 & 11.134 & 0.466 & 10.033 & 12.200 \\
\hline V02-StrendSilica & 93 & 5.2917 & 0.3785 & 4.2533 & 6.8367 \\
\hline V21-StrendFloatF & 93 & 82.029 & 2.160 & 77.167 & 86.667 \\
\hline V26-AmineRate & 93 & $\odot .10318$ & $\odot .02438$ & 0.05133 & 0.15667 \\
\hline V01-MISAFactor & 93 & 1.6020 & 0.1688 & 1.1892 & 2.1042 \\
\hline V๑4-MisSilica & 93 & $\odot .055178$ & $\odot .0 \odot 2915$ & $\odot .046450$ & $\odot .061470$ \\
\hline V11-MisMagFe & 93 & $\odot .19785$ & ๑. . 00519 & 0.18598 & 0.21189 \\
\hline V๑7 - MISHIS & 93 & $\odot .18752$ & $\odot .07544$ & 0.04613 & $\odot .46266$ \\
\hline V๑8-MISIBC & 93 & $\odot .10013$ & $\odot .07931$ & $\odot . ๑ \odot \odot \odot \odot \odot \odot \odot \odot$ & ๑. 29712 \\
\hline V०9-MISLL34 & 93 & 0.40194 & ๑. 08039 & 0.23011 & 0.66677 \\
\hline V10-MISLL12 & 93 & 0.3061 & 0.0974 & 0.0594 & 0.5375 \\
\hline Experiment & 93 & -0.5914 & 0.8108 & -1.0000 & 1.0000 \\
\hline OutFine & 93 & 1.0000 & ๑. . 000000000 & 1.0000 & 1.0000 \\
\hline V50-Total slate & 93 & 0.2876 & 0.1183 & 0.1051 & 0.6068 \\
\hline V51- (V11-V12) & 93 & ๑. 000658 & 0.006221 & -0.015020 & 0.015530 \\
\hline
\end{tabular}

\section{Correlation analysis}

The data exhibited significant multicollinearity as evidenced by the fragment of a correlation table below. P-values less than 0.05 indicate a statistically significant correlation. The first such correlation (between V22 and V24) is highlighted, and only the first few rows of the correlation table are shown here for purposes of explanation. (The remainder can be found in Final01.doc)

\section{Correlations: V22-RodMillF, V24-MetDryRe, V12-MagFeRMF, V23-ConcProd, ...}

V22-RodMillF V24-MetDryRe V12-MagFeRMF V23-ConcProd

V24-MetDryRe $\quad-0.350$

\subsection{1}




$\begin{array}{lrrrr}\text { V12-MagFeRMF } & -0.292 & 0.979 & & \\ \text { V23-ConcProd } & 0.004 & 0.000 & & \\ & 0.800 & 0.277 & 0.327 & \\ \text { V05-ConcSili } & 0.000 & 0.007 & 0.001 & \\ & 0.045 & -\odot .027 & -0.122 & 0.008 \\ \text { V16-ConcMagF } & 0.671 & 0.794 & 0.244 & 0.936 \\ & -0.045 & 0.029 & 0.124 & -0.008 \\ \text { V20-ConcGrin } & 0.668 & 0.784 & 0.238 & 0.939 \\ & 0.277 & -0.450 & -0.361 & -0.003 \\ & 0.007 & 0.000 & 0.00 \odot & 0.980\end{array}$

Cell Contents: Pearson correlation

P-Value

\section{Principal components analysis}

An alternate way to comprehend high dimensional data with a complex correlation structure is to perform a principal components analysis (PCA). PCA reduces the dimension of a problem by finding linear combinations of the original variables that contain the information in those variables. The first component found is that linear combination explaining the most variation; the second component is the linear combination orthogonal to the first explaining the most remaining variation. The scree plot below summarizes the proportion of variation explained by each additional principal component. For this data, the first component explains $24 \%$ of the total variation in the data and by the $4^{\text {th }}$ component, $58 \%$ of the variation is obtained. It is also apparent that components after the $8^{\text {th }}$ add very little to the explanatory power.

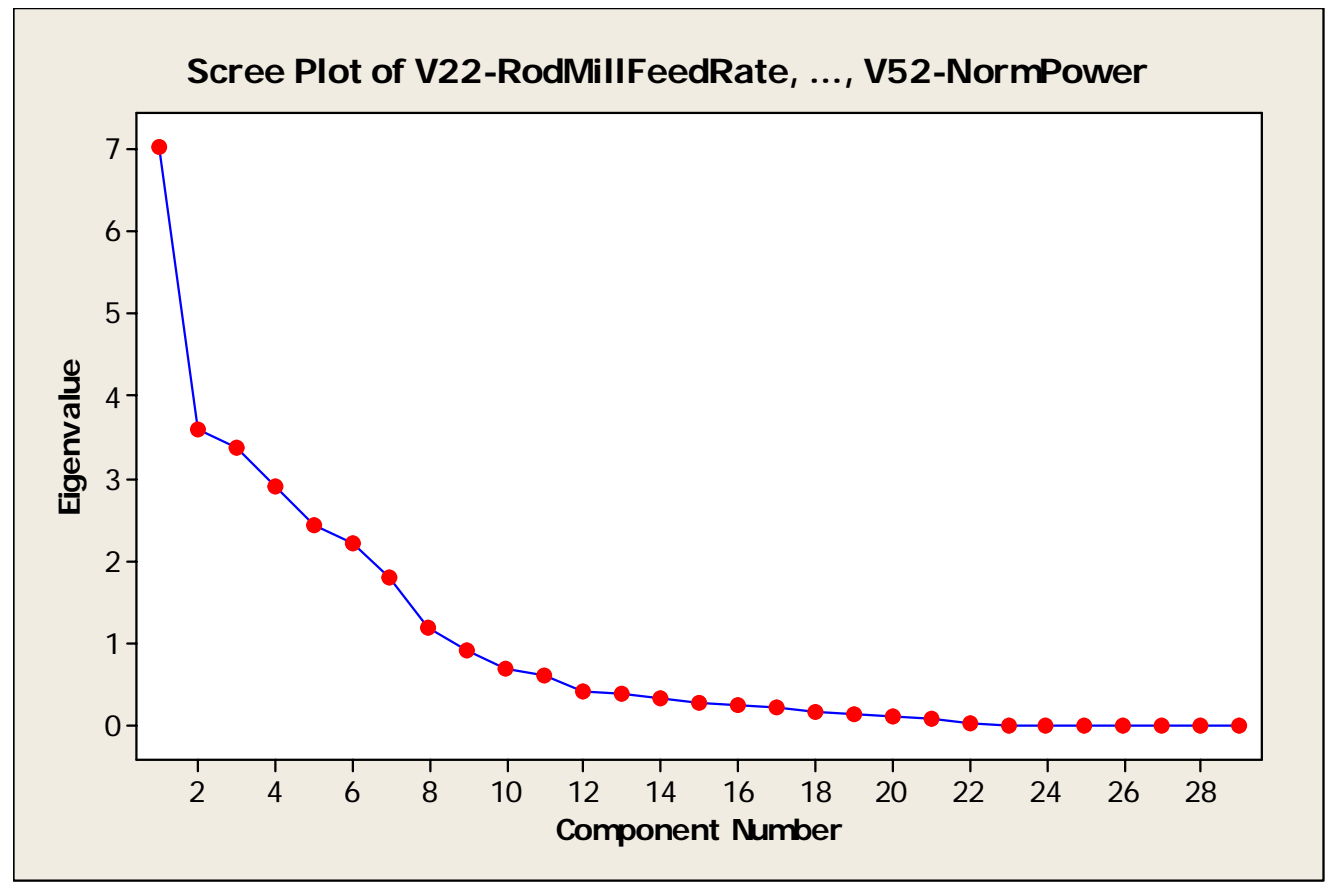


One difficulty with PCA is interpretation of the components. For example the first (most important) principal component here has the formula below. No variable dominates the component, nor do any group of logically associated variables so we would find it quite difficult to make use of this component to explain any patterns in the data.

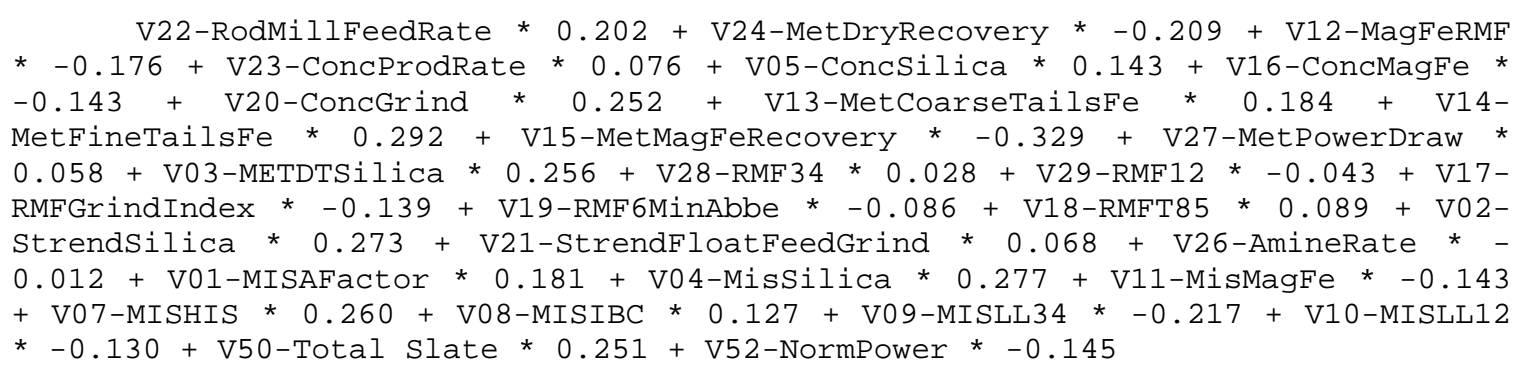

\section{Summary of inter-relationships}

Nearly any variable we attempted to predict was predictable to some extent. For example, 98\% of the variation in V15 is predicted with Equipment (Step 2 or 3), V13, V14 and V12. Other variables were more difficult to predict: only 25\% of the variation in V12 was predicted in most models. A table summarizing the amount of variance predicted (r-squared) and the predictors is shown in the tables below:

\begin{tabular}{|c|c|c|}
\hline $\mathbf{r}^{2}$ & MEAN & \\
\hline & & FE TAILS - PREDICTION. INPUT = ALL BEFORE + T/S + STEP \\
\hline $60 \%$ & 0.0114 & $\begin{array}{l}\text { V14-MetFineTailsFe }=0.0298+0.00457 \text { V50-Total Slate }+0.00114 \text { V18-RMFT85 + } 0.0955 \text { V03- } \\
\text { METDTSilica + 0.00866 V07-MISHIS + 0.0264 V29-RMF12 - } 0.0618 \text { V28-RMF34 + } \\
\text { 0.000279 Equipment }\end{array}$ \\
\hline $55 \%$ & 0.0291 & $\begin{array}{l}\text { V13-MetCoarseTailsFe }=0.0401+0.00163 \text { Equipment - } 0.000029 \text { V22-RodMillFeedRate + } 0.0119 \text { V07- } \\
\text { MISHIS - 0.00461 V08-MISIBC }\end{array}$ \\
\hline & & SILICA - PREDICTION. INPUT = ALL BEFORE + T/S + STEP \\
\hline $85 \%$ & 5.29 & V02-StrendSilica $=-0.598+9.70$ V03-METDTSilica + 98.9 V04-MisSilica \\
\hline $34 \%$ & 0.427 & V03-METDTSilica = - 0.00033 - 0.083 V04-MisSilica + 0.00905 V02-StrendSilica \\
\hline $84 \%$ & 0.0552 & V04-MisSilica $=0.0140+0.00786$ V02-StrendSilica -0.0071 V03-METDTSilica \\
\hline & & MAGFE - PREDICTION. INPUT = ALL BEFORE + T/S + STEP \\
\hline $83 \%$ & 0.933 & $\begin{array}{c}\text { V15-MetMagFeRecovery }=0.832+0.641 \text { V12-MagFeRMF }+0.000826 \text { V17-RMFGrindIndex - } 1.88 \\
\text { V13-MetCoarseTailsFe - 0.0205 V50-Total Slate }\end{array}$ \\
\hline $49 \%$ & 0.654 & $\begin{aligned} \text { V16-ConcMagFe } & =0.672-0.297 \text { V03-METDTSilica + 0.0158 V07-MISHIS + 0.0121 V09-MISLL34 - } \\
& 0.827 \text { V04-MisSilica + 0.00610 V02-StrendSilica }\end{aligned}$ \\
\hline & & GRIND - PREDICTION. INPUT = ALL BEFORE + T/S + STEP \\
\hline $47 \%$ & 0.854 & $\begin{aligned} \text { V20-ConcGrind } & =0.823+0.0510 \text { V07-MISHIS + } 0.402 \text { V03-METDTSilica + } 0.0668 \text { V29-RMF12 - } \\
& 0.259 \text { V12-MagFeRMF }\end{aligned}$ \\
\hline $34 \%$ & 82.0 & $\begin{array}{c}\text { V21-StrendFloatFeedGrind }=102-114 \text { V12-MagFeRMF - } 15.7 \text { V07-MISHIS + 323 V04-MisSilica - } \\
\text { 1.15 V18-RMFT85 + 6.15 V08-MISIBC }\end{array}$ \\
\hline & & PRODUCTION - PREDICTION. INPUT = ALL BEFORE + T/S + STEP \\
\hline $59 \%$ & 0.0276 & $\begin{array}{c}\text { V52-NormPower }=-0.00411-0.00104 \text { Equipment }+0.00745 \text { V09-MISLL34 + 0.197 V04-MisSilica + } \\
\text { 0.0806 V12-MagFeRMF + 0.0184 V26-AmineRate }\end{array}$ \\
\hline $58 \%$ & 0.103 & V26-AmineRate = 3.36 - 5.74 V16-ConcMagFe + 0.0619 V09-MISLL34 - 0.0137 V18-RMFT85 - 2.04 \\
\hline
\end{tabular}




\begin{tabular}{|c|c|c|}
\hline & & V04-MisSilica + 0.519 V28-RMF34 + 0.0193 V27-MetPowerDraw \\
\hline & & SILICA - INTERACTION. INPUT = V1 - V6 ONLY \\
\hline $9 \%$ & & $\begin{array}{c}\text { V06-MetFloatTailsSilica }=0.143-1.61 \text { V03-METDTSilica + } 0.0223 \text { V01-MISAFactor + } 0.0131 \text { V02- } \\
\text { StrendSilica + 0.35 V04-MisSilica + 1.51 V05-ConcSilica }\end{array}$ \\
\hline $57 \%$ & 1.60 & $\begin{array}{c}\text { V01-MISAFactor }=-0.109+0.0758 \text { V02-StrendSilica - 5.96 V03-METDTSilica + 38.9 V04-MisSilica - } \\
\text { 12.6 V05-ConcSilica + 0.346 V06-MetFloatTailsSilica }\end{array}$ \\
\hline $86 \%$ & 5.29 & $\begin{aligned} & \text { V02-StrendSilica }=-0.407+0.186 \text { V01-MISAFactor + 14.0 V03-METDTSilica + 89.4 V04-MisSilica - } \\
& 5.56 \text { V05-ConcSilica }+0.548 \text { V06-MetFloatTailsSilica } \\
&\end{aligned}$ \\
\hline $52 \%$ & 0.0427 & $\begin{array}{c}\text { V03-METDTSilica }=-0.0132-0.00653 \text { V01-MISAFactor + 0.0100 V02-StrendSilica - } 0.091 \text { V04- } \\
\text { MisSilica }+0.482 \text { V05-ConcSilica - 0.0264 V06-MetFloatTailsSilica }\end{array}$ \\
\hline $86 \%$ & 0.0552 & $\begin{aligned} \text { V04-MisSilica }= & 0.0100+0.00316 \text { V01-MISAFactor }+0.00658 \text { V02-StrendSilica }-0.0093 \text { V03- } \\
& \text { METDTSilica }+0.114 \text { V05-ConcSilica }-0.00124 \text { V06-MetFloatTailsSilica }\end{aligned}$ \\
\hline $37 \%$ & 0.0536 & $\begin{aligned} \text { V05-ConcSilica } & =0.0266-0.00691 \text { V01-MISAFactor }-0.00228 \text { V02-StrendSilica }+0.275 \text { V03- } \\
& \text { METDTSilica }+0.635 \text { V04-MisSilica }+0.0118 \text { V06-MetFloatTailsSilica }\end{aligned}$ \\
\hline & & FE - INTERACTION. INPUT = ALL BEFORE + T/S + STEP + INTERVARIALBES \\
\hline $49 \%$ & 0.198 & $\begin{aligned} \text { V11-MisMagFe }= & 0.239-0.000611 \text { Equipment - 0.00747 V01-MISAFactor - } 0.00391 \text { V02-StrendSilica - } \\
& 0.0270 \text { V10-MISLL12 }\end{aligned}$ \\
\hline $25 \%$ & 0.197 & V12-MagFeRMF = $0.176-0.000130$ Equipment + 0.0363 V08-MISIBC + 0.0442 V09-MISLL34 \\
\hline $52 \%$ & 0.0291 & $\begin{array}{c}\text { V13-MetCoarseTailsFe }=0.0421+0.00179 \text { Equipment }+0.0108 \text { V07-MISHIS }-0.000034 \text { V22- } \\
\text { RodMillFeedRate }\end{array}$ \\
\hline $54 \%$ & 0.0114 & $\begin{array}{l}\text { V14-MetFineTailsFe }=-0.00574+0.000255 \text { Equipment }+0.00853 \text { V50-Total Slate }+0.000978 \text { V18- } \\
\text { RMFT85 + 0.0892 V03-METDTSilica }\end{array}$ \\
\hline $98 \%$ & 0.933 & $\begin{array}{c}\text { V15-MetMagFeRecovery }=0.901-0.000017 \text { Equipment - } 1.48 \text { V13-MetCoarseTailsFe - 2.31 V14- } \\
\text { MetFineTailsFe + 0.514 V12-MagFeRMF }\end{array}$ \\
\hline $100 \%$ & Lo Ex & $\begin{array}{c}\text { V15-MetMagFeRecovery }=0.907-0.000002 \text { Equipment - } 1.47 \text { V13-MetCoarseTailsFe - } 2.17 \text { V14- } \\
\text { MetFineTailsFe + 0.472 V12-MagFeRMF }\end{array}$ \\
\hline $55 \%$ & 0.654 & $\begin{aligned} \text { V16-ConcMagFe } & =0.675-0.000048 \text { Equipment }-0.256 \text { V03-METDTSilica + 0.0220 V07-MISHIS + } \\
& \text { 0.00765 V09-MISLL34 - 0.701 V04-MisSilica + 0.00441 V02-StrendSilica - } 0.00625 \\
& \text { V50-Total Slate }\end{aligned}$ \\
\hline $51 \%$ & 0.000658 & $\begin{aligned} \text { V51 }(\text { V11-V12 })= & 0.0112-0.00100 \text { Equipment }+0.314 \text { V04-MisSilica }-0.00329 \text { V01-MISAFactor + } \\
& 0.0106 \text { V09-MISLL34 }\end{aligned}$ \\
\hline
\end{tabular}

KEY

$\begin{array}{llll}\text { Equipment: } & \text { Step } 2=-1 & \text { Experiment: } & \text { No Split }=-1 \\ & \text { Step } 3=+1 & \text { Split }=+1\end{array}$




\begin{tabular}{|c|c|c|}
\hline $\mathbf{r}^{2}$ & MEAN & \\
\hline & & LAYERS W/ HIS \& IBC \\
\hline $47 \%$ & 0.198 & V11-MisMagFe $=0.175+0.0465$ V08-MISIBC + 0.0460 V09-MISLC34 \\
\hline $17 \%$ & 0.0427 & V03-METDTSilica $=0.0550-0.0208$ V09-MISLC34 - 0.0128 V10-MISLC12 \\
\hline $17 \%$ & 0.0536 & V05-ConcSilica = $0.0484+0.0210$ V08-MISIBC + 0.0101 V10-MISLC12 \\
\hline \multirow[t]{2}{*}{$17 \%$} & 0.654 & V16-ConcMagFe = 0.659 - 0.0178 V08-MISIBC - 0.00855 V10-MISLC12 \\
\hline & & LAYERS W/ TOTAL SLATE \\
\hline $31 \%$ & 0.198 & V11-MisMagFe = $0.197+0.0204$ V09-MISLC34 - 0.0240 V10-MISLC12 \\
\hline $15 \%$ & 0.0427 & V03-METDTSilica $=0.0380+0.0165$ V50-Total Slate \\
\hline $11 \%$ & 0.0536 & V05-ConcSilica $=0.0591-0.0138$ V09-MISLC34 \\
\hline \multirow[t]{2}{*}{$11 \%$} & 0.654 & V16-ConcMagFe = $0.650+0.0117$ V09-MISLC34 \\
\hline & & PRODUCTION - PREDICTION. INPUT = ALL BEFORE + T/S + STEP \\
\hline $59 \%$ & 0.0276 & $\begin{array}{c}\text { V52-NormPower }=-0.00411-0.00104 \text { Equipment }+0.00745 \text { V09-MISLC34 + 0.197 V04-MisSilica + } \\
\text { 0.0806 V12-MagFeRMF + 0.0184 V26-AmineRate }\end{array}$ \\
\hline \multirow[t]{2}{*}{$58 \%$} & 0.103 & $\begin{array}{c}\text { V26-AmineRate }=3.36-5.74 \text { V16-ConcMagFe + } 0.0619 \text { V09-MISLC34 - } 0.0137 \text { V18-RMFT85 - } 2.04 \\
\text { V04-MisSilica + 0.519 V28-RMF34 + 0.0193 V27-MetPowerDraw }\end{array}$ \\
\hline & & SILICA - INTERACTION. INPUT = V1 - V6 ONLY \\
\hline $9 \%$ & & $\begin{array}{c}\text { V06-MetFloatTailsSilica }=0.143-1.61 \text { V03-METDTSilica + 0.0223 V01-MISAFactor + } 0.0131 \text { V02- } \\
\text { StrendSilica }+0.35 \text { V04-MisSilica }+1.51 \text { V05-ConcSilica }\end{array}$ \\
\hline $57 \%$ & 1.60 & $\begin{array}{c}\text { V01-MISAFactor }=-0.109+0.0758 \text { V02-StrendSilica - 5.96 V03-METDTSilica + 38.9 V04-MisSilica - } \\
\text { 12.6 V05-ConcSilica + 0.346 V06-MetFloatTailsSilica }\end{array}$ \\
\hline $86 \%$ & 5.29 & $\begin{aligned} \text { V02-StrendSilica } & =-0.407+0.186 \text { V01-MISAFactor + 14.0 V03-METDTSilica + 89.4 V04-MisSilica - } \\
& 5.56 \text { V05-ConcSilica }+0.548 \text { V06-MetFloatTailsSilica }\end{aligned}$ \\
\hline $52 \%$ & 0.0427 & $\begin{array}{c}\text { V03-METDTSilica }=-0.0132-0.00653 \text { V01-MISAFactor }+0.0100 \text { V02-StrendSilica - } 0.091 \text { V04- } \\
\text { MisSilica }+0.482 \text { V05-ConcSilica }-0.0264 \text { V06-MetFloatTailsSilica }\end{array}$ \\
\hline $86 \%$ & 0.0552 & $\begin{aligned} \text { V04-MisSilica }= & 0.0100+0.00316 \text { V01-MISAFactor }+0.00658 \text { V02-StrendSilica }-0.0093 \text { V03- } \\
& \text { METDTSilica }+0.114 \text { V05-ConcSilica }-0.00124 \text { V06-MetFloatTailsSilica }\end{aligned}$ \\
\hline \multirow[t]{2}{*}{$37 \%$} & 0.0536 & $\begin{aligned} \text { V05-ConcSilica } & =0.0266-0.00691 \text { V01-MISAFactor }-0.00228 \text { V02-StrendSilica }+0.275 \text { V03- } \\
& \text { METDTSilica }+0.635 \text { V04-MisSilica }+0.0118 \text { V06-MetFloatTailsSilica }\end{aligned}$ \\
\hline & & FE - PREDICTION. INPUT = ALL BEFORE + T/S + STEP + INTERVARIALBES \\
\hline $49 \%$ & 0.198 & $\begin{aligned} \text { V11-MisMagFe }= & 0.239-0.000611 \text { Equipment - 0.00747 V01-MISAFactor - 0.00391 V02-StrendSilica - } \\
& 0.0270 \text { V10-MISLC12 }\end{aligned}$ \\
\hline $25 \%$ & 0.197 & V12-MagFeRMF = $0.176-0.000130$ Equipment + 0.0363 V08-MISIBC + 0.0442 V09-MISLC34 \\
\hline $52 \%$ & 0.0291 & $\begin{array}{c}\text { V13-MetCoarseTailsFe }=0.0421+0.00179 \text { Equipment }+0.0108 \text { V07-MISHIS - } 0.000034 \text { V22- } \\
\text { RodMillFeedRate }\end{array}$ \\
\hline $54 \%$ & 0.0114 & $\begin{array}{c}\text { V14-MetFineTailsFe }=-0.00574+0.000255 \text { Equipment }+0.00853 \text { V50-Total Slate + } 0.000978 \text { V18- } \\
\text { RMFT85 + 0.0892 V03-METDTSilica }\end{array}$ \\
\hline $98 \%$ & 0.933 & $\begin{array}{c}\text { V15-MetMagFeRecovery }=0.901-0.000017 \text { Equipment - } 1.48 \text { V13-MetCoarseTailsFe - 2.31 V14- } \\
\text { MetFineTailsFe + 0.514 V12-MagFeRMF }\end{array}$ \\
\hline $100 \%$ & Lo Ex & $\begin{array}{c}\text { V15-MetMagFeRecovery }=0.907-0.000002 \text { Equipment - } 1.47 \text { V13-MetCoarseTailsFe - } 2.17 \text { V14- } \\
\text { MetFineTailsFe + 0.472 V12-MagFeRMF }\end{array}$ \\
\hline $55 \%$ & 0.654 & $\begin{aligned} \text { V16-ConcMagFe } & =0.675-0.000048 \text { Equipment }-0.256 \text { V03-METDTSilica }+0.0220 \text { V07-MISHIS + } \\
& \text { 0.00765 V09-MISLC34 - 0.701 V04-MisSilica + 0.00441 V02-StrendSilica - } 0.00625 \\
& \text { V50-Total Slate }\end{aligned}$ \\
\hline $51 \%$ & 0.000658 & $\begin{aligned} \text { V51 }(\text { V11-V12 })= & 0.0112-0.00100 \text { Equipment }+0.314 \text { V04-MisSilica }-0.00329 \text { V01-MISAFactor }+ \\
& 0.0106 \text { V09-MISLC34 }\end{aligned}$ \\
\hline
\end{tabular}

KEY

Equipment: Step 2 = -1

Experiment: $\quad$ No Split $=-1$

$$
\text { Step } 3=+1
$$$$
\text { Split }=\quad+1
$$ 
A graphic summary of the various multiple linear regression analyses done is shown on the following page. Variables for which predictions were attempted are shown at the left margin of the table. Potential predictors are listed at the top of the table. If multiple analyses were done for a variable, multiple lines appear for it in the table.

R-squared is coded by four symbols as follows:

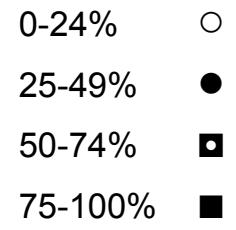

The nature of a variable's influence is coded as follows:

$\boldsymbol{\nabla}$ Negative influence

$\Delta \quad$ Positive influence

So, for example, the first line of the table tells us that V01 was predicted with an R-squared from $50-74 \%$ by the variables V02-V06. We can also see the influences of variables V02, V04 and V06 were positive (positive sign on the regression coefficient) and the influences of the remaining predictors were negative. Variables without a sign either were not ever included in the model or were not significant predictors. 


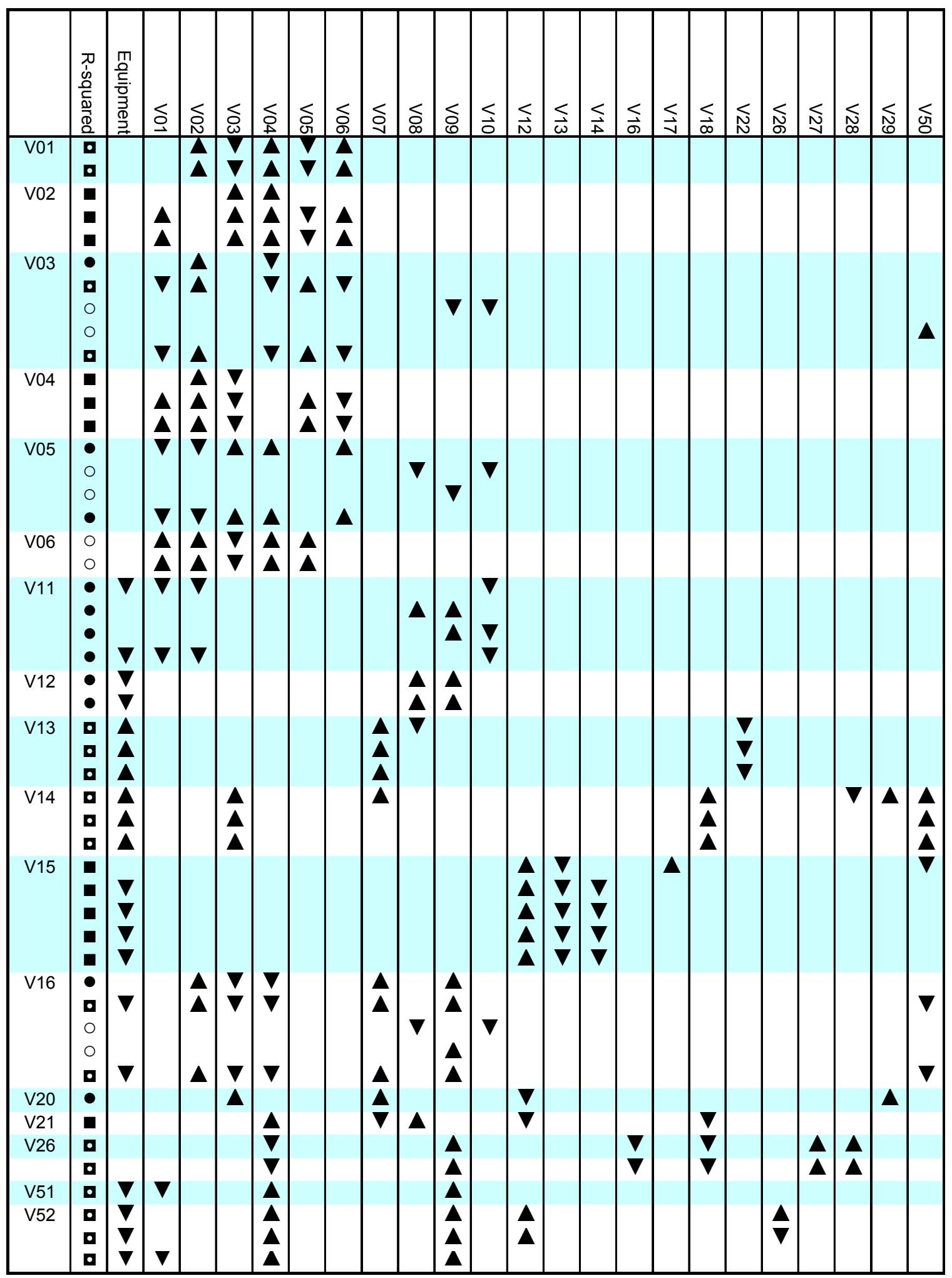




\section{Using the discoveries}

\section{Prediction}

\section{Point estimates}

Point estimates for any predicted variable can be computed by substituting predictor variable values into a prediction equation. Point estimates in themselves convey no information about their precision or believability, so interval estimates are used when these properties are of interest.

\section{Confidence and prediction intervals}

Confidence interval estimates for the average response at a given set of predictor settings, and prediction interval estimates for an individual response under the same conditions are available in Minitab. Confidence intervals will always be more precise (narrower) than prediction intervals because the latter must account for individual response variability from the mean. Both types of intervals will be narrowest near the mean of the predictor values and predictions at extremes of the predictors will be least precise. These properties are apparent in the plot below where both confidence limits (CLIM) and prediction limits (PLIM) are shown of the range of a predictor.

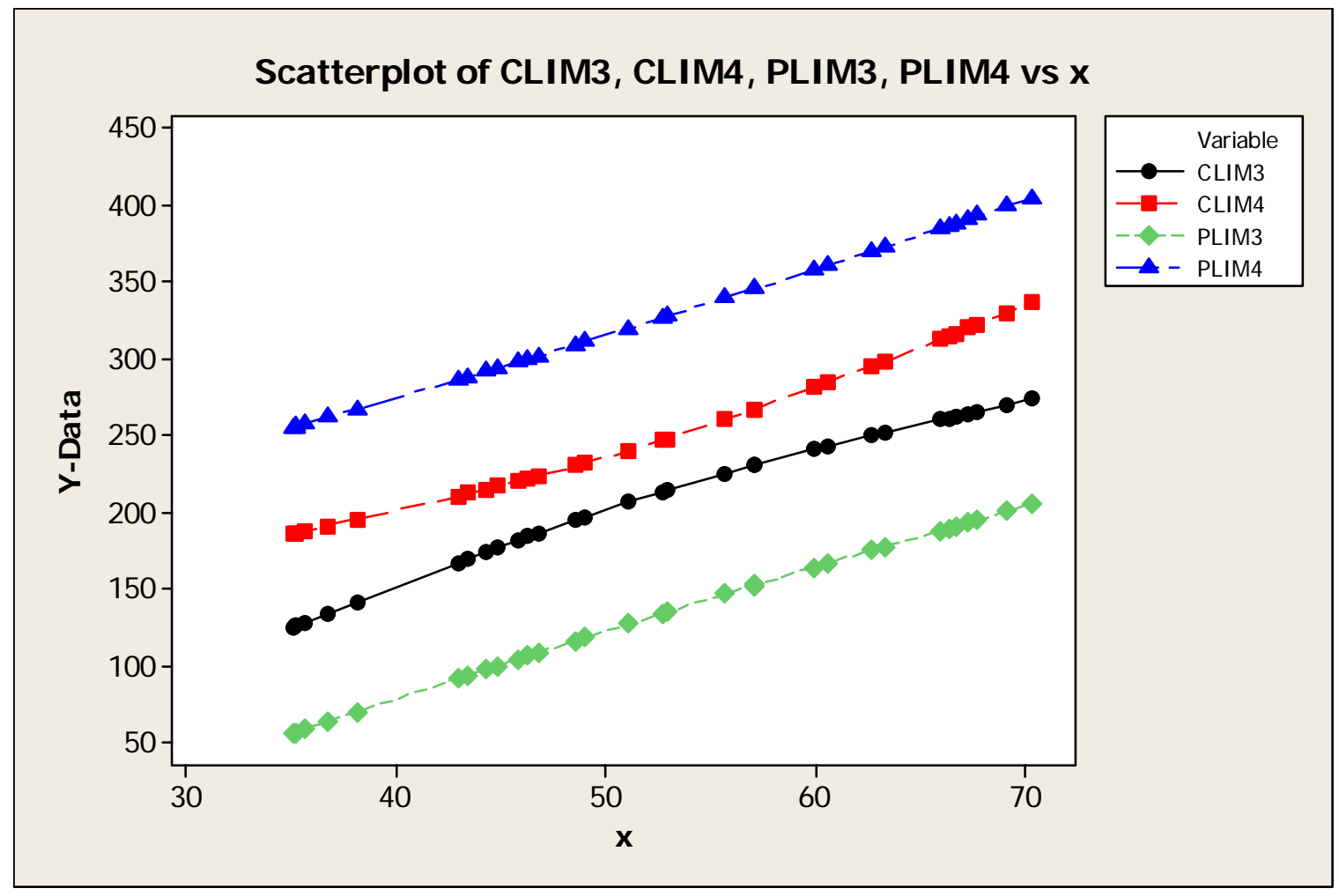




\section{Propagation of error}

Response variability can be approximately predicted at any given setting of predictors if the variance-covariance matrix of the predictors is available. The propagation of error formula for multiple predictors is:

$$
\operatorname{Var}(\hat{Y})=\sum_{i=1}^{k}\left(\frac{\partial f}{\partial x_{i}}\right)^{2} \sigma_{i}^{2}+2 \sum_{k<j} \frac{\partial f}{\partial x_{j}} \frac{\partial f}{\partial x_{k}} \sigma_{j k}+\sigma_{e}^{2}
$$

Here, the prediction equation is $y=f\left(x_{1}, \ldots x_{\mathrm{k}}\right), \sigma_{i}$ is the standard deviation of predictor $i, \sigma_{\mathrm{jk}}$ is the covariance of predictors $j$ and $k$, and $\sigma_{e}$ is the square root of mean squared error obtained from the analysis of variance.

\section{Limitations}

\section{Extrapolation}

Predictions can only be made with confidence under similar conditions and with similar predictor settings as those encountered during the period of observation. Extrapolation is easy to avoid with simple one-variable models because it is obvious when the limits of the predictor variable are reached. With multivariate models this is more difficult because a combination of predictor settings can be well outside the range of the original data even when each individual predictor is within its range. Consider the "type 2" point in the graph below: if the data used to build the prediction model are denoted "type 1", then prediction at the type 2 point would be extrapolation, even though settings at that point are within the range of each individual predictor variable.

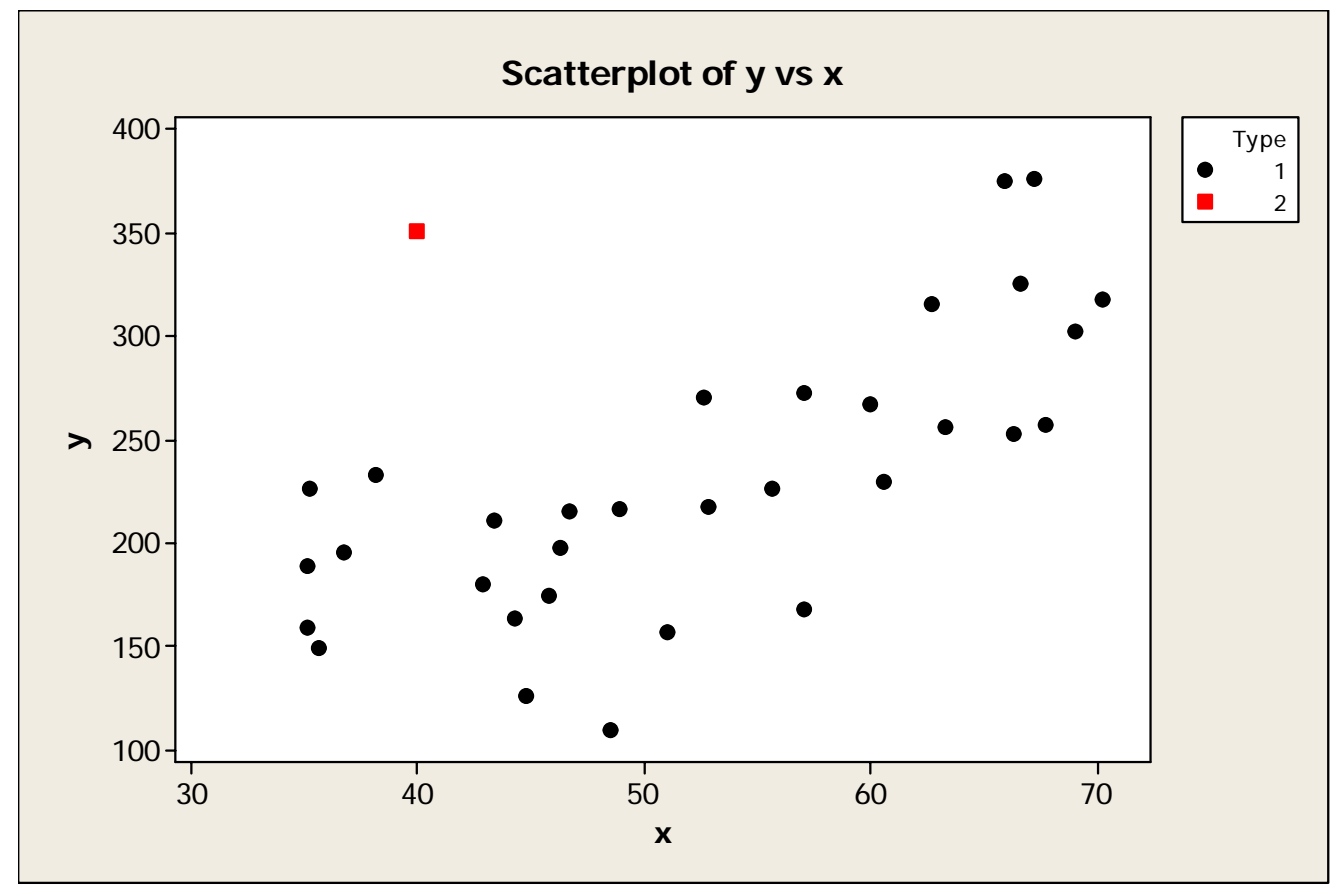


Mahalanobis distance is of some use in discovering combinations of predictor values far from the norm, but its utility depends on the assumption that the original distribution of predictors had at least an approximately multivariate normal distribution. When this assumption is unfounded, cluster analysis may prove useful in detecting outlying prediction points.

\section{Unobserved variables}

Plant operations require frequent human intervention and adjustment of equipment settings that were not recorded or accounted for during the period of observation. These could have the effect of accentuating or hiding some effects that might have been discovered in a more controlled experiment.

Unobserved variables can also have the effect of causing spurious correlations between other variables by affecting both variables in unison. For this reason, we should be careful to interpret correlations and predictions within a scientific framework: if there is not good reason to expect one variable to cause a difference in another, we should not infer such causal action even in the presence of significant correlation.

\section{Discovery methods}

\section{Data processing}

\section{Assumptions and simplifications}

Some data was given by shift, some by day, so shiftly data was averaged to create one observation per day. Variables were renamed consistently with naming syntax for Minitab. Indicator variables for experiment $(-1=$ no experiment) and equipment $(-1=$ step12) were created.

\section{Synthetic variables}

Some analyses required lagged variables, which are simply prior observations of the same variable. For example Lag2 $(x)=$ the value of $x$ two days before this one. Products and powers of variables were also created for some analyses.

\section{Linear regression analysis}

Multiple linear regression was performed in Minitab: a standard statistical software package.

\section{Models and estimation}

Linear regression assumes that a response $(y)$ can be predicted by one or more predictor variables $\left(x_{i}\right)$ to some extent by a model linear in its parameters $\left(\beta_{i}\right)$. The difference between actual and predicted values is modeled by an error term. An essential underlying assumption to statistical tests employed to choose predictors is that these error terms are independent and identically normally distributed random variables with fixed variance and zero mean. 


\section{Least squares estimates}

Least squares estimation selects estimates that minimize the sum of squared differences between actual and predicted values. Under the usual assumptions regarding error terms, least squares estimates are also maximum likelihood estimates, which have been proven to have optimal properties when compared with some alternative methods.

\section{Effects tests}

Tests for significant effects based on the F-distribution were used. Reported pvalues were compared to the typical cut-off value of 0.05 , which seemed appropriate given that the data set was of a sufficient size to allow detection of practically significant effects.

\section{Diagnostics}

Regression diagnostics were based primarily on a visual examination of residuals, as is shown in the example below. Outliers were the most common cause of assumption violation, and in these cases outliers were removed and the data re-analyzed. This is one of the reasons some small differences between estimated model coefficients will be found if not exactly the same set of variables were in the model.

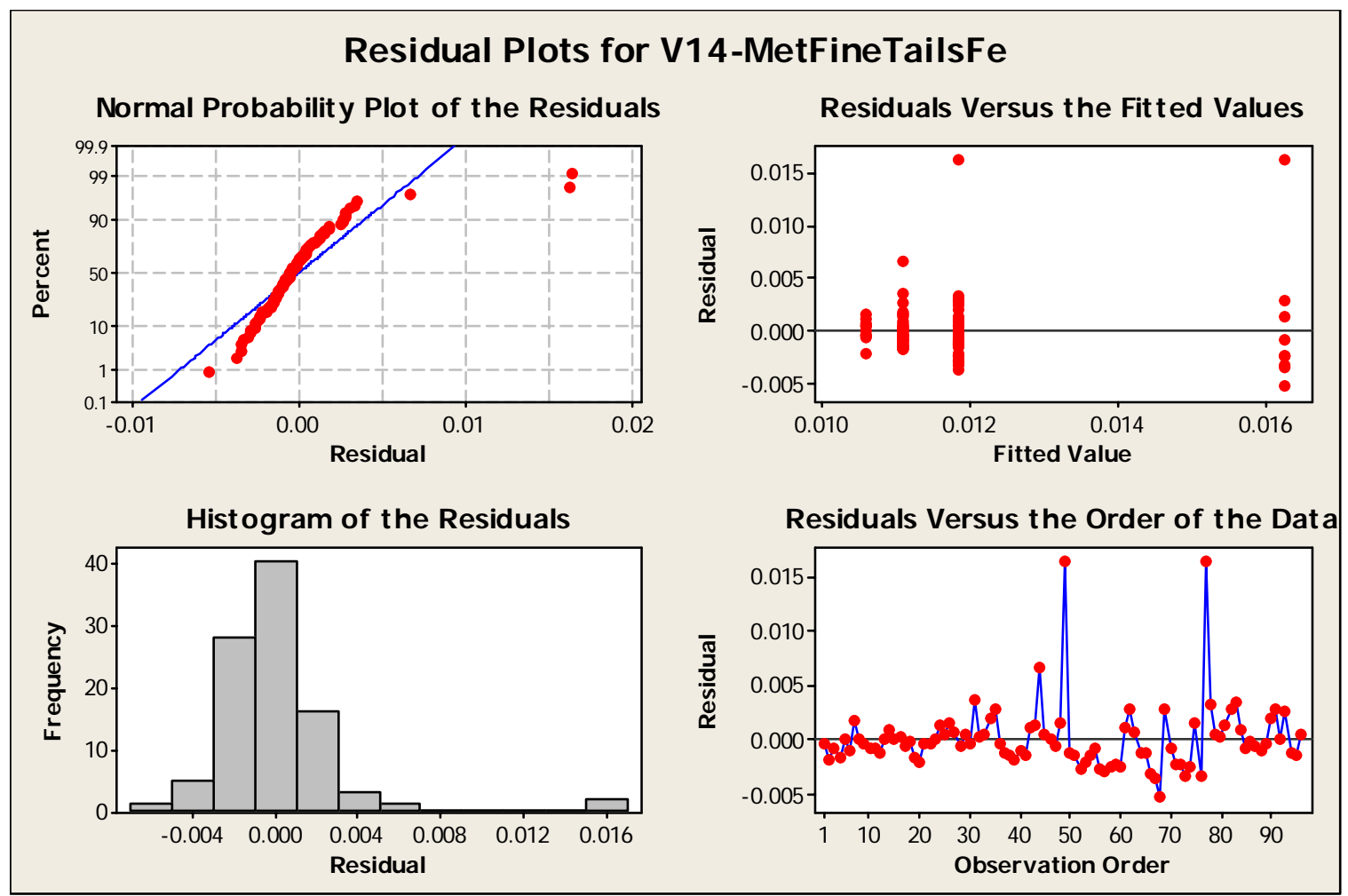




\section{Stepwise regression}

Variable selection is an important consideration in linear regression: select too few variables and prediction is inaccurate; select too many and spurious predictors in the model induce extra variation when making predictions outside the original data while giving the impression that prediction is actually improved. Stepwise regression is a variable selection technique that successively (a) adds the variable with the greatest contribution to prediction and (b) checks to see if any variables presently in the model can be dropped without significant loss of predictive ability.

We used stepwise regression to select a model, and then did a more thorough analysis of the selected model. Only the final model chosen is reported in most cases.

\section{Overview of analyses}

\section{Phase 1 version 1}

The basic goal of this first phase of research was to predict output (ConLTPH) with other variables available. Best subsets regression indicated that Lab Magfe and MIGI Sl account for $47 \%$ of the variance in ConLTPH. Residual analysis showed significant partial autocorrelations for at least the first three time periods; this observation prompted the version 2 analysis below.

\section{Phase 1 version 2}

In this second phase of the analysis of the passive data set we included an EWMA predictor for the output. The decision to add this predictor was based upon our belief that unmeasured (or unmeasurable) variables were influencing output, and that information on one day's output could probably be obtained from an observation of the process performance on prior days. The EWMA is the tool of choice for such prediction because it provides a predictor with an adjustable length of memory - the relative importance of recent data can be changed to optimize prediction. In this case an EWMA predictor with lambda $=0.27538$ was used to predict output based on prior outputs. This particular value of lambda was chosen because it minimized the prediction error (in the absence of other predictors). Using this type of predictor, a prediction $\left(\mathrm{y}_{\mathrm{n}}\right)$ for each day's output $\left(\mathrm{x}_{\mathrm{n}}\right)$ is made as follows:

$$
y_{n}=\lambda x_{n-1}+(1-\lambda) y_{n-1}
$$

Stepwise regression analysis indicated that the EWMA predictor, Abbe, and Lab MagFe are useful predictors, eventually accounting for two thirds of the variance in the data.

\section{Phase 2}

We investigated the relationship between High Silica/IBC and coarse /fine tails. ANCOVA (analysis of covariance) was used with stream (12 or 3) as the sole categorical variable. HIS has a significantly positive effect on Coarse tails, and IBC has a significantly negative effect. $50 \%$ of the variation in coarse fines was accounted for by this model. HIS has a significantly positive effect on fine tails, and IBC has a 
significantly positive effect as well.. 38\% of the observed variation in fine tails was accounted for by this model.

We also investigated relationships between High Silica/IBC and percent dry recovery and Float feed Davis tube weight recovery). 10\% of the observed variation in Dry Recovery was accounted for by this model. HIS had a significantly negative effect on the result. Only $4 \%$ of the observed variation in Davis Tube readings was accounted for by this model, but both HIS and IBC had significantly positive effects.

Finally we investigated relationships between High Silica/IBC and concentrate silica and flotation silica. $10 \%$ of the variation in Concentrator percent silica was predictable with HIS and IBC. Only IBC was a (positively) significant predictor. A negligible percent of the variation in TailsSiO2 was predicted. About $10 \%$ of the variation in float Feed $\mathrm{SiO} 2$ was predicted, and IBC was the only (positively) significant predictor.

\section{Phase 3}

The general goal of this phase of analysis is to predict variables from one another, with special focus on (13) met rpt mag fe coarse and (14) met rpt mag fe fine. The difference between (11) and (12) is also somewhat of a mystery so efforts were made to predict that difference.

V11-V12 is predicted well (67\% R-sq) by V24, V02, V10 and V15.

Coarse tails MagFe is predicted fairly well (45\% R-sq) by four variables: V02, V07, V04, V22.

Fine tails MagFe is predicted only partially (best R-sq is 28\%). Predictors change throughout the stepwise procedure indicating some complex relationships among the predictors: V01, V03, V07, V17 predict $18 \%$ of variance, but V01, V02, V07, V11 predict $28 \%$.

Power draw is very well predicted by Rod Mill Feed, but this is no surprise more material to process means more power draw. When the residuals from this regression are predicted, HIS (V07) is the most powerful predictor, but there are still apparent time trends.

V16 (concentrate mag Fe) prediction is trivial if concentrate silica is included, but leaving it out, $66 \%$ of the variation is predicted by V02, V03, V04, V17, V09, V26

Amine rate (V26) is predicted moderately well (R-sq=37\%) by V28, V10, V03, V19, V09, and V11.

\section{Phase 3 version 2}

This version of the analysis presents minor enhancements and corrections compared to the prior version. 


\section{Phase 4}

This analysis consisted of a simple comparison with the time split in addition to equipment split. Total slate was defined as HIS+IBC. An initial analysis with some outliers removed produced the following results:

Analysis of Variance for V14-MetFineTailsFe, using Adjusted ss for Tests

\begin{tabular}{|c|c|c|c|c|c|c|}
\hline Source & DF & Seq SS & Adj SS & Adj MS & $\mathrm{F}$ & $P$ \\
\hline Split & 1 & ๑.0000316 & $\odot .000 \odot 722$ & $\odot .0000722$ & 24.87 & $\odot . \odot \odot \odot$ \\
\hline ETime & 1 & $\odot .0000249$ & $\odot .0 \odot \odot \odot 277$ & $\odot .0000277$ & 9.54 & $\odot .003$ \\
\hline Split*ETime & 1 & $\odot .0 \odot \odot \odot 429$ & $\odot .0 \odot \odot \odot 429$ & $\odot . \odot \odot \odot \odot 429$ & 14.80 & $\odot . \odot \odot \odot$ \\
\hline Error & 89 & ๑.0002583 & ๑. 0002583 & ๑. $0000 \odot 29$ & & \\
\hline Total & 92 & $\odot .0003578$ & & & & \\
\hline
\end{tabular}

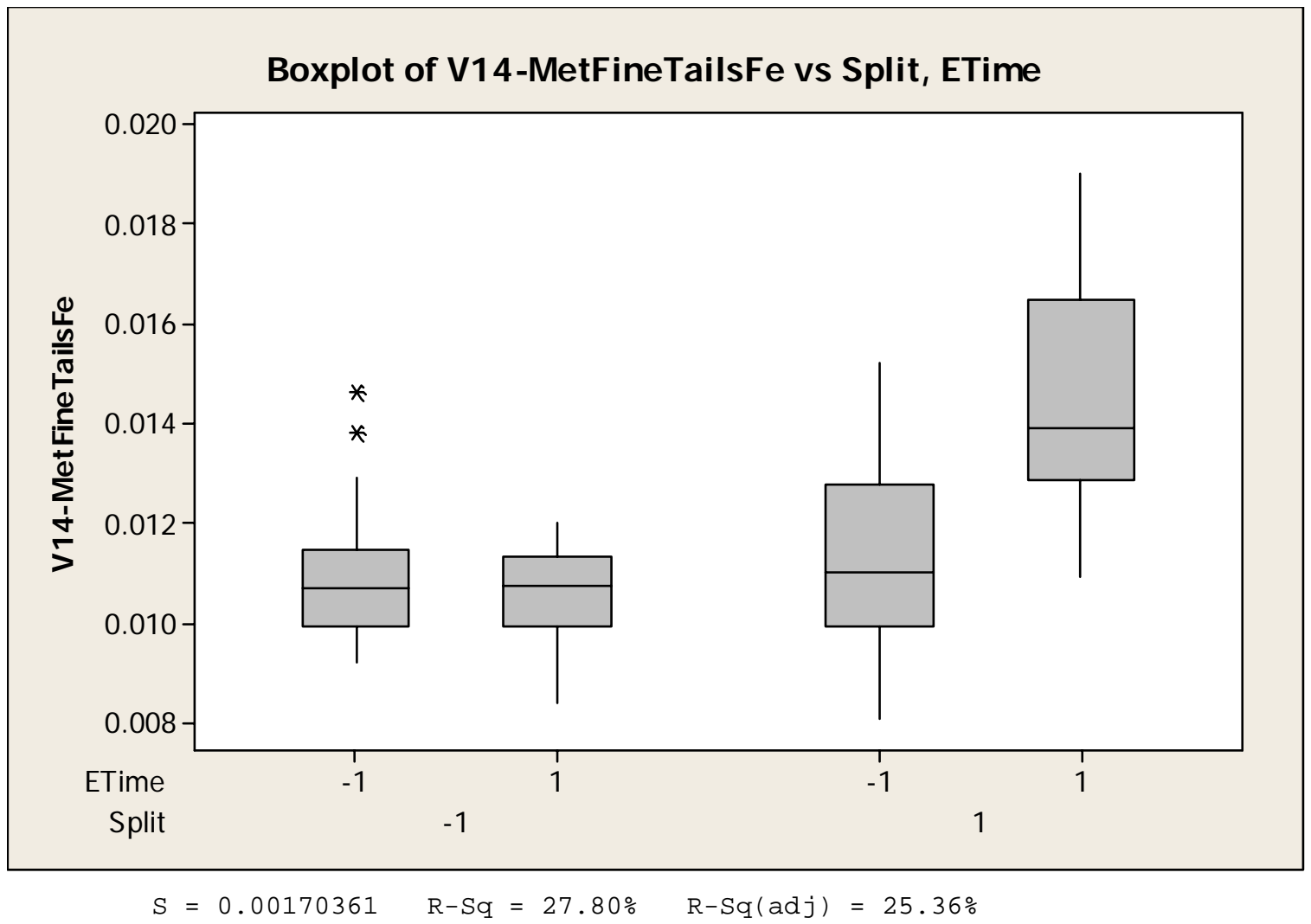

A boxplot reveals that the +1 side of the split is consistently more variable and has larger fine tails than the -1 side, and that the experiment made results worse (as expected) in the +1 side of the split, but did not improve performance in the -1 side of the split (not expected). 


\section{Phase 4 version 2}

In this analysis we discovered that, for the equipment getting the better input material, fine tails were generally unaffected by the experiment. For the equipment getting the more difficult input material, fine tails were significantly affected by the experiment. The equipment getting the more difficult input material ( +1 above) was also more variable that the other equipment set, whether during the experiment or not.

Coarse tails for both equipment lines were affected by the experiment: the equipment receiving the better material had lower coarse tails and the equipment getting the harder material had higher coarse tails.

Predictions including total slate (HIS+IBC) were done for important responses.

For fine tails (as the response) stepwise regression led to the following model:

\section{Regression Analysis: V14-MetFineT versus V50-Total SI, V18-RMFT85, ...}

The regression equation is

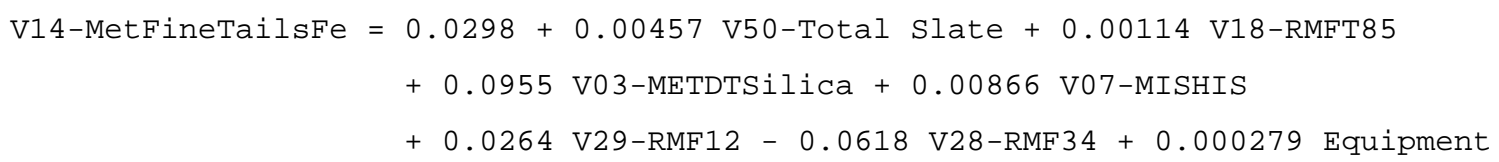

\begin{tabular}{|c|c|c|c|c|}
\hline Predictor & Coef & SE Coef & $\mathrm{T}$ & \\
\hline Constant & $\odot .02976$ & $\odot .02038$ & 1.46 & 0.1 \\
\hline V50-Total Slate & $\odot .0 \odot 4567$ & ๑. .๑1896 & 2.41 & $\odot .0$ \\
\hline V18 - RMFT85 & $\odot .0 \odot 11438$ & $\odot . \odot \odot \odot 3 \odot 48$ & 3.75 & $\odot . \odot$ \\
\hline V๑3-METDTSilica & $\odot .09546$ & $\odot .03066$ & 3.11 & $\odot . \odot$ \\
\hline V๑7 - MISHIS & 0.008665 & 0.003075 & 2.82 & $\odot . \odot \odot$ \\
\hline V29-RMF12 & $\odot .026388$ & $\odot . \odot \odot 9 \odot 93$ & 2.90 & $\odot . \odot$ \\
\hline V28 - RMF34 & $-\odot .06180$ & $\odot .0259 \odot$ & -2.39 & $\odot .01$ \\
\hline Equipment & $\odot .0 \odot \odot 2792$ & $\odot .0 \odot \odot 154 \odot$ & 1.81 & $\odot . \odot$ \\
\hline
\end{tabular}

The stepwise procedure selected a variable set predicting $60 \%$ of the variation in fine V14 (fine tails Fe). (Note that the same procedure only predicted $25 \%$ of the variation in the response if the outliers were left in the data.) V50,18, 3, 7, 29, 28, and equipment were selected as predictors. The final regression confirmed this conclusion, and validated the assumptions necessary for valid tests and predictions. Note that a more parsimonious model is available: V50, V18, V03.

The corresponding analysis for coarse tails prediction is shown below: 


\section{Regression Analysis: V13-MetCoars versus Equipment, V22-RodMillF, ...}

\begin{tabular}{|c|c|c|c|c|}
\hline $\begin{aligned} 13-\text { MetCoarseTailsFe }= & 0 . \Theta \\
& +\odot\end{aligned}$ & $\begin{array}{l}01+0.00163 \\
0119 \text { V๑7-MISH }\end{array}$ & $\begin{array}{l}\text { Equipment - } \\
\text { IS - } 0.00461\end{array}$ & $\begin{array}{r}0.00002 \\
\text { V08-MI }\end{array}$ & $\begin{array}{l}29 \text { V22- } \\
\text { ISIBC }\end{array}$ \\
\hline Predictor & Coef & SE Coef & $\mathrm{T}$ & $\mathrm{P}$ \\
\hline Constant & $\odot .040072$ & $\odot .005391$ & 7.43 & $\odot .0 \odot \odot$ \\
\hline Equipment & 0.0016266 & $\odot .0003320$ & 4.90 & $\odot .0 \odot \odot$ \\
\hline V22-RodMillFeedRate & $-\odot .00 \odot \odot 2855$ & $\odot .0 \odot \odot \odot 1201$ & -2.38 & $\odot .020$ \\
\hline VO7-MISHIS & 0.011895 & $\odot . \odot \odot 2334$ & 5.10 & $\odot .000$ \\
\hline V08-MISIBC & -0.004614 & $\odot .0 \odot 2093$ & -2.20 & 0.030 \\
\hline
\end{tabular}

Prediction of coarse tails (V13) was attempted using the dataset with outliers (for fine tails) removed using the following candidate predictors: V1, 2, 4, 11, 7, 8, 9, 10, 28, 29, 3, 12, 17, 18, 19, 22, and equipment. These are variables determined before the processing step occurs. Equipment, V07, V22 and V08 were selected as predictors. The regression with only these variables confirmed that tests and predictions can be made validly.

We also investigated inter-relationships between V02, V03 and V04. This analysis was done on the dataset with the fine tails outliers removed. An additional observation was removed after it appeared as an outlier in the first of the regression analyses.

From the graph below it is obvious that these variables are all positively correlated with one another. Regression analyses confirm this relationship. 85\% of the variation in V02 is accounted for by the other variables. Only V02 predicted V03, and it predicted $34 \%$ of the variation in V03. Only V02 predicted V04, and with $84 \%$ of the variation accounted for.

Distributions of all variables and descriptive statistics were also generated. 


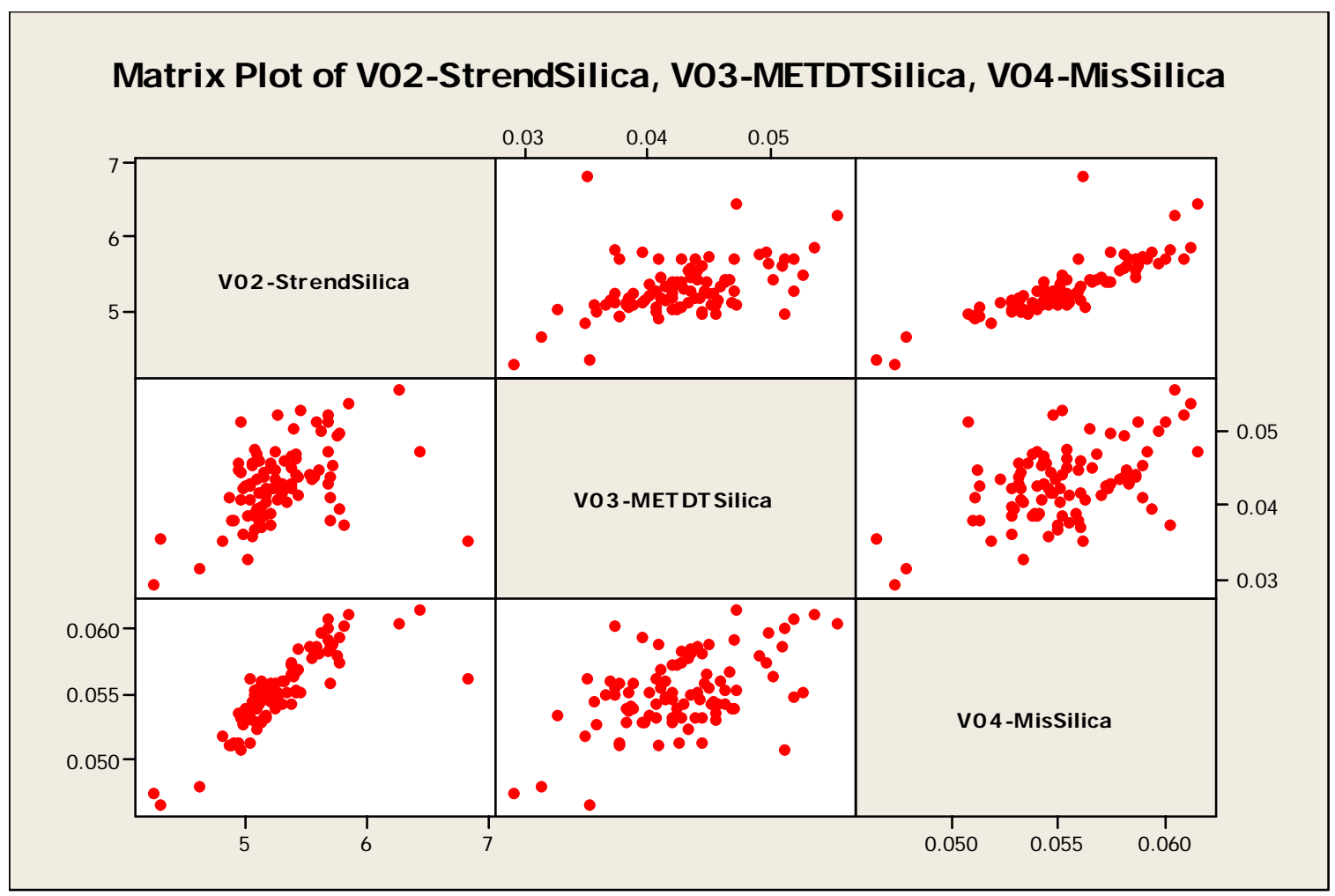

\section{Phase 4 version 3}

This phase of work commenced with a grind analysis: predictive models for V15, V16, V20 and V21. The following variables were considered as candidate predictors for this set of analyses: Equipment, V1, V2, V4, V11, V7, V8, V9, V10, V28, V29, V3, V12, V18, V17, V19, V22, V13, V11 and V50 (total slate). Outliers (according to previous fine tails regressions) were removed before analysis.

For V15-MetMagFe, the equipment seemed to be the most important predictor, but when Experiment is added as a variable (because it was confounded with equipment) it seems that the observed variation in V15 may be mostly due to the experiment, but is not well-predicted by other variables.

For ConMagFe, Five variables predicted $49 \%$ of the variance in the response. Model assumptions seem to be satisfied. Significant predictors were V03-METDTSilica, V07-MISHIS, V09-MISLL34, V04-MisSilica and V02-StrendSilica.

For ConcGrind, four variables (V07-MISHIS, V03-METDTSilica, V29-RMF12, V12-MagFeRMF) predicted $44 \%$ of the variation.

For StrendFloatF, five variables were required to predict $30 \%$ of the variation: V12-MagFeRMF, V07-MISHIS, V04-MisSilica, V18-RMFT85 and V08-MISIBC.

The next analysis was of power draw normalized by feed rate: V52NormPower=V27/V22. Predictor candidates included all other variables. 59\% of the variation is accounted for by a five-variable model including Equipment, V09-MISLL34, 
V04-MisSilica, V12-MagFeRMF and V26-AmineRate.

Next was an analysis to predict amine rate (V26). Six variables predicted 55\% of the variation in the response: V16-ConcMagFe, V09-MISLL34, V18-RMFT85, V04MisSilica, V28-RMF34 and V27-MetPowerDraw.

V06 (float tails silica) has not been included in any analysis to date - even as a candidate predictor. This variable was created from col BL: Met Report Flotation Tails \% SiO2. As can be seen from the plot below V06 is highly correlated with other silica variables:

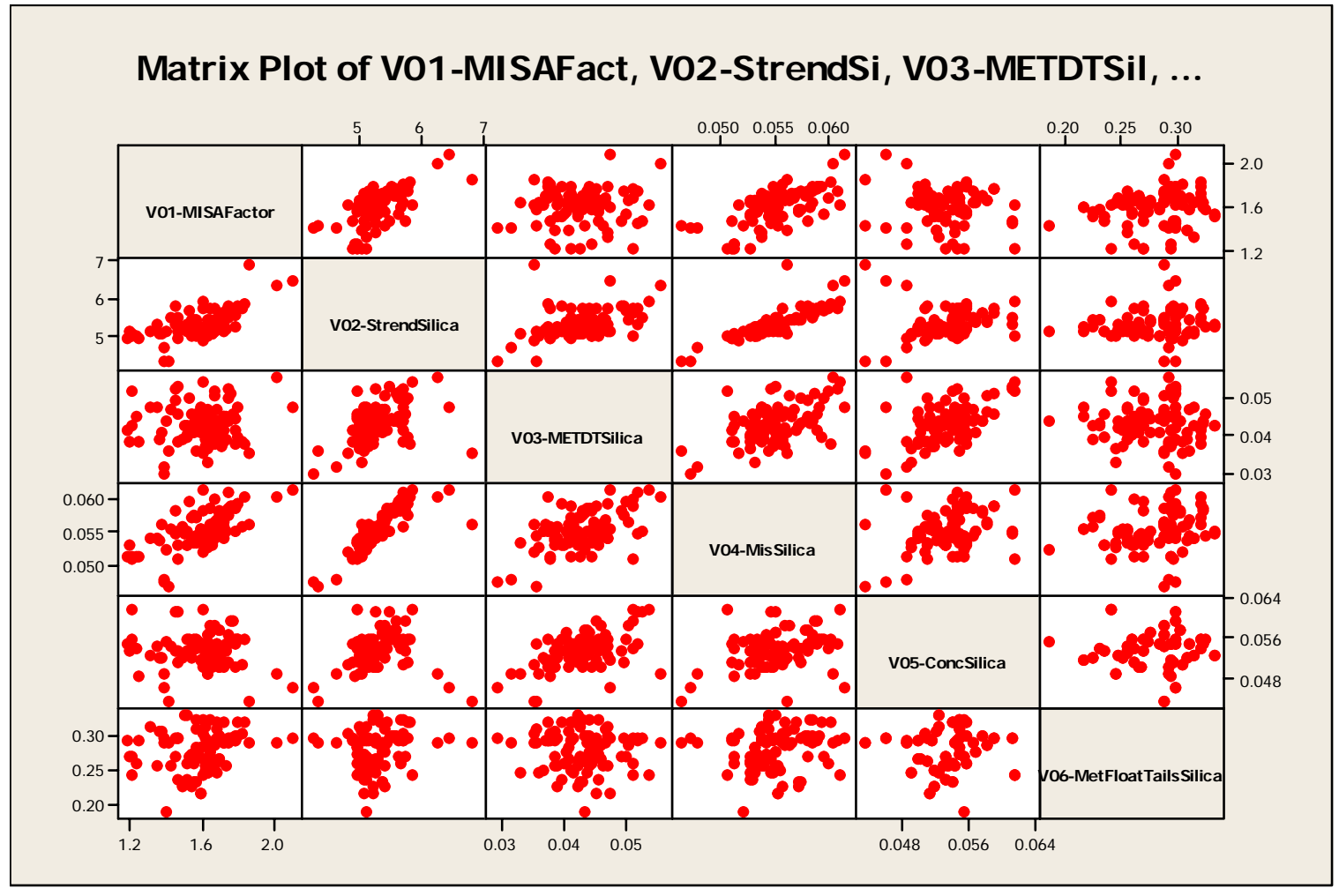

Summary regression analyses are given below:

\section{Regression Analysis: V06-MetFloat versus V03-METDTSil, V01-MISAFact, ...}

The regression equation is

V06-MetFloatTailsSilica $=0.143-1.61$ V๑3-METDTSilica +0.0223 V01-MISAFactor

$+\odot .0131$ V๑2-StrendSilica + 0.35 V๑4-MisSilica

+1.51 Vo5-ConcSilica

$\begin{array}{lrrrr}\text { Predictor } & \text { Coef } & \text { SE Coef } & \text { T } & \text { P } \\ \text { Constant } & 0.14261 & 0.06824 & 2.09 & 0.040 \\ \text { V03-METDTSilica } & -1.6058 & 0.8302 & -1.93 & 0.056 \\ \text { V01-MISAFactor } & 0.02231 & 0.02711 & 0.82 & 0.413 \\ \text { V02-StrendSilica } & 0.01307 & 0.01579 & 0.83 & 0.410 \\ \text { V04-MisSilica } & 0.353 & 2.354 & 0.15 & 0.881\end{array}$




$$
\begin{aligned}
& \begin{array}{lllll}
\text { V@5-ConcSilica } & 1.510 & 1.166 & 1.29 & 0.199
\end{array} \\
& \mathrm{~S}=0.0290914 \quad \mathrm{R}-\mathrm{Sq}=9 . \odot \% \quad \mathrm{R}-\mathrm{Sq}(\operatorname{adj})=3.8 \%
\end{aligned}
$$

\section{Regression Analysis: V01-MISAFact versus V02-StrendSi,...}

The regression equation is

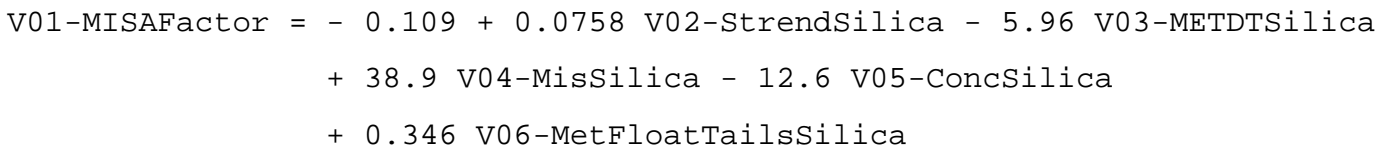

$S=0.114600$

$\mathrm{R}-\mathrm{Sq}=56.4 \%$

$\mathrm{R}-\mathrm{Sq}(\operatorname{adj})=53.9 \%$

\section{Regression Analysis: V02-StrendSi versus V01-MISAFact, ...}

The regression equation is

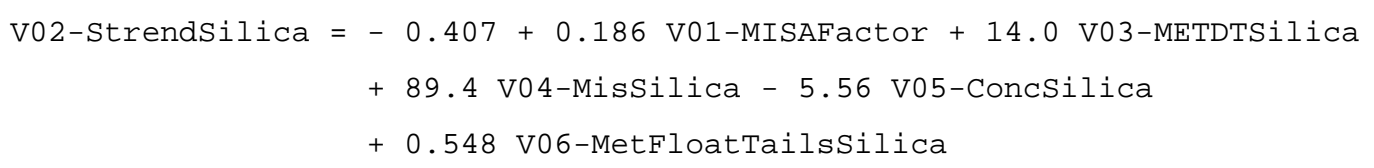

$S=0.130999 \quad R-S q=86.3 \% \quad R-S q(\operatorname{adj})=85.5 \%$

\section{Regression Analysis: V03-METDTSil versus V01-MISAFact,...}

The regression equation is

V03-METDTSilica $=-0.0132-0.00653$ V๑1-MISAFactor +0.0100 V๑2-StrendSilica

- ๑.๑91 V๑4-MisSilica + ๑.482 V๑5-ConcSilica

- 0.0264 V๑6-MetFloatTailsSilica 


\begin{tabular}{|c|c|c|c|c|}
\hline Predictor & Coef & SE Coef & $\mathrm{T}$ & $P$ \\
\hline Constant & -0.013221 & $\odot .0 \odot 8461$ & -1.56 & $\odot .122$ \\
\hline V01-MISAFactor & -0.006527 & $\odot .0 \odot 3229$ & -2.02 & $\odot . \odot 46$ \\
\hline V๑2-StrendSilica & 0.010049 & $\odot .0 \odot 2682$ & 3.75 & $\odot .000$ \\
\hline V๑4-MisSilica & -0.0913 & $\odot .3369$ & -0.27 & 0.787 \\
\hline V05-ConcSilica & 0.4818 & 0.1329 & 3.63 & $\odot .000$ \\
\hline V@6-MetFloatTailsSilica & $-\odot .02636$ & 0.01268 & -2.08 & $\odot .041$ \\
\hline
\end{tabular}

\section{Regression Analysis: V04-MisSilic versus V01-MISAFact,...}

The regression equation is

V๑4-MisSilica $=0.0100+0.00316 \mathrm{~V} 01$-MISAFactor $+0.00658 \mathrm{~V} \odot 2-$ StrendSilica

- 0.0093 V03-METDTSilica + 0.114 V05-ConcSilica

- $\odot .0 \odot 124$ V๑6-MetFloatTailsSilica

$\begin{array}{lrrrr}\text { Predictor } & \text { Coef } & \text { SE Coef } & \text { T } & \text { P } \\ \text { Constant } & 0.010033 & 0.002523 & 3.98 & 0.000 \\ \text { V01-MISAFactor } & 0.003155 & 0.001001 & 3.15 & 0.002 \\ \text { V02-StrendSilica } & 0.0065836 & 0.0005935 & 11.09 & 0.000 \\ \text { V03-METDTSilica } & -0.00934 & 0.03448 & -0.27 & 0.787 \\ \text { V05-ConcSilica } & 0.11381 & 0.04396 & 2.59 & 0.011 \\ \text { V06-MetFloatTailsSilica } & -0.001238 & 0.004156 & -0.30 & 0.767 \\ & & & & \\ \text { S = } & & & & \end{array}$

\section{Regression Analysis: V05-ConcSili versus V01-MISAFact ...}

The regression equation is

V05-ConcSilica $=0.0266-0.00691$ V๑1-MISAFactor -0.00228 V02-StrendSilica

+0.275 V๑3-METDTSilica +0.635 V๑4-MisSilica

+0.0118 V06-MetFloatTailsSilica

$\begin{array}{lrrrr}\text { Predictor } & \text { Coef } & \text { SE Coef } & \text { T } & \text { P } \\ \text { Constant } & 0.026625 & 0.005815 & 4.58 & 0.000 \\ \text { V01-MISAFactor } & -0.006906 & 0.002384 & -2.90 & 0.005 \\ \text { V02-StrendSilica } & -0.002284 & 0.002172 & -1.05 & 0.296 \\ \text { V03-METDTSilica } & 0.27525 & 0.07591 & 3.63 & 0.000 \\ \text { V04-MisSilica } & 0.6353 & 0.2454 & 2.59 & 0.011 \\ \text { V06-MetFloatTailsSilica } & 0.011803 & 0.009741 & 1.21 & 0.229\end{array}$


$S=0.00265597 \quad R-S q=37.2 \% \quad R-S q(\operatorname{adj})=33.6 \%$

This phase of the analysis also created predictive models for V11, V12, V13, V14, V15, V16 and magdiff (V11-V12). Representative regression analyses are given below:

\section{Regression Analysis: V11-MisMagFe versus Equipment...}

The regression equation is

V11-MisMagFe $=0.239-0.000611$ Equipment -0.00747 V01-MISAFactor

- 0.00391 V02-StrendSilica - 0.0270 V10-MISLL12

Predictor

$\begin{array}{rrrr}\text { Coef } & \text { SE Coef } & \text { T } & P \\ 0.238771 & 0.006142 & 38.87 & 0.000 \\ -0.0006107 & 0.0004236 & -1.44 & 0.153 \\ -0.007470 & 0.003061 & -2.44 & 0.017 \\ -0.003913 & 0.001378 & -2.84 & 0.006 \\ -0.026971 & 0.004128 & -6.53 & 0.000\end{array}$

$S=0.00379052 \quad R-S q=49.0 \% \quad R-S q(\operatorname{adj})=46.7 \%$

\section{Regression Analysis: V12-MagFeRMF versus Equipment,...}

The regression equation is

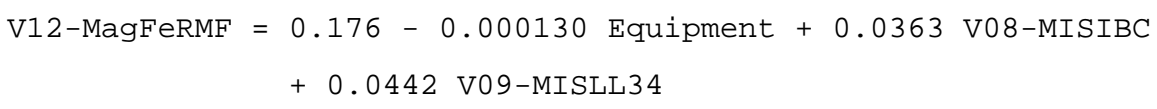

Predictor Coef SE Coef $\quad T \quad P$

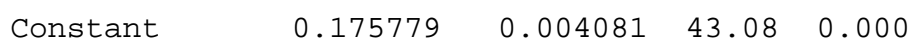

$\begin{array}{lllll}\text { Equipment } & -0.0001304 & 0.0005847 & -0.22 & 0.824\end{array}$

$\begin{array}{lllll}\text { V๑8-MISIBC } & 0.036299 & 0.008727 & 4.16 & 0.00 \odot\end{array}$

$\begin{array}{lllll}\text { V09-MISLL34 } & 0.044233 & 0.008692 & 5.09 & 0.000\end{array}$

$S=0.00553879 \quad R-S q=25.2 \% \quad R-S q(\operatorname{adj})=22.7 \%$

\section{Regression Analysis: V13-MetCoarseTai versus Equipment,...}

The regression equation is

V13-MetCoarseTailsFe $=0.0421+0.00179$ Equipment +0.0108 V07-MISHIS

- $\odot .000034$ V22-RodMillFeedRate

Predictor

Coef SE Coef $T$ P

Constant

0.042128

0.005423

7.77

0.000

Equipment

๑. 0017855

$\odot .0003310$

$5.39 \quad 0.00 \odot$ 


\begin{tabular}{|c|c|c|c|c|}
\hline VO7-MISHIS & 0.010823 & 0.002331 & 4.64 & 0.000 \\
\hline V22-RodMillFeedRate & $-\odot .00003374$ & $\odot .00001203$ & -2.80 & 0.006 \\
\hline
\end{tabular}

\section{Regression Analysis: V14-MetFineT versus Equipment,...}

The regression equation is

V14-MetFineTailsFe $=-0.00574+0.000255$ Equipment +0.00853 V50-Total Slate

$$
+0.000978 \text { V18-RMFT85 + } 0.0892 \text { V03-METDTSilica }
$$

$\begin{array}{lrrrr}\text { Predictor } & \text { Coef } & \text { SE Coef } & \text { T } & \text { P } \\ \text { Constant } & -0.005737 & 0.003468 & -1.65 & 0.102 \\ \text { Equipment } & 0.0002547 & 0.0001457 & 1.75 & 0.084 \\ \text { V50-Total Slate } & 0.008534 & 0.001322 & 6.45 & 0.000 \\ \text { V18-RMFT85 } & 0.0009776 & 0.0003099 & 3.15 & 0.002 \\ \text { V03-METDTSilica } & 0.08915 & 0.03154 & 2.83 & 0.006 \\ & & & & \\ \text { S = } 0.00136155 & \text { R-Sq }=54.4 \% & \text { R-Sq(adj })=52.3 \%\end{array}$

\section{Regression Analysis: V15-MetMagFe versus Equipment,...}

The regression equation is

V15-MetMagFeRecovery $=0.901-0.000017$ Equipment -1.48 V13-MetCoarseTailsFe - 2.31 V14-MetFineTailsFe + 0.514 V12-MagFeRMF

\begin{tabular}{|c|c|c|c|c|}
\hline Predictor & Coef & SE Coef & $\mathrm{T}$ & $P$ \\
\hline Constant & $\odot .900564$ & $\odot .001553$ & 579.73 & $\odot . \odot \odot \odot$ \\
\hline Equipment & -0.00001673 & $\odot .0 \odot \odot \odot 549 \odot$ & $-\odot .3 \odot$ & $\odot .761$ \\
\hline V13-MetCoarseTailsFe & -1.48321 & $\odot .02521$ & -58.82 & $\odot .000$ \\
\hline V14-MetFineTailsFe & -2.30813 & $\odot .02424$ & -95.22 & $\odot .000$ \\
\hline V12-MagFeRMF & 0.514017 & $\odot .007145$ & 71.94 & $\odot .00 \odot$ \\
\hline
\end{tabular}

\section{Regression Analysis: V16-ConcMagF versus Equipment,...}

The regression equation is

V16-ConcMagFe $=0.675-0.000048$ Equipment -0.256 V03-METDTSilica

$$
\begin{aligned}
& +0.0220 \text { V07-MISHIS + } 0.00765 \text { V09-MISLL34 - } 0.701 \text { V๑4-MisSilica } \\
& +0.00441 \text { V02-StrendSilica - } 0.00625 \text { V50-Total Slate }
\end{aligned}
$$

Predictor

Constant

$\begin{array}{rrrr}\text { Coef } & \text { SE Coef } & \text { T } & P \\ 0.675162 & 0.005183 & 130.28 & 0.000\end{array}$




$\begin{array}{lrrrr}\text { Equipment } & -0.0000484 & 0.0002296 & -0.21 & 0.834 \\ \text { V03-METDTSilica } & -0.25641 & 0.05090 & -5.04 & 0.000 \\ \text { V07-MISHIS } & 0.021993 & 0.004897 & 4.49 & 0.000 \\ \text { V09-MISLL34 } & 0.007649 & 0.003417 & 2.24 & 0.028 \\ \text { V04-MisSilica } & -0.7013 & 0.1441 & -4.87 & 0.000 \\ \text { V02-StrendSilica } & 0.004410 & 0.001069 & 4.13 & 0.000 \\ \text { V50-Total Slate } & -0.006253 & 0.003264 & -1.92 & 0.059 \\ & & & & \\ \text { S = } 0.00200179 & \text { R-Sq }=55.1 \% & \text { R-Sq(adj })=51.4 \%\end{array}$

Regression Analysis: V51-(V11-V12) versus Equipment, ...

The regression equation is

V51- $($ V11-V12 $)=0.0112-0.00100$ Equipment +0.314 V04-MisSilica

- 0.00329 V01-MISAFactor +0.0106 V09-MISLL34

$\begin{array}{lrrrr}\text { Predictor } & \text { Coef } & \text { SE Coef } & T & P \\ \text { Constant } & 0.011246 & 0.003239 & 3.47 & 0.001 \\ \text { Equipment } & -0.0010049 & 0.0001480 & -6.79 & 0.000 \\ \text { V04-MisSilica } & 0.31425 & 0.06545 & 4.80 & 0.000 \\ \text { V01-MISAFactor } & -0.003292 & 0.001095 & -3.01 & 0.003 \\ \text { V09-MISLL34 } & 0.010592 & 0.001829 & 5.79 & 0.000\end{array}$

$S=0.00133291 \quad R-S q=53.1 \% \quad R-S q(\operatorname{adj})=51.0 \%$

\section{Phase 4 version 4}

This phase of the analysis consisted of checking some prior results. In cases where updates or corrections are made, only the final results are reported in the summary at the beginning of this report. This document should be used rather than the prior one when reporting final results.

\section{Phase 4 version 5}

This phase of analysis consisted of further regression analyses and refinements of prior analyses. In particular:

V11-MisMagFe versus V08-MISIBC, V09-MISLL34

V03-METDTSilica versus V09-MISLL34, V10-MISLL12

V05-ConcSilica versus V08-MISIBC, V10-MISLL12

V16-ConcMagFe versus V08-MISIBC, V10-MISLL12

V11-MisMagFe versus V09-MISLL34, V10-MISLL12

V03-METDTSilica versus V50-Total Slate 


\section{V05-ConcSilica versus V09-MISLL34 \\ V16-ConcMagFe versus V09-MISLL34}

Some histograms missing from prior analyses were also supplied.

\section{Phase 5}

This phase of the analysis was directed at predicting V12 - MagFeRMF - using shift-specific data and lagged variables. The results, summarized below, show that prediction is better during the time the experiment was run. This is not surprising, as incoming material quality was more controlled during this time. Prediction quality by equipment set was comparable regardless of whether the experiment was in progress or not.

\begin{tabular}{|c|c|c|c|c|c|c|c|c|}
\hline \multirow{2}{*}{$\begin{array}{l}\text { Exp. } \\
\text { No }\end{array}$} & \multicolumn{3}{|c|}{ Equipment set 1} & \multicolumn{5}{|c|}{ Equipment set 2} \\
\hline & $\begin{array}{l}\text { Predictor } \\
\text { Constant } \\
\text { V@7-MISHIS } \\
\text { V04-MisSilica } \\
\text { E125V11-MisMagFe } \\
\text { E125V28-RMF34 } \\
\text { E25V01-MISAFactor } \\
\text { E25V10-MISLL12 } \\
\text { R-Sq }=45.4 \%\end{array}$ & $\begin{array}{r}\text { Coef } \\
-0.2136 \\
0.0006 \odot \\
0.005 \odot \\
1.3138 \\
0.1454 \\
\odot .009907 \\
-0.01977\end{array}$ & $\begin{array}{c}P \\
0.523 \\
0.968 \\
0.989 \\
0.026 \\
0.587 \\
0.324 \\
0.172\end{array}$ & $\begin{array}{l}\text { Predictor } \\
\text { Constant } \\
\text { V07-MISHIS } \\
\text { V04-MisSilica } \\
\text { E125V11-MisMagFe } \\
\text { E125V28-RMF34 } \\
\text { E25V01-MISAFactor } \\
\text { E25V10-MISLL12 } \\
\text { R-Sq }=47.0 \%\end{array}$ & $\begin{array}{r}\text { Coef } \\
0.036 \odot \\
-0.0489 \odot \\
0.2519 \\
1.397 \odot \\
-0.130 \odot \\
0.00755 \\
-0.01512\end{array}$ & $\begin{array}{r}\text { SE Coef } \\
0.2161 \\
0.01781 \\
0.3869 \\
0.5184 \\
0.2161 \\
\odot .01519 \\
0.01635\end{array}$ & $\begin{array}{r}\mathrm{T} \\
0.17 \\
-2.75 \\
0.65 \\
2.69 \\
-0.60 \\
0.50 \\
-0.92\end{array}$ & $\begin{array}{l}+ \\
0.865 \\
0.016 \\
0.519 \\
0.011 \\
0.552 \\
0.622 \\
0.362\end{array}$ \\
\hline Yes & $\begin{array}{l}\text { Predictor } \\
\text { Constant } \\
\text { V07-MISHIS } \\
\text { V04-MisSilica } \\
\text { E125V11-MisMagFe } \\
\text { E125V28-RMF34 } \\
\text { E25V01-MISAFactor } \\
\text { E25V10-MISLL12 } \\
\text { R-Sq }=88.9 \%\end{array}$ & $\begin{array}{c}\text { Coef } \\
-1.0 .06 \\
-0.01664 \\
0.069 \\
1.377 \\
2.0109 \\
-0.00770 \\
-0.08996\end{array}$ & $\begin{array}{ll}\mathrm{P} & \\
5 & 0.816 \\
& 0.961 \\
& 0.644 \\
& 0.103 \\
& .921 \\
0.078 & 0.078\end{array}$ & $\begin{array}{l}\text { Predictor } \\
\text { Constant } \\
\text { V07-MISHIS } \\
\text { V04-MisSilica } \\
\text { E125V11-MisMagFe } \\
\text { E125V28-RMF34 } \\
\text { E25V01-MISAFactor } \\
\text { E25V10-MISLL12 } \\
\text { R-Sq }=86.4 \%\end{array}$ & $\begin{array}{r}\text { Coef } \\
-0.405 \\
-0.00893 \\
-0.532 \\
3.069 \\
0.067 \\
-0.02112 \\
0.02439\end{array}$ & $\begin{array}{r}\text { SE Coef } \\
1.696 \\
0.03637 \\
1.034 \\
3.087 \\
1.982 \\
0.01712 \\
0.06859\end{array}$ & $\begin{array}{r}\mathrm{T} \\
-0.24 \\
-0.25 \\
-0.51 \\
0.99 \\
0.03 \\
-1.23 \\
0.36\end{array}$ & $\begin{array}{l}r \\
0.827 \\
0.822 \\
0.642 \\
0.393 \\
0.975 \\
0.305 \\
0.746\end{array}$ \\
\hline
\end{tabular}

\section{List of computer files}

Name

\begin{tabular}{|l|l|}
\hline Final01.doc & Additional files for final report: correlation and PCA \\
\hline LessonsLearned from Ore SegregationTest 3.doc & Single variable analyses \\
\hline Pezutto.MTW & Minitab version of Pezutto data \\
\hline Pezuttoanalysis PhaseIV ver04 RegEqn2.doc & Summary of regressions - part 1 \\
\hline Pezuttoanalysis PhaseIV ver04 RegEqn3.doc & Summary of regressions - part 2 \\
\hline Pezutto II flat.MTW & Minitab version of SEGTEST3MASTER Sep 202004.xls \\
\hline Pezuttophase II - indicators added.MTW & \\
\hline Pezuttophase IV ver02.MTW & \\
\hline Pezuttophase IV ver05.MTW & \\
\hline Pezuttophase IV ver06.MTW & \\
\hline Pezuttophase IV.MTW & \\
\hline PezuttoPhase V.MTW & \\
\hline PezuttoPhase Va.MTW & \\
\hline
\end{tabular}




\begin{tabular}{|c|c|}
\hline \multicolumn{2}{|l|}{ PezuttoPhase Va11.MTW } \\
\hline \multicolumn{2}{|l|}{ PezuttoPhase Va-11.MTW } \\
\hline \multicolumn{2}{|l|}{ PezuttoPhase Va1-1.MTW } \\
\hline \multicolumn{2}{|l|}{ PezuttoPhase Va-1-1.MTW } \\
\hline \multicolumn{2}{|l|}{ PezuttoPhase V-E.MTW } \\
\hline \multicolumn{2}{|l|}{ PezuttoPhase V-EShift2.MTW } \\
\hline \multicolumn{2}{|l|}{ PezuttoPhase V-EShift2E1.MTW } \\
\hline \multicolumn{2}{|l|}{ PezuttoPhase V-EShift2E2.MTW } \\
\hline \multicolumn{2}{|l|}{ PezuttoPhase V-EShift2N1.MTW } \\
\hline \multicolumn{2}{|l|}{ PezuttoPhase V-EShift2N2.MTW } \\
\hline Pezzutto.xls & Initial data set with five variables \\
\hline \multicolumn{2}{|l|}{ Phase 1.doc } \\
\hline \multicolumn{2}{|l|}{ Phase 1 ver 2.doc } \\
\hline \multicolumn{2}{|l|}{ Phase 2.doc } \\
\hline \multicolumn{2}{|l|}{ Phase 3 ver 2.doc } \\
\hline \multicolumn{2}{|l|}{ Phase 3.doc } \\
\hline \multicolumn{2}{|l|}{ Phase 4 ver 3.doc } \\
\hline \multicolumn{2}{|l|}{ Phase 4 ver $4 . d o c$} \\
\hline \multicolumn{2}{|l|}{ Phase 4 ver $5 . d o c$} \\
\hline \multicolumn{2}{|l|}{ Phase 5 ver 2.doc } \\
\hline \multicolumn{2}{|l|}{ Phase 5 ver 3.doc } \\
\hline \multicolumn{2}{|l|}{ Phase 5 ver 4. doc } \\
\hline \multicolumn{2}{|l|}{ Phase 5.doc } \\
\hline \multicolumn{2}{|l|}{ Phase 5.doc } \\
\hline SEGTEST3MASTER 14 Mar2005.xls & Contains all variables and data processing to date \\
\hline SEGTEST3MASTER 21NOV04.xls & Contains all variables and data processing to date \\
\hline SEGTEST3MASTER 26NOV04.xIs & Contains all variables and data processing to date \\
\hline SEGTEST3MASTER 6 Mar 2005.xls & \\
\hline SEGTEST3MASTER 7 OCT2004.xls & Contains all variables and data processing to date \\
\hline SEGTEST3MASTER addendum 7 OCT 04.xIs & Graphs added \\
\hline SEGTEST3MASTER Sep 202004.xls & Larger data set with most variables \\
\hline SEGTEST3MASTER Sep 282004.xls & Updated to include audit train and some data processing \\
\hline Variable definitions.doc & Definitions of variables supplied \\
\hline
\end{tabular}

